\title{
Sprache und Glaube
}

Eine Untersuchung zur Bedeutung der Sprache in der Theologie Gerhard Ebelings

\author{
Dissertation \\ zur Erlangung des Doktorgrades \\ der Theologischen Fakultät \\ der Georg-August-Universität Göttingen
}

vorgelegt von

Myeonghee Kim

geboren in Seongnam

Göttingen, 2019 


\section{Betreuungsausschuss}

Erstbetreuer/in: Prof. Dr. Martin Laube

Weitere Betreuer/innen: Prof. Dr. Christian Polke

Prof. Dr. Dr. h.c. Christine Axt-Piscalar

Weitere Mitglieder der Prüfungskommission:

Prof. Dr. Jan Hermelink

Tag der mündlichen Prüfung: 09. 05. 2019 


\section{Vorwort}

Diese Studie wurde von der Theologischen Fakultät der Georg-August-Universität Göttingen als Dissertation angenommen.

Zuerst möchte ich meinem Doktorvater Prof. Dr. Martin Laube von ganzem Herzen für seine lehrreiche und geduldige Betreuung während der Arbeit an meinem Promotionsprojekt danken. Auch bei Prof. Dr. Christian Polke, dem Zweitgutachter dieser Dissertation, bedanke ich mich für seine freundliche Unterstützung.

Außerdem möchte ich Rev. Dr. Younghoon Lee aus meiner Kirche, der Yoido Full Gospel Church, danken. Er hat mir die Chance gegeben, meinen kirchlichen Dienst zu pausieren und in Deutschland mit Hilfe eines Stipendiums zu promovieren. Für hilfreiche und ermutigende Diskussionen bin ich Rev. Dr. Panho Kim zu großem Dank verpflichtet. Darüber hinaus bedanke ich mich bei meinen deutschen Freunden, insbesondere bei Alexander Böttcher und Thomas Nicola, die einzelne Ausschnitte dieser Arbeit Korrektur gelesen und mir beim Vorbereiten der Disputation geholfen haben.

Meinen Schwestern und meinem Bruder möchte ich herzlich dafür danken, dass sie mich in jeder Hinsicht von Herzen unterstützt und für mich ständig gebetet haben. Mein ganz besonderer Dank gilt Gott. Vor allem ohne sein Verheißungswort $($ Gen 28, 15) hätte ich diese Arbeit weder begonnen noch vollendet.

Gott widme ich diese Arbeit.

Myeonghee Kim

Göttingen, am 25. May 2019 


\section{INHALTSVERZEICHNIS}

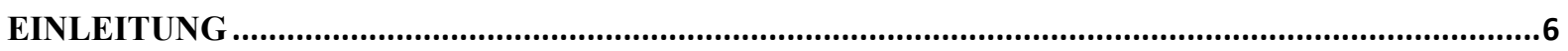

KAPITEL I. ENTWICKLUNG DES SPRACHVERSTÄNDNISSES...............................................16

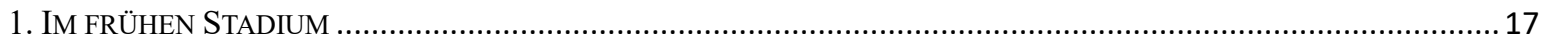

1.1. Das Erstlingswerk: > Evangelische Evangelienauslegung< (1942) ............................................... 17

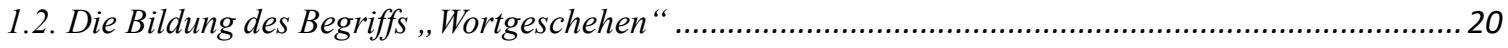

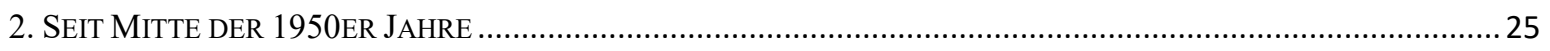

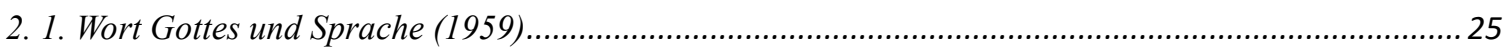

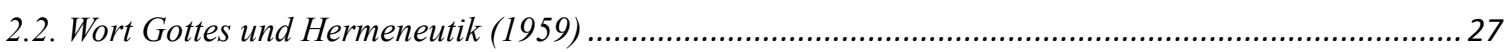

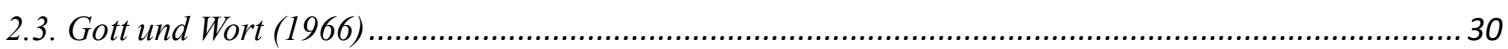

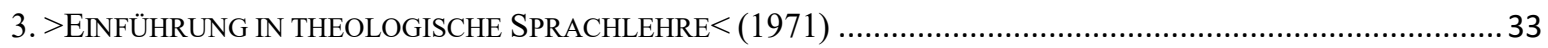

3.1. Die Notwendigkeit der theologischen Sprachlehre ..................................................................... 34

3.2. Der umfassende Horizont der theologischen Sprachlehre ................................................................... 36

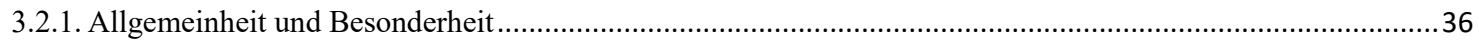

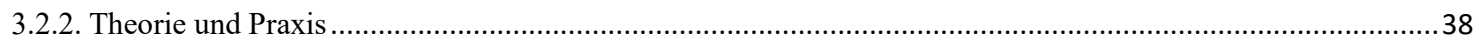

3.2.3. Hermeneutik für ,eine Sprachlehre von umfassendstem Horizont “ “...........................................................42

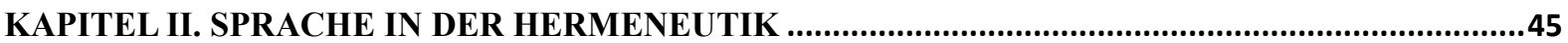

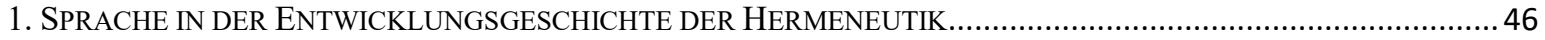

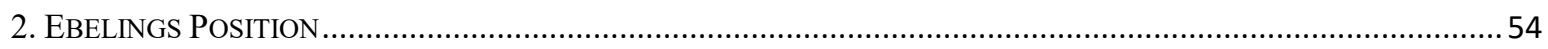

2.1. Gemeinsamkeit und Differenz mit Fuchs ..............................................................................5 55

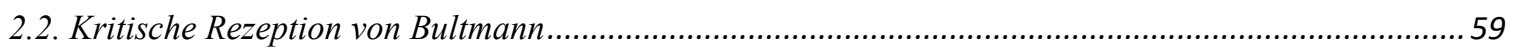

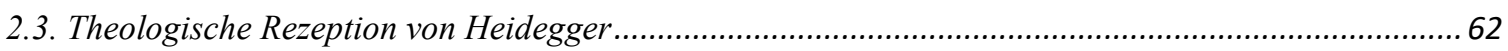

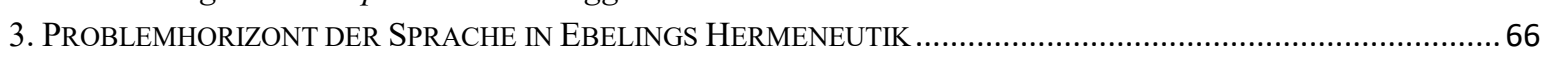

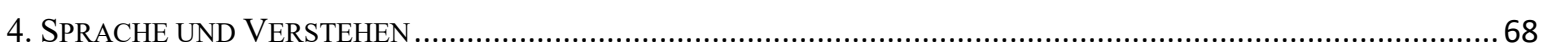

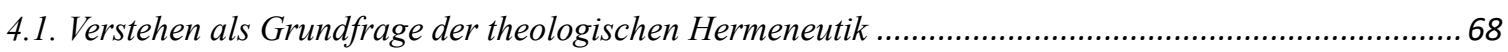

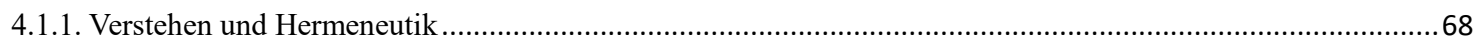

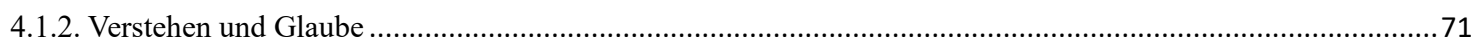

4.2. Sprache für die antimetaphysische und relationalontologische Verstehenskonstitution ....................... 72

4.2.1. Zum Wirklichkeitsverständnis als Grundlage des Verstehens .................................................................. 72

4.2.2. Zur Verifikation als theologischer Entfaltung des Verstehens .................................................................. 77

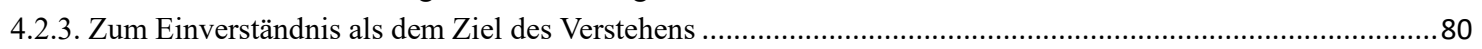

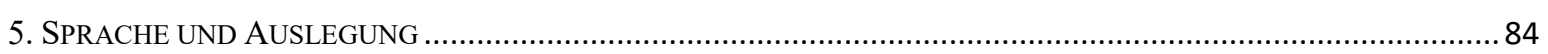

5.1. Existentiale Interpretation als theologisches Auslegungsprinzip..................................................... 85

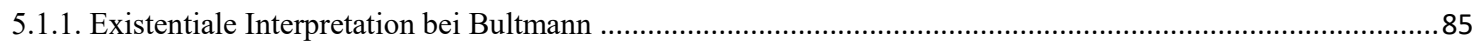

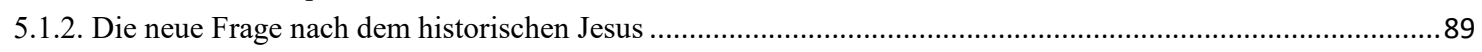

5.2. Sprache für die Integration historischer und dogmatischer Exegese in existentialer Interpretation ....93

5.2.1. Zum Recht der historisch-kritischen Methode .................................................................................. 94

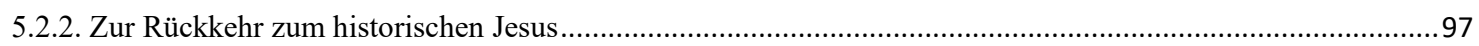

5.2.3. Zur Möglichkeit und Grenze der existentialen Interpretation ...................................................................... 102

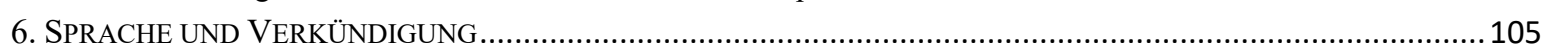

6.1. Verkündigung als fundamentale Ausrichtung der theologischen Hermeneutik.................................. 106

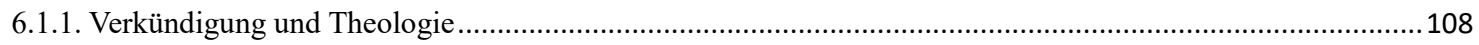

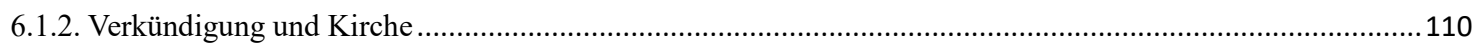

6.2. Sprache für die aktuelle Verkündigung des Wortes Gottes..........................................................112

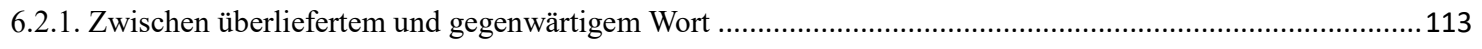

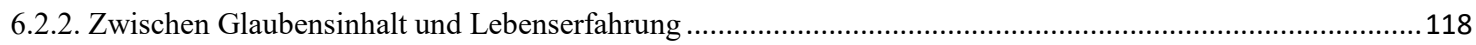




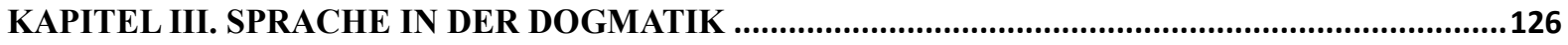

1. PROBLEMHORIZONT DER SPRACHE IN DER > DOGMATIK DES CHRISTLICHEN GLAUBENS < ......................... 126

1.1. Die Zusammenstellung von Dogmatik und Glaubenslehre ....................................................... 126

1.2. Die Darstellung des Glaubens als ein Ganzes....................................................................... 130

1.3. Die Entdeckung der Sprachlichkeit im Relationsbegriff des Glaubens ............................................. 134

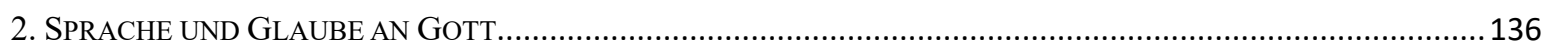

2.1. Das Gebet als die Sprache des Glaubens für die Relation ................................................................ 138

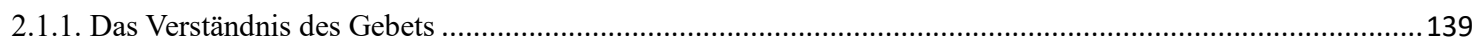

2.1.2. Der dogmatische Ort des Gebets als ein hermeneutischer Schlüssel zur Gotteslehre ...................................141

2.1.3. Der Charakter des Gebets für die Relationsbestimmung von Gott und Menschen .......................................147

2.1.4. Der Beitrag des Gebets zur relationalen Ontologie...................................................................................... 150

2.2. Der Sprachcharakter der göttlichen Eigenschaften........................................................................ 154

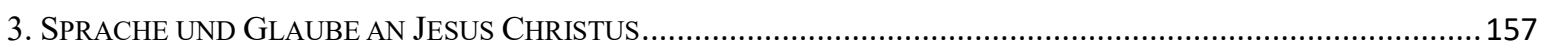

3.1. Die Untrennbarkeit der zwei Naturen Jesu ............................................................................... 157

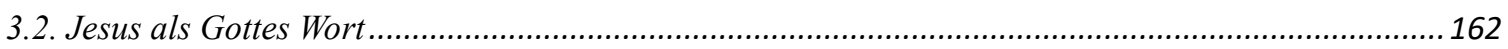

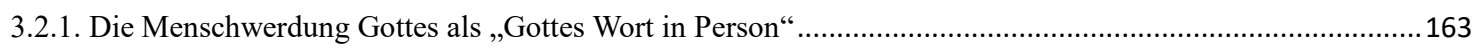

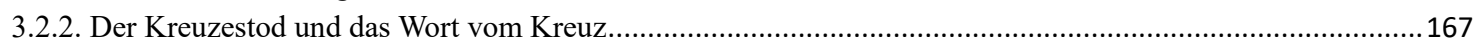

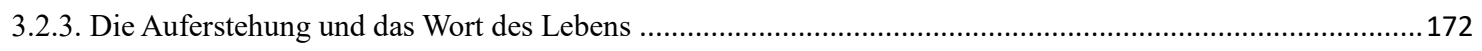

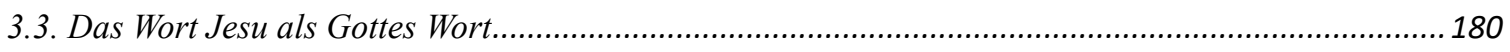

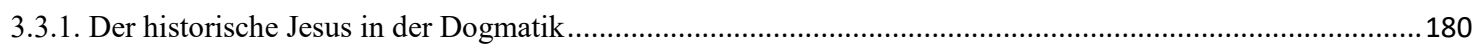

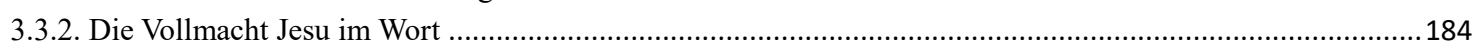

4. SPRACHE UND GLAUBE AN DEN HEILIGEN GEIST ............................................................................. 188

4.1. Die sprachliche Personalität des heiligen Geistes .................................................................... 192

4.2. Das worthafte Wirken des heiligen Geistes............................................................................. 193

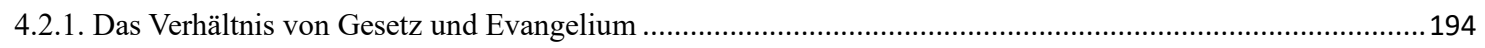

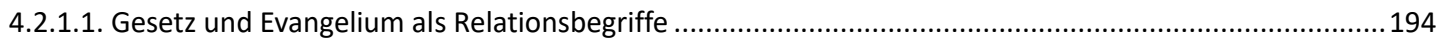

4.2.1.2. Die Unterscheidung zwischen Gesetz und Evangelium .............................................................. 199

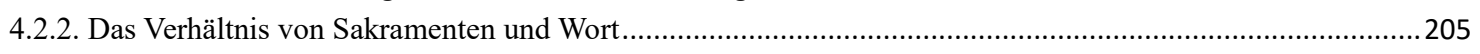

4.2.2.1. Die Unterordnung der Sakramente unter dem Wort........................................................................208

4.2.2.2. Das Verständnis des Sakraments im Geschehenscharakter des Wortes..................................................212

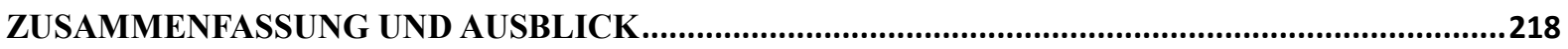

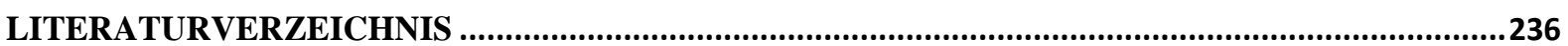




\section{ABKÜRZUNGEN}

D I Dogmatik des christlichen Glaubens, Bd. I: Prolegomena. Erster Teil: Der Glaube an Gott den Schöpfer der Welt, Tübingen ${ }^{2} 1982$.

D II Dogmatik des christlichen Glaubens, Bd. II: Zweiter Teil: Der Glaube an Gott den Versöhner der Welt, Tübingen ${ }^{2} 1982$.

D III Dogmatik des christlichen Glaubens, Bd. III: Dritter Teil: Der Glaube an Gott den Vollender der Welt, Tübingen ${ }^{2} 1982$.

EEA Evangelische Evangelienauslegung. Eine Untersuchung zu Luthers Hermeneutik, Darmstadt 1969.

EEA $^{3}$ Evangelische Evangelienauslegung. Eine Untersuchung zu Luthers Hermeneutik, Darmstadt ${ }^{3} 1991$ (mit Nachwort).

LuSt I Lutherstudien, Bd. I, Tübingen 1971.

LuSt II /1 Lutherstudien, Bd. II: Disputatio de homine, 1. Teil: Text und Traditionshintergrund, Tübingen 1977.

LuSt II/2 Lutherstudien, Bd. II: Disputatio de homine, 2. Teil: Die philosophische Definition des Menschen. Kommentar zu These 1-19, Tübingen 1982.

LuSt III Lutherstudien, Bd. III: Begriffsuntersuchungen - Textinterpretationen - Wirkungs -geschichtliches, Tübingen 1985.

Luther Luther. Einführung in sein Denken, Tübingen ${ }^{4} 1981$.

Sprachlehre Einführung in theologische Sprachlehre, Tübingen 1971.

ThV Theologie und Verkündigung. Ein Gespräch mit Rudolf Bultmann, Tübingen 1962.

Wesen Das Wesen des christlichen Glaubens, München/Hamburg ${ }^{2} 1965$.

WG Wort und Glaube, Tübingen ${ }^{2} 1962$.

WG II Wort und Glaube, Bd. II: Beiträge zur Fundamentaltheologie und zur Lehre von Gott, Tübingen 1969.

WG III Wort und Glaube, Bd. III: Beiträge zur Fundamentaltheologie, Soteriologie und Ekklesiologie, Tübingen 1975.

WG IV Wort und Glaube, Bd. IV: Theologie in den Gegensätzen des Lebens, Tübingen 1995.

WGT Wort Gottes und Tradition, Göttingen 1964. 


\section{EINLEITUNG}

Gerhard Ebeling wird als einer der bedeutendsten deutschen Theologen des 20. Jahrhunderts gewürdigt. Über Jahrzehnte hinweg forschte er leidenschaftlich, schrieb zahlreiche Werke und beeinflusste als Lutherforscher, Hermeneutiker, Dogmatiker und auch als Wissenschaftsorganisator die theologischen Diskussionen und Reflexionen in Deutschland. Darüber hinaus ist Ebeling einer von denen, die das Thema der Sprache ins Zentrum des theologischen Gespräches setzten. Das Thema der Sprache in der Theologie hat nicht nur mit der Frage nach den antiken Sprachen des Alten und Neuen Testaments wie Hebräisch, Aramäisch und Griechisch oder mit der Frage nach den religiösen Formen der Sprache wie Symbol, Mythos und Metapher zu tun, sondern auch mit der fundamentalen Frage nach der Sprache selbst. Gerade mit dieser Frage beschäftigt sich Ebeling.

Wegen des Ausdrucks „fundamental“ könnte man an die Frage nach dem Ursprung der Sprache denken. Dieser wurde schon von Platon und Aristoteles thematisiert und im 18. Jahrhundert noch intensiver von J.P. Süßmlich und J.G. Herder unter ihren gegenseitigen Aspekten erforscht. Süßmlich suchte zu beweisen, dass „die erste Sprache ihren Ursprung nicht von Menschen, sondern allein vom Schöpfer erhalten habe“ und wollte damit den Ursprung der Sprache nicht auf der Seite des Menschen, sondern in einer göttlichen Umgebung liegen lassen. ${ }^{1}$ Herder wollte dagegen den Ursprung der Sprache in der natürlichen Fähigkeit des Menschen finden und dadurch ihre Rolle für die Identität des Menschen nachweisen. ${ }^{2}$ Die von Ebeling ausgearbeitete Frage nach der Sprache ist eigentlich nicht von der Frage nach ihrem Ursprung getrennt. Er sieht theologisch die Sprache nicht nur in Bezug auf das Denken oder die Fähigkeit des Menschen, sondern mehr in Bezug auf Gott. Diesen ursprünglichen Sachverhalt zu entdecken, ist dennoch nicht die Hauptaufgabe seiner Sprachforschung. Er beschäftigt sich vielmehr mit der Frage nach der theologisch fundamentalen Bedeutung der Sprache. Das heißt: Wie wird die Sprache unter dem theologischen Aspekt verstanden? In welchem Zusammenhang steht die Sprache mit den theologischen Themen? Wozu ist die theologische Untersuchung über die Sprache erforderlich?

Ebeling hat gewiss zur theologischen Reflexion über die Sprach beitragen. Über seinen Beitrag gibt es aber verschiedene und widersprüchliche Meinungen. ${ }^{3}$ W. Pannenbergs Analyse von Ebelings Sprachlehre zeigt beispielhaft solche ambivalenten Bewertungen. Auf der einen Seite kritisiert er, dass Ebeling die Funktion der Sprache nur als Kommunikationsmittel von Person zu Person begreift, indem er in seinem Ansatz „die anthropologische Phänomenbreite sprachlicher Strukturen“ nicht integriert,

\footnotetext{
${ }^{1}$ J.P. Süßmlich, Versuch eines Beweises, daß die erste Sprache ihren Ursprung nicht von Menschen, sondern allein vom Schöpfer erhalten habe, Berlin 1766.

2 J.G. Herder, Abhandlung über den Ursprung der Sprache, Berlin ${ }^{4} 2017$.

${ }^{3}$ Vgl. P. Ricoeur, Gerhard Ebeling. Rückwendung zur Reformation und Wortgeschehen, in: Gerhard Ebeling. Mein theologischer Weg. Hermeneutische Blätter, Sonderheft Okt. 2006, 75-94, bes. 86; J. L. Austin, How to Do Things with Words, Oxford 1962, 6f; und A.C. Thiselton, The new hermeneutic, in: I.H. Marshall (Hg.), New Testament Interpretation. Essays on Principles and Methods I, Carlisle UK (Paternoster) 1972, 308-333, bes. 325f.
} 
sondern von Anfang an „als sekundär“ ausschließt. ${ }^{4}$ Diese Reduktion, die schon bei Heidegger angedeutet war, wird von Ebeling, der die heideggerische existentiale Konzeption der Sprache aufgenommen hat, wieder in das theologische Gebiet gewendet. Ebelings Sprachlehre beruft sich, nach der Darstellung Pannenbergs, auf eine ,personalistische Sprachdeutung, die von der Aussagestruktur und Darstellungsfunktion der Sprache absieht und damit der an der Aussagestruktur von Behauptungssätzen orientierten analytischen Philosophie in der Phase des logischen Positivismus diametral entgegengesetzt" ist. ${ }^{5}$

Trotz solcher Schwächen schätzt Pannenberg Ebelings Versuch aber prinzipiell hoch, die in der Sprachphilosophie oder Sprachwissenschaft behandelten Sachfragen in die Theologie hineinzubringen und über die Sprache theoretisch zu reflektieren. Es gibt allerdings andere Theologen, die versuchen, das Problem der Sprache durch theologische Anwendung einer linguistischen und sprachphilosophischen Theorie zu behandeln. Derartige Versuche kann man an Beispielen von E. Güttgemanns und H. Fischer finden. Der Erstere übertrug das Konzept und Instrument der generativen Transformationsgrammatik Chomskys auf die Theologie und der Letztere wendete die Theorie der Abhängigkeit des Denkens von der Sprache, den sogenannten Sprachrelativismus auf die Theologie an und beschäftigte sich intensiv mit einem von der Syntax der Sprache ausgehenden Denkzwang. ${ }^{6} \mathrm{Im}$ Hinblick auf die Versuche von Güttgemanns und Fischer äußert sich Pannenberg wie folgt: Sie „sind mehr oder weniger durch einseitigen Anschluss an ein bestimmtes Modell gekennzeichnet, ohne dass die kritische Diskussion seiner Grundlagen hinreichende Berücksichtigung gefunden hätte und zum Ausgangspunkt einer in die Tiefe dringenden Neuformulierung aus theologischer Perspektive geworden wäre. ${ }^{\text {"7 }}$ Gegenüber solchen Versuchen findet Pannenberg bei Ebeling eine Spezialität und weist mit Recht darauf hin, dass bei ihm ,jedenfalls die Sache der Theologie den Leitfaden für ein tieferes Verständnis der Sprache bildet und nicht nur eine säkulare Sprachtheorie auf die Theologie appliziert wird". 8

Beim Behandeln des Sprachproblems gibt Ebeling der theologischen Herangehensweise stets den Vorrang vor der philosophischen oder linguistischen Fragestellung. Das ist ein wichtiger Punkt. An Ebeling wird kritisiert, dass er in seinen „fachlichen Voraussetzungen in Bezug auf die Sprache“9 vorgeprägt ist und damit die einseitige Sicht hat. Soll die fachliche Voraussetzung aber nur im negativen

\footnotetext{
${ }^{4}$ W. Pannenberg, Anthropologie in theologischer Perspektive, Göttingen ${ }^{2} 2011,381$.

${ }^{5}$ W. Pannenberg, Anthropologie in theologischer Perspektive, Göttingen ${ }^{2} 2011,381$.

6 E. Güttgemanns, Theologie als sprachbezogene Wissenschaft, in: Studia Linguistica Neotestamentica. Gesammelte Aufsätze zur linguistischen Grundlage einer neutestamentlichen Theologie, 1971, 184-230; H. Fischer, Glaubensaussage und Sprachstruktur, Hamburg 1972, 222ff, 236ff, 245ff; Zitiert nach W. Pannenberg, Anthropologie in theologischer Perspektive, Göttingen ${ }^{2} 2011,378 \mathrm{ff}$.

${ }^{7}$ W. Pannenberg, Anthropologie in theologischer Perspektive, Göttingen ${ }^{2} 2011,380$.

${ }^{8}$ W. Pannenberg, Anthropologie in theologischer Perspektive, Göttingen ${ }^{2} 2011,380$.

${ }^{9}$ D. Stellmacher, Zum Sprachverständnis Ebelings, in: U. Gerber/ E. Güttgemanns (Hg.), Linguistische Theologie. Biblische Texte, christliche Verkündigung und theologische Sprachtheorie, Bonn ${ }^{3} 1975,56-58,57$.
} 
Sinne betrachtet werden? Sie ist m.E. unvermeidlich, zugleich in gewissem Maße konstitutiv für die Identität jedes Faches. Denn das Wesen der Sprache, ihr Charakter oder ihre Funktion können in der Linguistik, Philosophie, Kultur- und Sozialanthropologie oder in der Theologie unterschiedlich befragt und beantwortet werden. Ebeling ist kein Sprachwissenschaftler, sondern Theologe. Das äußert sich insbesondere in seiner starken Anlehnung an das Wort Gottes. Erstens, da er sich dem biblischen Begriff für das Wort Gottes anschließt, ja sowohl das paulinische euangelion in den Blick nimmt, das die Christusbezogenheit aufzeigt und nicht nur die mündliche Überlieferung Jesu bedenkt, sondern auch Leben, Persönlichkeit sowie das Wirken Jesu als Ganzes umfasst; als auch das hebräische dabar, in dem sich kein Unterschied zwischen dem Wort und der Tat bzw. dem Geschehen als Ergebnis oder Verwirklichung des Wortes befindet. Zweitens, da er sich der reformatorischen Prägung für das Wort Gottes anschließt. Im Hintergrund von Ebelings Auffassung, dass das Wort seine eigene hermeneutische Funktion hat, steht das reformatorisch geprägte Vertrauen in die selbstwirkende Macht des Wortes Gottes. Seine Sprachforschung ist also eine Fortführung der theologischen Reflexion über das Wort, die von Luther über Barth, Gogarten und Bultmann an ihn vererbt wird. ${ }^{10}$ Das heißt, er sucht einerseits mit den philosophischen oder linguistischen Fragen nach der Sprache umzugehen und andererseits bei diesem Umgehen seinen Platz im Fach der Theologie nicht zu verlieren. Seine Reflexion über die Sprache übertritt darum nicht nur die Grenze der semantischen Untersuchung, sondern übertrifft auch andere Versuche, linguistische und philosophische Theorien auf die Theologie lediglich anzuwenden. Mit Rücksicht auf Ebelings Leistung und Beitrag zur theologischen Reflexion über die Sprache kommt Pannenberg nun zum Schluss, dass Ebelings hermeneutische Analyse der Sprache „trotz aller Begrenztheit des von ihm entwickelten hermeneutischen Zugangs zum Phänomen der Sprache“ „den meisten der neueren Versuche immer noch überlegen" sei. $^{11}$

Die vorliegende Arbeit untersucht das bemerkenswerte Sprachdenken Ebelings und zielt darauf ab, die Rolle der Sprache bzw. des Konzepts der Sprachlichkeit in seiner gesamten Theologie darzustellen, um sein Sprachdenken umfassend und damit möglicherweise richtig zu verstehen und die Bedeutung der Sprache für seine Theologie erneut zu erörtern.

Ein Leitinteresse der vorliegenden Untersuchung ist die gegenwärtige theologische und kirchliche Situation in Korea. Bisher wurde das Thema der Sprache selbst in Korea theologisch nicht richtig behandelt, weil es lieber als ein humanwissenschaftliches Thema verstanden wird. Ohne die theologischen Reflexionen oder Diskussionen gibt es in den koreanischen Kirchen nur allgemeine Perspektiven auf die Sprache. Einerseits gibt es eine negative Perspektive auf die Sprache, die ursprünglich aus den traditionellen asiatischen Philosophien und Religionen wie Konfuzianismus und

\footnotetext{
${ }^{10}$ I.U. Dalferth, Hermeneutische Theologie - heute?, in: Ders. u.a. (Hg), Hermeneutische Theologie - heute?, Tübingen 2013, 3-38, 30.

${ }^{11}$ W. Pannenberg, Anthropologie in theologischer Perspektive, Göttingen ${ }^{22} 211,380$.
} 
Buddhismus kommt. Sie haben den grundlegenden Standpunkt gemein, dass das Wesentliche von Denken, Wahrheit oder Religion durch die Sprache weder übertragen noch ausgedrückt werden kann, weil es dem Gebiet der Vernunft sowie des Sinns als Grundlage der Sprache überlegen ist. Konfuzianismus prägt vor allem die koreanische Kultur, insbesondere den Ahnenkult und die Stabilität der Gesellschaft, und beeinflusst auch als Morallehre stark die Verhaltensweise zugunsten Zurückhaltung oder Humilität. ${ }^{12}$ Weniger Sprechen als eine Art der sittlichen Gespräche wird oftmals für eine Tugend gehalten. Es gibt andererseits ein positives, aber blindes Vertrauen auf die Kraft der Sprache, die von vielen koreanischen Pastoren ausgesprochen wird. Oft zitieren sie dafür zwei Bücher, die in Korea beide einmal als Sensation galten. Das eine ist das Buch des japanischen Wissenschaftlers Masaru Emoto, der durch Experimente mit Wasser behauptet, dass das Wasser entweder mit einem positiven Wort wie Danke oder Liebe oder mit einem negativen Wort wie Hass oder Krieg einen vollkommenen oder einen zerbrochenen Eiskristall formt. ${ }^{13}$ Das andere ist das sehr beliebte, weltliche Buch des amerikanischen Pastors Joel Osteen, der die positive, kreative Wirkung der Sprache auf das alltägliche Leben unterstreicht. ${ }^{14}$ Derartige Rede über die Sprache wird kritiklos mit dem christlichen Glauben verbunden und in die Kirche, also in die Predigt oder Seelsorge getragen.

Dieser in der koreanischen Kirche vorherrschende Trend ist, radikal gesagt, als Misstrauen und Missbrauch der Sprache zu bezeichnen. Gewissermaßen schuldig ist die Abwesenheit der theologischen Reflexion. Die einheimische Theologie in Korea muss sich nun der Aufgabe stellen, die in der Theologie bisher vernachlässigte Frage nach der Sprache nun selbst zur Diskussion zu bringen und dadurch ein sachgemäßes, theologisches Sprachverständnis zu erarbeiten. Ich hoffe, durch die vorliegende Untersuchung über das Sprachdenken Ebelings, der das Sprachproblem theologisch behandelt und in Korea noch nicht so bekannt ist, eine Möglichkeit für die Durchführung der theologischen Sprachlehre aufzuzeigen und zur weiteren Diskussionen in der koreanischen Theologie beizutragen.

\section{Forschungsüberblick und Fragestellung}

Die Sprache hat einen wichtigen Platz in Ebelings theologischem Denken, sodass er zusammen mit seinem Kollegen Fuchs und mit ihren Nachfolgern E. Jüngel und G. Bader immer wieder als Vertreter der sog. „Sprachtheologie“ oder „Theologie der Sprache“ genannt wird. ${ }^{15}$ Mit Rücksicht auf die

\footnotetext{
${ }^{12}$ Vgl. K.-F. Daiber, Religion in multikulturellen und multireligiösen Staaten Ostasiens, Frankfurt a.M. 2014, 96101; Byong-ik Koh, Confucianism in Contemporary Korea. in: Tu Wei-ming (Hg), Confucian Traditions in East Asian Modernity, Harvard University Press, 1996.

${ }^{13}$ Masaru Emoto, Die Antwort des Wassers, Koha-Verlag 2002.

${ }^{14}$ Joel Osteen, Your Best Life Now, Faith Words 2015.

${ }^{15}$ Christof Gestrich, Die Sprache der Versöhnung. Theologie und Sprachphilosophie in Begegnung. Erwägungen zu G.W.F. Hegel und W. von Humboldt über die Frage der Verhinderung destruktiver Gewalt, in: ZThK 94 (1997), 488-510, 490.
} 
wichtige Stellung der Sprache bei Ebeling ist sie in vielen Untersuchungsarbeiten über seine Theologie behandelt worden. Diese Behandlungen können grob in zwei Richtungen betrachtet werden.

Erstens wurde die Sprache oftmals in Bezug auf ein bestimmtes Thema behandelt: Dafür ist z.B. $>$ Glaube und Erfahrung< $(1992)^{16}$ von Katrin Gelder zu nennen, wobei sie aufzuzeigen versuchte, wie Ebeling in seinem Hauptwerk $>$ Dogmatik des christlichen Glaubens $<$ die Bedeutung und die Funktion der Erfahrung im Glaubensgeschehen erörtert. Beim Analysieren der christlichen Erfahrung thematisierte Gelder einmal den Zusammenhang von Sprache und Erfahrung und versuchte, das wesentlich zusammenhängende Verhältnis von Wort, Glaube und Glaubenserfahrung zu entdecken. ${ }^{17}$ Im gleichen Jahr veröffentlichte der katholische Theologe Herbert Schlögel ein Buch über das Gewissensverständnis Ebelings und charakterisierte dieses als „,nicht moralisch, sondern theologisch“, so wie der Titel seines Buches anzeigt. ${ }^{18}$ Schlögel erläutert, dass bei Ebeling die Wortsituation des Menschen und seine Wortverantwortung mit dem Gewissen als anthropologischem Ort des Glaubens verbunden sind. ${ }^{19}$ Der österreichische katholische Theologe Franz Gmainer-Pranzl schrieb eine Dissertation über das Verhältnis von Glaube und Geschichte bei K. Rahner und Ebeling (1996) ${ }^{20}$, die er durch den Vergleich von zwei unterschiedlichen Aspekten von „transzendentaler und hermeneutischer Theologie“ untersuchte. In Hinsicht auf das Verhältnis von Sprache und Geschichte zeigte GmainerPranzl auf, dass Ebeling „nicht nur eine Beschreibung der Geschichtlichkeit menschlicher Sprache“ liefert, „sondern eine Definition der Geschichte von der Sprache her: Die als Sprachgeschehen zu verstehende Grundbewegung ist das Wesen der Geschichte“. 21

Unter den neuesten Publikationen nach 2000 ist die Dissertation von Oliver Pilnei $>$ Wie entsteht christlicher Glaube $<(2007)^{22}$ zur Sprache zu bringen, in der er die Glaubenskonstitution in der hermeneutischen Theologie bei deren drei Vertretern Bultmann, Fuchs und Ebeling untersuchte. In Bezug auf die Sprache fällt auf, dass Pilnei versuchte, durch die Analyse des Begriff des Wortgeschehens, also dessen Verhältnisses zur Sprache und zum Wort Gottes sowie seines Charakters von Zeitlichkeit und Verborgenheit, seine tiefe Bedeutung für den christlichen Glauben zu entdecken. ${ }^{23}$ Ein Jahr später untersuchte R. Goltz in seiner Dissertationsschrift $>$ das Werden der Gewissheit< $(2008)^{24}$ das protestantische Verständnis von der „Offenbarung als Grund des Glaubens im Anschluss

\footnotetext{
${ }^{16}$ K. Gelder, Glaube und Erfahrung, Neukirchen-Vluyn 1992.

${ }^{17}$ K. Gelder, Glaube und Erfahrung, Neukirchen-Vluyn 1992, 99-112.

${ }^{18}$ H. Schlögel, Nicht moralisch, sondern theologisch, Mainz 1992.

${ }^{19}$ H. Schlögel, Nicht moralisch, sondern theologisch, Mainz 1992, 45-60.

${ }^{20}$ F. Gmainer-Pranzl, Glaube und Geschichte bei Karl Rahner und Gerhard Ebeling, Innsbruck/Wien, 1996.

${ }^{21}$ F. Gmainer-Pranzl, Glaube und Geschichte bei Karl Rahner und Gerhard Ebeling, Innsbruck/Wien, 1996, 198243 , bes. 206.

22 O. Pilnei, Wie entsteht christlicher Glaube?, Tübingen 2007.

${ }^{23}$ O. Pilnei, Wie entsteht christlicher Glaube?, Tübingen 2007, 289-316.

${ }^{24}$ R. Goltz, Das Werden der Gewissheit, Leipzig 2008.
} 
an die Theologie von Barth, Ebeling und Herms“. In Hinsicht auf Ebelings Beitrag sagte Goltz, er intendiere unter dem Einfluss von Luther und Schleiermacher „mit seiner hermeneutischen Konzeption einen dritten Weg zwischen Offenbarungspositivismus und natürlicher Theologie zu beschreiten“. ${ }^{25}$ Goltz wies dabei mit Recht darauf hin, dass Ebeling die Offenbarung als ein Wortgeschehen verstehen will, das sich im Zusammenhang mit der menschlichen Erfahrung vollzieht.

Zweitens wurde die Sprache als ein Unterthema für die Charakterisierung oder Zielbestimmung seiner theologischen Arbeit. Zum Beispiel strebte Klaas Zwanepol in seiner Habilitationsschrift (1993) an, den Hintergrund, das Motiv und die Methode in Ebelings Theologie zu erhellen und kennzeichnete sie mit der Konzeption „Unterscheiden“. ${ }^{26}$ Zwanepol behandelte dabei einmal den Unterschied von Gotteswort und Menschenwort als ein Unterthema ${ }^{27}$ und wies mit Recht darauf hin, dass das rechte Unterscheiden für Ebeling nicht eine Trennung der Gegensätze, sondern die Wahrnehmung ihres streitigen Zusammenseins oder Beieinanderseins bedeutet, und dass für diesen rechten Unterschied zwischen Gott und Mensch die Sprache eine wichtige Rolle in seiner theologischen Hermeneutik spielt. Als neueste Untersuchungen sind dazu noch zwei Dissertationen zu betrachten. Die erste ist die Dissertation von Ruth Görnadt über die > Metaphysikkritik Gerhard Ebelings und ihre Vorgeschichte< (2016). Görnadt versuchte, Ebelings Metaphysikkritik zu begreifen, einerseits im tiefen Zusammenhang mit der Geschichte der evangelischen Metaphysikkritik, die bei Ritschl entstand und sich durch Herrmann und Bultmann entwickelte ${ }^{28}$; und andererseits in der zeitgenössischen Situation der Theologie, die noch von der Übermacht der Metaphysik geprägt ist, vor allem von der „,metaphysische(n) Gotteserkenntnis“, die Ebeling als Synonym für „natürliche Gotteserkenntnis“, „natürliche Theologie“, „philosophische Theologie“ bzw. ,philosophische Gotteserkenntnis“ sieht. ${ }^{29}$ Hinsichtlich der Sprache stimme ich Görnadt zu, dass die Auswirkung der Metaphysikkritik in Ebelings hermeneutische Theologie hineinreicht und sich mit seiner Sprachauffassung verbindet. Diese entwickelt sich grundsätzlich durch die Kritik an dem Verständnis der Sprache als bloßes Instrument für das Zeichensystem, damit an dem signifikativen Sprachverständnis, das auf der antiken Unterscheidung von signum und res aufbaut und sich in metaphysischen Denkhorizonten bewegt. ${ }^{30}$ Die zweite ist die Dissertation von Eunhoi Kim (2017), in der er die fundamental-theologischen Gedanken Ebelings untersuchte, um die implizierte Deutung seiner hermeneutischen Theologie zu erörtern. Kim behandelte dabei das Verhältnis von Glaube und Sprache ${ }^{31}$ als eins von den verschiedenen fundamental-

\footnotetext{
${ }^{25}$ R. Goltz, Das Werden der Gewissheit, Leipzig 2008, 147.

${ }^{26}$ K. Zwanepol, Unterscheiden, Bern 1993.

${ }^{27}$ K. Zwanepol, Unterscheiden, Bern 1993, 214-261.

${ }^{28}$ R. Görnadt, Die Metaphysikkritik Gerhard Ebelings und ihre Vorgeschichte, Tübingen 2016, $15 \mathrm{ff}$.

${ }^{29}$ R. Görnadt, Die Metaphysikkritik Gerhard Ebelings und ihre Vorgeschichte, Tübingen 2016, $181 \mathrm{ff}$.

${ }^{30}$ R. Görnadt, Die Metaphysikkritik Gerhard Ebelings und ihre Vorgeschichte, Tübingen 2016, $270 f$.

31 E. Kim, Wort und Glaube. Fundamentaltheologische Erörterungen Gerhard Ebelings in theologischen Krisenzeiten, Frankfurt a.M. 2017, 310-323.
} 
theologischen Themen und zeigte durch die Beschäftigung mit Ebelings Buch $>$ Einführung in die theologische Sprachlehre $<$ auf, dass Ebeling die Krise der modernen Theologie auf das Sprachproblem bezog, also nicht auf den problematischen gegenwärtigen Sprachgebrauch, sondern auf „die falsche Beschäftigung mit dem Wort Gottes als kümmerliche Erwiderung auf die theologischen und weltlichen Umwälzungen der Neuzeit““.32

Den oben aufgezeigten Forschungen will ich mich anschließen und sie doch um eine Frage ergänzen. Auch wenn die Sprache bereits als eine gemeinsame These in vielen Arbeiten über Ebeling untersucht wurde, kommt sein Sprachdenken dadurch hinreichend zur Geltung? Diesbezüglich scheint eine sachgemäße und umfassende Untersuchung über Ebelings Sprachdenken m.E. aus den folgenden Gründen noch erforderlich zu sein:

Erstens gibt es keine richtige Untersuchung, die sich hauptsächlich und intensiv am Thema der Sprache selbst orientiert. Wie und wozu das Sprachdenken bei Ebeling geformt und entwickelt wird, wurde nicht befragt und betrachtet. Das könnte wahrscheinlich auf den Charakter des Themas der Sprache selbst gründen. Die Sprache als ein Thema der Theologie zu wählen, scheint ungewöhnlich und in den meisten Fällen wird sie dann ausschließlich aus der strengen traditionellen theologischen Perspektive betrachtet. Denn das zunächst in den Blick geratende Thema der Theologie ist nicht die Sprache, sondern das Wort Gottes. Die große theologische Tradition erzählt deshalb vom Wort, wodurch die Rede vom Wort in der Theologie durchaus üblich ist, die Rede von der Sprache demgegenüber aber relativ „fremd“ klingt. ${ }^{33}$ Das gilt aber nicht für Ebeling. Dieser behandelt die Sprache, so wie Ricoeur sagt, „nicht als das Sekundärproblem einer Ausdruckhülle in Bezug auf einen bereits ausgedrückten Inhalt" ${ }^{34}$ Das Thema der Sprache dient bei Ebeling, wie in den oben genannten Forschungen aufgezeigt, der Auffassungen von Erfahrung, Geschichte, Offenbarung oder Gewissen und ist doch nicht lediglich ein dafür erforderliches Sekundärproblem. Er fordert uns auf, das Interesse mehr auf die Sprache selbst zu richten. Die Sprache hat das Recht, zumindest in der Untersuchung über Ebeling, als ein Hauptthema intensiv behandelt zu werden.

Zweitens muss man an den theologischen Ort des Themas der Sprache bei Ebeling denken. Beispielsweise fügt er den Vortrag „Wort Gottes und Sprache“, in dem er durch die Analyse des Verhältnisses zwischen göttlichem und menschlichem Wort eine grundlegende Reflexion über die Sprache anstellt, dem Buch $>$ Das Wesen des Glaubens $<$ (1964) als Anhang an, in dem er sich, wie schon der Titel reflektiert, mit fundamentaltheologischen Themen befasst. Er erläutert hier die sprachbildende

\footnotetext{
32 E. Kim, Wort und Glaube. Fundamentaltheologische Erörterungen Gerhard Ebelings in theologischen Krisenzeiten, Frankfurt a.M. 2017, 313.

${ }^{33}$ G. Bader, Art. Sprache/Sprachwissenschaft/Sprachphilosophie, IV. Systematisch-theologisch, in: TRE 31 (2000), 765-781, 765f.

${ }^{34}$ P. Ricoeur, Gerhard Ebeling. Rückwendung zur Reformation und Wortgeschehen, in: Gerhard Ebeling. Mein theologischer Weg, Hermeneutische Blätter, Sonderheft Okt. 2006, 75-94, 76.
} 
Bedeutung des Wortes für den Glauben und sagt, dass der Aufsatz über die Sprache nicht nur zeitlich, sondern auch „sachlich“ dazu gehört. ${ }^{35}$ Später, in der >Einführung in die theologische Sprachlehre< (1973), äußert er deutlicher, dass die theologische Sprachlehre ,aufs engste mit dem Aufgabenbereich von Fundamentaltheologie“ verknüpft sei und damit ,zumindest ein wichtiges Ingrediens von Fundamentaltheologie“ darstelle. ${ }^{36}$ Darüber, was er mit der „Fundamentaltheologie“ meint, muss man aber noch nachdenken. Sie bedeutet für ihn weder einen Vorbau zur Theologie oder eine theologische Disziplin, noch die elementare Grundstufe der Dogmatik, sondern die theologisch grundlegende Lehre, die mit der Besinnung auf das Wesen der ganzen Theologie zu tun hat und die sachgemäße Grundlage aller theologischen Arbeit erfragt. ${ }^{37}$ Sofern er die Sprachlehre als die Fundamentaltheologie sieht, bedeutet sie bei ihm eine theologische Fundamentallehre. Damit ist gemeint, dass Ebeling die Fundamentaltheologie nicht für ein Teilgebiet der Theologie hält und auf dieses beschränkt er die Sprache auch nicht. Das Thema der Sprache muss bei ihm deshalb m.E. im Verhältnis zu seiner Gesamttheologie betrachtet werden, um es im vollen Umfang zu verstehen.

Da kommt der dritte Punkt zur Sprache. Was ist damit gemeint, die Sprache im Verhältnis zur Gesamttheologie Ebelings zu untersuchen? Weil er in der Tat zahlreiche Bücher schrieb und dabei facettenreiche Thematiken behandelte, ist es unmöglich, seine ganze Theologie als den Gegenstand dieser Untersuchung zu bestimmen. Stattdessen sollen die Hauptarbeitsfelder betrachtet werden. Mit Ausnahme der Lutherforschung sind als Hauptgebiete Ebelings die Hermeneutik und die Dogmatik zu nennen. ${ }^{38}$ Die Hermeneutik ist unbestritten ein zentraler Schwerpunkt von Ebelings Lebensarbeiten, sodass T. Lorenzmeier sie als das „Kardinalthema“ für Ebeling bezeichnet. ${ }^{39}$ Ebelings besonderes Interesse für die Hermeneutik wird in seinen zahlreichen Veröffentlichungen und auch in seiner akademischen Laufbahn bezeugt. So gründete er ein Institut für Hermeneutik in Zürich und forschte dort bis zu seiner Emeritierung im Jahr 1979. Darüber hinaus gilt es zu beachten, dass den engsten Umkreis seiner Arbeit doch die Universität darstellt. Als Professor im Fach der systematischen Theologie beschäftigte er sich dort intensiv mit den Hauptfragen von Gotteslehre, Christologie, Anthropologie, Soteriologie, Ekklesiologie usw. Diese dogmatischen Fragen arbeitete er am Ende

\footnotetext{
${ }^{35}$ Wesen, Vorwort.

${ }^{36}$ Sprachlehre, 227.

${ }^{37}$ Vgl. „Erwägung zu einer evangelischen Fundamentaltheologie“ in: WG IV, 377-419; Studium der Theologie. Eine enzyklopädische Orientierung, Tübingen 1975, $163 \mathrm{f}$.

${ }^{38}$ Obwohl die Lutherforschung hier als ein spezielles, dadurch etwas beschränktes Arbeitsfeld ausgeklammert wird, bleibt sie doch als ein inhaltlicher oder wesentlicher Aspekt erhalten. Dazu sei ein Hinweis von Albrecht Beutel, der die drei wichtigsten Arbeitsfelder von Ebeling als Hermeneutik, Dogmatik und Lutherforschung bestimmt und ihre Beziehung wie folgt erklärt: Sie sind für Ebeling „nicht drei beziehungslos nebeneinanderstehende Arbeitsfelder, sondern die einander bedingenden Dimensionen seines ganzen, ungeteilten Lebenswerks.“ Ders., In memoriam Gerhard Ebeling, Lutherjahrbuch 69 (2002), 13-19, 15.

${ }^{39}$ T. Lorenzmeier, Exegese und Hermeneutik. Eine vergleichende Darstellung der Theologie Rudolf Bultmanns, Herbert Brauns und Gerhard Ebelings, Hamburg 1968, 80.
} 
seiner akademischen Lehrtätigkeit in dem dreibändigen Buch $>$ Dogmatik des christlichen Glaubens $<$ heraus. So sagte er selbst, die Trilogie sei „die Haupternte meines Lebens mit der Theologie im kirchlichen Dienst und an der Universität" ${ }^{40}$ Es ist das wichtige und zeitlich relativ späte, damit sein theologisches Denken zusammenfassende Werk. Obwohl die Sprache bei ihm eng mit der Hermeneutik verbunden ist, belässt er sein Sprachdenken nicht nur in der Hermeneutik, sondern bezieht es auf seine dogmatischen Entwürfe. Es wurde aber fast nicht oder nur partiell behandelt, in welchem Zusammenhang er in der $>$ Dogmatik des christlichen Glaubens $<$ sein Sprachdenken mit seinen dogmatischen Aussagen stehen lässt.

Durch diese Arbeit wird auch aufgezeigt, wie Ebeling auf die Frage antworten würde, inwiefern die Sprache für den christlichen Glauben erforderlich ist. Ebelings Glaubensauffassung wird sachlich anhand seiner hermeneutischen und dogmatischen Arbeiten befragt und beantwortet. Er hält die Hermeneutik nicht bloß für eine Interpretationslehre, sondern fragt durch sie letztlich nach dem Glauben. Er sieht die Dogmatik nicht nur als eine wissenschaftliche Arbeit, sondern lässt sie vielmehr zu einem Bekenntnis des Glaubens werden. Meine Arbeit zielt letztlich darauf ab, durch die Entdeckung der Rolle der Sprache in der Hermeneutik und Dogmatik ihre Bedeutung für den christlichen Glauben erneut zu erörtern.

\section{Aufbau}

Die Hauptaufgabe der vorliegenden Arbeit besteht darin, in seiner Hermeneutik und der $>$ Dogmatik des christlichen Glaubens $<$ die Rolle und Stellung der Sprache bzw. der Sprachlichkeit zu erläutern. Konkret wird diese Untersuchung folgendermaßen aufgebaut:

Im ersten Kapitel geht es als Vorarbeit um die Entwicklung des Sprachverständnisses Ebelings. Das Thema der Sprache wird hier chronologisch untersucht. Diese Untersuchung wird grob in drei Zeiträume geteilt und konzentriert sich auf die Analyse seiner einigen Schriften, die in Bezug auf die Sprache nach ihrer Relevanz und Wichtigkeit ausgewählt werden.

Im zweiten Kapitel wird die Rolle der Sprache bzw. Sprachlichkeit in der Hermeneutik Ebelings behandelt. Vor der sachlichen Untersuchung kommen noch zwei Aspekte zur Sprache, die der Vorbereitung der weiteren Arbeit dienen. Erstens wird für das Verständnis des Hintergrundes zunächst die an der Sprache orientierte Entwicklungsgeschichte der Hermeneutik (Kap. II, 1) und danach Ebelings Position, die durch die Auseinandersetzung mit Fuchs, Bultmann und Heidegger klar gemacht wird (Kap. II, 2), betrachtet. Zweitens versuche ich für eine systematische und nähere Untersuchung der Funktion der Sprache in Ebelings Hermeneutik diese zunächst zu strukturieren (Kap. II, 3). Sonst könnte sie, weil sie sich in seinen zahlreichen Schriften verstreut befindet und mit vielen verschiedenen

\footnotetext{
${ }^{40}$ Vorwort: in. D I, V.
} 
Themen verknüpft ist, nicht im Ganzen betrachtet, sondern nur in Bezug auf eine eingeschränkte oder detaillierte Thematik behandelt werden. Die Hermeneutik besteht für Ebeling aus drei Unterkategorien: Verstehen als grundlegende Frage der Hermeneutik (Kap. II, 4), Auslegung als streng genommene, wirkliche hermeneutische Arbeit (Kap. II, 5) und Verkündigung als völlige Erfüllung der Aufgabe der Hermeneutik (Kap. II, 6). Im jedem Abschnitt wird zuerst Ebelings Verständnis von Verstehen, Auslegung und Verkündigung selbst identifiziert und danach gefragt, wie die Sprache in jeder Unterkategorie funktioniert.

Im dritten Kapitel untersuche ich, wie Ebeling die Konzeption der Sprache bzw. Sprachlichkeit in den drei Bänden der $>$ Dogmatik des christlichen Glaubens $<$ entfaltet. Im Unterschied zur Hermeneutik hat die Dogmatik vergleichsweise eine feste Struktur, weil sie selbst die systematische und bewusst strukturierte Aussage von theologischen Materialien ist. Es ist darum nicht nötig, eine neue Struktur aufzubauen. Es ist stattdessen sinnvoll, die Struktur der Dogmatik zu analysieren und danach zu entscheiden, welche Themen in Bezug auf die Sprache bzw. Sprachlichkeit als passende Gegenstände ausgewählt werden sollen, um im Fluss von zahlreichen, miteinander verwickelten dogmatischen Themen den Weg zum Ziel dieser Arbeit nicht zu verlieren. Dafür bilde ich zwei Maßstäbe: Der erste misst, was Ebeling in jedem Band als das Hauptthema bearbeitet. Der zweite misst, worauf er seine Aufmerksamkeit beim Behandeln dieses Themas richtet und wodurch er seine Eigentümlichkeit zeigt. Demzufolge analysiere ich im ersten Abschnitt als Vorarbeit zunächst die ganze Struktur der $>$ Dogmatik des christlichen Glaubens $<$ und versuche, die darin versteckte Absicht Ebelings und sein Ziel zu entdecken (Kap. III, 1). Im zweiten Abschnitt wird die Gotteslehre als das Hauptthema des ersten Bandes betrachtet, das unter dem Aspekt des Gebets als ein sprachliches Phänomen beschrieben wird (Kap. III, 2). Im dritten Abschnitt geht es um die Christologie als Hauptthematik des zweiten Bandes, die äußerlich aus den zwei Naturen Jesu besteht und letztlich auf die Worthaftigkeit Jesu hinführt (Kap. III, 3). Der vierte Abschnitt identifiziert die Pneumatologie als der Hauptthematik des dritten Bandes, die eine besondere Betonung auf das worthafte Wirken des heiligen Geistes legt (Kap. III, 4). 


\section{KAPITEL I. ENTWICKLUNG DES SPRACHVERSTÄNDNISSES}

Das Denken bezieht sich auf den Sitz im Leben. Für eine Untersuchung über die Entwicklung des theologischen Denkens bei Ebeling ist es erforderlich, seinen Lebenslauf einmal zu betrachten und dabei ein bemerkenswertes Ereignis zu finden, das ihn theologisch auf einen bestimmten Weg führt. Dieser ist bei ihm zuallererst der Weg zur Hermeneutik, die den Charakter seiner Theologie am besten kennzeichnet. Sein Sprachdenken hat auch eine enge Beziehung mit seinem Weg zur Hermeneutik und kann keinesfalls getrennt von dieser gedacht werden, also davon, wie sie sich bei ihm entwickelt und wann sie verstärkt wird.

Ebeling behandelt die Hermeneutik schon in seiner Dissertation und nimmt diese als ein Instrument, Luther neu zu interpretieren. So hat er bereits zu Beginn seines Studiums ein Interesse für die Hermeneutik, doch streng genommen nicht für diese selbst, sondern vorrangig für die Lutherforschung. Es gibt in seinem Lebenslauf einen anderen Zeitpunkt, an dem der hermeneutische Charakter offensichtlich klar wird. Dafür kommen zwei Wechselereignisse zur Sprache, nämlich der Fachwechsel von der Kirchengeschichte zur systematischen Theologie und der Ortswechsel in Zürich.

Beide Ereignisse können unterschiedlich gewichtet werden. Ruokanen sagt z.B., dass die Frage nach dem Problem von Hermeneutik und Verstehen seinen Fachwechsel 1954 motivierte und der hermeneutische Charakter danach eine größere Bedeutung bekam. ${ }^{41}$ Beutel wählt hingegen einen späteren Zeitpunkt und behauptet, dass die Hermeneutik erst zwei Jahre später, mit Antritt seines ersten Lehrstuhls in Zürich zum zentralen „Thema und Leitmotiv seiner theologischen Arbeit“ wurde. ${ }^{42}$ Die zwei Entscheidungen über Fach- und Ortwechsel getrennt zu denken und nur eine einzige als den genauen Grund oder den detaillierten Zeitpunkt für die akademische Wende zur Verstärkung der Hermeneutik für Ebeling zu bestimmen, scheint aber m.E. unnötig. Denn in der Tat beziehen sie sich aufeinander, so wie beim Zurückblicken auf seinen theologischen Weg Ebeling selber sagt, dass der Fachwechsel und der Ortswechsel „deutlich nacheinander als zwei verschiedene Entscheidungen“ erfolgten und doch sie „miteinander“ zusammenhingen. ${ }^{43}$ Ich nehme hier Ebelings Meinung auf und führe meine Arbeit unter dem umfassenden Gesichtspunkt, dass die Entscheidungen über den Fach- und Ortswechsel in der Mitte der 1950er Jahre miteinander zusammenhängend zum Wendepunkt seiner Forschungsrichtung und zum Ausdruck seines verstärkten Interesses für die Hermeneutik wurden.

\footnotetext{
${ }^{41}$ M. Ruokanen, Hermeneutics as an Ecumenical Method in the Theology of Gerhard Ebeling, Helsinki 1982, 31 u. 41 .

${ }^{42}$ A. Beutel, Gerhard Ebeling. Eine Biographie, Tübingen 2012, 258.

${ }^{43}$ Ebeling, Mein theologischer Weg, in: Gerhard Ebeling. Mein theologischer Weg, Hermeneutische Blätter, Sonderheft Okt. 2006, 5-67, 59.
} 
Mit Rücksicht auf diesen Wendepunkt wird die Entwicklung des Sprachverständnisses Ebelings nun grob in drei Phasen geteilt untersucht: Die erste Phase beginnt mit der Veröffentlichung seiner Dissertation über Luthers Auslegung, die 1942 als seine offiziell erste Publikation erschien und die grundlegenden Entwürfe von seinem hermeneutischen und theologischen Gedanken vorlegt (Kap. I, 1); die zweite bezieht sich auf die seit der Mitte der 1950er Jahre geschriebenen Schriften, wobei seine Sprachauffassung parallel mit der Verstärkung des hermeneutischen Charakters seiner Theologie präzisiert und sein signifikanter Terminus „Wortgeschehen“ als eine äußerliche Kennzeichnung im vollen Maße verwendet wird (Kap. I, 2); und für die dritte kommt als Höhepunkt der Entwicklung seines Sprachverständnisses die Publikation $>$ Einführung in theologische Sprachlehre< (1971) in Betracht, in der er seine Auffassungen der Sprache umfassend darstellt und Sprachlehre als eine Prinzipienlehre für die Theologie feststellen will (Kap. I, 3).

\section{Im frühen Stadium}

Ebeling beginnt seine offizielle akademische Laufbahn mit Luthers Theologie, also mit seiner Dissertation >Evangelische Evangelienauslegung<, die im Herbst 1938 an der theologischen Fakultät der Universität Zürich abgeschlossen und 1942 veröffentlicht wird. Der Einfluss Luthers auf ihn ist sehr groß und wirkt so grundlegend, dass er am ehesten Luthers Schüler sein will. ${ }^{44}$ Das gilt auch für sein Sprachverständnis. Obwohl das Thema der Sprache selbst nicht direkt von seiner Lutherforschung her kommt, hat der hermeneutische Charakter der Sprache bei Ebeling mit dem von Luther übernommenen Verständnis der Hermeneutik zu tun, also damit, dass Luther das Verhältnis von Wort und Glaube im Prozess des Verstehens und der Auslegung der Schrift bestimmt. Außer dem Einfluss Luthers kommt im frühen Stadium Ebelings noch ein Gespräch über den Terminus „Wortgeschehen“ dazu, der dabei nicht als ein vollständiger Begriff, sondern als dessen Wurzel vorkommt.

1.1. Das Erstlingswerk: > Evangelische Evangelienauslegung< (1942)

Ebelings Dissertation > Evangelische Evangelienauslegung < zeigt seine ersten Schritte zum Verständnis nicht nur von der Hermeneutik, sondern auch von Luther. Das Lutherverstehen ist geschichtlich verändert worden. So gilt Luther etwa als Prophet, Lehrer, Prediger, Dogmatiker, Reformator, Politiker oder auch als Bahnbrecher der Neuzeit. Ebeling sieht Luther von Anfang an, worauf H.C. Knuth mit Recht hinweist, ,als Ausleger der Schrift ${ }^{\text {‘45 }}$, weil für Luther die Schrift gerade ein Gegengewicht zu der

\footnotetext{
${ }^{44}$ Vgl. Ebeling, Umgang mit Luther, Tübingen 1983, 1-7; WG IV, 647.

${ }^{45}$ H.C. Knuth, Verstehen und Erfahrung. Hermeneutische Beiträge zur empirischen Theologie, Hannover 1986, 17.
} 
kirchlich- institutionellen, sogar absichtlich versteckten Wahrheit darstellt, womit der Schriftauslegung ihre besondere Bedeutung zukommt. Luthers Auslegung ist in seinen Augen gewiss eine evangelische Auslegung der Schrift und kann zeigen, was evangelische Evangelienauslegung ist. Um „die heute brennend gewordene hermeneutische Frage “46 zu klären, nimmt Ebeling deshalb Luther als einen Helfer in Anspruch und versucht, Gegenwartsbezug und Traditionszusammenhang zugleich zu ergreifen. ${ }^{47}$

Im Vorwort äußert Ebeling seine Hauptthese klar: „Dass wir die hermeneutische Frage stellen müssen, hat darin seinen Grund, dass uns darüber Klarheit mangelt, wie Christus durch sein Wort gegenwärtig ist. ${ }^{“ 48}$ Er beschäftigt sich mit der theologisch und hermeneutisch grundlegenden Frage, „wie Christus durch sein Wort gegenwärtig ist“ und wie sich die Geschichte Jesu Christi zu unserem Dasein verhält. Er stellt zunächst Luthers kritische Aneignung und Überwindung der traditionellen hermeneutischen Methodik seiner Zeit dar, z.B. vierfacher Schriftsinn und Allegorese. Es ist hier schon wahrnehmbar, dass für Ebeling das hermeneutische Problem über exegetische Methodik oder Stile hinaus darin besteht, wie der in der Heiligen Schrift bezeugte Christus vom Menschen erfasst wird; und dass die Auslegung der Schrift untrennbar mit der Frage nach der Beziehung des gegenwärtigen Menschen zum Christusereignis verbunden ist. Er selbst erläutert wie folgt: „Darin spiegelt sich das Grundproblem der Theologie, wie es in besonderer Weise bei Luther zur Sprache gekommen ist: wie die geschichtliche Offenbarung, Jesus Christus, in der Verborgenheit gegenwärtig ist.“49

Das dritte Kapitel stellt das Zentrum der Studie dar. Ebeling setzt die Evangelienauslegung Luthers mit der gesamtchristlichen exegetischen Überlieferung ins Verhältnis und macht im Vergleich zu ihr das Besondere bei Luther erkennbar. Daraus folgt: erstens, „die Verwandtschaft Luthers mit der Tradition“ ist größer, als die übliche Vorstellung erwarten lässt. Luther agiert vor dem Hintergrund der Tradition, die seinen Bildungshorizont in wissenschaftlicher und spiritueller Hinsicht bestimmt. ${ }^{50}$ Zweitens lässt sich das wesentliche Neue in Luthers Evangelienauslegung nicht auf einen Begriff bringen, sondern nur auf einen Namen: Jesus Christus. Denn allein in Christus kann die Schrift verstanden werden. Insofern die Schrift auf Jesus Christus hin zu verstehen ist, zielt sie auf den Menschgewordenen und Gekreuzigten; diese Erkenntnis ist nur im Glauben möglich. Ebeling stellt die hermeneutische Grundeinsicht Luthers heraus, als „dass sich Gott allein in Christus allein durch die Schrift allein dem Glauben mitteilt“"51. Wenn solus Christus gilt, ist die Schrift nur Wort Gottes, darum sola scriptura. ${ }^{52}$ Damit ist gemeint, dass das Schlagwort der Reformation sola scriptura nicht lediglich das formale oder konstitutionelle Prinzip meint, mit dem die Autorität der Heiligen Schrift als Wort

\footnotetext{
${ }^{46}$ EEA, 9.

${ }^{47}$ EEA $^{3}$, Nachwort, 557.

${ }^{48}$ EEA, 9.

49 EEA, 92.

${ }^{50}$ EEA, $269 f$.

${ }^{51}$ EEA, 277.

52 EEA, 359ff.
} 
Gottes gewährt wird, sondern auch das hermeneutische Prinzip des sui ipsisus interpres der Schrift durch Christus als ihre Grundsache. Ebeling benennt abschließend die christologische Auslegung als die einzige Begründung der Hermeneutik Luthers: „Nicht die Kompliziertheit des Stils oder der Logik, sondern die Anstößigkeit der Christologie“"53; „Die Logik der Hermeneutik ist keine andere als die Logik der Christologie. Wer die Methoden der Evangelienauslegung lernen will, der muss sie von Christus

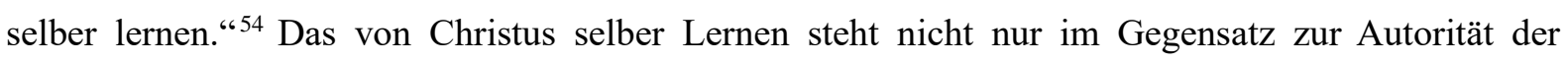
traditionellen Exegesemethoden, sondern auch im Gegensatz zum Verständnis von Christus als einen biblischen Lehrer. Christus ist kein Lehrer einer bestimmten Hermeneutik, sondern Gottes Handeln am Menschen. Ebeling verweist ,auf das opus proprium Christi, auf den Punkt, der allezeit jeden trifft: die Vergebung der Sünden“. ${ }^{55}$ Wenn die Schrift so auf das Handeln Gottes durch Christus am Menschen ausgelegt wird, wird sie dann evangelisch ausgelegt. Ebeling zeigt im Kapitel IV weiter auf, dass Luther wegen dieser christologisch orientierten Hermeneutik in dogmatische Kämpfe geriet, nämlich gegen Rom, die Schwärmer, Humanisten und Sakramentierer und dadurch die Hauptlinien der Hermeneutik deutlich entwickelte.

In diesem Zusammenhang ist nun zu sagen: Ebeling bestimmt die Logik der Hermeneutik bei Luther zuallererst als „die Logik der Christologie“. Er versucht dadurch zuerst die Struktur von Wort und Glaube in Christus zu zeigen. Der Wortbegriff Luthers kann und muss seinem Verständnis der Christologie entsprechend verstanden und mit diesem besprochen werden, denn ,allein durch das Wort wird die Geschichte Jesu Christi geistlich und gegenwärtig“ ${ }^{\text {(56 }}$ und „,das Wort allein eröffnet den Zugang zu Jesus. “57 Ebeling, durch Luther stark inspiriert, zentriert später selbst sein theologisches Denken in hohem Maße auch christologisch und gibt in seiner Christologie dem Wort den Vorrang. Ferner charakterisiert Ebeling Luthers hermeneutische Methode als existentiale Interpretation ${ }^{58}$, die als Spur

\footnotetext{
${ }^{53}$ EEA, 380.

${ }^{54}$ EEA, 452.

55 EEA, 452.

${ }^{56}$ EEA, 318.

57 EEA, 363.

${ }^{58}$ Ebelings Bezeichnung von Luthers Interpretation als existential ist umstritten, kritisch zur Diskussion gestellt: Der katholische Theologe E. Iserloh kritisiert z.B. in seinem Aufsatz „Existentiale Interpretation in Luthers erster Psalmenvorlesung?" nicht direkt Ebeling, sondern Brandenburgs Zustimmung zu Ebelings Analyse der Exegese Luthers. Ders., Existentiale Interpretation in Luthers erster Psalmenvorlesung?, in: Theologische Revue 59 (1963), 73-84. Er behauptet, dass Ebelings Lutherrezeption gewiss eine Tendenz haben sollte, die Bedeutung des Sakraments und damit auch die der Kirche als Heilsinstitution zu schwächen. Denn die These von der existentialen Interpretation beinhalt ,eine Entleerung der Objektivität der Heilstatsachen“ und ist darum nicht passend dazu, dass sich Luther „die applicatio des Heilswerkes nicht allein im Worte denkt“ und „die Zuordnung von Wort und Sakrament viel mehr realisiert, als man das wahrhaben will“ (77f). Diese Kritik scheint aber in einer einseitigen Perspektive zu verbleiben, nämlich der sogenannten Katholizität Luthers. Es gibt allerdings eine Unterscheidung zwischen dem katholischen und dem evangelischen Sakramentsverständnis und wahrscheinlich im Bereich evangelischer Theologie die Stimme, die Sakramente in ihrer Bedeutung abzuwerten oder zu reduzieren. Dafür ist zu nennen z.B. R. Schäfer, der etwa die Auffassung vertritt, dass der „,christliche Glaube [...] sich beschreiben
} 
schon in seiner Dissertation erkennbar ist. Für Luther ist nach der Meinung Ebelings die Geschichte Jesu Christi keine Wirklichkeit aus der Vergangenheit, die gesondert beschrieben werden kann, um sich danach die Frage zu stellen, wie sie sich zu unserem Dasein verhält. ${ }^{59}$ Die Geschichte Jesu Christi hat ihre Wirkung „für uns“ und „an uns“. Darum wird sie nur dann gut und sinnvoll ausgelegt, wenn sie in ihrem „Warum und Wozu“ für uns und an uns, d.h. existential interpretiert wird. Ebeling hält hier die Auslegung der Schrift für untrennbar von der Frage nach der Beziehung des gegenwärtigen Menschen zum Christusereignis und verbindet den Schriftsinn mit dem Sinn „für uns“ oder ,,an uns“.

Man kann so bereits in Ebelings Dissertation die grundlegenden Elemente seines hermeneutischen Entwurfes und die Möglichkeit der existentialen Annäherung an die Sprache finden. Er bezieht sich hier aber noch streng auf die Bindung des Wortes an Christus, während sich sein Blick in den späteren Texten mehr auf die allgemeine Wortstruktur von Wirklichkeit richtet. Als Schlüssel, um von der Lutherforschung zu seinem selbstverantworteten Verständnis von Hermeneutik und Sprache überzugehen, wählt Ebeling den Begriff „Wortgeschehen“.

1.2. Die Bildung des Begriffs „Wortgeschehen“

(lässt), ohne dass man auf die Notwendigkeit des Abendmahls geführt wird“ (Ders., Der evangelische Glaube, Tübingen 1973, 147), aber streng genommen nicht Ebeling, so wie er selbst beispielweise in seinem Aufsatz „Worthafte und sakramentale Existenz" verteidigt, mit der Behauptung, die Auffassung, dass die evangelische Lehre von den Sakramenten gerade im Dienst einer präzisen Erfassung des Wortes Gottes und damit des Glaubens stehen muss, bedeute „keine Abwertung der Sakramente“, sondern deren „rechte Wahrnehmung gegen spiritualistischen und sakramentalistischen Enthusiasmus." WGT, 215; und auf protestantischer Seite wurde das Problem der Realität des extra nos zur Diskussion gestellt, z.B. durch S.E. Ozment, der sich in >Homo spiritualis< (1969) sowohl mit Hunziger als auch mit Ebeling auseinandersetzt. Ders., Homo Spiritualis. A Comparative Study of the anthropology of Johannes Tauler, Jean Gerson and Martin Luther (1509-16) in the context of their theological Thought, Netherland, 1969. 87ff. Ozment kritisiert hier Hunzingers ,neoplatonische“ Interpretation (100) und stimmt einerseits darin mit Ebeling überein, dass der Dualismus in Luthers Psalmenvorlesung kein metaphysischer Gegensatz zwischen der unsichtbaren bzw. intelligiblen und der sichtbaren bzw. sensiblen Welt meint, und im Vergleich zu Hunzingers These hält er Ebelings existentiale Interpretation für einen fruchtbareren Weg zum Verständnis des Dualismus bei Luther. Doch redet er andererseits von der Schwäche der existentialen Interpretation und folgert, Ebeling und Hunzinger beruhten beide auf der irrtümlichen Annahme, dass Luther daran liege, unvereinbare Organisationen zu unterscheiden und zu widersetzen; und doch in Bezug auf den Dualismus liege Luthers Interesse primär darin, die Gegensätze zu „reconcile“, nach Luthers Konzept simul (103f). Wenn Ozment von Luthers "reconciled" Dualismus redet, versteht er ihn aber als ein solches, in dem die Gegensätze gleichzeitig koexistieren. Solche Meinung scheint m.E. doch schon die radikale Unterscheidung der zueinander gesetzten Realitäten bei Hunzinger vorauszusetzen. Die Kritik Ozments kommentiert Ebeling selber dahingehend, dass sie auf dem Missverständnis beruhe, ,als sei die gelegentliche Redeweise von zwei Möglichkeiten des Existenzverständnisses im Sinne von deren beliebiger Verfügbarkeit gemeint“. LuSt II/2, 236, Anm. 111.

${ }^{59}$ EEA, 419. 
Dass „das Wort geschieht“, ist keine Einsicht, die Ebeling als erster gehabt hätte. Das ist eine Vorstellung der Bibel, die etwa in Joh. 1. 1ff. als Inkarnation des göttlichen Logos skizziert wird. Dazu ist noch zu berücksichtigen, dass Barth, Bultmann und Gogarten mit dem Geschehensbegriff bereits vor Ebeling gearbeitet haben, ebenso wie der Philosoph Heidegger. ${ }^{60}$ Den Terminus „Wortgeschehen“ selbst hat Ebeling aber substantivisch zur Bildung gebracht. Diesen Terminus hält Knauer für einen „der tragenden Begriffe ${ }^{\text {“61 }}$ der Theologie Ebelings, und Ruokanen betrachtet ihn als den „Ausgangspunkt, auf den er ein; im Hinblick auf seine Axiome konsequentes, theologisches System aufbaut.“ 62 Ebeling selber benennt das Wortgeschehen als das „hermeneutische Prinzip“ 63 und verwendet es für das Verständnis von Hermeneutik und Sprache und von ihrem Verhältnis.

Es ist zuerst anzumerken, dass sich in seiner Dissertation häufig substantivische Bildungen im Zusammenhang mit dem Geschehensbegriff befinden, beispielsweise verbunden mit Offenbarung oder Christus. ${ }^{64}$ Durch die Verwendung des Geschehensbegriffs versucht Ebeling den Charakter der Hermeneutik Luthers zu bezeichnen: Diese ist nichts anderes als die „Auslegung des einst Geschehenen als noch heute Geschehenden“65, das aufgrund der Gegenwärtigkeit des Auferstandenen möglich ist, ${ }^{66}$ und ,das ,für mich“ geschieht hier im Glauben wirklich an mir“. ${ }^{67}$ So ist der Geschehensbegriff bei Ebeling seit $1942 \mathrm{zu}$ einem in der Lutherinterpretation verwurzelten, christologisch und existential hermeneutischen Problem geworden. Hier ist vertretend auf ein paar Aufsätze hinzuweisen, die den Geschehensbegriff weiter entwickeln und letztlich zur Bildung des Terminus von Wortgeschehen beitragen: ${ }^{68}$

In der Tübinger Habilitationsvorlesung zum Thema „Kirchengeschichte als Geschichte der Auslegung der Heiligen Schrift“(1946) ${ }^{69}$ weist Ebeling z.B. auf die „im deutschen Wort ,Geschichte' enthaltene Dialektik zwischen dem objektiven Geschehen in der Vergangenheit und dem subjektiven Verstehen des vergangenen Geschehens in der Gegenwart ${ }^{670}$ hin und macht noch darauf aufmerksam, dass die Kirchengeschichte mit zum Offenbarungsgeschehen gehört, weil sie „zwischen

\footnotetext{
${ }^{60}$ H.C. Knuth, Verstehen und Erfahrung. Hermeneutische Beiträge zur empirischen Theologie, Hannover 1986, 31-35.

${ }^{61}$ P. Knauer, Der Glaube kommt vom Hören. Ökumenische Fundamentaltheologie, Bamberg 51986, 75f, Anm. 86.

${ }^{62}$ M. Ruokanen, Das Problem der Gnadenlehre in der Dogmatik Gerhard Ebelings, in: KuD 35 (1989) 2-22, 10.

${ }^{63}$ WG 348.

64 „Christusgeschehen“ in EEA, 333, 450; „Offenbarungsgeschehen“ in EEA, 134, 136, 452; oder „Heilsgeschehen“ in EEA, 293.

${ }^{65}$ EEA, 409.

${ }^{66}$ EEA, 406f, 450.

${ }^{67}$ EEA, 424.

${ }^{68}$ Vgl. H.C. Knuth, Verstehen und Erfahrung. Hermeneutische Beiträge zur empirischen Theologie, Hannover 1986, 35-41.

${ }^{69}$ WGT, 9-27.

${ }^{70}$ WGT, 14.
} 
uns und der Offenbarung Gottes in Jesus Christus“ steht. ${ }^{71}$ Im Beitrag zur „Bedeutung der historischkritischen Methode für die protestantische Theologie und Kirche“ $(1950)^{72}$ zielt Ebeling darauf ab, den inneren Sachzusammenhang zwischen reformatorischer Rechtfertigungslehre und historisch-kritischer Methode aufzuzeigen und damit die Zusammengehörigkeit von Protestantismus und historischer Kritik herauszustellen. Er bestimmt dabei die Offenbarung als ein Geschehen, „das, obwohl es als einmaliges historisches Geschehen bezeugt ist und als solches einer bestimmt fixierten Vergangenheit angehört, dennoch nicht zur Vergangenheit wird, sondern von fortdauernder Gegenwärtigkeit ist. “73 Ebeling verwendet diesen Offenbarungsgeschehensbegriff wieder in dem Beitrag >Die Anfänge von Luthers Hermeneutik $<(1951)^{74}$, der ebenfalls an die hermeneutischen Problemstellungen seiner Dissertation anknüpft.

Der Geschehensbegriff findet sich noch in der Schrift über >Die Geschichtlichkeit der Kirche und ihrer Verkündigung als theologisches Problem< (1954) hinsichtlich der Frage nach der Bedeutung der Tradition und des Kanons, wie das Phänomen der Geschichtlichkeit der Kirche selbst sowie die Heilige Schrift als jene Urkunde theologisch zu bewerten sei. Er unterscheidet hier die Offenbarung Gottes als historisches Geschehen von anderen historischen Geschehen, weil sie ,als historisches Geschehen der historischen Betrachtung vollkommen offen liegt“ und ,als Offenbarung dagegen sich nur durch das bezeugende Wort dem Glauben erschließt“ ${ }^{\text {“ }}{ }^{75}$ An diesem Offenbarungsbegriff scheitert „die Zerlegung in ein objektives und ein subjektives Geschehen“, so dass das im historischen Geschehen verborgene eschatologische Geschehen nur der Glaube erkennt und im Glauben gegenwärtig wird. ${ }^{76}$ Und diese eschatologische Tat Gottes wird gerade in der Verkündigung tradiert. ${ }^{77}$

Erst in seinem Aufsatz über Bonhoeffers Programm „die nicht-religiöse Interpretation biblischer Begriffe“ $(1955)^{78}$ begegnen wir zum ersten Mal dem Terminus „Wortgeschehen“, und zwar hier gleich neben dem anderen Terminus „Sprachgeschehen“. Die beiden Termini werden bei Ebeling synonym

\footnotetext{
71 WGT, 25.

72 ZThK 47 (1950), 1-46; Wiederabdruck in: WG, 1-49. Die folgenden Nachweise beziehen sich auf die letztgenannte Publikation.

${ }^{73} \mathrm{WG}, 14 \mathrm{f}$.

${ }^{74}$ ZThK 48 (1951), 172-230; Wiederabdruck in: LuSt I, 1-68.

${ }^{75}$ Ebeling, Die Geschichtlichkeit der Kirche und ihrer Verkündigung als theologisches Problem, Tübingen 1954,
} 60.

${ }^{76}$ Ebeling, Die Geschichtlichkeit der Kirche und ihrer Verkündigung als theologisches Problem, Tübingen 1954, 80. Dazu erklärt er weiter: „Wenn aber das Verhältnis zu Jesus Christus in seiner eschatologischen Bedeutung nur so da ist, dass ich mir das Zeugnis davon im Glauben gesagt sein lasse, dann ist es kein Widerspruch, gehört vielmehr zum Wesen des Glaubens, dass dieses eschatologische Geschehen verborgen ist im geschichtlichen Geschehen, nämlich in dem geschichtlichen Geschehen, das mir die Begegnung mit dem Zeugnis von Jesus Christus.“(80).

${ }^{77}$ Ebeling, Die Geschichtlichkeit der Kirche und ihrer Verkündigung als theologisches Problem, Tübingen 1954, 67.

${ }^{78}$ ZThK 52 (1955), 296-360. Ebenfalls in: Die mündige Welt II, München 1956, 12-73; Wiederabdruck in: WG, 90-160. Die folgenden Nachweise beziehen sich auf die letztgenannte Publikation. 
verwendet. Obwohl „Wort“ und „Sprache“ sich wesentlich unterscheiden, sofern mit „Wort“ die transzendente Wirklichkeit des Wortes Gottes gemeint ist, werden die Termini gleichbedeutend verwendet, wobei Ersteres häufiger benutzt wird. Die Bedeutung des Terminus „Wortgeschehen“ wird von Ebeling selber hier nicht präzisiert, doch seine Absicht dafür ist trotzdem wahrnehmbar.

Ebeling versucht, Bonhoeffers Formel „nicht-religiöse Interpretation biblischer Begriffe“ durch das Verhältnis von Gesetz und Evangelium zu erklären. ${ }^{79}$ Bonhoeffers Religionskritik kommt von der Tendenz her, dass die Religion eine zusätzliche, spezielle Erfahrung von der mündigen Welt fordert und sich ihr damit entfremdet. Ohne diese hat die Religion aber kein Verhältnis zwischen Gott und der Welt. Bonhoeffers Kritik daran interpretiert Ebeling als die Kritik an einem falschen Verständnis, das das Gesetz zu etwas macht, das der Mensch ohne Rücksicht auf sein wirkliches Leben haben soll. Er erklärt, dass das Gesetz das Leben umfasst und das Evangelium nur diesbezüglich das Evangelium sein kann. Dieses Verhältnis von Gesetz und Evangelium erklärt er so: „Ohne die Predigt des Gesetzes kann das Evangelium gar nicht als Evangelium gepredigt werden. Dass Christus die Erfüllung und damit das Ende des Gesetzes ist, kann nur bezeugt werden, indem das Gesetz zur Sprache kommt. Will man das Evangelium predigen, ohne das Gesetz zu predigen, so macht man eo ipso aus dem Evangelium Gesetz und verfälscht damit zugleich das Gesetz, indem man aus dem Evangelium ein religiöses Sondergesetz macht, das mit der den Menschen als Menschen angehenden Wirklichkeit nichts zu tun hat, sondern den Menschen, um ihn zu Christen zu machen, der Wirklichkeit entfremdet" ${ }^{\circ}{ }^{80}$ Ebeling interpretiert die Lebensbedingungen des modernen Menschen bei Bonhoeffer als Gesetz und den mündigen und religionslosen Menschen als den Menschen unter dem Gesetz. Die Implikation der mündigen Welt in der Rede von Gott, die Bonhoeffer in den Gefängnisbriefen behauptet, interpretiert Ebeling, das Evangelium in Bezug auf die Wirklichkeit zu predigen. Ebeling formuliert den der nicht-religiösen Interpretation zugrundeliegenden Gedanken schließlich wie folgt: „Die entscheidende Frage lautet

\footnotetext{
${ }^{79}$ Ebelings Bonhoeffer-Interpretation ist umstritten. Z.B. E. Bethge, der die nicht-religiöse Interpretation im Anschluss an Ebeling als eine hermeneutische Frage an die Verkündigung der Kirche und das Lebensgestalt der Gemeinde versteht, sagt, „Ebeling hat davor gewarnt, Bonhoeffer zu einem Befürworter neuer ,Gestalt entgegen neuer Sprache zu machen“. Ders., Dietrich Bonhoeffer. Eine Biologie, München 1967, 987. Dagegen behauptet G. Sauter, Bonhoeffers Programm sei nicht hermeneutisch, sondern dogmatisch zu verstehen, also als „eine Reflexionsformel in Bezug auf den Sachgehalt der Theologie, auf ihr dogmatisches Leitmotiv; eine Besinnung auf das der Theologie zentral aufgegebene Thema“ (285). Nicht-religiöse Interpretation ist laut ihm dann für ein neues Verständnis des Gedankens der „Herrschaft Christi“ und nicht für das Verhältnis von Gesetz und Evangelium, wie Ebeling interpretiert. Ders., Zur Herkunft und Absicht der Formel „Nicht-religiöse Interpretation biblischer Begriffe“ bei Dietrich Bonhoeffer, in: EvTh 25 (1965), 283-297. Später kommt noch eine stärkere Kritik von E. Feil. Dieser behauptet, Bonhoeffer ziele auf das Handeln, nicht auf die Hermeneutik sowie die Verkündigung. „Man wird hier schließen dürfen, dass es Bonhoeffer nicht primär um ein Sprechen, um eine Interpretation, um die Verkündigung, sondern um die Gestalt des religionslosen Christentums und dessen Praxis geht.“ (381f). Unter diesem Aspekt kritisiert er, „,dass Bonhoeffers Theologie nicht von der Dialektik von Gesetz und Evangelium her interpretiert werden kann, wie Ebeling möchte“" (382, Anm. 4). Ders., Die Theologie Dietrich Bonhoeffers. Hermeneutik, Christologie, Weltverständnis, München 1971.
}

${ }^{80} \mathrm{WG}, 140 \mathrm{f}$. 
darum: Wie predigen wir dem religionslosen Menschen das Evangelium als Freiheit vom Gesetz. [...] Wie bringen wir das Gesetz, unter dem er de facto steht, zur Sprache? [...] denn an der Verständlichkeit und Verbindlichkeit der Predigt des Gesetzes hängt die Verständlichkeit und Verbindlichkeit der Predigt des Evangeliums. “81

Aufgrund solcher Interpretation von Bonhoeffers Formel ist es bezüglich des Terminus „Wortgeschehen“ erforderlich, den dies verwendeten Text noch näher zu betrachten. Ebeling analysiert hier die drei Voraussetzungen, auf denen Bonhoeffers Problemstellung beruht. Insbesondere in der dritten Grundvoraussetzung geht es um „die Ausrichtung auf die Aufgabe der Verkündigung“ ${ }^{82}$ Aus der Verkehrung des Verhältnisses von Wort und Glaube, die darauf beruht, dass nicht der Ungläubige, sondern der Gläubige das Kriterium der Verständlichkeit der Verkündigung geworden ist, folgt „nicht nur die Fremdsprachlichkeit der Verkündigung“, sondern auch „das Sprachloswerden des echten Glaubens". ${ }^{83}$ Ebeling sagt weiter, die eigentümliche sympathisierende Nähe des Glaubenden zum Religionslosen werde so ,zum echten Symptom der gegenwärtigen Situation des Christentums. Es geht dabei gerade nicht um missionarische Annäherungsversuche, sondern um ein Zurückgeworfenwerden auf die Anfänge des Verstehens, und um ein stammelndes neues Zu-Worte-Kommen des Wortes Gottes, ein tastendes Neuentdecken dessen, was eigentlich christlicher Glaube heißt." ${ }^{\text {"84 }}$ Dazu gibt Ebeling eine kurze Erläuterung: „Nicht zufällig treibt es Bonhoeffer zu dichterischen Versuchen - ein Symptom des eigenen Hineingerissenseins in das Wort- und Sprachgeschehen." 85 Die Wendungen von „Zurückgeworfenwerden auf die Anfänge des Verstehens“ und „Zu-Worte-Kommen des Wortes Gottes“ haben ein Verständnis des Offenbarungsgeschehens als Wortgeschehen zur Folge. Die Entstehung des Terminus „Wortgeschehen“ bzw. „Sprachgeschehen“ ist unter diesen Umständen nicht erstaunlich, weil die nicht-religiöse Interpretation biblischer Begriffe für Ebeling die Frage nach einer der religionslosen Wirklichkeit angemessenen Verkündigung fordert und letztlich zum Sprachproblem wird: „In dem Problem der nicht-religiösen Interpretation geht es darum wirklich entscheidend um die Aufgabe der Verkündigung ${ }^{\star 86}$ und weiter das ist „,das Problem der Verkündigung und damit ein Problem der Interpretation und damit wiederum ein Problem der Sprache“ .87

Im Hinblick auf die Entstehung des Terminus des Wortgeschehens ist nun zu sagen: Während Ebeling bei den vorliegenden Untersuchungen durch die unterschiedlichen Kompositionen des Geschehensbegriffs wie Offenbarungs-, Christus- oder Vergegenwärtigungs-Geschehen den existentialen Charakter der Hermeneutik darzustellen versucht, lässt er diesen Geschehenscharakter

\footnotetext{
${ }^{81} \mathrm{WG}, 145$.

${ }^{82} \mathrm{WG}, 114$.

${ }^{83} \mathrm{WG}, 120$.

${ }^{84} \mathrm{WG}, 121$.

${ }^{85} \mathrm{WG}, 121$. Anm. 104.

${ }^{86} \mathrm{WG}, 117$. Anm. 86.

${ }^{87} \mathrm{WG}, 118$.
} 
schließlich auf der Verkündigung und auf dem Wort selbst beruhen und bringt den Terminus „Wortgeschehen“ knapp zum Ausdruck, damit er bewahrend und besser den reformatorischen und ontologischen Charakter seines Denkens zeigen kann.

\section{Seit Mitte der 1950er Jahre}

Die Hermeneutik wird, wie bereits erwähnt, seit Mitte der 1950er das zentrale Thema und Leitmotiv Ebelings Theologie. Sein Sprachverständnis scheint dabei parallel einen konkreten Fortschritt zu machen. Anhand dreier Aufsätze soll gezeigt werden, wie er die Sprache den die Grundlage seines hermeneutischen und theologischen Gedankens bildenden Themen wie Wort Gottes, Hermeneutik und Gott gegenüberstellt und dadurch sein Sprachkonzeption präzisiert. Es wird auch deutlich wahrnehmbar, dass der Terminus „Wortgeschehen“, mit dem Ebeling das Wesen der Sprache bestimmt, seitdem im vollen Maße verwendet wird.

2. 1. Wort Gottes und Sprache (1959)

Die Frage nach dem Verhältnis vom Wort Gottes und der Sprache des Menschen ist eine theologisch wichtige, auf die Grundsätze kirchlichen Handelns weithin einflussreiche Frage. Vor allem aus evangelischer Sicht ist sie eine fundamentaltheologische Frage und bildet das Zentrum theologischer Hermeneutik. Auf diese Frage versucht Ebeling im Vortrag über „Wort Gottes und Sprache“ ${ }^{\text {(88 }}$ zu antworten.

In Hinsicht auf das Verhältnis von Gotteswort und Menschenwort gibt es zwei entgegensetzte Standpunkte in der Theologie; einerseits die Betonung der Differenz bzw. Unvereinbarkeit der beiden und andererseits ihre Relativität sowie die positive Möglichkeit des menschlichen Wortes, Gotteswort zu tragen. Gegenüber der Betonnung der Unvereinbarkeit und der Unterscheidung zwischen Gotteswort und Menschenwort hat ihre Korrespondenz eine kritische Spitze durch das metaphysische Denken, in dem das Gotteswort ein besonderes, übernatürliches Wort gehalten wird. Die Vermittlung zwischen Gotteswort und Menschenwort und die Interpretation wird im Katholizismus mit der Tradition, bzw. mit dem kirchlichen Lehramt verbunden und in der protestantischen Orthodoxie durch die Lehre von der wörtlichen Inspiration der Heiligen Schrift in Verbindung mit einer sogenannten Akkomodationstheorie erreicht. Die dialektische Theologie geht auch von der Scheidung zwischen

\footnotetext{
${ }^{88}$ Dieser Vortrag wurde am 22. Februar 1959 im Süddeutschen Rundfunk gesendet und erstmals in der Neuen Zürcher Zeitung (8. 3. 1959) abgedruckt. Wiederabdruck in: Wesen, 178-187. Die folgenden Nachweise beziehen sich auf die letztgenannte Publikation.
} 
Gotteswort und Menschenwort aus. Vornehmlich bei Barth zielt die Lehre vom Wort Gottes in konsequent durchgehaltener Distanz zum Menschenwort auf Gottes Wort.

Das Wort Gottes ist bei Ebeling aber kein übernatürliches Sonderwort und unterscheidet sich daher formal nicht von jedem anderen menschlichen Wortgeschehen. Zur Klärung des Verhältnisses zwischen dem Wort Gottes und der menschlichen Sprache liegt sein Ansatz in der Fragestellung, ob vom Wort Gottes etwas für unsere Sprachnot zu erwarten und umgekehrt, ob das Wort Gottes selbst in Sprachnot geraten sei. Dementsprechend unterscheiden sich die „Haltungen derer, die vom Wort Gottes nichts erwarten, und derer, die von ihm das Entscheidende erwarten“. ${ }^{89} \mathrm{Zu}$ erwarten, „dass Gottes Wort zur Sprache kommen will und wird“, bedeutet aber nicht, dass die Schwierigkeit des Verhältnisses dabei ignoriert wird. Diese Erwartung entsteht laut Ebeling viel eher aus der Gewissheit, dass Gottes Wort schon ,zur Sprache gekommen ist“. ${ }^{90}$ Das schon gekommene Wort Gottes ist die Bibel, die von „Verkündigungsgeschehen, dessen Anspruch sich als Wort Gottes ausgibt“", zeugt. ${ }^{91}$ Dabei besteht leider noch das Problem, dass dieses Verkündigungsgeschehen heute kein Geschehen mehr ist, nur ein Gerede, nämlich „kein gegenwärtiges Zur-Sprache-Kommen des Wortes Gottes“ “92 Zur Lösung des Problems schlägt Ebeling mit Blick auf Bonhoeffers Aussage „die Hoffnung auf ein neues Zur-Sprache-Kommen des Wortes Gottes“ vor: „Es wird eine neue Sprache sein, vielleicht ganz unreligiös, aber begreifend und erlösend, wie die Sprache Jesu, dass sich die Menschen über sie entsetzen und doch von ihrer Gewalt überwunden werden, die Sprache einer neuen Gerechtigkeit und Wahrheit, die Sprache, die den Frieden Gottes mit den Menschen und das Nahen seines Reiches verkündigt." ${ }^{93}$ Hinsichtlich des Verhältnisses zwischen Wort Gottes und menschlicher Sprache betont Ebeling also den Standpunkt, dass das schon zur Sprache gekommene Wort Gottes wieder neu zur Sprache kommen werden kann und muss. Er will dadurch abschließend die Hoffnung auf das Gotteswort wecken, darauf, dass Menschenwort Gotteswort vermitteln vermag.

Dieses positive Verhältnis vom Wort Gottes zur Sprache bezieht sich bei Ebeling auf die Auffassung des Wesens des Wortes. Das Wesen des Wortes als ein Sinnganzes erschließt sich erst „,von seinem Gesprochenwerden her“, und wird daher ,als mündliches, geschehendes Wort“ bestimmt. ${ }^{94}$ Dabei ist das Wortgeschehen als Mitteilung zu charakterisieren, aber nicht von Informationen, weil es dem andern etwas von der Existenz des Sprechenden mitteilt und daran Anteil nimmt. Das Wesen des Wortes erreicht man deshalb, nach Ansicht Ebelings, nicht mit der Frage, „,was das Wort enthält“, sondern mit der Frage, „was das Wort wirkt, was es anrichtet, welche Zukunft es eröffnet. “95 Gerade im Anschluss

\footnotetext{
${ }^{89}$ Wesen, 178.

${ }^{90}$ Wesen, 179.

${ }^{91}$ Wesen, 179.

92 Wesen, 180.

${ }^{93}$ D. Bonhoeffer, Widerstand und Ergebung, Siebenstern-Taschenbuch I, 153. Hier zitiert nach Wesen, $180 \mathrm{f}$.

${ }^{94}$ Wesen, 181.

${ }^{95}$ Wesen, 183.
} 
an die Auffassung, dass das Wort wesentlich nicht mehr für nur ein technisches Verständigungsmittel zum Transport von Informationen gehalten werden darf, sondern sein Wesen in seiner Wirkung liegt, finden wir Ebelings Lösung dafür, wie Gottes Wort in der Gestalt menschlichen Wortes begegnen kann. Mit dem Wort Gottes ist für ihn nichts anderes gemeint als „reines, wahres Wort, in dem das, was das Wort eigentlich sein und wirken soll, zur Erfüllung kommt und geschieht“.96

Die Unterscheidung zwischen Wort und Sprache ist bei Ebeling auch wahrnehmbar. Er bestimmt das Wort als „ein Sinnganzes“ entsprechend einer Rede, die als gutes, treffendes Wort bezeichnet wird, und meint mit der Sprache jenen Raum, der uns aufgetan ist, „durch den das Wortgeschehen ermöglicht und bestimmt ist ${ }^{\text {“ }}{ }^{97} \mathrm{Er}$ charakterisiert dabei die Sprache mit den Problemen von Geschichtlichkeit, Verständigung, Geist und Wirklichkeitsverständnis. ${ }^{98}$ Dieser terminologischen Unterscheidung soll dennoch ein systematisierender Zugang zu Ebelings Texten vorausgehen, wobei darauf zu achten ist, dass Geschehens- und Aussageaspekt der Sprache begrifflich nicht streng auf Wort und Sprache verteilt, sondern terminologisch variierend zur Geltung gebracht werden. Das rechtfertigt außerdem die Tatsache, dass Ebeling den Unterschied zwischen Wort und Sprache nicht weiter entwickelt, sondern einen austauschbaren Gebrauch dieser Begriffe vorzieht.

Insbesondere aufgrund des Zusage-Charakters des Wortes, nämlich dass einer das, wovon die Rede ist (zu-sagt), durch sein Sagen auf den anderen hinträgt, hätte das Wort also Gott zuzusagen, in dem es um Gott geht. Durch das Wort kommt Gott zum Menschen und sagt sich ihm zu. ${ }^{99}$ Von solcher Besinnung des Wortes her bestimmt Ebeling die Beziehung zwischen Gott, Menschen und Welt in ihrem worthaften Zusammenhang: die Welt, die als die uns angehende Wirklichkeit immer ,schon zur Sprache gekommen ist“, als „Anruf, Anfrage Gottes“, Menschenwort als Antwort, und Gottes Wort als das neu zur Sprache Bringen der uns angehenden Wirklichkeit. ${ }^{100}$ Diese worthafte Beziehung zwischen Gott, Menschen und Welt entwickelt sich weiter in seinen späteren Werken inkl. seiner Dogmatik und dient zur Bildung des theologischen, ontologischen Charakters seines Sprachverständnisses.

\subsection{Wort Gottes und Hermeneutik (1959)}

Die untrennbare thematische Verbindung von Wort Gottes und Hermeneutik hat einen reformatorischen Ursprung. Mit der reformatorischen Konzentration auf das Wort Gottes wurden aber oftmals

\footnotetext{
${ }^{96}$ Wesen, 185.

${ }^{97}$ Wesen, 184.

${ }^{98}$ Vgl. Wesen, 183f: Die Sprache ist „,in Jahrhunderten und Jahrtausende“ herangewachsen und wachsend noch im „Wandelprozess“; Die Sprache schafft das Problem der Verständigung, ,immer zugleich Verstehen und Nichtverstehen“; „Die Sprachen unterscheiden sich durch ihren Geist“; Durch Sprache ist „uns Wirklichkeit erschlossen und ein ungeheurer Reichtum überliefert (ist), aus dem unser Reden schöpft“.

${ }^{99}$ Wesen, $185 f$.

${ }^{100}$ Wesen, 186.
} 
ironischerweise die Probleme der Hermeneutik vernachlässigt. Das Verhältnis zwischen beiden behandelt Ebeling vor allem in dem Aufsatz $>$ Wort Gottes und Hermeneutik $<(1959)^{101}$ als das leitende Thema und behauptet, dass diese Vernachlässigung aus dem falschen Verständnis des reformatorischen Schriftprinzips sola scriptura kommt. Sola scriptura muss ihm zufolge als eine hermeneutische These bestimmt werden. ${ }^{102}$ Dass die Heilige Schrift sui ipsius interpres sei, wie Luther formulierte, expliziert nur dessen hermeneutischen Sinn. Ebeling erklärt: „Die Schrift ist nicht dunkel [...] Die Schrift eignet vielmehr claritas, d.h. sie hat erhellende Kraft, so dass von ihr klärendes Licht ausstrahlt." ${ }^{103}$ Dieser hermeneutische Sinn des sola scriptura lässt das Verhältnis vom Wort Gottes und der Schrift zum Problem werden.

An der orthodoxen Lehre, die eine starke Betonung auf verbum Dei scriptum legt, kritisiert man gewöhnlich, dass hier die Schrift ununterscheidbar mit dem Wort Gottes identifiziert sei. Und man korrigiert den Satz „Die Schrift ist das Wort Gottes“, zu „Die Schrift enthält oder bezeugt das Wort Gottes. “104 Über den entscheidenden Mangel der orthodoxen Position sagt Ebeling aber, dass ,von der Heiligen Schrift als Wort Gottes geredet wird unter Absehen von der Verkündigung, also ohne dass die Zukunft mit zur Sprache kommt, auf die die Heilige Schrift als auf ihre eigene Zukunft vorausweist.“105 Das heißt, der Begriff des „Wort Gottes“ muss in einem noch viel umfassenderen Sinne auf Geschehen hin interpretiert werden. Allein nach diesem Verständnis des Wortsbegriffs als Geschehen kann man zur richtigen Auffassung der Hermeneutik bei Ebeling kommen. Die Begriffe von „Wort Gottes und Hermeneutik" stehen bei ihm in einem notwendigen Verhältnis zueinander, so dass der Glaube an das Wort Gottes die hermeneutische Fragestellung verbietet und die hermeneutische Fragestellung die Bedeutung des Wortes Gottes auflöst.

Ebeling bestimmt die erste Definition von Hermeneutik ${ }^{106}$ wie folgt: „Wie immer nun auch ,Hermeneutik' genauer zu bestimmen sein mag - jedenfalls hat sie als Lehre vom Verstehen mit dem Wortgeschehen zu tun. Und zwar, wie jede Wissenschaft, letztlich in praktischer Abzielung, als Hilfe zum Wortgeschehen, nämlich als Anleitung dazu, wie geschehenes Wort zum Verstehen kommt.“107

\footnotetext{
${ }^{101}$ Der Aufsatz wurde erstmals auf der Herausgebertagung der ZThK 56 (1959) veröffentlicht. Wiederabdruck in: WG, 319-348. Die folgenden Nachweise beziehen sich auf die letztgenannte Publikation.

$102 \mathrm{WG}, 321$.

${ }^{103} \mathrm{WG}, 320 \mathrm{f}$.

$104 \mathrm{WG}, 326$.

105 WG, 326f.

${ }^{106}$ Diese Definition wird noch genauer bestimmt, indem Ebeling einleitend auf das Verhältnis von Exegese und Hermeneutik eingeht: „Nach der landläufigen Auffassung unterscheidet man scharf zwischen Exegese als dem Vorgang der Auslegung selbst und Hermeneutik als der Theorie der Auslegung. Und zwar versteht man dabei als Objekt der Auslegung, d.h. als das, was der Auslegung bedarf, die sprachliche Äußerung. Je nach der Art der sprachlichen Äußerung kann sich die allgemeine Hermeneutik in Spezialhermeneutiken differenzieren, freilich ohne damit den umgreifenden Rahmen allgemeiner Hermeneutik zu verlassen.“ (WG, 329).

107 WG, 328.
} 
Damit darf die Hermeneutik nicht auf eine Sammlung von Regeln reduziert werden. In Hinsicht auf den Begriff der Hermeneutik knüpft Ebeling, wie J. Rohls mit Recht betont, ,an das erweiterte Verständnis dieses Begriffs ausgehend von Schleiermacher, Dilthey und Heidegger“" 108 an, nämlich dass die Hermeneutik als die Lehre vom Verstehen bestimmt wird und mit den Bedingungen der Möglichkeit des Verstehens zu tun hat. Ebeling geht einen Schritt weiter und formuliert seine eigene Auffassung des Verstehensphänomens, nämlich dass das primäre Verstehensphänomen nicht „das Verstehen von Sprache“, sondern „das Verstehen durch Sprache“ ist. ${ }^{109}$ Das heißt, das Wort ist eigentlich kein Objekt des Verstehens. Wenn man das Verstehensphänomen als das Verstehen von Sprache ergreift, bedarf das Wort hinsichtlich des Verstehensproblems und zu dessen Lösung der Hermeneutik als der Verstehenslehre. Das Verstehen durch Sprache bedeutet aber, dass das Wort selbst Verstehen „eröffnet“ und „,vermittelt“ und etwas „zum Verstehen bringt“. ${ }^{110}$ Das Wort selbst hat dabei die hermeneutische Funktion, so dass es keiner Verstehenshilfe bedarf, sondern selbst Verstehenshilfe ist. ${ }^{111}$

Nun ergeben sich Ebelings drei wichtige Perspektiven auf die Hermeneutik: Erstens, Hermeneutik ist nur dann erforderlich, wenn das Wortgeschehen aus irgendeinem Grund gestört ist. Die hermeneutische Hilfe kann nur darin bestehen, „Störungen zu beseitigen, das Wort in seiner eigenen hermeneutischen Funktion wirken zu lassen“. ${ }^{112}$ Zweitens, insofern Hermeneutik die eigene hermeneutische Funktion des Wortes wirken lässt und damit nur zu „der Selbstverständlichkeit des Wortes“ dient, ist ihr Inhalt und Gegenstand nichts anderes als das Wortgeschehen. Ebeling formuliert diesen Sachverhalt folgendermaßen: „wo Wort geschieht, wird Verstehen ermöglicht“. ${ }^{113}$ Und schließlich, wenn für die Hermeneutik das Verstehen ermöglichende Wort konstitutiv ist, hat die Hermeneutik ,immer schon mit dem zu tun, was durch das Wortgeschehen zum Verstehen gebracht werden soll“ und darf dann nicht ,auf rein Formales“ beschränkt werden. ${ }^{114}$

Die so auf das Wortgeschehen bezogene Hermeneutik muss sich, nach Ansicht Ebelings, in irgendeiner Weise an Sachverhalten orientieren. ${ }^{115}$ Die Beziehung des Vernehmenden zur sprachlichen Äußerung muss demzufolge stets mit entsprechender Beziehung zur Wirklichkeit verbunden sein. Ebeling stellt sich somit einerseits in eine Linie mit Bultmann, indem er Hermeneutik nicht als eine methodische Hilfsdisziplin zum besseren Verständnis der Texte begreift, sondern als Interpretation von Wirklichkeit in einem grundsätzlichen Sinne. Andererseits geht er über Bultmann hinaus seinen eigenen Weg mithilfe der sprachlichen Verfassung von Wirklichkeit: „, [...] indem die Hermeneutik dem Wort

\footnotetext{
108 J. Rohls, Protestantische Theologie der Neuzeit II. Das 20. Jahrhundert, Tübingen 1997, 581.

109 WG, 333.

${ }^{110} \mathrm{WG}, 333 \mathrm{f}$.

111 WG, 334.

112 WG, 334.

${ }^{113} \mathrm{WG}, 334 \mathrm{f}$.

$114 \mathrm{WG}, 335$.

115 WG, 336.
} 
zugewandt ist, ist sie der Wirklichkeit zugewandt, die durch das Wort zum Verstehen kommt. "116 Denn Wirklichkeit als der Bereich dessen, was tatsächlich existiert und als Gegebenheit wahrnehmbar und erfahrbar ist, wird laut Ebeling nur durch Sprache verständlich. Die Sprachlichkeit der Wirklichkeit wird deshalb zum zentralen Thema seiner Hermeneutik. Von diesem hermeneutischen Gedanken her ergreift er die Worthaftigkeit als das verbindende Element zwischen göttlicher und menschlicher Wirklichkeit und damit als Ansatz für die Möglichkeit der Rede von Gott ${ }^{117}$, die als das wichtige Problem der theologischen Hermeneutik ihre Klimax im Wort „Gott“ hat.

\subsection{Gott und Wort (1966)}

Das Wort Gott ist das Hauptthema von Ebelings Aufsatz $>$ Gott und Wort $<(1966) .{ }^{118}$ Er vertritt hier die These, dass „der Sinn des Wortes Gott [...] die Grundsituation des Menschen als Wortsituation“"119 ist. Der erste Beleg dafür, dass Ebeling das Wort Gott auf die Grundsituation des Menschen bezieht, befindet sich in dem Aufsatz $>$ Hermeneutische Theologie $<{ }^{120}$ von 1965, in dem er sich mit der Charakterisierung seiner Theologie als eine Theologie der Hermeneutik durch Moltmann auseinandersetzt. In diesem Aufsatz endet Ebeling die Ausführungen mit dem programmatischen Satz: „So ist es die elementarste Aufgabe hermeneutischer Theologie, das Wort Gott an der Grundsituation des Menschen zu verifizieren.“ ${ }^{121}$ Die Grundsituation des Menschen bedeutet bei $\mathrm{Ihm}$ „diejenige Situation, die für das Menschsein konstitutiv ist und die allen nur denkbaren Situationen des Menschen als letztlich bestimmend zugrundeliegt und in ihnen präsent ist“. ${ }^{122}$ Die so für jeden Menschen grundlegende Situation bezieht er auf den Sinn des Wortes Gott. Dieses Thema entwickelt er ein Jahr später in dem Aufsatz $>$ Gott und Wort $<$ und behandelt wieder in der $>$ Dogmatik des christlichen Glaubens $<{ }^{123}$. Hier gehen wir noch näher auf die in dem Aufsatz $>$ Gott und Wort $<$ aufgestellte These ein, also mit der Frage, was Ebeling mit dieser These im Blick hat und wie sie sich auf sein Sprachverständnis bezieht.

\footnotetext{
116 WG, 335.

${ }^{117}$ Vgl. WG, 369: „[...] dass das Wort es ist, was Gott und unsere Wirklichkeit verklammert und verbindet, dass also Gott und unsere Wirklichkeit eins sind in der Worthaftigkeit.“

${ }^{118}$ Dieser Aufsatz stammt aus Ebelings Vorlesung über das Verhältnis von Gott und Wort, die im Feb. 1966 auf der Interdenominational Pastoral Conference gehalten und im gleichen Jahr publiziert wurde. Wiederabdruck in: WG II, 396-432. Die folgenden Nachweise beziehen sich auf die letztgenannte Publikation.

${ }^{119}$ WG II, 416.

${ }^{120}$ WG II, 99-120.

${ }^{121}$ WG II, 120.

122 D I, 189.

${ }^{123}$ D I, 182-191.
} 
Für die Argumentation knüpft Ebeling zuerst an die Situation des modernen Menschen an, für den das Wort Gott nichtsagend geworden ist. ${ }^{124}$ Das Reden von Gott scheint für ihn heute nur noch „ein totes Sprachrelikt der Vergangenheit“ zu sein, dessen Sprachzentrum gewissermaßen den Vorvätern der Bibel gewesen ist. ${ }^{125}$ Und in einer Wesensanalyse des Wortes sucht er die Möglichkeit, in der Säkularität der Neuzeit das Reden von Gott verantwortlich halten zu können. Er sieht die wichtigste Ursache für den Bedeutungsverlust des Wortes Gott in einem signifikativen Sprachverständnis, in dem die Sprache die Welt abbildet. Das Wort Gott wird dabei als signum einer res aufgefasst, über deren Existenz auf eine außersprachliche Weise entschieden wird. Wenn man dieser Spur weiter folgt, führt sie zum Atheismus, in dem das Wort Gott sinnlos geworden ist. ${ }^{126}$ Wie kann es dann wieder für sinnvoll gehalten werden?

Gemäß Ebelings Sprachauffassung ereignet sich doch das Wort stets „als ein zeitliches Geschehen“127, denn das gesprochene Wort ist immer in die Zeit hineingestellt und nur dann kann es den in der Zeit lebenden Menschen treffen. Der Satz als die elementare Sinneinheit der Sprache fügt „das, wovon die Rede ist, im Medium der Zeit“" zusammen. ${ }^{128}$ Darum ist das Wort niemals von der Situation getrennt, „der es entspricht, in die hinein es geschieht und die es dadurch verändert“ ${ }^{\text {“129 }}$ und in jeder solchen konkreten Situation befindet sich jeder Mensch, so dass die Grundsituation des Menschen als Wortsituation bestimmt wird. Und deshalb haben wir in unserem Dasein auch unsere Sprache, die jeder Einzelne zu verantworten hat. Der Wortsituation entspricht immer die „Wortverantwortung “130, dass derjenige, der etwas sagen will, etwas zu sagen hat, sich bei seinem Wort behaften lassen muss. ${ }^{131}$ Der Zusammenhang von der Wortsituation und der Wortverantwortung macht das Wort zum „Erfahrungshorizont dessen, was wir meinen, wenn wir Gott sagen.“ ${ }^{132}$ Deshalb im Sachverhalt, dass jeder einzelne Mensch in der vom Wort untrennbaren Situation existiert und für das Wort, das er sagt, verantwortlich ist, ist das Wort Gott sinnvoll.

In der These, dass mit dem Wort Gott die menschliche Grundsituation als Wortsituation angegeben wird, kommt schließlich Ebelings Verständnis vom Wesen der Sprache und vom Sein Gottes überein. Für ihn ist Sprache wesentlich gottbezogen und folgend auch der Mensch, der durch seine

\footnotetext{
${ }^{124} \mathrm{Vgl}$. WG II, 408.

${ }^{125}$ WG II, 398.

${ }^{126}$ WG II, 408.

${ }^{127}$ WG II, 409.

${ }^{128}$ WG II, 409.

${ }^{129}$ WG II, 410.

${ }^{130} \mathrm{Vgl}$. WG II $1-41$.

${ }^{131}$ WG II, 410. Zum Verständnis der Wortsituation und der damit gegebenen Wortverantwortung gehört für Ebeling die Kategorie des Einzelnen. Dieses ist anzumerken, weil Ebeling davor warnt, aus einem ,vermeintlichen Individualismus Begriffe wie Innerlichkeit, Gewissen und dergleichen auf den index verborum prohibitorum" zu setzen. Sprachlehre, 55.

${ }^{132}$ WG II, 415.
} 
Sprachlichkeit definiert und gerade in seiner Sprachlichkeit wesenhaft ist. ${ }^{133}$ Für ihn ist das Thema „Wort“ bzw. „Sprache“ nicht zu behandeln, ohne sich zugleich mit „Gott“ auseinanderzusetzen. Diese Gottbezogenheit zeigt einerseits, dass Ebeling gründlich theologisch argumentiert, d.h. bei dem unverbrüchlichen Wort-Zusammenhang von Gott und Mensch einsetzt, und andererseits, dass Ebelings Auffassung von Sprache und die damit korrespondierende Sicht auf die Beziehung von Gott und Mensch nicht substanzontologisch, sondern relationsontologisch sind. Es ist deshalb anzumerken, dass Ebeling später die Relation coram Deo, die alle Relationen umgreift, als ,sprachliche Personalitätsrelation" bestimmt, ${ }^{134}$ weil die Sprachlichkeit des Menschen seine Personalität impliziert, so wie Gott als Person spricht. ${ }^{135}$

Von der Auffassung herkommend, dass die Wortsituation des Menschen den Ort sinnvoller Rede von Gott bezeichnet, führt Ebeling weiter aus, dass das Wort Gott dem Menschen die Bewegungsrichtung weist, die sich im Gebrauch des Wortes Gott ereignet und die sich im Vokativ oder in der „Anrede“ auf Gott selbst vollzieht. ${ }^{136}$ Aber der anrufende oder ausdrücklich „,betende“137 Gebrauch des Wortes Gott bedarf einer besonderen Ermächtigung, die dem Menschen nicht von sich aus erteilt ist. Denn der Mensch ist letztlich nicht Täter, sondern Empfänger, der von der Macht des Wortes Gottes lebt, das nicht das seine ist. Hier wendet sich Ebeling vom Wort Gott zum Wort Gottes und zum Verhältnis von beiden.

Die Ermächtigung, das Wort Gott zum Anruf Gottes zu gebrauchen, kann freilich nicht aus der Vokabel Gott geschöpft werden. Dazu bedarf es, dass Gott im Wort vernehmbar wird. Der Sinn des Wortes Gott wird nicht ohne das Wort Gottes geglaubt, ${ }^{138}$ weil dieses den Gebrauch des Wortes Gott erst möglich und notwendig macht. Das Wort Gottes wird dabei nicht einfach als die biblische Sprachüberlieferung verstanden, sondern als gewissmachende und in der Geschichte rettend wirkende Sprache und als eine sprachlosen Mächten überlegene Vollmacht des Wortes. ${ }^{139}$ Im Sinne der biblischen Überlieferung handelt es sich bei dem Wort Gottes, nach der Darstellung Ebelings, um „sich ständig erneuerndes“, „Welt öffnendes“ und „sprachschöpferisches“ Wortgeschehen ${ }^{140}$, das sich selbst „verifiziert, indem es den Menschen verifiziert“141, und ihn schließlich zur Wahrheit bringt. Das heißt, dass das Wort Gottes nicht der von außen kommenden Bestätigung bedarf. Das Wort Gottes ist für

\footnotetext{
${ }^{133}$ WG II, 418.

134 WG III, 422.

$135 \mathrm{Vgl}$. D II, 71.

${ }^{136}$ WG II, 420.

137 WG II, 422.

138 WG II, 420.

${ }^{139}$ Vgl. J. Werbick, Die Aporetik des Ethischen und der christliche Glaube. Studien zur Fundamentaltheologie Gerhard Ebelings, München 1976, 314.

${ }^{140}$ WG II, 426.

${ }^{141}$ WG II, 426.
} 
Ebeling ein konkretes Ereignis, das die faktische Situation des Menschen entscheidend ändern kann. ${ }^{142}$ Solches Wort ist aber nichts anderes als „das tiefe Geheimnis der Wirklichkeit“" und also Gott selbst. ${ }^{143}$ P. Knauer fasst Ebelings Gedanken so zusammen: Der Begriff des Wortes Gottes ist in seinem „eigentlichen“ Sinn so zu verstehen, dass er „,das Ganze des göttlichen Heilshandelns umfasst und die ganze Wirklichkeit des Menschen trifft". 144

Angesichts der Frage, ob das Wort Gottes mit dem menschlichen Wort und auch mit dem Wort Gott grundsätzlich unvereinbar ist, ${ }^{145}$ nimmt Ebeling die beiden Aspekte auf, sowohl von der Übereinstimmung durch die Erfahrung als auch von der Unvereinbarkeit durch die Offenbarung. Die Beiden integrieren „Entsprechung“ und „Widerspruch“ in der Unterscheidung zwischen Gotteswort und Menschenwort. ${ }^{146}$ Das Wort Gott eignet sich in seiner Vermittlungsfunktion in der Unterscheidung zwischen Gottes Wort und Menschenwort, weil in dem Wort Gott die Macht und zugleich die Ohnmacht des Menschenwortes gezeigt wird. Das Wort Gott ist nicht der Ausdruck eines beliebigen Bewusstseins von Transzendenz, sondern der innere Widerspruch von der „Gottlosigkeit“ des Menschen und seiner Ambiguität, „von Gott reden zu müssen, und doch nicht zu können“. ${ }^{147}$ Hier schon besteht der voraussichtliche Umschlag von der Entsprechung zum Widerspruch. Die davon ausgehenden wichtigen Linien führen, wie Beutel sagt, einerseits ,in den Grundriss einer theologischen Sprachlehre“ und andererseits ,in die reife dogmatische Rechenschaft, welche die betende Anrufung Gottes als den hermeneutischen Schlüssel zur Gotteslehre" versteht. ${ }^{148}$

\section{3. > Einführung in theologische Sprachlehre $<$ (1971)}

Die Konzeption über die theologische Sprachlehre erscheint bei Ebeling schon in seinem Aufsatz $>$ Hauptproblem der protestantischen Theologie in der Gegenwart< (1960), z.B. im Satz „Die Theologie gilt es zu fassen als Hermeneutik, d.h. als Verstehenslehre und Sprachlehre des Glaubens“"149. Der Ausdruck ,theologische Sprachlehre“ selbst findet sich erst in der Veröffentlichung >Einführung in theologische Sprachlehre $<.{ }^{150}$ Dieses Buch könnte, so wie Ebeling selber im Vorwort äußert, eine bloße

\footnotetext{
142 WG II, 429.

${ }^{143}$ WG II, 431.

${ }^{144}$ P. Knauer, Der Glaube kommt vom Hören, Ökumenische Fundamentaltheologie, Bamberg 51986, 75.

145 WG II, $401 f$.

${ }^{146}$ WG II, 402.

${ }^{147}$ WG II, 407.

${ }^{148}$ A. Beutel, Gerhard Ebeling. Eine Biographie, Tübingen 2012, 334.

${ }^{149}$ WG II, 69f.

${ }^{150}$ Den Inhalt dieses Buches hat Ebeling ursprünglich im Sommersemester 1970 unter dem Titel „Prolegomena zu einer theologischen Sprachlehre“ vorgetragen und ein Jahr später gründlich überarbeitet und als ein kleines Buch in die Welt gebracht.
} 
Einführung sein, mit der die Erwartung eines hohen Niveaus seitens der Leser nicht erfüllt werden könnte. ${ }^{151}$ In der Tat behandelt er hier aber verschiedene Aspekte der Sprache und ihre verflochtene, vielfältige Problematik und führt uns etwa zu einem „Reichtum““ ${ }^{152}$ Ebeling zielt offenbar darauf, angesichts der Sprachkrise des Christentums die theologische Sprachlehre als eine Prinzipienlehre festzustellen. Um dieses Ziel zu erreichen, versucht er die Notwendigkeit der theologischen Sprachlehre zu betonen (3.1), und ihren umfassenden Horizont zu bestimmen (3.2).

\subsection{Die Notwendigkeit der theologischen Sprachlehre}

Ebeling sieht die Krise des gegenwärtigen Christentums am Sprachproblem und an der seinerzeit vielfach beschworene „Sprachkrise“. Als ihre problematischen Phänomene nennt er beispielweise die „Technisierung“, die beim Anbieten von vielen oberflächlichen Informationen die Sprache „bloß zur Chiffre" macht, oder die „Ideologisierung“, die die Sprache etwa magisch in der Art von „Ideologie“ oder „bloßer Redewendung“ verwendet und ihren eigentlichen Inhalt außer Acht bleiben lässt. ${ }^{153}$ Von derartigen Symptomen kann die gegenwärtige Theologie und Kirche nicht frei sein. Die Krise des Christentums bezeichnet Ebeling vorzugsweise mit dem Ausdruck „Überdruss an der Sprache“ bzw. „Überdruss am Wort“, der „eine Allergie gegenüber der anspruchsvollen, aber inhaltsleer empfundenen Rede vom Wortes Gottes“ hervorruft und das wirklich Gesagte daher aus dem Blick verliert. ${ }^{154}$ Das Vertrauen auf das Wort, auf dem sich das Leben des christlichen Glaubens begründet, ist nun verschwunden oder gering geworden, weil die Sprache des Glaubens durch die „Entfremdung vom Sachverhalt" ihre Sicherheit verliert. ${ }^{155}$

Ebeling ist grundsätzlich der Meinung, dass die heutige Krise des Christentums sowie die Inflation des christlichen Wortes und damit der Schwund des Vertrauen auf das Wort oder dessen Schwäche über ihre zeitgenössische Relevanz hinaus ,in sehr viel weitere(n) geschichtliche(n) Zusammenhänge(n)“ stehen. ${ }^{156}$ Dafür macht er u.a. die dialektische Theologie verantwortlich, die sich gegen den frommen Subjektivismus in Rückwendung auf das reformatorische Erbe etwa als die

\footnotetext{
${ }^{151}$ Sprachlehre, XIIf.

${ }^{152}$ P. Knauer, Rez. G. Ebeling, Einführung in theologische Sprachlehre, in: ThPh 47 (1972), 300. Das könnte vielleicht auf Ebelings Darstellungsweise beruhen, wie A. Beutel sagt, „,nach der breiten, weit ausholenden Problemschürzung erst ganz am Ende auf eine dichte, knapp andeutende Problemlösung“ zuzusteuern. Ders, Gerhard Ebeling. Eine Biographie, Tübingen 2012, 394; oder auf die literarische Gattung dieses Buches, weder als eine Monographie, ein Kompendium noch eine Programmschrift, sondern als „den Still der Meditation“, der intellektuelle Erbauung des Autors gewährt und den Leser auffordert, „sich zu eigenen Nachdenken Zeit““ zu lassen. Sprachelehre, XIV.

${ }^{153}$ WG II, 63f.

${ }^{154}$ Sprachlehre, 3.

${ }^{155}$ Sprachlehre, 74.

${ }^{156}$ Sprachlehre, 5.
} 
Theologie des Wortes versteht. Die Konzeption der dialektischen Theologie für das Wort gründet sich auf das Denken von Barth, der das ewige Wort Gottes in einen unversöhnbaren Gegensatz zu allem Zeitlichen, Weltlichen bzw. Menschlichen stellt und sich darauf richtet, die absolute Autorität Gottes bzw. dessen Wortes dogmatisch festzulegen. In solcher Beschäftigung mit dem Wort Gottes wird der Mensch als der Adressat des Worts Gottes sowie dessen Lebens- und Situationsbezogenheit ausgeklammert. Ebeling kritisiert, dass die sogenannte Theologie des Wortes den Begriff des Wortes „in polemischer Antithese zum Phänomen der Erfahrung“ setzt und Schuld daran hat, „einen orthodox erstarrten und verkümmerten Begriff des Wortes“ wieder herzurufen. Sie erscheint ihm „als eine Art magischer Formel, als Ideologie oder als bloße Redewendung“ ohne verantwortlichen Vollzug. ${ }^{157}$

Angesichts einer solchen sprachlich charakterisierten Krise stellt sich Ebeling die Frage: Wie kann der christliche Glaube gegen die Sprachverwirrung in vertrauensvolle Worte gebracht werden? ${ }^{158}$ Mit dieser Fragestellung betont er die Notwendigkeit der theologischen Sprachlehre und versucht dadurch, „die Sprache auf ihre Echtheit“ zu prüfen, um ,gegebenenfalls verdeckte Sprachkrisen in heilsamer Weise“ kenntlich zu machen und die Sprache des Glaubens in „Widerfahrnis gegenwärtig machender Gegenwart“ zu entbinden. ${ }^{159}$ Dieser Versuch hat letztlich, nach der Einsicht Ebelings, mit der fundamentaltheologischen Besinnung auf das Verhältnis von Wort und Glauben zu tun. In Hinsicht auf die fundamentaltheologische Aufgabe der theologischen Sprachlehre und den diese als solchen erfordernden Umstand erklärt Ebeling wie folgt: „Theologische Sprachlehre berührt sich aufs engste mit dem Aufgabenbereich von Fundamentaltheologie. Sie stellt zumindest ein wichtiges Ingrediens von Fundamentaltheologie dar. [...] Theologische Sprachlehre wird als gesondertes theologisches Unternehmen dann erforderlich, wenn die Theologie in eine Sprachkrise gerät, jedoch keine der bestehenden Disziplinen ausreichend Gelegenheit bietet und ein dafür geeignetes Instrumentarium besitzt, diese Problematik thematisch zu reflektieren. Denn alle herkömmlichen theologischen Disziplinen sind gleichermaßen von der Krise befallen. Deshalb bedarf es um deren Überwindung willen eines neuen Zugangs zu der gemeinsamen theologischen Aufgabe, an der, wenn sie gelingen soll, alle Disziplinen sich ihrer Zusammengehörigkeit wieder bewusst werden und $\mathrm{zu}$ fruchtbarer Kooperation gelangen müssen. “160 Die theologische Sprachlehre kommt für Ebeling dann weder aus

\footnotetext{
${ }^{157}$ Sprachlehre, $3 \mathrm{f}$.

${ }^{158}$ E. Jüngel bringt für die Bedrohung des christlichen Glauben dagegen die Mangel an den „rechten Worte(n)“ und an der „Sprachlosigkeit“ zum Ausdruck: „Der christliche Glaube ist von Sprachlosigkeit bedroht - nicht weil ihm die Worte fehlte, sondern weil ihm die rechten Worte fehlen. Die den christlichen Glauben bedrohende Sprachlosigkeit ist zugleich eine elementare Bedrohung der Sachlichkeit des christlichen Glaubens. Denn die Sache des christlichen Glaubens drängt zur Sprache. Bleiben die rechten Worte aus, so ist der Verstehende offensichtlich noch nicht bei der Sache.“ Ders., Gott - als Wort unserer Sprache, in: Ders., Unterwegs zur Sache. Theologische Bemerkungen, München 1972, 80.

${ }^{159}$ Sprachlehre, 83f.

${ }^{160}$ Sprachlehre, 227f.
} 
einer gegenwärtigen akademischen Tendenz, in der die Sprache als ein wissenschaftliches, philosophisches Problem behandelt wird, sondern aus dem Krisensymptom selbst, in dem aus seiner Sicht alle herkömmlichen, bisher traditionellen theologischen Disziplinen gestört sind. Ein neuer Zugang ist nun nötig, was aber keineswegs eine neue theologische Sprachlehre meint. Ebeling richtet sich mit der theologischen Sprachlehre nicht auf eine neue theologische Sprachdisziplin oder -regelung, in der eine bestimme Sprache mit besonderer Redewendung oder Vokabular einexerziert wird, ${ }^{161}$ sondern auf die theologische Reflexion über die Sprache des Glaubens als den Dialog mit der Welterfahrung.

\subsection{Der umfassende Horizont der theologischen Sprachlehre}

Ebelings Bemühung, den Horizont der theologischen Sprachelehre auf die Ebene des Lebens zu erweitern, geht bemerkenswerterweise in zwei Richtungen: ihren theologischen Charakter als Besonderheit $\mathrm{zu}$ bewahren und zugleich Allgemeinheit nicht $\mathrm{zu}$ verlieren einerseits; und dem Missbrauch der Praxis zu widerstehen und die Trennung zwischen Theorie und Praxis zu überwinden andererseits. Die Hermeneutik ist für Ebeling die für die theologischen Reflexionen geeignete und umfassendste Betrachtungsweise der Sprache.

\subsubsection{Allgemeinheit und Besonderheit}

Ebelings Interesse für die Sprache entsteht, wie oben aufgezeigt, eigentlich aus seinem Interesse für das Wort Gottes, so dass seine Sprachlehre theologischer Art und nicht in eine allgemeine Sprachlehre ${ }^{162}$ als Humanwissenschaft einzuordnen ist. Er erarbeitet das Thema der Sprache in der Spezialisierung der theologischen Sprachlehre. Die Spezialität des Faches schließt bei Ebeling Allgemeinheit allerdings keineswegs aus, sondern wird von dieser begleitet. Daher interessiert es zunächst, wie er das Verhältnis der allgemeinen und der besonderen bzw. theologischen Sprachlehre versteht. Das thematisiert er in der $>$ Einführung in theologische Sprachelehre $<$ und zeigt seinen grundsätzlichen Standpunkt, obwohl er einräumt, die dabei aufgeworfenen Probleme könnten „nur andeutungsweise“ behandelt werden. ${ }^{163}$

Das Verhältnis zwischen der allgemeinen und der theologischen Sprachlehre ist mit anderen, in der Theologie geläufigeren Themen zu vergleichen: zunächst mit dem Verhältnis von Theologie und Wissenschaft, auf der es genauer gesagt beruht. Zwischen Theologie und Wissenschaft bestehen ganz

\footnotetext{
161 Sprachlehre, 230.

${ }^{162}$ Mit dem Wort „,allgemein“ meine ich hier den kontrastiven Begriff von „,theologisch“. Das heißt, ,allgemeine Sprachlehre" bedeutet hier nicht das bestimmte Fachgebiet der Sprachwissenschaften, das sich nicht mit Einzelsprachen, sondern mit der menschlichen Sprache beschäftigt und sich einerseits von der angewandten Sprachwissenschaft und andererseits von der historischen Sprachwissenschaft grenzt.

163 Sprachlehre, 221-226.
} 
differente Gesichtspunkte wie „Gegenstandbereich, Methode, Befragungshinsicht und Praxisbezug“ $1{ }^{164}$ Theologie unterscheidet sich diesbezüglich von den anderen wissenschaftlichen Fächern. Die Theologie enthält aber laut Ebeling zugleich „Allgemeinverständlichkeit“ oder „Allgemein-gültigkeit“, weil sie „das entsprechende Verfahren einer Konfrontation des christlichen Glaubens mit aller Welterfahrung “ bewähren muss. ${ }^{165}$ Das Verhältnis der allgemeinen zu der theologischen Sprachlehre ist auch mit dem der hermeneutica profana zu der hermeneutica sacra zu vergleichen. Hinsichtlich dieses Verhältnisses gibt es einen traditionellen Gesichtspunkt, in dem von vornherein eine Ausnahmeposition für die Heilige Schrift festgesetzt wird. Der grundlegende Standpunkt Ebelings spricht sich gegen diese strenge Unterscheidung zwischen ihnen aus. Er sieht beide nicht im gegenseitigen Verhältnis, sondern im kooperativen, anders als bei Barth, der vor Angst um die Abhängigkeit der Theologie an eine allgemeine Hermeneutik das hermeneutische Problem selbst auszuschließen versucht. Ebeling unterscheidet aber zugleich die theologische Hermeneutik von der allgemeinen und hält jene neben dieser fest, womit er sich auch von Bultmanns Position abgrenzt. ${ }^{166}$

Ähnlich wie die Verhältnisbestimmung zwischen Theologie und Wissenschaft sowie zwischen hermeneutica profana und hermeneutica sacra hat eine theologische Sprachlehre einerseits ihre theologische Eigenschaft und andererseits einen allgemeingültigen Charakter. Aufgrund dessen hat eine theologische Sprachlehre mit einer allgemeinen Sprachlehre zu tun, „die für alle besonderen Gestalten von Sprachlehre relevant ist, zumindest in der Weise, dass diese sich mit ihr auseinandersetzten müssen“. ${ }^{167}$ Als Beispiele für allgemeine Relevanz sind Grammatik und Dialektik zu nennen, die Ebeling selber in seiner theologischen Sprachlehre behandelt. ${ }^{168}$ Sofern die theologische Sprachlehre Allgemeingültigkeit hat, bedeutet das doch nicht, dass sie allgemeinen Kriterien unterliegt. Ebeling erklärt: „Die Besorgnis ist nicht unberechtigt, die Theologie werde einer ihr übergeordneten und sie umgreifenden Disziplin subsumiert und fremden Kriterien unterworfen; sie werden auf diese Wiese des Eigenständigen beraubt, über dessen Möglichkeiten zu urteilen und dessen Grenzen zu bestimmen einer allgemeinen Sprachlehre überlassen bleibt. “ ${ }^{\text {169 }}$ Dagegen müssen beide jede Eigenständigkeit bewahren, damit sie zum fruchtbareren, wissenschaftlich sinnvolleren Unternehmen gelingen können, weil „die Tendenz zu fortschreitender Spezialisierung“ „eine mächtige Triebkraft wissenschaftlicher Arbeit“ ist; ${ }^{170}$ und ,eine umfassend angelegte Sprachlehre allgemeiner Art“ muss sich „,an konkreten Sachverhalten orientieren und an spezielle Aspekte halten“, sonst gerät sie in Gefahr, ,mit zunehmender

\footnotetext{
164 Sprachlehre, 223.

165 Sprachlehre, 222.

166 WG, 330-333.

${ }^{167}$ Sprachlehre, 223.

168 Sprachlehre, $223 \mathrm{ff}$.

${ }^{169}$ Sprachlehre, 221.

${ }^{170}$ Sprachlehre, 223.
} 


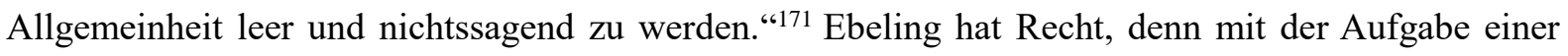
Sprachlehre gänzlich im Allgemeinen zu verharren, ohne die spezifischen Probleme besonderer Sprachbereiche thematisch werden zu lassen, wäre ein unergiebiges Unterfangen.

Es sei nun zu erwähnen: Die theologische Sprachlehre gehört als ein besonderes Gebiet gegenüber der allgemeinen Wissenschaft zur Theologie und hat doch zugleich mit der allgemeinen, für alle besonderen Sprachlehren relevanten Sache zu tun. In Hinsicht auf das Verhältnis der theologischen Sprachlehre zur allgemeinen schließt Ebeling wie folgt: „Von diesen Überlegungen her wird deutlich, wie abwegig es wäre, die theologische Sprachlehre einer allgemeinen Sprachlehre als deren Spezialfall zuzuordnen. In der ausschlaggebenden Hinsicht könnte man eher sagen, die theologische Sprachlehre folge stärker, als es bei anderen Gestalten von Sprachlehre der Fall zu sein pflegt, dem Zug ins Umfassende. Indem sie die Aufmerksamkeit auf die Grundfragen lenkt und dank der Orientierung an ihnen das einzelne in seinen großen Zusammenhängen sehen lehrt, besteht Grund zu der Erwartung, dass sie einen wichtigen Beitrag zur allgemeinen Sprachlehre leistet." ${ }^{172}$ Bei der Bestimmung des Charakters der theologischen Sprachelehre will Ebeling solcherweise einen Besonderheit und Allgemeinheit umfassenden Aspekt herausgreifen. Er erklärt aber leider nicht genau, welche Begrenzung beide voneinander haben und in welchem Kooperationsverhältnis sie stehen.

\subsubsection{Theorie und Praxis}

Die Bemühung Ebelings, eine umfassend konzipierte Sprachlehre zu erarbeiten, findet sich auch in seinem Versuch, die Trennung von Theorie und Praxis zu überwinden und dafür ein passendes Verständnis der Praxis festzulegen. Im Hinblick auf das Verhältnis von Theorie und Praxis bedenke man die alte scholastische Fragestellung, ob die Theologie scientia speculativa oder scientia practica sei. Ebeling selber integriert diese Fragestellung in seine theologische Sprachlehre. Nach dem kurzen geschichtlichen Überblick über das Spannungsverhältnis zwischen scientiae speculativae und practicae an Beispielen von Thomas von Aquin und Luther, die Ebeling als Vertreter des gegenseitigen Gesichtspunktes benennt, geht es darum, auf welchen Standpunkt sich Ebeling stellt und in welche Beziehung zu seiner Sprachlehre er dieses Schema setzt. ${ }^{173}$

Das Argument des Verhältnisses von Theorie und Praxis geht ursprünglich zurück auf das Argument über die Wissenschaftlichkeit der Theologie im Mittelalter. Bei Augustinus wurde Theologie zunächst nicht als Wissenschaft (scientia), sondern als Weisheit (sapientia) verstanden, die er als „die höchste der Wissenschaften“ bestimmt. ${ }^{174}$ Er unterscheidet Wissenschaft und Weisheit aufgrund der Differenz

\footnotetext{
${ }^{171}$ Sprachlehre, 224.

172 Sprachlehre, 224.

${ }^{173}$ Sprachlehre, 30-39.

${ }^{174}$ W. Pannenberg, Wissenschaftstheorie und Theologie, Frankfurt a.M. 1973, $14 f$.
} 
von Zeit und Ewigkeit. Theologie als Weisheit beschäftigt sich nicht mit zeitlichen und irdischen Digen, sondern mit dem Ewigen, z.B. mit Gott als dem höchsten Gut oder mit der ewigen Gemeinschaft mit Gott als Ziel menschlichen Lebens. ${ }^{175}$ Unter dem Einfluss von Augustinus wurden Theologie als sapientia und allgemeine Wissenschaft als scientia in einem unüberwindbaren Gegensatz zueinander verstanden. Durch die Entstehung der Universitäten wurde im 13. Jahrhundert eine Veränderung der Bestimmung der Theologie als sapientia herausgefordert. Denn die Theologie wurde dabei unter die anderen Fakultäten eingeordnet und ihre Stellung im Kontext der Wissenschaften rief die Frage nach dem wissenschaftlichen Charakter der Theologie hervor. ${ }^{176}$

Vor allem Thomas von Aquin versuchte den Wissenschaftscharakter der Theologie darzulegen, indem er durch die aristotelische Unterscheidungsweise zwischen vorgeordneten und abgeleiteten Wissenschaften die Theologie als eine abgeleitete Wissenschaft bestimmte. Die vorgeordneten Wissenschaften wie Arithmetik und Geometrie gewinnen demzufolge ihre Prinzipien durch den Verstand; die abgeleiteten Wissenschaften gewinnen sie aus ihren vorgeordneten Wissenschaften. Die Theologie bekommt in diesem Sinne ihre Prinzipien aus einem höheren Wissen, nämlich „scientia Dei et beatorum“. ${ }^{177}$ Thomas begriff dabei die Theologie primär als eine scientiam speculativam. Er argumentierte, Theologie sollte vorrangig von religiösen, göttlichen Gegenständen handeln, dagegen sekundär von menschlichen Handlungen und insofern sie so zur Gotteserkenntnis führt, die zum Glauben gehört und damit die Oberhand in Sachen der Theologie erhält, sollte sie hauptsächlich spekulativ sein. Er unterschied scientiam speculativam von scientiae practicae, die er als scientiam moralem verstand. Gerade an diesem Punkt kritisiert Ebeling, dass Thomas den Begriff des Praktischen eng ,im Sinne des moralischen Handelns“ fasste. ${ }^{178}$

Gegenüber dem thomistischen Verständnis setzt Ebeling Luthers Theologieverständnis. Die Frage, ob die Theologie praktisch oder theoretisch sei, übernahm Luther prominent bei Gabriel Biel, der im Prolog des $>$ Collectorium $<$ diese Frage stellte. Um die Bedeutung der Praxis für die Theologie zu betonen, machte Luther die Unterscheidung zwischen dem theoretischen und dem praktischen Charakter der Theologie zwar in den gegensätzlichen Begriffen von unwahr und wahr: „Die wahre Theologie ist praktisch, ihr Fundament ist Christus, dessen Tod durch den Glauben ergriffen wird. [...] Die spekulative Theologie, die gehört in die Hölle zum Teufel. “" ${ }^{179}$ Er wollte aber grundsätzlich das dichotomische Schema von Theorie und Praxis sowie Spekulation und Aktion bei Scholastikern brechen

\footnotetext{
${ }^{175}$ M. Rothgangel, Naturwissenschaft und Theologie. Wissenschaftstheoretische Gesichtspunkte im Horizont religionspädagogischer Überlegungen, Göttingen 1999, $103 \mathrm{f}$.

${ }^{176}$ W. Pannenberg, Wissenschaftstheorie und Theologie, Frankfurt a.M. 1973, 11.

${ }^{177}$ M. Rothgangel, Naturwissenschaft und Theologie. Wissenschaftstheoretische Gesichtspunkte im Horizont religionspädagogischer Überlegungen, Göttingen 1999, 105.

${ }^{178}$ Sprachlehre, 33.

${ }^{179}$ WAT 1,72,16-24 Nr. 153 (Dez. 1531/Jan. 1532).
} 
und beide im Begriff vita passiva erhalten. ${ }^{180}$ Weil Theologie sowie Glaube eigentlich nicht zum opus des Menschen, sondern Gottes gehören, ${ }^{181}$ hat sie weder mit der intellektuellen Spekulation noch mit dem moralischen Verhalten zu tun, sondern primär mit sapientia experimentalis, die der Mensch nicht macht, sondern durch Erfahrungen des Handelns Gottes in konkreten Situationen des Lebens bekommt. ${ }^{182}$ Wenn es um das rechte Verstehen des Wortes geht, ist es auch offenbar, dass die wirkliche Konzentration auf das Wort unerlässlich die Konzentration auf die Praxis mit sich führt. Luthers Verständnis der Theologie hat damit einen konstitutiven Zug in die Praxis, ins Leben und in die Erfahrung.

Ebeling plädiert grundsätzlich für Luthers Sichtweise. Er sagt, dass für Luther das Praktische anders als bei Thomas „das zu bestehende Leben selbst“ bedeutete, damit der Glaube gerade „,auf die Seite der Praxis“ gehört, „nicht um der Werke willen, die ihm folgen, sondern weil er selbst in fundamentaler Weise lebensentscheidend ist" ${ }^{183}$ Im Anschluss an Luther wendet sich Ebeling gegen den ideologischen Missbrauch der Praxis, der ,nicht erst in der marxistischen Gestalt, sondern auch bereits in den verschiedenen Varianten liberaler, puritanischer oder klerikaler Art" besteht und uns zur Verkennung der Relevanz des Wortes sowie zur Flucht vor der Wortverantwortung führt. ${ }^{184}$ Ebeling warnt, dass diese falsche Beschäftigung mit der Praxis ein Krisensymptom der gegenwärtigen Theologie sei. Was meint dann die Praxis eigentlich?

Die Praxis dient bei Ebeling nicht lediglich zum Gegensatz zur theoretischen Haltung. Sofern diese als die „Distanznahme vom Lebensprozess“ gesehen wird, betrifft die Praxis dann „eine bestimmte Verhaltensweise des Menschen“ und beschränkt sich auf eine von Menschen ausgemachte bestimmte konkrete Praxis. ${ }^{185}$ Aber in solchem beschränkten Sinn kann man laut Ebeling keineswegs den Begriff

\footnotetext{
${ }^{180}$ Ob Luther selber den Begriff vita passiva erfand, ist aber unklar, z.B. Oswald Bayer sagt, „Das Dritte, das er findet, ist ein Vorgang und Weg so eigener Art, dass er auch seine eigene Benennung erhalten sollte - und bei Luther im Begriff der vita passiva denn auch erhalten hat.“ Ders., Martin Luthers Theologie. Eine Vergegenwärtigung, Tübingen 2003, 43. Dagegen behauptet Philipp Stoellger, „Es war weder erst Luther, der das tradierte Schema von actio und contemplatio problematisierte und überschritt, noch erfand er die vita passiva als Metapher des Lebens im Zeichen der Passion. Luther ist weder der begriffsgeschichtliche Stifter des Ausdrucks vita passiva noch ist er von deren Tradition ganz frei.“, Ders., Passivität aus Passion. Zur Problemgeschichte einer ,categoria non grata', Tübingen 2010, 299.

${ }^{181}$ Man muss auch beachten, dass die Passivität für Luther keinen Identitätsverlust bedeutet. Vgl. Sprachlehre, 34: Ebeling erklärt, dass Luther ,nicht eine Passivität, die das Menschsein vergewaltigt oder gar das Personsein überhaupt eliminiert, sondern die Passivität, der sich das Menschsein verdankt und die das Personsein konstituiert“ meint und diese Art der Passivität in der Aussage „Ich bin geliebt“ gefunden wird.

182 WA $5,163,28 f$.

${ }^{183}$ Sprachlehre, $33 \mathrm{f}$

${ }^{184}$ Sprachlehre, 31.

${ }^{185}$ Sprachlehre, 33. Ebelings Abstand von der konkreten Praxis kann man z.B. in seinem Aufsatz über „Kirche und Politik“ (1973) finden, wobei er anhand des Unterschiedes zwischen der Sache des Glaubens bzw. der Kirche und der Aufgabe des Politischen das christliche Bedürfnis nach der Weltverantwortung erörtern will. Er behauptet hier: „Der Christ könne die Teilnahme an der politischen Verantwortung nur als etwas ansehen, was indirekt Sache
} 
der Praxis richtig verstehen. Dagegen bestimmt er Praxis als nichts anders als „die Wirklichkeit des Lebens selbst “. ${ }^{186}$ Von diesem grundlegend an Luther anschließenden Standpunkt aus führt er den wesentlich notwendigen Praxisbezug der Theologie weiter in seiner theologischen Sprachlehre.

Ebeling bezeichnet hier die Sprache als „Lebensvorgang“ und erörtert seine Sprachlehre im „intensiven Lebensbezug“, um die Trennung von Theorie und Praxis zu transzendieren. ${ }^{187}$ Menschliches Leben bewegt sich ihm zufolge mit seinem Versuchen, die Wirklichkeit zu bewältigen, immer in den Sprachvollzügen und dazu gehört das „längst in Gang befindliche Sprachgeschehen, in dem sich in unendlichen Variationen Welterfahrung niederschlägt". ${ }^{188}$ Und nur in der umfassenden Weite eines Lebensvollzuges kann die Sprachlehre keine ,,praxisferne Theorie“ sein. ${ }^{189}$ Die umfassende Weite des Lebensvollzuges befindet sich im fundamental praktischen Gebrauch der Sprache, nämlich in der Polarität von „Reden“ als aktiver Umgang mit der Sprache und „Hören“ als passiver Umgang, denn ,je fundamentaler die Aufgabe von Sprachlehre erfasst wird, desto mehr schwindet der Anschein eines Theoretisierens über die Sprache.“ 190 Er bezeichnet dabei Reden und Hören als „Komplementäraspekte eines einzigen Sachverhalts“, weil das eine grundsätzlich auf das andere ausgerichtet und sie einander ,im konkreten Umgang mit der Sprache“ durchdringen, so dass sie sich für das gemeinsame hermeneutische Ziel des Verstehens, besser des Einverständnisses richten. ${ }^{191}$ Den Grundsachverhalt von Reden und Hören und damit die Grundstruktur dessen, wie sich die Sprache als Lebensvorgang darstellt, drückt Ebeling durch die folgende einfache Formel aus: „Ich sage etwas zu dir““ ${ }^{192}$ Das besagt, dass bei ihm das Handeln der Sprache bzw. der Sprechakt als Reden und Hören, damit als Gespräche zwischen mir und dir, unterstrichen wird.

Ebeling bestimmt darum die Grundstruktur des Wortes nicht als Aussage, sondern, nach seiner Darstellung, „Mitteilung, gewiss nicht in dem abgeblassten Sinne von Information, sondern in dem gefüllten Sinne von Partizipation und Kommunikation“, die beide in Lebenssituationen passieren. ${ }^{193}$ In diesem Sinne ist die Behauptung von P. Bühler richtig, dass Ebelings Wortgeschehensbegriff ,in seiner grundlegenden Performativität wie ein Sprechakt verstanden werden kann, dessen Gelingen von bestimmten Bedingungen abhängig ist, die mit dem jeweiligen Kommunikationskontext

des christlichen Glaubens ist [...] Sache des christlichen Glaubens ist das Heil der Welt und nur mittelbar das Wohl der Welt. Wer diese Unterscheidung und damit den Primat des Glaubens aufgibt, der verwirre nicht nur das Christliche, sondern gefährdet auch das Politische“ (WG III, 514); „die Sache des christlichen Glaubens nicht Politik sei und seine Wahrheit sich nicht im politischen Handeln erfülle“ (WG III, 593).

${ }^{186}$ Sprachlehre, 32.

${ }^{187}$ Sprachlehre, 195.

${ }^{188}$ Sprachlehre, 248.

${ }^{189}$ Sprachlehre, 198.

${ }^{190}$ Sprachlehre, 196.

${ }^{191}$ Sprachlehre, $196 f$.

${ }^{192}$ Sprachlehre, 201.

${ }^{193}$ WG, 342. 
zusammenhängen. “ ${ }^{\text {"194 }}$ Sofern bei Ebeling das Praktische so geartete Lebensbezogenheit bedeutet, kann aber keine Rede von Methodik oder praktischer Anwendung der Sprache sein, sondern nur die Rede von der sogenannt praxistheoretischen Perspektive, die z.B. durch Gebets- oder Predigtslehre geprägt ist, die oft in seinen hermeneutischen und dogmatischen Arbeiten als Hauptthese behandelt und als einer seiner Beiträge zur heutigen Theologie gewürdigt wird. ${ }^{195}$

\subsubsection{Hermeneutik für „eine Sprachlehre von umfassendstem Horizont“}

Die hermeneutische Betrachtungsweise der Sprache steht gegenüber der analytischen in der Linguistik. Zwischen ihnen besteht ein grundlegender Unterschied und diesen formuliert Ulrich H. J. Körtner wie folgt: „Während hermeneutische Konzeptionen das Wesen der Sprache in ihren geschichtlichen, d.h. aber diachronen Bezügen zu erfassen versuchen, rekurrieren linguistische Theorien auf die synchrone Dimension der Sprache als eines in einer bestimmten Gegenwart funktionierenden Zeichensystems. “196 Den Unterschied zwischen hermeneutischer und linguistischer Sprachbetrachtung so mit dem zeitlichen Begriff von „diachron“ oder „synchron“ zu charakterisieren, macht einen gewissen Sinn, aber scheint aus meiner Sicht nicht ausreichend.

Ebeling wendet sich grundsätzlich auch gegen die Auffassung, dass Sprache als ein Gegenstand des Verstehens oder als bloßes Instrument für das Zeichensystem verstanden wird, womit er sich auch gegen das signifikative Sprachverständnis positioniert, das auf der antiken Unterscheidung von signum und res aufbaut und sich in metaphysischen Denkhorizonten bewegt. ${ }^{197}$ Seine Sprachforschung ist dann als ein Weg zur Metaphysikkritik zu halten. ${ }^{198}$ Im metaphysischen Sprachverständnis wird das Wort als Zeichen für eine Sache verstanden und die Sprache hat dementsprechend die Bezeichnungsfunktion. Die Leistung der Sprache besteht in der Fassung der objektiven Sachverhalte. Solches Sprachverständnis könnte die Sprache auf ein bloßes Instrument der Verständigung oder der Informationsvermittlung reduzieren. Die Sprache könnte dabei nur im Verhältnis zur von ihr hingewiesene Sache betrachtet werden und somit ihr eigener ursprünglicher Aspekt wie das Wesen der Sprache vernachlässigt werden. Unter dem großen Einfluss des signifikativen Sprachverständnisses würde Sprachlehre dann, nach der Darstellung Ebelings, zumeist auf ,einen Pol der Sprache“ beschränkt, nämlich „,auf das Zustandekommen von Sprache im Zusammenspiel von Sprache

\footnotetext{
${ }^{194}$ P. Bühler, Wort Gottes und Hermeneutik. Gerhard Ebelings Erbe aus heutiger Sicht, in: I.U. Dalferth u.a. (Hg.), Hermeneutische Theologie - heute?, Tübingen 2013, 49.

${ }^{195}$ Vgl. W. Jetter, Redliche Rede vor Gott - über den Zusammenhang zwischen Predigt und Gebet. Eine Erinnerung an Gerhard Ebelings Beitrag zur Predigtlehre, in: E. Jüngel u.a. (Hg.), Verifikationen. Festschrift für Gerhard Ebeling zum 70. Geburtstag, Tübingen 1982, 385-424.

${ }^{196}$ U.H.J. Körtner, Theologie des Wortes Gottes. Positionen, Probleme, Perspektiven. Göttingen 2001, 100.

${ }^{197}$ WG II, 408.

${ }^{198}$ R. Görnadt, Die Metaphysikkritik Gerhard Ebelings und ihre Vorgeschichte, Tübingen 2016, $270 f$.
} 
als formalem System und Sache als Inhalt gesprochener Sprache“. ${ }^{199}$ Die Bestimmung der Sprache als ein System scheint sie, nach Ansicht Ebelings, in ein „verschlossenes Gefäß“ einzuschränken. ${ }^{200}$

Die linguistische Betrachtungsweise haftet sich relativ stärker an den Text als die hermeneutische. Aus der Sicht der Hermeneutik, vor allem der nach der ontologischen Wendung entwickelten Hermeneutik, geht die Sprache über ihre den Text interpretierende Funktion hinaus. Den so über den beschränkten Horizont des Textes hinausgehenden Charakter der Hermeneutik bezeichnet Anthony C. Thieselton als „two horizons“, also den Horizont des Textes und den des Interpreten bzw. des Kontextes. ${ }^{201}$ Ähnlicherweise sieht Ebeling die Hermeneutik als „Bemühung um eine Sprachlehre von umfassendstem Horizont" ${ }^{202}$ Er verneint äußerlich nicht die Tatsache, dass in der Interpretation die hermeneutische Betrachtungsweise nicht radikal von der linguistischen getrennt sein kann, und selber versucht, linguistische Elemente wie Grammatik zu behandeln, obwohl er diesbezüglich starker Kritik unterliegt. Zum Beispiel verwirft D. Stellmacher, dessen Ausgangspunkt die Linguistik ist, Ebelings Grammatikverständnis, denn diesem würde „nicht nur ein Grammatikbegriff von gestern, sondern von vorgestern“ zugrunde liegen, „,mit dem nicht mehr gearbeitet werden kann“. Überdies kritisiert er weiter, dass Ebeling beim Behandeln der Sprache eine falsche Richtung nehme und infolgedessen zum falschen Schluss komme, da Ebeling die Funktion der Sprachlehre ,in der Hinwendung zu bescheidenem, gewissenhaftem, genauem und ehrlichem Sprachgebrauch“ sieht und „moraltheologisch“ schließt. ${ }^{203}$ In seinen Augen ist Ebelings Sprachlehre „nicht mehr linguistisch“ und keine richtige Sprachlehre. ${ }^{204}$

Ebelings Sprachlehre hat aus linguistischer Sicht sicherlich Schwächen. Im Vergleich mit der linguistischen Betrachtungsweise der Sprache hat die hermeneutische einen für ihn unverzichtbaren Vorteil. Dieser liegt darin, unser Interesse von der Form und dem Inhalt der Sprache zu entfernen und mehr auf die Funktion der Sprache zu richten, auf ihre „Kraft“, „,den Augenblick zu transzendieren“. 205 Diese transzendierende Kraft der Sprache vermag das, „,was nicht mehr und was noch nicht ist“, zu vergegenwärtigen. ${ }^{206}$ Diese Kraft der Sprache beschränkt sich nicht nur auf das zeitliche Verhältnis, also darauf, Vergangenheit und Zukunft zu vergegenwärtigen, sondern erweitert sich zum Präsentieren des

\footnotetext{
199 Sprachlehre, 197.

200 Wesen, 183.

${ }^{201}$ A.C. Thiselton, The two horizons. New Testament Hermeneutics and Philosophical Description, Grand Rapids 1980, 120.

202 Sprachlehre, 188.

${ }^{203}$ D. Stellmacher, Zum Sprachverständnis Ebelings, in: Linguistische Theologie. Biblische Texte, christliche Verkündigung und theologische Sprachtheorie, U. Gerber/ E. Güttenmanns (Hg.), Bonn ${ }^{3} 1975,58$.

${ }^{204}$ D. Stellmacher, Zum Sprachverständnis Ebelings, in: Linguistische Theologie. Biblische Texte, christliche Verkündigung und theologische Sprachtheorie, U. Gerber/ E. Güttenmanns (Hg.), Bonn ${ }^{3} 1975$, 58. Vgl. A. Gibson, An Exhibition of theological Fallacies. A Critique of Gerhard Ebeling's Analysis of Language, in: The Heythrop Journal Vol. 15(4) 1974, 423-440.

205 Sprachlehre, 54.

${ }^{206}$ Sprachlehre, 54.
} 
„Verborgenen“, damit zur „Ansagbarkeit des Unsagbaren“. ${ }^{207}$ Dadurch kann das verborgene Geheimnis der Wirklichkeit Gottes dem Menschen zugänglich werden. Ebeling will durch die hermeneutische Betrachtungsweise den so wesentlichen, offenen Charakter der Sprache aufzeigen. Dieser wesentlich offene Charakter meint den neuen Horizont der Sprache, also über die Begrenzung des Verhältnisses zur Sache und die Zeitlichkeit zwischen dem Gesprochene und dem Sprechende hinaus, die Problemdimension der Sprache zur religiösen Dimension zu erweitern.

${ }^{207}$ Sprachlehre, 54. 


\section{KAPITEL II. SPRACHE IN DER HERMENEUTIK}

Interpretieren ist ein grundlegender Akt des menschlichen Denkens. In der Tat interpretieren wir alles, was uns täglich vom Aufstehen bis zum Einschlafen betrifft. Obwohl diese andauernde Interpretation auf vielen nicht-sprachlichen Ebenen des menschlichen Lebens stattfindet, muss sich jede Theorie der Interpretation zuerst auf das Phänomen der Sprache beziehen, weil kein anderes von Menschen benutztes Medium die Sprache in deren Beschaffenheit und Vermögen übertrifft. Die Wissenschaft der Interpretation ist zusammenfassend mit dem Wort „Hermeneutik“ zu bezeichnen. Das Stichwort „Hermeneutik“ prägt das Denken Ebelings äußerst stark und die Hermeneutik ist damit das „Kardinalthema“ in seiner Theologie, weil es sich seiner Ansicht nach in ihr entscheidet, ob die Verkennung der Offenbarung oder deren gläubige Annahme stattfindet. ${ }^{208}$ Angesichts des Themas der Hermeneutik bei Ebeling wird „Sprache“ in den Mittelpunkt meiner Arbeit gestellt.

Ebeling beginnt seinen Artikel „Hermeneutik“ in > Religion in Geschichte und Gegenwart< (1959) mit dem Satz: „Die etymologische Herkunft von $\varepsilon \rho \mu \eta v \varepsilon l v$ samt Derivaten ist umstritten, weist aber auf Wurzeln mit der Bedeutung ,sprechen“, ,sagen“، “209 Der erste Teil herme des Wortes „Hermeneutik“ ist laut ihm verwandt mit sermo (sprechen) oder verbum (Wort) im Lateinischen. ${ }^{210}$ Obwohl diese etymologische Analyse noch umstritten ist, so wie Robinson kritisiert, dass Ebeling diese Etymologie trotz ihrer Unsicherheit einführte, um die Ausrichtung seiner eigenen Hermeneutik als eine Sprachbewegung anzugeben, ${ }^{211}$ wird die Bedeutsamkeit der Sprache für die Hermeneutik nicht reduziert. Denn die möglichen Bedeutungsvarianten der Hermeneutik wie „erklären“, ,auslegen“ oder „übersetzen“ usw. zeigen alle im wesentlichen Sinn sprachliche Tätigkeiten. Es ist darum kein Zufall, dass in der Antike das griechische Wort für die Hermeneutik $\varepsilon \rho \mu \eta v \varepsilon ı \alpha$ beispielsweise bei Xenophon oder bei Aristoteles mit der Sprache (oder Rede) zwar als synonym gesetzt wurde. ${ }^{212}$ Schließlich gibt es eine bestimmte untrennbare, besonders enge Beziehung zwischen der Hermeneutik und der Sprache.

Solche Beziehung ist auch in der Entwicklungsgeschichte der Hermeneutik zu finden. Im Folgenden wird als der Hintergrund der Untersuchung des Verhältnisses von Sprache und Hermeneutik bei Ebeling zunächst die Entwicklungsgeschichte der an der Sprache orientierten Hermeneutik beschrieben.

\footnotetext{
${ }^{208}$ T. Lorenzmeier, Exegese und Hermeneutik. Eine vergleichende Darstellung der Theologie Rudolf Bultmanns, Herbert Brauns und Gerhard Ebelings. Hamburg 1968, 80.

${ }^{209}$ Ebeling, Art. Hermeneutik, in: RGG ${ }^{3}$ III (1959), 242-262, 243.

${ }^{210}$ Ebeling, Art. Hermeneutik, in: RGG $^{3}$ III (1959), 242.262, 243. Zur etymologischen Bedeutung der Hermeneutik siehe K.-O. Apel, Transformation der Philosophie, Bd. 1. Sprachanalytik, Semiotik, Hermeneutik. Frankfurt a.M. 1973, 278-283; R.E. Palmer, Hermeneutics. Interpretation Theory in Schleiermacher, Dilthey, Heidegger and Gadamer. Evanston 1969, 12-32.

211 J.M. Robinson, Die Hermeneutik seit Karl Barth, in: Ders./J.B. Cobb (Hg), Die neue Hermeneutik, Zürich/Stuttgart 1965, 13-108, 15 f.

${ }^{212}$ Claus v. Bormann, Art. Hermeneutik I. Philosophisch-theologisch, in: TRE 15 (1986), 108-137, 111.
} 
Insbesondere wird herausgestellt, inwiefern die Sprache dabei hilft, die Hermeneutik als ein unabhängiges oder umfangreiches Wissenschaftsgebiet festzustellen. Danach wird Ebelings Position erläutert. Ich versuche dadurch zu beweisen, dass Ebeling einem Trend der an Sprache orientierten Hermeneutik folgt und zugleich durch den Abstand von anderen, die einen großen Einfluss auf seine Hermeneutik nehmen, seinen eigenen Weg geht.

\section{Sprache in der Entwicklungsgeschichte der Hermeneutik}

Der Ausdruck „Hermeneutik“ war bis ins 17. Jahrhundert terminologisch nicht konkret bestimmt, obwohl er auf antike Wurzeln, für deren frühsten Beleg die Verwendung des griechischen Wortes $\varepsilon \dot{\varepsilon} \mu \eta v \varepsilon v \tau ו \kappa \eta ~ b e i ~ P l a t o ~ g e h a l t e n ~ w i r d,{ }^{213}$ zurückgeht. Er erschien zuerst um 1629/30 in einer Arbeit von J.C. Dannhauer im Kontext seiner Behandlung der Aristotelischen Logik und Rhetorik und als ein Buchtitel in seiner $>$ Hermeneutica Sacra sive methodus exponendarum Sacrarum Literarum $<(1654) .{ }^{214}$ Der Verdienst der Begründung der Hermeneutik geht aber gewöhnlich auf Luther zurück, ${ }^{215}$ insofern es gilt, dass das Problem der Hermeneutik durch die Reformation ins Zentrum der Auseinandersetzungen gerückt wurde, indem sich bei dem Kampf gegen die katholischen Positionen das sola scriptura als das hermeneutische Prinzip durchsetzte. Luther reduzierte das klassische traditionelle Auslegungsprinzip der vier Punkte auf sensus literalis, das durch die alleinige Schriftautorität begründet wird, so dass das Interesse der Auslegung auf die Bibel selbst gerichtet wurde. Er war für eine wichtige Wende in der Geschichte der Hermeneutik verantwortlich. Streng genommen wurde das hermeneutische Prinzip jedoch nicht von ihm entwickelt, da er sich ohne eine bestimmte hermeneutische Theorie mit exegetischen Arbeiten beschäftigte, sondern wurde von M. Flacius konzipiert, der die erste neuzeitliche hermeneutische Theorie der Heiligen Schrift mit seiner $>$ Clavis scripturae sacrae< $(1567)$ erfasste. ${ }^{216}$

Flacius hob dabei Sprachkenntnisse für die protestantische Hermeneutik hervor und erklärte, dass alle Schwierigkeiten, die die Heilige Schrift bereitet, an der Dunkelheit der Sprache selbst hängen: „Die Sprache ist nämlich ein Zeichen oder ein Bild der Dinge und gleichsam eine Art Brille, durch welche

\footnotetext{
${ }^{213}$ Claus v. Bormann, Art. Hermeneutik I. Philosophisch-theologisch, in: TRE 15 (1986), 108-137, 109.

${ }^{214}$ Ebeling, Art. Hermeneutik, in: RGG ${ }^{3}$ III (1959), 242-262, 243; H. Birus, Hermeneutische Positionen. Schleiermacher, Dilthey, Heidegger, Gadamer, Göttingen 1982, 7.

${ }^{215}$ Vgl. W. Dilthey, Die Entstehung der Hermeneutik, in: GS V, 317-338, 324f; Das hermeneutische System Schleiermachers in der Auseinandersetzung mit der älteren protestantischen Hermeneutik (1860), in: GS XIV, 595-787, bes. 597.

${ }^{216}$ L. Gelsetzer würdigt die Bedeutung der Clavis und behauptet in der Einleitung zum Neudruck des 2. Teiles der $>$ Clavis scripturae sacrae< unter dem Titel: De ratione cognoscendi sacras literas. Über den Erkenntnisgrund der Heiligen Schrift, Düsseldorf 1968, „dass Flacius die theologische Dogmatik so ausschließlich auf die eine biblische Textgrundlage verwies und dadurch der Bibelexegese die maßgebliche Stellung innerhalb der theologischen Wissenschaft einräumte.“
} 
wir die Dinge selbst anschauen. Wenn daher die Sprache an sich oder für sich dunkel ist, so erkennen wir mühsam durch sie die Sachen selbst. [...] hier (in den Sprachkenntnisse) liegt nämlich wohl die vorwiegende Quelle der Schwierigkeit der Heiligen Schrift, dass fast niemals die Theologen mit höchster Sorgfalt sich darum bemüht haben, die Heilige Schrift und den Text vollständiger zu erkennen oder anderen zu erklären.“217 Die Kenntnis der sprachbezogenen Disziplinen der Freien Künste wie Grammatik, Dialektik und Rhetorik war die Grundlage der Schriftauslegung. Wenn man die Bibel verstehen will, soll man nicht „Träumen von Allegorien oder Himmelsgleichnissen nachhängen“, sondern sich um den „einfachen und eigentlichen Sinn des Textes“ kümmern. ${ }^{218}$ Und nach diesen allgemeinen Anwendungen führt Flacius aus, wie man sich ganz konkret dem Text nähren soll, und erhebt den Ablauf des Verstehens zur Methode. ${ }^{219}$ Seine hermeneutische Theorie galt bis zum späten 18. Jahrhundert als ein grundlegendes Werk auf dem Gebiet der Exegese. Die Hermeneutik wurde dabei nur als eine kleine Unterabteilung innerhalb eines Teilgebietes betrachtet. ${ }^{220}$

Erst seit Beginn des 19. Jahrhunderts wurde ein deutlicher Wandel im Verständnis von Hermeneutik beobachtet und dabei nimmt Schleiermacher einen entscheidenden Platz ein. ${ }^{221}$ „Die Hermeneutik als Kunst des Verstehens existiert noch nicht allgemein, sondern nur mehrere spezielle Hermeneutiken.“222 Diese Aussage, mit der Schleiermacher die Vorlesung über Hermeneutik im Jahr 1819 begann, zeigt sein grundlegendes Ziel, die allgemeine Hermeneutik als Kunst des Verstehens aufzufassen, d.h. nicht den Begriff der Hermeneutik als eine Gesamtheit von Regeln zu sehen, sondern als eine Wissenschaft, die die Bedingungen für Verständigung durch Gespräche darstellt. Bei Schleiermacher überwindet die Hermeneutik den Status einer bloßen Hilfsdisziplin und bekommt eine umfassende Bedeutung.

\footnotetext{
${ }^{217}$ M. Flacius, De ratione, 7; 25, hier zitiert nach: J. Gordin, Einführung in die philosophische Hermeneutik, Darmstadt 2001, 56.

${ }^{218}$ A. Gardt, Geschichte der Sprachwissenschaft in Deutschland. Vom Mittelalter bis ins 20. Jahrhundert, Berlin/New York 1999, 90.

${ }^{219}$ A. Gardt, Geschichte der Sprachwissenschaft in Deutschland. Vom Mittelalter bis ins 20. Jahrhundert, Berlin/New York 1999, 91-97.

${ }^{220}$ J. Grondin, Einführung in die philosophische Hermeneutik, Darmstadt 2001, 13-15.

${ }^{221}$ Gegen Schleiermacher als Begründer einer allgemeinen Hermeneutik, argumentiert z.B. Oliver R. Scholz, dass Dannhauer eine Hermeneutik als eine unabhängige Disziplin ausgebildet hätte, denn er behandelt eine allgemeine Wissenschaft der Interpretation, die für andere Fakultäten wie Theologie, Recht und Medizin alle Instrumente zur Auslegung schriftlicher Aussagen bereitstellen soll. Ders., Verstehen und Rationalität. Untersuchungen zu den Grundlagen von Hermeneutik und Sprachphilosophie, Frankfurt a.M. 2001, 36f. Aber die allgemeine Hermeneutik meint keine Interpretationstheorie, sondern nach der Beschreibung Gadamers, „eine universale Lehre des Verstehens und Auslegens“, die „von allen dogmatischen und okkasionellen Momenten“ abgelöst ist. Ders., WM II, 97. In diesem Sinne unterscheidet sich Schleiermachers Konzeption der Hermeneutik von den anderen. Joachim Wach sagte auch, „In Schleiermacher geriet zum ersten Mal ein wirklicher, systematischer Denker, ein philosophischer Kopf über die Hermeneutik.“ Ders., Die theologische Hermeneutik von Schleiermacher bis Hofmann, Bd. I, Tübingen 1929, 33. Die Bedeutung Schleiermachers für die Hermeneutik wurde aber vor allem von W. Dilthey herausgestellt, der behaupte, dass „die definitive Begründung einer wissenschaftlichen Hermeneutik" als erstes Schleiermacher zugeschrieben wird. Ders., GS V, 327.

${ }^{222}$ F. Schleiermacher, Hermeneutik und Kritik, M. Frank (Hg.), Frankfurt a.M. 1977, 75.
} 
Um die Allgemeinheit der Hermeneutik bei Schleiermacher zu verstehen, ist mit der Voraussetzung zu beginnen, dass sowohl der Autor als auch der Interpret Menschen sind, weil die allgemein menschliche Natur als die Grundlage des Verstehens dient. Die allgemeine Hermeneutik dehnt sich dann über alle Lebensäußerungen aus und zielt darauf ab, die kongeniale Erfassung mit dem Menschen, der hinter den verschiedenen Lebensäußerungen steht, zu erreichen. Schleiermacher sieht dabei die Sprache als das wichtigste Verbindungselement zwischen der allgemeinen menschlichen Natur und der besonderen sprachlichen Lebensäußerung. ${ }^{223}$ Wenn es um die allgemeine Hermeneutik geht, muss man deshalb mit dem Problem der Sprache beginnen. „Alles vorauszusezende in der Hermeneutik“ ist, nach der radikalen Aussage Schleiermachers, „nur Sprache und alles zu findende, wohin auch die anderen objektiven und subjektiven Voraussezungen gehören muss aus der Sprache gefunden werden.“ ${ }^{224}$ Die Sprache begründet für Schleiermacher nun die Totalität des hermeneutischen Untersuchungsgegenstandes.

Wenn er zwei Seiten der Hermeneutik, nämlich die grammatische Interpretation und die psychologische (oder technische) Interpretation unterscheidet, stellt er sie wie folgt dar: „Verstehen in der Sprache und Verstehen im Sprechenden“225. Die grammatische Interpretation sieht er die Sprache als den totalen Sprachgebrauch, während die psychologische (oder technische) als Ausdruck eines Inneren fasst. Das Ziel der Interpretation bei Schleiermacher besteht darin, den Verfasser richtig zu verstehen, also das, was er sagen wollte, sogar besser als er selbst zu verstehen. Die äußere Sprache soll darum durch ihre Rückbezogenheit auf das innere Denken des Autors zum Verständnis gebracht werden. Schleiermacher betont darum die Einheit von Denken und Sprache mit der Behauptung, dass beide Interpretationsperspektiven sich nicht voneinander trennen sollen, sondern bei jedem Verstehen vom Interpreter unterschiedlich gewichtet. 226

${ }^{223}$ H. Kimmerle, Hermeneutische Theorie oder ontologische Hermeneutik, in: ZThk (59) 1962, 114-130, 116f. Das erklärt Viktor Lau wie folgt: Die Sprache enthält auf der einen Seite einen ,allgemeinen“, nämlich „konventionellen Fundus an Verben, Flexionen, Begriffen, syntaktischen Verknüpfungsmöglichkeiten“ und auch „an Signifikations- und Kommunikationspotential“; auf der anderen Seite ist sie ein jeweils ,individueller“, damit „aktiver und lebendiger“ Vollzug dieser Möglichkeiten. Ders., Erzählen und Verstehen. Historische Perspektiven der Hermeneutik, Würzburg 1999, 290.

${ }^{224}$ F. Schleiermacher, Hermeneutik, H. Kimmerle (Hg.), Heidelberg 1959, 38.

${ }^{225}$ F. Schleiermacher, HK (1805), 56; Zitiert nach H. Birus, Schleiermachers Begriff der „Technischen Interpretation“, in: K.-V. Selge (Hg.), Internationaler Schleiermacher-Kongreß. Berlin 1984, Bd. I, Berlin/New York 1985, 591-600, 591.

${ }^{226}$ Eine Veränderung kann man aber im späteren Stadium Schleiermachers sehen. H. Kimmerle sagt, Schleiermacher wende sich auf den Vorteil der psychologischen Interpretation und der entscheidende Faktor dieser Wendung von der an der Sprache orientierten Hermeneutik zur psychologischen sei die Preisgabe der Einheit von Denken und Sprache. Ders., Hermeneutische Theorie oder ontologische Hermeneutik, in: ZThk (59) 1962, $114-$ 130, 117. An diesem Punkt kritisiert Richard E. Palmer, ,that Schleiermacher goes astray and give up the more fruitful possibility of a truly language-centered hermeneutics and falls into bad metaphysics". Ders., Hermeneutics. Interpretation Theory in Schleiermacher, Dilthey, Heidegger and Gadamer, Evanston 1969, 92f. 
Schleiermacher markiert einen Wendepunkt in der Geschichte der Hermeneutik, weil diese dank ihm nicht mehr nur eine Disziplin ist, die zu einem anderen Bereich wie Theologie, Literaturwissenschaft oder Jura gehört, sondern zu einer Kunst des Verstehens von allen schriftlichen Äußerungen wurde. Er sieht dabei die Interpretation der Heiligen Schrift nicht mehr als Sonderdisziplin an, sondern versucht sie in die allgemeine Verstehenslehre ein- oder unterzuordnen.

Diese erweiterte Hermeneutik Schleiermachers wird insbesondere von Dilthey, der die Grundlage für eine Geisteswissenschaft zu schaffen versucht, übernommen. Die Leitidee Diltheys lautet: „Die Natur erklären wir, das Seelenleben verstehen wir“. ${ }^{227}$ Entgegen der Naturwissenschaft, die Erkenntnis durch messbare Ergebnisse in Experimenten gewinnt, begründet er die Selbstständigkeit der Geisteswissenschaft. ${ }^{228}$ Die Hermeneutik wird dabei ein Prinzip zum Verständnis des Seelenlebens als des Gegenstandes der Geisteswissenschaft. Für Dilthey hilft sie in der Auseinandersetzung mit dem Historismus, den Abstand zwischen der Vergangenheit und der gegenwärtigen Interpretation (bzw. den historischen Relativismus) zu überwinden und eine objektive Erkenntnis zu gewinnen, die bei ihm weder mit dem nicht-historischen allgemeinmenschlichen Naturbegriff noch mit dem Denken im Einzelnen, sondern mit dem geschichtlichen, also gemeinsam geschichtlich bedingten Leben zu tun hat. Der Menschen bezeichnet sich bei ihm als ein „Geschichtliches“ ${ }^{“ 229}$ bzw. „ein historisches Wesen“230 und das Verständnis des menschlichen Lebens erfordert den Horizont der Geschichte. Die Geschichtlichkeit wird nun zu einem Kernthema seiner Hermeneutik. Und die Sprache, vornehmlich die Schriftsprache, spielt dabei eine wichtige Rolle: „Darin liegt nun die unermessliche Bedeutung der Literatur für unser Verständnis des geistigen Lebens und der Geschichte, dass in der Sprache allein das menschliche Innere seinen vollständigen, erschöpfenden und objektiv verständlichen Ausdruck findet. Daher hat die Kunst des Verstehens ihren Mittelpunkt in der Auslegung oder Interpretation der in der Schrift enthaltenen Reste menschlichen Daseins. “231 Bei Dilthey ist die Sprache das einzige Medium für das objektive Verstehen des menschlichen Geistes, das uns durch schriftliche Äußerungen vererbt wird. Das Verstehen ist also nur im Zusammenhang mit Sprachdenkmälern möglich. Bei ihm ist so wie bei Schleiermacher die allgemeine Menschennatur der Ausgangspunkt für sprachliche Äußerung und daher ist das Verstehen dieser Äußerung an das Verstehen der Menschennatur selbst gebunden.

Im 20. Jahrhundert schritt der Versuch fort, die Hermeneutik in umfassender Weise zu verstehen und wurde durch eine ontologische Wendung zu ihrer Universalisierung verstärkt. Diese Tendenz ist, wie K. Zwanepol mit Recht hinweist, „eng mit einer Erweiterung der Bedeutung von Sprache“ verbunden. 232

\footnotetext{
${ }^{227}$ W. Dilthey, GS V, 144.

228 W. Dilthey, Die Entstehung der Hermeneutik, Materialien zur Ideologiegeschichte der deutschen Literaturwissenschaft, Band 1, Tübingen 1973, 55-68.

${ }^{229}$ W. Dilthey, GS VII, 291.

${ }^{230}$ W. Dilthey, GS VII, 278.

${ }^{231}$ W. Dilthey, GS V, 319.

${ }^{232}$ K. Zwanepol, Unterscheiden, Bern 1993, 216.
} 
Die Sprachkonzeption wurde durch die Hermeneutik Schleiermachers und Diltheys als das subjektive Ausdrucksmittel und auch als das Mittel des objektiven Verstehens verstanden und konnte trotzdem das Subjekt-Objekt-Denken-Schema, in dem die Sprache als ein Instrument dem Herrschaftswissen des Menschen dient, noch nicht überwinden. Die neue Tendenz der Hermeneutik im 20 Jahrhundert versteht die Sprache aber nicht länger als ein objektives oder subjektives Interpretationsinstrument. Stattdessen zeigt sie Interesse an ihrem ontologischen Charakter, den die existentiale Analyse von Menschen und Welt und von ihrem Verhältnis bringt. Obwohl das Bestreben, die moderne Wirklichkeitsauffassung zu überwinden, unterschiedliche Wurzeln hat und nicht ausschließlich mit einer bestimmten philosophischen Richtung gleichsetzt werden kann, wird die philosophische Hermeneutik von Heidegger und Gadamer dabei für wichtig gehalten. ${ }^{233}$

In seinen Arbeiten hat Heidegger von Anfang bis Ende mit dem hermeneutischen Prozess zu tun, durch den das Sein zum Leuchten gebracht wird. ${ }^{234}$ Der junge Heidegger geht von der existentialen Analytik des Daseins aus. Diese hat laut ihm eine wichtige Stellung zur Erarbeitung der Frage dessen, was der Mensch sei, und den Vorrang vor psychologischer, anthropologischer oder biologischer Frage. ${ }^{235}$ Das Dasein betrifft das Wesen des Menschen und verhält sich immer zu seiner eigenen Existenz. ${ }^{236}$ Weil das Menschsein wesenhaft in die Welt geworfen ${ }^{237}$ und damit durch „,das In-der-WeltSein konstituiert wird, ist selbst je sein »Da«“" ${ }^{238}$ Das kursive „,ist“ nennt die Existenz und das „Da“ die Unverschlossenheit. Dieses Seiende trägt deshalb, ,in seinem eigensten Sein den Charakter der Unverschlossenheit“. ${ }^{239}$ Das Sein des Menschen als Dasein ist in der Welt nicht einfach nur vorhanden, sondern verhält sich zu allem, was ihm in der Welt begegnet. Dasein als In-der-Welt-Sein ist dann ein

\footnotetext{
${ }^{233}$ K. Zwanepol, Unterscheiden, Bern 1993, 217.

${ }^{234}$ Der hermeneutische Charakter bei dem frühen und späten Heidegger ist noch umstritten. Die Grundfrage nach dem Sinn des Seins wird in seinem frühen Werk >Sein und Zeit< auf dem Wege einer hermeneutischen Phänomenologie des Daseins ausgearbeitet. Nach der sogenannten Kehre beschäftigte er sich mit dem Problem des Seins selbst und vor allem mit der Frage, wie das Sein in statischen und essentiellen Termini verstanden wurde, indem er die griechischen und modernen Konzeptionen des Seins analysierte. Zunehmend im späten Stadium konzentrierte er sich auf Textinterpretation, vornehmlich auf Interpretation der antiken Fragmente und Gedicht. An diesem Punkt behauptet Richard E. Palmer, in späteren Veröffentlichungen würde der hermeneutische Charakter des Denkens Heideggers stärker. Ders., Hermeneutics. Interpretation Theory in Schleiermacher, Dilthey, Heidegger and Gadamer. Evanston 1966, 141. J. M. Robinson merkt allerdings kritisch an, es gehe nicht um „eine Theorie der Auslegung“, sondern eher um „,den Vorgang des Auslegens selbst“. Ders., Die Hermeneutik seit Karl Barth, in: Ders.J.B. Cobb (Hg), Die neue Hermeneutik, Zürich/Stuttgart 1965, 13-108, $68 \mathrm{f}$.

${ }^{235} \mathrm{M}$. Heidegger, SZ, 60.

${ }^{236}$ Vgl. M. Heidegger, SZ, 416: „Die Substanz des Menschen ist die Existenz.“

${ }^{237}$ Diese Faktizität des Daseins in seiner Geworfenheit ist die Voraussetzung der Ontologie Heideggers. Vgl. M. Heidegger, SZ, 180: „Faktizität ist nicht die Tatsächlichkeit des facum brutum eines Vorhandenen, sondern ein in die Existenz aufgenommener, wenngleich zunächst abgedrängter Seinscharakter des Daseins.“; SZ, 237: „Die Geworfenheit darin sich die Faktizität phänomenal sehen läßt, gehört zum Dasein, dem es in seinem Sein um dieses selbst geht. Dasein existiert faktisch.“

${ }^{238}$ M. Heidegger, SZ, 176.

${ }^{239}$ M. Heidegger, SZ, 176.
} 
Mitsein und wird im Verhältnis zu anderen Seienden charakterisiert. Verstehen ist dabei ein Grundvollzug des menschlichen Daseins, in dem sich der Mensch die Welt deutend erschließt und auf die Möglichkeit seines Daseins hin entwirft. Der Mensch ist also ein Wesen, das sich seine Welt durch Verstehen erschließt und daraus die notwendige Orientierung für seine Lebensmöglichkeiten empfängt. Und „die Ausbildung des Verstehens“ nennt Heidegger „Auslegung“. 240 Seine Hermeneutik ist deshalb „Auslegung des Seins des Daseins“, in der dem Dasein die Grundstrukturen seines Daseins kundgegeben werden. ${ }^{241}$

Heideggers Auffassung der verstehenden Seinsweise des Daseins als In-der-Welt-Seins versetzt die Sprache in einen neuen Kontext. Die Situationen, in denen sich Dasein befindet und verstehend ist, sind laut Heidegger immer sprachlich, „weil die Sprache „schon eine ausgebildete Begrifflichkeit in sich birgt“. ${ }^{242}$ In der Sprache bzw. Rede artikuliert sich die Verständlichkeit der Erschlossenheit. ${ }^{243}$ Die Sprache in ihrem Wesen ist deshalb „existenzial gleichursprünglich“ zusammen mit Befindlichkeit ${ }^{244}$ und Verstehen, die Heidegger als „die beiden gleichursprünglichen konstitutiven Weisen, das Da zu sein ${ }^{\text {“245 }}$, bestimmt. ${ }^{246}$ Von diesem Standpunkt kritisiert er die Theorien, in denen die Sprache bloß für ein Hilfsmittel der Kommunikation gehalten wird. ${ }^{247}$ Die Sprache bleibt beim jungen Heidegger aber noch als die Sprache des Daseins, nämlich des Menschen.

Der späte Heidegger setzt die Sprache dagegen im unmittelbaren Verhältnis zum Sein selbst ein und damit versteht er die Frage nach dem Sinn des Wortes als unabhängig von ihren subjektiven Bedingtheiten. Das Verhältnis zwischen dem Sein und der Sprache bestimmt er in der folgenden Formel: „Die Sprache ist das Haus des Seins.“248 Die Sprache wird dabei als Medium, durch welches das Sein sich offenbart, vorgestellt. Das innerweltliche Seiende zu sein bedeutet deshalb immer ,unterwegs zur Sprache“ zu sein und impliziert die Unverborgenheit des Seins auf dem Weg zur Sprache. Aufgrund dieser Charakteristik des in der Sprache unverborgenen Seins wird alles Seiende in der Welt nur durch die Sprache verstanden. ${ }^{249}$ Der Seinsbegriff steht dabei ganz und gar im Dienste der Aufhebung der modernen Subjektivität, die sich die Wirklichkeit unterwürfig gemacht hat. ${ }^{250}$ Der besondere Platz, den

\footnotetext{
${ }^{240}$ M. Heidegger, SZ, 197.

${ }^{241}$ M. Heidegger, SZ, 50.

${ }^{242}$ M. Heidegger, SZ, 208.

${ }^{243}$ M. Heidegger, SZ, 214f: „Die befindliche Verständlichkeit des In-der-Welt-Seins spricht sich als Rede aus. [...] Als existentiale Verfassung der Erschlossenheit des Daseins ist die Rede konstitutiv für dessen Existenz. [...] Alle Rede [...] hat zugleich den Charakter des Sichaussprechens. Redend spricht sich Dasein aus.“

${ }^{244}$ Die Befindlichkeit ist bei Heidegger diejenige Seinsstruktur, die etwa die psychologischen Stimmungen vorliegenden Stimmung ermöglicht. Vgl. M. Heidegger SZ, 180.

${ }^{245}$ M. Heidegger, SZ, 177.

${ }^{246}$ M. Heidegger, SZ, 213.

${ }^{247}$ M. Heidegger, SZ, 215-221.

${ }^{248}$ M. Heidegger, Über den Humanismus, Frankfurt a.M. 1949, 5.

${ }^{249}$ M. Heidegger, Erläuterungen zu Hölderlins Dichtung, GA. Bd. 4, Frankfurt a.M. 1981, 39f.

${ }^{250}$ M. Heidegger, Vorträge und Aufsätze, GA. Bd. 7, Frankfurt a.M. 2000, 116-124.
} 
der Mensch sich im Subjekt-Objekt-Schema angeeignet hat, wird zunichte gemacht, indem der Mensch umgekehrt zu einem Faktor im Geschehen des Seins gemacht und diesem unterworfen wird. Die geheimnisvolle Macht des Seins wird dem Menschen durch die Sprache zu-geteilt. Ohne die Sprache ist für uns alles Seiende verschlossen und der Mensch kein Mensch mehr. ${ }^{251}$ Es ist nach Heideggers Bemerkung deshalb eine Illusion, dass der Mensch die Sprache erfindet. Die Sprache steht ihm zufolge im Gegensatz zum Streben des Menschen, die Sprache zu einem Instrument zu machen, mit dem er die Wirklichkeit benennt und beherrscht. Das eigentliche Subjekt des Sprechens ist deshalb nicht der Mensch, sondern die Sprache selbst und damit das Sein. ${ }^{252}$ Und der Mensch spricht vielmehr, ,insofern er der Sprache entspricht. “253 Der Mensch ist in diesem Prozess im Grunde passiv. Seine wichtigste Aktivität ist das Hören, durch das er zum Reden ermächtigt wird und damit zur Macht des Seins gehört. Dadurch werden das Subjekt-Objekt-Schema und das daraus folgende Herrschaftswissen des modernen Subjekts, deren Überwindung der junge Heidegger durch seine existentiale Interpretation versuchte, nun im gewissen Sinne erfolgreich besiegt. ${ }^{254}$

Dieses Sprachverständnis in Bezug auf Seinsoffenbarung bringt einen Umsturz der Hermeneutik, weil die hermeneutische Funktion gerade als das Wesen der Sprache bestimmt wird. Durch die hermeneutische Funktion der Sprache offenbart ein Text sich selber. Das heißt, die Disziplin der Interpretation soll nichts anderes als einen Schritt zurück machen, nämlich nicht mehr durch Analyse und Erklärung erfolgen, sondern durch Hören auf das, was in einem Text offenbart wird. ${ }^{255}$ Für Heidegger ist die Hermeneutik ein geheimnisvoller Prozess als die Präsenz des Seins.

Die Konzeption der Hermeneutik als methodologische Basis der Geistwissenschaften wird nun zurückgelassen und ihr Status als eine Methode selbst wird in Frage gestellt. Die Methode, insbesondere die Objektivität garantierende Methode ist laut Gadamer kein Weg zur Wahrheit. Gegen die Objektivität garantierende Methode, welche eine Wahrheit absolut geltend machen soll, stellt Gadamer einen kommunikativen Prozess, dessen Erkenntnisgewinn nicht in einer absoluten Wahrheit liegt, sondern im Verstehen, das für ihn ein dialektisches und produktives Verhalten ist. In dem folgenden Satz erläutert Gadamer selbst durch die Zielsetzung seiner Untersuchung den ontologischen Charakter: „Der Sinn

\footnotetext{
${ }^{251}$ Vgl. M. Heidegger, Unterwegs zur Sprache, GA. Bd. 12, Frankfurt a.M. 1985, 9: ,[...] erst die Sprache befähige den Menschen, dasjenige Lebewesen zu sein, das er als Mensch ist. Als der Sprechende ist der Mensch.“

${ }^{252}$ M. Heidegger, Unterwegs zur Sprache, GA. Bd. 12, Frankfurt a.M. 1985, $10 \mathrm{ff}$.

${ }^{253}$ M. Heidegger, Unterwegs zur Sprache, GA. Bd. 12, Frankfurt a.M. 1985, 30.

${ }^{254}$ Es ist noch umstritten, ob Heidegger die Metaphysik ganz und gar überwindet. Vgl. J. Habermas, Der philosophische Diskurs der Moderne, Frankfurt a.M. 1985, 158-190; M. Müller, Ende der Metaphysik? Für Martin Heidegger zum 75. Geburtstag am 26. 9. 1964, in: Philosophisches Jahrbuch 72 (1964), 1-48, bes. 18f.

${ }^{255}$ Aufgrund dieser Autonomie des Textes wird die Hermeneutik Heideggers mit der „Neu(en) Kritik“ verglichen, in der nicht der biografische oder historische Hintergrund, sondern der Text selbst am gründlichsten behandelt wird. z.B. sagt R.E. Palmer sogar, ,that Heidegger's hermeneutics might provide the basis for a revitalized form of New Criticism.“" Ders., Hermeneutics. Interpretation Theory in Schleiermacher, Dilthey, Heidegger and Gadamer. Evanston 1966, 159.
} 
meiner Untersuchungen ist jedenfalls nicht, eine allgemeine Theorie der Interpretation und eine Differenziallehre ihrer Methoden zu geben, wie das Betti vorzüglich getan hat, sondern das allen Verstehensweisen Gemeinsame aufzusuchen und zu zeigen, dass Verstehen niemals ein subjektives Verhalten zu einem gegebenen Gegenstande ist, sondern zur Wirkungsgeschichte, und das heißt, zum Sein dessen gehört, was verstanden wird. “ ${ }^{256}$ Er stellt also die Frage nicht mehr nach der Methode oder nach dem Subjekt des Verstehens, sondern nach dem Verstehen selbst im ontologischen Horizont.

Unter dem Einfluss von Heidegger geht Gadamer davon aus, dass jedes Verstehen in eine hermeneutische Situation eingebettet ist und charakterisiert ihren Begriff dadurch, dass „man sich nicht ihr gegenüber befindet und daher kein gegenständliches Wissen von ihr haben kann“ ${ }^{257}$ Aufgrund dieser Situationsgebundenheit des Verstehens ist ein objektives Verstehen unmöglich. Gadamer entwickelt hier über Heidegger hinaus seine eigenen Gedanken: Beim Verstehen befinden sich Menschen immer bereits in der „Wirkungsgeschichte“, nämlich sowohl in der durch Herkommen und Traditionen gewahrten Kontinuität der Geschichte als auch in der Wechselwirkung zwischen Vergangenheit und Gegenwart. ${ }^{258}$ Es ist durchaus möglich, weder diese Wirkungsgeschichte zu transzendieren noch das Vergangene unmittelbar $\mathrm{zu}$ betrachten. Deshalb garantiert nicht die Methode, sondern das „wirkungsgeschichtliche Bewusstsein“, das Gadamer als das „,im Gang der Geschichte erwirkte und durch die Geschichte bestimmte Bewusstsein“ versteht, die Einheit unserer Erkenntnis. ${ }^{259}$ Dies setzt beim Interpretieren eines Textes das Bewusstmachen der eigenen Vorurteilsstruktur sowie die Bereitschaft zum Gespräch voraus. Verstehen ist dann der „Vorgang der Verschmelzung solcher

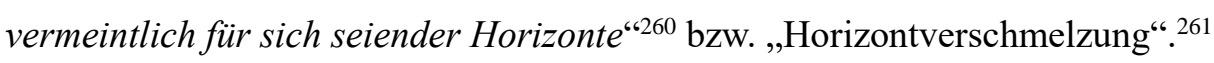

Die Grundlage des Universalitätsanspruchs der Hermeneutik ist, einerseits auf seinem Verständnis der Geschichte, das oben aufgezeigt wurde, aufgebaut, andererseits jedoch im Grunde auf seiner Perspektive der Sprache, weil die Zugehörigkeit zur Sprache von uns und von einem Text laut Gadamer einen allgemeinen Horizont für die Begegnung mit der Vergangenheit und das Verstehen der Überlieferung im Text eröffnet. Es ist vornehmlich anzumerken, dass Gadamer für die ontologische Wendung der Hermeneutik geradezu am Leitfaden der Sprache arbeitet. ${ }^{262}$ Es geht ihm darum, zu zeigen, dass Sprache etwas anderes „als ein bloßes Zeichensystem zur Bezeichnung des gegenständlichen Ganzen“ ist ${ }^{263}$. Er setzt sich wie Heidegger gegen die Zeichentheorie ein, weil diese die Sprache im Begriff der Gegenständlichkeit, ,welche die Wissenschaft erkennt und durch die sie die ihr eigene

\footnotetext{
${ }^{256}$ H.-G., Gadamer, WM I, ${ }^{2} 1965$, Vorwort, XIX.

${ }^{257}$ H.-G., Gadamer, WM I, ${ }^{5} 1986,307$.

${ }^{258}$ H.-G., Gadamer, WM I, ${ }^{5} 1986$, bes. $305 \mathrm{ff}$.

${ }^{259}$ H.-G., Gadamer, WM I, ${ }^{2} 1965$, Vorwort, XXIf.

${ }^{260}$ H.-G., Gadamer, WM I, ${ }^{5} 1986,311$.

${ }^{261}$ H.-G., Gadamer, WM I, ${ }^{5} 1986,312$.

${ }^{262}$ H.-G., Gadamer, WM I, ${ }^{5} 1986,387-494$.

${ }^{263}$ H.-G., Gadamer, WM I, ${ }^{5} 1986,420$.
} 
Objektivität erhält“, einschränkt. Stattdessen behauptet Gadamer, dass der Sprache ,auf eine rätselhafte Weise Gebundenheit an das ,Abgebildete‘, Zugehörigkeit zum Sein des Abgebildeten“ zukommt. ${ }^{264}$ Diese Perspektive bringt die Sprache schließlich zum Horizont einer hermeneutischen Ontologie: „Sein, das verstanden werden kann, ist Sprache.“265 Gadamer betont insbesondere die Möglichkeit der Welterfahrung in der Sprache, dass sich die Welt selber in der Sprache darstellt und die Menschen die Welt nur durch die Sprache erfahren können. ${ }^{266}$ Das menschliche Weltverhältnis ist schlechthin sprachlich und damit verständlich. Die Sprachlichkeit der menschlichen Welterfahrung gibt der Analyse der hermeneutischen Erfahrung einen erweiterten Horizont. Die Hermeneutik ist dabei nicht nur die methodische Basis der Geisteswissenschaften, sondern insofern auch „ein universaler Aspekt der Philosophie “. ${ }^{267}$ Gadamers Konzeption steht damit im Mittelpunkt der Universalhermeneutik und bildet ihren Höhenpunkt. ${ }^{268}$

In der oben aufgezeigten Entwicklungsgeschichte der Hermeneutik bis Gadamer kann man nun sehen, dass Sprache eine wichtige Rolle beim Bestreben spielt, die Hermeneutik als ein unabhängiges und weiter als ein umfangreiches Wissenschaftsgebiet festzustellen, und dass sich die auf Allgemeinheit und Universalisierung richtende Hermeneutik gerade an der Sprache orientiert. Die Weiterführung solcher an Sprache orientieren Hermeneutik erfolgt auch in der Theologie, vornehmlich unter dem Namen „hermeneutische Theologie“, die Ebeling zusammen mit seinem Kollegen Fuchs vertritt.

\section{Ebelings Position}

Die von Heidegger entwickelte Konzeption der Hermeneutik wird zuerst von Bultmann auf die Theologie angewandt. ${ }^{269}$ Dieser beschäftigt sich mit dem Problem der Existenz und seine zentrale Fragestellung lautet: „Wie wird die menschliche Existenz in der Bibel verstanden?“270 Er wird deshalb für den Gründer der neuen Hemeneutik in der Theologie gehalten, aber streng genommen stammt der Begriff der „,neue(n) Hermeneutik“ in der Theologie von seinen Schülern Fuchs und Ebeling. ${ }^{271}$ Viele Äußerungen Ebelings zum Problem der Hermeneutik befinden sich in Auseinandersetzungen über den Stellenwert der Hermeneutik generell und den Entwurf der „hermeneutischen Theologie“ speziell.

\footnotetext{
${ }^{264}$ H.-G., Gadamer, WM I, ${ }^{5} 1986,420$.

${ }^{265}$ H.-G., Gadamer, WM I, ${ }^{5} 1986,478$.

${ }^{266}$ H.-G., Gadamer, WM I, ${ }^{5} 1986,442 \mathrm{ff}$.

${ }^{267}$ H.-G., Gadamer, WM I, ${ }^{5} 1986,479$.

${ }^{268}$ Vgl. Claus v. Bormann, Art. Hermeneutik I. Philosophisch-theologisch, in: TRE 15 (1986), 108-137, 130: „In Gadamers Werk hat die Hermeneutik wohl ihre letzte große Ausprägung erfahren.“

${ }^{269}$ Vgl. R. Bultmann, GuV IV, 163.

${ }^{270}$ R. Bultmann, GuV IV, 168.

${ }^{271}$ Vgl. E. Fuchs, Freundesbriefe von Ernst Fuchs, in: G. Ebeling u.a. (Hg.), Festschrift für Ernst Fuchs, Tübingen 1973, 1-66, hier Brief von 8.12.1959, 48.
} 
Mit dem Namen „hermeneutische Theologie“ ist hier eine Richtung der evangelischen Theologie in der zweiten Hälfte des 20. Jahrhunderts gemeint, die sich entwickelt, eng verknüpft einerseits mit der reformatorischen Fortschreibung der Theologie Bultmanns und andererseits mit der ontologischen Umwendung der philosophischen Hermeneutik seit Heidegger. ${ }^{272}$ Ebeling setzt sich also als der Hauptvertreter der hermeneutischen Theologie ein und seine hermeneutischen Auffassungen lehnen sich maßgebend an ihr Gedankengut an. Ebelings Position als Vertreter der hermeneutischen Theologie ist in den folgenden Richtungen zu untersuchen: erstens durch einen Vergleich mit seinem Kollegen Fuchs, dessen Ideen von der Hermeneutik ihm mitgeteilt sind, und dessen Leistung im Bereich der theologischen Hermeneutik von ihm hoch geschätzt wird. ${ }^{273}$; zweitens durch eine Analyse des Verhältnisses Ebelings zu Bultmann einerseits und zu Heidegger andererseits, wobei die Aufmerksamkeit intensiv auf ihre unterschiedlichen Perspektiven auf die Sprache gerichtet wird.

\subsection{Gemeinsamkeit und Differenz mit Fuchs}

Unter dem Namen „hermeneutische Theologie“ und vornehmlich durch ihre gleichzeitigen Tätigkeiten sowie in ihrer nahen wechselseitigen Beziehung, gibt es eine große Gemeinsamkeit zwischen Fuchs und Ebeling. Durch sie gewann das Thema Hermeneutik eine neue Aufmerksamkeit und wurde nach 1959 in das Zentrum der deutschen Theologie gestellt. Die Diskussion des hermeneutischen Problems war, wie Gadamer sagt, „,wohl nirgends so lebhaft wie im Bereiche der protestantischen Theologie.“274 1954 veröffentlichte Fuchs einen bedeutsamen Band mit dem Titel $>$ Hermeneutik $<1956$ schrieb Ebeling in der dritten Auflage der RGG einen Artikel über die Hermeneutik und hob durch die begriffliche Analyse sowie die geschichtliche Untersuchung die Bedeutung der Hermeneutik hervor, die als Schlagwort der zweiten Auflage der RGG fehlte. Im gleichen Jahr publizierte Fuchs einen Band seiner gesammelten Aufsätze mit dem Titel $>$ Zum hermeneutischen Problem in der Theologie $<$. Das Thema Hermeneutik wurde außerdem in ihren zahlreichen Aufsätzen behandelt. Seit 1962 gaben Fuchs und Ebeling gemeinsam mit Manfred Mezger die Reihe der $>$ Hermeneutischen Untersuchungen zur Theologie $<$, in der bis heute internationale theologische Arbeiten zum Gebiet der Hermeneutik veröffentlicht werden, heraus. Darüber hinaus wurde 1962 an der Universität Zürich ein Institut für Hermeneutik unter der Leitung Ebelings gegründet und im nächsten Jahr an der Universität Marburg ein ähnliches Institut unter der Leitung von Fuchs. Durch ihre Bemühung und ihren Einfluss hat das Wort „Hermeneutik“ einen neuen Klang erhalten.

\footnotetext{
${ }^{272}$ Vgl. J. Lauster, Religion als Lebensdeutung. Theologische Hermeneutik heute, Darmstadt 2005; U.H.J. Körtner, Einführung in die theologische Hermeneutik, Darmstadt 2006; I.U. Dalferth u.a. (Hg.), Hermeneutische Theologie - heute?, Tübingen 2013.

${ }^{273}$ Vgl. Ebeling, Art. Hermeneutik, in: RGG ${ }^{3}$ III (1959), 242-262, 256.

${ }^{274}$ H.-G., Gadamer, Hermeneutik und Historismus, in: WM I, ${ }^{2} 1965$, Anhang, 477-512, 492.
} 
In einem Brief an Ebeling bezeichnet Fuchs ,ihre“ Hermeneutik als „,neue“ Hermeneutik und erklärt dazu: „weil wir nicht mehr nur nach dem Sinn des Textes fragen, sondern nach der mit dem Text selbst gegebenen hermeneutischen Hilfe. Das ist etwas völlig Neues. Und da Du ja darin mit mir völlig einig bist, greife ich Dir kaum vor, wenn ich von einer, neuen' Hermeneutik und spreche und sie gelegentlich als die ,unsre‘, d.h. als die Deine und meine, bezeichne. Dass jeder von uns beiden auf seinem Wege zu diesem Resultat kam, ist ja deutlich genug. Aber ich denke, Du bist damit einverstanden, dass Gemeinsamkeiten auch als solche bezeichnet werden“. ${ }^{275}$ Was diese hermeneutische Hilfe meint, erläutert Fuchs selbst wie folgt: „Soll sich nicht alles im Kreise drehen, so werden uns die Texte selbst sagen müssen, wer uns da helfen kann. [...] Unsre Hilfe kann nur Jesus selber sein, den wir freilich als Gottes Wort verkündigen sollen, sobald wir verstanden haben. Sage ich Jesus, so meine ich den historischen Jesus.“276

Ebeling und Fuchs haben einen gleichen Gesichtspunkt über den Text und seine Auslegung. Ebeling sagt: „Die Schrift ist nicht dunkel, [...] Die Schrift eignet vielmehr claritas, d.h. sie hat erhellende Kraft, so dass von ihr klärendes Licht ausstrahlt.“277 Fuchs beschäftigt sich auch mit der Frage, was die biblischen Texte selbst zu dem Ausleger bringen, weil für ihn das Neue Testament selbst „ein hermeneutisches Lehrbuch“ ist. ${ }^{278}$ Beide konzentrieren sich deshalb auf das Verstehen des Textes selbst, nämlich auf das, was der Text selbst sagt. Es geht ihnen also um die hermeneutische Kraft des Textes selbst, nicht um die Technik der Exegese als die methodische Frage nach angemessenen Regeln. Der Text gewinnt dadurch einen neuen Platz im Vorgang des Verstehens, so dass er nicht mehr nur ein Gegenstand ist, der von uns verstanden wird, nicht mehr in einer passiven Position beim Verstehensprozess verharrt, sondern er selbst uns zum Verstehen bringt: „Im Umgang mit dem Text schlägt das Ausgelegtwerden des Textes um in ein Ausgelegtwerden durch den Text. Aus der Auslegung des Textes im Sinne eines Genitivus obiectivus wird eine Auslegung des Textes im Sinne eines Genitivus subiecktivus.“279 Dieses Merkmal ihrer neuen Hermeneutik wird von Dalferth mit Recht so umformuliert, dass ihre leitende, sie von anderen unterscheidende Differenz weder „zwischen Autorintention und Textsinn“ noch „Zwischen Textsinn und Textlektüren“, sondern „zwischen dem eigentlichen und dem uneigentlichen Sinn eines Textes“ liegt. ${ }^{280}$ Dalferth erklärt richtigerweise, dass sich dieser Sinn darin entscheidet, „ob ein Text im konkreten Gebrauch zum Wortgeschehen wird, das Menschen dasjenige Selbst-, Welt- und Gottesverständnis erschließt“ ${ }^{281}$.

\footnotetext{
${ }^{275}$ E. Fuchs, E. Fuchs, Freundesbriefe von Ernst Fuchs, in: G. Ebeling u.a. (Hg.), Festschrift für Ernst Fuchs, Tübingen 1973, 1-66, hier Brief von 8.12.1959, 48.

${ }^{276}$ E. Fuchs, GA I, 97.

${ }^{277} \mathrm{WG}, 320 \mathrm{f}$.

${ }^{278}$ E. Fuchs, GA III, 169.

279 ThV, 15.

${ }^{280}$ I.U. Dalferth, Radikale Theologie, Leipzig 2010, 163.

${ }^{281}$ I.U. Dalferth, Radikale Theologie, Leipzig 2010, 163.
} 
Die selbstständige Auslegung des Textes bei Fuchs und Ebeling bringt uns nun zu ihrem Sprachverständniss und ihrer Betonung der hermeneutischen Funktion der Sprache. Beide stimmen völlig darin überein, dass die Sprache das einzige Verstehensmedium ist, und dass die Hermeneutik in der Theologie nun nichts anderes als die Sprachlehre des Glaubens ist. Die Sprache ist deshalb ein fundamentales Thema der neuen Hermeneutik von Fuchs und Ebeling und in deren hermeneutischem, theologischem Verständnis der Sprache entstehen die Begriffe von Wort- oder Sprachgeschehen und Sprachereignis.

Sie wollen beide die theologische Aufmerksamkeit auf die Sprache richten, aber jeder mit seinem eigenen Terminus. Ebeling erarbeitet also seine eigene Hermeneutik insbesondere mit dem Terminus „Wortgeschehen“ gegenüber dem Terminus „Sprachereignis“ bei Fuchs. Beide Begriffe bestehen völlig in der theologischen Kategorie und zeigen das kreative Geschehen des Wortes Gottes in konkreten Situationen des menschlichen Lebens. Denn die Begriffe von Wortgeschehen und Sprachereignis verweisen beide auf das Wirken des Wortes in Lebenssituationen, dessen Begriff in Aufnahme und Fortführung von Barths Rede vom Geschehen des Wortes Gottes und Bultmanns Präzisierung von Heideggers Analyse des existierenden Daseins gebildet wurde. Eine größere Betonung legt Fuchs als Neutestamentler aber auf den Text, während Ebelings Wortverständnis dagegen grundsätzlich vom gesprochenen Wort ausgeht, in dem das Wort dynamisch und prozesshaft ist. ${ }^{282}$ Bei Ebeling ist das Wortgeschehen ein Prozess. Es ist jedoch nicht ganz richtig, dass es ein Unterscheidungsmerkmal zwischen Fuchs und Ebeling sei, ob die Sprache als ein Prozess verstanden wird oder nicht. Denn die Sprache wird bei beiden für „Vorgang“ oder „Vollzug“ gehalten, so wie man diese zusammenfassend als „Sprachbewegung“ bezeichnen kann. ${ }^{283}$ Diese Eigenschaft der Sprache scheint Ebeling mit dem Wort „Geschehen“ deutlicher darzustellen, weil das Wort „Ereignis“ dagegen nur als ein singulärer und instanter Akt verstanden werden könnte. Er bevorzugt deshalb, anders als sein Mitstreiter und Freund Fuchs, den Begriff „Wortgeschehen“ gegenüber „Sprachereignis“.

Das, was Ebeling durch Erfindung und Verwendung seines eigenen Terminus erreichen will, ist aber m.E. keine bestimmt begriffliche Distanz zu Fuchs, ${ }^{284}$ sondern nur die Verdeutlichung des Sprachkonzepts als „Lebensvorgang“285 und damit die Betonung der Sprachlichkeit der Erfahrung und der Geschichte, während Fuchs den ontologischen Charakter der Sprache mehr fokussieren will, weil bei diesem Sprache eo ipso „Ereignis des Seins“ ist, ${ }^{286}$ so wie er sie als „Versammlung des Seins““287 bezeichnet. Die in der Verwendung der unterschiedlichen Termini von Wortgeschehen und

\footnotetext{
${ }^{282}$ Vgl. WG, 258 u. 334.

${ }^{283}$ E. Biser, Theologische Sprachtheorie und Hermeneutik, München 1970, $310 f$.

${ }^{284}$ Nicht nur Ebeling, sondern Fuchs selber verwendet auch den Ausdruck des Wortgeschehens. Ders, Die Spannung im neutestamentlichen Christusglauben, in: ZThK 59 (1962), 32-45, 41.

285 Sprachlehre, 195.

${ }^{286}$ E. Fuchs, Was ist ein Sprachereignis? Ein Brief, in: GA II, 1960, 424-430, 426.

${ }^{287}$ E. Fuchs, Was ist ein Sprachereignis? Ein Brief, in: GA II, 1960, 424-430. 425.
} 
Sprachereignis angelegte Differenz zwischen Fuchs und Ebeling liegt deshalb nicht darin, ob sie den Charakter der Sprache gegenseitig jeweils als prozesshaft oder als punktuell verstehen. Stattdessen ergibt sie sich darin, dass sie unter dem gemeinsamen, energetischen, auf den Vollzugscharakter abhebenden Sprachverständnis eine unterschiedliche Akzentuierung haben und damit jeweils den lebensbezogenen und den ontologischen Charakter der Sprache hervorheben wollen. ${ }^{288}$

Hinsichtlich der Gemeinsamkeit und der Differenz zwischen Fuchs und Ebeling ist die Argumentation Dalferths ebenfalls beachtenswert. Dalferth sagt, dass sie als ihr Hauptthema den grundlegenden Zusammenhang ,,von cognitio dei und cognitio hominis“ haben und sich die Begriffe von Wortgeschehen und Sprachereignis ,in reformatorischer Tradition zentral am Mensch gewordenen verbum dei“ orientieren. ${ }^{289}$ Aber es gibt dabei laut Dalferth einen charakteristischen, unterschiedlichen Standpunkt zwischen ihnen. Während Fuchs am leitenden Begriff des Sprachereignisses eine Hermeneutik erstellt, ,in der alles, auch die cognitio hominis, von der sich selbst als solche erschließenden cognitio dei her entfaltet wird“, entwickelt Ebeling am Begriff des Wortgeschehens eine Hermeneutik, ,in der die cognitio dei von der - durch die Dialektik von Sünde und Glaube geprägten - cognitio hominis her entfaltet wird“. ${ }^{290}$ In diesem Sinne schließt er, dass Ebeling „den Explikationsrahmen der theologischen Hermeneutik“ in „einer theologischen Anthropologie“ untersucht. ${ }^{291}$ Damit liegt er teilweise richtig, weil Ebeling stark von einer Erscheinung des Gotteswortes im menschlichen Wort, nämlich von dem Wortgeschehen durch den sündigen Menschen redet. Ebelings hermeneutische Theologie ist also eine Hermeneutik des Wortes Gottes, der sein Wort an die Menschen richtet. In seiner eigenen Aussage über das Verhältnis zwischen Gottes- und Selbsterkenntnis scheinen beide aber in gleicher Höhe gehalten zu werden: „Der Glaube vollzieht und entfaltet sich als ein Erkenntnisgeschehen, in dem Gotteserkenntnis und Selbsterkenntnis zu einem einzigen Vorgang werden. [...] Deshalb handelt es sich bei dem Ineinander von Gottes- und Selbsterkenntnis in Wahrheit um einen Zirkel, der in beiden Richtungen umläuft.،"292

Das theologische Argument über die Zusammengehörigkeit von cognitio dei et hominis, das offenbar einen Konsens unter den Reformatoren darstellte, ${ }^{293}$ spitzt sich in der modernen Theologie vornehmlich bei Barth und Bultmann wegen ihrer gegenseitigen Gesichtspunkte zu. Denn der Versuch zum theologischen Verstehen Gottes ist bei Bultmann „vom menschlichen Selbstverstehen her“ zu entfalten, bei Barth aber „vom göttlichen Selbstverstehen her“. ${ }^{294}$ Dass Ebeling und Fuchs den Gegensatz

\footnotetext{
${ }^{288} \mathrm{Vgl}$. H.C. Knuth Verstehen und Erfahrung. Hermeneutische Beiträge zur empirischen Theologie, Hannover $1986,57 f$

${ }^{289}$ I.U. Dalferth, Radikale Theologie, Leipzig 2010, 29.

${ }^{290}$ I.U. Dalferth, Radikale Theologie, Leipzig 2010, 30.

${ }^{291}$ I.U. Dalferth, Radikale Theologie, Leipzig 2010, $157 f$.

${ }^{292}$ D I, $181 f$.

${ }^{293} \mathrm{Vgl}$. LuSt I, $221 \mathrm{ff}$.

${ }^{294}$ I.U. Dalferth, Radikale Theologie, Leipzig 2010, $78 f$.
} 
zwischen Bultmann und Barth gemeinsam im Ansatz überwinden wollen, ist ein alter, doch immer noch überzeugender und bevorzugter Aspekt ihres Verhältnisses zu den beiden Theologen. Aufgrund der oben erwähnten unterschiedlichen Akzentuierung von der cognitio dei und der cognitio hominis stellt Dalferth Ebeling näher zu Bultmann, während er Fuchs (u. Jüngel) näher zu Barth ordnet. ${ }^{295}$ Obwohl seine Meinung zum Teil richtig ist, muss man doch vorsichtig den genauen Ort der Theologie Ebelings und Fuchs' zwischen Barth und Bultmann bestimmen sowie die davon angegriffene, unterschiedliche Position als eine feste Differenz zwischen Ebeling und Fuchs bezeichnen.

In Hinsicht auf das Verhältnis Ebelings zu Fuchs ist die Auffassung m.E. vorrangig, dass sie sich mit ihrer Hermeneutik auf das gemeinsame Ziel richten, zu einer der zeitnächsten Formen der protestantischen Theologie zu gehören und auf die Herausforderungen der gegenwärtigen Welt zu antworten. Danach weist man äußerst vorsichtig auf mögliche Differenzen hin, denn eine radikale Unterscheidung könnte in die Gefahr geraten, den Umfang der Begriffe einzeln zu beschränken oder einseitig zu machen, insbesondere wenn es um die Sprache als gemeinsames Wendungsthema zu ihrer neuen Hermeneutik geht. ${ }^{296}$ Ihre Gemeinsamkeit wird deutlicher in der Gegenüberstellung von Bultmann.

\subsection{Kritische Rezeption von Bultmann}

Beim Vergleichen mit Bultmann kommt als Erstes zur Sprache, dass Ebeling so wie Bultmann in seiner Hermeneutik von der Fraglichkeit der Existenz ausgeht, er aber anders als Bultmann die Fraglichkeit nicht nur der Existenzkategorie zuordnet, sondern sie sprachlich begreift. Ebeling kritisiert, dass Bultmann in seiner reformatorischen Orientierung nicht weit genug gegangen sei und damit die Bedeutung des Wortes Gottes und der Sprachlichkeit menschlicher Wirklichkeit nicht richtig erfassen könne. ${ }^{297}$ Er schlägt deshalb die Hermeneutik in der Konzentration auf das Wortgeschehen als die zweckmäßige Vertiefung von Bultmanns existentialer Interpretation vor. Er will sich dadurch von Bultmann abgrenzen und äußert seine Meinung zum Verhältnis zu diesem wie folgt: „Die mir immer wieder zugeschriebene Bultmann-Schülerschaft trifft nur in sehr eingeschränktem Maße zu“. 298 Ähnliche Aussage finden sich auch bei seinem Kollegen Fuchs, der eine starke Kontinuität zu Bultmann hat und diesen doch dahingehend kritisiert, dass „die Sprachlichkeit der menschlichen Existenz“ nicht

\footnotetext{
${ }^{295}$ I.U. Dalferth Radikale Theologie, Leipzig 2010, 30.

${ }^{296}$ Z.B. I.U. Dalferth führt die strenge Unterscheidung zwischen den Begriffen von Wortgeschehen und Sprachereignis vor Augen und charakterisiert das Sprachverständnis bei Ebeling als „sakramental“ und bei Fuchs als „christologisch“. Ders., Radikale Theologie, Leipzig 2010, 161. Diese Bestimmung ist m.E. aber nicht unstrittig, da die Sprache bei Ebeling nicht nur den sakramentalen Charakter wie Gottes Anwesenheit oder die Wirkung der Heiligkeit, sondern auch den christusbezogenen Charakter hat, der deutlich in seinem Formular von Gesetz und Evangelium dargestellt wird. Vgl. Kap. III. 4.2.

${ }^{297}$ WG, 333, vgl. 306f u. 338f.

${ }^{298}$ WG IV, 647.
} 
genügend berücksichtigt wird ${ }^{299}$ : „Gewiss ist so die Sprache auf den Mensch angelegt und das Sein existenzbezogen. Darin stimme ich mit Bultmann doch wohl überein. Aber umgekehrt ist nun auch sowohl das Sein als auch der Mensch auf Sprache angelegt. [...] Die Sprache ist nicht die Abbreviatur des Denkens, sondern das Denken ist Abbreviatur der Sprache. [...] Deshalb ging ich dazu über, die Geschichtlichkeit der Existenz als Sprachlichkeit der Existenz aufzuweisen. “300 Daher betont er, seine Rede von „Sprachereignis“ dürfe nicht auf das von Bultmann vorgeschlagene „Sprechereignis“301 reduziert werden, ${ }^{302}$ weil die Sprache nicht einfach der Akt des Sprechens ist, sondern ,vielmehr primär ein Zeigen oder sehen Lassen, ein Bedeuten im aktiven Sinne ${ }^{\text {(303 }}$. Ebeling und Fuchs grenzen sich von Bultmann also am Sprachverständnis ab.

Anders als Bultmann zeigt Ebeling seine eigene Besonderheit vornehmlich durch die Betonung der positiven Funktion der Sprache im hermeneutischen Prozess. Bultmann glaubt, dass die Sprache das richtige Verstehen des Wortes Gottes erschweren kann, weil sie die Sache durch Formalität und Autorität mythisch objektiviert und eigentlich der Sachkritik, die als eine Kritik an der benutzten Sprache „zwischen Gesagtem und Gemeintem unterscheidet und das Gesagte am Gemeinten misst“"304, gegenübergestellt werden muss. Bei Ebeling dagegen ist die Sprache ein positiver und wesentlicher Faktor des menschlichen Lebens und damit eine Bedingung für das Wirksamwerden des Wortes Gottes. Auch mit dem Begriff von Wort- und Sprachgeschehen scheint sich Ebeling von Bultmann abzugrenzen, genauer gegen den punktuellen Charakter der Sprache bei Bultmann. Denn der Letztere hält das Wort Gottes als „Anrede“ für ein punktuelles „Ereignis“, dem nur in einer gläubigen, gehorsamen Entscheidung Folge geleistet werden kann. ${ }^{305}$ Bei Ebeling basiert die Macht des Wortes jedoch nicht auf der autoritären Anrede, sondern auf der Tatsache, dass das Wort Verstehen selbst bewirkt. Die so unterschiedlichen Sprachverständnisse von Bultmann und Ebeling sind durch den unterschiedlichen Einfluss Heideggers zu erklären, nämlich jeweils von dem frühen und dem späten Heidegger. Obwohl man Gedanken des frühen und des späten Heideggers nicht radikal trennen kann, weil nicht nur Differenz, sondern auch Kontinuität zwischen ihnen erkennbar ist, ist es doch ganz klar, dass man in

\footnotetext{
${ }^{299}$ E. Fuchs, Das hermeneutische Problem, in: Zeit und Geschichte, E. Dinkler (Hg.), Tübingen 1964, 357-366, 363f; Zum hermeneutischen Problem in der Theologie, in: GA I, 1959, 107-115, 113-115.

${ }^{300}$ E. Fuchs, Was ist ein Sprachereignis? Ein Brief, in: GA II, 1960, 424-430, 427ff.

${ }^{301}$ Vgl. Bultmanns Brief an Fuchs, 8. 3. 1960 (Nachlass G. Ebeling, UAT 633/616), hier zitiert nach: A. Beutel, Gerhard Ebeling. Eine Biographie, Tübingen 2012, 265.

${ }^{302}$ E. Fuchs, Was ist ein Sprachereignis? Ein Brief, in: GA II, 1960, 424-430, 424: "Bultmann hält mir vor, dass ich Sprache und Sprechen verwechsle, weil ich von einem Sprachereignis rede, statt mich etwa mit dem Ausdruck ,Sprechereignis' zu begnügen, der nach seiner Ansicht für das, was ich meine, allenfalls angemessen wäre. Ich wundere mich."

${ }^{303}$ E. Fuchs, Hermeneutik, Bad Cannstatt 1954, 131.

${ }^{304}$ R. Bultmann, Das Problem einer theologischen Exegese des Neuen Testaments, in: J. Moltmann (Hg.), Anfänge der dialektischen Theologie Teil II, München ${ }^{3}$ 1977, 47-72, 53.

${ }^{305}$ R. Bultmann, GuV I, 282 f.
} 
seinen späten Werken ein großes Interesse für die Sprache selbst und die Äußerungen über ihr Wesen unmittelbar in Verbindung mit dem Sein überall finden kann. Gerade unter dem Einfluss dieses späten Heideggers steht Ebeling, während Bultmann unter dem des frühen steht, der sich maßgeblich mit dem Problem der menschlichen Existenz beschäftigt.

Das unterschiedliche Verständnis der Sprache bei Bultmann und Ebeling bringt eine erneuerte Bedeutung für Begriffe wie Verkündigung oder Überlieferung, die durch Sprache vermittelt werden, und damit eine Veränderung für den Charakter der neuen Hermeneutik. Bei Ebeling wird die Bibel immer neu und anders nicht nur ausgelegt sondern auch verkündigt, weil der Inhalt des Textes in die Situation des Predigers und seiner Hörer übertragen werden muss und diese Situation veränderlich ist. Wenn Bultmann sagt, dass Jesus ins Kerygma auferstanden ist, so könnte Ebeling (u. Fuchs) sagen, nach dem Ausdruck Robinsons, ,das durch Jesu Wort ausgelöste Wortgeschehen ereigne sich heute in der Verkündigung der Kirche.“ ${ }^{\text {306 }}$ Der Terminus Kerygma, der die Trennung des historischen Jesus von der kirchlichen Verkündigung anzeigt, schwindet nun allmählich aus dem Wortschatz der neuen Hermeneutik und wird durch die Begriffe „Sprachereignis“ oder „Wortgeschehen“, für die Jesus und die Verkündigung der Kirche zusammengehören, ersetzt. Aufgrund dieses Begriffs des Wortgeschehens spielt bei Ebeling die Überlieferung der Tradition und der Auslegungsgeschichte anders als bei Bultmann eine wichtige Rolle, denn er hält den hermeneutischen Prozess für ein Geschehen, das als Ganzes bestimmt wird und das das, was im Text festgelegt worden ist, das, was in der Tradition ausgelegt wurde und auch das, was in der Gegenwart zur Sprache gebracht wird, umfasst. ${ }^{307}$

Das Verhältnis Ebelings zu Bultmann kommt oft gepaart mit dem zu Barth zur Sprache, weil der Dissens innerhalb der dialektischen Theologie, bei der Ebeling einsetzt und deren hermeneutisches Defizit er aufzuheben versucht, gewöhnlich mit den Namen der beiden angedeutet werden kann. Wenn im allgemeinen Sinne Ebelings Theologie schematisiert und idealtypisch bestimmt wird, dann gehört sie gewiss zu der Bultmanns und Ebeling somit zur Schule Bultmanns. Sofern es um das Thema Sprache geht, ist es aber nicht einfach, Ebeling näher zu Bultmann oder zu Barth zu stellen. Zumindest hinsichtlich der Betonung der Macht des Wortes Gottes und die damit resultierenden Auswirkungen auf das Verstehen scheint Ebeling, wie M. Ruokannen sagt, näher an Barth als an Bultmann zu stehen. ${ }^{308}$ Ebelings Stellung zu Barth und seine Anhängerschaft darf nicht unterschlagen werden. ${ }^{309}$ Es geht

\footnotetext{
306 J.M. Robinson, Die Hermeneutik seit Karl Barth, in: Ders./J.B. Cobb (Hg), Die neue Hermeneutik, Zürich/Stuttgart 1965, 13-108, 89f.

${ }^{307}$ Vgl. Ebeling, Art. Tradition VII. Dogmatisch, in: RGG ${ }^{3}$ VI (1962), 976-984, 977; ThV, 10-18.

${ }^{308}$ M. Ruokanen, Hermeneutics as an Ecumenical Method in the Theology of Gerhard Ebeling, Helsinki 1982, 135, vgl. 131 u. 149.

309 Z.B. erklärt L. Steiger Ebelings Anhängerschaft an Barth wie folgt: Ebeling nimmt „,nicht nur die Denkbewegungen des frühen Barths aus der Zeit des Römer-Briefes auf, um herkömmlich gewisse gute Ansätze gelten zu lassen, sondern er bezieht seine hermeneutische Bemühung um eine Theologie des Wortes zu einem wesentlichen Teil auf die Kirchliche Dogmatik, der gegenüber der sich gegen den Vorwurf, sie verfalle einem
} 
allerdings zu weit, Ebeling eine größere Übereinstimmung mit Barth als mit Bultmann zuzuschreiben, weil sich sein grundlegender Standpunkt über das Verhältnis zwischen Gotteswort und Menschenwort Barth widersetzt.

Ebeling versucht, wie bereits erwähnt, den Gegensatz zwischen Barth und Bultmann zu überwinden und bestimmt die „Problemskizze“ als Vergröberung ihres Gegensatzes folgendermaßen: „Auf der einen Seite tendiert das Pathos des Wortes Gottes auf Bagatellisierung des hermeneutischen Problems; auf der anderen Seite scheint das Interesse am hermeneutischen Problem das Reden vom Worte Gottes zu gefährden“ “. ${ }^{310}$ Diese im Verhältnis von Hermeneutik und Wort Gottes anliegende Differenz hält Ebeling doch für gleichbedeutend. Im Blick auf die Wirklichkeit der beiden Seiten, nämlich die des Menschen von Gott und die des Gottes vom Menschen, will er keine einseitig hervorheben. In der umfassenden Betonung auf den Wortcharakter der Wirklichkeit der zwei Seiten kann der „Grund-Satz der Theologie“ bei Ebeling wie folgt kurz ausgedrückt werden: ,allein Gott“ kommt „,im Wort allein“ ${ }^{311}$ L. Steiger weist mit Recht darauf hin, dass solcher Wortzusammenhang eine Ortbestimmung der Theologie Ebelings zwischen Barth und Bultmann schwierig macht, denn Ebeling wendet sich nicht nur ,gegen die objektive Darstellung der Dogmatik“ bei Barth, die uns in Gefahr bringt, den Bezug eines dabei entfalteten Glaubensgegenstandes zum Geschehen des Wortes und damit zur Wirklichkeit des Glaubens zu verlieren, sondern auch „gegen die kerygmatische Erfahrungslosigkeit der Theologie“ bei Bultmann. ${ }^{312}$ In diesem Sinne darf Ebelings hermeneutische Theologie und sein Sprachverständnis nicht allgemein, sondern nur im Speziellen als bultmannisch oder als anti-barthianisch bezeichnet werden.

\subsection{Theologische Rezeption von Heidegger}

Ebelings Sprachkonzept steht maßgehend unter dem Einfluss vom späten Heidegger. Ebenso wie dieser denkt Ebeling die Sprache an der Quelle des Menschenseins und dessen Lebens. Die Sprache ist für beide eine einzige Weise, wie sich der Mensch manifestiert und zur Wahrheit gelangt, weil sie das Verborgene aus Licht bringt. Gleichermaßen identifizieren sie das Zu-sagen oder Zu-sprechen als die grundlegende Funktion der Sprache und bezeichnen die menschliche Sprache wesentlich als Antwort, bei der das Hören vorrangig vor dem Sprechen ist. ${ }^{313}$ Ihre Sprachverständnisse setzten sich gegen das

Offenbarungspositivismus, offenzuhalten weiß“. Ebeling hält die Aporie des Denkens Barths also für „eine unaufgebbare theologische“. Ders., Sprachschule des christlichen Glaubens. Zur Theologie Gerhard Ebelings, in: Kirche in der Zeit 17 (1962), 105-113, 106.

310 WG, 324.

311 WG II, 41.

${ }^{312}$ L. Steiger, Sprachschule des christlichen Glaubens. Zur Theologie Gerhard Ebelings, in: Kirche in der Zeit 17 (1962), 105-113, 106.

${ }^{313}$ DG I, 400; WG II 418. Vgl. M. Heidegger, Unterwegs zur Sprache, GA. Bd. 12, Frankfurt a.M. 1985, 29 u. 248 . 
moderne Subjekt-Objekt-Denken, in dem das Subjekt die Weltwirklichkeit gegenüberstellt und die Sprache im Zeichensystem instrumentalisiert. Aufgrund dieses Sprachverständnisses charakterisiert Ebeling die Aufgabe der Hermeneutik als „die Aufgabe einer Hinterfragung des Subjekt-ObjektSchemas in Richtung auf eine ontologisch begründete, am Sprachproblem orientierte allgemeine Hermeneutik“. ${ }^{314}$ Die an der Sprache orientierte Hermeneutik wird bei Heidegger und Ebeling zum fundamentalen Bereich ausgebaut, nach der Darstellung K. Zwanepols, jeweils zu einer „Fundamentalontologie“ und zu einer „Fundamentaltheologie“.315

Ebeling in der Beziehung zu Heidegger zu betrachten, ist aber umstritten. Negativ betrachtet kann man sagen, dass Ebeling entweder Heideggers Denken in seine Theologie nicht richtig aufnehmen oder das reformatorische Erbe verderben würde, weil Heidegers philosophische Rede theologischen Themen wie Gott, Sünde und Glaube widerspricht. R. Lorenz kritisiert z.B. heftig, dass Ebeling das Unvereinbare, nämlich Luthers Theologie und Heideggers hermeneutischen Entwurf zu vereinigen versuchte, inhaltlich jedoch keinem von beiden gerecht werden konnte. Denn Theologie, die sich auf die eine oder andere Weise an Luther anschließt, kann laut Lorenz unmöglich hermeneutisch sein, weil darin ein Gegensatz zwischen Gott und Mensch konstruiert wird, der jegliche Vermittlung ausschließt. Von einer Erschließung der Wahrheit von der menschlichen Erfahrung her kann dann keine Rede sein, da der Gottesbegriff dies verbietet und ausschließt. Theologie geht nicht von der Erschlossenheit des Daseins aus, weil diese als hermeneutischer Zirkel den Verstehensprozess auf der Suche nach der Wahrheit des Seins offenhält, während eine vorgängige Fixierung des Daseins im Gottesbezug die hermeneutische Kraft preisgibt. Die beiden Ursprünge der Hermeneutik Ebelings, von Luther und Heidegger herkommend, stoßen laut Lorenz folglich auf einen inneren Widerspruch, so dass das Vorhaben, eine hermeneutische Theologie zu schaffen, prinzipiell gescheitert ist. ${ }^{316}$ Schließlich behauptet Lorenz, dass Luthers Theologie als apologetisch statt hermeneutisch charakterisiert werden solle, weil sie nicht auf Erschließung, sondern auf einen Beweis zielt. ${ }^{317}$

Ebeling in der doppelten Bindung an Luther und Heidegger zu interpretieren erweist sich als schwierig. Lorenz scheint aber „hermeneutisch“ und „nicht-hermeneutisch“ zu radikal oder zu einfach zu unterscheiden. Es kann nicht sein, dass eine Theologie, die von einer Antithese zwischen Gott und Mensch ausgeht, einfach für nicht-hermeneutisch gehalten wird, während sie umgekehrt dann als hermeneutisch gilt. ${ }^{318}$ Auch wenn die skeptische Frage nach dem Verhältnis von Theologie und philosophischer Hermeneutik bereits seit Barth existiert, der fürchtete, dass die Theologie in die

\footnotetext{
${ }^{314}$ Ebeling, Art. Hermeneutik, in: RGG ${ }^{3}$ III (1959), 242-262, 256.

${ }^{315}$ K. Zwanepol, Unterscheiden, Bern, 221.

${ }^{316}$ R. Lorenz, Die unvollendete Befreiung vom Nominalismus. Martin Luther und die Grenzen hermeneutischer Theologie bei Gerhard Ebeling, Gütersloh 1973, 289-315.

${ }^{317}$ R. Lorenz, Die unvollendete Befreiung vom Nominalismus. Martin Luther und die Grenzen hermeneutischer Theologie bei Gerhard Ebeling. Gütersloh 1973, 317f, bes. 324 .

${ }^{318}$ Vgl. K. Zwanepol, Unterscheiden, Bern, 245-252.
} 
Abhängigkeit einer allgemeinen Hermeneutik geraten würde, und das hermeneutische Problem daher absichtlich nicht zum eigenständigen Thema der Theologie machte, kann die Theologie wesentlich nicht un-hermeneutisch sein. ${ }^{319}$ Denn die Theologie hat mit der Frage zu tun, wie Menschen zum Verstehen Gottes kommen und damit zum Glauben, nach der Darstellung Dalferths, zum „Verstehen des menschlichen Verstehens Gottes, der sich selbst den Menschen als Gott verständlich macht“ . 320

Die theologische Frage wird mit Heidegger allerdings nicht nur in Einzelheiten verknüpft. In ihm kommt vielmehr die ganze Tradition abendländischen Denkens kritisch auf die Theologie zu, also ein Vorgang, den die Theologie im Hinblick auf ihre eigene Tradition zu verantworten hat. Diesbezüglich sagt Ebeling selber, dass die Phänomene wie „Entgötterung der Welt, Entmythologisierung, Säkularisierung und Vergeschichtlichung der Wirklichkeit" die Theologie fraglich werden und in Auseinandersetzung mit den Problemen der Neuzeit treten lassen. ${ }^{321}$ Die Theologie stößt dann unvermeidlich auf das hermeneutische Problem, dass das Verhältnis von Glaube und Skepsis gerade die Frage, auf die die theologische Hermeneutik antworten soll, ist. Da kommt nun die Frage auf, wie eine philosophische Hermeneutik, die mit der Offenbarung Gottes nichts zu tun hat, das Instrumentarium für Theologie liefern kann. Für Ebeling besteht die Hermeneutik nicht nur in der Unterstützung für das Verstehen nach außen, sondern es drängt sich ihm auch „die Notwendigkeit einer Hermeneutik des innertheologischen Gesprächs“ auf,, ${ }^{322}$ erstens, weil Glaube und Theologie mit Verstehen zu tun haben

${ }^{319}$ Z.B. behauptet Heinrich Ott, Theologie sei „eigentlich Hermeneutik“, weil der Glaube danach drängt, „sich selber im Medium der Helle des Denkens darzustellen“. Ders., Was ist systematische Theologie?, in: J.M. Robinson/J. Cobb (Hg.), Der spätere Heidegger und die Theologie, Zürich/Stuttgart 1964, 65-133, 96. P. Ricoeur plädiert auch für die Notwendigkeit des Begriffs der Hermeneutik für die Theologie, behauptend: „Die Hermeneutik ruft in Erinnerung, dass der biblische Glaube von der Bewegung der Interpretation, die ihn zur Sprache bringt, nicht zu trennen ist.“ Ders., Philosophische und theologische Hermeneutik, in: Ders./E.Jüngel (Hg.), Matapher. Zur Hermeneutik religiöser Sprache, München 1974, 24-45, 43. In einem Artikel „Hermeneutik“ in der >Theologischen Realenzyklopädie<(1986) behauptet Claus v. Bormann, dass die hermeneutische Theologie mit der Betonung auf die Sprache von Ebeling (auch von Fuchs und Jüngel) schon in den sechziger Jahren nicht nur ,ihren Höhenpunkt“, sondern auch ,ihr vorläufiges Ende“ erreichte, weil die „Bedeutung und Diskussion von Hermeneutik in der Theologie, wo sie einmal ihr wichtigstes Aufgabenfeld gefunden hatte“, nun „,gering geworden bzw. verstummt“ ist. Ders., Bormann, Art., Hermeneutik, I. Philosophisch/theologisch, in: TRE 15, Berlin/New York 1986, 108-137, 129. Ähnliches schreibt Klaus Scholder schon 1971: „Die Hermeneutik wurde von ihrem Thron gestoßen, und wer heute noch nach ihr fragt, beweist damit nur, dass er von gestern ist.“ Ders., Einführung, in: VF 16 (1971), 1-4, 1; zitiert nach U.H.J. Körtner, Theologie des Wortes Gottes. Positionen, Probleme, Perspektiven. Göttingen 2001, 242. Das Thema der Hermeneutik war in der Tat einige Zeit außer der theologischen Interesse. Als ein Versuch, die notwendige Stellung der Hermeneutik innerhalb der Theologie wieder zu beweisen und für die Bedeutung der hermeneutischen Theologie für heute ein Bewusstsein zu schaffen, ist ein Buch vorzustellen, dessen Grundstock die bei einer Tagung 2009 in Zürich vorgetragenen Beiträge bilden. Dalferth/Bühler/Hunziker (Hg), Theologische Hermeneutik - heute?, Tübingen 2013. Dieser Titel $>$ Hermeneutische Theolgie - heute? $<$ scheint den oben gesehenen negativen Aspekt mit einem Fragezeichen zu reflektieren und zugleich lässt sich fragen, ob ein solch negativer Aspekt richtig zur Darstellung kommt.

${ }^{320}$ I. U. Dalferth, Vorwort, in: Ders. u.a. (Hg.), Hermeneutische Theologie - heute?, Tübingen 2013, XIVf.

${ }^{321} \mathrm{WG}, 358$.

${ }^{322}$ WG II, 101. 
und zweitens, weil sich Schriftauslegung und Verkündigung in einem hermeneutischen Vorgang vollziehen. Er glaubt, dass das hermeneutische Problem für die Theologie ,zum Ort der Begegnung mit der Philosophie“ wird, worin stets sowohl Gemeinsamkeit als auch Gegensatz liegt. ${ }^{323}$

In Hinsicht auf das Sprachverständnis Heideggers gibt es auch ambivalente Aspekte: Zum Beispiel sagt Paul J. Meier, dass die Theologie im Sprachverständnis des späten Heideggers den nächsten Gesprächspartner trifft. ${ }^{324}$ Demgegenüber behauptet Ingolf U. Dalferth, dass bei Heidegger die Sprache keine Rolle „als Lösungshorizont zur Bestimmung der Beziehung“ zwischen Philosophie und Theologie, sondern „,als Problemanzeige ihrer Differenz“ hat. ${ }^{325}$ Ebelings Sprachverständnis hat seine ontologische Basis gewiss in Heideggers Auffassung der Sprache als Selbstauslegung des Seins. Heideggers Bezeichnung der Sprache als „das Haus des Seins“, in dem Geste, Schweigen und sogar Donner als Sprache interpretiert werden, ${ }^{326}$ geht aber sehr viel weiter als Ebelings Standpunkt. ${ }^{327}$ Das unmäßig erweiterte Sprachkonzept Heideggers akzeptiert Ebeling geradezu im Rahmen der Theologie.

Während die philosophischen Hermeneutik im Bereich des menschlich Erfahrbaren bleibt, transzendiert die theologische Hermeneutik diesen menschlichen Bereich also durch die Berufung auf die Offenbarung. Das Verifikationsprozess der philosophischen Hermeneutik, das Gott außer Betracht lässt, entspricht nicht dem der theologischen Hermeneutik, in dem Gott eine führende Rolle spielt, da Gott bzw. sein Wort selbst den Menschen verifiziert. Aus diesem Grund plädiert Ebeling für das Festhalten an einer besonderen theologischen Hermeneutik neben der allgemeinen philosophischen Hermeneutik. ${ }^{328}$ Theologie muss ihm zufolge unbedingt als Theologie ausgezeichnet werden. Der Begriff des Wortgeschehens, mit dem er das Wesen der Sprache bestimmt und den er unter dem Einfluss des späten Heideggers als die ontologische Bezogenheit der Sprache bezeichnet, muss dann zuerst als ein theologischer verstanden werden, ${ }^{329}$ weil er ihn primär in Anlehnung an das Wort Gottes erarbeitet und dabei die biblischen Begriffe wie das paulinische euangelion und das hebräische dabar berücksichtigt. Die Abgrenzung Ebelings von Heidegger ist schon an seiner eigenen Aussage erkennbar: Heideggers Denken sei „nicht Wort des Glaubens, nicht Evangelium, sondern Interpretation des Gesetzes.“330 Er selber setzt hier seinen Differenzpunkt gegen Heidegger dahingehend, dass er die hermeneutische Differenz der Theologie festhält und sich selbst auf den Vorrang der Theologie bezieht,

\footnotetext{
${ }^{323}$ WG, 333.

${ }^{324}$ Paul J. Meier, Fundamental ontology and positive theology: Martin Heidegger's way of thinking, in: Journal of Religious Thought, vol. 17 (1960), 101-115, 114.

${ }^{325}$ I.U. Dalferth, Radikale Theologie, Leipzig 2010, 238.

${ }^{326}$ M. Heidegger, Unterwegs zur Sprache, GA. Bd. 12, Frankfurt a.M. 1985, $200 \mathrm{ff}$.

${ }^{327} \mathrm{Vgl}$. Sprachlehre, 107.

${ }^{328}$ WG, 330ff.

${ }^{329}$ Vgl. I.U. Dalferth, Radikale Theologie, Leipzig 2010, 90-97 u. 161.

${ }^{330}$ Ebeling, Verantworten des Glaubens in Begegnung mit dem Denken Heideggers. Thesen zum Verhältnis von Philosophie und Theologie, in: ZThK, Beiheft 2 (1961), 119-124, 122; Wiederabdruck in: WG II, 92-98.
} 
ausdrücklich anhand der Unterscheidung von Gesetz und Evangelium, die er als Art und Weise des Theologietreiben sieht.

In diesem Zusammenhang ist die Ansicht Schlögels, mit der dieser hinsichtlich der Gewissensthematik das Verhältnis Ebelings zu Heidegger erläutert, auch in Bezug auf das Sprachkonzept sinnvoll zu betrachten: Ebeling spricht zuerst von „Begegnung“ mit dem Denken Heideggers, aber später von „Auseinandersetzung“, 331 in der er die theologischen Begriffe zuspitzt. Für Ebeling gilt die Priorität der Theologie. ${ }^{332}$ Eine Positionsbestimmung der Hermeneutik Ebelings in Bezug auf Heidegger muss dann immer der Frage folgen, welche theologischen Motive an sie geknüpft sind. Denn das von Heidegger beeinflusste ontologische Sprachkonzept Ebelings kann nur im theologischen Rahmen richtig verstanden werden.

\section{Problemhorizont der Sprache in Ebelings Hermeneutik}

Der Platz der Sprache in der Hermeneutik ist bei Ebeling sehr bedeutsam und auch charakteristisch. Um den Problemhorizont der Sprache in seiner Hermeneutik zu eruieren, wird zunächst danach gefragt, was er mit „Hermeneutik“ oder „hermeneutisch“ eigentlich meint, oder genauer gesagt: wie er den Bereich der Hermeneutik sieht und ihr Aufgabegebiet bestimmt.

In seinem Aufsatz $>$ Hermeneutische Theologie? $<333$ versieht Ebeling die Charakterisierung einer Theologie als hermeneutische Theologie zuerst mit einem Fragezeichen. Das bedeutet aber nicht, dass er an dem hermeneutischen Charakter der Theologie zweifelt. Viel mehr rührt dieses Vorgehen daher, dass die hermeneutische Theologie oft missverstanden und als „Parteidenken einer theologischen Sekte proklamiert" wird. ${ }^{334}$ In der Frage nach dem hermeneutischen Charakter der Theologie muss außerdem die Vorstellung ausgeschlossen werden, dass es um eine Teildisziplin oder eine bestimmte, technische Methode für die Theologie ginge. Denn „das Stichwort hermeneutische Theologie“ verweist vielmehr auf das, „was eo ipso zur Theologie gehört und bei jedem Theologietreiben wirksam ist“". ${ }^{335}$ Der Theologiebegriff selbst ist bei ihm mit dem Begriff „hermeneutisch“ vereinbar, sodass er sie folgerichtig zu einer „hermeneutischen Theologie“ verbinden kann. Dalferth bezeichnet diese Art der Hermeneutik

\footnotetext{
${ }^{331}$ H. Schlögel, Nicht moralisch, sondern theologisch, Mainz 1992, 142. Ähnlicherweise sagt A. Jäger, dass sich Ebeling kritisch „gegen Heideggers Seinsdenken im Ganzen“ abzugrenzen sucht. Ders., Gott. Nochmals Martin Heidegger, Tübingen 1978, 94.

${ }^{332}$ In diesem Sinne behauptet J. M. Robinson, dass die hermeneutische Wurzel bei Ebeling eher im Denken Luthers als im Denken Heideggers gesucht werden müsse. Ders., Die Hermeneutik seit Karl Barth, in: Ders./J.B. Cobb (Hg), Die neue Hermeneutik, Zürich/Stuttgart 1965, 13-108, 91.

${ }^{333}$ WG II, 99-120.

${ }^{334}$ WG II, 99.

${ }^{335}$ WG II, 105.
} 
als die „theologische Grundlagenwissenschaft“, denn sie meint „keine bloß technische Hermeneutik“, die bestimmten exegetischen Methoden, Regeln oder Disziplinen für das Verständnis des biblischen Textes sucht, sondern fragt nach den Bedingungen und den Grundstrukturen des Verstehens, das sich wieder mit dem Glauben verbindet. ${ }^{336}$ In der Hermeneutik Ebelings nimmt die Frage nach dem Verstehen, die sowohl die hermeneutische Grundfrage als auch fundamentaltheologische Sache ist, daher einen zentralen Platz ein.

Wenn Theologie als hermeneutisch bezeichnet wird, ist sie laut Ebeling sogleich für die Existenz des Menschen relevant, weil es ,um eine das Menschsein umfassend und letztinstanzlich betreffende Wortverantwortung“" geht. ${ }^{337}$ Hier ist die theologische Verantwortung hinsichtlich des Redens von Gott in der Situation des Menschen auszusprechen. Ohne die Reflexion über die Existenz des Menschen ist deshalb die Rede über Ebelings Hermeneutik unmöglich, sodass seine Theologie sowohl hermeneutische Theologie als auch existentiale Theologie, damit schließlich als existentialhermeneutische Theologie zu bezeichnen ist. ${ }^{338}$

Hinsichtlich der theologischen Verantwortung beim Reden über Gott will Ebeling gegenüber einer übermäßigen Theoretisierung der Hermeneutik deren praktische Aufgabe hervorheben und mit dem Wort „Verkündigung“ speziell betonen. Denn Ebelings hermeneutische Theologie ist eine Hermeneutik des Wortes Gottes, der sein Wort an Menschen richtet, so dass die Bemühung theologischer Hermeneutik darauf zielt, das Wort Gottes in die Menschen, in ihr Leben hinein wirken zu lassen. Das bedeutet, der Zirkel der theologischen Hermeneutik besteht darin, dass die Hermeneutik den Text der Heiligen Schrift auslegt und dann in der Predigt zur Ausführung kommt. Das „Kernproblem“ der theologischen Hermeneutik liegt deshalb laut Ebeling ,in dem Zusammenhang zwischen Auslegung des Textes als geschehene Verkündigung und Ausführung des Textes in geschehender Verkündigung“، 339 Er bestimmt die Theologie als eine ,verantwortende Wissenschaft ${ }^{\star 340}$ und gibt als Motiv für seinen Fachwechsel von der Kirchengeschichte zur systematischen Theologie im Rückblick an, christliches Wortgeschehen angesichts gegenwärtiger Wirklichkeit zu verantworten. ${ }^{341}$

In diesem Zusammenhang sei nun erwähnt: Die Bestimmung „hermeneutisch“präzisiert für Ebeling den Theologiebegriff im fundamentaltheologischen Sinn und zeigt die Relevanz für die Existenz des

\footnotetext{
${ }^{336}$ I.U. Dalferth, Vorwort, in: Ders. u.a. (Hg.), Hermeneutische Theologie - heute?, Tübingen 2013, XIV. ${ }^{337}$ WG II, 106.

${ }^{338}$ M. Roukanen bezeichnet Ebelings Hermeneutik als "existential theological hermeneuntic, which can be regarded as a part of the new theological hermeneutics". Ders., Hermeneutics as an Ecumenical Method in the Theology of Gerhard Ebeling, Helsinki 1982, 35. Ich verwende hier absichtlich einen umformulierten Ausdruck der „existentialen hermeneutischen Theologie“. Denn es gibt, strenggenommen, einen Unterschied zwischen den Namen der „theologischen Hermeneutik“ und der „hermeneutischen Theologie“ und diese ist eine bestimmte Richtung der vielen Versionen von jener. Vgl. I.U. Dalferth, Radikale Theologie, Leipzig, 2010, $23 f$.

${ }^{339} \mathrm{WG}, 347$.

${ }^{340} \mathrm{ThV}, 104$.

${ }^{341}$ Vgl. Ebeling, Die Wahrheit des Evangeliums. Eine Lesehilfe zum Galaterbrief, Tübingen 1981, VI.
} 
Menschen und gibt schließlich die Antwort auf die Frage nach dem Grund der Verantwortung der Theologie. Im Anschluss an diese Bestimmung erweitert er das Arbeitsgebiet der theologischen Hermeneutik: vom Verständnis des Verstehens als grundlegende Frage der Hermeneutik, über die Schriftauslegung als strenggenommen hermeneutische Arbeit, die bei ihm als existentiale Interpretation der Bibel für moderne Menschen bezeichnet wird, zur Verkündigung als völlige Erfüllung der Aufgabe der theologischen Hermeneutik. Das Thema der Sprache in Ebelings Hermeneutik ist dementsprechend in drei Arbeitsgebieten zu behandeln, das heißt, es geht nun jeweils um das Verhältnis der Sprache zum Verstehen (Kap. II, 4), zur Auslegung (Kap. II, 5) und zur Verkündigung (Kap. II, 6).

\section{Sprache und Verstehen}

Es gibt eine untrennbare Beziehung zwischen Verstehen und Sprache. Vor allem die Bemühung Ebelings erschließt sich im Nachvollzug seiner Intention, die Theologie als „Sprachlehre des Glaubens“ zu betreiben, deren grundlegende Einsicht darin besteht, „,dass sich die theologische Problematik mit der von Sprache und Verstehen überhaupt eigentümlich verflocht“ ${ }^{\star 342}$. Bevor das Verhältnis von Verstehen und Sprache bei Ebeling untersucht wird, muss zunächst der Begriff des Verstehens selbst betrachtet werden.

\subsection{Verstehen als Grundfrage der theologischen Hermeneutik}

Was heißt Verstehen? Wenn der Begriff des Verstehens verwendet wird, geht er über bloßes Wissen, das wir durch wissenschaftliche Forschung oder durch Nachdenken erlangen, hinaus und hat eine grundlegende und umfassende Bedeutung. Verstehen geschieht in verschiedenen Bereichen des Lebens und wird in vielfältigen Gebieten der Wissenschaft wie Philosophie, Psychologie und Soziologie als ein wichtiges Thema untersucht. Verstehen hat aber primär mit der Hermeneutik zu tun, da das Bedürfnis nach ihr primär durch Verstehensschwierigkeiten erweckt wird und weil es sich bei ihr um Modifikationen der Grundbedeutung von Verständlichmachen, „Verstehensvermittlung“ bzw. „ZumVerstehen-Bringen“ handelt, wie ihr vom Götterboten Hermes abgeleiteter Name selbst andeutet. ${ }^{343}$

\subsubsection{Verstehen und Hermeneutik}

Verstehen ist die Grundfrage der Hermeneutik und zugleich das Ziel der hermeneutischen Arbeit. Die Hermeneutik ist deshalb nicht nur als Interpretationskunst, sondern zuerst als Verstehenskunst zu

\footnotetext{
${ }^{342}$ Sprachlehre, XIII.

${ }^{343}$ Ebeling, Art. Hermeneutik, in: RGG ${ }^{3}$ III (1959), 242-262, 243.
} 
bezeichnen. ${ }^{344}$ Die Fragen, auf die die Hermeneutik eine Antwort zu geben versucht, sind immer Verstehensfragen und diese lassen sich auf das normalerweise mit der Begrifflichkeit des hermeneutischen Zirkels behandelte Problem zurückführen. Die Vorstellung eines Zirkels ist darin vorfindlich, dass es keinen direkten Weg zum Verstehen gibt, sondern der Verstehende sich in einer verstehenden Annäherungsbewegung befindet. Das heißt, dass sich der Verstehende dem Ziel des Verstehens in dem hermeneutischen Zirkel annähert. Dabei reden wir oft beispielweise von Vorverständnis, weil niemand von ihm befreit und nichts ohne es verstanden werden kann. Im Lichte eines Vorverständnisses gewinnen wir neue Erfahrungen und Einsichten und im aktuellen Verstehen wird das Vorverständnis korrigiert oder gereift. Das Problem des Verstehens wird deshalb im Zusammenhang mit anderen Sachen, die als Faktoren des Vorverständnisses oder als Bedingungen der Möglichkeit des Verstehens bewusst oder unbewusst mitwirken, behandelt, z.B. Existenz, Geschichte, Leben oder Sprache usw. Das Verstehensproblem in einem derartig komplizierten Zusammenhang zu analysieren und damit den Charakter des Verstehens zu bestimmen, beansprucht einen wichtigen Aspekt innerhalb moderner Hermeneutik. Weil die Entwicklungsgeschichte der Hermeneutik schon in Kapitel II-1 erfasst und ihre Orientierung an der Sprache dabei fokussiert wurde, ist es sinnvoll, folgend nur die Veränderung des Verstehensbegriffs zu skizzieren:

Schleiermacher begründet die Notwendigkeit der allgemeinen Hermeneutik aus der Tatsache, dass das Verstehen der Rede sowie der Schrift eines Anderen nicht selbstverständlich und das Nichtverstehen oder das Missverstehen nicht selten ist. Das Verstehensproblem bekommt dadurch Aufmerksamkeit. Der Begriff des Verstehens selbst wird aber erst bei Dilthey richtig behandelt, denn er weist auf die grundlegende Funktion des Verstehens hin und entdeckt damit eine innere Logik der Hermeneutik. Er unterscheidet zwei Arten des Wissens von Erklären und Verstehen und bezeichnet das Letztere als die spezifische Erkenntnisweise der Geisteswissenschaften, deren Grundprinzip als die empirische Erkenntnis der Gesamtheit menschlicher Lebensäußerungen aufzufassen ist. Das Verstehen kommt bei ihm insbesondere im Verhältnis von Erlebnis ${ }^{345}$ und Ausdruck zur Sprache: „Das Verstehen beruht nun primär auf der in jedem Erlebnis, das als Verstehen charakterisiert ist, enthaltenen Beziehung des Ausdrucks zu dem, was in ihm ausgedrückt ist. “" ${ }^{346}$ Hier charakterisiert er Erlebnis bereits als

\footnotetext{
${ }^{344}$ Vgl. F. Hermanns, Linguistische Hermeneutik. Überlegungen zur überfälligen Einrichtung eines in der Linguistik bisher fehlenden Teilfachs, in: A. Linke u.a. (Hg.), Sprache und mehr. Ansichten einer Linguistik der sprachlichen Praxis, Tübingen 2003, 125-163, 131.

${ }^{345}$ W. Dilthey definiert den Begriff „Erlebnis“ als „eine Realität, unmittelbar als solche auftretend, ohne Abzug innegeworden, nicht gegeben und nicht gedacht.“ Ders., GS VI, 314. G. Matteucci weist mit Recht darauf hin, dass Erlebnis für Dilthey die Art ist, ,,in der das Leben selbst zur Erfahrung wird, [...] das, was als Erlebnis auftritt, evident und bekannt im Sinne von etwas ist, was von sich aus als real erscheint“. Ders., Dilthey. Das Ästhetische als Relation, Würzburg 2004, 65f. Vgl. K. Cramer, Art. Erleben, Erlebnis, in: J. Ritter (Hg.), Historisches Wörterbuch der Philosophie, Bd. 2, Basel 1972, 702-711.
}

${ }^{346}$ W. Dilthey, GS VII, 218. 
Verstehen und das Verstehen des Erlebnisses von Selbst ist dabei immer vorrangig, weil nur wer sich erlebt und versteht, Ausdruck hat. ${ }^{347} \mathrm{Im}$ Vorgang des Verstehens unterstreicht er die Begründung der geisteswissenschaftlichen Objektivität, die die Verschiedenheit der Ausdrucksweise in den geschichtlichen und kulturellen Lebenskontexten hat und doch denen zugrunde liegt.

Verstehen gewinnt bei Heidegger eine ganz neue Bedeutung, indem er die fundamentale Zirkelstruktur des Verstehens aufzeigt. Er bemerkt, dass der Zirkel des Verstehens „,nicht ein Kreis (ist), in dem sich eine beliebige Erkenntnisart bewegt“, sondern „der Ausdruck der existenzialen VorStruktur des Daseins selbst“. ${ }^{348}$ Denn das Verstehen richtet sich nicht mehr auf verschiedene Lebensäußerungen oder Kulturgegenstände, sondern auf das Dasein selbst, seine Bestimmung oder Verfassung. Das Verstehen gehört nun zur existentialen Verfassung des Daseins. Das heißt, dass hermeneutische Theorien auch in der ontischen Verbindung mit dem Dasein liegen und sich um das Verständnis der Seinsweise der Existenz bemühen müssen. Diese existenziale Vorstruktur des Verstehens wird von Gadamer übernommen. Dieser thematisiert primär das zeitliche Verhältnis des Verstehens in Anbetracht unseres gegenwärtigen Verstehens. „Die Kontinuität des Herkommens und der Tradition“ füllt seiner Ansicht nach den Abstand der Zeit mit Sinn und damit wird ,wahrhaftes Verstehen“ ermöglicht. ${ }^{349}$ Er sieht Verstehen im Kontext der Wirkungsgeschichte der Tradition und bestimmt es als „Einrücken in ein Überlieferungsgeschehen“. ${ }^{350}$ Durch den Begriff der Anwendung löst er das Horizontproblem des Verstehens, das mit dem Horizont des Textes verbunden worden war. Im Verstehen geschieht, wie Gadamer sagt, ,immer so etwas wie eine Anwendung des zu verstehenden Textes auf die gegenwärtige Situation des Interpreten“, ${ }^{351}$ weil Verstehen selbst ein Geschehen ist, das sich als „,das wirkungsgeschichtliche Bewußtsein“" verwirklicht. ${ }^{352}$

Über die Entwicklung der Fragerichtungen bezüglich des Verstehensproblems gibt uns Dalferth eine kurze, doch umfassende und sinnvolle Übersicht und erklärt: Es gehe in der klassischen Hermeneutik um „den Gegenstand oder den Gegenstandsbereich des Verstehens“; im 19. Jahrhundert um „die Subjekte“ oder „die Verfahrensweise des Verstehens“; und im 20 Jahrhundert um „das Verständnis des Verstehens selbst“, nämlich um die Frage, ,worin es bestehe, wie es sich vollziehe, was es leiste, unter welchen Bedingungen es möglich sei, wo seine Grenzen liegen, und was es besage, dass verstanden bzw. nicht verstanden wird“. ${ }^{353}$ Die Frage nach dem Verstehen selbst wurde sowohl auf dem Gebiet der Philosophie als auch auf dem der Theologie gestellt, vor allem von den Vertretern der hermeneutischen Theologie, die keine bestimmten exegetischen Methoden oder Disziplinen zur Auslegung des

\footnotetext{
${ }^{347}$ Vgl. W. Dilthey, GS VII, 209f.

${ }^{348}$ M. Heidegger, SZ, 203.

${ }^{349}$ H.-G., Gadamer, WM I, ${ }^{5} 1986,302$.

${ }^{350}$ H.-G., Gadamer, WM I, ${ }^{5} 1986,295$.

${ }^{351}$ H.-G., Gadamer, WM I, ${ }^{5} 1986,313$.

${ }^{352}$ H.-G., Gadamer, WM I, ${ }^{5} 1986,346$.

${ }^{353}$ I.U. Dalferth, Radikale Theologie, Leipzig 2010, $38 \mathrm{ff}$.
} 
biblischen Textes zu schaffen suchten, sondern die Bedingungen und die Grundstrukturen des Verstehens klären wollten.

\subsubsection{Verstehen und Glaube}

In der Apostelgeschichte befragt Philippus den Kämmerer aus Mohreland, „Verstehst du auch, was du liest?“ (Act 8,30) Diese Frage zeigt exemplarisch, dass wir beim Lesen der Bibel auf das Verstehensproblem stoßen können. Im Korintherbrief stellt Paulus eine ähnliche Frage nach dem Verstehen beim Reden und auch beim Beten (1Kor 14,15-16). Und Jesus selber legt uns die alttestamentlichen Texte sowie seine eigenen Aussagen aus und bringt uns dadurch zum Verstehen (Luk 24,27). Beim Lesen der Bibel, Hören des Wortes, Predigen und auch beim Beten werden wir mit dem Problem des Verstehens konfrontiert, z.B. mit den text- oder kommunikationsbezogenen hermeneutischen Problematik, die sich alle auf Glauben beziehen. Das Verstehensproblem wurde theologisch zuerst als ein vernünftiger Vorgang, als das sog. Verhältnisproblem von Glauben und Erkennen thematisiert, beispielsweise in der alten bekannten Formulierung credo ut intelligam von Anselm, der gegenüber dem Ansatz credo quia absurdum den Glauben rational begründen wollte. Die Formel „Glauben und Erkennen“ wird bei Bultmann bezeichnenderweise zur Formel „Glauben und Verstehen“ umgearbeitet, indem er an der Stelle einer metaphysischen Erkenntnistheorie die Hermeneutik setzt.

Die Formel „Glauben und Verstehen“ ist programmatisch bei Bultmann, der seine Theologie in Anlehnung an die Existenzphilosophie des frühen Heideggers entwickelt. Bultmann hebt den Zusammenhang von Glauben und menschlichem Existenzverständnis hervor und bestimmt den christlichen Glauben als ausgezeichnete Weise des Verstehens. ${ }^{354}$ Gegen die den Glauben missverstehende historisch-kritische Exegese plädiert Bultmann für die theologische Exegese, wie Körtner mit Recht hinweist, als „Schriftinterpretation des Glaubens“, „d.h. eine solche, die im Glauben als der Beziehung zum Gegenstand, zur Offenbarung klarstellt, was die Schrift sagt“ “355. Er beschäftigt sich zunächst mit der Frage, was die biblischen Texte, genauer die Texte des neuen Testaments, dem modernen Menschen zu sagen haben. Dafür leitet er unter dem Stichwort der existentialen Schriftauslegung die heideggerische Analyse der Existenz in die theologische Hermeneutik über, weil sich die theologische Interpretation auf Gott und die durch ihn bestimmte menschliche Existenz als Gegenstand der biblischen Texte bezieht. Das heißt, dass das Verstehen bei Bultmann nicht von der Existenz des In-der-Welt-Seins getrennt werden kann: „Alles Verstehen von etwas (d.h. von Welt) ist

\footnotetext{
${ }^{354}$ R. Bultmann, GuV III, 28ff.

355 U.H.J. Körtner, Zur Einführung, in: Ders (Hg.), Glauben und Verstehen. Perspektiven hermeneutischer Theologie, Neukirchen-Vluyn 2000, 3.
} 
letztlich immer ein Verstehen meiner selbst, ein ,Mich in meiner Welt zurechtfinden“ ““356 Und dass das Verstehen „letztlich immer ein Verstehen meiner selbst“" ist, gilt auch für das Verstehen der neutestamentlichen Texte. Das Selbstverständnis der Existenz bzw. „das existentielle Selbstverständnis“, in dem „das Selbst mit sich zugleich das Begegnende versteht“, also „die begegnenden Personen, die begegnende Welt“", ${ }^{457}$ bezeichnet Bultmann nun als das hermeneutische Prinzip seiner Theologie. ${ }^{358}$

Ein Leser oder ein Ausleger kann deshalb den Text nicht von einem neutralen Standpunkt aus verstehen, sondern der Text erhebt auf ihn einen seine Existenz bestimmenden Anspruch. Das Verstehen vollzieht sich dabei darin, das dem Leser oder dem Ausleger im Text begegnende Daseinsverständnis als die Möglichkeit seiner eigene Existenz zu begreifen: „Im Text werden wir dann nicht merkwürdige vorfindliche und bis dahin unbekannte Dinge bekannt gemacht, ein Wissen über unbekannte Vorgänge vermittelt, sondern es werden mir Möglichkeiten meiner selbst erschlossen, die ich nur verstehen kann, soweit ich für meine Möglichkeiten erschlossen bin und mich erschließen lassen will. Ich kann das Gesagte nicht einfach als Mitteilung akzeptieren, sondern ich verstehe nur bejahend

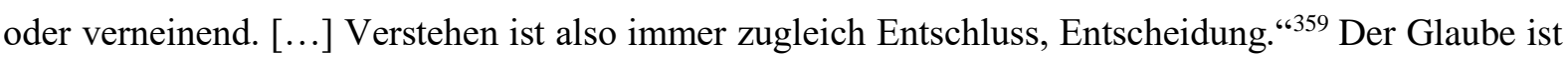
folglich weder eine besondere Form der Inspiration noch eine Voraussetzung oder ein Resultat der Auslegung, sondern eine bestimme Weise, die biblischen Texte zu verstehen, und letztlich ein menschliches Selbstverständnis, bei dem sich der Interpret durch die biblischen Texte neu versteht.

\subsection{Sprache für die antimetaphysische und relationalontologische Verstehenskonstitution}

Ebeling verbindet so wie Bultmann das Verstehensproblem primär mit dem existentialen Verständnis des Selbst, weiter mit dem Glauben und bringt es doch durch neue Akzentuierung und Fragestellung zu seiner eigenen Einsicht. Ebelings Verständnis des Verstehens ist m.E. mit den drei Begriffen von Wirklichkeitsverständnis, Verifikation und Einverständnis zu erfassen und zu charakterisieren. Die Sprache ist bei ihm bemerkenswerterweise mit jedem Begriff verbunden und dient somit für den Totalbegriff des Verstehens konstitutiv.

\subsubsection{Zum Wirklichkeitsverständnis als Grundlage des Verstehens}

Das von Ebeling angegriffene hermeneutische Problem und sein Verstehensverständnis erfordern zuallererst eine Besinnung auf Wirklichkeit, weil das, was durch Sprache zum Verstehen kommt, laut

\footnotetext{
${ }^{356}$ R. Bultmann, GuV I, 155.

${ }^{357}$ R. Bultmann, KuM II, 201.

${ }^{358}$ Vgl. F. Hohmeier, Das Schriftverständnis in der Theologie Rudolf Bultmanns. Berlin 1964, 13.

${ }^{359}$ R. Bultmann, GuV I, 127.
} 
ihm nichts anders als die Wirklichkeit ist. ${ }^{360}$ Ebeling redet dadurch von einem bestimmten Verhältnis von Wirklichkeit und Sprache in der Verstehensproblematik und auch von einem Merkmal seines Verstehensverständnisses, das daran erkennbar ist, wie er die Wirklichkeit versteht und bezeichnet.

Er vollzieht die Besinnung auf Wirklichkeit in Auseinandersetzung mit anderen Wirklichkeitsverständnissen, z.B. mit dem Historismus, ${ }^{361}$ dem Rationalismus ${ }^{362}$ und der Naturwissenschaft ${ }^{363}$. Weil er glaubt, dass sie alle in unterschiedlicher Weise die „Sprache der Metaphysik" sprechen, ${ }^{364}$ sucht er vor allem das metaphysische Wirklichkeitsverständnis zu überwinden; gegen dessen Abstraktion von der Lebenssituation besinnt er sich auf die Wirklichkeit mit dem Ansatz, dass das menschliche Leben in einen Wirklichkeitszusammenhang eingebettet ist. Ebeling bestimmt die Wirklichkeit als „das in irgendeiner Weise Wirksame, Tätige, Mächtige [...], was als wirklich zu beeindrucken, sich zur Geltung zu bringen, Beachtung zu fordern, den Menschen anzugehen vermag und, indem es Möglichkeiten in sich birgt, also etwas vermag, auf Zukunft ausgerichtet ist.“365 Derartiges Wirklichkeitsverständnis entwickelt er in bemerkenswerter Weise anhand der Begriffe von Existenz und Erfahrung.

Unter dem Einfluss der Existenzphilosophie und -theologie, die so wie bei Ebeling auf die Überwindung der Metaphysik abzielt und sich dafür an der Realität des Menschen orientiert, akzeptiert er ihren Grundsatz, dass Wirklichkeit fassbar ist, nur wenn die Existenz des Menschen verstanden werden kann. Er besteht so wie Bultmann auf die Annahme, dass sich Wirklichkeit immer nur unter Einschluss der menschlichen Existenz denken lässt, denn die den Menschen umgebende Wirklichkeit spricht ihn immer schon auf seine Existenzmöglichkeiten hin an. ${ }^{366} \mathrm{Im}$ Hintergrund dieses existenzbezogenen Wirklichkeitsbegriffs steht Ebelings Anliegen an den theologischen Ansatz, den christlichen Glauben in seiner die Existenz des Menschen völlig bestimmenden Macht wirken zu lassen. Er arbeitet also den Wirklichkeitsbezug des Glaubens heraus, um dessen Existenzbezug zu betonen. Bei ihm bezieht sich deshalb das Verstehens- und Glaubensproblem grundsätzlich immer auf das Existenzverständnis.

\footnotetext{
${ }^{360} \mathrm{WG}, 335$.

${ }^{361}$ WG, $35 f f$ u. 324f; WG II, $115 f f$ u. 129f.

${ }^{362}$ Ebeling, Kritischer Rationalismus? Zu Hans Alberts > Traktat über kritische Vernunft<, Tübingen 1973, 56ff.

${ }^{363}$ WG III, $1 \mathrm{ff}$.

${ }^{364}$ Ebeling, Art. Theologie und Philosophie III. Dogmatisch, in: RGG ${ }^{3}$ VI (1962), 819-830, 825. Die Grundstruktur der Metaphysik skizziert Ebeling folgendermaßen: „Metaphysik ist das Grund-Verständnis im Horizont der Vernunft, dementsprechend der Mensch als vernünftiges und gemäß seiner Rationalität (als Herr auch seiner selbst) tätiges Subjekt außer Frage steht, das Sein als dem Denken korrespondierendes Vorhandensein des gegenständlich Selbständigen unter Absehen von der Zeit vorausgesetzt ist, die Sprache als Aussage(Kategorien) und Bezeichnungsfunktion verstanden wird und deshalb Wahrheit ihren Ort hat im Bereich des Vorgestellten.“(825).

${ }^{365}$ WG, 398.

${ }^{366} \mathrm{WG}, 398$.
} 
Ebeling hat den Akzent auf den Existenzbezug in seinen früheren Arbeiten gelegt und scheint ihn doch auf den Erfahrungsbezug seit Anfang der 1970er Jahre zu verschieben. ${ }^{367}$ Er interessiert sich allerdings schon seit dem Beginn seiner wissenschaftlichen Arbeiten für das Erfahrungsproblem als ein hermeneutisch relevantes $\mathrm{Thema}^{368}$ und in seinen späteren Arbeiten wird dieses Interesse offensichtlich verstärkt. Wenn er in der Vorlesung zum „Wesen des christlichen Glaubens“ im Jahr 1959 die Frage nach der Wirklichkeit und dem Ort des Glaubens stellt, behauptet er dabei, dass durch den Versuch, eine Sonderwirklichkeit und einen besonderen Ort für den Glauben anzusprechen, die Sache des Glaubens nicht zu fassen sei. Jede abstrakte Rede von der Welt und der menschlichen Situation steht ihm gemäß dem Wesen des christlichen Glaubens entgegen: „Sein Wesen ist nicht gedachter, sondern gelebter Glaube, nicht Idee, sondern Geschehen. Wesen nicht als Substantiv, sondern Wesen als Zeitwort. [...] Wenn man doch bei der Besinnung auf das Wesen des Glaubens vor allem dies eine lernte, dass der Glaube nicht an sich, sondern konkret geglaubt sein will.“369 Ebelings Gedanken über den Ort des Glaubens in der konkreten Situation des Menschen wird in seinen späteren Arbeiten speziell anhand des Grundbegriffs „Erfahrung“" verdeutlicht. ${ }^{370}$

Ebeling hebt vertretungsweise in einem Vortrag zur $>$ Klage über das Erfahrungsdefizit in der Theologie als Frage nach ihrer Sache $<(1974)^{371}$ den Begriff der Erfahrung hervor. Hier bezeichnet er den Mangel an der Erfahrung als eine Erkrankung der Theologie, die für den Glauben und die Theologie tödlich sein könnte, ${ }^{372}$ und sucht nach einem passenden Erfahrungsbegriff, den er zusammenfassend in der Formel „Erfahrung mit der Erfahrung“373 ausdrückt und als die im „Doppelsinn von Gegenstand

\footnotetext{
${ }^{367}$ Vgl. P. Bühler, Wort Gottes und Hermeneutik. Gerhard Ebelings Erbe aus heutiger Sicht, in: I.U. Dalferth u.a. (Hg.), Hermeneutische Theologie - heute?, Tübingen 2013, 39-54, 50f; K. Gelder, Glaube und Erfahrung, Neukirchen-Vluyn 1992, 7.

${ }^{368}$ EEA, 391-402.

${ }^{369}$ Wesen, 147 u. 154.

${ }^{370}$ Als eine mögliche Ursache für dieses verstärkte Interesse für die Erfahrung ist seine intensive Beschäftigung mit Schleiermachers Theologie zu nennen, z.B. in Aufsätzen wie „Schleiermachers Lehre von den göttlichen Eigenschaften“, in: WG II, 305-342; „Frömmigkeit und Bildung“, in: WG III, 60-95; „Beobachtungen zu Schleiermachers Wirklichkeitsverständnis“, in: WG III, 96-115; und „Zum Religionsbegriff Schleiermachers“, in: WG IV, 55-57. Außerdem gehörte Ebeling von 1972 bis 1995 zu den Mitherausgebern der kritischen Gesamtausgabe der Werke Schleiermachers. Bezüglich solcher Wendung erklärt R. Goltz so: Während Ebeling „,in seinen frühen Veröffentlichungen „noch ganz der Theologie Luther - und dem lutherischen Verständnis der Theologie als Wortlehre - verpflichtet" ist, ist in seinen späten Publikationen durch die Theologie Schleiermachers „der Aspekt der Erfahrungsdimension menschlichen Seins“ und damit auch „das Verständnis der Theologie als Glaubenslehre" stärker geworden. Ders., Das Werden der Gewissheit, Leipzig 2008, 154, Anm. 699.

${ }^{371}$ Ein Vortrag auf dem Gründungskongress der Wissenschaftlichen Gesellschaft für Theologie am 3.4.1974 in Göttingen; Wiederabdruck in: WG III, 3-28. Die folgenden Nachweise beziehen sich auf die letztgenannte Publikation.

372 WG III, 3.

${ }^{373}$ Ob Ebeling diese Formel aus sich selbst geschaffen hat, ist nicht sicher. In der Anmerkung sagt Ebeling selber, er würde ,erst bei der Drucklegung“ darauf aufmerksam, „,dass Jüngel dieser Wendung bedient hat“, und nahm es „für ein gutes Zeichen dafür, dass zwei Theologen miteinander unterwegs zur Sache sein können.“ WG III, 22.
} 
und Aufgabe" verstandene Sache der Theologie bestimmt. ${ }^{374}$ Erweiternd in >Dogmatik des christlichen Glaubens $<$ führt er den Erfahrungsbegriff, genauer den Erfahrungsbezug des Glaubens und der theologischen Aussagen als Grundgedanken seiner Argumentation, weil durch den Erfahrungsbegriff „die Lebenswirklichkeit aufgeboten und in die dogmatische Aufgabe einbezogen“ “375 wird.

Vor allem in der $>$ Dogmatik des christlichen Glaubens $<$ interessiert Ebeling sich zuallererst dafür, worauf K. Gelder mit Recht hinweist, nämlich dass die Erfahrungsthematik der „Herausarbeitung des Existenz- und Lebensbezuges des Glaubens“ dient, womit er darzulegen versucht, wie alle dogmatischen Themen „die Existenz des Menschen und mit ihr seine Erfahrungswirklichkeit betreffen und ihm wahre Erfahrung allererst erschließen“. ${ }^{376}$ Bei Ebeling stehen Existenz-, Erfahrungs- und Lebensbegriff in einem engen Zusammenhang miteinander und die menschliche Existenz, unter deren Einschluss Wirklichkeit immer gedacht werden muss, ist wiederum durch Erfahrung auf Wirklichkeit bezogen. Die Akzentverschiebung von Existenzbezug zu Erfahrungsbezug soll nicht im Sinne verstanden werden, dass sie den Existenzbegriff oder den ontologischen Charakter schwächt, sondern im Sinne, dass sie einerseits das miteinander verbundene Glied von Existenz- und Erfahrungsbezug darstellt und andererseits den Lebensbezug, auf den beide hinzielen, deutlicher aufzeigt, um den der rationalen oder abstrakten Zuständigkeit entzogenen Wirklichkeitsbezug hervorzuheben. Ebeling bestimmt Wirklichkeit folglich als Erfahrungsraum, der für den Menschen in allen Momenten seines Lebens vorgegeben ist. Das durch Erfahrung gewonnene Wirklichkeitsverständnis stellt sich nun als ein realistisches und auch ganzheitliches Verstehen dar.

Die so das realistische und ganzheitliche Verstehen des Lebens und des Menschen ermöglichende Erfahrung bezeichnet Ebeling „als solche schon immer sprachlicher Art“. Die Sprachlichkeit der Erfahrung erklärt er näher mit den Begriffen von „Erfassung und Vermittlung“377. Erfahrung kann nur durch sprachliche Vermittlung gesammelt werden und dann zur Erschließung von Wirklichkeit führen. Denn die Möglichkeiten eigener Erfahrung sind laut Ebeling „durch die Teilhabe an sprachlicher Überlieferung bedingt, ohne die sich Erfahrung gar nicht erschließt. Schwindet die geschichtlich

Ebenfalls sagt Günter Bader, dass die Redewendung bei Jüngel und Ebeling ,fast gleichzeitig, spontan und unabhängig voneinander" gefunden werde. Ders., Erfahrung mit der Erfahrung, in: H.F. Geisser/W. Moster (Hg.), Wirkungen hermeneutischer Theologie. Eine Zürcher Festgabe zum 70. Geburtstag Gerhard Ebelings, Zürich 1983, 137-153, 140. Jüngel sagt dagegen, dass er selber die Redewendung erstmals auf einer Herausgebertagung der $>$ Zeitschrift für Theologie und Kirche $<$ zur Sprache brachte und Ebeling sie dabei hörte und notierte. Ders., Erfahrungen mit der Erfahrung. Unterwegs bemerkt, Stuttgart 2008, 9f. A. Beutel folgert, es bleibe unklar, „ob Ebeling die Herkunft der Wendung bereits kurz darauf wieder vergessen oder die Auskunft, erst nachträglich von Jüngels Wortprägung erfahren zu haben, tatsächlich wider das bessere Wissen Jüngels und seiner selbst publiziert hätte.“ Ders., Gerhard Ebeling. Eine Biographie, Tübingen 2012, 411. Anm. 475. Vgl. B. Schröder, Erfahrung mit der Erfahrung. Schlüsselbegriff erfahrungsbezogener Religionspädagogik, in: ZThK 95 (1998), 277-294.

${ }^{374}$ WG III, 24.

${ }^{375}$ DG I, 41.

${ }^{376}$ K. Gelder, Glaube und Erfahrung, Neukirchen-Vluyn 1992, 6 f.

${ }^{377}$ Sprachlehre, 118. 
vermittelte Bildung, so verkümmert auch die Erfahrung“، ${ }^{378}$ Dinge und Sachverhalte, die nach ihrer Art in verschiedener Weise vorgegeben sind und in einer bestimmten Erfahrung unterschiedlich wahrgenommen werden können, werden weiterhin wirklich vor dem expliziten Sprachvorgang wahrgenommen. Das heißt, dass sich die Erfassung der Sache bzw. die Wahrnehmung sprachlich vollzieht. Es ist dann unmöglich, „durch ein Entfernen der sprachlichen Hüllen“ zur reinen Wahrheit vorzudringen. ${ }^{379}$ Das Kommen zur eigenen Erfahrung bedeutet, den sprachlich gearteten Prozess durchzuführen.

In diesem Sachverhalt ist zu erwähnen, dass Erfahrung keineswegs unabhängig von Sprache geschieht, weil sie sich einerseits durch sprachlich vermittelte Überlieferung erschließt und weil sie andererseits durch Sprache zur Deutlichkeit gebracht wird. Dieser sprachliche Charakter der Erfahrung ist bei Ebeling nun von primärem Interesse. Schließlich lässt er Sprache durch die Sprachlichkeit der Erfahrung ihren Realitätsbezug gewinnen und verteidigt sie dagegen, als eine eigene oder übergeordnete Wirklichkeitssphäre mystifiziert zu werden. Damit spricht er ihr einen hohen Stellenwert für das Verständnis der Wirklichkeit zu und verleiht ihr den realistischen Charakter des Verstehens, der durch sie ermöglicht wird.

Bezüglich des Verstehensproblems ist noch eine weitere Bedeutung der Erfahrung zu betrachten. Wirklichkeit steht eigentlich gegenüber der Möglichkeit. Sofern das Mögliche nicht nur das Wirkliche, sondern auch das Nicht-Wirkliche sein kann, gibt es ,einen Spielraum der Möglichkeit gegenüber der Notwendigkeit“, weil das, was wirklich ist, auch möglich ist, aber nicht umgekehrt. ${ }^{380}$ In diesem Sinne kann man sagen, dass Wirklichkeit zwischen Möglichkeit und Notwendigkeit steht. Solche Stellung der Wirklichkeit ist gültig auch in Bezug auf das Verstehensproblem. Wenn Wirklichkeit dem Menschen zu verstehen gegeben ist und zugleich ihn $\mathrm{zu}$ einem Verständnis seiner selbst bringt, ist sie nicht selbstevident in ihrer Bedeutung. Wirklichkeit hat damit in sich die Möglichkeit des Verstehens und zugleich des Missverstehens. Da kommt die Erfahrung als der Ort ins Spiel, der zum Verstehen der Wirklichkeit führt, an dem es möglich und gegebenenfalls notwendig ist, die Erfahrung daraufhin prüfend in Frage zu stellen, was als wahre Wirklichkeit verstanden werden kann. Das bedeutet aber keinesfalls, dass Ebeling seine Aufmerksamkeit auf den Evidenzcharakter der Erfahrung oder auf den erweisbaren Zusammenhang von Erfahrung und Wahrheit richtet. Allerdings redet er von Evidenz, genauer von „begrenzte(r) Evidenz“ als einer notwendigen Voraussetzung für Wahrheitssuche und spricht den Zusammenhang von Erfahrung und Wahrheit an. ${ }^{381}$ Aber die Frage danach, ,wie dieser Zusammenhang zu bestimmen ist“ und „wo die Grenze des Evidenzverständnisses liegt“, wie K. Gelder

\footnotetext{
${ }^{378}$ Ebeling, Dogmatik und Exegese, in: ZThK 77 (1980), 269-286, 277f; Wiederabdruck in: WG IV, 492-509, 500f. Die folgenden Nachweise beziehen sich auf die letztgenannte Publikation.

${ }^{379}$ Sprachlehre, 116.

${ }^{380}$ W. Janke, Art., Wirklichkeit, I. Philosophisch, in: TRE 36, Berlin/New York 2004, 114-120, 115.

${ }^{381}$ Ebeling, Kritischer Rationalismus?. Zu Hans Alberts Traktat über kritische Vernunft, Tübingen 1973, 24f.
} 
kritisiert, bleibt bei Ebeling unbeantwortet. ${ }^{382}$ Stattdessen behandelt er das Wahrheitsproblem als das Gewissheitsproblem, das mit dem Begriff der Verifikation verbunden ist.

\subsubsection{Zur Verifikation als theologischer Entfaltung des Verstehens}

Das Wort „Verifikation“ kommt von dem lateinischen Wort veritas (Wahrheit) und facere (machen) und bedeutet damit, zu prüfen und nachzuweisen, ob Vermutetes oder Behauptetes wahr ist. Der Begriff der Verifikation wird in der Wissenschaftstheorie als logischer oder empirischer Nachweis dafür verstanden, dass eine Hypothese richtig ist und ist laut Ebeling insbesondere der Leitbegriff einer unter dem Gesichtspunkt der Sprachanalyse und der Orientierung an den Naturwissenschaften im angelsächsischen Bereich geführten Debatte. ${ }^{383}$ Er selber verwendet auch den Begriff der Verifikation, jedoch nicht im Sinne einer wissenschaftlichen Wahrheitstheorie, denn diese scheint ihm für das theologische Wahrheitsproblem nicht geeignet. Angesichts Ebelings Verwendung des Terminus Verifikation weist O. Pilnei mit Recht darauf hin, „dass er zwar an die Behandlung der Wahrheitsfrage in der zeitgenössischen philosophischen Diskussion anknüpft, aber deren Frontstellungen überwinden möchte“. 384

In Blick auf die Theologie betrachtet Ebeling das Verifikationsproblem bezüglich der Wirklichkeit ${ }^{385}$ zuerst in den folgenden zwei Fragerichtungen: zum einen, ob sich „das, wovon die Theologie redet, als Wirklichkeit“ verifizieren lässt ${ }^{386}$; und zum anderen, ob „das, wovon die Theologie redet, die Wirklichkeit verifiziert“. ${ }^{387}$ Anders gesagt, die erste Frage handelt von der Verifizierung der theologischen Rede als Wirklichkeit, und die zweite handelt von der Verifizierung der Wirklichkeit durch die theologische Rede. Die theologische Rede hat dabei zwei Gestalten, nämlich in der ersten Fragestellung als das Objekt des Verifikationsgeschehens und in der zweiten als sein Subjekt. Wenn die theologische Rede wie in der ersten Fragestellung als das Objekt des Verifikationsgeschehens bezüglich der Wirklichkeit gesehen wird, bestehen noch zwei mögliche Probleme: Einerseits könnte man von der ersten Fragestellung den Eindruck bekommen, dass die Theologie von etwas redet, das als die Wirklichkeit nicht verifizierbar ist. Andererseits könnte unter dem herrschenden Wirklichkeitsverständnis die theologische Rede von ihren Gegenständen wie Gott und Glauben eingeschränkt werden. Ebeling setzt darum der ersten Fragestellung die zweite vor und erklärt dazu,

\footnotetext{
382 K. Gelder, Glaube und Erfahrung, Neukirchen-Vluyn 1992, 153.

${ }^{383}$ WG II, 402.

${ }^{384}$ O. Pilnei, Wie entsteht christlicher Glaube?, Tübingen 2007, 311.

${ }^{385}$ Das theologische Verifikationsproblem bezüglich der Wirklichkeit thematisiert Ebeling in seinem Aufsatz „Theologie und Wirklichkeit, in: ZThK 53 (1956), 372-383; Wiederabdruck in: WG, 192-202. Die folgenden Nachweise beziehen sich auf die letztgenannte Publikation.

386 WG, 194-197.

${ }^{387} \mathrm{WG}, 197-200$.
} 
dass sich die erste noch „im Bann der erkenntnistheoretischen Fragestellung“ befindet, „welche voraussetzt, dass das betrachtende Wahrnehmen der eigentliche Ort des Problems der Verifizierung sei“, aber die zweite in einer „Dimension der Wirklichkeitsbegegnung, in der es nicht nur um die Wahrheit unserer Erkenntnis, sondern um die Wahrheit unserer Wirklichkeit selbst geht“. ${ }^{388}$ Weil die erkenntnistheoretische Frage als einschränkender Zugang zur Sache verstanden und damit als ein Teilbereich des Verifikationsproblems dargestellt werden kann, hat die erste Fragestellung ihren entsprechenden Ort nur im Horizont der zweiten und diese muss immer vorrangig sein.

Weiterführend verbindet Ebeling die Verifikation der Wirklichkeit mit dem Glaubensproblem ${ }^{389}$ und zeigt dabei die Unterscheidung von Glauben und Wissen und auch die Zusammengehörigkeit von Glauben und Verstehen. Er fordert, dass der Ort des Glaubens nicht das Wissen, sondern das Verstehen sein soll, weil sich das Wissen auf die Erforschung von einem einzelnen Bereich des Seienden bezieht und dagegen das Verstehen auf die Wirklichkeit als Ganzes. Und die Wirklichkeit als Ganzes zu verstehen, bedeutet, sie nicht als die Summe ihrer einzelnen Teile zu begreifen, sondern „dass an einem einzigen Punkt alles miteinander auf dem Spiel steht““. ${ }^{390}$ Dieser einzige Punkt ist laut Ebeling das Gewissen des Menschen, denn in diesem fällt ,die Entscheidung über die ganze Wirklichkeit: die Entscheidung zwischen Gewissheit und Verzweiflung, zwischen Freiheit und Knechtschaft, zwischen Leben und Tod“. ${ }^{391}$ Man hat Gewissheit, wenn sein Gewissen fröhlich und getrost ist. Wenn man dagegen Angst und Verzweiflung in seinem Gewissen erlebt, wird die ganze Welt in die Verzweiflung hineingerissen. ${ }^{392}$ Im Gewissen geschieht dann die Entscheidung über die Verifikation der Wirklichkeit.

Ebeling argumentiert des Weiteren, dass sich das Wahrsein der Existenz im Seinsvollzug äußert. Er verdeutlicht diesen Sachverhalt am Beispiel von Wahrnehmen und Wahrmachen: „Wenn ich z.B. sage: ,Ich nehme eine Gelegenheit wahr', oder, ich nehme mein Amt wahr', so schwingt darin gewiss auch ein Moment der Erkenntnis mit; aber der Skopus besteht doch gerade nicht darin, dass ich etwas nur erkennte, sondern darin, dass ich von etwas Gebrauch mache, dass ich also die Gelegenheit nütze oder das Amt ausübe, und das heißt, dass ich selbst zum Einsatz komme, mich mit etwas identifiziere. Oder wenn ich sage: ,Ich mache ein Versprechen wahr' oder: ,ich mache wahr, was ein anderer sich von mir verspricht‘, so ist freilich auch hier ein Moment der Erkenntnis mit im Spiel; aber dieses Wahrnehmen, dieses Verifizieren ist nicht das prüfende Bewahrheiten eines Erkenntnisbezuges, sondern ein sich selbst Bewähren im Existenzvollzug. ““993 Hier befindet sich Ebelings Unterscheidung von erkenntnismäßigem und verifizierendem Verstehen. Das zur Verifikation führende Verstehen ist also bei ihm sinnvoll.

\footnotetext{
388 WG, 198.

${ }^{389}$ Vor allem in seinem Aufsatz, „Glaube und Unglaube im Streit um die Wirklichkeit“, in: WG, 393-406.

390 WG, 404.

$391 \mathrm{WG}, 405$.

392 WG, 404.

${ }^{393} \mathrm{WG}, 198$.
} 
Ebeling wendet sich gegen die Verwendung des Verifikationsbegriffs für die Bezeichnung von Stringenz, die logisch nachgewiesen oder empirisch - wobei die Erfahrung lediglich für gewiss objektive Tatsache gehalten wird - nachgeprüft wird. ${ }^{394}$ Denn der Vorgang der Verifizierung erscheint ihm nicht als erkenntnistheoretisch vernünftiger Akt, vielmehr als existenzialer Vollzug, der zur Selbstidentität mit dem Ruf des Gewissens, zum Wahrsein der Existenz und zum Glauben wird. Anders gesagt, verbindet er durch den Begriff der Verifikation Verstehen mit der existentialen Gewissheit und betont damit das Verständnis des Glaubens als fiducia, als „grundlegendes, daseinsbestimmendes Vertrauen“ ${ }^{395}$ auf den Gott. Er bestimmt schließlich das wahre, theologisch sinnvolle Verstehen als solches, das nicht mit der Erkenntnis, sondern mit der Existenz und weiter mit Tat und Verantwortung zu tun hat.

In solcher Verifikationsproblematik spielt Ebelings Sprachkonzept, insbesondere der Begriff des Wortgeschehens eine wichtige Rolle. Der Gebrauch der Sprache stellt eigentlich nicht nur die Bedingung, „dass er in sich selbst sprachlich korrekt sein“ sollte, sondern auch die, „dass er wahr sei“", denn sprachliche Äußerung erfordert „Verifikation, die sich nur in einer wie auch immer näher zu bestimmenden kritischen Konfrontation von Sprache und Sache vollziehen kann“. ${ }^{396}$ Diese Verifikation im Verhältnis von Sprache und Sache hat dabei sowohl mit dem Sinn als auch mit dem Realitätscharakter des Sachverhaltes, nämlich mit dem, was in Wahrheit so ist, wie es erscheint, zu tun.

Diese Doppelaspekte der Verifikation erscheinen theologisch - entsprechend den oben aufgezeigten zwei Richtungen des auf die Wirklichkeit bezogenen Verifikationsproblems in der Theologie einerseits als die Überprüfung des Wahrheitsanspruches der christlichen Rede von Gott und diesbezüglichen Begriffen und andererseits als das Geschehen, das die Wahrheit für den Menschen manifestiert. ${ }^{397}$ Diese als Geschehen erwiesene Verifikation ist „Wort-Geschehen“ zu nennen, denn das Wort Gottes bezeichnet sich selbst als Geschehen und auch als Verifikation: „Wort Gottes ist vielmehr selbst Verifikation. Es verifiziert sich selbst, indem es den Menschen verifiziert. “398 Das heißt, durch das Wort Gottes gewinnt der Mensch ein grundlegendes Verständnis über sich selbst sowie die Wirklichkeit und damit auch die Wirklichkeitsverifikation. Die Gewissheitserfahrung hat nun ihren eigentlichen Ort nicht im erfahrenden Subjekt, sondern im Wort Gottes, an dem auch der Glaube hängt. Das Geschehen des Wort Gottes, das keiner anderen Bestätigung bedarf, macht also die Existenz des Menschen im Gewissen als „Ort des Menschen“ vor Gott ${ }^{399}$ gewiss und weckt den Glauben. Ebeling

\footnotetext{
${ }^{394}$ Vgl. WG, 198; WG II, 402.

${ }^{395}$ W. Härle, Dogmatik, Berlin ${ }^{3} 2007,58$.

396 Sprachlehre, 117.

${ }^{397}$ WG II, $199 \mathrm{ff}$.

${ }^{398}$ WG II 426.

${ }^{399}$ WG, 404f. Ebeling lehnt sich dagegen auf, das Gewissen ,als ins Herz geschriebener Sittenkodex“ (WG, 404) in allgemeinem und moralischem Verständnis zu bestimmen. H. Schlögel markiert den Gewissensbegriff bei Ebeling darum ganz deutlich mit seinem Buchtitel „nicht moralisch, sondern theologisch“ und erklärt, dass er von
} 
richtet sich deshalb zuallererst auf das Wortgeschehen, das auch die Verifikation im ersten Sinne, die sich als die Überprüfung des Wahrheitsanspruches der christlichen Rede von Gott erweist, ermöglicht. Die Tatsache, dass die Verifikation als Wortgeschehen eine Überprüfung des Wahrheitsanspruches ermöglicht, erläutert Ebeling am Wort „Gott“, dessen Sinn ohne das Wort Gottes und sein Handeln weder richtig verstanden, noch bezüglich der Wahrheit in Anspruch genommen werden kann. ${ }^{400}$

Unter der Voraussetzung der Verifikation, die von Ebeling als das die menschliche Existenz im Gewissen treffende Sprachgeschehen ausgemacht wird, lässt sich das, was Wahrheit meint, nur im Horizont von Sprache erschließen. Wahrheit entsteht aus Sprache. Radikal gesagt, nur weil der Mensch Sprache hat, kommt Wahrheit für ihn in Betracht. Die Frage: „Was aber heißt: die Wahrheit sagen?“, beantwortet Ebeling nun wie folgt: „Wahrheit ist die ins Wort gefasste Wirklichkeit.““01 Der von ihm als existenzieller Tatvollzug bestimmte Vorgang der Verifizierung ist im Horizont von Sprache zu verstehen, nämlich als verlässliches Wort. Wo Sprache in Unstimmigkeit zwischen Wort und Tat unverantwortlich gebraucht wird, erscheint sie als leeres Wort, das nichts mehr mitzuteilen hat. Als dessen Beispiel redet Ebeling von einem „abgestandenen und faulgewordenen Reden“, das auf einer „Entwertung des Wortes überhaupt“ oder auf einem „Schwinden verantwortlichen Umgangs mit der Sprache“ beruht. ${ }^{402}$ Er folgert: Taten erweisen sich als „eine Gestalt des Wortgeschehens. Als Antwort auf einen Anspruch ist das Wirken selbst also Wahrnehmung der Verantwortung, wie sie im Augenblick gefordert ist.“403

Aus dem Zusammenhang von Wort, Wirklichkeit und Werk ist bei Ebeling vom Ethischen für den Bereich des Verstehens in der Verifikationsproblematik zu reden, also in dem Sinne, dass ethisches Verhalten die Einheit von Tat und Wort oder von Handlungsvollzug und Sprache meint. Die Äußerung von E. Thaidigsmanns ist dabei für sinnvoll zu halten, dass sich bei Ebeling „das ethische, das ontologische und das theologische Problem des Menschen“ „in einem fundamentalen Verantwortlichsein des Menschen“ berühren. ${ }^{404}$

\subsubsection{Zum Einverständnis als dem Ziel des Verstehens}

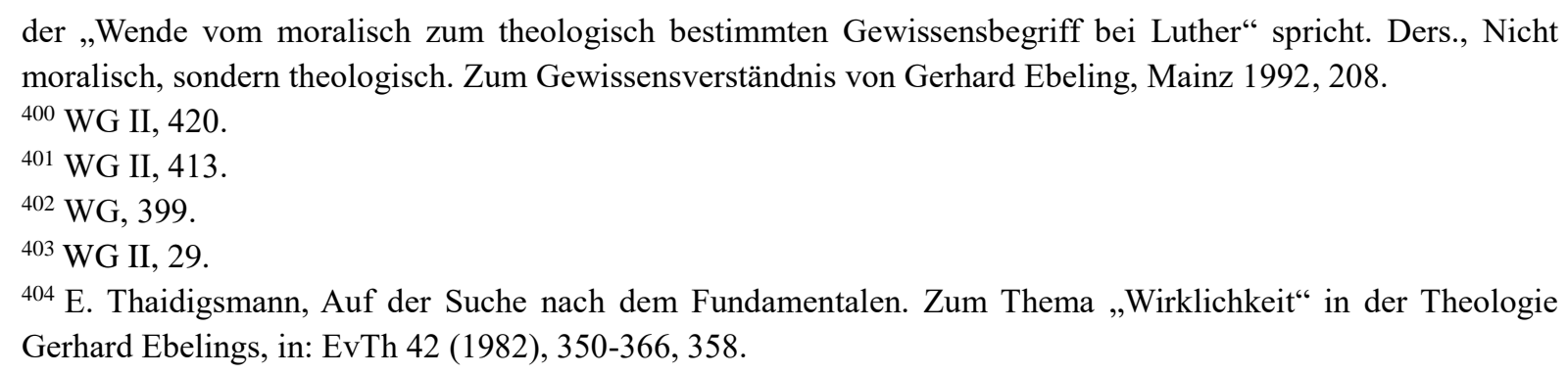


Einverständnis meint im allgemeinen Sprachgebrauch zuerst „Billigung, Zustimmung“ und auch „Übereinstimmung, Einigkeit in Bezug auf etwas, wozu jemand anderes die gleiche Einstellung hat“ 405 Eine besondere Bedeutung des Einverständnisbegriffs findet sich in der Diskussion um die Hermeneutik Gadamers, dessen Einverständnisauffassung z.B. von J. Habermas widersprochen, aber von F. Mildenberger und P. Stuhlmacher aufgenommen wird. ${ }^{406}$ Gadamer hält Einverständnis für eine hermeneutisch bedeutsame Einsicht und behauptet, dass nicht nur das Ziel alles Verstehens das Einverständnis in der Sache sei, sondern auch, dass sich ein „tragendes Einverständnis“ allem Missverstehen vorsetze ${ }^{407}$ und dass Verständigung „nur auf dem Boden eines ursprünglichen Einverständnisses“ gelinge. ${ }^{408}$ Einverständnis wird für Gadamer dann zum Horizont des auf Verständigung zielenden Auslegungsvorganges.

Ebeling plädiert wie Gadamer zuerst für den Begriff des zum Einverständnis führenden Verstehens. ${ }^{409}$ Es ist aber unklar, ob Einverständnis bei ihm auch als Voraussetzung für Verstehen betrachtet werden kann. Beispielweise behauptet P. Stuhlmacher, dass bei Ebeling die ,postulierte Reihenfolge von Verstehen und Einverständnis auch in ihrer Umkehr“ bedacht werden kann, ${ }^{410}$ denn er sieht, dass sich der zum Einverständnis führende Verstehensvorgang ,als ein überaus verwickeltes Hinund Hergehen zwischen verbum und res sowie zwischen überliefertem Text und eigenem Ausgeliefertsein an das Leben“" vollzieht ${ }^{411}$ und damit Verstehen und Einverständnis einen Zirkel im

405 Art. Einverständnis, in: Duden online Wörterbuch, https://www.duden.de/suchen/dudenonline/Einverst $\%$ C3\%A4ndnis.

${ }^{406} \mathrm{~J}$. Habermas widersetzt sich dem Begriff des Einverständnisses von Gadamer, der sich auf der Allgemeinheit bzw. Universalität der Sprache gründet, und behauptet, dass die Sprache ,auch ein Medium von Herrschaft und sozialer Macht“ damit „,ideologisch“ sei und der sprachlichen Übereinstimmung keine gewaltfrei erreichte Verständigung zugrunde liege. Ders., Zu Gadamers „Wahrheit und Methode“, in: K.-Otto Apel u.a. (Hg.), Hermeneutik und Ideologiekritik, Frankfurt a.M. 1971, 287f; Ders., Universalitätsanspruch der Hermeneutik, in: R. Bubner u.a. (Hg.), Hermeneutik und Dialektik Bd. 1, Tübingen 1970, 73-103, bes. 98ff. F. Mildenberger nimmt Gadamers Einverständnisauffassung dagegen auf und versucht, gegenüber dem fundamentalistischen Biblizismus und der historischen Kritik das zusammenhängende Verhältnis von Auslegung und Bekenntnis hervorzuheben: „Im Bekenntnis wird das Einverständnis darüber ausgesprochen, was als die Sache der Bibel gehört worden ist. So lässt sich theologisch beschrieben, was als kirchliches Urteil - oder Vorurteil - über die Sache der Bibel anzunehmen ist und wieder unser Verstehen dieser Sache leiten soll." Ders., Die halbe Wahrheit oder die ganze Schrift. Zum Streit zwischen Bibelglauben und historischer Kritik, München 1967, 37f. Darüber hinaus verwendet P. Stuhlmacher den Begriff des Einverständnisses von Gadamer im Sinne des „wirkungsgeschichtlichen Bewusstsein(s)“ und sieht es als eine Voraussetzung für die sachgemäße Schriftauslegung, weil beim Betrachten der biblischen Texte der Ausleger nicht auf dem neutralen Standpunkt, sondern in ihrer Wirkungsgeschichte steht. Ders., Schriftauslegung auf dem Wege zur biblischen Theologie, Göttingen 1975, 122ff. Vgl. D. Graf, Unterwegs zu einer biblischen Theologie. Perspektiven der Konzeption von Peter Stuhlmacher, Göttingen 2011. 141.

${ }^{407}$ H.-G., Gadamer, Die Universalität des hermeneutischen Problems (1966), in: WM II, 219-231, 223.

${ }^{408}$ H.-G., Gadamer, WM I, ${ }^{4} 1975$, Nachwort, 529.

${ }^{409}$ WG IV, 497f; Sprachlehre, 13.

${ }^{410}$ P. Stuhlmacher, Exegese und Erfahrung, in: E. Jüngel u.a. (Hg.), Verifikation. Festschrift für G. Ebeling zum 70. Geburtstag, Tübingen 1982, 62-89, $71 \mathrm{f}$.

${ }^{411}$ WG IV, 498f. 
Interpretationsgang bilden. Ebeling hält es jedoch noch für „vorschnell zu behaupten“, dass man Text und die darin ausgesagte Sache erst dann verstehe, wenn man einverstanden ist. ${ }^{412} \mathrm{R}$. Sohns weist darauf hin, dass Ebeling Einverständnis im Sinne einer Voraussetzung des Verstehens nicht thematisiert, ${ }^{413}$ während Fuchs den Begriff des Einverständnisses in seiner $>$ Hermeneutik< (1954) im Zusammenhang seiner Erwägung über das Selbstverständnis thematisiert und es dabei als Ermöglichungsgrund des Verstehens bestimmt, indem er offensichtlich behauptet, dass alles Verstehen „im Einverständnis“ gründet. ${ }^{414}$ Obwohl Ebeling den Begriff des Einverständnisses nicht so intensiv wie Gadamer oder Fuchs behandelt, ist es dennoch ratsam, einen kurzen Überblick darüber zu geben, welche Bezeichnung das Verstehensproblem bei ihm durch den Begriff des Einverständnisses gewinnt und wie sie wieder mit seinem Sprachverständnis verbunden ist.

Zum einen sieht Ebeling das Einverständnis als ein selbstverantwortliches Einstimmen, das sich am historischen Abstand und gegenwärtigen Widerstand vollzieht. Der Ansatzpunkt für das so geartete Einverständnis befindet sich bei ihm im Verhältnis von Verstehen und Zeit. Die Rede von der Interpretation eines Buches widerlegt schon den grundlegenden Zweifel, ob ein die Zeit transzendierendes Verstehen möglich sei. Ebeling ist grundsätzlich der Meinung, dass eine Verständigung möglich ist, die ein die zeitliche Distanz transzendierendes Einverständnis bringt. ${ }^{415} \mathrm{Er}$ unterscheidet dabei zwischen einem „ererbten“ Einverständnis und einem „wahren“. Ein ererbtes Einverständnis, das er metaphorisch als ein „Zuhausesein in der christlichen Sprachüberlieferung“ beschreibt, ${ }^{416}$ ergibt sich mit der christlichen Tradition im Verlauf der Weltgeschichte. ${ }^{417}$ Ein wahres und volles Einverständnis erscheint dagegen in Auseinandersetzung mit der überlieferten Tradition sowie der gegenwärtigen Welterfahrung als ein „selbstverantwortes

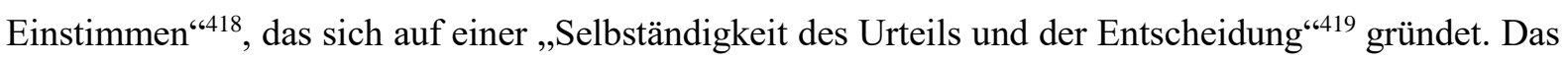
heißt, dieses wahre und volle Einverständnis muss nicht nur die traditionellen Ansprüche und das Bewusstsein einer geschichtlichen Kontinuität anerkennen, sondern braucht auch den historischen Abstand bzw. die Verfremdung des Überlieferten und den gegenwärtigen Widerstand. Deshalb ist ein kritischer Dialog mit der Überlieferung nötig und Einverständnis ist nun im Sinne der eigenverantwortlichen Einstimmung zu verstehen: „Denn dadurch wird der Gefahr begegnet, das Einverständnis an falscher Stelle zu suchen und es sich so zu erschleichen oder aber vorschnell für

\footnotetext{
412 WG IV, 497.

413 Vgl. Ricarda Sohns, Verstehen als Zwiesprache, Hermeneutische Entwürfe in Exegese und Religionspädagogik, Münster u.a. 2003, 52-65, bes. 61 .

${ }^{414}$ E. Fuchs, Hermeneutik, Bad Cannstatt 1954, 136.

415 Sprachlehre, 13.

416 Sprachlehre, 8.

${ }^{417}$ Sprachlehre, 6ff. 8f.

${ }^{418}$ Sprachlehre, 13.

${ }^{419}$ Sprachlehre, 9.
} 
unmöglich zu erklären. Damit ist, aufs äußerste stilisiert, die Aufgabe formuliert, die sich der Theologie in der Bildungssituation der Neuzeit stellt. Um Missverständnissen vorzubeugen, die sich an dieser Abbreviatur entzünden könnten, sei ausdrücklich betont: Wenn die um Verstehen bemühte Interpretation ernsthaft die Möglichkeit des Einverständnisses erproben will, muss sie sich der ganzen Vielfalt gegenwärtiger Welterfahrung stellen; denn echtes Einverständnis kann nicht zustande kommen, wenn der darin sich vollziehenden Konfrontation künstliche Schranken gesetzt werden.“420

Ebeling bestimmt solches wahre Einverständnis als mögliches Ziel des Verstehens und macht Sprachbewegung zu seiner Grundlage. Er erklärt dazu, dass „die Sprache selbst in ihrer Geschichtsgesättigtheit, in ihrer geschichtlichen Konstanz und zugleich in ihrer geschichtlichen Wandelbarkeit“ „alle Einwände gegen die Möglichkeit von Interpretation“ widerlegt und letztlich „nichts anderes als die Verstehen erzeugende, sich zum Verstehen bringende Macht“ ist. ${ }^{421}$ Solches Verständnis der Sprache führt uns zu einem Sprachoptimismus, dessen Ansatz auf der Prämisse beruht, dass Sprache nicht nur als ein technisches Verständigungsmittel dient, sondern Verstehen garantiert, damit Verstehen und Interpretieren grundsätzlich möglich sind.

Zum anderen sieht Ebeling das Einverständnis als Einklang auf einer kommunikativen Ebene und bezieht es auf die sprachliche Kommunikation zwischen Personen. Sprache bestimmt eigentlich den Wirklichkeitsraum des menschlichen Zusammenlebens, weil Menschen durch sie miteinander in Verbindung kommen, sich aufeinander verlassen, sich deshalb gegenseitig Anteil an ihrem Leben und Sein geben können. ${ }^{422}$ Sie ermöglicht darum Menschen die Kommunikation und die Partizipation im Zusammenleben mit anderen, ${ }^{423}$ indem sie „Redenden und Hörenden am selben Ort“ versammelt und ein Verstehen anstrebt, ,in dem der Redende und der Hörende nicht bloß dies und das miteinander teilen, sondern, gewiss vermittelt durch solche partielle Verständigung, einander verstehen lernen und so letztlich zum Einverständnis, ins Einvernehmen gelangen““ ${ }^{424}$ Es gibt aber noch, wie Ebeling selber darstellt, „die eigentümliche Ambivalenz der Sprache“, die darin besteht, dass sie zugleich Verstehen und Missverstehen schafft, weil sie selbst nicht nur das Mittel zum Verstehen, sondern auch „Ursache von Nichtverstehen und Missverstehen“" sein, sogar absichtlich für Missverständigung oder Täuschung verwendet werden kann, so dass sie Gemeinschaft als den Raum des menschlichen Zusammenlebens „stiften“ und auch „zerstören“ kann. ${ }^{425}$ Diese Ambivalenz wird aber bei Ebeling nur theologisch ausgefochten, indem er sie mit dem biblischen Hinweis auf die Doppelzüngigkeit der menschlichen Zunge im Jakobusbrief verbindet und damit die entscheidende Funktion der Sprache im Menschsein

\footnotetext{
${ }^{420}$ Sprachlehre, $18 \mathrm{f}$.

${ }^{421}$ Sprachlehre, 13.

422 WG II, 39.

${ }^{423} \mathrm{WG}, 342$.

${ }^{424}$ Sprachlehre, $197 \mathrm{f}$.

425 Sprachlehre, 109.
} 
und „das Bewusstsein der Sprachverantwortung“, die theologisch auf ihre Verifikation und ihren heilsamen Gebrauch ausgerichtet wird, betont. ${ }^{426}$ Ebeling erklärt die Ambivalenz der Sprache als die Ursache für die Störung der Kommunikation hamartiologisch, nämlich in Bezug auf Sünde als Ursache für alle Verwicklungen, und bezeichnet Sprachvollmacht und Einverständnis demgemäß als Einklang in Bezug auf das Verhältnis zu Gott. Da kommt die sprachliche Personalitätsrelation zum Tragen. Denn „Person als das Sein des Menschen vor Gott ist konstituiert durch das Getroffensein von dem Wort Gottes, das den Menschen in seinem Gewissen richtet und freimacht. “427 Das heißt, das Einverständnis als Einklang im Verhältnis zu Gott entsteht allein in der personalen Begegnung mit Gott, die sich mittels der Sprache vollzieht.

\section{Sprache und Auslegung}

Auslegung bedeutet, einen Text in bestimmter Weise deutend zu interpretieren. Die Auslegung der Bibel wird oft als (biblische) Exegese bezeichnet. Die Schriftauslegung gewinnt durch die Reformation ihre zentrale Stellung in der theologischen Diskussion, indem Luther dem Anspruch auf die autoritative Auslegungstradition der Kirche für das rechte Verständnis der Bibel widersprach und damit einen hermeneutischen Paradigmenwechsel herbeiführte. Körtner sagt, im Hinblick auf die in der reformatorischen Tradition stehende Theologie dürfe die Schriftauslegung nicht allein für die „Voraussetzung ihrer Darstellung des christlichen Glaubens und seiner Inhalte“ gehalten werden. ${ }^{428}$ Ebeling bestimmt die Kirchengeschichte, die die Geschichte der Dogmen und der Theologie enthält, als „Geschichte der Auslegung der Heiligen Schrift“. ${ }^{429}$ Er erklärt dazu, dass die Kirchengeschichte wesentlich „Zwischen uns und der Offenbarung Gottes in Jesus Christus“ steht und die Kirche in der Geschichte kraft des in der Auslegung der Heiligen Schrift vollzogenen Zeugnisses von Jesus Christus existiert. ${ }^{430}$ Das heißt, Jesus Christus wird in der Kirchengeschichte weder „,in einfacher Wiederholung der Heiligen Schrift“ noch „,in Imitation der Nachfolge seiner Jünger“, sondern „,in

\footnotetext{
${ }^{426}$ Sprachlehre, 110.

${ }^{427}$ Luther, 233.

${ }^{428}$ Ulrich H. J. Körtner, Art., Schriftauslegung IV. Systematisch-theologisch, in: TRE 30 (1999), 489-495, 489.

${ }^{429}$ Ebelings Entwurf „Kirchengeschichte als Geschichte des Auslegung der Heiligen Schrift“ wurde zum ersten Mal in der Probevorlesung der Habilitation 1947 aufgezeigt und später wiederabgedruckt in: WGT, 9-27. Es gab starken Widerspruch gegen diesen Entwurf, z.B. K. Heussi, Schriften zur Geschichtslogik und zur Geschichtstheologie II, in: ThLZ 73 (1948), 393-398; F. de Boor, Kirchengeschichte oder Auslegungsgeschichte?, in: ThLZ 97 (1972), 401-414. Die Kritiken gegen Ebeling zielen zumeist, wie A. Beutel mit Recht herausstellt, ,auf den Begriff der Auslegung, den man gegenüber der Lebensfülle der Kirchengeschichte als eine hermeneutische Verengung empfand“. Ders., Protestantische Konkretion. Studien zur Kirchengeschichte, Tübingen 1998, 20f.

${ }^{430}$ WGT, $25 f$.
} 
Auslegung" bezeugt. ${ }^{431}$ Ebeling scheint damit die Auslegung im Sinne einer Verantwortung des biblischen Grundes für den Glauben in jeder geschichtlichen Situation zu erfassen. Solche Auslegung betrifft die existentiale Interpretation. Als Ebelings Auslegungsprinzip stehen sie und seine daran geknüpfte Sprachkonzeption darum im Mittelpunkt dieses Abschnitts.

\subsection{Existentiale Interpretation als theologisches Auslegungsprinzip}

Existentiale Interpretation ist, nach G. Bornkamms Definition, „eine Auslegung, die nach dem Verständnis von menschlicher Existenz in einem Text fragt“. ${ }^{432}$ Der theologische Anspruch der existentialen Interpretation kommt grundsätzlich vom Gedanken her, dass sich die Grundstruktur des menschlichen Daseins in den biblischen Texten spiegelt, und richtet sich darauf, wie menschliche Existenz durch den biblischen Text verstanden werden kann. Weil das dabei angemessene Daseinsverständnis im Glauben angenommen werden muss, wird die theologische existentiale Interpretation, wie M. Oeming sagt, „nicht primär Sache der Wissenschaft, sondern des Glaubens““433. Sie ist dann als Interpretation des christlichen Glaubens im Hinblick auf die menschliche Existenz zu verstehen.

Der Begriff der existentialen Interpretation kommt in den fünfziger und sechziger Jahren des letzten Jahrhunderts im Bereich der Theologie am häufigsten vor, insbesondere bei Bultmann, dessen Gedanken der existentialen Interpretation Ebeling weiterführt. Bevor dessen Ausführung der existentialen Interpretation behandelt wird, ist es daher nötig zu betrachten, wie Bultmann die existentiale Interpretation entwickelt und auf sein Entmythologisierungsprogramm sowie seine Jesusforschung bezieht.

\subsubsection{Existentiale Interpretation bei Bultmann}

Ein Kernbegriff in der Hermeneutik Bultmanns ist offenbar das Existenzverständnis und das darauf beruhende Auslegungsprinzip ist die existentiale Interpretation. Durch diese stellt er sich grundsätzlich der Position der Offenbarungstheologie gegenüber, deren Ansatz vom wesentlichen, qualitativen Unterschied zwischen Gott und Mensch ausgeht, weil die existentiale Interpretation trotz dieses Abstandes eine Möglichkeit bietet, von Gott zu reden. Die anti-metaphysische Tendenz, die sich in der

\footnotetext{
${ }^{431}$ WGT, 27.

${ }^{432}$ G. Bornkamm, Mythos und Evangelium. Zur Diskussion des Problems der Entmythologisierung der neutestamentlichen Verkündigung, in: Ders./W. Klaas, Mythos und Evangelium. Zum Programm R. Bultmanns (ThEx 26), München 1951, 3-29, 5, Anm. 3.

${ }^{433}$ M. Oeming, Biblische Hermeneutik, Darmstadt 1998, 165.
} 
Erweiterung des Erkenntnisproblems auf die Frage nach dem theologischen Sachengehalt findet, hat Bultmann von seinem Lehrer Hermann übernommen. ${ }^{434}$

Vor allem mit der Frage, ,welchen Sinn hat es, von Gott zu reden“, bringt Bultmann sein Grundmotiv der existentialen Interpretation zum Ausdruck. ${ }^{435}$ Seine Grundposition besagt, dass erstens nicht Gott, sondern das Reden von Gott als die zentrale theologische Fragestellung gesehen wird und zweitens, dass das Reden von der menschlichen Existenz die einzig legitime theologische Art und Weise ist, um von Gott zu reden. Die theologische Wurzel seiner existentialen Interpretation ist die NichtObjektivierbarkeit Gottes. Für diese nimmt Bultmann zwei fundamentale, miteinander zusammenhängende biblische Gottesbegriffe auf, also Gott als „das ganz Andere“4436 und „die Alles bestimmende Wirklichkeit“ ${ }^{437}$ Gerade in der Verbindung von diesen beiden Begriffen betont er die Zusammengehörigkeit vom Reden von Gott und vom Reden von sich selbst. Gott ist allererst keine Gegebenheit unter andern, sondern der ganz Andere, dessen Transzendenz Bultmann im Charakter des unverfügbaren Geschehens versteht. „Die Transzendenz Gottes ist in der Bibel nicht gedacht als die Jenseitigkeit des Geistes gegenüber der Sphäre des Materiellen, Sinnlichen, als die Zeitlosigkeit gegenüber Werden und Vergehen, sondern als die schlechthinnige Autorität, die Unverfügbarkeit und ständige Zukünftigkeit Gottes.“ ${ }^{438}$ Über diesen Gott kann man nicht wie über ein Objekt reden. Bultmann behauptet weiter, sofern Gott zugleich die alles bestimmende Wirklichkeit ist, ist das Reden von ihm doch zur Existentialität zu zwingen, weil es um die „tatsächliche Wirklichkeit seiner Existenz ${ }^{‘ 439}$ geht. Das heißt, wenn man Gott als die alles bestimmende Macht erfährt, kann man dann erst den sich offenbarenden Gott verstehen, so wie die Liebe ist, nicht indem man theoretisch über sie redet, sondern nur ,indem ich liebe oder geliebt werde“. ${ }^{440}$ Gottes Offenbarung ist darum primär keine Mitteilung von bestimmten Gedankeninhalten, sondern die von einem neuen Selbstverständnis. Bultmann folgert; „Will man von Gott reden, so muss man offenbar von sich selbst reden.“441

Die existentiale Interpretation bezieht sich bei Bultmann gewissenmaßen auf sein Entmythologisierungsprogramm ${ }^{442}$ und auf seine Kritik gegen historische Jesusforschung. Eine

\footnotetext{
${ }^{434}$ Vgl. WG, II, 346.

${ }^{435}$ R. Bultmann, GuV I, 26-37.

${ }^{436}$ R. Bultmann, GuV I, 29

${ }^{437}$ R. Bultmann, GuV I, 26.

${ }^{438}$ R. Bultmann, GuV III, 157.

${ }^{439}$ R. Bultmann, GuV I, 27.

${ }^{440}$ R. Bultmann, GuV I, 28.

${ }^{441}$ R. Bultmann, GuV I, 28.
}

${ }^{442}$ Die Verhältnisbestimmung von Entmythologisierung und existentialer Interpretation bei Bultmann ist umstritten: z.B. sieht E. Dinkler die existentiale Interpretation als die positive Seite der Entmythologisierung und diese als Konsequenz von jener. Ders., Rudolf Bultmann als Lehrer und Mensch (1959), in: Ders., Im Zeichen des Kreuzes, O. Merk/M. Wolter (Hg.), Berlin/New York 1992, 421-432; H. Fischer versteht die Entmythologisierung bei Bultmann als Fortsetzung der existentialen Interpretation. Ders., Systematische Theologie. Konzeptionen und Probleme im 20. Jahrhundert, Stuttgart u.a. 1992, 127; und U.H.J. Körtner sagt auch, „dass bei Bultmann die 
Betrachtung der beiden Bezüge ist nötig, nicht nur um die existentiale Interpretation Bultmanns, sondern auch die Ebelings besser zu verstehen, weil der Letztere gerade an diesem Punkt den Abstand gegenüber dem Ersteren deutlich werden lässt.

Die existentiale Interpretation betrifft bei Bultmann die eigentliche Intention des Mythos. In der Frage, was die neutestamentlichen Texte dem modernen Menschen zu sagen haben, stößt Bultmann auf Schwierigkeiten, da die mythischen Züge des neutestamentlichen Weltbildes, die sich an Geist und Wunder knüpfen, damit dem aufgeklärten und naturwissenschaftlichen Weltbild widersprechen. Um diese Schwierigkeiten $\mathrm{zu}$ lösen, muss das Neue Testament entmythologisiert werden. Entmythologisierung bedeutet hier, mythisches Material nicht zu entfernen oder zu eliminieren, sondern richtig zu interpretieren: „Entmythologisierung ist eine hermeneutische Methode, das heißt, eine Interpretationsmethode, eine Methode der Exegese. “ ${ }^{443}$ In diesem Sinne weist mit Recht U.H.J Körtner hin, dass Entmytholoisierung bei Bultmann ,nicht die Eliminierung des Mythos, sondern seine Reinterpretation“ bedeutet. ${ }^{444}$ Bultmann behauptet, die Redeweise des Mythos muss in eine solche, dem Verständnis des modernen Menschen von sich und seiner Welt entsprechenden, übersetzt werden, gerade mittels der existentialen Interpretation. ${ }^{445}$

In jedem Mythos wird laut Bultmann zwar etwas Wesentliches über die menschliche Existenz ausgesagt, doch durch die Darstellungsweise verdunkelt, Der Mythos stellt das Jenseitige als etwas Diesseitiges dar und seine Intention besteht darin, keine objektiven Aussagen über das Jenseitige zu machen, sondern ein Welt- und Selbstverständnis darzulegen. ${ }^{446}$ Er argumentiert, der Mythos wolle keinesfalls ein historisches Geschehen ausdrücken und Mythologie sei deshalb „,nicht auf ihren objektivierenden Vorstellungsgehalt hin zu befragen, sondern auf das in diesen Vorstellungen sich

\footnotetext{
Entmythologisierung kein Selbstzweck, sondern lediglich die Kehrseite der von ihm begründeten existentialen Interpretation des Neuen Testaments ist." Ders., Der inspirierte Leser. Zentrale Aspekte biblischer Hermeneutik, Göttingen 1994, 143. Darüber hinaus scheint P. Stuhlmacher beide gleichzusetzen. Ders., Biblische Theologie des Neuen Testaments I, Göttingen 1992, 19. Im Gegenteil setzt H.-P. Müller die unklare Verhältnisbestimmung zwischen ihnen voraus, mit der Behauptung, dass ,in Bultmanns Programm das Verhältnis von Entmythologisierung und existentialer Interpretation ungeklärt" sei. Ders., Albert Schweitzer und Rudolf Bultmann. Theologische Paradigmen unter der Herausforderung durch den Säkularismus, in: ZThK 93 (1996), 101-123, 102f; und C. Landmesser redet von der Gefahr der Zusammensetzung von beiden, „dass das MythosProblem die Einsicht in die existentiale Interpretation verstellt", und behauptet, die existentiale Interpretation sei fundamentaler gegenüber der Entmythologisierung. Ders., Wahrheit als Grundbegriff neutestamentlicher Wissenschaft, Tübingen 1999, 280-282. Die Betrachtungsweise, beide gleichzusetzen, so wie das bei Stuhlmacher gemacht, ist gewiss vorschnell. Sie beziehen sich m.E. gewissermaßen aufeinander, weil Bultmann sie für einen gleichen Zweck verwendet, den eigentlichen Sinn der biblischen Aussagen zu finden. Hier stelle ich aber nicht den Unterschied zwischen beiden heraus, sondern ihren Bezug zueinander, um später aufzuzeigen, dass Ebeling seine existentiale Interpretation gegen das Entmythologisierungsprogramm bei Bultmann entwickelt.

${ }^{443}$ R. Bultmann, GuV IV, 163.

${ }^{444}$ U.H.J Körtner, Einführung in die theologische Hermeneutik, Darmstadt 2006, 53.

${ }^{445}$ R. Bultmann, KuM I, 22.

${ }^{446}$ R. Bultmann, GuV IV, 133.
} 
aussprechende Existenzverständnis hin. ${ }^{6447}$ Er versucht das objektivierende wissenschaftliche Denken zu überwinden und die auf die Existenz bezogene und zugleich verborgene Intention des Mythos durch die existentiale Interpretation ans Licht zu bringen. Denn durch die existentiale Interpretation unterscheiden sich mythologische Darstellung als Form bzw. Oberflächenstruktur der biblischen Texte und Kerygma als ihre Sache, damit unnötige Verstehenshindernisse beseitigt werden können. Im Entmythologisierungsprogramm wendet sich Bultmann mit seiner Kritik am Mythos nun gegen das neuzeitliche Missverständnis des Mythos als objektive Aussage und zielt mit der existentialen Interpretation darauf, den richtig verstandenen Mythos in einer zeitlos gültigen Weise zu erkennen.

Die existentiale Interpretation als Mittel zur Entmythologisierung bringt Bultmann weiter zur historischen Jesusfrage, weil auf die Gestalt Jesu die mythologischen Vorstellungen der jüdischapokalyptischen und der hellenistisch-gnostischen Gedankenwelt übertragen wurden. ${ }^{448}$ Als Beispiel dafür ist sein Aufsatz $>$ Das christologische Bekenntnis des ökumenischen Rates $<(1951)^{449}$ zu nennen. Er versucht hier nachzuweisen, dass die mit den historischen Berichten über Jesus eng verbundenen mythologischen Aussagen nicht die Göttlichkeit Jesu meinen, sondern seine Bedeutsamkeit für uns zum Ausdruck bringen. Er richtet dabei seine Aufmerksamkeit auf den Hoheitstitel Jesu im Neutestament wie Messias, Knecht Gottes, Logos, Kyrios und Richter usw. und argumentiert, der Sinn aller Hoheitstitel Jesu liege darin, dass in Christus Gott selber zu uns redet. Er findet aber die reinste Bezeichnung Jesu im Johannesevangelium, in dessen Prolog, dass Jesus selbst das Wort Gottes sein soll, und auch im Selbstbekenntnis Jesu: „Ich bin der Weg“(Joh 14, 6). Diese Bezeichnung Jesu als das Wort Gottes und als der Weg bedeutet, dass das Wesentliche darin besteht, dass Jesus die Botschaft verkündet, und gerade hier befindet sich die Bedeutsamkeit Jesu für uns. Bultmanns existentiale Interpretation geht von der Auffassung aus, dass die Bibel eigentlich nicht über das An-sich Jesu, sondern über seine Heilsbedeutung für uns spricht.

Eine historische Untersuchung über Jesus bleibt bei Bultmann dagegen außer Acht. Denn der Frage nach der Person Jesu und seinem Leben unter rein historischen Gesichtspunkten und der dadurch gewonnenen Antwort kommt seiner Ansicht nach keine theologische Bedeutung zu. In seinem Buch $>$ Jesus< (1927) äußert er deutlich, dass wir ,vom Leben und von der Persönlichkeit Jesu so gut wie nichts mehr wissen können“. ${ }^{450}$ Die Frage, wer und was Jesus eigentlich ist, kann laut ihm keinesfalls durch historische Untersuchungen beantwortet werden, sondern nur im Glauben. Anders ausgedrückt, es geht um das Selbstverständnis, das bei Jesus „uns als Fragen“ begegnet, „wie wir selbst unsere

\footnotetext{
${ }^{447}$ R. Bultmann, KuM I, 23.

${ }^{448}$ K. Reinhardt, Der dogmatische Schriftgebrauch in der katholischen und protestantischen Christologie von der Aufklärung bis zur Gegenwart, München u.a. 1970, $258 f$.

${ }^{449}$ R. Bultmann, GuV II, 246-261.

${ }^{450}$ R. Bultmann, Jesus, Tübingen 1951, 11.
} 
Existenz auffassen wollen“. ${ }^{451}$ Es geht bei Bultmann dann nicht um Jesus selbst, so wie Ernst Lohmeyer sein Buch $>$ Jesus $<$ als „ein Buch von Jesus ohne Jesus“ ${ }^{452}$ urteilt. Bultmann unterscheidet den historischen Jesus vom Christus des Glaubens. Wenn man jedoch auf den historischen Jesus zurückzugreifen versucht, entfernt man sich deshalb vom Glauben an Christus; und wenn man durch historische Untersuchung eine feste Grundlage für Glauben aufzubauen versucht, widerspricht man eher dem Wesen des Glaubens.

Der negative Einfluss der historischen Untersuchung besteht laut Bultmann darin, dass sie uns von dem Wesen des Glaubens entfremdet und uns an historische, sachliche Verschiedenheiten bindet, z.B. an den Widerspruch der mythologischen Vorstellungsweisen des Christusgeschehens bindet, die aus verschiedenen historischen Traditionen kommen. Man kann allerdings die verschiedenen Deutungen Christi wahrnehmen, wenn dieser unterschiedlich als der Messias oder als der zweite Adam bezeichnet wird. Ebenfalls gibt es einen Unterschied zwischen dem Gedanken von der Jungfrauengeburt und dem der Präexistenz und auch zwischen der Vorstellung als Kenosis und der als dem wundertätigen Messias. ${ }^{453}$ Bultmann argumentiert, dass diese unterschiedlichen Vorstellungen eigentlich nicht nur einen Teilaspekt Christi zeigen, sondern wenigstens im Ansatz eine ganze Auffassung über Christus darlegen wollen. Das heißt, die Christusbotschaft des Neuen Testamentes kann nicht in einer widersprüchlichen Mischung von historischen Elementen aufgelöst werden, und um den eigentlichen Sinn der biblischen Aussagen zu begreifen, spielen solche sachlichen Widersprüche keine Rolle. Das negative Resultat der historischen Untersuchung zeigt folglich, dass die biblische Wahrheit nicht auf der Ebene der historischen, zeitlichen, objektiven Wahrheit liegen kann. Bultmann sagt sogar, von einer historischen Forschung dürfen keine oder nur sehr geringe Ergebnisse erwartet werden. ${ }^{454}$

In diesem Zusammenhang sei nun zu sagen: In Hinsicht auf die theologische Auslegung steht Bultmann der historischen Methode relativ skeptisch gegenüber und plädiert für die existentiale Interpretation. Denn er glaubt, das Erstere entferne den Interpreter der Bibel von ihrem eigentlichen Sinn und so auch von dem Wesen des Glaubens; und das Letztere stelle dagegen die in der historischen Kritik beschädigten und zerstörten Aussagen der Bibel in einem neuen Sinne wieder her, nämlich im Selbstverständnis des Gläubigen.

5.1.2. Die neue Frage nach dem historischen Jesus

\footnotetext{
${ }^{451}$ R. Bultmann, Jesus, Tübingen 1951, 14.

${ }^{452}$ E. Lohmeyer, Rez. R. Bultmann, Jesus, in: ThLZ 52 (1927), 433-439, zitiert nach: C. Danz, Grundprobleme der Christologie, Tübingen 2013, 25.

${ }^{453}$ R. Bultmann, KuM I, 23.

${ }^{454}$ R. Bultmann, Das Verhältnis der urchristlichen Christusbotschaft zum historischen Jesus, Heidelberg 1960, 10-
} 14. 
Die von Bultmann entwickelte existentiale Interpretation wird von einer Gruppe von Theologen übernommen, z.B. von Ernst Käsemann, Herbert Braun, Ernst Fuchs, James Robinson, Heinrich Ott und auch von Ebeling. Sie stimmen mit Bultmann darin überein, dass die biblischen Aussagen mittels der existentialen Interpretation richtig und sinnvoll verstanden werden können, und beschäftigen sich darüber hinaus mit der Frage, wie sich die biblische Offenbarung überhaupt als wahrhaft erweist. ${ }^{455} \mathrm{An}$ dieser Stelle findet sich aber nicht nur Übereinstimmung, sondern auch Unterschied. Dieser Unterschied fokussiert auf die nеuе Frage nach dem historischen Jesus, die von den Schülern Bultmanns gestellt und weiter von der Schule Bultmanns entfaltet wurde.

Die „neue“ Frage nach dem historischen Jesus wurde offensichtlich erstmals von Ernst Käsemann gestellt, der bei einer Tagung am 20. Oktober 1953 einen Vortrag über „Das Problem des historischen Jesus “456 hielt. In diesem Vortrag zeigte er sowohl die Gefahr des direkten Zugriffs auf die Historie als auch die Gefahr der radikalen Skepsis gegen sie auf. Um diesen Widerspruch zu klären, versuchte er mittels kritischer Rücksicht auf die vorliegenden Jesusforschungen dem historischen Jesu seinen verlorenen, aber neu sinngegebenen Platz in der Theologie zu geben. Er sagte, die gegenwärtige Situation werde nun ,dadurch gekennzeichnet, daß die genuin liberale Frage nach dem historischen Jesus wieder zunehmend an theologischem Gewicht gewinnt, paradoxerweise freilich in einer Zeit, in welcher der Liberalismus kirchlich weitgehend ausgeschaltet ist, und im Gegenschlag zu einer auf dem Boden des Liberalismus erwachsenen historischen und theologischen Kritik. “457 Dieser berühmte Vortrag hat, wie von U.H.J. Körtner metaphorisch knapp dargestellt, ins Wasser der theologischen Debatte tatsächlich einen „Stein“ geworfen, der „weite Kreise“ zog, ,in denen das anfängliche Interesse historisch-sachlich, methodisch und hermeneutisch vielfältig weiterentwickelt wurde“. 458

Käsemann war einer der Schüler Bultmanns, die dessen Auffassung nicht übernehmen wollten, dass wir von dem historischen Jesus, wie in seinem Buch $>$ Jesus $<$ beschrieben, „vom Leben und von der Persönlichkeit Jesu so gut wie nichts mehr wissen können“459. Das bedeutet aber nicht, dass sie wieder zur Absicht der liberalen Theologie zurückkehrten. Sie hatten kein besonderes Interesse an der historischen Sache selbst; weder wollten sie die historische Forschung über den Mann aus Nazareth als ihre zentrale Untersuchungsaufgabe festlegen, noch die Bedeutung der durch die historisch-kritische Methode gewonnenen faktischen Erkenntnisse für das Verständnis der Identität des Christentums

\footnotetext{
${ }^{455}$ Vgl. K. Reinhardt, Der dogmatische Schriftgebrauch in der katholischen und protestantischen Christologie von der Aufklärung bis zur Gegenwart, München u.a. 1970, 271-296.

${ }^{456}$ E. Käsemann, Das Problem des historischen Jesus, in: Ders., Exegetische Versuche und Besinnungen, Bd. 1. Göttingen ${ }^{6} 1970,187-214$.

${ }^{457}$ E. Käsemann, Das Problem des historischen Jesus, in: Ders., Exegetische Versuche und Besinnungen, Bd. 1. Göttingen ${ }^{6} 1970,189$.

${ }^{458}$ U.H.J. Körtner, Jesus im 21. Jahrhundert. Bultmanns Jesusbuch und die heutige Jesusforschung, NeukirchenVluyn 2001, 52. Anm. 130.

${ }^{459}$ R. Bultmann, Jesus, Tübingen 1951, 11.
} 
hochhalten. Stattdessen entwickelten sie aus dem Bewusstsein über den Mangel der Kerygmatheologie ihres Lehrers, der den Glauben auf das christliche Kerygma begründet hatte, die Notwendigkeit der historischen Rückfrage, weil ohne diese das Kerygma selbst eher zu einem Mythos werden könnte.

Die neue Frage nach dem historischen Jesus verbindet sich natürlich mit dem Geschichtsverständnis, doch genauer mit der „Frage eines angemessenen Verständnisses von Geschichte“, die nach der Meinung E. Käsemanns ,sich beim Theologen notwendig und exemplarisch zu dem Problem des historischen Jesus und seiner Bedeutung für den Glauben konkretisieren muss“ ${ }^{460}$ Er erklärt, „Denn Historie wird eben nicht durch Tradition als solche, sondern durch Interpretation, nicht durch das einfache Feststellen von Tatsachen, sondern durch das Verstehen der in Fakten gegenständlich gewordenen und erstarrten Ereignisse der Vergangenheit geschichtlich belangreich. [...] Geschichtliche Bedeutung besitzt Historie nur soweit, wie sie fragend und antwortend in unsere Gegenwart hineinspricht, also Interpreten findet, welche ihre Frage und Antwort für unsere Gegenwart hören und vertreten." ${ }^{\text {“461 }}$ Unter diesem Aspekt hat die Geschichte ihren Sinn nur in Bezug auf die Gegenwart und die Frage nach der Geschichte nur in Bezug auf die Antwort für die Gegenwart.

Die neue Frage nach dem historischen Jesus brachte dazu noch eine methodische Erneuerung. Dafür ist die redaktionsgeschichtliche Methode zu nennen, die sich als eine historisch-kritische Methode bezüglich der Exegese biblischer Texte in den 1950er Jahren entwickelte, z.B. von Hans Conzelmann, der sich speziell mit der lukanischen Theologie beschäftigt und in seiner Habilitationsschrift $>$ Die Mitte der Zeit< (1954) die Redaktionskritik zum ersten Mal verwendet hat; von Willi Marxen, der in seiner Habilitation $>$ Der Evangelist Markus< (1956) mit dem Untertitel ,Studien zur Redaktionsgeschichte des Evangeliums" den Namen der neuen Auslegungsmethode bestimmt und ihren Begriff geprägt hat; und auch von Günther Bornkamm und seinen Schülern, die das Matthäusevangelium durch die redaktionsgeschichtliche Methode bearbeitet und ihre Ergebnisse gemeinsam im Buch > Überlieferung und Auslegung des Matthäusevangeliums $<(1960)$ publiziert haben. ${ }^{462}$ Sie verstanden die Evangelisten nicht lediglich als Sammler oder Vermittler von Überlieferungsmaterial, sondern als Redakteure, die jeweils mit ihren eigenen bestimmten Positionen ihre Evangelien entwarfen. Unter diesem Aspekt versuchten sie die biblischen Schriften in Bezug auf das gegenseitige Wirken der Redakteure zu betrachten und die Evangelien letztlich mit den Gesamtkonzeptionen zu untersuchen, weil die vier Evangelien von Markus, Matthäus, Lukas und Johannes nicht nur unterschiedliche Jesusbilder

\footnotetext{
${ }^{460}$ E. Käsemann, Das Problem des historischen Jesus, in: Ders., Exegetische Versuche und Besinnungen, Bd. 1. Göttingen ${ }^{6} 1970,189$.

${ }^{461}$ E. Käsemann, Das Problem des historischen Jesus, in: Ders., Exegetische Versuche und Besinnungen, Bd. 1. Göttingen ${ }^{6} 1970,191 f$.

${ }^{462}$ Vgl. Hans Conzelmann, Die Mitte der Zeit. Studien zur Theologie des Lukas. Tübingen 1954; Willi Marxen, Der Evangelist Markus. Studien zur Redaktionsgeschichte des Evangeliums, Göttingen 1956; und Günter Bornkamm u.a., Überlieferung und Auslegung im Matthäusevangelium, Neukirchen-Vluyn 1960.
} 
entwerfen, sondern jeder sein eigenes Evangelium auch den anderen gegenüberstellen und diese überbieten will. ${ }^{463}$

Das entscheidende Merkmal der von den Schülern Bultmanns wiederherstellten Jesusforschung besteht aber darin, die Kontinuität zwischen der Verkündigung des vorösterlichen Jesus und der Verkündigung der nachösterlichen bzw. frühchristlichen Gemeinde aufzuzeigen. Die Frage nach dem historischen Jesus ist, nach der Einsicht Käsemanns, „legitim die Frage nach der Kontinuität des Evangeliums in der Diskontinuität der Zeiten und in der Variation des Kerygmas“. ${ }^{464}$ Wenn der verkündigte Christus keinen sachlichen Bezug zum historischen Jesus hätte, würde er bloß für ein Modell oder Vorbild für ein Projekt der frühchristlichen Gemeinden gehalten. Die neue Suchbewegung bezeichnet C. Danz mit Recht als „die dogmatische Konstruktion des historischen Jesus“ ${ }^{465}$ Die so geartete Suche wurde in der Schule Bultmanns weiter geführt, wobei die Frage nach dem historischen Jesus als eine theologische Frage behandelt wurde, die notwendig die Frage nach dem Ursprung der Christologie impliziert. Dafür ist Ebeling als ein vertretender Theologe zu nennen.

Die neue Frage nach dem historischen Jesus seit den 1950er Jahren richtete sich darauf, den dogmatischen Christus an den historischen Jesus anzubinden,, während sich die Jesusforschung seit der Aufklärung darauf gerichtet hatte, den historischen Jesus von dessen dogmatischer Verkleidung zu befreien, nach der Darstellung Käsemanns, ,aus den Fesseln kirchlicher Dogmatik zu befreien“466. Das wird jedoch in der dritten Phase wieder verändert, die im englischsprachigen Raum eingebürgert wurde und sich gewöhnlich als „Third Quest“ bezeichnet. Diese Veränderung erklärt D. du Toit klar wie folgt: „Weil Forscher der zweiten Phase von dem Interesse geleitet wurden, das Verhältnis zwischen dem historischen Jesus und dem verkündigten Christus zu bestimmen, neigten sie dazu, einerseits die Elemente der Kontinuität zwischen Jesus und der frühen Kirche und andererseits die Diskontinuität zum Judentum zu betonen. In der gegenwärtigen Jesusforschung besteht nun teilweise die umgekehrte Tendenz, Jesu Kontinuität zum Judentum und seine Diskontinuität zum frühen Christentums hervorzuheben.“ ${ }^{\text {“467 }}$ Mit dem Akzent auf der Kontinuität von Jesus und Judentum sah z.B. J. D. Crossan Jesus als einen jüdischen Kyniker, behauptend, dass Jesus „vielmehr ein Vertreter jener bäuerlichen, volkstümlichen, mündlichen philosophischen Praxis (war), die man als jüdischen Kynismus (oder

\footnotetext{
${ }^{463}$ C. Danz, Grundprobleme der Christologie, Tübingen 2013, 27.

${ }^{464}$ E. Käsemann, Das Problem des historischen Jesus, in: Ders., Exegetische Versuche und Besinnungen, Bd. 1. Göttingen ${ }^{6} 1970,213$.

${ }^{465}$ C. Danz, Grundprobleme der Christologie, Tübingen 2013, $25 f$.

${ }^{466}$ E. Käsemann, Das Problem des historischen Jesus, in: Ders., Exegetische Versuche und Besinnungen, Bd. 1. Göttingen ${ }^{6} 1970,190$.

${ }^{467}$ D. du Toit, Erneut auf der Suche nach Jesus. Eine kritische Bestandsaufnahme der Jesusforschung am Anfang des 21. Jahrhunderts, in: U.H.J. Körtner (Hg.), Jesus im 21. Jahrhundert: Bultmanns Jesusbuch und die heutige Jesusforschung, Neukirchen-Vluyn 2001, 91-134, 116. Anm. 106.
} 
kynisches Judentum) bezeichnen könnte "4668; und Geza Vermes, der seine Aufmerksamkeit insbesondere auf die Wunderhandlungen Jesu richtete, verstand diesen als einen jüdischen Charismatiker, als den "galiläische(n) Chassid oder heilige(n) Mann"“469. Es ist aber zu bezweifeln, ob man bei dem so in der Kontinuität mit dem Judentum verstandenen Jesus einen Sinn für die evangelische Theologie sowie den christlichen Glauben finden kann. Die Jesusforschung in der dritten Phase charakterisiert C. Danz darum als den ,programmatische(n) Verzicht auf theologische Fragen“ und erklärt dazu: „Ging es in der ersten Runde noch um die Erneuerung des Christentums durch den Mann aus Nazareth und in der zweiten um dessen dogmatische Konstruktion, so ist dieser Zugang zur Problemstellung in der dritten Runde obsolet geworden“. .70

Die Frage nach dem historischen Jesus, die in der ersten Phase durch die historisch-kritische Methode ins Zentrum der Theologie gerückt war, wurde in der zweiten Phase erneut durch die dogmatische Kontinuität gestellt, in der dritten wieder neu durch die jüdische Kontinuität und wahrscheinlich heute auch noch $n e u^{471}$.

\subsection{Sprache für die Integration historischer und dogmatischer Exegese in existentialer} Interpretation

Ebeling nimmt von Bultmann die anti-metaphysische Tendenz auf, ebenso wie die existentiale Interpretation, die bei Bultmann einer theologischen Auslegungsmethode diente. Ebeling stimmt deshalb grundsätzlich Bultmanns Intention und Motivation zu und lenkt seine Aufmerksamkeit gleich auf die Fragestellung, welchen Sinn es hat, von Gott zu reden. Er sagt: „Rede ich von Gott, so rede ich von der alles bestimmenden Wirklichkeit, also von der meine konkrete Existenz bestimmenden Macht ${ }^{\text {“ }}{ }^{472}$ Obwohl Ebeling äußert, Bultmann hätte in einigen Punkten deutlicher sein können, ${ }^{473}$ sieht er keinen Grund, auf die Hauptthese Bultmanns, dass das Reden von Gott das Reden von der Existenz des Menschen, ja von uns selbst bedeutet, zu verzichten. Wie für Bultmann gibt es für Ebeling keinen anderen Zugang zu Gott als den über die Betroffenheit der Existenz, weil jeder andere Zugang einen

\footnotetext{
${ }^{468}$ J.D. Crossan, Der historische Jesus, München ${ }^{2} 1995,533$.

${ }^{469}$ G. Vermes, Jesus der Jude. Ein Historiker liest die Evangelien, Neukirchen-Vluyn 1993, V.

${ }^{470}$ C. Danz., Grundprobleme der Christologie, Tübingen 2013, 34.

${ }^{471}$ Die eschatologische Deutung Jesu ist neu zur Sprache zu bringen, z.B. bei J. Schröter und J. Frey. Vgl. J. Schröter, Jesus von Nazareth. Jude aus Galiläa - Retter der Welt, Leipzig 2006; J. Frey, Der historische Jesus und der Christus der Evangelien, in: J. Schröter/R. Brucker (Hg.), Der historische Jesus. Tendenzen und Perspektiven der gegenwärtigen Forschung, Berlin/New York 2002, 273-336.

${ }^{472}$ WG II, 353.

${ }^{473}$ Ebeling stellt sich z.B. die Frage, ob Bultmann die Unterscheidung von „über Gott“ und „aus Gott“ richtig zum Ausdruck bringt, weil wer von etwas redet, seine Rede aus dem schöpfen muss, wovon er redet: „Nur dann kann er durch sein Reden auch dem andern das vermitteln, wovon er redet, ihm durch das Wort die Sache selbst mitteilen.“ WG II, 362.
} 
Standpunkt unabhängig von Gott voraussetzt und nach seiner Auffassung den „Rückzug von Gott auf den homo religiosus, von der Theologie auf die Anthropologie“ darstellt. ${ }^{474}$

Ebeling geht aber über Bultmanns existentiale Interpretation hinaus seinen eigenen Weg. Vor allem Bultmanns Entmythologisierungsprogramm sieht aus Ebelings Sicht für den christlichen Glauben gefährlich aus, weil der bestimmte Teil der biblischen und christlichen Sprachüberlieferung, der wirklich Wesentliches in sich enthält oder sich auf es bezieht, der willkürlichen Exklusion der Entmythologisierung zum Opfer fallen könnte. Ebeling stellt sich vor allem die Frage, ob eine existentiale Interpretation des Christusgeschehens die Bindung an etwas geschichtlich, objektiv Vorhandenes aufgeben muss. Um diese Frage zu beantworten, versucht er zuerst das Recht der Anwendung der historisch-kritischen Methode in der Theologie nachzuweisen, obwohl er dabei ihre Beschränkung auch nicht außer Betracht lässt; danach will er durch die sachgemäße Fragestellung nach dem historischen Jesus den Sinn der historischen Jesusforschung wiederherstellen, wobei er durch die hermeneutische Frage eine Brücke zwischen historischer und dogmatischer Untersuchung bauen will. Er lässt seine Sprachkonzeption dabei dem Geschichtsverständnis dienen, sodass er nicht nur die Möglichkeit der existentialen Interpretation, sondern auch ihre Grenze zeigt.

\subsubsection{Zum Recht der historisch-kritischen Methode}

Ebeling hält die Bibel als die Heilige Schrift für „die Urkunde des Glaubens“, weil sie „das Zeugnis der vorläufigen und der endgültigen Verkündigung Gottes“ und damit „die Quelle gegenwärtiger Verkündigung“ sowie „der maßgebende Text der Theologie“ ist. ${ }^{475}$ Bei ihm ist die Bibel aber auch ein überlieferter historischer Text und ruft die „historische Aufgabe“ hervor, den Text „,in seiner historischen Gegebenheit als geschehene Verkündigung“ zu verstehen. ${ }^{476}$ Weil das Verstehen der Bibel als eines historischen Textes für die gegenwärtige Verkündigung erforderlich ist, plädiert Ebeling für die Brauchbarkeit der Anwendung der historisch-kritischen Methode zur Interpretation der biblischen Texte. Über diese Brauchbarkeit hinaus geht er einen Schritt weiter und verteidigt die Notwendigkeit einerseits mit der Teilhabe der Theologie an der geistesgeschichtlichen Situation der Neuzeit; andererseits mit der rechten Aufnahme der reformatorischen Theologie.

Kirche und Theologie partizipieren, worauf Ebeling mit Recht hinweist, an „der geistesgeschichtlichen Situation der Neuzeit“, weshalb jedes Problem, das sie anrühren, sich ,in ein historisches“ verwandelt. ${ }^{477}$ Der Theologie fällt nun die Aufgabe zu, angesichts dieser geistesgeschichtlichen Situation der Neuzeit den christlichen Glauben zu verstehen, d.h. sich zu

\footnotetext{
${ }^{474}$ WG II, 352.

${ }^{475} \mathrm{WG}, 450$.

${ }^{476} \mathrm{WG}, 347$.

${ }^{477} \mathrm{WG}, 382$.
} 
bemühen „um ein Verstehen, an dem wir beteiligt sind als die, die wir sind, als Menschen der Neuzeit, als Menschen dieser ganz weltlich, ganz geschichtlich gewordenen Welt" und damit um ein Verstehen, „das kein gespaltenes Bewusstsein zulässt". ${ }^{478}$ Neben dieser aus der Situation erwachsenden Veranlassung zur historischen Arbeit nimmt Ebeling die Forderung notwendiger Aufnahme der reformatorischen Theologie in Anspruch: „Der Protestantismus hat sich im Prinzip für die historischkritische Methode entschieden und damit für den vorhin gekennzeichneten gefahrvollen Weg. Und er hat sich damit recht entscheiden. [...] Der des 19. Jahrhunderts hat durch die prinzipielle Entscheidung für die historisch-kritische Methode in veränderter Situation dem römischen Katholizismus gegenüber die reformatorische Entscheidung des 16. Jahrhunderts festgehalten und bekräftigt. " 479 Durch die Ausbildung der historisch-kritischen Methode gelangt man, laut Ebeling, viel besser zum rechten Verständnis „dessen, was die Aufgabe der Theologie im reformatorischen Sinne ist“" ${ }^{480}$ als durch altprotestantische Orthodoxie, die ohne Wissen um die historisch-kritische Methode die reformatorische Rechtfertigungslehre festzuhalten versucht, dabei jedoch nur „den Grundirrtum eines Traditionalismus“ verrät, „,der sich durch die reformatorische Theologie der eigenen verantwortlichen theologischen Arbeit enthoben glaubt"، ${ }^{481}$

Ebeling argumentiert weiter, die historisch-kritische Methode stehe vor allem in „einem tiefen inneren Sachzusammenhang mit der reformatorischen Rechtfertigungslehre“, 482 nämlich mit dem sola fide. Denn durch dieses werden alle Sicherungen der Vergegenwärtigung, die sich in „ontologischer, sakramentaler oder hierarchischer Art" vorfinden können, ausgeschlagen und ihrer Entscheidungskraft für den Glauben beraubt. Stattdessen wird ,im Sinne echt geschichtlicher, personaler Begegnung“, die sich im „Hören auf das Wort“ bzw. im Glauben allein ereignet, die Vergegenwärtigung verstanden. 483 Das sola fide enthält darum nicht nur die Ablehnung des „Offenbarungsdoketismus, der der Geschichtlichkeit der Offenbarung dadurch ausweicht, dass er sie zu einer Geschichte sui generis macht, von deren heiligem Raum die historisch-kritische Methode ängstlich ferngehalten werden muss ${ }^{6484}$, sondern auch die Entdeckung der echten Geschichtlichkeit von Offenbarung und Glauben sowie die Forderung auf die historisch-kritische Forschung. Der Glaube ist nun „der ganzen Anfechtbarkeit und Zweideutigkeit des Historischen preisgegeben“ und „das Ja zur Ungesicherheit“ ist als „die Kehrseite

\footnotetext{
${ }^{478}$ WG, 390. Vgl. E. Troeltsch, Über historische und dogmatische Methode der Theologie (1900), in: F. Voigt (Hg.), Ernst Troeltsch Lesebuch, Tübingen 2003, 2-25, 8: „So hat die historische Methode auch die Theologie ergriffen, erst schüchtern und fragmentarisch mit allerhand Vorbehalten und Einschränkungen, dann immer energischer und umfassender, bis sie auch hier bewirken musste, was sie überall sonst bewirkt hat, eine prinzipielle Veränderung der gesamten Denkweise und der ganzen Stellung zum Gegenstande.“

${ }^{479} \mathrm{WG}, 41$.

${ }^{480} \mathrm{WG}, 87$.

${ }^{481} \mathrm{WG}, 45$.

${ }^{482} \mathrm{WG}, 43 \mathrm{f}$.

${ }^{483} \mathrm{WG}, 44$.

${ }^{484} \mathrm{WG}, 45$.
} 
der Heilsgewissheit sola fide" zu verstehen. ${ }^{485}$ In diesem Sinne behauptet Ebeling, dass eine Theologie, die auf die historisch-kritische Methode anspricht, sich dann auch dem rechten Sinn der reformatorischen Rechtfertigungslehre bewusst ist.

Neben der Betonung eines solchen inneren Sachzusammenhangs zwischen der reformatorischen Rechtfertigungslehre und der historisch-kritischen Methode und neben dem Recht auf deren Anwendung zur Interpretation der Bibel, bringt Ebeling auch die Grenze der historischen Forschung zur Sprache. Diese Grenze besteht seiner Meinung nach darin, die Theologie im Glauben zu vollziehen und dem geschichtlichen und weltlichen Wirklichkeitsverständnis der neuzeitlichen Menschen zur Wahrheit gelangen zu helfen. ${ }^{486}$ Und sofern die historische Forschung der Wahrheit und dem Glauben dient, muss man laut Ebeling auf Folgendes achten: erstens, dass die Aufgabe der historischen Forschung nicht für eine statistische Sammlung toten Materials wie Geschichtsfakten gehalten werden soll; zweitens, dass die Forderung an die historische Forschung keinesfalls in der alles relativierenden Weise ausgeführt werden soll, wie der am Ende des 19. Jahrhunderts vorherrschende Historismus ,alle Normen und Werte hinein in einen grenzenlosen Relativismus“ $\operatorname{zog}^{487}$; letztlich, dass der Ruf zur historisch-kritischen Methode keineswegs als kritiklose Zustimmung mit der Geschichte der protestantischen Theologie verstanden werden soll, sondern mehr als kritische Auseinandersetzung mit ihr „im Sinne sachgemäßer Orientierung am reformatorischen Grundansatz“. ${ }^{488}$ Der historische Abstand muss immer im Blick des Auslegers behalten werden und als „kritisches Korrektiv des geschichtlichen Verstehens" wirken. ${ }^{489}$

Ebeling argumentiert weiter, für die rechte Anwendung der historisch-kritischen Methode sei auch die selbstkritische Haltung des Auslegers gegenüber seinen eigenen Vorurteilen nötig, weil „die unablässige kritische Selbstkorrektur zum Wesen der historisch-kritischen Methode“ gehöre. ${ }^{490} \mathrm{Er}$ behauptet darum, die historisch-kritische Methode als solche, die „das Ganze des hermeneutischen Prozesses in sich beschließt“", solle ausgeführt werden. ${ }^{491}$ Das heißt, die historische Interpretation vollzieht sich in einem hermeneutischen Zirkel, in dem es zu wechselseitiger Erhellung zwischen Text und Interpret kommt, nach Ebelings Darstellung: zur „geschichtlichen, personalen Begegnung mit dem

\footnotetext{
${ }^{485} \mathrm{WG}, 45$. Über die Geschichtlichkeit des Glaubens kann man weiter in Bezug auf Vergeschichtlichung und Verweltlichung nachdenken, denn eine starke Betonung auf die Geschichtlichkeit des Glaubens Gefahr hat, in radikaler Vergeschichtlichung zu geraten, die wieder als Verweltlichung verstanden werden könnte. Diesbezüglich behauptet Ebeling, man müsse aber darauf achten, die Vergeschichtlichung oder die Verweltlichung nicht einfach als gegen das Christentum gerichtet, bzw. als antichristlich zu bezeichnen, weil der Glaube geschichtsbezogen ist und weil die Welt für den Gott als ihren Schöpfer und Herrn bekennenden Glauben „entgöttert“ ist. WG, 390.

${ }^{486} \mathrm{WG}, 392$.

${ }^{487} \mathrm{WG}, 35$.

${ }^{488} \mathrm{WG}, 46$.

${ }^{489} \mathrm{WG}, 36$.

${ }^{490} \mathrm{WG}, 47$.

${ }^{491} \mathrm{WG}, 36$.
} 
Text ${ }^{\star 492}$. Er lässt dadurch die historisch-kritische Methode dem Prozess des Sich-Verstehens bzw. der Erfassung des Problems geschichtlichen Selbstverständnisses dienen.

Wenn die historisch-kritische Methode so zum Prozess des Selbstverständnisses beiträgt, richtet sich die historische Frage dann nicht auf den Tatsachenbegriff. Gegenüber dem historischen Geschichtsbegriff, der am Tatsachenbegriff orientiert ist, macht sich Ebeling zum Anwalt für den hermeneutischen Geschichtsbegriff, der sich am Wortgeschehen orientiert. Die Orientierung am Tatsachenbegriff impliziert, dass der historische Gegenstand nicht total, sondern nur teilweise in den Blick gerät, weil er von dem nur partiell beteiligten Historiker in den Blick genommen wird und führt zur Relativierung sowohl des historischen Gegenstandes als auch des Vorgangs der historischen Erfassung selbst. ${ }^{493}$ Die Wurzel dieses historischen Geschichtsverständnisses liegt laut Ebeling in einer „depravierten Auffassung von Wort: die Abstraktion von Wortgeschehen und die Reduktion auf den Aussagecharakter“. ${ }^{494}$ Weil die Wirklichkeit der menschlichen Existenz doch eigentlich in der Sprache vorkommt und dies Zur-Sprache-Kommen in bestimmten geschichtlichen Situationen entsteht, behauptet er, die historische Frage soll sich vielmehr, am Wortgeschehen und damit an der Sprachlichkeit der Wirklichkeit" orientieren. ${ }^{495}$ Ebeling bringt solcherweise die historische Frage in Zusammenhang mit der Frage nach dem Sprachereignis und argumentiert, die an der Sprachlichkeit der Wirklichkeit orientierte historische Arbeit könne das einmalige historische Geschehen über den zeitlichen Abstand neu zur Sprache bringen.

Das am Wortgeschehen orientierte Geschichtsverständnis erfordert historische Arbeit als hermeneutische Arbeit. In Hinsicht auf das historische Geschehen ist die sachgemäße Frage dann bei Ebeling nicht, was passiert ist, sondern: „Was ist zur Sprache gekommen?“496 Sie fragt vornehmlich in Hinsicht auf den historischen Jesus, nicht nach seinen biografischen Daten oder objektiven persönlichen Informationen, sondern danach, „was ist in Jesus zur Sprache gekommen“4497, um richtig zu verstehen, welche Bedeutung das Leben Jesu und sein Wirken in der Geschichte gewinnen.

\subsubsection{Zur Rückkehr zum historischen Jesus}

Bezüglich des historischen Jesus wird bei Ebeling, insbesondere in seinen frühen Schriften, eine vehemente Diskussion mit Bultmann gesehen und dabei das Verhältnis zwischen dem historischen Jesus

\footnotetext{
492 WG, 307.

493 WG, 306.

${ }^{494}$ WG, 307. Anm. 13.

495 WG, 307.

496 WG, 307.

497 WG, 308.
} 
und dem Glauben thematisiert. ${ }^{498}$ Bultmann hat eine gewissermaßen skeptische Meinung vom historischen Jesus und richtet sich darum gegen die Überzeugung der sog. liberalen Theologie des 19. Jahrhunderts, mit Hilfe der Leben-Jesu-Forschung hinter die dogmatische Einstellung Jesu in der christlichen Tradition zum reinen, historischen Jesus zurückzukehren. Ebeling ist jedoch unzufrieden mit der Auffassung Bultmanns von der Bedeutung des historischen Jesus für den Glauben, weil er grundsätzlich der Meinung ist, dass die Christologie ohne geschichtliche Anbindung in der Luft hängt, wenn zwischen dem historischen Jesus und dem verkündigten Christus keine sachliche Kontinuität besteht: „Jesus ist keine mythische, sondern eine geschichtliche Gestalt. Hätte Jesus nicht gelebt oder würde sich der Glaube an ihn als ein Missverständnis dessen erweisen, worum es dem historischen Jesus zu tun war, so würde offenbar dem christlichen Glauben der Boden entzogen. “499

Für diese sachliche Kontinuität muss zuallererst die sachgemäße Frage nach dem historischen Jesus gestellt werden. Ebeling formuliert sie so: „Was ist in Jesus zur Sprache gekommen?“500 Er behauptet, gerade auf diese Frage solle sich die Aufgabe der historischen Jesusforschung richten, weil sie zusammenfassend charakterisiere, „was in Verkündigung und Verhalten des historischen Jesus eine schlechthin Entscheidende und alles Bestimmende ist“. Seine eigene Antwort: „In Jesus ist der Glaube zur Sprache gekommen“. 501

Die Auffassung, dass in Jesus der Glaube zur Sprache gekommen ist, bedeutet bei Ebeling keinesfalls eine „psychologisierende“ Interpretation Jesu. ${ }^{502}$ Er will dadurch die sachliche Relevanz des historischen Jesus für den Glauben zeigen, genauer dass der historische Jesus der Jesus des Glaubens ist. Wenn man den historischen Jesus mit dem Jesus des Glaubens identifizieren will, besteht jedoch eine besondere Schwierigkeit in der Eigenschaft der vorhandenen Quellen, weil diese die Gestalt Jesu in der Reflexion des Osterglaubens und darin andersartig zu Worte kommen lassen. Und es wäre auch fraglich, wie sich der vorösterliche Jesus zu dem nachösterlichen Christus verhält. Angesichts solcher Schwierigkeiten stellt Ebeling seinen Gesichtspunkt fest, mit der Behauptung, die historische Forschung dürfe sich weder skeptisch gegen das Geschehen der Auferstehung Jesu richten, noch in der Feststellung der Diskontinuität zwischen dem vorösterlichen Jesus und dem nachösterlichen Christus stehenbleiben, sondern müsse sich darum bemühen, diese Diskontinuität zu verstehen und die darin

\footnotetext{
${ }^{498}$ Z.B. Jesus und Glaube (1958), Was heißt Glaube? (1958), Die Frage nach dem historischen Jesus und das Problem der Christologie(1959), Der Zeuge des Glaubens und der Grund des Glaubens(1959), Zwei Glaubensweisen (1961), und Theologie und Verkündigung (1962). Vor allem im letzteren Werk, wie im Untertitel „ein Gespräch mit Rudolf Bultmann“ angedeutet, versucht Ebeling sich mit Bultmann, der sich vertretend in $>$ Jesus $<$ (1926) und später zusammenfassend in der Abhandlung > Das Verhältnis der urchristlichen Christusbotschaft zum historischen Jesus $<(1960)$ äußert, auseinanderzusetzen.

${ }^{499}$ Wesen, 42.

${ }^{500} \mathrm{WG}, 308$.

${ }^{501} \mathrm{WG}, 308$

${ }^{502} \mathrm{WG}, 309$
} 
trotzdem wirksame Kontinuität zu finden, weil offensichtlich „ein geschichtlicher Zusammenhang zwischen Jesus und der Urgemeinde" bestehe. ${ }^{503}$

Ebeling argumentiert weiter, eher durch die Diskontinuität sei die sachliche Kontinuität zwischen dem historischen Jesus und dem geglaubten Christus vermittelt, weil das Glauben an Jesus gerade durch das Ostergeschehen entsteht ${ }^{504}$ und weil der Verkündiger mit Ostern zum Gegenstand der Verkündigung wird. Diese Wendung des Subjekts der Verkündigung zu ihrem Objekt erinnert uns an Bultmanns Frage: „Warum musste der Verkündiger zu Verkündigten werden?“505 Auf diese Frage sucht Ebeling in seiner eigenen Weise eine Antwort, indem er einerseits die von Bultmann unterbrochene Verbindung zwischen Verkündiger und Verkündigtem wiederherstellt und andererseits den Begriff des Glaubensgrundes, den W. Hermann vom Begriff des Glaubensinhalts unterscheidet, ${ }^{506}$ aufnimmt. Das Werden Jesu zum Verkündigten bedeutet für Ebeling keineswegs, zum bloßen Gegenstand der Verkündigung zu werden. Seine Meinung dazu ist diese: „In der Osterüberlieferung geht es darum, dass Jesus als der Zeuge des Glaubens zum Grund des Glaubens wurde“ und „die so Glaubenden“ werden als „Zeugen des Glaubens“ wieder zu „Zeugen Jesu“. ${ }^{507}$ Die Auferstehung Jesu ist laut ihm der Ort, an dem der historische Jesus zugleich eine kerygmatische Dimension erhält. Der Glaubensgrund verhindert nicht, Glaubenszeuge zu sein, sondern realisiert es. Das heißt, Jesus muss der Grund des Glaubens werden, um ganz und gar dessen Zeuge zu sein. Die Auferstehung ist darum nach Ebelings Darstellung als „das Zum-Ziel-Gekommensein“ ${ }^{\circ 50}$ des historischen Jesus als Glaubenszeugen zu bestimmen. Für diese Deutung Jesu als der Grund und Zeuge des Glaubens, benennt er den biblischen, prägnanten Sinn des „Anführers und Vollenders des Glaubens“ (Hebr. 12, 2). ${ }^{509}$ Ebeling lässt die Relevanz Jesu für den Glauben darin bestehen, dass Jesus der Zeuge und der Grund des Glaubens ist und beide eine Einheit bilden.

\footnotetext{
${ }^{503} \mathrm{WG}, 314$.

${ }^{504}$ Vgl. WG III, 301: Das Bekenntnis „Er ist auferstanden“ ist „Glaubensaussage über Jesus als Glaubensgrund“. ${ }^{505}$ R. Bultmann, Das Verhältnis der urchristlichen Christusbotschaft zum historischen Jesus, Heidelberg 1960, 23. Mit dieser Frage meint er hier nicht „die Frage nach der historischen Kontinuität“ oder „die Frage nach der Kausalität des historischen Vorgangs“, sondern nur „die Frage nach der inneren Notwendigkeit“ (23). Vom historischen Jesus ist nötig laut ihm nur „das ,Daß‘ seiner Geschichte“ (9).

${ }^{506} \mathrm{Vgl}$. W. Hermann behauptet, das, was nur für den Glauben wirklich ist, sei Glaubensinhalt und dies könne doch nicht der Glaubensgrund sein, also als das, was in der Anfechtung des Glaubens den Zweifel aushält: „Denn der um seine Existenz kämpfende Glaube muss etwas haben, was ihm als etwas Wirkliches sichtbar bleibt und ihn hält in den Momenten, wo er zum letzten greifen muss. Diesen Dienst kann ihm Christus in dem Glanze der Herrlichkeit, die der durch ihn erlöst Mensch sehen lernt, nicht leisten. Denn das als etwas Wirkliches sehen, heißt eben, in der Kraft des Glaubens stehen. Das ist Inhalt des Glaubens, aber nicht sein letzter Grund. Wenn wir es als solchen gebrauchen, so werden wir doch wieder dazu verleitet, etwas äußerlich anzunehmen, was uns innerlich fremd ist.“. Ders., Christus der Grund unseres Glaubens, in: ZThK 2 (1892), 232-273, 251.

507 WG, 314 .

${ }^{508}$ Wesen, 54.

${ }^{509} \mathrm{WG}, 317$.
} 
Wir müssen hier noch näher betrachten, was Ebeling mit den Begriffen des Zeugen und des Grundes des Glaubens meint: Er bezeichnet Jesus zuerst als Glaubenszeuge in dem Sinne, dass die ganze Existenz Jesu darauf abzielt, Glauben zu erwecken. Ebeling begründet hier die Verbindung von Jesus und Glauben „nicht im Reden Jesu über seinen eigenen Glauben“, sondern in seiner „Mitteilung des Glaubens“. ${ }^{510}$ Das heißt, Jesus ist „,der Zeuge des Glaubens im Dasein für andere“. ${ }^{511}$ Die Begegnung mit Jesus von Nazareth bedeutet darum nicht allein die Begegnung mit einer historischen Gestalt, die uns von ihrem Glauben berichtet, sondern die Begegnung mit dem Zeugen des Glaubens, der uns den Glauben mitteilt, sodass dieses Begegnungsgeschehen hier als Wortgeschehen zur Sprache kommen kann. ${ }^{512}$ Auch wenn der irdische Jesus so durch seine Verkündigung und sein Leben den Glauben schon erweckt, wird es erst durch seine gehorsame Hingabe am Kreuz und seine Auferstehung allen Menschen möglich, in seinen Glauben einzustimmen, damit Jesus zugleich zum Grund des Glaubens für alle wird.

Der Grund des Glaubens bedeutet bei Ebeling weder einen von außen gegebenen Beweis für den Glauben, noch „eine Stütze, die einen des Glaubens zum Teil enthöbe,“ bzw. ein „,vom Glauben dispensierendes Fundament“, sondern „das, was den Glauben Glauben sein lässt und den Glauben dabei erhält, dass er wirklich Glaube bleibt, worauf also der Glaube letztlich angewiesen ist." ${ }^{513}$ Der Glaubensgrund befindet sich darum nicht außerhalb, sondern innerhalb des Glaubens und ist untrennbar von dem Glauben selbst. Ebeling sagt, die Frage nach dem Grund des Glaubens sei keinesfalls „im Sinne einer dem Wesen des Glaubens fremden, ihn ganz oder zum Teil überflüssig machenden ,Begründung' zu verstehen, vielmehr gerade als Frage nach dem, was den Glauben zum Glauben macht, woraus also Glauben entsteht, was zum Glauben die Freiheit gibt und was den Glauben dabei erhält, reiner Glaube zu sein. “514 In diesem Sinne wäre der Grund des Glaubens einfach als Wort Gottes zu nennen. Dies dürfe aber, sagt Ebeling, nicht mit dem Begriff von Kerygma eingesetzt werden. Ebeling wendet die Frage nach dem Grund des Glaubens von dem Kerygma lieber zum historischen Jesus. Denn das Verständnis des Wortes Gottes ist, laut ihm „,von Verkündigung und Verhalten Jesu her zu erhellen“ und das Kerygma ist dahingehend zu interpretieren, „dass sein Charakter als Wort Gottes an der Berufung auf Jesus hängt“. ${ }^{515}$ Zum Voraussein Jesu vor dem Kerygma erklärt er weiter: „Explizites christologisches Kerygma hat seinen Grund im impliziten christologischen Kerygma, das die Person Jesu selbst ist. Explizites christologisches Kerygma kommt von daher, dass Jesus Gott konkret ansagt. Eben das bekennt das Kerygma und ist die Summe aller christologischen Prädikationen: Jesus - das Wort Gottes. In ihm ist Gott gekommen. Jesus hat Gott zum Verstehen gebracht. “" ${ }^{\text {516 }}$ Für

\footnotetext{
$510 \mathrm{WG}, 309 \mathrm{f}$.

${ }^{511} \mathrm{WG}, 309 \mathrm{f}$.

512 WG, 310.

513 WG, 317.

$514 \mathrm{ThV}, 32$.

515 ThV, 74.

516 ThV, 79f.
} 
Ebeling ist Jesus selbst das Ereignis des Wortes Gottes. Sein Argument, dass Jesus nicht als Gegenstand des Glaubens, sondern als dessen Zeuge und Grund betrachtet werden sollte, zielt letztlich darauf ab, „unmissverständlich zum Ausdruck zu bringen, dass die Zusammengehörigkeit von Jesus und Glauben im Wortgeschehen gründet". 517

Durch seine Annahme, dass in Jesus der Glaube zur Sprache gekommen ist, distanziert sich Ebeling von Bultmanns kritischer Einstellung zur historischen Jesusforschung und lehnt es ab, Jesus auf ein bloßes „Dass“, nämlich auf ein „zur bloßen Historizität abstrahiertes Faktum“ zu reduzieren. ${ }^{518}$ Die Untersuchung über Jesus hat laut Ebeling umfassend mit Jesu „Reden, Tun und Verhalten“ zu tun und ist dahingehend zu befragen, wie sie „zum Glauben herausforderte“ ${ }^{519}$ Denn in Bezug auf den Glauben sind die Worte Jesu untrennbar von der Person Jesu selbst. Die Einheit von Wort und Person Jesu besteht darin, „dass er selbst für die Wahrheit dessen, was er sagt, eintritt, dass er in seiner Person selber das ist, was er in seinem Wort ausspricht, dass er sich selbst darin darstellt“ ${ }^{520}$ Als Beispiel dafür nennt Ebeling Jesu Sprachebrauch des ó $\mu \eta v$. Dies zeigt, wie „Jesus sein Reden verstanden hat und verstanden wissen wollte“, nämlich ,als ein Reden vor Gott, bei dem Gott selbst Garant dieses Redens ist, der über der Bewahrheitung dieses Wortes wacht, d.h. dafür eintritt, dass es geschieht“. Das Amen bedeutet dann „die Wahrheit und Wirklichkeit Gottes“. ${ }^{521}$ Und wenn Jesus das Amen sagt, bedeutet es nicht nur eine Bejahung, sondern dass er selber dabei sich Gott ausliefert. Jesu Gebrauch des Amens zeigt deshalb, dass er „sich selbst ganz mit seinen Worten identifiziert“, und dass er sich in dieser Identifikation „der Wirklichkeit Gottes preisgibt" und seine Existenz darin begründet, ,dass Gott dieses Wort wahr macht und wirklich sein lässt““. ${ }^{522}$ Das heißt, im Amengebrauch Jesu kommt zum Ausdruck, dass er Gott als Garanten für die Wahrheit und Wirklichkeit seiner Worte versteht, und auch, dass er durch diese Garantie Gottes die Gewissheit seiner Existenz gewinnt und selbst zur Gewissheit für andere wird. ${ }^{523}$ Ebeling spricht darum nicht von dem Kerygma, das er tatsächlich nur in der Auseinandersetzung mit Bultmann einführt, sondern eigentlich von dem Wortgeschehen in der Person Jesus. Jesus bringt nicht nur durch seine Verkündigung, sondern auch durch sein Verhalten, also durch sein ganzes Leben die Wirklichkeit so zur Sprache, dass er selber das Sprachereignis ist.

Zum Schluss sei noch Folgendes zu erwähnen: die erneute Frage nach dem historischen Jesus und danach, was in Jesus selbst zur Sprache gekommen ist, beschert Ebeling einen hermeneutischen Ansatz für die historische Jesusforschung. Er versucht dadurch den Horizont der Debatte um den historischen

\footnotetext{
${ }^{517} \mathrm{ThV}, 124$.

${ }^{518} \mathrm{ThV}$, 68. Vgl. R. Bultmann, Das Verhältnis der urchristlichen Christusbotschaft zum historischen Jesus, Heidelberg 1960, 9 ff.

${ }^{519} \mathrm{WG}, 242$.

${ }^{520}$ DG II, 471.

${ }^{521} \mathrm{WG}, 244$.

522 WG, $244 \mathrm{f}$.

${ }^{523} \mathrm{WG}, 203-254,317$.
} 
Jesusforschung vom „bloßen Dass“ auf die umfassende Untersuchung über Jesus zu erweitern. Gleichzeitig baut er seine Argumentation über diese Frage zur Feststellung der sachlichen Relevanz des historischen Jesus für den Glauben und zur Bestimmung Jesu als Zeugen und Grund des Glaubens aus. Er will solcherweise den historischen Jesus in das dogmatische Christusbild miteinbeziehen. Das bedeutet, dass Ebeling den Sinn der historischen Forschung in der sachlichen Bezogenheit auf die dogmatische Theologie findet und diese die historische Frage in sich aufnehmen lässt, was wieder auf das Gebiet der Hermeneutik führt. Bei ihm geht es in der Frage nach dem historischen Jesus nun „um den hermeneutischen Schlüssel zur Christologie“. ${ }^{524}$ Ebeling folgert darum, dass die Frage nach dem historischen Jesus und das Problem der Christologie miteinander verbunden sind und dass Jesus selbst für die Christologie „konstitutiv“ ist. ${ }^{525}$ Mit der Betonung auf diese konstitutive Beziehung bringt Ebeling sogar die folgende radikale Alternative zum Ausdruck: „Entweder zerstört die Frage nach dem historischen Jesus die Christologie, oder aber die Frage nach dem historischen Jesus muss sich als identisch erweisen mit dem christologischen Problem - tertium non datur.“ 526

\subsubsection{Zur Möglichkeit und Grenze der existentialen Interpretation}

Die eigentliche Aufgabe der existentialen Interpretation liegt daran, die biblische Botschaft in das Verständnis des heutigen Menschen zu übersetzen. So wie bei Bultmann sind auch bei Ebeling die biblischen Aussagen als Ausdruck des menschlichen Selbstverständnisses der existentialen Interpretation zugänglich. Die existentiale Interpretation gilt darum bei beiden als Mittel zur Auslegung der biblischen Texte. Bultmann versucht mithilfe der existentialen Interpretation, die in der Bibel enthaltene und doch mit Mythos bedeckte Christusbotschaft aufzudecken und dadurch den christlichen Glauben auf den Glauben an das Christuskerygma zurückzuführen. Ebeling ist hingegen der Auffassung, dass die kerygmatischen bzw. christologischen Geschehen nicht allein durch die existentiale Interpretation, sondern erst durch die Anwendung auf den historischen Jesus zu unverwechselbaren Aussagen würden. Um den Bezug der kerygmatischen Aussagen auf Jesus bzw. seine historische Erscheinung als notwendig nachzuweisen, führt er als Gründe an: erstens, dass „,die Eindeutigkeit der christologischen Aussagen“ gerade daran hängt, „als auf Jesus bezogene Aussagen“ verstanden zu werden; und zweitens, dass „die Verständlichkeit christologischer Aussagen“ an ihrer entstehungsgeschichtlichen Notwendigkeit hängt, nämlich „,an der Qualifizierung der Situation als kerygmatischer", aus der heraus sie entstanden. ${ }^{527}$ Die Frage nach dem historischen Jesus ist deswegen für Ebeling theologisch notwendig, weil gegenüber dem historischen Denken der Neuzeit eine Pflicht

\footnotetext{
$524 \mathrm{ThV}, 52$.

$525 \mathrm{WG}, 300$.

$526 \mathrm{WG}, 302$.

$527 \mathrm{ThV}, 51$.
} 
des Theologen steht, ,historische Phänomene als historische“ ernst zu nehmen ${ }^{528}$; und weil anhand des Begriffs des auf den Namen Jesus (bzw. seine Person) konzentrierten Kerygmas die Interpretationsaufgabe fordert, nach dem Anhalt der „kerygmatischen Aussagen über ihn“ bzw. des „,in ihnen explizierte(n) Glaube(n) an ihn“" am historischen Jesus selbst zu fragen, um klar zu machen, dass es sich bei diesen Aussagen nicht um Symbol, Mythos oder Idee handelt. ${ }^{529}$ In diesem Sinne sagt er, dass die christologischen Aussagen nur dann zu verantworten sind, wenn sie weiter interpretieren, was in dem historischen Jesus zur Sprache gekommen ist. Und gerade das ist der Glaube, weil bei dem historischen Jesus sich Person und Werk „in ein Einziges“ konzentriert haben, eben in den Glauben. ${ }^{530}$ Um das Christuskerygma auf den historischen Jesus zu gründen, richtet Ebeling seine Aufmerksamkeit deshalb auf die sachliche Relevanz des historischen Jesus für den Glauben, wie oben aufgezeigt, indem er Jesus als Zeugen und Grund des Glaubens bestimmt und damit den historischen Jesus in das dogmatische Christusbild einbezieht.

Diese Begründung des Christuskerygmas in dem historischen Jesus hängt bei Ebeling aber vor allem mit seinem Verständnis der Sprache bzw. des Wortes zusammen. Im Unterschied zu Bultmanns Auffassung, dass Sprache keinem statischen, sondern einem ständig veränderten System unterworfen ist, sieht Ebeling in dem Wort nicht mehr den unvollkommenen Ausdruck eines existentiellen Geschehens, das sich in sprachloser Tiefe vollzieht. Er ist der Meinung, dass die Wirklichkeit der menschlichen Existenz in der Sprache hervorkommt und sich dieses Zur-Sprache-Kommen in konkreten geschichtlichen Situationen ereignet. Angesichts historischer Geschehen muss man darum nicht fragen, was in ihnen tatsächlich passiert ist, sondern danach, was in ihnen zur Sprache gekommen ist. Ebeling bringt dadurch den bei Bultmann unzureichend bedachten Sachverhalt zur Geltung, dass alles Verstehen des Menschen in seiner Vorprägung durch die vorgegebene Sprachtradition sprachlich ausgerichtet ist.

An diesem Sachverhalt ist aber nicht nur die Möglichkeit, sondern auch die Grenze der existentialen Interpretation zur Sprache zu bringen. Denn die positive Einbeziehung der Geschichte und der Sprache in den Bereich der Existenz ist in ihrem Resultat ambivalent: einerseits löst sie dadurch eine gewisse Enge der existentialen Interpretation, andererseits dehnt sie die Herrschaft der existentialen Interpretation auf die anderen Bereiche aus, die doch als eigenständige Bereiche anerkannt werden können. Da stellt sich aber die Frage, ob solche ausgedehnte Arbeit unten die Kategorie der existentialen Interpretation fällt. Auch wenn solche Ausdehnung als ein Teil der existentialen Interpretation akzeptabel wäre, würde doch die Frage bleiben, ob Ebeling die Grenze der existentialen Interpretation tatsächlich überwindet, also ob durch die Einbeziehung der Geschichte in den Bereich der Existenz

\footnotetext{
$528 \mathrm{ThV}, 61$.

529 ThV, 63f.

${ }^{530} \mathrm{WG}, 310$.
} 
seine existentiale Interpretation nicht mehr Gefahr liefe, den Horizont der biblischen Aussagen zu verkürzen.

In der Rückkehr Ebelings zum historischen Jesus findet man die Absicht, durch die hermeneutische Fragestellung historische und dogmatische Arbeit zu verbinden damit dem modernen Menschen einen Platz in der Christologie zu geben. Für Ebeling bleibt die existentiale Interpretation nicht mehr in der Kategorie der biblischen Theologie, sondern sie zielt darauf ab, als Übersetzung biblischer Aussagen in das heutige Verständnis, aus heutigem Verständnis heraus die Christologie systematisch zu entfalten. Das bedeutet, der Auslegungsvorgang endet erst in der systematischen Theologie. Ebelings Ausführung verbreitet dadurch den Horizont der existentialen Interpretation und scheint jedoch weit über ihre Kategorie als eine Auslegungsmethode der biblischen Texte hinaus zu gehen. Wenn das moderne Subjekt überdies seinen Platz in der Christologie einnähme und ein Interpret so aus seiner eigenen Situation heraus die „Christologie als sachgemäße Weise des Redens“ nachvollziehen könnte, ${ }^{531}$ bestünde noch eine Gefahr, auf die K. Reinhardt mit Recht hinweist: dass der Interpret die historische Eigenständigkeit der Texte missachten, sie in der existentiellen Anwendung umdeuten und damit die Bibel ohne Weiteres in seinem eigenen System einschränken könnte. ${ }^{532}$

Die Möglichkeit und die Grenze der existentialen Interpretation kommen bei Ebeling noch genauer in Bezug auf den Geschichtsbegriff zur Sprache. Z.B. stellt sich J. Moltmann in seiner Anfrage und Kritik zu Ebelings $>$ Theologie und Verkündigung $<$ gegen dessen Auffassung, am Begriff des Sprachereignisses die Geschichte $\mathrm{zu}$ betrachten, und befürchtet dabei eine Auflösung des Tatsachenbegriffes: „Das historisch-kritische Tatsachendenken lässt sich nicht in die Hermeneutik von Wortgeschehen und Überlieferung aufnehmen, denn es bemüht sich gerade um die Tatsachen, abgesehen von den Überlieferungen, in denen sie zu Wort kommen. “533 Moltmann scheint hier den konstitutiven Zusammenhang von Sprache und Tatsachenwirklichkeit im Begriff des Wortgeschehens bei Ebeling zu verkennen. Für diesen muss die Ausrichtung auf Faktisches verbindlich bleiben, so wie die historische Frage nach Jesus auf die Tatsächlichkeit von Jesu Verhalten ausgerichtet ist. Von einer Suspension der kritischen Frage nach historischen Tatsachen ist darum bei Ebeling keine Rede. Eine sachgemäße Kritik gegen Ebeling ist vielmehr am Begriff der Geschichtlichkeit zu üben. Denn auch wenn der Begriff des Wortgeschehens und die daran orientierte existentiale Interpretation historische Tatsachen voraussetzt, geht es bei Ebeling, streng genommen, nicht um den Begriff der Geschichte, sondern um den der Geschichtlichkeit.

\footnotetext{
531 ThV, 50.

${ }^{532}$ K. Reinhardt, Der dogmatische Schriftgebrauch in der katholischen und protestantischen Christologie von der Aufklärung bis zur Gegenwart, München u.a. 1970, 296.

${ }^{533}$ J. Moltmann, Anfrage und Kritik zu Gerhard Ebelings Theologie und Verkündigung, EvTh 24, 1964, 25-34, bes. $26 f$.
} 
Die Geschichtlichkeit, die Heidegger als umfassende Seinsweise der menschlichen Existenz bezeichnet, bedeutet das auf der Zeitlichkeit der Existenz basierende Verhältnis zur Geschichte. ${ }^{534}$ Wenn Ebeling von historischen Tatsachen redet, legt er den Akzent immer auf ihre Beziehung zur Existenz des Menschen, also auf die Auffassung der Geschichte als „Menschheitsgeschehen“535. Damit meint er, dass der Mensch nicht nur „ein bloßer Faktor in einem mechanischen Kausalzusammenhang“ ist, sondern ein „selbständiges Glied in einem Verantwortungszusammenhang“ oder „eine Stimme in einem Sprachzusammenhang, ein Zeuge in einem Überlieferungsgeschehen, in dem sich je und je Unableitbares ursprunghaft ereignet" ${ }^{536}$ Er gibt dadurch dem Menschen die Rolle als das Sinngebende in einem Überlieferungszusammenhang. Sprache dient dabei als das „Medium der Geschichtlichkeit des Menschen “537, das die geschichtliche Begegnung der Wirklichkeit für den Menschen ermöglicht. Dass Gottes Wort dem Menschen geschichtlich begegnet, bedeutet nun, dass es ihn in der Existentialstruktur seiner Geschichtlichkeit bzw. in seiner Sprachlichkeit betrifft.

Hier ist aber noch eine grundlegende Frage zu stellen, ob das Problem der Geschichtlichkeit mit dem der Geschichte zusammenfällt. Hinsichtlich dieser Frage stellt sich G. Eichholz der Auseinandersetzung mit Ebeling und argumentiert: „Der Horizont der existentialen Interpretation nimmt den Horizont der biblischen Aussage nur begrenzt auf, der nicht nur ein Horizont des Verstehens, sondern auch des Geschehens ist. Was spielt für den Ansatz beim Glauben Jesu das ,eschatologische Treuegeschehen Gottes' für eine Rolle? Sowohl der biblische Begriff des Eschatologischen, der einen umfassenden Zusammenhang von Geschichte voraussetzt, wie der Begriff der Treue Gottes übersteigen den Horizont der existentialen Aussage, gehören aber wieder mit der Wirklichkeit der Geschichte Jesu von Nazareth als der Wirklichkeit des Handelns Gottes extra me/pro me zusammen." ${ }^{\text {538 }}$ Er ordnet hier den Begriff der Geschichte dem der Existenz über, weil der Mensch nicht anders als ,in der Geschichte“ existiert. Eichholz widersetzt sich darum Ebelings Betrachtungsweise, die Geschichte in den Bereich der Existenz einzubeziehen, weil biblischer Gehalt dabei verloren werden könnte. ${ }^{539}$ In diesem Sinne bleibt bei Ebeling dann noch die typische kritische Frage nach der Grenze der existentialen Interpretation, ob deren Horizont den der biblischen Aussagen in eine Beschränkung führt.

\section{Sprache und Verkündigung}

\footnotetext{
${ }^{534}$ Vgl. M. Heidegger, SZ, 379.

535 WG III, 289.

536 WG III, 289f.

${ }^{537}$ WG II, 200.

${ }^{538}$ G. Eichholz, Die Grenze der existentialen Interpretation, in: EvTh 22 (1962), 565-579. 579. Anm. 7.

${ }^{539}$ G. Eichholz, Die Grenze der existentialen Interpretation, in: EvTh 22 (1962), 565-579. 579.
} 
Aus den bisherigen Ausführungen zur Auslegung ist deutlich geworden, dass Ebeling versucht, durch die Sprachlichkeit der Wirklichkeit und den Begriff des Wortgeschehens historische und dogmatische Exegese in der Kategorie der existentialen Interpretation zu verbinden, obwohl es noch fraglich bleibt, ob er tatsächlich die Grenze der existentialen Interpretation überwindet. Er will sich dadurch von Bultmann und dessen existentialer Interpretation absetzen. Der entscheidende Abstand zu ihm wird aber klarer mit dem Begriff der Verkündigung, so dass diese als eine wichtige Kennzeichnung der neuen Hermeneutik benannt wird.

Der Begriff der Verkündigung kommt eigentlich aus dem Neuen Testament, das vielfach von den Verkündigungen Jesu und seiner Jünger berichtet. In neuerer Zeit steht es in erster Linie für das Zeugnis der Kirche im Dienst am Wort Gottes, nämlich für den Predigtdienst der Kirche. Wenn es um den Begriff der Verkündigung geht, betrifft er nicht nur die Predigt, sondern jede Weise, die Sache des Glaubens weiterzusagen, so wie Ebeling selber sagt, die Predigt sei nur „eine von vielen Möglichkeiten“, „wie das Wort Gottes in rein verbaler Gestalt ergeht “ ${ }^{540}$ Er richtet seine Aufmerksamkeit trotzdem zuallererst auf den an der kirchlichen Predigt angeschlossenen Verkündigungsbegriff und beschäftigt sich stark mit ihm. Um den so gefassten Verkündigungsbegriff und dessen Verhältnis mit seinem Sprachkonzept handelt es sich in diesem Abschnitt.

\subsection{Verkündigung als fundamentale Ausrichtung der theologischen Hermeneutik}

Weil das Thema der Predigt üblich in das Gebiet der praktischen Theologie fällt, scheint es wohl ungewöhnlich, sie als eine wichtige Kennzeichnung der Theologie Ebelings, immerhin systematischer Theologe, zu bestimmen. Jedoch stößt man in seinen Arbeiten tatsächlich sehr häufig auf Äußerungen über die Predigt ${ }^{51}$ und auch in den Untersuchungen der gegenwärtigen Homiletik nicht selten auf die Rede von seinem Beitrag zur Predigtlehre ${ }^{542}$. Ebeling hat gewiss ein großes Interesse an der Predigt. Für dieses Interesse ist, nach der Meinung von W. Jetter, zuallererst der Einfluss von seinen Lehrern Bultmann und Brunner zu nennen und dazu noch vielleicht eine ferne Wirkung Barths und die nahe

\footnotetext{
${ }^{540}$ D III, 296.

${ }^{541}$ Es gibt zunächst der Aufsatz „Fundamentaltheologische Erwägungen zur Predigt“ in: WG III, Tübingen 1975, 554-573. Dazu sind andere Beiträge zur Ekklesiologie in WG III für das Thema der Predigt zu nennen, z.B. „Das Grund-Geschehen von Kirche“ (463-467); „Der Theologe und sein Amt in der Kirche“ (522-532) und „Die Notwendigkeit des christlichen Gottesdienstes“ (533-553). Die Publikation >Theologie und Verkündigung< (1961), vornehmlich die zwei Aufsätze „Die Spannung zwischen , wissenschaftlicher` Theologie und ,kirchlicher` Verkündigung“(1-9) und „Leitsätzen zur Ekklesiologie“ (93-103) müssen ebenfalls berücksichtigt werden.

${ }^{542} \mathrm{Vgl}$. H. Hirschler, In welchem Sinne hilft Ebelings Dogmatik dem Prediger heute?, in: ZThK 78 (1981), 491513; W. Jetter, Redliche Rede vor Gott - über den Zusammenhang zwischen Predigt und Gebet. Eine Erinnerung an Gerhard Ebelings Beitrag zur Predigtlehre, in: E. Jüngel u.a. (Hg.), Verifikationen. Festschrift für Gerhard Ebeling zum 70. Geburtstag, Tübingen 1982, 385-424; H. M. Müller, Homiletik. Eine evangelische Predigtlehre, Berlin/New York 1996.
} 
Begegnung mit Bonhoeffer. ${ }^{543}$ Sein Interesse an der Predigt würde wohl auch durch seinen Pfarrdienst in der Bekenntnisgemeinde Berlin-Hermsdorf verstärkt.

Wenn man vom Thema der Predigt bei Ebeling reden will, muss man dabei immer im Kopf haben, dass sie nicht isoliert betrachtet werden darf. Das heißt, Ebeling sieht die Predigt als ein Teilgebiet der Hermeneutik, die bei ihm die Möglichkeit des Kommens des Wortes Gottes zur menschlichen Sprache voraussetzt. Er bestimmt den Ort der Predigt in der hermeneutischen Bewegung, „die vom Text der Heiligen Schrift zur Predigt führt ${ }^{\star 544}$. Das ist der Grund, warum die Predigt als die dritte Aufgabe der Hermeneutik Ebelings in dieses Kapitel eingeordnet wird. In der Hermeneutik Ebelings spielt die Verkündigung bzw. Predigt eine wichtige Rolle. Sie soll sowohl den Horizont der Hermeneutik auf eine praktische Ebene erweitern, als auch gegenüber der allgemeinen Hermeneutik als der „Lehre vom Wort“ die Eigenschaft der theologische Hermeneutik als der „Lehre vom Wort Gottes“ zeigen. ${ }^{545}$ Über die Gewicht der Verkündigung für die theologische Hermeneutik schreibt Ebeling in seinem Beitrag für den Sammelband >Die neue Hermeneutik< (1965): „Das Problem theologischer Hermeneutik wäre nicht erfasst ohne Einbeziehung der Verkündigungsaufgabe; es erhält dadurch überhaupt erst seine entscheidende Zuspitzung [...], weil auf die biblischen Texte nicht richtig gehört wäre, wenn nicht die Aufgabe der Verkündigung in den Blick käme." “546

Ferner sei auch darauf geachtet, dass es bei Ebeling um die elementare Sache der Predigt geht. So bezeichnet er seine Vorstellungen der Predigt als „Fundamentaltheologische Erwägungen zur Predigt" im Unterschied zur praktischen Theologie folgendermaßen: „Dass im übrigen die Fundamentaltheologie nicht etwa der Praktischen Theologie die Predigtlehre abnehmen will, ergibt sich schon daraus, dass für sie die Predigt stets nur als das besonders aufschlussreiche Modell eines Sachverhalts in Betracht kommt, der mutatis mutandis den gesamten Lebensbereich christlichen Glaubens bestimmt.“ ${ }^{547}$ Des Weiteren stellt er dar, dass es um die „elementare Besinnung auf verantwortliches Reden von Gott“" gehe. ${ }^{548}$ Er beschäftigt sich mit der elementaren Besinnung auf die Predigt und entwickelt sie in der Kategorie der Fundamentaltheologie, die immer mit der grundlegenden Frage zu tun hat, wie alles dem Glauben gemäß auf Gott bezogen ist. Darin, dass es bei Ebeling um diese fundamentaltheologischen Erwägungen zur Predigt nicht nur „,vor allem“, sondern auch ,in allem“ geht, findet W. Jetter das Spezifische Ebelings und erklärt, dass das besondere Profil seines

\footnotetext{
${ }^{543} \mathrm{~W}$. Jetter, Redliche Rede vor Gott - über den Zusammenhang zwischen Predigt und Gebet. Eine Erinnerung an Gerhard Ebelings Beitrag zur Predigtlehre, in: E. Jüngel u.a. (Hg.), Verifikationen. Festschrift für Gerhard Ebeling zum 70. Geburtstag, Tübingen 1982, 385-424, 396.

${ }^{544} \mathrm{WG}, 326$.

${ }^{545} \mathrm{WG}, 338$.

${ }^{546}$ Ebeling, Wort Gottes und Hermeneutik, in: J.M. Robinson/J.B. Cobb (Hg.), Die neue Hermeneutik, Zürich $1965,109-146,143$.

${ }^{547}$ WG III, 567.

${ }^{548} \mathrm{WG}, 349$.
} 
Beitrags zum evangelischen Predigtverständnis vom „beharrlichen Insistieren auf das Elementare“ und „vom unablässigen Drängen auf ebenso gründliche wie redliche fundamentaltheologische Rechenschaft" geprägt ist. ${ }^{549}$

Unter den oben aufgezeigten Grundkennzeichnungen geht es nun im Folgenden darum, wie Ebeling den Begriff der Verkündigung verwendet und worauf er dabei den Akzent legt, wenn er sie jeweils der Theologie und der Kirche gegenüberstellt.

\subsubsection{Verkündigung und Theologie}

Ebeling thematisiert das Spannungsverhältnis von Theologie und Verkündigung zunächst in der Publikation mit dem Titel > Theologie und Verkündigung $<$, in der er kurz und bündig formuliert: „Theologie ohne Verkündigung ist leer und Verkündigung ohne Theologie ist blind. ${ }^{“ 550}$ Dieser kurze Satz zeigt ganz deutlich, dass sich beide eng aufeinander beziehen. Über diese enge Beziehung sagt Ebeling zweierlei: erstens, dass die Theologie mit der Verkündigung am Verantworten des Wortes Gottes teilhat, und zweitens, dass die von der Theologie wahrzunehmende Verantwortung einen geschichtlichen Charakter hat und dieser der Geschichtlichkeit der Verkündigung entspricht. Ebeling setzt beide aber nicht gleich, sondern unterscheidet sie durch ihre Ortsbestimmung, nämlich indem er die Theologie in die Wissenschaft und die Verkündigung in die Kirche einordnet. Er bezeichnet dementsprechend die Verkündigung ,als Vollzug von Kirche“ und die Theologie ,als Vollzug von Wissenschaft“ ${ }^{551}$ Er erklärt, dass der Unterschied von ihnen darin besteht, dass die Theologie „in kritischer Reflexion allgemein und insofern abstrakt und uneigentlich sagt, was nur als in konkreter Situation gesagt und gehört zu seiner eigentlichen Wahrheit kommt, aber um dieser konkreten Weise der Verantwortung willen der Frage theologischer Verantwortbarkeit ausgesetzt werden muss “ ${ }^{552}$ Diese unterschiedliche Ortsbestimmung muss ihre Grenze für die „Sachidentität von Theologie und Verkündigung“" halten. 553

Unter der Voraussetzung solcher Gemeinsamkeit und Unterschiedlichkeit hat Ebeling die Betonung auf einen Zusammenhang von der theologisch-wissenschaftlichen Aufgabe und der kirchlichen Verkündigungsaufgabe gelegt. Die der Aufgabe der Theologie kann schließlich durch den Dienst der Verkündigung erfüllt werden. Umgekehrt ist für die Verkündigung als das „homologische Reden von Gott“ „die Rechenschaft disziplinierten Denkens darüber, also wissenschaftliche

\footnotetext{
${ }^{549}$ W. Jetter, Redliche Rede vor Gott - über den Zusammenhang zwischen Predigt und Gebet. Eine Erinnerung an Gerhard Ebelings Beitrag zur Predigtlehre, in: E. Jüngel u.a. (Hg.), Verifikationen. Festschrift für Gerhard Ebeling zum 70. Geburtstag, Tübingen 1982, 385-424, 399.

$550 \mathrm{ThV}, 9$.

${ }^{551} \mathrm{ThV}, 9$.

$552 \mathrm{WG}, 455$.

${ }^{553} \mathrm{ThV}, 9$.
} 
Theologie“ erforderlich. ${ }^{554}$ Dieses wechselseitige Verhältnis von beiden bringt er so kurz zum Ausdruck: Die Sache der Theologie findet ihren ,eigentlichen Ernstfall“ am Ort der Verkündigung und diese dient zum „Kriterium der Theologie“. 555 Eine derartige Vorstellung des Zusammenhangs von Theologie und Verkündigung findet man sehr häufig bei Ebeling. Beispielsweise stellt er die untrennbare faktische Beziehung von beiden in einem Artikel über "Theologie“ in RGG wie folgt dar: „wo das Verkündigungsgeschehen auf seine Geschichtlichkeit hin verantwortet wird, [...] da stößt man faktisch auf das Phänomen der theologischer Sprachgestalt. “556 Aus Anlass dieser Beziehung behauptet er, die Aufgabe der Theologie bestehe darin, „um der Sache des christlichen Glaubens willen das Sicheinlassen der Verkündigung auf die Geschichtlichkeit zu bedenken, damit neuer geschichtlicher Situation gegenüber im Hören auf überlieferte Sprache in rechter Weise Sprache gewonnen wird, aber auch gewonnene Sprache um der Verkündigung willen nicht für die Sache selbst gehalten wird. “557 Das heißt, in Bezug auf die Verkündigung hat die Theologie die ambivalente Aufgabe, einerseits darüber nachzudenken, wie Verkündigung in je neuer theologischer Sprachgestalt verantwortet werden muss, und andererseits dafür zu sorgen, dass die jeweilige Sprache der Verkündigung nicht mit deren Sache verwechselt wird.

Wenn Ebeling „Diskussionsthesen für eine Vorlesung zur Einführung in das Studium der Theologie“ vorschlägt, ${ }^{558}$ redet er sogar von einer Notwendigkeit der Theologie im Verhältnis zur Verkündigung bzw. Predigt: „Theologie ist notwendig, um dem Prediger das Predigen so schwer wie nötig zu machen. ${ }^{\text {“559 }}$ Er bringt gleichermaßen eine Schwierigkeit wie Notwendigkeit zum Predigen und auch eine darauf bezogene Notwendigkeit der Theologie zur Sprache. Anders gesagt, die Theologie ist notwendig ,als Hermeneutik des Glaubens“ ${ }^{\text {560 }}$ und diese Notwendigkeit hat doch nicht mit der Schwierigkeit der Bibeltexte selbst, sondern mit der ihrer Verkündigung als Wort Gottes zu tun. Diesen Sachverhalt bringt Ebeling noch mal stärker zum Ausdruck: „Die Theologie ist nur insoweit notwendig,

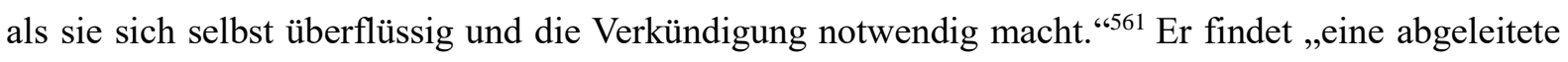
Notwendigkeit der Theologie“ gerade in ihrer Beziehung zur Verkündigung und bezeichnet die Theologie sogar als „Sprachschule der Verkündigung“ ${ }^{562}$.

Durch solche Betonung auf den engen Zusammenhang von Theologie und Verkündigung scheint Ebeling die Entfernung der Theologie von der Verkündigung und damit von der Kirche zu vermeiden,

\footnotetext{
${ }^{554}$ Ebeling, Art. Theologie I. Begriffsgeschichtlich, in: RGG ${ }^{3}$ VI (1962), 754-769, 759.

${ }^{555}$ Ebeling, Vom Gebet. Predigten über das Unser-Vater, Tübingen 1963, 6.

${ }^{556}$ Ebeling, Art. Theologie I. Begriffsgeschichtlich, in: RGG $^{3}$ VI (1962), 754-769, 761.

${ }^{557}$ Ebeling, Art. Theologie I. Begriffsgeschichtlich, in: RGG ${ }^{3}$ VI (1962), 754-769, 761.

558 WG, 447-457.

${ }^{559} \mathrm{WG}, 447$.

${ }^{560} \mathrm{WG}, 447$.

$561 \mathrm{WG}, 448$.

562 Ebeling, Art. Theologie und Philosophie III. Dogmatisch, in: RGG ${ }^{3}$ VI (1962), 819-830, 822.
} 
obwohl beide ihren je selbstständigen Ort und ihre je eigentümliche Aufgabe haben. Die Theologie beweist sich bei ihm deshalb als kirchliche Wissenschaft, die sich von anderen Wissenschaften unterscheidet, insbesondere von der philosophischen Wissenschaft. Diesen Unterschied bezeichnet er als „verschiedene Weisen des Wortes“ und erklärt folgendermaßen: „Philosophische Rede ist selbst das Wort, um das es der Philosophie zu tun ist: welches das Fragen fragender macht. Theologische Rede ist dienend auf das Wort der Verkündigung gerichtet: welches das Gewissen gewiss macht" . 563 Soll die spezifische Wissenschaftlichkeit der Theologie erörtert werden, ist das bei Ebeling deshalb ohne die Reflexion über ihr Verhältnis zur Verkündigung unmöglich. Für ihn ist die Theologie, wie Bühler sagt, „nur in der Verbindung mit der Verkündigung als ihrer praktischen Grundausrichtung angemessen“ richtig zu erfassen. ${ }^{564}$

\subsubsection{Verkündigung und Kirche}

Die Verkündigung bzw. Predigt wird gemäß der oben aufgezeigten Ortsbestimmung von der Kirche getragen. Über diese Beziehung von beiden hinausgehend bezeichnet Ebeling mit der Verkündigung sogar die Existenz der Kirche, behauptend, dass die Kirche durch die Verkündigung nicht nur zur Funktion der Mitteilung des Wortes Gottes, sondern auch zur Bezeugung des Daseins Gottes in Christus dienen kann. Wenn er im Anschluss an Bonhoeffer äußert, die Kirche habe für andere da zu sein, bezeichnet er die „Existenz“ der Kirche und ihren eigenen „Existenzgrund“ als Verkündigung, denn ihr Dasein für andere beweist sich allein durch die Verkündigung als die „Bezeugung“ dessen, „dass Gott in Christus für andere da ist" ${ }^{565}$

Ebelings Versuch, das Wesen der Kirche auf die Verkündigung zurückzubringen, wird noch deutlicher in seinen „Leitsätzen zur Ekklesiologie“"566. Er bestimmt hier die Kirche als „das Geschehen ihres Grundes" und scheint dadurch die dialektische Beziehung zwischen ihrem geschichtlichen und eschatologischen Charakter auszudrücken. In der Bezeichnung der Kirche als das Geschehen ihres Grundes befindet sich eine Zusammenstellung von zwei Begriffen von dem „Grund der Kirche“ und dem „Geschehen des Grundes“. 567

Die Frage nach dem Grund der Kirche unterscheidet Ebeling von der Frage nach ihrem historischen Ursprung und will daher eher wissen, „was Kirche zur Kirche macht“. Der Grund der Kirche ist darum „nicht ihr Anfang, sondern die Ermächtigung, kraft deren allein von ihrem Anfang an Kirche war und

\footnotetext{
${ }^{563}$ WG II, 94.

${ }^{564}$ P. Bühler, Wort Gottes und Hermeneutik. Gerhard Ebelings Erbe aus heutiger Sicht, in: I.U. Dalferth u.a. (Hg.), Hermeneutische Theologie - heute?, Tübingen 2013, 39-54, 44.

${ }^{565}$ WG, 118; Vgl. WG III, 522-532, $522 \mathrm{f}$.

$566 \mathrm{ThV}, 93-103$.

567 ThV, 93.
} 
ist" ${ }^{568}$ nämlich Jesus als Wort Gottes. In Bezug auf das Verhältnis zwischen dem historischen Jesus und der Entstehung der Kirche wird die Aussage des katholischen Theologen Alfred Loisys oft zitiert: „Jesus hat das Reich Gottes angekündigt, und gekommen ist dafür die Kirche“569. Die Verkündigung des Reiches Gottes von Jesus hat gewiss mit der Kirche zu tun. Es geht aber nicht darum, dass Jesus die Kirche gegründet oder die Gründung der Kirche ausgelöst hat. Kann man aus den Worten Jesu, „Du bist Petrus, und auf diesen Felsen will ich meine Kirche bauen, und die Pforten der Hölle werden sie nicht überwältigen“ (Mt 16,18) sagen, dass er schon eine sichtbare Gemeinschaft gegründet hat? Historisch betrachtet gibt es aber keine Anhaltspunkte dafür, dass Jesus selbst die Kirche gewollt hat, weshalb die Bezeichnung Jesu als des Gründers der christlichen Kirche für unrecht zu halten ist. Auf die Frage nach dem Verhältnis Jesu zur Kirche versucht Ebeling darum eine klarere Antwort zu geben. Er sagt: „Jesus ist nicht der Gründer der Kirche, sondern der Grund der Kirche“ ${ }^{570}$, weil sich der Grund der kirchlichen Vollmacht auf ihn beruft. Er behauptet, dass die Vollmacht der Kirche ihre Vollmacht nur insoweit ist, „als sie Jesu Vollmacht bleibt“. ${ }^{571}$ Durch die Begründung der kirchlichen Vollmacht auf die Vollmacht Jesu und damit die Bestimmung des kirchlichen Grundes als Jesu beweist Ebeling die untrennbare, hinzugehörende Beziehung Jesu zur Kirche.

Zu klären bleibt aber, wie sich die Kirche auf Jesus als den Grund ihrer Vollmacht beruft. Ebeling bringt dafür nichts anderes als das vollmächtige Wortgeschehen der Kirche zur Sprache, nämlich die Verkündigung. Denn die Delegierung von Vollmacht Jesu besteht laut ihm nicht im Nachweis, dass Jesus „kraft seiner Autorität“ an die Kirche Autorität übertragen hat, sondern darin, die Autorität Jesu „geltend“ zu machen. ${ }^{572}$ Ebeling behauptet, „Viel mehr ist Kirche durch den Tod Jesu gleichsam freigesetzt worden als der Leib, d.h. als die geschichtliche Präsenz des Auferstandenen, [...] Wenn die Berufung auf Jesus sinnvoll sein soll, besteht die ekklesiologische Relevanz des Ostergeschehens nicht in der Herstellung des Grundes der Kirche, sondern in seiner Proklamation und damit in der Unterscheidung der Kirche von ihrem Grund“. ${ }^{573}$ Jesus wird schließlich in der kirchlichen Proklamation offenbart und seine Vollmacht manifestiert in dem vollmächtigen Wortgeschehen der Kirche. Die Kirche, die aus der Vollmacht Jesu hervorgegangen ist, ist nun als deren „fortdauernde Präsenz ${ }^{\text {‘574 }} \mathrm{zu}$ bezeichnen. Und die Kirche als die Präsenz der Vollmacht Jesu beweist sich, laut Ebeling, „nur im Bekenntnis“ von ihrer „Unverfügbarkeit, das aber als Ausrufung seines Namens Bekenntnis [...] der

\footnotetext{
${ }^{568} \mathrm{ThV}, 94$.

${ }^{569}$ A. Loisy, L'évangile et l'église, Paris $1903^{2}$, 155. Zitiert nach Johannes Kubik, Kirche in der Moderne moderne Kirche, in: G. Koretzki/R. Tammeus (Hg.), Werkbuch 11: Religion entdecken, verstehen, gestalten, Göttingen 2003, 108-120, 110.

${ }^{570}$ DG III, 359.

571 ThV, 97.

572 ThV, 95.

${ }^{573} \mathrm{ThV}, 95 \mathrm{f}$.

${ }^{574} \mathrm{ThV}, 97$.
} 
Gewissheit der Vollmacht Jesu ist“, weil vollmächtiges Wort „nicht durch die Bemühung um Vollmacht, sondern durch Hingabe an das Wort" zuteilt wird. ${ }^{575}$ In solcher Weise bestimmt er die Kirche als das vollmächtige Wortgeschehen aufgrund der Vollmacht Jesu und ihr Wesen als Verkündigungsgeschehen.

Hat die Kirche ihr Wesen als Verkündigungsgeschehen, wird sie in erster Linie nicht als die Gemeinschaft der Gläubigen, sondern als Wortkirche verstanden. Ebeling sagt, die Verkündigung, die die Kirche zu vollziehen hat, sei „das Zu-Worte-Kommen des Wortes Gottes ${ }^{\text {“577 }}$ und die Kirche habe ihre vorwiegende Aufgabe, das Glauben weckende Wort Gottes zu predigen, und existiere eigentlich für die Ungläubigen. Für ihn gehört die Kirche damit primär auf die Seite des Wortes Gottes, in dessen Ergehen sie Vollmacht hat und von Jesus her mit ihrem Wort zum Ziel kommt. Solche Betonung auf den an der Verkündigung angeschlossenen Kirchenbegriff zeigt einerseits, dass sich Ebeling gegen die römisch-katholische Auffassung setzt, dass die Kirche selbst „die direkte Fortsetzung der Inkarnation und damit der Geschichte Jesu Christi “"577 sei, und damit gegen ihren Versuch, die Kirche auf sich selbst $\mathrm{zu}$ gründen. Andererseits will er dadurch den Aspekt der Kirche lediglich als einer menschlichen Gemeinschaft vermeiden, der z.B. bei Schleiermacher erkennbar ist, der die Kirche primär als das neue Gesamtleben des Menschen bezeichnet. ${ }^{578}$ Allein mit dem Begriff der Verkündigung kann man Ebelings Verständnis der Kirche nicht vollständig erklären und eins ist doch offensichtlich: dass der Begriff der Verkündigung bei ihm eine entscheidende Rolle für seinen grundsätzlichen Standpunkt über das Wesen der Kirche spielt. ${ }^{579}$

\subsection{Sprache für die aktuelle Verkündigung des Wortes Gottes}

Die Verkündigung hat mit der Sprache zu tun, weil ihre Durchführung grundsätzlich eine sprachliche Aufgabe ist. Es ist gar nicht schwer, das enge Beziehung von Verkündigung und Sprache bei Ebeling zu finden. Er ist der Meinung, dass die wesentliche Funktion der Sprache darin bestehe, eine Sache nicht zu bezeichnen, sondern zu vermitteln, und dass die Kraft der Sprache insbesondere für das Präsentieren des Verborgenen wirkt. Das verborgene Geheimnis der Wirklichkeit Gottes wird dann auch nur durch die Sprache vermittelt, vornehmlich in Form der Verkündigung bzw. der Predigt. Ebeling lässt die Verkündigung darum zum Ausgangspunkt seiner theologischen, hermeneutischen Reflexion über die Sprache werden und plädiert im verantwortlichen Bewusstsein der Kraftlosigkeit der Predigt für die Notwendigkeit einer theologischen Sprachlehre. ${ }^{580}$

\footnotetext{
$575 \mathrm{ThV}, 98 \mathrm{f}$.

576 WG, 175.

577 WGT, 19.

${ }^{578}$ F. Schleiermacher, CG, Bd. II, § 113, 229ff.

${ }^{579} \mathrm{Vgl}$. D. Lange, Kirche im Zeichen der Zwei-Reiche-Lehre. Ein Beitrag zur Ekklesiologie Gerhard Ebelings, in: ZThK 108 (2011), 72-87.

${ }^{580}$ Sprachlehre, 69ff.
} 
Darüber hinaus hat die Sprache einen besonderen Platz in Ebelings Vorstellungen der Predigt, die eine spannungsreiche Struktur hat. Er selber macht die Spannungsfelder der Predigt in seinem Vortrag $>$ Fundamentaltheologische Erwägungen zur Predigt $<$ aus und formuliert sie in drei Polaritäten: „Überliefertes und gegenwärtiges Wort“, „Glaubensinhalt und Lebenserfahrung“ und „Glaubensgrund und Glaubensäußerung“ “581 Diese Formula werden im Folgenden verwendet, um nachzuweisen, wie sich Ebelings Auffassung von der Predigt auf sein Sprachverständnis bezieht oder gründet. Es wird auch aufgezeigt, dass Ebeling angesichts der Spannungsfelder der Predigt seine eigene Lösung finden will, die als ein Versuch zu verstehen ist, einerseits dualistische Methoden der theologischen Arbeit zu überwinden, und andererseits die Kraft der Predigt zu restaurieren.

\subsubsection{Zwischen überliefertem und gegenwärtigem Wort}

Es ist ein allgemeiner, für jeden bewusster Sachverhalt, dass die Predigt ihren biblischen Text hat, der ihr ,als ein Legitimationsausweis“ und ,als ein anspruchsvoller Maßstab“ vorsteht. ${ }^{582}$ Das ähnelt einer Auslegung, der ebenfalls der Bibeltext zugrunde liegt. Ebeling sagt, dass das Verhältnis von Text und Predigt jedoch nicht auf das von Text und Auslegung reduziert werden darf, weil das Erstere mit der Reduktion auf das Letztere, bei dem man oft allein an eine durch Textschwierigkeiten verursachte Auslegungsbedürftigkeit denkt, nicht recht zu erfassen ist. Obwohl er die Auslegung nicht nur als Vorbereitung für die Predigt, sondern als solche, die „ausdrücklich in die Predigt eingeht“", versteht,, ${ }^{583}$ unterscheidet er trotzdem die Predigt von der Auslegung des Textes und bezeichnet sie lieber als „Ausführung des Textes“: „die Predigt [...] ist nicht Auslegung des Textes als geschehener Verkündigung, sondern ist selbst geschehende Verkündigung und das heißt nun: Die Predigt ist Ausführung des Textes. Sie bringt zur Ausführung, was der Text will. Sie ist Verkündigung dessen, was der Text verkündigt hat. Und damit kehrt sich gewissermaßen der hermeneutische Richtungssinn um. Der in der Auslegung zum Verstehen gekommene Text hilft nun, das zum Verstehen zu bringen, was durch die Predigt zum Verstehen kommen soll. “584 Ebeling zeigt durch diese Bezeichnung der Predigt als „Ausführung des Textes“ ganz klar, dass das Geschehen des christlichen Wortes durch die kirchliche Predigt nach der Intention des Textes weiter fortgeht. Die Predigt als Ausführung bzw. Fortführung des Textes hat darum sowohl mit der Vergangenheit der geschehenen Verkündigung als auch mit der Gegenwart der geschehenden Verkündigung zu tun. Gerade aus diesem Sachverhalt ergibt sich das Spannungsfeld zwischen überliefertem und gegenwärtigem Wort.

\footnotetext{
${ }^{581}$ WG III, 554-573, bes. 558ff.

582 WG III, 558.

583 WG III, 558.

${ }^{584} \mathrm{WG}, 347$.
} 
Ebeling zufolge liegt die Verantwortung der Predigt in der Spannung zwischen überliefertem und gegenwärtigem Wort. Denn sie ist repräsentativ „für die gesamte Wirklichkeit“ dessen, was in der ganzen Geschichte des Christentums dargestellt ist. ${ }^{585}$ Keine Predigt ist von der Kirchengeschichte, von der christlichen Tradition zu trennen, weil sie von ihr die Identität des christlichen Glaubens lernt und christliches Gedankengut sowie Einsicht für das Verstehen der biblischen Texte übernimmt, sodass sie das Wort des Glaubens „,von fern her“586 weiter sagt und selbst zur ununterbrochenen Überlieferung gehört. Sie bezeichnet sich darum als eine traditionsmäßige Rede. Allerdings ist sie keine einfache Wiederholung oder Nachfolge des überlieferten Wortes, sondern wendet sich in immer neuen Formen und Gedanken zur Gegenwart, damit der Glaube, die Kirche und ihre Geschichte dadurch wiederum neu konstituiert werden. Schließlich ist jede Predigt für ihre eigenen, hier und jetzt existierenden Hörer. In diesem Spannungsverhältnis zwischen überliefertem und gegenwärtigem Wort, also in der Kontinuität und im Unterschied zwischen ihnen sowie in den Bedingungen historischen Denkens und den geschichtlichen Veränderungen hat die Verantwortung der Predigt ihren Ursprung. Das Gewicht der theologischen Arbeit für die Predigt liegt dementsprechend, nach der Einsicht Ebelings, einerseits „in den biblischen Disziplinen mit allem Aufwand historischer Sorgefalt“, andererseits ,,in den Disziplinen, die der Gegenwart zugewandt sind“. ${ }^{587}$ Seiner Argumentation, dass beide Polen der theologischen Arbeit immer zugleich in Betracht bleiben müssen, ist sicherlich zuzustimmen. Das heißt, um sich im Spannungsverhältnis zwischen überliefertem und gegenwärtigem Wort richtig zu positionieren, wird vom Prediger die „Gesamtverantwortung“ verlangt: er soll das Ganze im Blick behalten und die kooperative Arbeit von der historischen und der systematischen Theologie verrichten. ${ }^{588}$

Hinsichtlich des Spannungsverhältnisses zwischen überliefertem und gegenwärtigem Wort hat Ebeling zweierlei Intention. Auf der einen Seite möchte er, dass die Predigt ohne Rücksicht auf ihren Zeitbezug weder für eine Sache der menschlichen, individuellen Empfindung, noch für eine Angelegenheit der reinen Lehre gehalten werden darf. Auf der anderen Seite verfolgt er das Ziel, dass sie mit Rücksicht auf ihren Zeitbezug doch nicht bloß für ein historisches Produkt oder für die nur zu einem bestimmten Zeitraum gehörende Sache gehalten wird. Aus dieser doppelten Sackgasse sucht er einen eigenen Ausweg, der sich in seinem Verständnis des Verhältnisses von Zeit und Wort offenbart. Dieses Verhältnis thematisiert Ebeling in einem Aufsatz als den Versuch einer Richtungsangabe, „wie das Zeitproblem im 20. Jahrhundert theologisch zu präzisieren wäre“. ${ }^{589}$ Weil es für ihn ganz klar ist, dass „die Sache der Theologie das Wort ist, das der kirchlichen Verkündigung aufgetragen ist“590,

\footnotetext{
585 WG III, 559.

${ }^{586}$ WG II, 133.

587 WG III, 559f.

588 WG III, 560.

${ }^{589}$ WG II, 123.

${ }^{590}$ WG II, 133.
} 
betrachtet er das Thema der Zeit theologisch in ihrem Verhältnis zum Wort. Dies Verhältnis wird in drei Schritten betrachtet: die Sprachlichkeit der Zeit“, „die Zeitlichkeit des Wortes“ und „die Zeitmacht des Wortes". .991

Es ist hier nicht nötig, das Thema der Zeit selbst vollständig zu behandeln, und doch ist es hilfreich, einen kurzen Überblick auf Ebelings Grundstandpunkt zu werfen. In Hinsicht auf die Zeit setzt er sich zuallererst kritisch mit dem unendlichen qualitativen Unterschied von Zeit und Ewigkeit in der frühen dialektischen Theologie auseinander. Er positioniert sich insbesondere gegen Barths Auffassung von Zeitlichkeit als „Negation der Ewigkeit ${ }^{4592}$ und darum gegen den Versuch, durch die Ferne zur Zeit die Ewigkeit „als Inbegriff der Vollkommenheit Gottes“ und „als tragender Grund aller theologischen Aussagen über das ewige Wort" zu retten ${ }^{593}$. Ebeling versucht stattdessen die Besonderheit des biblischen Zeitverständnisses herauszuarbeiten und behauptet, die Bibel zeige, dass Gott die Welt zeitlich ordnet und sich als der Herr der Zeit beweist. ${ }^{594}$ Die Ewigkeit Gottes darf deshalb nicht als Unberührtheit Gottes vom Wechsel der Zeit gedacht werden. Sie bezeichnet sich nicht als „Zeitlosigkeit“, sondern als „Zeitfülle und Zeitvollmacht““. ${ }^{595}$ Darüber hinaus betont Ebeling, dass die Zeit nach dem biblischen Verständnis immer konkrete Zeit ist, weil sie von Gott als dem Herrn der Zeit konkret bestimmt wird. In diesem Sinne spricht sich Ebeling gegen eine metaphysische und mythische Auffassung der Zeit aus. Im Vergleich zu dieser Auffassung steht dem biblischen Zeitverständnis laut ihm das historische Zeitverständnis näher, das sich z.B. in der Ritschlischen Schule findet, die das Verhältnis von Zeit und Ewigkeit hinsichtlich der „Geschichtlichkeit der Offenbarung“ betrachtet. ${ }^{596}$

Ebeling richtet seine Aufmerksamkeit, vermutlich unter dem Einfluss von Heideggers Daseinsanalyse, mehr auf den „Nötigungscharakter der Zeit“597, behauptend, im Unterschied zu allem anderen Zeitlichen sei der Mensch nicht einfach in der Zeit, sondern es zeichne ihn als Menschen aus, sich zur Zeit verhalten zu müssen. Die Erfahrung der Zeit ist für die Existenz des Menschen notwendig, nämlich dafür, zu existieren, sich zur Zeit zu verhalten und darin seine eigene Existenz zu verantworten. Der Mensch ist dann durch die Erfahrung der Zeit bestimmt und Zeit ist umgekehrt die Bedingung der Möglichkeit der menschlichen Erfahrung. Durch solche Gleichursprünglichkeit von Zeiterfahrung und Selbstbewusstsein zeigt Ebeling, dass das menschliche Bewusstsein zeitlich strukturiert ist. ${ }^{598}$

\footnotetext{
591 WG II, 135-137.

${ }^{592}$ WG II, 126.

${ }^{593}$ WG II, 125.

${ }^{594}$ WG II, 126f. Vgl. Ps 31,16; Gen 8,22; Pred 3,1.

${ }^{595}$ WG II, 127.

${ }^{596}$ WG II, 127.

${ }^{597}$ WG II, 13.

${ }^{598}$ Im Hinblick auf das existentielle Zeitverständnis Ebelings erklärt Karl H. Manzke den Hintergrund von Feuerbach und Kant wie folgt: „Hinter die Bezugnahme Ebelings auf Feuerbachs Votum: ,Nur die Existenz in Raum und Zeit ist Existenz'(WG II, 125) - ist der Rückgriff auf Kants These von der transzendentalen Idealität der Zeit angebracht, um die ganze Tragweite jener Entwicklung zu verstehen, die den theologischen
} 
Die Zeit präsentiert sich dem Menschen seiner Meinung nach aber immer als „problematische“, „strittige“ Zeit, weil Vergangenheit und Zukunft den Menschen beanspruchen und davon abhalten, nur gegenwärtig zu leben. Damit bringen die Erinnerung von Vergangenheit und die Erwartung von Zukunft die Frage mit sich, was über die Gegenwart des Menschen bestimmt. Die Zeit wird darum nicht eindeutig, sondern strittig erfahren. Dieser Zusammenhang der Zeit ist laut Ebeling „,identisch mit dem Ursprung der Sprache““ ${ }^{599}$ Er stellt solchen Sachverhalt als „die Evidenz der Gleichursprünglichkeit von Zeiterfahrung und Sprache“ fest: „Die Strittigkeit der Zeit wird als Anspruch der Zeit und Infragestellung durch die Zeit, als Gewährung und Versagung in unendlicher Mannigfaltigkeit sprachlicher Bezüge erfahren. [...] Sprache kommt schon immer her von der sprachlich erfahrenen Zeit und ist herausgefordert, den Anspruch der Zeit zu erfüllen, aber auch dem Anspruch der Zeit zu widerstehen. Denn abstrakte Zeit ist sprachlos gemachte Zeit. Konkrete Zeit ist, als Zeit $z u$ etwas, sinnvolle, im Sprachzusammenhang wahrgenommene Zeit." “600

Ebeling versucht durch die Beschreibung der sprachlichen Zeiterfahrung den Zeitbezug des Menschen in der Sprachlichkeit der Zeit zu begründen, und behauptet, dass für den Menschen nur durch Sprache Vergangenheit und Zukunft vergegenwärtigt werden und Gegenwart eine Tiefdimension von ihnen gewinnt. Diese Auffassung der sprachlichen Zeiterfahrung wirft aber noch die Frage auf, erstens, ob das wahrnehmbare Phänomen der Zeit als die Sprachlichkeit der Zeit vollständig beschrieben werden kann. Dieser Punkt ist insbesondere dann kritisch, wenn man bedenkt, dass die Zeit als eine von den jeden Verstehensakt ermöglichenden Bedingungen zum vorsprachlichen Bereich gehört; ${ }^{601}$ und zweitens, ob das komplizierte Problem von Zeit und Zeiterfahrung dadurch genügend erklärt werden kann. Gerade an diesem Punkt kritisiert beispielweise Oliver Pilnei, dass solche „Phänomenbeschreibung“ bei Ebeling problematisch ist: „Sicherlich lässt sich die in der ursprünglichen Zeiterfahrung enthaltene Zumutung an die Existenz begrifflich als ,Anspruch der Zeit ${ }^{\star}$ zur Sprache bringen, aber es sollte davon Abstand genommen werden, damit den sprachlichen Charakter von Zeiterfahrung generell zu erklären. Nur weil der Zeiterfahrung des Daseins ein Anspruchscharakter im Sinne von Zumutung zukommt, ist sie noch nicht sprachlicher Natur. Diese Zuweisung liegt freilich auf der Ebene des Wortverständnisses Ebelings, das er nicht ausschließlich an die sprachliche Äußerung gekoppelt wissen möchte [...], sondern als das Angegangen-, Angesprochen- und Herausgefordertsein des Daseins generell versteht. Aber auf diesem Wege kehren dieselben Probleme wieder, die schon oben berührt wurden.“ 602

\footnotetext{
Ewigkeitsbegriff zumindest problematisch gemacht hat.“ Ders., Ewigkeit und Zeitlichkeit. Aspekte für eine theologische Deutung der Zeit, Göttingen 1992, 21.

${ }^{599}$ WG II, 135.

${ }^{600}$ WG II, 135.

${ }^{601}$ P. Bieri, Zeit und Zeiterfahrung. Exposition eines Problembereichs, Heidelberg 1972, 177ff.

${ }^{602}$ Oliver Pilnei, Wie entsteht christlicher Glaube?, Tübingen 2007, 301.
} 
Im Vergleich zu seiner umstrittenen Ausführung über die Sprachlichkeit der Zeit scheint Ebelings zweiter Gesichtspunkt über die Zeitlichkeit des Wortes überzeugender und plausibel zu sein. Die Zeitlichkeit des Wortes ist als eine umgekehrte Richtung im wechselseitigen Bezugsverhältnis von Wort und Sprache zu nennen. Denn Ebeling unterscheidet beide nur terminologisch und macht austauschbar von ihnen Gebrauch. Während er oben mit dem Begriff der Sprachlichkeit der Zeit den existentialen Sprachbezug der Zeit bzw. die sprachliche Zeiterfahrung des Menschseins zeigt, hebt er nun mit dem Begriff der Zeitlichkeit des Wortes hervor, dass das Wort die Struktur der Zeitlichkeit hat und sich als zeitliches Geschehen ereignet. So erweist sich das Wort im Grunde zuerst als „Zeitwort“, denn wenn jemand ein Wort sagt, „so macht er eine Zeitaussage“ und es ist „als gesprochenes stets Zeitwort“. 603 Weil für ihn die Wirklichkeit immer in untrennbarer Einheit mit Sprache begegnet, die ,als Überlieferung von Wirklichkeits-auslegung“ verstanden wird, betont er gegenüber dem naturwissenschaftlich orientierten, rein signifikativen Sprachverständnis stets die ,konstitutive Bedeutung der Zeit für die Wirklichkeit der Sprache“604. Damit ist gemeint, dass sich die Zeitlichkeit des Wortes nicht darin erweist, dass es etwas über die Zeit sagt oder etwas in der Zeit vermittelt, sondern dass der Reichtum der Sprache in „der in ihr versammelten Geschichte“ liegt und all dies nur „Folge des zeitlich sich vollziehenden Wortgeschehens“ ist. Zeitlich ist dann „nicht nur das Ausgesagte, sondern auch die Aussage selbst“, nämlich das Aussagegeschehen selbst. Ebeling hebt dadurch den Geschehenscharakter des Wortes bzw. sein Wesen als das zeitlich sich vollziehende Geschehen hervor. Weil er das Wort selbst so wesentlich als Geschehen versteht, ist seine Terminologie des Wortgeschehens „eine Tautologie“ zu nennen. ${ }^{605}$

Ebeling erklärt dazu, dass das Verständnis des Wortes als Geschehen nicht nur „,vor der unterschätzenden Isolierung zu bloßem Wort“, sondern auch „,vor der Überschätzung des ausgesprochenen Wortes gegenüber der worthaften Tat oder dem schweigenden Achten auf das Unausgesprochene“ bewahrt bleibe. ${ }^{606}$ Diese Beobachtung rührt wiederum daher, dass es sich weiter auf die Frage bezieht, was durch das Wort geschieht, nämlich auf die Wirkung des Wortes und die dementsprechende Wortverantwortung. Hinsichtlich der Wirkung des Wortes mag man vordergründig von der durch Informationsvermittlung oder zwischenmenschliche Verständigung bewirkten Veränderung oder Beeinflussung reden. Dagegen behauptet Ebeling, dass das Wort „letztlich und eigentlich“ dem Menschen Zukunft gewähren und ihn für die Gegenwart frei machen muss, ${ }^{607}$ weil „Eröffnung wahrer Zukunft“ die höchste Möglichkeit des Wortes wäre. ${ }^{608}$ Gerade darin erweist sich die

\footnotetext{
${ }^{603}$ WG II, 409.

${ }^{604}$ WG II, 409.

${ }^{605}$ WG II, 136.

${ }^{606}$ WG II, 136.

${ }^{607}$ WG II, 412.

${ }^{608}$ Wesen, 183.
} 
letzte Kennzeichnung des Verhältnisses von Zeit und Wort - die Zeitmacht des Wortes. Das Spannungsverhältnis von Zeit und Wort soll laut ihm weder im Sinne „Zeit überbrückender Übersetzung“ noch im Sinne „eines Wettlaufs mit der Zeit“, sondern im Sinne „schöpferischer Vollmacht über die Zeit" behandelt werden. ${ }^{609}$

Die Erwartung einer positiven Wirkung der Sprache, also sogenannter Sprachoptimismus, findet sich bei Ebeling dementsprechend im Verhältnis zur Zeit. Denn seine optimistische Meinung von Sprache beruht auf deren Potential für die Vermittlung des Wortes Gottes, der der Herr der Zeit ist und dessen Wort darum die herrliche Macht über Zeit hat. Und nur in der auf die zeitlich unabhängige, schöpferische Vollmacht der Sprache gegründeten Predigt wird Ebelings hermeneutisches Leitprinzip erfüllt, aus dem in die Schrift eingegangenen Wortgeschehen der Vergangenheit wieder gegenwärtiges Wortgeschehen zu machen und dadurch Zukunft zu eröffnen.

\subsubsection{Zwischen Glaubensinhalt und Lebenserfahrung}

Die Predigt ist, wie oben aufgezeigt, eine textgebundene, auf die biblischen Texte bezogene Rede. Sie besteht aber weder in einem Vorlesen der biblischen Texte noch in einem Bericht der biblischen Tatsachen. Der Inhalt der biblischen Texte muss in die Situation des Predigers und der Predigerin übertragen werden und diese Situationen sind sogar veränderlich. Wegen der veränderlichen Situationen und der daraus gewonnenen verschiedenen Erfahrungen, stößt ein Prediger auf eine Schwierigkeit. Diese findet Ebeling im zweiten Spannungsfeld der Predigt, nämlich im Ringen zwischen Glaubensinhalt und Lebenserfahrung. Man hält dieses Ringen normalerweise für ein solches, das „dem »Soll« des Glaubens und dem »Ist« des Lebens“ gerecht wird, „wobei man dann allzu leicht die Lebenserfahrung dem Glauben anpasst und gutschreibt, während der Glaube als bloßes »Soll« dem Leben vorgeschrieben wird“. ${ }^{610}$ Ebeling will aber ebenjenes Spannungsverhältnis auf eine grundlegende Ebene bringen. Denn es geht nicht bloß um die Hinzufügung der situationsbezogenen Anwendung zum fixierten Glaubensinhalt. Es geht vielmehr um den wesentlichen Lebensbezug des Glaubens. Ebelings eigener Darstellung nach: dass der Glaube „allein in seinem Lebensbezug“ recht erfasst und ausgesagt werden kann und „,nur als Lebensbezug Glaube ist““611

In Hinsicht auf das Verhältnis von Glaube und Leben ist Ebeling nun der Auffassung, dass der Lebensbezug des Glaubens das ganze Leben umfasst, also nicht irgendwelche religiösen Sonderbereiche; und dass die Lebenserfahrung mit Hilfe der Glaubensüberlieferung auf ihre Transzendenzbezüge hin zu erhellen ist. Immer wieder betont er die untrennbare, freilich einander

\footnotetext{
${ }^{609}$ WG II, 134.

${ }^{610}$ WG III, 561.

${ }^{611}$ WG III, 562.
} 
beeinflussende Beziehung zwischen ihnen und argumentiert sogar, dass eine Stagnation dessen, „dass Glaube und Erfahrung im Fortgang des Lebens einander sprachschöpferisch durchdringen“, letztlich zu einer Stagnation des Glaubens selbst führe und dass sich ein solcher Sachverhalt „geschichtlich und sachlich“ erweise ${ }^{612}$. Beispielhaft führt er an, dass als das Christentum offensichtlich die Alleinherrschaft hatte und damit eine unflexible Verbindung von dem christlichen Glauben und dem politischen und sittlichen System entstand, ein Stagnationsphänomen in beiden Bereichen beobachtet worden wäre. Umgekehrt führt eine radikale Unterscheidung „von Glauben und Handeln, von Gottesbezug und Weltbezug“ zur „Entmythologisierung, Gott-ist-tot-Theologie, der politischen Theologie“ usw. und verhindert die Entwicklung des Glaubens. ${ }^{613}$ Bezüglich eines solchen Sachverhaltes steht die Aufgabe der Predigt laut Ebeling heute noch vor der Frage, wie bei einem Ernstnehmen des Erfahrungsbezuges die Sache des Glaubens als der Kern der Predigt unbeschädigt bleiben und verifiziert werden kann. Diese Aufgabe der Predigt ist aber nicht einfach. Ebeling beschreibt sie als „Kernschwierigkeit der Predigt“. Schließlich weiß er, dass man dort, wo man auf die Predigt stößt, Fragen über Fragen gegenübersteht, die die Gewissheit des christlichen Glaubens vom Wort mit den Erfahrungen konfrontieren, die uns in der Wirklichkeit unseres Lebens umdrängen. ${ }^{614}$

Angesichts der Spannung zwischen Glaubensinhalt und Lebenserfahrung tun sich zwei Wege für die Predigtarbeit hervor: entweder mit einem Fokus auf das Erstere dessen entscheidende Kernsache auszumachen, oder im Blick auf das Letztere herauszufinden, wo der Glaube seinen Ort im Leben hat. Die Diskussion um die so unterschiedliche Fokussierung hat die Homiletik an eine prominente Stelle gerückt und vor allem seit den 1960er Jahren zu einer sogenannten empirischen Wende geführt, in der sich die Homiletik den konkreten Problemen der pastoralen Praxis zuwendet. E. Lange spricht z.B. vom Begriff der „homiletischen Situation“, die er als „diejenige spezifische Situation des Hörers bzw. der Hörergruppe“ bestimmt, die er für die Predigtarbeit für konstitutiv hält. Gemäß der Notwendigkeit der konkreten Predigtakte fordert er, dass Gehalt und Absicht der Predigt in erster Linie durch die jeweils besondere Erfahrung der Gottesdienstgemeinde bestimmt werden sollten. ${ }^{615}$ Rudolf Bohren argumentiert dagegen, die Praxis der Predigtarbeit solle sich nicht durch die Situation begründen, weil „der Prediger, der mit der Situation beginnt, gewöhnlich in ihr stecken bleibt" und „sich zu ihrem Gefangenen“ macht. ${ }^{616}$ Friedrich Mildenberger lehnt die Orientierung der Predigenden an der konkreten Situation ebenfalls ab, da das Ausgehen von der Situation die theologische Priorität des Evangeliums gefährde und dann bloß nach der Nützlichkeit oder dem Verwendungszweck befragt

\footnotetext{
${ }^{612}$ WG III, 561f.

${ }^{613}$ WG III, 562.

${ }^{614}$ WG III, 562.

${ }^{615}$ E. Lange, Zur Theorie und Praxis der Predigtarbeit, in: Rüdiger Schloz (Hg.), Predigen als Beruf. Aufsätze zur Homiletik, Liturgie und Pfarramt, München 1982, 9-51, 22.

${ }^{616}$ R. Bohren, Die Differenz zwischen Meinen und Sagen. Anmerkungen zu Ernst Lange, Predigen als Beruf, WPKG 70 (1981), 416-430, 424.
} 
würde. ${ }^{617}$ Ebeling engagiert sich nicht direkt in dieser zeitgenössischen homiletischen Diskussion. Und trotzdem ist er in systematisch-begrifflicher Hinsicht gewiss als einer der leitenden Theologen zu nennen, die das theologische Verständnis der Situation für die Predigt erläutern. ${ }^{618}$

In Hinsicht auf die oben genannten zwei Wege für die Predigtarbeit scheint Ebeling eine neutrale Haltung einzunehmen oder eine prinzipielle Perspektive zu geben. Er behauptet, dass sie zueinander nicht „als echte Alternative“ stehen, sondern „zu gegenseitiger Ergänzung und Kontrolle“ werden sollen, weil das Moment der Erfahrung und das Moment der Überlieferung auf beiden Wegen notwendig vereint werden. ${ }^{619}$ Bemerkenswert ist, dass die Ermöglichung der Konvergenz beider Momente bei ihm von der Sprache anhängt, genauer gesagt von der Sprachlichkeit von Erfahrung und Überlieferung. Die Erfahrung ist laut ihm wesentlich sprachlich, weil sie allein durch Sprache nicht nur erfasst, sondern auch vermittelt werden kann. ${ }^{620}$ Das heißt, Erfahrung kann nur durch sprachliche Vermittlung gesammelt werden, was dann zur Erschließung der Wirklichkeit führen kann. Die Möglichkeiten eigener Erfahrung sind darum „durch die Teilhabe an sprachlicher Überlieferung bedingt, ohne die sich Erfahrung gar nicht erschließt.“ ${ }^{621}$ Solche durch die Partizipation an sprachlicher Überlieferung erschlossene Erfahrung hält Ebeling für „lebensrelevante Überlieferung“, die die eigene Erfahrung nicht zu ersetzen vermag, „wohl aber zu entdecken und zu erwecken.“622 Aufgrund dieses Sachverhalts bezeichnet er Erfahrung als Partizipation ,an bestimmter Sprache und somit an Sprachüberlieferung“ und Überlieferung als ,sprachlich übermittelte Erfahrung“. ${ }^{623}$ Er bringt Erfahrung und Überlieferung damit in eine durch Sprache geschaffene Beziehung und macht den Charakter ihrer Sprachlichkeit für die Verbindung zwischen ihnen ausschlaggebend.

Allein unter der Voraussetzung der so vereinten Momente von Erfahrung und Überlieferung kann man laut Ebeling der Predigtarbeit nachgehen und sich entscheiden, entweder mit der Frage nach dem Glaubensinhalt oder mit der Analyse der Lebenserfahrung zu beginnen. Es geht aber nicht darum, unter beiden Wegen ein Gewicht oder einen Fokus auf den einen eher als auf den anderen zu setzen. Weil Ebeling das Thema der Predigt, wo oben erwähnt, fundamentaltheologisch erarbeiten will, hat er eigentlich kein Interesse dafür, über den besseren Weg zu entscheiden, vielmehr versucht er nur nachzuweisen, dass bei beiden Wegen der innere Zusammenhang von Glaubensinhalt und Lebenserfahrung immer bewusst sein und die Balance zwischen ihnen bewahrt werden muss:

\footnotetext{
${ }^{617}$ F. Mildenberger, Kleine Predigtlehre, Stuttgart u.a. 1984, $24 f$.

${ }^{618} \mathrm{Vgl}$. J. Hermelink, Die homiletische Situation. Zur jüngeren Geschichte eines Predigtproblems, Göttingen 1992, 18-25; J. Block Die Rede von Sünde in der Predigt der Gegenwart, Zürich 2012, 187-191.

${ }^{619}$ WG III, 563.

${ }^{620}$ Sprachlehre, $116 f$.

${ }^{621}$ WG IV, $500 f$.

${ }^{622}$ WG IV, 501.

${ }^{623}$ WG III, 563.
} 
Wenn man mit dem Glaubensinhalt beginnt, muss man zuerst überlegen, was er ist, oder anders gesagt, was er nicht sein kann. Der Glaubensinhalt wird normalerweise so verstanden, dass die Bibel seine Grundlage ist und in den christlichen Glaubensbekenntnissen zum Ausdruck gebracht wird sowie in der Dogmatik systematisch dargelegt ist. Weil Ebeling, wie bereits aufgezeigt, den Erfahrungsbezug des Glaubens betont und nur einen aus Erfahrung bezogenen Glauben für empfehlenswert hält, ist der Glaube für ihn folglich kein Akt des Gehorsams, kein bloßes Anerkennen und kein „leerer Sack“, der in der Predigt mit den ,vorgeschriebene christlichen Glaubensgegenstände(n)“ gefüllt wird. ${ }^{624}$ Ebeling behauptet, dass der Glaubensgrund keineswegs eine bestimmte, fixierte Form wie ein Buch, ein Ritus oder ein Gesetz sei, sondern Jesus als „Gottes glaubenschaffendes Wort in Person“. ${ }^{625}$ Wer Jesus ist, das können wir aber seiner Meinung nach nur durch Begegnung mit ihm, nämlich durch die Erfahrung aussagen. Diese Erfahrung entsteht in verschiedenen Lebens- und Sprachräumen, so dass das Glaubenszeugnis verschiedene Sprachen gewinnt. Die Erscheinung Jesu wird deshalb dadurch charakterisiert, keine bestimmte Tradition zu fixieren, sondern ein „lebendige(s), vielstimmige(s) Überlieferungsgeschehen“ zu entbinden. Sie bezeichnet sich keinesfalls „als Glaubensgrundsatz“, sondern nur „als Grundgeschehen des Glaubens“. ${ }^{626}$ Soll sich Jesus als das Grundgeschehen des Glaubens zeigen, gehört der Fortgang der Begegnung mit Jesus, der in verschiedenen Lebenssituationen geschieht, deshalb zur Sache selbst. In diesem Sinne schließt Ebeling, dass die Sprache des Glaubens selbst schon den Dialog mit der Wirklichkeitserfahrung impliziere. ${ }^{627}$

Wenn man dagegen mit einer Analyse der Lebenserfahrung beginnt, soll man sich laut Ebeling darum bemühen, „,von da aus die theologische Sache auf deren Wirklichkeitsbezug hin“ zu erläutern. ${ }^{628}$ Man kann durch die Erfahrungsanalyse wahrscheinlich eine Frage finden und erwarten, dass der christliche Glaube sie beantwortet. Das Wissen um den Glaubensinhalt kann als eine „Orientierungsanweisung“ oder als eine „Interpretationshilfe“ dienen. Ebeling gibt allerdings zu bedenken, dass dem Fragenden dabei zwei Missverständnisse unterlaufen können; erstens kann man sich der erfahrungsbezogenen Bezeugung des christlichen Glaubens unbewusst sein oder zweitens, im übermäßigen Anschluss an die gegenwärtige Erfahrung den Platz des Glaubensinhalts vermindern: „Das berechtigt jedoch wiederum nicht zu einem Monologisieren, das den christlichen Glauben ohne Rücksicht auf Erfahrung oder dann richtiger: in unverantworteter Rezeption von Fremderfahrung vorbringt. Ebensowenig wäre freilich ein Monologisieren berechtigt, das aus gegenwärtigen Erfahrungen schöpft und nur mit christlichen Sprachfetzen verbrämt wird“. ${ }^{629}$ Dagegen fordert den

\footnotetext{
${ }^{624}$ Wesen, 17.

625 WG III, 563.

${ }^{626}$ WG III, 564.

627 WG III, 565.

628 WG III, 565.

${ }^{629}$ WG III, 565.
} 
Prediger auf, sich „mitsamt der gegenwärtigen Erfahrung der christlichen Glaubensäußerung“" vorzustellen. ${ }^{630}$

Darüber hinaus ist es nötig, Ebelings Formulierung von ,in unverantworteter Rezeption von Fremderfahrung“ etwas eingehender zu bedenken. Seine Darstellung der unverantworteten Rezeption von Fremderfahrung ist im Verhältnis zur Selbsterfahrung zu verstehen. Denn man erfährt in seiner eigenen Erfahrung nicht nur sich selbst, sondern in der besonderen Gestalt der Fremderfahrung den Anderen, so dass Selbsterfahrung und Fremderfahrung immer verbunden sind. Wenn man die Erfahrung von Anderen aber nicht auf sich selbst, nicht auf seine Selbsterfahrung bezieht, bedeutet das, die Erfahrung selbst nicht richtig zu berücksichtigen. In der Erfahrung darf der Mensch nicht bloß passiv, sondern im Sinne der eigenen Verantwortung aktiv sein. Dieser Sachverhalt wird auch in Ebelings eigenen Aussagen deutlich: „Denn $o b$ mir etwas und was mir zur Erfahrung kommt, ist nicht einfach nur durch die Empfänglichkeit der Sinne bedingt, sondern hängt auch an der Aufgeschlossenheit für Sinn, an den bereits mitgebrachten Möglichkeiten, etwas als etwas zu bestimmen, etwas auf etwas hin zu betrachten, etwas zu anderem in Beziehung zu setzen, mit ihm zu vergleichen, in ursächlichem oder zielgerichtetem und zweckbestimmtem Verhältnis zu sehen usw. Man mag sich das im Einzelnen daran erläutern, wie in einer bestimmten Erfahrungssituation von verschiedenen Menschen ganz Verschiedenes wahrgenommen wird, also ihnen nicht dasselbe zur Erfahrung kommt. “631 Schließlich schlägt Ebeling vor, in der Predigt christliches Wort deshalb als „eigenes“ Wort zu sagen, nicht in dem Sinne, dass es das eigene ist, sondern in dem Sinne, dass es durch die eigene Erfahrung hindurchgegangen sein muss und das Zeugnis an der Eigenverantwortung hängt. ${ }^{632}$ Das so eigenverantwortliche Predigen sieht er als Schlüssel gegen die Predigtnot.

In Hinsicht auf das Spannungsverhältnis von Glaubensinhalt und Lebenserfahrung findet man Ebelings Intention nun darin, dass die Predigt eigentlich weder von der Lebenssituation absehen noch sich ihr entziehen kann, sondern mit ihr verantwortlich umgehen muss, weil sie ihren Hörern nicht bloß Glaubensvorstellungen, sondern Glaubenserfahrung vermitteln und sie in den Lebensvollzug des Glaubens, darum weiter in ein Lebensverhältnis $\mathrm{zu}$ Gott hineinführen will. ${ }^{633}$ Solche Situationsbezogenheit der Predigt wird bei Ebeling vor allem durch die Sprachsituation unterstützt. Über die Sprachsituation erklärt er wie folgt: „Indem einer gerade dies in dieser Situation zu diesem sagt, kann es geschehen, dass er keineswegs nur zuspricht, was er ausspricht, sondern dadurch in gewisser Weise sich selbst schenkt.“634 Dieser Sachverhalt von Sprache, Situation und Menschen als Sprecher weist auf den Kern dessen, worum es in der Sprachlichkeit des Menschen geht. Ein Wort

\footnotetext{
${ }^{630}$ WG III, 565.

${ }^{631}$ Sprachlehre, 116.

${ }^{632}$ WG III, 568f.

${ }^{633}$ WG III, 495 u. $561 f$.

${ }^{634}$ Sprachlehre, 106.
} 
auszusprechen, bedeutet, dafür Verantwortung zu übernehmen. Der Wortsituation entspricht laut Ebeling die Wortverantwortung. Die Auffassung, dass die Sprache bzw. ein Wort selbst untrennbar von der Situation des Sprechens zu verstehen ist und für diese auch verantwortlich ist, wird zur Grundlage von Ebelings Gedanken über die Situationsbezogenheit der Predigt.

Darüber hinaus behauptet Ebeling, ein Wort beanspruche situationsgerecht zu sein. Damit ist nicht gemeint, dass ein Wort „einer schon begriffenen Situation angepasst ist“, sondern dass es „eine noch verschlossene Situation öffnet“ oder ,in Bewegung versetzt“ und somit ermöglicht, „etwas Zukünftiges“ anzusagen und wahrzunehmen. ${ }^{635}$ Zum Wort gehört die Situation, „,der es entspringt“ und ,in die hinein es geschieht und die es verändert“. ${ }^{636}$ In diesem Sinne schließt Ebeling: es sei erforderlich, den „Situationsbezug der Sprache [...] sich einmal durch Zusammenstellung der vielen Wörter und Wendungen bewusst (zu) machen, welche die Sprache selbst dafür bereit hält, den Akt des Sprechens bereits von seinem Situationsbezug her und auf ihn hin zu benennen“. 637

Ebelings Auffassung vom Situationsbezug der Sprache und seine oben aufgezeigten Entfaltung des Verhältnisses von Zeit und Wort laufen nun zusammen. Denn durch den Zeit- und den Situationsbezug des Wortes bzw. der Sprache weisen sie in der Tat auf denselben Sachverhalt hin: Wenn sich das Wort als zeitliches Geschehen ereignet, bedeutet das, dass es von der jeweiligen Situation abhängig ist. Nur in eine Situation, in einen geschichtlichen Kontext eingebunden, ist es das sich ereignende Wort. Die Predigt, die sich in Sprache vollzieht, ist als das geschehende Wort darum abtrennbar von dem Kontext. Eine positive Wirkung der Sprache und die daran geknüpfte Kraft der Predigt, für die Ebeling plädiert, kann nur dadurch erwartet und erzielt werden.

\subsubsection{Zwischen Glaubensgrund und Glaubensäußerung}

Als das letzte Spannungsfeld der Predigt bringt Ebeling das Verhältnis von Glaubensgrund und Glaubensäußerung zur Sprache. Es ist offensichtlich, dass der Glaubensgrund keineswegs gleich mit der Glaubensäußerung ist. Es gibt in der Predigt den Glaubensgrund aber nur als Glaubensäußerung, weil man dabei nicht mit einer himmlischen Sprache oder Engelszungen, sondern mit menschlicher Sprache redet. Das Spannungsverhältnis von Glaubensgrund und Glaubensäußerung wurde bereits in

\footnotetext{
${ }^{635} \mathrm{TuV}, 99$.

${ }^{636}$ WG II, 409. An diesem Punkt vergleicht M. Petzoldt Ebeling mit J.L. Austin, behauptend, dass er irgendwie ,in der Nähe zur Austin's Unterscheidung zwischen lokutionärem (with a certain meaning) und illokutionärem (with a certain force) Akt der Sprache“ stehe, ,obwohl diese Nähe nicht von seiner Absicht kommt und ihm sogar lange Zeit nicht bewusst gewesen ist". Ders., Kommunikations- und medientheoretische Anmerkungen zur subjektivitätstheoretischen Kritik an der Wort-Gottes-Theologie, in: I.U. Dalferth (Hg.), Krisen der Subjektivität, Tübingen 2005, 417-453, 453.

${ }^{637}$ Sprachlehre, 106.
} 
der Rede von der zeit- und situationsbezogenen Bezeugung des christlichen Glaubens impliziert, weil sich die Glaubensäußerung als ein auf den Kontext bezogener Akt des Sprechens erweist.

Ebeling erläutert dieses Spannungsverhältnis hier noch einmal kurz in Bezug auf die Frage, „wie sich in der Predigt das zusammenreimt, was sich zu widersprechen scheint." ${ }^{\text {"638 }}$ Es geht also um den widersprüchlichen Charakter der Predigt. Ebeling formuliert ihn mit drei Polaritäten: erstens als „Unbedingtheit und Bedingtheit“, weil die Predigt einerseits ,,auf ein verlässliches, letztgültiges Wort“ ansprechen und sich andererseits „der Beschränktheit und Relativität der Aussage“ bewusst sein soll; zweitens als „das Eine und die Vielfalt", weil sie „auf ein Einziges und das Wissen“ ausgerichtet sein soll, „davon nur in einer Vielfalt reden zu können und sogar zu sollen, die das Eine nie erschöpfend erreicht"; und letztlich als „Gebundensein und Freiheit“, weil sie an den Glauben als ihren Auftrag und ihre notwendige Voraussetzung gebunden ist und zugleich die Freiheit hat, „die jedes redlichen, verantwortlichen Wortes ist, das so auch die Predigt sein soll“. ${ }^{639}$

Der widersprüchliche Charakter kommt ursprünglich von dem Sachverhalt, dass die Predigt zwei unvereinbare Worte in sich enthält, nämlich Gotteswort und Menschenwort. Er hat darum mit einer alten Frage der Predigt zu tun: Wie kann ein Mensch eine Predigt halten? Ist das eigentlich möglich? ${ }^{640}$ Hinter dieser Frage steht der Gedanke, dass die Predigt nicht bloß menschliche Rede ist, dass sie nicht bloß das den Inhalt der Bibel als einen Text erklärende Wort ist, sondern dass sie das das Wort Gottes irgendwie vermittelnde Wort ist. Die Predigt so als eine Rede von Gott im Gottesdienst zu verstehen, gründet sich auf die Verheißung der Bibel, dass ,der Glauben aus der Predigt“ kommt, die „,aus dem Wort Gottes" kommt (Röm 10, 17) und dass in der Menschenrede das aus dem Mund Gottes stammende Wort vernommen wird, das nicht zu ihm leer zurückkommt, sondern völlig durchführt, was er will (Jes $55,11)$. Die Verheißung Gottes und das Vertrauen des Menschen auf sie sowie die Wirkung des Wortes Gottes bilden darum den Ermöglichungsgrund der Predigtpraxis. Die Tatsache, dass Gott erlaubt, sein Wort in Menschenmund zu legen, steht dann für die Stellung und Würde der Predigt. Das heißt, so wie Gott trotz der Sünde der Menschen diese als seine Gemeinschaft erachtet, ermöglicht und würdigt Gott selbst trotz des unüberwindbaren Unterschieds zwischen göttlichem und menschlichem Wort die Predigt. Da ist die berühmte Rede von Heinrich Bullinger zu betrachten,, „Praedicatio verbi Dei est verbum Dei“: „Wenn daher heute dieses Wort Gottes durch rechtmäßig berufene Prediger in der Kirche verkündigt wird, so glauben wir, dass Gottes Wort selbst verkündigt und von den Gläubigen

\footnotetext{
${ }^{638}$ WG III, 565.

639 WG III, 565.

${ }^{640}$ Die Frage „Predigen - wie kann man das?“ wird schon durch K. Barth gestellt, der mit ihr „,das spezifische Pfarrerproblem der Predigt“ bezeichnet. Ders., Not und Verheißung der christlichen Verkündigung, in: Ders., Das Wort Gottes und die Theologie. Gesammelte Vorträge, München 1924, 103, vgl. 99-124.
} 
aufgenommen wird und dass man kein anderes Wort Gottes erfinden oder vom Himmel erwarten darf.“ 641

Ebeling ist der Auffassung, dass in der Predigt das Reden von Gott möglich ist und die Predigt ihren eigentlichen Wert in der Aufgabe hat, durch Mitteilung des Wortes Gottes den Glauben zu wecken. Vor allem in seinem frühen Vortrag über $>$ Wort Gottes und Sprache< (1959) versucht er, das Verhältnis zwischen Gottes Wort und Menschenwort zu bestimmen und betont, dass das schon zur Sprache gekommene Wort Gottes neu zur Sprache kommen werden kann und muss. ${ }^{642}$ Aufgrund dessen, dass Menschenwort Gotteswort zu vermitteln vermag, will er die Hoffnung auf das Gotteswort wecken und die Kraft der Predigt restituieren. ${ }^{643}$ Diese Intention unterliegt stets seinem Reden von der Predigt. Sein hermeneutisches Sprachkonzept für die Predigt wird ambivalent urteilt. Einerseits wird sie aus zweierlei Gründen stark kritisiert, also wegen des unbegrenzten, kritiklosen Vertrauen auf die Sprache, die in ihrer Macht Zauberei zu ähneln scheint, und wegen der daraus resultierenden Verschiebung der übermäßigen Verantwortung hin zu dem die Sprache sagenden Prediger. ${ }^{644}$ Andererseits wird sie als ein Ansatz zu einer neuen Homiletik hoch geschätzt, weil sie eine neue Anerkennung von der Sprache schafft und damit die Predigt als Partizipation am Wort Gottes würdigt. ${ }^{645}$

${ }^{641}$ H. Bullinger, Confessio Helvetica Posterior (1562/66), in: P. Jacobs (Hg.), Reformierte Bekenntnisschriften und Kirchenordnung in deutscher Übersetzung, Neukirchen 1949, 178.

${ }^{642}$ Wesen, 178-187.

${ }^{643}$ Wesen, $181 \mathrm{f}$.

${ }^{644} \mathrm{Vgl}$. A.C. Thiselton, The New Hermeneutic, in: I.H. Marshall (Hg.), New Testament Interpretation. Essays on Principles and Methods I, Carlisle UK (Paternoster) 1972, 308-333; D. Lose, Whither Hence, New Homiletic? in: The Papers of the annual meeting of the American Academy of Homiletics, Dec. 2000, 255-265. bes. 259ff.

${ }^{645}$ Ebeling hat einen großen Einfluss auf die sog. „New Homiletic“, vornehmlich bei Randolph und Craddock. Vgl. D. Randolph, The Renewal of Preaching, Philadelphia 1969; Fred B. Craddock, As One Without Authority, St. Louis, 1971. Seit den frühen 1990er Jahren wird aber die „New Homiletic“ und ihr Verhältnis zur neuen Hermeneutik kritisch überprüft. Z.B. berichtet M. Nicol in seiner Erlanger Antrittsvorlesung „Preaching from Within. Homiletische Positionslichter aus Nordamerika“ (Pastoraltheologie 86, 1997, 295-309) und in seinem Aufsatz „Homiletik, Positionsbestimmung in den neunziger Jahren“ (ThLZ 123, 1998, 1049-1066), dass wesentliche Impulse zur „New Homiletic“ in den USA von Ebeling (u. Fuchs) mit seiner Überlegung zum Wortgeschehenen ausgegangen sind. 


\section{KAPITEL III. SPRACHE IN DER DOGMATIK}

\section{Problemhorizont der Sprache in der >Dogmatik des christlichen Glaubens<}

Die Bezeichnung „Sprache in der Dogmatik“ bedeutet hier nicht, Sprache als ein dogmatisches Thema zu betrachten. Wenn Sprache als ein dogmatisches Thema behandelt wird, wird sie gewöhnlich für eine Eigenschaft des Menschen gehalten und der Anthropologie als einem Teilgebiet der Dogmatik zugeordnet. Ebeling hält die Sprache aber nicht für ein anthropologisches Thema. Für ihn gehört sie, wie bereits erwähnt, zuallererst zur Fundamentaltheologie, die er als die theologische Fundamentallehre ansieht. Sie untermauert seine ganze Dogmatik, genauer seine Entwürfe von Gott, Menschen, Jesus, Sünde, dem heiligen Geist, Sakrament usw. Die Entdeckung solcher Unterstützung des Konzepts der Sprache bzw. Sprachlichkeit in der Dogmatik Ebelings wird die Aufgabe dieses Kapitels.

Als Vorarbeit ist es zunächst noch nötig, den Titel $>$ Dogmatik des christlichen Glaubens $<$ sowie ihre Struktur zu analysieren und Ebelings darin liegende Intention zu finden. Es geht näher darum, erstens, wie er das Verhältnis von Dogmatik und Glauben bestimmt und warum er unter den Vorzeichen des Glaubens seine Dogmatik stehen lässt (1.1); und zweitens, wie er den Begriff des Glaubens auslegt und dementsprechend seine Dogmatik aufbaut (1.2). Man wird demzufolge zur Erkenntnis kommen, dass Ebelings Entwurf der Dogmatik von seinem Glaubensverständnis ausgeht und dieses sich eng auf den Begriff der Sprachlichkeit bezieht (1.3).

\subsection{Die Zusammenstellung von Dogmatik und Glaubenslehre}

Dogmatik wird im Wörterbuch als „wissenschaftliche Darstellung des christlichen Glaubens“646 definiert. Eine derartige Definition der Dogmatik ist aber relativ jung, da sie bis zum 17. Jahrhundert eng in Verbindung mit dem Dogma betrachtet und eher für die Lehre von den Dogmen gehalten wurde. ${ }^{647}$ Die Dogmatik hat nicht nur äußerlich, sondern auch sachlich mit dem Dogma zu tun. Man muss dennoch zugleich beachten, dass die zentrale Aufgabe der Dogmatik nicht lediglich die systematische Entfaltung und Interpretation von Dogmen ist, sondern eigentlich oder letztlich darin besteht, durch den rationalen Umgang mit dem Glauben dessen Gesamtinhalt zu verstehen. Dogmatik und Glaube sind wesentlich aufeinander bezogen.

Entgegen der Sitte, Dogma in Bezug auf eine autoritative Entscheidung des kirchlichen Lehramtes zu verstehen und den Begriff der Dogmatik von dem so verstandenen Dogma als dem Gegenstand der Dogmatik herzuleiten, entwickelte sich im 19. Jahrhundert ein Trend, für die Bezeichnung der

\footnotetext{
${ }^{646}$ Art. Dogmatik, in: Duden Online Wörterbuch. http://www.duden.de/suchen/dudenonline/dogmatik.

${ }^{647}$ H. Filser, Dogma, Dogmen, Dogmatik, Münster u.a. 2001, 686ff.
} 
Dogmatik den Terminus „Dogmatik“ selbst zu vermeiden. Als ein Vorreiter dieses Trends ist zuallererst Schleiermacher zu nennen. Dieser definierte den Begriff der Dogmatik als „die Wissenschaft von dem Zusammenhang der in einer christlichen Kirchengesellschaft zu einer gegebenen Zeit geltenden Lehre“ 648 und hielt den Terminus „Dogmatik“ für eine Darstellung des kirchlichen Lehrbegriffs. Obwohl er in seiner Ausführung noch von Dogma oder Dogmen sprach, wurde bei ihm der Schwerpunkt auf den in der Dogmatik sich aussprechenden Glauben sowie die Glaubensdarstellung gelegt. Sein Standpunkt lautet: „Christliche Glaubenssätze sind Auffassungen der christlich frommen Gemütszustände in der Rede dargestellt." ${ }^{649}$ Er betitelte deshalb seine dogmatische Arbeit, die 1821/22 in zwei Bänden erschien, mit der „Glaubenslehre“. Die dogmatische Arbeit eng in Bezug auf den Glauben zu verstehen und dementsprechend als „Glaubenslehre“ oder „Glauben“ zu bezeichnen, wurde seit Schleiermacher als ein Merkmal des Dogmatikkonzepts im 19. Jahrhunderts geprägt und weiter von Theologen wie Ernst Troeltsch, Horst Stephan und Werner Elert aufgenommen. ${ }^{650}$

In der ersten Hälfte des 20. Jahrhunderts erlebte die Konnotation des Dogmatikbegriffs in der evangelischen Theologie jedoch eine Wende. Vermutlich unter dem Einfluss des Kirchenkampfes und der ökumenischen Gespräche, wurde die Funktion der Dogmatik für die Kirche noch wichtiger und ihr Begriff mit dieser Perspektive neu gedacht. Im Unterschied zur römisch-katholischen Lehre wurde aber dabei weder die Kirche für eine lehramtliche Instanz, welche ein Dogma endgültig fixiert oder garantiert, noch der Begriff des Dogmas bzw. der Dogmatik für ein Lehroder Glaubensgesetz gehalten, sondern Dogmatik als kritische Überprüfung der Dogmen an der ursprünglichen Offenbarung verstanden. K. Barth bezog die Dogmatik z.B. auf die konkrete Verkündigung der Kirche und definierte sie als „eine Funktion der Kirche“ oder als „,wissenschaftliche Selbstprüfung der christlichen Kirche hinsichtlich der ihr eigentümlichen Rede von Gott ${ }^{“ 651}$, so dass er seine Dogmatik mit der „kirchliche(n) Dogmatik“ betitelte. Im Anschluss an Barth sah Emil Brunner die Dogmatik in Bezug auf die Kirche und sagte, sie sei die „Selbstbesinnung der christlichen Gemeinde über Grund, Sinn und Inhalt der ihr gegebenen und aufgetragenen Botschaft " ${ }^{652}$ Otto Weber verstand den berechtigten Gebrauch des Dogmenbegriffs als kirchliche Lehrentscheidung. ${ }^{653}$

\footnotetext{
${ }^{648}$ F. Schleiermacher, CG, Bd. I, §19, 143.

${ }^{649}$ F. Schleiermacher, CG, Bd. I, §15, 127.

${ }^{650}$ E. Troeltsch, Glaubenslehre, München/Leipzig 1925; H. Stephan, Glaubenslehre, Gießen 1920, Berlin ${ }^{3} 1941$;

W. Elert, Der christliche Glaube, Hamburg ${ }^{3} 1956$.

${ }^{651} \mathrm{~K}$. Barth, KD, I/1,1;1,3.

${ }^{652}$ E. Brunner, Dogmatik I, Zürich ${ }^{3} 1960,7$.

${ }^{653}$ O. Weber, Grundlagen der Dogmatik, Bd. I, Neukirchen 1959², 43-49.
} 
Angesichts der Spannung zwischen den oben beschriebenen beiden Varianten ${ }^{654}$ von Dogmatik und Glaubenslehre, entwickelt Ebeling seine eigene Meinung. In Bezug auf die Gotteserkenntnis bezeichnet sich Ebelings Dogmatik offenbar als eine Glaubenslehre. An diesem Punkt redet man oft von Ebelings Anlehnung an Schleiermacher, der die dogmatische Tradition als Glaubenslehre begründet. Es muss m.E. dazu noch geprüft werden, warum Ebeling trotzdem die Schleiermacherische Betitelung der Glaubenslehre nicht übernimmt. Wenn ein Theologe seine Dogmatik betitelt, macht er das absichtsvoll. Ebeling scheint eben eine bestimmte Intention für die Bezeichnung der $>$ Dogmatik des christlichen Glaubens $<$ zu haben. Damit ist gemeint, dass er für seine dogmatische Arbeit absichtlich den Terminus „Dogmatik“ in Verbindung mit dem Ausdruck „Glauben“ benutzt und nicht direkt als eine „Glaubenslehre“ bezeichnet, so wie es Schleiermacher tut.

Durch die Benutzung des Wortes „Dogmatik“ in Verbindung mit dem Ausdruck „Glauben“ zeigt Ebeling, dass er sich gegen das verengte Verständnis von Dogmatik des 19. Jahrhunderts wendet, das den römisch-katholischen, auf autoritativer, lehramtlicher Befestigung kirchlicher Lehre fußenden Dogmenbegriff ${ }^{655}$ voraussetzte und die negative Stimmung gegen den Terminus „Dogmatik“ machte. ${ }^{656}$ Dagegen behauptet er, zwischen Dogmatik und Glauben bestehe „kein Konkurrenzverhältnis“, „sofern dem Glaubensverständnis in verschiedener Hinsicht eine lebendige innere Spannung zugestanden wird: von Überlieferung und gegenwärtiger Verantwortung, von Lehre und Lebensvollzug, von kirchlichen Konsens und Überzeugung des Einzelnen, von Gewissheit und kritischer Wachsamkeit“. ${ }^{657}$ Diese Polaritäten gehören zum Wesen des Glaubens, aber sie stellen laut Ebeling auch „die Frage der konfessionellen Bestimmtheit der Dogmatik ${ }^{\text {‘658 }}$. Denn die Interpretation der dogmatischen Tradition soll zugleich als „Rechenschaft über den christlichen Glauben“ geschehen und die „Konzentration auf die materiale Dogmatik“ durch die hermeneutische Besinnung auf die Grunderfahrungen, die den Glaubensaussagen zugrunde liegen, verantwortet werden. ${ }^{659}$ Auf solche Weise richtet Ebeling seine Aufmerksamkeit auf die grundlegende Gemeinsamkeit zwischen Dogmatik und Glauben und versucht dadurch zwei Varianten von Dogmatik und Glaubenslehre zusammenzustellen. Die inhaltliche

\footnotetext{
${ }^{654}$ Es gibt allerdings noch andere Alternativen für die Bezeichnung der Dogmatik. Z.B. wählt Paul Tillich den Titel „Systematische Theologie“. Das, was Tillich mit dem Terminus „Systematische Theologie“versteht, ist nicht erklärt. Er scheint dabei Apologetik, Dogmatik und Ethik zu umfassen und die christlichen Inhalte mit der Korrelationsmethode in unserer gegenwärtigen Lage erörtert. Ders., Systematische Theologie, 3 Bde., Stuttgart 1955-1966.

${ }^{655}$ Solcher Dogmenbegriff wird erkennbar z.B. in den Aussagen Karl Rahners: Dogma sei „ein Satz, der Gegenstand der fides divina et catholica ist, also ein Satz, den die Kirche ausdrücklich durch das ordentliche Lehramt oder durch eine päpstliche oder konziliare Definition als von Gott geoffenbart so verkündigt, dass seine Leugnung Häresie ist.“ Ders./H. Vorgrimler, Art. Dogma, in: Kleines Theologisches Wörterbuch, Freiburg ${ }^{15} 1985$, 83.

${ }^{656} \mathrm{Vgl}$. WGT, $168 \mathrm{ff}$.

${ }^{657} \mathrm{D} \mathrm{I}, 13$.

${ }^{658} \mathrm{D} \mathrm{I}, 13$.

${ }^{659} \mathrm{D}$ I, $6 \mathrm{f}$.
} 
Verbindung von beiden wurde schon von Schleiermacher versucht, doch lag nur eine negative Stimmung gegen die Dogmatik zugrunde. ${ }^{660}$ Derartige Intention zeigt Ebeling äußerlich und deutlich durch den Titel seiner Dogmatik an: $>$ Dogmatik des christlichen Glaubens $<$.

Für die wesentliche Gemeinsamkeit zwischen Glaubensaussage und dogmatischer Reflexion spielt bei Ebeling vor allem der Begriff der Erfahrung eine wichtige Rolle. In den Prolegomena erklärt er, was Dogmatik ist, indem er danach fragt, worauf sie sich gründet und worauf sie sich bezieht. Er stellt dar, dass sie sich auf Christus als Grund des Glaubens gründet und auf die Situation des Menschen bezieht, so dass beide auf die Quelle der Dogmatik verweisen: die Schrift und die Erfahrung. Der Umgang mit allem, „was unter dem verdächtigen Plural, die Quellen der Dogmatik über die heilige Schrift als das Urzeugnis des christlichen Glaubens hinaus angesprochen ist" "661, läuft bei Ebeling doch letztlich auf einen einzigen Begriff hinaus, nämlich Erfahrung. Denn durch den Begriff der Erfahrung „wird die Lebenswirklichkeit aufgeboten und in die dogmatische Aufgabe einbezogen. Unter den Begriff der Erfahrung fällt einmal die gesamte überlieferte Erfahrung mit dem christlichen Glauben, wozu auch dogmatische Tradition gehört, [...] ferner die eigene Lebenserfahrung einschließlich ihrer Fähigkeit zur Erweiterung, [...] endlich die wissenschaftliche Welterfahrung samt der Erfahrung, die wir wiederum lebensmäßig mit ihr machen.“ ${ }^{662}$ Die Erfahrung ist für Ebeling dann nichts anderes „als die Zugehörigkeit all dessen, was darunter stichwortartig begriffen wurde, zu dem, worum sich Dogmatik zu kümmern hat, wenn sie ihrer Aufgabe gerecht werden soll““. 663

Ebeling verweist auf die hermeneutische Überlegung, dass die heilige Schrift nur dann in ihrer Geschehensbewegung zwischen Wort und Text erfasst werden kann, wenn das Wort „in das Leben eingehet, wenn es also mit Erfahrung zu tun hat in der Weite menschlicher Lebenserfahrung. "664 Ohne den Umgang mit dem Leben kann die Dogmatik das sola scriptura nicht aufrichtig übernehmen, das nach dem sola experientia ruft. Es geht bei Ebeling um das Verhältnis von Lebens- und Glaubenserfahrung als Bedingung der Möglichkeit theologischer Erkenntnis. In der Verhältnisbestimmung von Glauben und Leben nimmt die Erfahrung eine vermittelnde Position ein. Alle allgemeinen Lebenserfahrungen, die einen Transzendenzbezug enthalten, sind auf die Glaubenserfahrung anwendbar. Und weil sich die Lebenswirklichkeit des Menschen durch die Erfahrung konstituiert, kann der Glaube allein in Bezug auf die Erfahrungsdimension in seiner Lebensrelevanz verstanden werden. In Hinsicht auf die Erfahrungsthematik in Ebelings $>$ Dogmatik des christlichen Glaubens $<$ weist K. Gelder zurecht darauf hin, dass sie zur „Herausarbeitung des Existenz-

\footnotetext{
${ }^{660}$ Vgl. H.-J. Birkner, Beobachtungen zu Schleiermachers Programm der Dogmatik (1963), in: H. Fischer (Hg.), Schleiermacher-Studien, Berlin/New York 1996, 99-123.

${ }^{661} \mathrm{D}$ I, 41.

${ }^{662} \mathrm{D} \mathrm{I}, 41 \mathrm{f}$.

${ }^{663} \mathrm{D} \mathrm{I}, 42$.

${ }^{664} \mathrm{D}$ I, 42.
} 
und Lebensbezuges des Glaubens" dient, womit Ebeling darzulegen sucht, wie alle dogmatischen Themen „die Existenz des Menschen und mit ihr seine Erfahrungswirklichkeit betreffen und ihm wahre Erfahrung allererst erschließen“ ${ }^{665}$

Ebeling ist grundsätzlich der Meinung, dass die Frage der Wissenschaftlichkeit der Theologie richtig behandelt werden kann, nicht durch das Bemühen um „die wissenschaftliche Anerkennung der Theologie“, sondern durch das Bemühen darum, „das Verhältnis von Wissenschaft und Leben“ richtigzustellen. „Denn nirgends durchdringen sich die Anforderung wissenschaftlicher Disziplin und die Verantwortung für das Leben in umfassendstem Sinne so erregend wie in dem Geschäft christlicher Dogmatik, der systematisch verfahrenden Rechenschaft über den christlichen Glauben.“ ${ }^{666}$ Der Verlust der Erfahrungsbezogenheit der Theologie ist für Ebeling sogar „eine Erkrankung, die tödlich sein kann“. 667

Es ist nun zu sagen: Ebelings Dogmatik vollzieht sich als Glaubenslehre, die doch keineswegs bloß als ein Lehrstück verstanden werden darf, sondern als eine Interpretation des christlichen Credos, die primär die Tatsache bedenkt, dass das Glaubensbekenntnis die Glaubenserfahrung und damit ein Bekenntnis des Glaubens ist. Ihr letztes Ziel wendet sich dann dahin, den Lesern nicht nur zu einem theologischen Wissenstand zu verhelfen, sondern für ein eigenes Nachdenken über den Glauben bereit werden zu lassen und ihnen zu einer eigenen „Sprachvollmacht zu verhelfen“. ${ }^{668}$ Allein in diesem Sinne wird die Verwendung des Begriffs der „Sprachschule des Glaubens“6699 für Ebelings Dogmatik ins Recht gesetzt.

Ebeling plädiert für das konkurrenzlose, wesentlich zusammengehörende Verhältnis von Dogmatik und Glauben. Er verwendet deshalb die Kombination von beiden für den Titel seiner Dogmatik und stellt jede Bandschrift unter das Vorzeichen des Glaubens. Er baut die Struktur der Dogmatik auch gemäß dem Verständnis des Glaubens auf.

\subsection{Die Darstellung des Glaubens als ein Ganzes}

In Bezug auf die Haupteinteilung seiner Dogmatik folgt Ebeling den drei Artikeln des Credos, die damit zum Gliederungsprinzip werden. Die Intention des Aufbaus besteht jedoch nicht darin, die Dogmatik „als Auslegung des Apostolikums“ darzustellen, sondern „die drei tief im Biblischen verankerten Hauptgesichtspunkte“ herauszustellen. ${ }^{670}$ Der christliche Glaube, der im Credo bekannt wird, hat eine dreifache Dimension: der trinitarische Glaube an Gott, den Schöpfer der

\footnotetext{
${ }^{665}$ K. Gelder, Glaube und Erfahrung, Neukirchen-Vluyn 1992, 6f.

${ }^{666} \mathrm{D}$ I, 60.

${ }^{667}$ WG III, 3 .

${ }^{668} \mathrm{D}$ I, 22f.

${ }^{669} \mathrm{D} \mathrm{I}, 22$.

${ }^{670} \mathrm{D}$ I, 71.
} 
Welt; den Versöhner der Welt und den Vollender der Welt. Diese klassische, dreifache Dimension des Glaubens könnte Ebeling etwa als Respekt vor der Tradition aufnehmen und zum Ausdruck bringen. Er hält sie aber nicht lediglich für ein traditionelles Schema oder für eine von Kirche überlieferte, religiöse Darstellung, sondern für den notwendigen Sachverhalt, der im christlichen Glauben selbst begründet ist und auch diesen wieder weckt, weil sich die Heilswirklichkeit in der Bibel immer im Zusammenhang zeigt. Dass Ebeling gemäß den drei Artikeln des Credos seine Dogmatik aufbaut, zielt schließlich darauf, den der trinitarischen Struktur des christlichen Glaubens tief innewohnenden Sachverhalt hervorzuheben. Dafür ordnet er die verschiedenen dogmatischen Themen sehr sorgfältig an:

In den drei Bänden behandelt Ebeling das je heilsgeschichtlich arrangierte Thema von Schöpfung, Versöhnung und Vollendung. Dieses trinitarische Gliederungsprinzip wurde schon häufig angewendet und gewöhnlich unter dem sogenannten heils-ökonomischen Aspekt der Trinitätslehre betont. Die einzelne Person der Trinität ist dabei zuordnungsweise mit dem heilsgeschichtlichen Wirken Gottes verbindet, also Gott der Vater mit der Schöpfung, Jesus Christus der Sohn Gottes mit der Versöhnung, der Heilige Geist mit der Erlösung oder Vollendung. Aber bei Ebeling geht es mit den unterschiedlichen Aspekten von Schöpfung, Versöhnung und Vollendung um den gleichen Gott, der in der gleichen Welt handelt, und um den gleichen Glauben an ein und denselben Gott. Genauer gesagt, er legt kein Gewicht auf die nebeneinanderstehende Folge des heilsgeschichtlichen Wirkens Gottes wie Schöpfung, Versöhnung und Vollendung. Er will sie weniger chronologisch verstehen und richtet seine Aufmerksamkeit darauf, dass Gott, der sich vor Sündern als Versöhner beweist, zugleich als Schöpfer und Vollender der Welt bekannt wird, ${ }^{671}$ obwohl der Mensch von oder vor Gott unterschiedlich bestimmt wird. Beim Aufbau seiner Dogmatik ist Ebeling daran gelegen, nicht die Nebeneinanderstellung der drei Artikel des Credos, sondern ihre Aufeinander-Bezogenheit, oder besser gesagt, ihr ineinander verwickeltes und auf Einheit ausgerichtetes Verhältnis aufzuzeigen. Er scheint sogar den Charakter von Einheit und wechselseitiger Durchdringung, der das Verhältnis der drei göttlichen Personen bezeichnet, zum Verhältnis mit Welt und Menschen zu erweitern: „Diese drei Dimensionen des christlichen Glaubens, die einerseits auf das trinitarische Gottesbekenntnis hinauslaufen, andererseits ein dreifaches Ja zur Welt eröffnen, sind damit zugleich zur Einheit zusammengefasst. “672 Der so geartete Sachverhalt wird konkreter, indem er in jedem Band mit unterschiedlichen thematischen Betonungen wiederholt wird.

\footnotetext{
${ }^{671} \mathrm{Vgl}$. Zu meiner >Dogmatik des christlichen Glaubens<, in: WG IV, 476-491, bes. 484: „Weil sich Gott dem Sünder als Versöhner bekannt gemacht hat, wird er nun auch erst wahrhaft als der Schöpfer und der Vollender bekannt.“ ${ }^{672}$ D I, 71.
} 
Der Inhalt des Credos als Gliederungsprinzip der Ebelingschen Dogmatik ist in einem Satz zusammenzufassen: Der Mensch glaubt an Gott als den Schöpfer, Versöhner und Vollender der Welt. Neben den drei Faktoren Gott, Welt und Menschen ist noch ein weiterer zu nennen: der Glaube. Ebeling wählt diese vier Faktoren als Bestandteil des „Koordinatensystems“673 für den Aufbau seiner Dogmatik und ordnet sie gemäß den Themen in je veränderter Reihenfolge an: Im ersten Teil, dessen Thema die Schöpfung ist, werden die Begriffe „Glaube“, „Gott““, „Welt“ und „Mensch“ nacheinander erläutert. Als grundlegenden Sachverhalt identifiziert Ebeling, dass der Glaube an Gott als den Schöpfer der Welt die Situation des Menschen bestimmt (Glaube - Gott Welt - Mensch). Der zweite Teil thematisiert die Versöhnung und beginnt mit der christologischen Aussage von Gott in Christus und dem Menschen Jesus, der in die von Gott geliebte Welt gekommen ist, und fokussiert auf den Glauben an Jesus Christus (Gott - Mensch - Welt - Glaube). Im dritten Teil geht es unter dem Thema der Vollendung um den Menschen in Christus, den rechtfertigenden Glauben und die Überwindung und Vollendung der Welt. In der Summe des Ganzen geht es um Gott, der alles in allem ist (Mensch - Glaube - Welt - Gott). Jeder der drei Teile behandelt also Glaube, Gott, Welt und Mensch. ${ }^{674}$

Indem Ebeling seine Dogmatik in einem durch die Hauptgesichtspunkte von Glaube, Gott, Welt und Mensch in ihrer wechselseitigen Reihenfolge markierten Koordinatensystem entfaltet, bringt er die Auffassung zum Ausdruck, dass die Aussagen über Gott, Mensch und Welt nur in ihrem Zusammenhang richtig verstanden würden und alle zusammen als Glaubensaussagen erscheinen. Die christliche Vorstellung des Menschen beginnt z.B. mit der Darstellung des Menschen coram Deo (§14), nämlich als Sünder (§15) und als Gottes Ebenbild (§16), entfaltet sich zur Rede von dem Menschen Jesus als dem historischen Jesus (\$21), dessen Wort (§22) und Verhalten (§23) dabei betrachtet werden, und vollzieht sich im Bild des Menschen in Christus, der im Streit zwischen Heiligem Geist und Menschengeist (§31) sowie dem alten und dem neuen Menschen (§32) sich als Gottes Werk (§33) erkennt und so lebt. Durch diese Struktur zeigt Ebeling, dass die theologische Betrachtung des Menschen, die Anthropologie, nur durch die Zusammenstellung der in drei Teilen beschriebenen Darstellungen des Menschen vollständig zur Geltung kommen kann. Gleichermaßen gilt, dass wenn das dreifache Wirken Gottes nicht zu Ende, also nicht als ein Ganzes gedacht wird, man keines der drei als bereits vollbracht betrachten kann. Das heißt, allein durch einen Teil der Dogmatik, allein durch einen Artikel des Glaubensbekenntnisses kann keine richtige, vollständige Vorstellung von Gott oder Welt und damit nicht vom christlichen Glauben entstehen. Ebeling sagt, der christliche Glaube sei keine „Summe von Gedanken, die bloße Addition verschiedener Glaubensinhalte ist“ und stelle vielmehr „eine Lebenseinheit“ dar, ,in der

\footnotetext{
${ }^{673} \mathrm{D}$ I, 73.

${ }^{674} \mathrm{D}$ I, $73 \mathrm{ff}$.
} 
Schöpfungsglaube, Versöhnungsglaube und Vollendungsglaube nur verschiedene Aspekte derselben Sache sind“. ${ }^{675}$ Er versucht daher, den christlichen Glauben immer als ein Ganzes zu sehen und zu beschreiben.

Ebelings Intention der Darstellung des Glaubens als ein Ganzes wird vor allem im Vergleich mit der Glaubenslehre Schleiermachers verdeutlicht. Die drei Aspekte von Gott, Welt und Mensch, die Schleiermacher für die Infrastruktur seiner Glaubenslehre verwendet, nimmt Ebeling auf. Er ergänzt sie jedoch um einen vierten Aspekt, nämlich den Glauben. Anders als Schleiermacher behandelt er das Thema des Glaubens nicht nur in Bezug auf den Menschen. Er will dadurch den Glauben von den anderen Aspekten nicht isolieren. Er will eher der Isolierung der Gesichtspunkte vorbeugen, indem er das Thema des Glaubens zum zentralen Thema macht, auf das alle drei Aspekte bezogen werden. Bezüglich des Gesichtspunkts des Glaubens bringt er selber den Unterschied zu Schleiermacher sowie seine darin versteckte Intention klar zum Ausdruck: „Es scheint mir wichtig zu sein, im Unterschied zu Schleiermacher den Gesichtspunkt des Glaubens [...] nicht einfach mit dem anthropologischen Aspekt, also mit dem Unterthema Mensch, ineins zu setzen. Vielmehr muss der Gesichtspunkt Glaube gesondert zum Thema werden, weil dadurch der Blick darauf gelenkt wird, was die Aussagen über Gott, Welt und Mensch zur Einheit verbindet und was den gemeinsamen Charakter dieser Aussagen ausmacht. Indem neben Gott, Welt und Mensch auch der Glaube zum Thema wird, tritt zu den dreien nicht eigentlich ein vierter Gesichtspunkt hinzu, sondern wird die Einheit zur Geltung gebracht, der diese verschiedenen Aussagerichtungen als Glaubensaussagen verbindet. “676

In diesem Zusammenhang sei nun zu erwähnen: Absichtsvoll stellt Ebeling seine Dogmatik unter das Vorzeichen des Glaubens und versucht durch den Aufbau seiner Dogmatik darzustellen, dass alle Glaubensaussagen in der Dogmatik im Grund des Glaubens miteinander zusammen hängen und auf ihn hin führen. Letztlich zielen sie also immer nur auf die Entfaltung des einen und einzigen Geheimnisses unserer Gemeinschaft mit dem einen Gott als dem Schöpfer, Versöhner und Vollender zugleich. Es ist auch kein Zufall, dass er die Dreieinigkeit Gottes als eine Zusammenfassung seiner ganzen dogmatischen Aussagen unter dem Thema „Gott alles im allem“ am Ende seiner Dogmatik platziert. Es gehört ja zu den Hauptaufgaben seiner Dogmatik als der Rechenschaft über den christlichen Glauben, erkennbar werden zu lassen, dass der Glaube ein unteilbares Ganzes ist und darum, worauf A. Beutel mit Recht hinweist, „nicht auf ein spezielles Lehrstück beschränkt, sondern ebenfalls als einen Gesamtaspekt dargestellt" werden muss. ${ }^{677}$

\footnotetext{
${ }^{675} \mathrm{D} \mathrm{I}, 67$.

676 D I, 74.

${ }^{677}$ A. Beutel, Gerhard Ebeling. Eine Biographie, Tübingen 2012, 427.
} 


\subsection{Die Entdeckung der Sprachlichkeit im Relationsbegriff des Glaubens}

Im Mittelpunkt des oben aufgezeigten Koordinatensystems der Ebelingschen Dogmatik steht der Glaube. Dieser bestimmt sich je in seinem Verhältnis zu den anderen Hauptaspekten von Gott, Welt und Menschen unterschiedlich, nämlich coram Deo, coram Mundo und coram meipso. Aus diesen drei coram-Relationen besteht der christliche Glaube. Der Begriff der „Relation“ spielt eine zentrale Rolle für Ebelings Glaubensverständnis und trifft sein Ziel, jedes einzelne Thema in der Dogmatik unter dem gesamten Aspekt des Glaubens zu betrachten und den christlichen Glauben sowohl als ein Ganzes als auch im Lebensbezug zu erweisen: „Das Beieinander der drei coramRelationen stellt einen Interpretationsrahmen bereit, in dem sich das Ganze des christlichen Glaubens artikulieren und strukturieren lässt, und dies nicht in einer abstrakten, theoretischen Weise, sondern so, dass dabei in jeder Hinsicht der Lebensbezug erkennbar wird. “678 Den coramRelationsbegriff erfindet Ebeling allerdings nicht selbst, sondern übernimmt ihn von Luther, ${ }^{679}$ der zusammen mit Schleiermacher den größten Einfluss auf seine Dogmatik ausübt. Ebeling macht den von Luther übernommenen coram-Relationsbegriff durch die Bestimmung der drei Relationen und ihrem Verhältnis zueinander zu seinem eigenen Begriff.

Jede Dimension der dreifachen Relationen des Glaubens ist ursprünglich und füreinander notwendig. Sie sind jedoch nicht alle gleichrangig. Denn unter den drei Relationen ist die Gottesrelation coram Deo fundamental und als der die anderen Relationen ermöglichende und umgreifende Sachverhalt zu begreifen, aus dem sich die Bestimmtheit und das Verhältnis der Relationen ergibt. Das heißt, die Gottesrelation begründet die coram-Struktur selbst und wird in der Weltrelation des Menschen konkretisiert, so dass sie über die Bestimmung der anderen Relationen entscheidet.

Die Bestimmtheit der Relation coram Deo begegnet laut Ebeling wiederum als eine Bestimmtheit der Relation coram meipso, weil Gottes- und Selbsterkenntnis aus Gründen der conditio humana miteinander verbunden sind. Die Auffassung, dass Gotteserkenntnis eine Gestalt von Selbsterkenntnis ist, gehört eigentlich zu den reformatorischen Einsichten. Beispielweise in der Auslegung des 51. Psalms (1532) bezeichnet Luther cognitio Dei et hominis als Gegenstand der Theologie und behauptet, was nicht mit der cognitio Dei et hominis zu tun hat, sei keine wahrhafte Theologie. ${ }^{680}$ Er nimmt die Zusammengehörigkeit von Gottes- und Selbsterkenntnis vor allem vom Geschehen der Rechtfertigung

\footnotetext{
${ }^{678} \mathrm{D}$ I, 355.

${ }^{679}$ Der Begriff der coram-Relation steht bei Ebeling schon im Mittelpunkt seiner Lutherstudien der sechziger Jahre, z.B. im Aufsatz „Die Notwendigkeit der Lehre von den zwei Reichen“ (1960, WG, 407-428) und im Band $>$ Luther. Einführung in sein Denken< (1964) und wird eingehend in der Dogmatik verwendet. In Hinsicht auf Ebelings Rekurs auf die coram-Relation erklärt Oliver Pilnei, er sei inspiriert einerseits ,durch das biblische Schrifttum“, andererseits „durch die Texte Luthers und die grammatikalischen Entdeckungen, die er dort gemacht hat." Ders., Wie entsteht christlicher Glaube?, Tübingen 2007, 273.

${ }^{680}$ Enarratio Ps. 51; WA 40/II,327,11-328,2.
} 
her in den Blick und sieht daher das eigentliche Thema der Theologie in der Explikation des rechtfertigenden Gottes und des gerechtfertigten Sünders. ${ }^{681}$ Hinsichtlich der zwei grundlegenden Fragen, wer Gott ist und wer Mensch ist, ist dann unter lutherischem Aspekt zu sagen, dass die eine Frage die andere einschließt und die eine ohne die andere nicht beantwortet werden kann. Diese reformatorische Einsicht, genauer gesagt die lutherische, weil in Ebelings Augen die Prägung der Einheit von cognitio Dei et hominis bei Luther viel stärker als bei anderen Reformatoren ist, ${ }^{682}$ nimmt Ebeling auf und legt die Betonung auch auf die Zusammengehörigkeit von Gottes- und Selbsterkenntnis: „Der Glaube vollzieht und entfaltet sich als ein Erkenntnisgeschehen, in dem Gotteserkenntnis und Selbsterkenntnis zu einem einzigen Vorgang werden. Es wäre nicht Gotteserkenntnis, wenn sie nicht Selbsterkenntnis bewirkte. Und es wäre nicht Selbsterkenntnis, wenn sie nicht auf Gotteserkenntnis verwiese und auf sie angewiesen wäre. “683

Würde die Zusammengehörigkeit der cognitio Dei et hominis so vorausgesetzt, sei nun zu erwähnen, dass der Relation coram meipso die Aufgabe gestellt ist, wie sie die Relation coram Deo auf ihre tatsächliche Bestimmtheit für den Menschen beziehen kann. Diesen Sachverhalt bringt Ebeling insoweit zum Zug, als er das Menschsein vor sich selbst als den „Ort der Versöhnung von Gott und Welt“"versteht, denn daran, ,wie ich mein Sein vor Gott erfahre und verstehe, entscheidet sich auch, mit welchem Ernst und welcher Hingabe ich mein Sein vor der Welt lebe“. ${ }^{684}$ Das Sein vor Gott und das Sein vor der Welt sind darum weder als wählbare Möglichkeiten noch als trennbare Wirklichkeiten, sondern in einer wechselhaften Beziehung zu verstehen. ${ }^{685}$ In solcher Wechselbeziehung der drei coram-Relationen ist der Mensch davon abhängig, wie er sich zu den anderen verhält und was diese von ihm halten.

$\mathrm{Zu}$ beachten ist, dass bei Ebeling das Sein des Menschen vor sich selbst das ist, was es ist, allein durch ein in der Gottes- und Weltrelation begegnendes Gegenüber. Er argumentiert, für das Sein des Menschen sei es konstitutiv, ,dass er ein Gegenüber hat und ein Gegenüber braucht, von dem her er überhaupt erst der wird, der er ist ${ }^{\text {“686 }}$ und die externe Relation „kommt(e) nicht zum Menschen hinzu, sondern konstituiert(e) sein Wesen“687. Gerade an diesem Punkt weisen Ebelings Reflexionen eine Merkwürdigkeit auf, auf die O. Pilnei mit Recht hinweist: „dass nicht nur die inhaltliche Bestimmtheit des Daseins coram seipso von den anderen Relationen abhängt, sondern auch seine formale Verfassung aus ihnen abgeleitet wird“688. Der coram-Relationsbegriff dient bei Ebeling deshalb als „Quelle der

\footnotetext{
${ }^{681}$ WA 40/II,328,17: „Theologiae proprium subiectum est homo peccati reus ac perditus et Deus iustiflcans ac salvator hominis peccatotis.“

${ }^{682}$ LuSt I, 255-272.

683 D I, 181.

${ }^{684} \mathrm{D}$ I, 355.

${ }^{685} \mathrm{Vgl}$. Luther, $227 \mathrm{f}$.

${ }^{686} \mathrm{D}$ I, 351.

${ }^{687}$ WG II, 299.

${ }^{688}$ O. Pilnei, Wie entsteht christlicher Glaube?, Tübingen 2007, 275.
} 
Ontologie der Relation“6889, die ein Gegenentwurf zur Substanzontologie ist. Während in dieser der Mensch primär ein Einzelner ist, zu dem die mit Anderen verbundenen Relationen hinzukommen und dann für sekundär gehalten werden, z.B. bei Thomas von Aquin sogar für die geringste Seinsform, ${ }^{690}$ wird in der Relationsontologie der Mensch als ein Bezogensein gesehen, für das die externen Relationen konstitutiv sind.

Solche Relationalität will Ebeling eigentümlich als die Sprachlichkeit erfassen, behauptend, „In der coram-Relation ist die Sprachlichkeit der Wirklichkeit begründet, oder richtiger: Die coram-Relation ist die Sprachlichkeit." ${ }^{\prime 691}$ Vor allem die Relation coram Deo, die als die fundamentale Relation alle anderen Relationen umgreift, bezeichnet er als „sprachliche Personalitätsrelation“692, so dass die Sprachlichkeit auch für die anderen Relationen gilt und als inneres Prinzip der coram-Relation konsequent durchgeführt wird. Das ist mein Ansatzpunkt dafür, die Sprache bzw. Sprachlichkeit in der ganzen Dogmatik Ebelings zu betrachten. Denn wenn die Relationalität bei ihm den Glaubensbegriff bezeichnet und wiederum als die Sprachlichkeit erfassen wird, ist diese auch als eine wichtige Kennzeichnung für seine Dogmatik zu nennen. Die sprachliche Relationalität des Glaubens bringt neue Aspekte und neue Betonungen in Ebelings dogmatische Arbeit hinein: Im ersten Band seiner Dogmatik lenkt er die Aufmerksamkeit auf die Sprachlichkeit in der Seinsbestimmung Gottes und des Menschen und legt dabei eine besondere Betonung auf das Gebet, das bei ihm als Schlüssel zur Gotteslehre dient (Kap. III-2). In seiner Christologie stellt Ebeling Jesus Christus zuallererst als Gottes Wort in Person dar, deren Wort wiederum Gottes Wort für uns ist, und unterstreicht beim Kreuzes- und Auferstehungsgeschehen ihren sprachlichen Charakter, so dass sich Jesus Christus als die Wirklichkeit der Sprachlichkeit Gottes bezeichnet (Kap. III, 3). Letztlich hat Ebeling in der Pneumatologie ein großes Interesse für das Geistwirken, das er primär als Sprachereignis vom Wort-Glaube sieht, besonders im Anschluss an die Begriffe von Gesetz und Evangelium einerseits und an das Thema des Sakraments andererseits (Kap. III, 4). Die so durch die $>$ Dogmatik des christlichen Glaubens $<$ durchgeführte Konzeption der Sprachlichkeit ist das Thema der folgenden Abschnitte.

\section{Sprache und Glaube an Gott}

Ebelings Auffassung von Gott wird, so wie bereits erwähnt, durch die ganze Dogmatik durchgeführt und jeder Band widmet sich einem besonderen Kapitel zur Gotteslehre. Ihr Schwerpunkt liegt jedoch hauptsächlich im zweiten Kapitel des ersten Bandes, den Ebeling ,in unüblicher Weise nach

\footnotetext{
${ }^{689} \mathrm{D}$ I, 351.

${ }^{690}$ Thomas von Aquin, De potentia, q. 9 a. 5 ad 2.

${ }^{691}$ Luther, 225. Vgl. D III, 211.

692 WG III, 422.
} 
verschiedenen Gestalten des Sprachlichseins Gottes“ gliedert: Reden über Gott, Reden zu Gott und Reden von Gott her. ${ }^{693}$ Die grundlegende Aussage von Gott als dem Schöpfer beschreibt Ebeling in Gestalt des Redens und setzt damit „das Sprachlichsein Gottes“ voraus. Er sagt, „dass und wo es Gott unbestreitbar gibt, nämlich in der Sprache“, so wie der Name der „Theo-logie“ selbst die untrennbar wesentliche Beziehung von beiden anzeigt. ${ }^{694}$ Durch diese sprachlich gestaltete Gliederung zeigt er bereits optisch seine Intention an: die Frage nach dem Sein Gottes in Bezug auf sein sprachliches Gegebensein zu beantworten. Das deutet schon an, welchen Stellenwert die Konzeption der Sprache bzw. Sprachlichkeit im Zentrum der Gottesauffassung Ebelings hat.

Auf diese Gliederung gehen wir noch näher ein. Ebeling unterscheidet die drei Modi des Redens von Gott durch die Verwendung der unterschiedlichen Präpositionen, die grammatikalisch die Funktion haben, ein bestimmtes Verhältnis anzuzeigen. Das bedeutet, dass das Reden von Gott eine Beziehung voraussetzt und dass sich eins von dem anderen dadurch unterscheidet, in welchem Modus der Beziehung es steht. Diese dem Reden von Gott inhärenten Beziehungen haben mit der unterschiedlichen Stellung des Menschen vor Gott zu tun und werden hierarchisch geordnet, weil man über Gott ,,in der dritten Person“ und zu Gott ,,in der zweiten Person“ spricht und das Reden von Gott her ,sein eigenes Reden in der ersten Person meint oder zumindest ein durch ihn autorisiertes Reden in seinem Namen“. ${ }^{695}$ Ebeling konstatiert, dass in den drei Phasen des Redens die menschliche Seite konstitutiv ist, also jeweils als der Redende, der Hörende oder beides. Soll die menschliche Seite konstitutiv sein, geht es Ebelings Gottesauffassung gar nicht um objektive Bestimmungen über Gott. Das von Menschen ausgesprochene, gehörte oder übermittelte Reden lässt sich sogar als vielfältig, ambivalent oder widersprüchlich charakterisieren. Gerade mit der Betonung der „Widersprüchlichkeit des Redens über Gott“ ${ }^{696}$ wendet sich Ebeling gegen die metaphysische Gotteslehre, die von der transzendenten Evidenz Gottes ausgeht, weil göttliche und menschliche Wirklichkeit hier als zwei getrennte Bereiche aufgefasst werden und die menschliche Situation darum nicht einbezogen wird. Dagegen sieht Ebeling die menschliche Situation, die menschliche Erfahrung und vor allem die Grundsituation des Menschen als „das Kriterium des Redens über Gott“697, die als Ortsbestimmung alles Redens über Gott zu verstehen ist.

Ausgehend von dem oben Gesagten ist nun die wichtigste Eigenart Ebelingscher Gotteslehre zu nennen: Das Gebet, in dem das Sprachlichsein Gottes äußerst unmittelbar erscheint und der Mensch als ein notwendiger Gesprächspartner zu Gott steht, hat seinen Platz gerade in der Mitte der

\footnotetext{
${ }^{693}$ D I, 158.

694 D I, 158.

${ }^{695} \mathrm{D}$ I, $158 \mathrm{f}$.

696 D I, 159.

${ }^{697}$ D I, 189.
} 
Gottesauffassung und ist letztlich sogar der „Schlüssel zur Gotteslehre“698. Der Fokus auf die Zentralfunktion des Gebets ist schon bei anderen Theologen zu beobachten, z.B. bei Luther und Brunner. Obwohl seine Theologie nicht das Gebet systematisiert, hat Luther immer eine Betonung auf die sprachliche Gemeinschaft von Gott und Menschen und auf die enge Beziehung von Gebet und Glaube gelegt, behauptend, die Gesamtheit des Glaubens sei nichts anders als das Gebet. ${ }^{699}$ Brunner bezeichnet das Gebet als den „Prüfstein des Glaubens“ und die Theologie des Gebetes als den „Prüfstein aller Theologie“ und behauptet: „Ob wir unter Gott einen Ich-Du-Gott verstehen oder ein namenloses Absolutes, entscheidet über die Christlichkeit einer Theologie." ${ }^{700}$ Beide haben einen bestimmten Einfluss auf Ebeling ${ }^{701}$ und dieser scheint einen Schritt weiter zu gehen. Ebelings Bezeichnung des Gebets als Schlüssel zur Gotteslehre zeigt uns nicht nur die Zentralfunktion des Gebets, sondern auch die Vorzugsstellung der Untersuchung des Themas von Gebet, weil es uns als Schlüssel die Tür zur Ebelingschen Gottesauffassung öffnet und nur aus dieser heraus seine Aussage über Gott richtig verstanden werden kann. Das heißt, der Übergang zur Rede von Gottes Sein und Attribute vollzieht sich erst durch die Überlegung darüber, was er als Gebet versteht. Dieser Abschnitt beginnt darum zuerst mit dem Thema des Gebets.

\subsection{Das Gebet als die Sprache des Glaubens für die Relation}

Das Gebet ist ein Sprachphänomen, weil es sich als das Reden zu Gott wesentlich sprachlich darstellt, auch im Fall, wenn es in der Ruhe, im Schweigen erscheint. Es erscheint gewiss in verschiedenen Gestalten des menschlichen Sprechakts und orientiert sich am menschlichen Sprachvermögen. Die Sprache des Gebets ist darum etwa als eine spezielle Kennzeichnung des Menschlichen zu verstehen, die sich über seine bloße biologische Vorfindlichkeit hinaus als ein besonderes Geschöpfsein von den anderen unterscheidet und damit als solches Sein vor Gott steht. Die besondere Bedeutung der Sprache des Gebets liegt aber darin, dass ein Mensch im Gebet der göttlichen Sache teilhaft wird. Das Gebet ist ein sprachlicher Ausdruck der menschlichen Zuwendung zur Gottheit und der elementare Sprechakt des Glaubens an Gott. Soll das Gebet in sich beides, also das Menschliche und das über diesem stehende göttliche Element enthalten, muss sein Wesen in Verbindung mit der Frage betrachtet werden, wie sich die Sprache des Gebets ohne den Verlust des Menschlichen auf die Gottheit bezieht, anders gesagt, wie sie als ein Berührungspunkt zwischen dem Menschlichen und dem Göttlichen

\footnotetext{
${ }^{698}$ D I, 193.

${ }^{699}$ WA 8,360,29. Vgl. O. Bayer, Promissio. Geschichte der reformatorischen Wende in Luthers Theologie, Göttingen 1971, 144-158; G. Wertelius, Oratio continua, Das Verhältnis zwischen Glaube und Gebet in der Theologie Martin Luthers, Studia theologica Lundensia Bd. 32, 1970, 317-339.

${ }^{700}$ E. Brunner, Dogmatik III, Zürich 1960, 368.

${ }^{701}$ Vgl. A. Beutel, Gerhard Ebeling. Eine Biographie, Tübingen 2012, 21.
} 
bestehen könnte. Als ein Versuch, einen solchen spannungsvollen Sachverhalt des Gebets in einer ursprünglichen Dimension zu beobachten und damit vermutlich die Distanz zwischen menschlichem und göttlichem Charakter zu verringern, kommt Ebelings Gebetsauffassung zur Sprache. ${ }^{702}$ Im Folgenden geht es nun darum, wie Ebeling das Gebet versteht (2.1.1), warum er die Gotteslehre in Korrelation zum Gebet setzt und dieses sogar als Schlüssel zur Gotteslehre bezeichnet (2.1.2); und schließlich welche Auswirkung das wiederum auf die Konstitution seiner Gotteslehre hat (2.1.3) und welchen Betrag das zur relationalen Ontologie hat, die sein Gottes- und Menschenverständnis charakterisiert (2.1.4).

\subsubsection{Das Verständnis des Gebets}

Ebeling sieht das Gebet einerseits aus dem Aspekt des Menschenseins und bestimmt es doch nicht bloß als ein menschliches, sondern stärker als „,eine Urgegebenheit des Menschseins“. Seiner Ansicht nach beweist die Tatsache, dass Menschen schon immer gebetet haben, ein mit der Geschichte selbst gegebenes menschliches Urphänomen: „Über seine Entstehung lässt sich außer in Mutmaßungen nichts aussagen. Soweit unsere Geschichtskenntnis reicht, wurde seit den primitivsten Anfängen menschlicher Kultur gebetet. Und es hat noch keine Geschichtsperiode gegeben, die das Gebet nicht gekannt hätte und in der es nicht ausgeübt worden wäre. Selbstverständlich kann man es nicht daraufhin als eine anthropologische Konstante ausgeben." ${ }^{703}$ Es ist nun wohl - ja, in einer radikalen Weise - zu sagen, dass der Mensch spricht und damit betet. Das nennt Ebeling „die

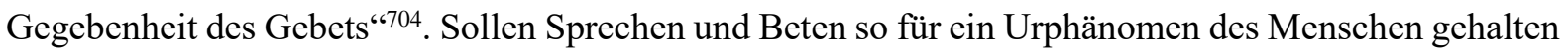
werden, hat das Gebet in der sprachlichen Verfasstheit der Wirklichkeit des Menschen seinen Grund. In diesem Sinne sagt J. Ringleben, dass die grundlegende Kennzeichnung von Ebelings Entwurf darin liegt, den Gebetsbegriff ,in eine anthropologische Fundamentalbesinnung“ einzuzeichnen. ${ }^{705}$ Andererseits bestimmt Ebeling das Gebet als „religiöses Grundphänomen“706, weil es allen Religionen eigen ist und zu jeder Religion als zentrale sprachliche Äußerungsform gehört. Das Gebet erweist sich für ihn dann als ein

\footnotetext{
${ }^{702}$ Zur Thematik des Gebets bei Ebeling kommt z.B. P. Selvatico, Theologie der Relation, in: Freiburger Zeitschrift für Philosophie und Theologie, 1980/27, 265-275; J. Ringleben, In Einsamkeit mein Sprachgesell. Das Gebet als Thema der Dogmatik, in: ZThK 79 (1982), 230-248; A. Kistenbrügge, Das Gebet in der Dogmatik. Untersucht am Beispiel von Gerhard Ebelings Dogmatik des christlichen Glaubens, Frankfurt am Main/Berlin, 2000.

${ }^{703}$ WG III, 417.

${ }^{704}$ WG III, 417.

${ }^{705}$ J. Ringleben, In Einsamkeit mein Sprachgesell. Das Gebet als Thema der Dogmatik, in: ZThK 79 (1982), 230$248,235$.

${ }^{706}$ WG III, 418.
} 
anthropologisches und religiöses Grundphänomen. Sein Gebetsverständnis schließt sich, wie Ringleben mit Recht hervorhebt, an die Definition des Gebets bei F. Heiler an, der eine beachtliche Sammlung von Gebetstheorien des 19. und 20. Jahrhunderts bietet, eine große Zahl unterschiedlicher Definitionen referiert und damit letztlich das Wesen des Gebetes allgemein gültig erfassen will. ${ }^{707}$

Solches Gebetsverständnis, das Ebeling schon im Aufsatz über $>$ das Gebet< (1973) zur fast vollständigen Geltung brachte, ${ }^{708}$ verwendet er auch in der Dogmatik und lässt es zum Einstieg in die Gotteslehre dienen. Das Gebet und die Gotteslehre stehen gemeinsam „in der Spannung zwischen dem Allgemeinen und dem spezifisch Christlichen“. ${ }^{709}$ Diese beiden Charakter bleiben für ihn untrennbar und ihr Verhältnis verläuft parallel zu seinem hermeneutischen Anliegen: die Spannung zwischen der Identifizierbarkeit des Christlichen und der Frage nach Wahrheit aufzuzeigen, die man entweder zusammen denken oder das eine jeweils im anderen wahrnehmen kann und soll, damit die Aussagen über den christlichen Glauben den Zusammenhang mit der geschichtlichen Wirklichkeit nicht verlieren.

In der Dogmatik erklärt Ebeling die Stellung des Gebets durch die „Unterscheidung von Metaphysik und Moral“, so ähnlich wie Luther das Gottesverständnis und den Glauben „gegenüber der Scholastik“ abgrenzte und Schleiermacher „gegenüber der Aufklärung und dem Idealismus“. ${ }^{710}$ Auch wenn man nicht sagen darf, der Glaube gäbe keine Denk- oder Handlungsimpulse, ist der Glaube ,weder für das eine noch für das andere bloßes Mittel zum Zweck“. Genauso wenig kann das Gebet „als Mittel zum Zweck“ verstanden werden. ${ }^{711}$ Es betrifft das Menschensein, das das Denken und das Tun als seine Seinsweise voraussetzt. Das Gebet markiert laut Ebeling ,die Grenze, die dem Denken und dem Tun in Bezug auf Gott gesetzt ist, während hier allein der Glaube am Platz ist. “712 Dieser Glaube ist der Glaube an Jesus Christus, weshalb das Gebet stets mit seinem Namen endet. Das, was als das Spezifische des christlichen Gebets zu gelten hat, ist dann „das Beten im Namen Jesu Christi, das es zu einem Beten im Geist und in der Wahrheit kommen lässt. “713

Ebeling behauptet, dieses spezifisch Christliche liege doch im Zusammenhang mit dem allgemein Religiösen und dem Grundmenschlichen: „Es wäre aber ein Irrtum zu meinen, man könnte dieses Christliche in Bezug auf das Gebet gewissermaßen rein für sich haben ohne die ständige Auseinandersetzung mit dem allgemein Religiösen und dem Grundmenschlichen am

\footnotetext{
${ }^{707}$ Vgl. Friedrich Heiler, Das Gebet. Eine religionsgeschichtliche und religionspsychologische Untersuchung, München/Basel ${ }^{5} 1969$.

${ }^{708}$ Ebeling, Das Gebet, in: ZThK 70 (1973), 206-225; Wiederabdruck in: WG III, 405-427.

709 D I, 207.

710 D I, 200.

711 D I, 200.

712 D I, 200

713 D I, 209.
} 
Gebet." ${ }^{714}$ Denn das Gebet spricht die Erfahrung des Glaubens aus, die von seiner jeweils gegebenen religiösen Äußerungsform und auch von der menschlichen Grundsituation sowie den konkreten Situationen nicht isolierbar ist. In dieser Erfahrung im Gebet treten grundlegend Religiöses sowie Menschliches und wesentlich Christliches in Relation zueinander. Hinsichtlich dieser Relation bleibt über Ebeling zu sagen: Das spezifisch Christliche im Gebet kann nicht einfach in das allgemeine Religiöse aufgenommen werden oder bloß additiv hinzugefügt werden, sondern vielmehr besteht zwischen beiden eine fundamentale Differenz, die sich in ihrem Ineinander zeigen soll. Es geht also um das Aufdecken einer tiefen Differenz auf dem Boden eines gemeinsamen Tatbestandes. ${ }^{715}$

Hier wird nun das Verhältnis von Gebet und christlichem Gottesverständnis wichtig. Insofern es in der christlichen Theologie um den im Alten und Neuen Testament sich offenbarenden Gott geht, der laut Luther „nicht im Gewordensein sondern im Werden“ besteht, so ist das Gebet „nicht ein religiöser Akt neben andern“, sondern in ihm konzentriert sich „das Ganze des Gottesverhältnisses“. ${ }^{716}$ Es geht im Gebet darum, „dass und wie Gott zur Erfahrung kommt““. ${ }^{717}$ Die Offenheit des christlichen Gottesverständnisses wird so „durch den Einstieg über das Gebet in die Gotteslehre zum Religiösen insgesamt und zum Menschlichen überhaupt gewahrt". ${ }^{718}$ Im Gebet vollzieht sich schon, was die Theologie schließlich verantworten soll, nämlich das Reden von Gott im Hinblick auf die jedem zugängliche Wirklichkeit. Ebeling sagt: „Hier fügt der Beter Gott und seine eigene Lebenswirklichkeit in einen und denselben Satz zusammen“. ${ }^{719}$ Das geschieht, indem beide zusammengesprochen werden. Mit diesem Gebetsverständnis markiert Ebeling seinen Ort in der Gotteslehre.

\subsubsection{Der dogmatische Ort des Gebets als ein hermeneutischer Schlüssel zur Gotteslehre}

Das Gebet als ein wichtiges Thema für die Theologie zu bestimmen, steht wohl unumstritten in Übereinstimmung mit den meisten evangelischen Theologen. ${ }^{720}$ Das Gebet als ein

\footnotetext{
714 D I, 209.

715 D I, 209.

716 D I, $208 f$ f.

717 D I, 199.

718 D I, $208 f$ f.

${ }^{719}$ D I, 210.
}

${ }^{720}$ Z.B. Luther sieht das Gebet als eine wichtige Methode für die theologische Arbeit (WA 3,448,38-40) und behauptet, dass Theologie das Gebet nicht belehrt, sondern beim Gebet in die Lehre geht (WA 45,541,34f); K. Barth bestimmt das Gebet als ,der erste und grundlegende Akt theologischer Arbeit, der dann in der Art eines anhaltenden Grundtons auch in den folgenden weitergehen wird.“ Ders., Einführung in das Studium der evangelischen Theologie, Gütersloh 19803, 126; E. Brunner bezeichnet das Gebet als „Prüfstein aller Theologie“. 
dogmatisches Thema zu behandeln, ist aber ein anderes umstrittenes Problem. ${ }^{721}$ Dies besteht in der Tatsache, dass die Lehre vom Gebet keinen festen Platz in der traditionellen Dogmatik hat. Wenn man einen Überblick über die Geschichte der evangelischen Theologie gibt, kann man keine richtige dogmatische Geschichte des Gebets finden, denn obwohl dieses eine zentrale Funktion in der Theologie der Reformatoren wie Luther und Calvin einnahm, ist es von der evangelischen Theologie nie richtig aufgenommen worden. Dogmatische Standardwerke der neuzeitlichen evangelischen Theologie haben das Thema des Gebets nur am Rand verhandelt oder haben ihm in einigen Fällen nicht einmal einen eigenen Paragraphen gewidmet. ${ }^{722}$ Dafür lassen sich verschiedene Gründe anführen. Vermutlich mag man das Gebet als eine zentrale Praxis des Glaubens lieber im Bereich der praktischen Theologie behandeln oder die alltagspraktische Dimension des Betens mag seine theoretische Erfassung behindern oder komplizieren. Die Randständigkeit des Themas des Gebets lässt sich zugleich auch als ein Reflex auf philosophische und religionspsychologische Kritik am traditionellen Gebetsverständnis lesen. Im Zuge der Aufklärung wird das Gebet von Philosophen wie Kant oder Schopenhauer als Heuchelei oder abergläubischer Wahn abgetan; und von psychoanalytischer Seite wird es für den Ausdruck eines kindlichen Bedürfnisses nach Glück oder Trost mit dem Ziel der Wunscherfüllung gehalten. ${ }^{723}$

Darüber hinaus, auch wenn das Thema des Gebets in die Kategorie der Dogmatik eingeordnet wird, gibt es noch ein Problem, weil es nicht in einem bestimmten Ort, sondern in unterschiedlichen theologischen Zusammenhängen zu behandeln ist: z.B. in Bezug auf die Trinitätslehre, weil beim Beten die Dreieinigkeit Gottes schon erkannt ist, indem wir an den Vater, durch den Sohn, im heiligen Geist beten; in Bezug auf die Ekklesiologie, weil das Gebet im Zentrum des kirchlichen Gottesdiensts liegt; und in Bezug auf die Pneumatologie, weil das Gebet das erste und herausragende Ergebnis der Vergegenwärtigungsmacht Gottes im heiligen Geist ist. Das Gebet ist auch in Bezug auf die Rechtfertigungslehre zur Sprache zu bringen. Immer wird es eng auf Gerechtigkeit bezogen, indem es als eine Folge der Rechtfertigung

Ders., Dogmatik III, Zürich 1960, 368; und Bernhard Häring als das „Herz der Theologie“. Ders., Gebet in einer weltlichen Welt, München 1972, 131.

${ }^{721}$ Vgl. W. Lohff, Erwägungen zur dogmatischen Lehre vom Gebet, in F. W. Bargheer/I. Röbbelen (Hg.), Gebet und Gebetserziehung, Heidelberg 1971, 9f; M. Wriedt, Gebet und Theologie, FZThPh 1984, 412-452.

${ }^{722}$ G. Müller, Art. Gebet VIII. Dogmatische Probleme gegenwärtiger Gebetstheologie, in: TRE 12 (1984), 84-94, 87f. Als Beispiele dafür nennt er hier H. Schmid, Die Dogmatik der evangelisch-lutherischen Kirche, H.G. Pöhlmann (Hg.), Gütersloh 1979' und H. Heppe/E. Bizer, Die Dogmatik der evangelisch-reformierten Kirche, Neukirchen 1958.

${ }^{723}$ G. Müller, Art. Gebet VIII. Dogmatische Probleme gegenwärtiger Gebetstheologie, in: TRE 12 (1984), 84$94,88$. 
gesehen wird ${ }^{724}$ oder unter deren Bedingung wirksam ist, ${ }^{725}$ oder noch stärker, so wie Bonhoeffer treffend beschreibt, indem das Gebet weder bloß Bedingung noch Folge von Rechtfertigung ist, sondern es ein sachliches Ineinander von ihnen gibt ${ }^{726}$. Außerdem kann das Gebet eben auch im Zusammenhang der Lehre von Vorsehung behandelt werden. ${ }^{727}$ Heinrich Benckert, der schon in den 1950er Jahren in seiner Antrittsvorlesung an der Universität Rostock die Frage stellte, ob man dem Gebet einen festen Ort innerhalb der Dogmatik geben müsste, denn die Gebetslehre sei in jedem Abschnitt der Dogmatik präsent, bestimmte es als „Vollzug des Gottesglaubens“, als „Vollzug der Rechtfertigung“ und als „Vollzug der Kindschaft durch den heiligen Geist “. ${ }^{728}$ So ähnlich sagt es G. Müller: das Gebet hat keinen einzelnen bestimmten Ort innerhalb der Dogmatik, sondern sollte deren Aussagen „im alles umgreifenden Horizont des Gebets" positionieren. ${ }^{729}$

In Hinsicht auf die so problematische Behandlung des Themas des Gebets in der Dogmatik hat Ebeling einen besonderen Platz. Zuerst ist es erwähnenswert, dass er dem Thema des Gebets einen festen Ort innerhalb der Dogmatik sichert. Das wird aber schon früher von Schleiermacher versucht, der als erster das Gebet in den Bereich der Dogmatik einbringt und ihm einen festen Platz in der Ekklesiologie gibt. Schleiermacher tut es doch nur als Gebet im Namen Jesu ab, im Zusammenhang der wesentlichen Kennzeichen der Kirche, das zum Ausdruck „richtigen Vorgefühls“ für das Heilsame wird und letztlich nur im Dank besteht. ${ }^{730}$ Während das Gebet bei Schleiermacher doch nur eine nebensächliche, marginale Rolle als ein Unterthema der Ekklesiologie spielt, nimmt es bei Ebeling die Zentralfunktion in seiner Dogmatik ein. Denn auf welche Weise die Koordinaten, die sich als vier Hauptgesichtspunkten seiner Dogmatik

\footnotetext{
${ }^{724}$ Z.B. legt Luther in seiner Auslegung von Ps 51,15 eine besondere Betonung auf „post iustificationem“ und betrachtet das Werk des kerygmatischen Lobens bzw. Dankens als „logische Folge der Rechtfertigung“. Matthias Mikoteit, Theologie und Gebet bei Luther. Untersuchung zur Psalmenvorlesung 1532-1535, Berlin/New York 2004, 138.

${ }^{725}$ Z.B. sieht Klaus Berger die ekklesiologische Voraussetzung für die Wirksamkeit des Gebets als die Existenz einer Gemeinde der Gerechten, behauptend, das Gebet sei „,immer eng auf Gerechtigkeit/Rechtfertigung bezogen und ist nur unter dieser Bedingung [...] auch wirksam. [...] Die Gerechten verwenden ihre Gerechtigkeit vor Gott für andere." Ders., Art. Gebet IV. Neues Testament, in: TRE 12 (1984), 47-60, 48.

${ }^{726}$ Bonhoeffer behauptet, „Nur der Gerechtfertigte betet - und nur der Betende wird gerechtfertigt“", zitiert nach G. Müller, Art. Gebet VIII. Dogmatische Probleme gegenwärtiger Gebetstheologie, in: TRE 12 (1984), 84-94, $89 f$.

${ }^{727}$ Vgl. W. Elert, Der christliche Glaube, Erlangen ${ }^{5} 1988$, 286; P. Althaus, Die christliche Wahrheit, Bd. 2. Gütersloh 1948, 17, 72, 74; W. Trillhaas, Dogmatik, Berlin 1962, 162-166.

${ }^{728}$ H. Benckert, Das Gebet als Gegenstand der Dogmatik, in: EvTh 15 (1955), 535-552, bes. 546, 548 u. 550.

${ }^{729}$ G. Müller, Art. Gebet VIII. Dogmatische Probleme gegenwärtiger Gebetstheologie, in: TRE 12 (1984), 84-94, 88. Vgl. Gerhard Sauter sagt ähnlich: Das Gebet ist „nicht nur ein Thema der Theologie, und eine arbiträre Angelegenheit theologischen Nachdenkens." Ders., Reden von Gott im Gebet, in: Bernhard Casper (Hg), Gott nennen. Phänomenologische Zugänge, Freiburg 1981, 227.

${ }^{730}$ F. Schleiermacher, CG, Bd. II, §146f, 417-426.
} 
von Glaube, Gott, Mensch und Welt bezeichnen und für jede Glaubensaussage zugrunde liegen, miteinander zusammenhängen, darüber gibt das Gebet eine Auskunft, indem es einen Vorschlag macht, wie der Mensch sein Sein vor der Welt und vor Gott im Gewissen verantwortet. ${ }^{731}$

Außer Schleiermacher sind bezüglich der dogmatischen Behandlung des Themas des Gebets wohl noch A. Ritschl und K. Barth zu nennen ${ }^{732}$. Ritschl behandelt das Thema des Gebets in der $>$ Unterricht in der christlichen Religion<, wobei er es als ein Glied der christlichen Vollkommenheit bezeichnet (§59) und auf die gemeinschaftliche Gottesverehrung (§ 78ff) bezieht, während er es im Teil über die einzelnen subjektiven Funktionen der Versöhnung (§ 60-62) nicht behandelt. ${ }^{733}$ In der $>$ kirchliche(n) Dogmatik $<$ Barths befindet sich das Thema des Gebets im dritten Band über die Schöpfungslehre, genauer im Teil über „das Gebot Gottes des Schöpfers“ in der Verbindung mit dem Gottesdienst, wobei er es als den „Kern des christlichen Gottesdienstes“ bestimmt. ${ }^{734}$ Beide eignen sich aber m.E. nicht als Beispiele für die feste Ortsbestimmung des Gebets innerhalb der Dogmatik, weil es bei ihnen seinen eigenen, allein ihm gewidmeten Teil nicht hat und streng genommen nicht als ein richtiges, selbstständiges dogmatisches Thema behandelt wird. Das wird verdeutlicht im Vergleich mit Ebeling, der dem Gebet einen Teil im ersten Band seiner Dogmatik widmet und seinen Ort auch optisch klar sichert.

Angesichts des Themas des Gebets bei Ebeling muss aber die Aufmerksamkeit mehr darauf gerichtet werden, dass er die Gotteslehre als den Hauptteil der Dogmatik gerade in die Gebetslehre einbettet und diese zum Gedankengerüst seiner Gotteslehre macht. Als ein äußerlich erkennbarer Beweis dafür ist die Stellung des Gebets in seiner Dogmatik zu nennen. In Ebelings Dogmatik kommt die Rede vom Gebet ungewöhnlicherweise vor der Rede vom Sein und den Attributen Gottes. Das bedeutet eine Abweichung vom traditionellen dogmatischen Vorgehen. Die Gotteslehre der klassischen Dogmatik beginnt normalerweise mit dem Thema Gott selbst, nämlich Gottes Sein und Attribute, z.B. mit der Aussage über Gottesbilder, Gottesbeweis, Transzendenz und Immanenz Gottes, über seine Eigenschaften wie Allmächtigkeit, Ewigkeit oder Liebe, oder über seine Dreieinigkeit usw. Ein solches Vorgehen folgt der Logik des Aufbaus, dass man zuerst wissen muss, wer und was Gott ist, und sich dann auch begründet etwas über das Verhältnis zu ihm

\footnotetext{
${ }^{731}$ Vgl. D I, 192f: „Im Gebet kommt zum Ausdruck, dass eine Manifestation des Geheimnisses der Wirklichkeit, eine bestimmte Weise letztgültigen Angegangenseins in die menschliche Grundsituation eingreift, sie als Sprachsituation in Bewegung versetzt und den Menschen auf Gott hin ausrichtet.“

${ }^{732}$ Nicht nur bezüglich des dogmatischen Ortes des Gebets, sondern auch bezüglich seiner Form kommen A. Ritschl und K. Barth zur Sprache, weil zwischen ihnen eine entgegensetzte Anschauung von der Gebetsform liegt: Für Ritschl sind „die Bitte und der Dank nicht gleichgestellte Arten“, da er das Dankgebet als die eigentliche Form des Gebets sieht, während er die Bitte nicht als Gott würdig erachtet. Ders., Unterricht in der christlichen Religion, Ch. Axt-Piscalar (Hg), Tübingen 2002, §79, 106. Barth sagt dagegen, es sei „wahr: beten heißt bitten“; das Gebet sei „nur als Bitte dann auch Dank“. Ders., KD III, 4, 99 u. 110.

${ }^{733}$ A. Ritschl, Unterricht in der christlichen Religion, Ch. Axt-Piscalar (Hg), Tübingen 2002.

${ }^{734}$ K. Barth, KD III, 4, $119 f f$.
} 
sagen lässt. Die Gotteslehre wird dabei vorrangig für die Lehre vom vorausliegenden Gottes Sein und Handeln oder von der An-Sich-Seinsweise Gottes gehalten. Im Gegenteil dazu lassen sich Erkenntnisse über Gott, nach Ebelings Ansicht, nur vom Gebet her erschließen. Er behauptet, dass allein im Reden zu Gott der Mensch alles zum Ausdruck bringt, was über ihn von menschlicher Seite her erkannt und ausgesagt werden kann. Denn er sieht die Gotteslehre nicht als solche, die von einer theoretischen Wahrheit redet, die den Menschen als Zuschauer unbeteiligt lässt, sondern als solche, die zeigt, wie im Bewusstsein des Menschen Gotteserkenntnis entsteht.

Die Beschreibung „wie“ meint hier den situativen Kontext von Glaubensaussagen über Gott. Das bedeutet, dass Ebeling dogmatische Aussagen, wie J. Ringleben mit Recht erklärt, „als Aussagen über den Vollzugssinn religiöser Praxis“" sieht. ${ }^{735}$ Ebelings Gedanke über das Verhältnis des Gebets zur Gotteslehre verläuft dann parallel zu seiner Auffassung von Theologie. Dementsprechend soll die Theologie weder reine Theorie noch bloße Praxis, sondern wissenschaftliche Gestalt von deren innerster Vermittlung sein und gegen eine abstrakte Theorie sowie gegen eine wahrheitsunfähige Praxis kämpfen. Für Ebeling hat die Theologie überhaupt einen konstitutiven Zug in der Praxis. Diesen übernimmt er eigentlich von Luther, der behauptet, „vera theologia est practica“736 und der anhand des Lebensbegriffs das christliche Verständnis von Wahrheit selbst als lebensbezogen erweisen will. Den wesentlich notwendigen Praxisbezug bzw. Lebensbezug der Theologie entfaltet Ebeling weiterhin auf das Verhältnis von Gebet und Gotteslehre.

Für die Betonung des notwendigen Lebensbezugs der Theologie sowie der erforderlichen Verbindung von Gebet und Gotteslehre zitiert Ebeling eine Notiz Kierkegaards: „Damit das Recht der Erkenntnis seine Gültigkeit habe, muss man sich ins Leben hinauswagen“737; und übersetzt sie in seine eigene Aussage: es geht darum, was „erst in der Lebenspraxis selbst zur seiner Wahrheit gelangt“"738. Das gilt auch für die Situation des Gebets. Das heißt, durch das Gebet werden alle Aussagen der Gotteslehre auf ihren Lebensbezug hin erhellt, womit die Gültigkeit des Rechts ihre Erkenntnisse gewinnt. In diesem Sinne bestimmt Ebeling die Gotteserkenntnis schließlich in gewissermaßen radikaler Formulierung als „die Sache des Lebens“ sowie „die Sache des Gebets“. ${ }^{739}$ Gerade darin, dass das Gebet die Gotteserkenntnis in eine enge Beziehung zum Leben bringt, befindet sich die Grundlage des Gebets: „Anstatt sich als Zuschauer herauszuhalten,

\footnotetext{
735 J. Ringleben, In Einsamkeit mein Sprachgesell. Das Gebet als Thema der Dogmatik, in: ZThK 78 (1982), 230248, 234.

${ }^{736}$ WAT 1;72, 16-24, Nr. 153 (Dez. 1531/Jan. 1532).

${ }^{737}$ S. Kierkegaard, Die Tagebücher. H. Gerdes (Übers.), Düsseldorf/Köln, 1840, 261f, zitiert nach, D I, 193.

${ }^{738}$ D I, 194.

${ }^{739}$ D I, 193.
} 
hat man sich in diejenige Situation zu geben oder richtiger, das es sich nicht um etwas Herzustellendes, sondern um etwas mit dem Leben selbst Gegebenes handelt, diejenige Situation wahrzunehmen, die einen zu Gott ruft, nach Gott schreien lässt und dazu herausfordert, sich auf das Wagnis einzulassen, ob Gott hört. Nicht die gekünstelte Haltung einer vom Lebensvollzug abstrahierenden Denkleistung, die Gott beweisen will, entspricht dem Dasein Gottes, sondern dies, dass einer, der sich ihm verdankt, vor ihm auf die Knie fällt.“740

Dem Gebet kommt hier eine besondere Bedeutung zu, da es als „eine maßgebende Interpretationsanweisung “ 741 die Erfahrbarkeit Gottes als Geheimnis der Wirklichkeit erschließt und als Beweis für das Bewusstsein des Gläubigen über die Wirklichkeit Gottes dient. Das wird in der folgenden Aussage Ebelings stärker dargestellt: „Man kann nicht anders beweisen, dass man mit der Wirklichkeit Gottes rechnet, als indem man zu ihm betet." ${ }^{\text {"742 }}$ Er sagt sogar, die Tatsache des Betens bringe die Behauptung des Seins Gottes besser als die bloße Existenzaussage zum Ausdruck: „Sowenig in der Tat die bloße Existenzaussage über Gott in das Gebet rückübersetzbar ist, bringt doch der Vollzug des Betens als solcher die Seinsaussage elementar zum Ausdruck. Wäre Gott nicht, wäre das Gebet sinnlos.“743

Der Satz „Wäre Gott nicht, wäre das Gebet sinnlos“, stellt bei Ebeling das Verhältnis von Gotteslehre und Gebet entscheidend dar und offenbart uns eine wichtige Wahrheit: Das Beten hat das Sein Gottes bzw. seine Wirklichkeit als eine notwendige Voraussetzung. Denn das Gebet ist weder Selbstgespräch noch reine Meditation, sondern hat eigentlich und notwendig das Gegenüber Gottes; und das wirkliche Anreden des Gegenübers beim Beten hat die Funktion, dieses Gegenüber Gottes als Wirklichkeit in Anspruch zu nehmen. Niemand kann und will wesentlich zu einem nicht-existierenden Gott sprechen und erwarten, von ihm zu hören. Umgekehrt gesagt heißt das, dass nur der betet, der weiß, dass Gott existiert und wirkt, und davon fest überzeugt ist. Die Gotteslehre ist nach Ebelings Darstellung deshalb etwas, „was der Beter im Rücken hat“. ${ }^{744}$ Es geht selbstverständlich nicht darum, durch das Phänomen des Gebets das Gottessein selbst zu beweisen. Schließlich wird im Gebet von Gott immer nur in bestimmter Weise, also in seinem So-Sein geredet, sodass das Sein Gottes selbst nicht in der Sprache des Gebets ausgesagt werden kann. Aber durch die Tatsache, dass wir in unserem Alltagsleben beten, können wir den Glauben an Gott, an sein Sein und Wirken am besten beglaubigen, ja wahrscheinlich viel besser als durch irgendeinen theoretischen Gottesbeweis. Vermutlich im

\footnotetext{
${ }^{740}$ D I, 193.

${ }^{741}$ D I, 194.

742 D I, 202.

${ }^{743}$ D I, 213.

${ }^{744}$ D I, 194.
} 
Anschluss daran, was Luther als blindes Suchen der Vernunft bzw. „Blinde-Kuh-Spielen“7745 bezeichnet, mit dem er darstellt, dass die natürliche Gotteserkenntnis unmöglich ist und uns nur dazu führt, Gott zu verfehlen, scheint Ebeling eine sich immer schon vollziehende Seinsaussage Gottes jenseits bestimmten Redens von Gott preiszugeben. Das, worum es in der Gotteserkenntnis geht, ist nicht das Sein Gottes, das im Sinne Ebelings ein Irgendwie-sein meint, sondern das So-sein Gottes, weil von Gott nur in einer bestimmten Weise geredet wird.

In diesem Zusammenhang ist nun klar zu sagen, was Ebeling durch die Ortsbestimmung des Gebets als Schlüssel zur Gotteslehre zeigen will. Er will zeigen, dass durch die Konzentration auf das Phänomen des Gebets die Gotteslehre tatsächlich zur Situation ihrer Verifizierung ${ }^{746}$ hinzuführen ist; und dass gerade an der Stelle der Verifikation das Reden von Gott weiter geführt werden kann oder muss. Er warnt uns daher eindringlich davor, dass die Rede von Gott nicht bloß in einer akademischen Dimension, nicht bloß in einem Buch der Dogmatik angesiedelt bleiben darf, sondern immer in Bezug auf die Praxis, das Leben, letztlich den Glauben als fiducia wahrgenommen werden soll.

Darüber hinaus ist noch zu sagen, dass bei dem Versuch, die Gotteslehre mit dem Gebetsgeschehen zu verbinden, Vorsicht geboten ist, weil sie begrenzt, einseitig und partiell sein könnte. Eine am Gebet orientierte Lehre von Gott könnte in Gefahr geraten, dass sie Gottes Absolutheit beschädigen und schließlich zu einer rein menschlichen, zu einer solchen, die bloß zur Anthropologie gehört, werden könnte. Deshalb sagt Ebeling, dass die Gotteslehre nicht von dem Gebet abhängig gemacht werden darf. Zugleich sagt er, dass hinsichtlich der Korrelation vom Gotteslehre und Gebetslehre ihr interaktives Verhältnis gedacht werden soll. Denn neben den durch die Betrachtung des Gebets gewonnenen Erkenntnissen über die Gotteslehre lässt sich erst durch die Gotteslehre das Verständnis und die Praxis des Gebets im richtigen Licht sehen. Auch wenn das Gebet von Herzen kommen und aufrichtig sein soll, versteht sich sein richtiger Umfang nicht von selbst. ${ }^{747}$

\subsubsection{Der Charakter des Gebets für die Relationsbestimmung von Gott und Menschen}

Beim Betracht des Themas des Betens interessiert sich Ebeling vornehmlich dafür, wie die Beziehung von Gott und Menschen dabei zum Ausdruck kommt. Die dem Gebet zugrunde

\footnotetext{
${ }^{745}$ WA 19,207,3-6.

${ }^{746}$ Mit dem Begriff der Verifikation behandelt Ebeling nicht das erkenntnisbezogene Wahrheitsproblem, sondern das Gewissheitsproblem, das eng auf das Glaubensverständnis bezogen ist, sodass er dem reformatorischen Glaubensverständnis folgt, das eine Betonung auf fiducia hatte, obwohl der Aspekt von notitia sowie assensus dabei nicht ausgeschlossen war. Für ein näheres Verständnis der Verifikation siehe das Kapitel II, 4.2.2.

${ }^{747}$ D I, 207.
} 
liegende Beziehung von Gott und Menschen bezeichnet er mit den drei Worten „Passivität“, „Angesprochensein“ und „Nichtobjektivierbarkeit“"Gottes, die er in Hinblick auf den Gebetsgestus, das Gebetswort und auf den Zusammenhang der beiden in Erwägung zieht:

Erstens es geht um die Passivität, mit der Ebeling die Abhängigkeit von Gott meint. Beim Gebet richtet Ebeling seine Aufmerksamkeit zuerst auf die Gebetsgeste als einen körperlichen Ausdruck, die beim Beten unwillkürlich gesucht oder konventionell gefördert wird. Sie erscheint etwa charakteristisch. Ihre spezifische Eigenart erklärt Ebeling wie folgt: „Das Falten der Hände, um sie gleichsam zu binden, ihr Emporheben im Gestus der Empfangsbereitschaft, das Niederknien als Zeichen der Unterwerfung. “748 In dieser Gebetsgeste manifestiert sich laut Ebeling das Abhängigkeitsverhältnis des Menschen zu Gott, indem sich der Mensch dabei als ein rein Empfangender vor Gott versteht. Hinsichtlich der Passivität bzw. der Abhängigkeit bringt Ebeling zwei weitere wichtige Punkte zur Sprache: Es geht einerseits um „das Leben des Menschen“ hinsichtlich dessen, „,worüber ihm die eigene Verfügungsmacht mangelt", also um die wesentliche Mangelhaftigkeit des menschlichen Lebens und damit um die Notwendigkeit des Verlangens nach Gnade und Heil Gottes, so dass sich ein soteriologischer Grundzug des Gebets äußert. ${ }^{749}$ Es geht andererseits um eine Abgrenzung des Gottesverhältnisses und des Glaubens „,gegen Metaphysik und Moral“ ${ }^{750}$ Ebeling erklärt, obwohl das Gebet das Sein des Menschen, damit sein Denken und Tun betrifft, weil ein Beter Denkender und Täter in einer Person ist, könne weder das Denken noch das Tun das Reden zu Gott erreichen und ersetzten. Dadurch betont er, dass das Gebet dieselbe Grenze hat, ,die dem Denken und dem Tun in Bezug auf Gott gesetzt ist, während hier allein der Glaube am Platze ist“ und dass Glaube und Gebet „im Grunde ein und dasselbe" sind. ${ }^{751}$

Zweitens bezeichnet Ebeling das Gebetswort „als Ausdruck des Angesprochenseins“"752. Es ist offenbar, dass das Gebet kein Selbstgespräch ist und sich seine Sprache immer auf ein Gegenüber in der zweiten Person richtet. In dieser Form der sprachlichen Kommunikation des Gebets erkennt Ebeling eine für das Gottesverhältnis konstituierende Größe, die andeutet, wie eng das Phänomen des Gebets mit der Gotteslehre verbunden ist. Dafür bringt er zuerst den völlig einzigartigen, nie veränderten Adressat des Gebets zur Sprache, der sich wesentlich von dem Adressaten des menschlichen Gespräches unterscheidet. Denn wenn mehrere beten, sprechen sie nicht zueinander, sondern zu einem gemeinsamen Gegenüber; und auch wenn ein Beter vor anderen betet, spricht er nicht zu ihnen, sondern zu einem gemeinsamen Gegenüber, nämlich immer zu Gott. Außer diesem wird beim Beten kein anderer Adressat angesprochen. Vor allem die Anrede „Du“ zu Gott zeigt, dass der Beter mit der

\footnotetext{
748 D I, 199.

749 D I, 199.

${ }^{750} \mathrm{D}$ I, 200.

${ }^{751} \mathrm{D}$ I, 200.

752 D I, 201.
} 
Gegenwart Gottes als dem Adressaten des Gebetes rechnet. ${ }^{753}$ Die Anrede Gottes durch den Menschen darf aber, laut Ebeling, keinesfalls als ,ein Produkt menschlicher Initiative“ verstanden werden, sondern vielmehr als Reaktion auf das Angesprochensein des Menschen von Gott, weil das Gebet die Wahrnehmung Gottes voraussetzt und durch das Reden Gottes zum Menschen konstituiert ist. ${ }^{754}$ Die Anrede Gottes wendet sich dann für den Redenden ins von Gott Angesprochenwerden. Das wird ebenfalls dadurch verdeutlicht, dass das Gebet mit Amen schließen soll. Denn diese Schließung bedeutet, dass der Beter nicht von sich aus den Schlusspunkt setzt, sondern „sich auf das definitive Faktum des Deus dixit" bezieht und daraufhin getrost schließen kann"“. ${ }^{755}$ In diesem Sinne behauptet Ebeling, das Entscheidende des Gebets liege darum nicht im Reden des Menschen, sondern im Angesprochensein des Menschen.

Drittens versteht Ebeling das Gebet als Ausdruck der „Nichtobjektivierbarkeit Gottes“. Gegenüber dem göttlichen Du, zu dem im Gebet geredet wird, gibt es laut Ebeling keine „,neutrale Distanz““756 Wenn es stimmt, dass anhand des Gebets herauskommt, was es mit dem Gottesverhältnis auf sich hat, dann kann Gott nicht zum Gegenstand einer neutralen Anschauung werden und lässt sich auch nicht als ein Objekt der wissenschaftlichen Untersuchung begreifen. „Gott entzieht sich der beobachtenden Feststellung und der kritischen Analyse“ ${ }^{\text {“757, }}$, weil er nur in einer Korrelation von Gotteserkenntnis und Selbsterkenntnis erfahren werden kann. Somit beruht die Aussage der Nichtobjektivierbarkeit Gottes darauf, dass der Mensch existenziell beteiligt ist. Daraus folgt, dass diese Nichtobjektivierbarkeit eine Beschreibung der Situation des Gottesverhältnisses ist und aus dem Grund in der Situation des Gebets anschaulich wird. ${ }^{758}$ In diesem Sinne ist das Gebet ein primärer Ausdruck der Tatsache, dass „Gott wesenhaft nicht zum Gegenstand neutraler Einstellung werden kann“. ${ }^{759}$ Mit dem Begriff der Nichtobjektivierbarkeit Gottes beschreibt Ebeling nicht eine Eigenschaft oder Wesensbestimmung Gottes, sondern das Verhältnis zwischen Gott und Menschen, das existenziell aufeinander bezogen ist und darum nicht voneinander getrennt gedacht werden kann und darf. So wird es in den oben aufgezeigten Überlegungen über das Verständnis des Gebets als Ausdruck von Passivität und Angesprochensein schon impliziert, weil ein relationaler Gehalt dabei gefunden werden kann. Das bezeichnet Ebeling bemerkenswerterweise mit dem Begriff der relationalen Ontologie.

\footnotetext{
${ }^{753}$ D I, 202.

754 Vgl. WG, 222f. Ebeling bezeichnet hier das Gebet als „ein Inanspruchnehmen auf Grund eines Inanspruchgenommenseins.“: „Das Gebet, das Gott als Person in Anspruch nimmt, ist das Faktum eines Inanspruchgenommenseins des Menschen als Person - eines Inanspruchgenommenseins, das sich einem geglaubten Gegenüber verdankt.“ (222).

755 D I, $202 \mathrm{f}$.

${ }^{756}$ D I, 204.

757 D I, 204.

${ }^{758} \mathrm{D}$ I, 205.

${ }^{759}$ D I, 204.
} 


\subsubsection{Der Beitrag des Gebets zur relationalen Ontologie}

Hinsichtlich des Begriffs der Ontologie der Relation liegt leider keine systematische Beschreibung von Ebeling selbst vor. Es ist nur zu sagen, dass Ebeling vermutlich den in der lutherischen coram-Relation wurzelnden Begriff der Relation bzw. Relationalität auf die Ebene der Ontologie bringt, ${ }^{760}$ für die Seinsbestimmung Gottes und des Menschen verwendet und damit als einen inneren Kernbegriff seiner Dogmatik einsetzt.

Ebeling entwickelt die Ontologie der Relation zuallererst als Gegenentwurf zur Substanzontologie, die als solches, was noch ,in hohem Maße auch das neuzeitliche wissenschaftliche Denken“ beherrscht, „dem Wirklichkeitsverständnis der objektivierenden ratio“ entspricht ${ }^{761}$ und sogar dafür verantwortlich ist, dass sie die Dogmatik ,in eine Richtung“ drängt, „die der biblischen Absicht kaum entspricht“"762. Vor allem für die biblische Rede vom Sein Gottes und des Menschen ist die Anwendung der Substanzontologie gar nicht passend, weil diese in ihrer Voraussetzung den Grundfehler hat, „dass man es mit separaten Größen zu tun hat, deren Sein unabhängig voneinander besteht und die man nachträglich auf ihre Vergleichbarkeit hin befragt ${ }^{\text {"763 }}$. Im Rahmen der Substanzontologie werden Gott und Welt als zwei separate Wirklichkeiten und das Sein des Menschen darum wesentlich als Selbstständiges verstanden. ${ }^{764}$ Das widerspricht aber der biblischen Rede von Gott und Menschen, die sich speziell und wesentlich auf den Schöpfungsglauben bezieht, wobei das Sein aller Kreaturen samt dem des Menschen ein Geschaffensein ist, das durch den Schöpfungsakt des Gottes erst ins Sein gerufen ist. Darum ist es nicht als selbständiges Sein zu verstehen, sondern als ein von Gott als dem Schöpfer abhängiges Sein. Die biblische Rede von der Geschöpflichkeit der Welt und dem Glauben an Gott als dem Schöpfer sowie die christliche dogmatische Auffassung von Gottes- und Menschensein, sofern sie die Schriftgemäßheit für ihre Grundlage und Kriterium als Prinzip aufnimmt, widerspricht dem substanzontologischen Gedanken. Stattdessen fordert sie laut Ebeling den ihr gegenüberstehenden, nicht-substanzzentrierten, sog. relationalontologischen Gedanken.

Gegen die Substanzontologie befindet sich der Ansatzpunkt der relationalen Ontologie darin, dass sich Gott und Menschen ontologisch aufeinander beziehen. Ebeling behauptet, „Das Sein Gottes ist nichts Getrenntes neben dem Sein der Welt, sondern ist das Zusammensein Gottes und der Welt, wie ebenso das Sein der Welt nichts Getrenntes, Abgesondertes meint neben dem Sein Gottes, sondern das

\footnotetext{
${ }^{760}$ Vgl. Luthers Wirklichkeitsverständnis, in: WG IV, $460 \mathrm{ff}$.

761 D I, 348.

762 D I, 339.

763 D I, 221.

${ }^{764}$ Vgl. D I, 350: „Substanzontologisch erscheint es als das Selbstverständliche, dass man primär ein Einzelner ist, zu dem dann verschiedene Relationen hinzukommen, die mit anderem verbinden.“
} 
Zusammensein von Welt und Gott. [...] so bilden Gott und Welt nicht zwei Wirklichkeiten. [...] Gemäß dem Verständnis von Sein als Zusammensein bilden Gott und Welt eine einzige Wirklichkeit, allerdings eine in sich selbst aufs tiefste und gewichtigste unterschiedene Wirklichkeit.“" ${ }^{675}$ Das ontologischrelational verstandene Sein bezeichnet sich als „Zusammensein“ und meint damit ein Gegenübersein, das weder die Wirklichkeit Gottes noch die Wirklichkeit der Welt zurückzieht. Darüber hinaus wird im Rahmen der relationalen Ontologie die Unterscheidung Gottes von dem Menschensein nicht beschädigt, sondern sinnvoller zur Sprache gebracht als im Rahmen der Substanzontologie. Das erklärt K. Zwanepol wie folgt: „In der Relationsontologie hat die Unterscheidung einen umfassenden und zugleich exklusiven Kontext. [...] In einer Substanzontologie kann von einer Unterscheidung eigentlich keine Rede sein, weil die Wirklichkeit hier auf die Substanz der Dinge hin durchleuchtet wird. d.h. bis auf das eigene Wesen, unabhängig vom Akzidentellen und ohne Berücksichtigung der Beziehung zu anderen Dingen. Die Substanzontologie geht von einer Scheidung aus, durch die die Dinge aus den Beziehungen, in denen sie zueinander stehen, herausgelöst werden. [...] Nur in einer Ontologie, in der die Wirklichkeit strukturell und von Anfang an als ein relationales Geflecht aufgefasst wird, ist eine Unterscheidung, in der das dynamische Verhältnis zwischen den Dingen ausgedrückt wird, sinnvoll.“766 Im Rahmen der relationalen Ontologie versucht Ebeling nicht nur die untrennbare Relation zwischen Gott und Menschen, sondern auch die unvereinbare Unterscheidung zwischen ihnen richtig zur Geltung zu bringen.

Die relationale Ontologie ist laut Ebeling auch schriftmäßig und konstituiert durch den Schöpfungsgedanken. Die ontologische Relation von Gott und Menschen wird durch nichts anderes als durch den Schöpfungsakt aufgebaut, womit sie sich gleichermaßen als Schaffendsein und als Geschaffensein aufeinander beziehen und sich einander gegenüber stellen. Gottessein ist als Schaffendsein darum nur in der Beziehung zu seinem Geschöpf richtig zu denken; und Menschensein als Geschaffensein nur in der Beziehung zu seinem Schöpfer. Ist der Mensch als das Geschaffensein auf Gott als seinen Schöpfer ontologisch bezogen, so ist diese Beziehung als durch die Abhängigkeit des Geschöpfs vom Schöpfer zu explizieren. Diese durch den Schöpfungsgedanken begründete, darum konstitutiv unaufhebbare Gottesbeziehung des Menschen steht bei Ebeling im Zentrum der relationalen Ontologie. Die konstitutive Beziehung zwischen Gott und Menschen hat eine besondere Bedeutung. Das Sein tritt in der Substanzontologie als Selbstständiges nachträglich mit anderem in Beziehung; die Externrelationen werden dabei für Unwesentliches gehalten. Dagegen wird unter der relationalen Ontologie das Sein des Seienden als Geschaffensein und damit nicht als ein Selbständiges, sondern als ein Abhängiges verstanden, aber nicht im Sinne einer einmaligen Abhängigkeit am Anfang der Kreatur, wenn diese ins Sein tritt, sondern im Sinne einer ständigen, ewigen Abhängigkeit. Denn das Sein der

\footnotetext{
765 D I, $222 \mathrm{f}$.

${ }^{766}$ K. Zwanepol, Unterscheiden, Bern 1993, 285.
} 
Kreatur ist nicht nur das von Gott geschaffene Sein, sondern auch von ihm „gewährtes“ und ihm „verdanktes" Sein; und das Sein Gottes ist entsprechend nicht nur das schaffende Sein, sondern auch „gewährendes Sein, zum Danken Anlass gebendes Sein“ ${ }^{767}$ Gott bezieht sich solcherweise von Anfang bis Ende immer auf das Geschaffensein. Ebeling schließt darum: „Das Geschaffensein der Kreatur bestimmt ihr Sein als die bleibende konstitutive Relation zu Gott und Gottes zur Kreatur." "768 Sofern die Geschöpflichkeit nicht lediglich eine zusätzliche Wesenseigenschaft des Seienden ist und die Relation zwischen Gott und dessen Geschaffensein so bleibend und konstitutiv ist, ist die Externrelation nicht für Unwesentliches zu halten.

Diese vom Geschehen der Schöpfung herrührende, doch noch bleibende, darum konstitutive Relation gibt dem Gebet einen Platz. Denn das wesentliche Abhängigkeitsverhältnis des Menschen zu Gott ist bei Ebeling, so wie bereits erwähnt, eine wichtige Kennzeichnung des Gebets, also im Sinne der wesentlichen Mangelhaftigkeit des menschlichen Lebens und damit im Sinne der Notwendigkeit des Verlangens nach Gnade und Heil Gottes. Sofern bei Ebeling die ontologische Relation des Menschen zu Gott durch den Schöpfungsgedanken konstituiert und durch das Phänomen des Betens geäußert wird, ist nun zu sagen: Auf die Frage, warum wir beten, würde also antworten: weil wir Geschaffensein sind und darum in der ontologisch untrennbaren Relation zu Gott bestehen. Radikal gesagt: weil wir von Gott geschaffen sind, beten wir an Gott.

Ferner ist entscheidend, dass „im Sinne relationaler Ontologie der Begriff des Personseins das Menschensein als Zusammensein mit Gott bestimmt und verständlich werden lässt, warum das Zusammensein Gottes mit dem Menschen als Gegenübersein angesprochen und dieses ebenfalls als Personsein präzisiert werden kann“769. Der Begriff des Personseins bzw. der Personalität, der in der Tradition christlicher Gotteslehre als ein Terminus für dreifache hypostatische Selbstständigkeit innerhalb der Trinität als Vater, Sohn und Geist, nämlich für Gottes interne Unterschiede verwendet wurde, wird bei Ebeling für Gottes Externrelation verwendet. Er erklärt, der Begriff des Personseins habe zwei aus der Begriffsgeschichte resultierende Bedeutungen, erstens „im Sinne von Gesicht, Aussehen bzw. Ansehen“, ursprünglich von der Bedeutung persona als Maske oder Gesichts kommt und sich weiter zur Bedeutung der Rolle entfaltet; und zweitens im Sinne von der „Einheit und Ganzheit des Menschen in seinem Sein vor Gott“, der für Luther dasselbe wie Gewissen bedeutet. ${ }^{770}$ Beide Personenbegriffe haben nach Ebeling mit dem unterschiedlichen Weisen zu tun, wie der Mensch an der Worthaftigkeit der Wirklichkeit und am Geschehen des Wortes Gottes in der Welt partizipiert. ${ }^{771}$ Diese Partizipation geschieht gerade beim Beten und hat damit zu tun, was am Gebet als Sprachphänomen

\footnotetext{
767 D I, 221.

768 D I, 221.

769 D I, 229.

${ }^{770}$ Luther, 230.

771 Vgl. Luther, 233.
} 
das überhaupt Entscheidende ist. Der entscheidende Sprachvorgang des Gebets besteht laut Ebeling darin, dass der Beter seine Welterfahrung vor Gott zur Sprache bringt. Denn der Beter wiederholt nicht lediglich die überlieferten Gebetswörter, sondern ,alles, was den Menschen bewegt, die Weltwirklichkeit um ihn her und das, was in seinem Herzen vor sich geht, [...] all das gehört in unerschöpflicher Weise in das Gebet hinein. Indem es vor Gott gebracht und Gott mit ihm konfrontiert wird, gerät die Sprache in eine unerhört wandlungsreiche Bewegung“، ${ }^{772} \mathrm{Im}$ Gebet geschieht eine Transformation von Weltsprache in Glaubenssprache, indem das Erste in der Konfrontation mit Gott zum Letzteren verarbeitet wird. Da das Gebet sich einerseits auf Gott und andererseits auf die Welt bezieht, gibt es eine Auskunft darüber, wie der Mensch als sein Sein vor der Welt und vor Gott im Gewissen verantwortet, nach Ebelings eigenem Ausdruck: wie Gott und die eigene Lebenswirklichkeit des Beters ,in einen und denselben Satz“ zusammengefügt werden können. ${ }^{773}$

In diesem Sinne bezeichnet Ebeling das Gebet als „,das aufschlussreiche Grundmodell“ dafür, wie man Gott und Welt zusammenbringen kann. Er führt aus, „ohne dass die Welt in ihrem Geschaffensein an Gottes Schöpfersein partizipiert und ihre Wirklichkeit als von Gottes Wirklichkeit gewährt verstanden wird“, könnte man Gott und Welt nicht zusammen sein lassen; und „nur dadurch, dass die Welterfahrung in das Gebet einströmt, erhält das Reden zu Gott sein Material, das es ermöglicht, Gott das ihm zukommende Sein und die ihm zukommenden Attribute zuzusprechen. “"774 Ohne Rücksicht auf das Gebet ist eine Rede unmöglich, nicht nur von Menschensein sondern auch von Gottessein, die beide in einer ontologischen Beziehung stehen.

Den Begriff „Relationsontologie“, der etwa philosophisch und spekulativ scheinen könnte, behandelt Ebeling solcherweise theologisch. Er verbindet ihn nicht nur mit dem biblischen Schöpfungsgedanken, sondern setzt ihn bemerkenswerterweise in Verbindung mit dem recht theologischen - im Sinne des Praxis- und Lebensbezugs der Theologie - Wort „Gebet“, das in sich dazu noch den personalen und sprachlichen Charakter hat. Weil Ebeling aber anhand des Begriffs der relationalen Ontologie sein Augenmerk auf die Externrelationen und auf das Gebet, das sich als die Sprachlichkeit Gottes für uns bezeichnet, legt, fehlt bei ihm leider die Rede von der Sprachlichkeit Gottes an sich. Er nimmt keine Rücksicht darauf nimmt, dass Gott immanent ein Gespräch mit sich selbst als der Dreieinige führt. Er bringt dann die Sprachlichkeit Gottes nicht völlig, sondern einseitig

\footnotetext{
772 D I, 210.

${ }^{773}$ D I, 210. Solchen Sachverhalt des Gebets bringt Ebeling in seinen anderen Werken über das Gebet unmittelbar zum Ausdruck, z.B. im Buch > Vom Gebet: Predigten über das Unser-Vater<, 53: „Wer also betet, der unterzieht sich, wie es scheint, einer Zerreißprobe. Auf der einen Seite fasst er Gott und auf der anderen Seite hält er die Welt.“; und im Aufsatz „Das Gebet“, in WG III, 423: „Das Gebet versteht die Grundsituation des Menschen als durch die Beziehung zu Gott entscheidend bestimmt“, wobei „der Gegenstand der Gottesbeziehung der Mensch in seinem Weltbezug ist."

774 D I, 223.
} 
zur Sprache, während Luther das innergöttliche Gespräch immer unterstreicht und es für „den ewigen Grund menschlicher Sprachlichkeit“" ${ }^{775}$ hält.

\subsection{Der Sprachcharakter der göttlichen Eigenschaften}

Die Gotteslehre erläutert das Themas „Gott“. Sie reflektiert sowohl darüber, dass Gott ist, als auch was und wie er ist, und beschreibt ihn aufgrund des Zeugnisses der Heiligen Schrift mit verschiedenen Eigenschaften wie Ewigkeit, Allgegenwart, Allmacht und Allwissenheit usw. Die Lehre von den göttlichen Eigenschaften antwortet auf das So-Sein Gottes.

Insofern das So-Sein Gottes von Menschen aufgrund ihrer Erfahrungen Gott zugesprochen wird, hat die theologische Rede von den Eigenschaften Gottes mit der menschlichen Erfahrung zu tun. Eine Ausführung der Lehre von den göttlichen Eigenschaften in Bezug auf die Erfahrung, findet sich zuallererst bei Schleiermacher, der die Gotteslehre ausschließlich als die Lehre von den Eigenschaften Gottes konzipiert. Für die diesbezügliche Ausführung lautet bei ihm der Grundsatz so: „Alle Eigenschaften, welche wir Gott beilegen, sollen nicht etwas Besonderes in Gott bezeichnen, sondern nur etwas Besonderes in der Art, das schlechthinnige Abhängigkeitsgefühl auf ihn zu beziehen." “776 Schleiermacher setzt somit die Dimensionen der Wirklichkeitserfahrung mit den göttlichen Eigenschaften in Beziehung: Zeit und Ewigkeit, Raum und Allgegenwart, Natur und Allmacht, Geist und Allwissenheit. Er positioniert sich dadurch gegen das metaphysische Schema der Artikulation der Eigenschaften Gottes, das sich von dem metaphysischen Verständnis des Wesens Gottes ableitet und das Göttliche auf eine abstrakte und spekulative Weise beschreibt. Er setzt seine Lehre von den göttlichen Eigenschaften so in Bezug auf die Erfahrung des Menschen aus und gründet sie auf die Sagbarkeit Gottes. Dagegen beginnt K. Barth mit der Unsagbarkeit Gottes. Indem er sich der Unterscheidung zwischen dem Deus absconditus und dem Deus revelatus eindeutig anschließt, verneint er die vollkomme Offenbarung und Darstellung des Wesens Gottes für Menschen und unterscheidet das Wesen Gottes von seinen Eigenschaften, die Menschen erfahren und beschreiben können: „Alles, was wir von Gott sagen, alle Eigenschaften, die wir Gott beilegen können, beziehen sich auf diese seine Taten. Also nicht auf sein Wesen als solches. Obwohl das Wirken Gottes das Wesen Gottes ist, ist es notwendig und wichtig, sein Wesen als solches von seinem Wirken zu unterscheiden.“777 Er betont „die Unbegreiflichkeit Gottes, die Unangemessenheit aller Erkenntnis des offenbarten Gottes“. ${ }^{778}$ Werner

\footnotetext{
775 J. Ringleben, Gott im Wort. Luthers Theologie von der Sprache her, Tübingen 2010, $70 \mathrm{ff}$. Bes. 78.

${ }^{776}$ F. Schleiermacher, CG, Bd. I, §50, 300.

${ }^{777}$ K. Barth, KD I/1, 9, 391.

${ }^{778}$ K. Barth, KD I/1, 9, 391.
} 
Elert geht noch einen Schritt weiter und verzichtet in seiner Dogmatik darauf, die Lehre von den göttlichen Eigenschaften selbst zu erörtern. ${ }^{779}$

In Hinsicht auf die Lehre von den Eigenschaften Gottes steht Ebeling nahe bei Schleiermacher. In seinem Aufsatz über $>$ Schleiermachers Lehre von den göttlichen Eigenschaften < (1968) sagt Ebeling, dass sie der christlichen Frömmigkeit zu „reichem sprachlichen Ausdruck“ verhilft und die „Erfahrung“ als „Ursprung der Sagbarkeit“ Gottes aufruft. ${ }^{780}$ Dem Weg Schleiermachers, der seine Lehre auf die Sagbarkeit Gottes gründet und in Bezug auf die Erfahrung des Menschen ausführt, folgt Ebeling in seiner Dogmatik. Er macht die Lehre von den Eigenschaften Gottes so wie Schleiermacher nicht zu einem abstrakten Versuch, das Wesen des Göttlichen zu beschreiben. Stattdessen entwirft er das erfahrungsbezogene Verfahren, indem er „die Konfrontation Gottes mit der den Menschen angehenden Wirklichkeit“ für „die Ursprungssituation der göttlichen Attribute“ hält. ${ }^{781}$ Diesbezüglich findet Ebeling seinen eigenen Weg. So wie W. Krötke mit Recht herausstellt, teilt Ebeling das Verfahren Schleiermachers nicht, „,on dem Bewusstsein der Sünde und der Erlösung sowie von dem darin vorausgesetzten Gottesbewusstsein her die göttlichen Eigenschaften zuzusprechen“" ${ }^{782}$ sondern führt diese vielmehr in die konkrete sprachliche Kommunikation Gottes mit dem Menschen ein. Da kommt das Gebet ins Spiel. Denn um nichts anderes als, „dass und wie Gott zur Erfahrung kommt“, 783 geht es bei Ebeling im Gebet.

In der Dogmatik entwirft Ebeling die Lehre von den Eigenschaften Gottes in Korrelation zur Lehre vom Gebet und hebt den Sprachcharakter der göttlichen Attribute hervor. Diesen erklärt er mit einer doppelten Sprachbewegung, die im Gebet entsteht und „die für die Gott zugesprochenen Attribute konstitutiv ist“784. Im Gebet bewegt sich die Sprache einerseits für die Prädikation Gottes: „Indem die den Menschen angehende Wirklichkeit in das Gebet einströmt und so vor Gott gebracht wird, entzünden sich in dieser Konfrontation Prädikationen Gottes, in denen sich die Weise des Zusammenseins Gottes mit der ihm dargebrachten Wirklichkeit expliziert. “"785 Diese Prädikationen Gottes betreffen laut ihm die „aus der Welt geschöpfte und auf Gott hin transferierte Sprache“. Er meint damit nicht, dass die Sprache „zur Entdeckung und Konstruktion göttlicher Eigenschaften“ dient, sondern dass das Gebet als Sprachphänomen ,immer schon von dem Kundgewordensein Gottes her“ kommt. ${ }^{786} \mathrm{Im}$ Gebet wird

\footnotetext{
779 W. Elert, Der christliche Glaube. Grundlinien der lutherischen Dogmatik, Hamburg 61988, 234-237.

780 Ebeling, Schleiermachers Lehre von den göttlichen Eigenschaften, in: ZThK 65 (1968), 459-494; Wiederabdruck in: WG II, 305-342, hier 317f.

781 D I, 237.

${ }^{782}$ Wolf Krötke, Die Attribute Gottes in der neueren deutschsprachigen evangelischen Dogmatik. Vortrag bei einer internationalen Tagung der Katholisch-Theologischen Fakultät Augsburg am 25. 07. 2013. http://wolfkroetke.de/vortraege/ansicht/eintrag/67.html.

${ }^{783}$ D I, 199.

${ }^{784}$ D I, 239.

${ }^{785} \mathrm{D}$ I, 239.

${ }^{786}$ D I, 239.
} 
durch bestimmte Prädikationen Gott zugesprochen, was Gott schon immer eigen ist. Das bedeutet zugleich jedoch nicht, dass das So-Sein Gottes schon festgelegt ist. Denn die Gottesprädikationen strahlen nach Ansicht Ebelings ,wieder auf den Betenden und die ihn angehende Wirklichkeit zurück und lassen auf alles ein anderes Licht fallen, so dass aus der Prädikation Gottes eine Aussage über den Menschen und seine Welt wird.“787 Die Prädikation Gottes wirkt darum auf alle Aussagen christlichen Glaubens. Im Gebet befindet sich also die gegenseitige Durchdringung der göttlichen Attribute sowie ihr Bezug auf alle Aussagen des christlichen Glaubens.

Ebeling erläutert die Attribute Gottes dementsprechend in Bezug auf die Hauptelemente des Gebets wie Anrede, Dank (bzw. Lob) und Bitte, weil jedes Element Gott zukommt und durch jedes „ein Grundzug im Wesen Gottes zugesprochen wird“.${ }^{788}$ Zum Beispiel wendet sich die Anrede im Gebet an die Heiligkeit Gottes, in der ein Doppeltes von der Verborgenheit und der Nähe Gottes begriffen ist. Das Lob im Gebet wendet sich an die Doxa Gottes, weil es „das einzige“ ist, „,was der Mensch Gott zu geben vermag: ihm die Doxa zuzusprechen, die Gott von sich aus hat, die er aber so haben will, dass

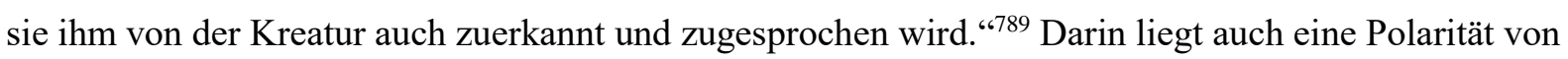
der Ewigkeit und der Schöpfermacht Gottes, die jeweils seine unterschiedliche Position zur Kreatur zeigt. Die Bitte im Gebet besteht im Vertrauen auf Gott und beruft sich auf die Liebe Gottes, in der wieder eine Polarität von der Gnade und der Wahrheit Gottes auftritt. ${ }^{790}$

Ebeling entwickelt die oben genannten drei Grundattribute Gottes wie die Heiligkeit, die Doxa und die Liebe im ersten Band nicht weiter. Er belässt es bei der skizzenhaften Darstellung bzw. bei der Form des Grundrisses, wobei er sich, streng genommen, nicht auf die Attribute Gottes selbst, sondern auf die Relation von den Gott zugesprochenen Attributen und dem Gebet fokussiert. Er versteht die Lehre von den göttlichen Eigenschaften nicht als eine solche, die lediglich einen Teilaspekt der speziellen Gotteslehre bildet, sondern sieht „das Verständnis der Attribute Gottes vom gesamten Inhalt des christlichen Glaubens her bestimmt ${ }^{\text {"791 }}$. Er entfaltet die Rede von den göttlichen Eigenschaften wieder im zweiten Band, also in der Christologie und behauptet, dass es kein Gottesattribut gibt, „das nicht unabhängig von Jesus Christus in der religiösen Tradition schon vorgegeben wäre; freilich ebenfalls keines, das nicht von Jesus Christus her seine Prägung empfinge. “792 Die Attribute Gottes sind für Ebeling dann christologisch und können allein von Jesus Christus her erfasst werden, weil die Menschwerdung Gottes in Jesus die Attribute der Liebe erschließt, die Versöhnung durch den Kreuzestod Jesu die Heiligkeit Gottes und die Auferstehung Jesu seine Doxa. ${ }^{793}$

\footnotetext{
787 D I, 239.

${ }^{788}$ D I, 241.

789 D I, 242.

${ }^{790}$ D I, 241-244.

791 D I, 240.

792 D II, 229.

${ }^{793}$ D II, 229-255.
} 


\section{Sprache und Glaube an Jesus Christus}

Im Credo bekennen wir unseren Glauben an Jesus, dass dieser zuallererst Gottes Sohn ist, aber auch als ein Mensch geboren wurde. Dieses Glaubensbekenntnis impliziert ein traditionelles Hauptthema der Christologie. Es geht um die zwei Naturen Jesu, die in den neutestamentlichen Bezeichnung „Gottes Sohn“"794 und „Menschensohn“"795 oder auch in der Grundformel des christologischen Dogmas vere Deus vere homo ausgedrückt werden. Die Vorstellung von den zwei Naturen Jesu wird üblich bezüglich der Frage nach dem Wesen Jesu formuliert. Je nachdem, wie sie interpretiert oder behandelt wird, charakterisieren sich auch weitere Aspekte der Christologie.

\subsection{Die Untrennbarkeit der zwei Naturen Jesu}

Das Thema der zwei Naturen verbindet sich mit dem methodischen Problem, dass es zwei Ausgangspunkte für die Christologie gibt: die Christologie „von oben“, die von der Gottheit Jesu ausgeht und den Akzent gewöhnlich mehr auf den Inkarnationsgedanken legt. Und die Christologie „von unten“, die vom geschichtlichen Menschen Jesus zum Verhältnis zum Vater Gott und zur Erkenntnis seiner Gottheit aufsteigt und dabei oft seine Botschaft vorzieht. Die Christologie „von oben" war in der altkirchlichen Christologie der häufig begangene Weg und findet sich auch in der neuzeitlichen, z.B. bei Barth und Bultmann, während die Christologie „von unten“ z.B. bei Schleiermacher und Tillich präsent ist. ${ }^{796}$ Vor diesem Hintergrund kann man die Frage stellen, ob es möglich oder gerecht ist, eine Christologie nur in einer alternativen Weise darzustellen oder sie als eine zu charakterisieren. Otto Weber bezweifelt die Legitimität der Christologie von unten und behauptet, „Niemand kann ja von einem irgendwie vorgegebenen $>$ Unten $<$ auf ein $>$ Oben $<$ zugehen, ohne dieses wenigstens potentiell in oder mit jenem $>$ Unten $<$ für ebenfalls gegeben zu halten“797. Dagegen ist die Christologie von oben, laut den frühen Überlegungen Pannenbergs, ein falscher Weg, weil sie sich auf den „Standpunkt Gottes“ stellt, während wir „faktisch immer von einer geschichtlich bestimmten

\footnotetext{
${ }^{794}$ Mt 16,16; Mk 1,1;11; Lk 1,35; Joh 1,14; Act 9,20; Rom 1,4; Heb 4,14 etc.

${ }^{795}$ Mt 11,19; Mk 2,10; Lk 24,7; Joh 12,34; Ofb 1,13 etc.

${ }^{796}$ Die Einordnung der Theologen könnte unterschiedlich bestimmt werden. z.B. Tillichs Christologie bezeichnet Pöhlmann als eine Christologie von unten, während Pannenberg sagt, die Einordnung zur Alternative „,von oben“ oder „,von unten“ sei bei Tillich „,nicht klar“, weil dieser „das ,Oben“ selbst vom Menschen her“ denkt. Vgl. H.G. Pöhlmann, Abriss der Dogmatik, Gütersloh 1973, 179f; W. Pannenberg, Grundzüge der Christologie, Gütersloh 1976 (mit Nachwort), 28. Anm. 41. Ich glaube, Tillich steht doch näher zur Christologie von unten, weil er Jesus eindeutig nicht als wahren Gott, sondern als wahren Mensch beschreibt und sogar die Inkarnation für „sinnlos“ hält und ablehnt. P. Tillich, Systematische Theologie, Bd. II, Stuttgart 1958, $103 \mathrm{f}$.

${ }^{797}$ O. Weber, Grundlagen der Dogmatik II, Berlin 1962, 35.
} 
menschlichen Situation aus“ denken, deren Grenzen wir keinesfalls „einfach überspringen“ können. ${ }^{798}$ Wilfried Joest verwirft sogar die alternative Methode selbst, weil diese eine von dem biblischen Zeugnis beschriebene Einheit der Naturen Jesu „,auseinander zu reißen“ droht, und behauptet: „Christologie von oben oder Christologie von unten (ist) eine falsche Alternative: Die Menschlichkeit Jesu ist nicht ohne das in seiner Geschichte sich vollziehende Wirken Gottes, Gottes Sein nicht ohne die Geschichte des Menschen Jesus zu denken. “799

In Hinsicht auf das von den zwei Naturen Jesu herkommende Schema einer Christologie „von oben“ und „von unten“ zeigt Ebeling in seiner Dogmatik eine ähnliche Meinung. Er hält die Fixierung auf die Zweiheit der Naturen Jesu und die daher kommende, einseitig verfahrende Christologie für gefährlich. Die Christologie von oben könnte in Gefahr geraten, nur als „eine Mythologie“ eingeschätzt zu werden, „sofern nicht überhaupt der Gottesgedanke seinen Wirklichkeitsbezug und damit seine Vollziehbarkeit verloren hat “ ${ }^{800}$ In diesem Fall ist von einer doketischen Gefahr zu reden, weil diese die Folge davon ist, dass Gottes strikte Unterschiedenheit zur Welt und damit die Offenbarung Gottes im Menschsein Jesu zweifelhaft wird. ${ }^{801}$ Daneben sieht Ebeling auch die Gefahr der Christologie von unten, Jesus als bloßen Menschen bzw. eine historische Person zu betrachten und somit Gottes Kraft in ihm zu übersehen. Er sagt darum, dass der Einsatz beim Menschen „keine echte Alternative zu dem, was der legitime Sinn einer Christologie von oben ist, nämlich dass Gott als der in Jesus Christus Handelnde zur Geltung kommt“802. Die Alternative soll laut ihm dann „nur einen sehr begrenzten Wert“ haben und auf eine tiefere Weise geführt werden, die anzeigt, dass „,beide Aspekte notwendig zusammen“ gehören. ${ }^{803}$ Die Zusammengehörigkeit von beiden erklärt er wie folgt: „Entscheidend ist nun aber, dass auch im Falle einer solchen Orientierung am Menschen Jesus die eigentliche Intention jener Christologie von oben gewahrt bleiben muss, wenn es überhaupt zur Christologie kommen soll. Durch das erzählende Beschreiben der Bewegung von Gott her sollte zum Ausdruck gebracht werden,

\footnotetext{
${ }^{798}$ W. Pannenberg, Grundzüge der Christologie, Gütersloh 1976, 29. Solcher frühe exklusive Gedanke wird aber später von Pannenberg selbst korrigiert, etwa auf die Weise, die Christologie von oben nicht kategorisch auszuschließen und die Menschheit Jesu vielmehr in seiner Gottesbeziehung darzustellen, um die Gefahr der Einseitigkeit einer Christologie von unten abzuwehren. Solche Veränderung befindet sich schon im Aufsatz „Christologie und Theologie“: „In der Tat kann der Ansatz bei der Verwiesenheit der Menschheit auf Gott als Thema ihrer Geschichte nur dann die Einseitigkeit einer Christologie von unten, die abstrakt mit einer von Gott isolierten Menschheit beginnt, überwinden, wenn diese Menschheit und ihre Geschichte als Setzung Gottes gedacht werden. Nur so nämlich wird Gott im Hinblick auf die Menschheit als Gott, als die alles bestimmende Wirklichkeit gedacht. Ohne diesen Gedanken wäre bei aller Hervorhebung der Religion und ihrer Bedeutung in der Geschichte der Menschheit nur von den Gottesvorstellungen der Menschen die Rede, nicht aber von der Wirklichkeit Gottes.“ Ders., Christologie und Theologie, in: Grundfragen systematischer Theologie. Gesammelte Aufsätze Bd. 2, Göttingen 1980, 129-145, 137.

${ }^{799}$ W. Joest/J.v. Lüpke, Dogmatik I: Die Wirklichkeit Gottes, Göttingen ${ }^{5} 2010,176$.

${ }^{800} \mathrm{D}$ II, 36.

${ }^{801} \mathrm{D}$ II, $82 \mathrm{f}$.

${ }^{802}$ D II, 43.

${ }^{803}$ D II, 43.
} 
dass in Jesus Gott selbst am Werke ist. [...] Es ist keine Rede davon, dass sie (Inkarnation) spekulativ aus dem Gottesbegriff das Christusgeschehen deduzierte. Sie zeigt vielmehr auf Jesus hin und gibt dazu einen theologischen Kommentar. [...] Insofern ist Christologie ebenso unaufgebbar Christologie von unten“ “ 804 Unter diesem Aspekt versucht Ebeling beispielweise, die Inkarnation, die gewöhnlich als der Ausgangpunkt der Christologie von oben gedacht wird, lieber als solches zu beschreiben, das die beiden wie „das Handeln Gottes von oben her und das Vernehmen und Begreifen des Menschen von unten her" ${ }^{\star 805}$ umfasst.

Es wäre voreilig, hier darüber zu urteilen, ob Ebeling seine dogmatische Christologie tatsächlich in der angeblich tieferen Weise erfolgreich ausführen könnte; ob er in der Dogmatik der Christologie von unten „die Perspektive einer Christologie von oben vorgeschaltet" ${ }^{\text {"806 }}$ sehen würde; oder ob er den Aspekt einer Christologie von unten nach wie vor verteidigen würde. Es ist doch offenbar zu sagen: In der Dogmatik versucht Ebeling, sich von der in seinem frühen Studium oft gefundenen Fixierung auf die Problematik des historischen Jesus sowie von der infolgedessen „,von unten“ verfahrenen Christologie zu lösen, und zumindest beide Aspekte zu umfassen oder das Gleichgewicht zwischen ihnen zu bewahren. Er versucht, die in der Zweinaturenlehre enthaltene Teilung von beiden zu überwinden und der Untrennbarkeit von ihnen einen Vorrang zu geben. Es ist m.E. sinnvoll, diesen Versuch zu betrachten und die Aufmerksamkeit darauf zu richten, auf welche Weise er gemacht wird.

Zuerst ist die Struktur der Christologie zur Sprache zu bringen. Dogmatiker zeigen ihre Absichten oft schon durch die Struktur der Dogmatik an. Pannenberg z.B. hält in seinem frühen Werk $>$ Grundzüge der Christologie< die „Einheit von Gott und Mensch in Jesus Christus“ für „das abschließende und krönende Thema der Christologie“" 807 und behandelt sie in einem selbstständigen letzten Teil. Er behandelt sie unter den zwei Überschriften von der Gottheit Jesu im ersten Teil und von seiner Menschheit im zweiten Teil, so dass er die Vereinbarkeit und Einheit von beiden an den Schluss seiner Christologie stellt. ${ }^{808}$ W. Joest hebt in seiner Dogmatik auch die Einheit von beiden Naturen Jesu hervor und versucht sie relational zu interpretieren. Dafür bringt er in der „relationale(n) Christologie“ zum Ausdruck, dass die zwei Naturen untrennbar zusammen gehören und die Einheit von beiden die doppelte Relation bedeutet, nämlich „das menschliche Verhältnis, in dem Jesus sich auf Gott, seinen Vater bezieht, und das göttliche Verhältnis, in dem Gott zum Menschen kommt und in seinem Sohn ganz gegenwärtig ist“ ${ }^{809}$ Er lehnt dabei aber die Formel der zwei Naturen selbst ab und entscheidet sich, seine Christologie nicht nach ihr zu strukturieren, weil sich Jesus bei ihm keinesfalls entweder nur als

\footnotetext{
${ }^{804}$ D II, 38.

805 D II, 39.

${ }^{806}$ M. Laube, Theologische Selbstklärung im Angesicht des Historismus, in: KuD (54) 2008, 114-137, 130.

${ }^{807}$ W. Pannenberg, Grundzüge der Christologie, Gütersloh 1976 (mit Nachwort), 291.

${ }^{808}$ W. Pannenberg, Grundzüge der Christologie, Gütersloh 1976 (mit Nachwort), 291-414.

${ }^{809}$ W. Joest/J.v. Lüpke, Dogmatik I: Die Wirklichkeit Gottes, Göttingen ${ }^{5} 2010,218$.
} 
Gottheit oder nur als Menschheit offenbart, sondern immer zusammen, also immer als Jesus Christus sowohl im Kreuzesgeschehen als auch im Ostergeschehen, die beide inhaltlich zum Hauptteil seiner Christologie dienen. ${ }^{810}$

Insofern es in der Christologie primär um das Wesen und Werk Jesu Christi geht, liegt Ebelings Schwerpunkt hauptsächlich in den Kapiteln 5 und 6. Der Kapitel 5 ist mit „Gott in Christus“ betitelt und der Kapitel 6 mit dem „Mensch(en) Jesus“. Wenn man wegen der beiden Titel vermuten oder erwarten würde, dass es in Kapitel 5 intensiv um die Gottheit und in Kapitel 6 um die Menschheit geht, wäre man fehlgeleitet. Ebeling selbst erklärt: „Vielmehr ist in beiden Kapiteln von dem Zusammensein von Gott und Mensch die Rede, das eine Mal so, dass, den überlieferten kerygmatischen Aussagen folgend, dasjenige, was in geradezu penetranter Weise das Menschsein bestimmt, nämlich Geburt und Tod, mit Gott in Zusammenhang gebracht wird; das andere mal so, dass dasjenige, was darüber hinaus von Jesus geschichtlich greifbar ist, sein Wort und sein Verhalten, auf den Gottesbezug hin bedacht wird. Damit wird das Verhältnis beider Kapitel zueinander deutlicher. “811 Anders als Pannenberg, der die Einheit der zwei Naturen in einem selbstständigen Teil thematisiert, hat sie bei Ebeling ihren Ort in beiden Kapiteln. Das heißt, im Teil über „Gott in Christus“, in dem er im Anschluss an die christlogische Tradition drei Geschehen Inkarnation, Kreuzestod und Auferstehung thematisiert, versucht Ebeling den Menschenbezug aufzuzeigen, umgekehrt im Teil über den „Mensch(en) Jesus“, also in der Beschreibung seines Wortes und Verhalten deren Gottesbezug hervorzuheben. Solcher Versuch ist auch in der Gliederung optisch erkennbar: In Kapitel 5 „Gott in Christus“ behandelt er unter dem Titel der „Menschwerdung Gottes“ (§18) als das erste Thema „das Menschsein des Menschen“ ( 18 A), im Teil des „Tod(es) Gottes“ (§19) geht es zunächst um „das Sterben des Menschen“ (§19 A) und im Teil des „Leben(s) Gottes“ (§20) gleicherweise um „das Leben des Menschen“ ( $\$ 20$ A). Und in Kapitel 6 „Der Mensch Jesus“ ist der zentrale Begriff nichts anderes als die „Vollmacht“, die eigentlich in der Göttlichkeit Jesu und völlig in dem Willen Gottes liegt. ${ }^{812}$

Ferner muss man seine Aufmerksamkeit darauf richten, dass Ebeling in seiner oben zitierten Aussage das Wesen Jesu mit dem „Zusammensein von Gott und Mensch in Jesus“ bezeichnet, dessen Bedeutung unter dem Aspekt der relationalen Ontologie interpretiert werden soll. In der relationalen

\footnotetext{
${ }^{810}$ W. Joest/J.v. Lüpke, Dogmatik I: Die Wirklichkeit Gottes, Göttingen 52010, 226-255.

811 D II, 43.

${ }^{812}$ Wenn man die Struktur der beiden Kapitel näher betrachtet, kann man Ebelings Intention für die Darstellung des untrennbaren Verhältnisses von Gott und Menschen in Jesus Christus deutlicher finden: Die Inkarnation ( $\$ 18$ B) beschreibt er einerseits „,in Hinsicht auf das Gottessein Gottes“ (II) und andererseits ,in Hinsicht auf die Menschwerdung des Menschen“ (III); über das Thema des Todes Jesu ( $\$ 19$ B) thematisiert er sowohl seinen „Grund“ bei Gott (II) als auch die „Folge“ für den Menschen (III); die Auferstehung Jesu (§20 B) bezieht er einerseits auf den „totenerweckende Gott“(II) und andererseits auf den „zum Leben berufende Mensch(en)“(III); und das Phänomen der Vollmacht charakterisiert er mit den Attributen, die zu Mensch- und Gottessein gehören ( $22 \mathrm{~A}$ ); und das Ja zur Ohnmacht als ein Zeichen der Vollmacht (§23 A. II) bezeichnet er „als Ja zu Gott“ (II-1) und auch ,als Ja zum Menschen“ (II-2).
} 
Ontologie, die er, so wie bereits in der Gotteslehre aufgezeigt, als Gegenentwurf zur Substanzontologie entwickelt, ist alles Sein das Zusammensein und die externe Relation somit konstitutiv. ${ }^{813}$ Er sieht Jesus auch unter dem gleichen relationalontologischen Aspekt. Jesus steht laut ihm in der Beziehung von Gott und Menschen und bestimmt sich nur in seiner wesentlichen doppelten Beziehung zu Gott und zum Menschen. Ebeling stellt Jesus dadurch aber nicht als das irgendwo zwischen Gott und Menschen bestehende Sein, „als ein Mittelding zwischen Gott und Mensch“ oder als „halb Gott und halb Mensch“ dar. Stattdessen erfasst er das Wesen Jesu unter dem soteriologischen Aspekt, dass Jesus als der „Mittler zwischen Gott und Mensch“ jenen vor diesem und diesen vor jenem vertritt und letztlich den von der Seite des Menschen gestörten Gottesbezug wiederherstellt. ${ }^{814}$ Der Relationsbegriff hat so bei Ebeling einen zentralen Platz für das Verständnis dessen, wer Jesus ist.

In diesem Sinne behauptet er, dass es für „die Wahrheit der Zweinaturenlehre“ nicht brauchbar sein würde, ,ihr unzureichendes (subtanz-)ontologisches Instrumentarium“ zu übernehmen, ${ }^{815}$ weil die Wirklichkeit hier auf die Substanz hin durchleuchtet wird. Des Weiteren sei von dem in Jesus wesentlich enthaltenen Beziehungsbegriff keine Rede und damit auch weder von dem Sinn der Unterscheidung, noch von dem der Vereinung. Stattdessen sieht Ebeling die zwei Naturen Jesu unter dem relationalontologischen Aspekt. Er beschäftigt sich nicht damit, was Gottheit und Menschheit Jesu heißt und welche Merkmale zu jeder gehört. Er interessiert sich nicht dafür, wie sie sich aufeinander beziehen und gegenseitig bestätigen. Er untersucht vielmehr, wie dieses Verhältnis von ihnen wieder mit der Beziehung zwischen Gott und Menschen zu tun hat. Solchen Sachverhalt scheint Ebeling eben durch die Bezeichnung Jesu als das „Zusammensein von Gott und Mensch in Jesus“ deutlich anzuzeigen, während das „Gottmenschsein“ als eine naturhafte oder physische Einheit verstanden werden könnte. Somit will er die Darstellung Jesu etwa als ein magisches oder mythisches Wesen einerseits ablehnen, und den in der Teilung von zwei Naturen in Jesu implizierten Gegensatz zwischen Gott und Menschen andererseits überwinden.

Letztlich ist es merkwürdig, dass Ebeling in die Mitte solcher relationalontologischen Interpretation nichts anderes als den Begriff des Wortes bzw. des Wortgeschehens setzt. Er sagt, das Zusammensein von Gott und Mensch in Jesus soll „als ein kommunikatives Zusammensein“ verstanden werden, „freilich nun so, dass sich der gegenseitige Austausch anstatt zwischen den Eigenschaften von grundverschiedenen Naturen in dem personalen Wortgeschehen zwischen Gott und Mensch vollzieht.

\footnotetext{
${ }^{813}$ Zur näherem Verständnis der relationalen Ontologie siehe das Kap. III. 2.1.4.

814 D II, 81 .

${ }^{815}$ D II, 30. Trotz seiner Kritik gegen die Substanzontologie und seines Versuchs, sie zu überwinden, ist es umstritten, ob Ebeling sie tatsächlich oder völlig überwinden würde. Z.B. Ingolf U. Dalferth, der sich gegen die ontologische Methode der Zweinaturenlehre setzt, behauptet, dass „die Wahrheitsbedingungen christologischer Aussagen“ „nicht in einer dualen Ontologie menschlich-göttlicher Sachverhalte“ bestehen, sondern „,vielmehr einheitlich in dem in sich differenzierten Heilshandeln Gottes“. Ders., Der auferweckte Gekreuzigte. Zur Grammatik der Christologie, Tübingen 1994, 152.
} 
[...] dass für die altkirchliche Christologie das kommunikative Zusammensein zweier Naturen in einer Person nicht ein beliebig anwendbares Reflexionsmodell ist, sondern ausschließlich den Sachverhalt kennzeichnet, der in Jesus gegeben ist kraft der Präsenz des Wortes Gottes, die sein Menschsein konstituiert. “816 Beim Beschreiben des kommunikativen Zusammenseins setzt Ebeling einen Akzent auf die in Jesus vollzogene Macht des Wortes Gottes, nämlich das Wortgeschehen. Die Worthaftigkeit Jesu zeigt bei ihm gleich an, dass Gott und Mensch dadurch zusammenkommen, „dass sie im Medium des Wortes beisammen sind“ " ${ }^{817}$ Dadurch scheint er die im ersten Band unter dem Aspekt des Gebets entwickelte, sprachliche Relation zwischen Gott und Menschen in der Christologie im zweiten Band fortzuführen.

Gerade darauf, wie Ebeling unter dem Aspekt der relationalen Ontologie den Begriff des Wortes bzw. des Wortgeschehens entfaltet, wird unsere Aufmerksamkeit gerichtet. Im Folgenden wird zuerst die Worthaftigkeit der drei Geschehen von der Menschwerdung Gottes in Jesus, dessen Kreuzestod und Auferstehung veranschaulicht (3.2); danach wird der geschichtliche Jesus, in dessen Wort und Verhalten sich die Vollmacht vollzieht, betrachtet (3.3).

\subsection{Jesus als Gottes Wort}

Wie können wir Jesus als Gottes Sohn bzw. Gott selbst erkennen oder begegnen? Darauf würde Ebeling antworten, dass wir es können, indem wir in ihm, also in ,seinem Menschsein, seinem Tod und seinem Auferstehen, dem Handeln Gottes begegnen, ja Gott selbst ${ }^{\star 818}$. Das heißt, der Lebensvorgang Jesu wie Geburt, Tod und Auferstehung hat seinen wesentlich von anderen Menschen unterschiedenen, einzigartigen Sinn der Gottheit und bedeutet nach Ebelings Darstellung „die Menschwerdung Gottes“(§18), den „Tod Gottes“ (§19) und „das Leben Gottes“ (§20), die auf die materialen christologischen Themen wie Inkarnations-, Versöhnungs- sowie Auferstehungslehre bezogen sind. ${ }^{819}$ In diesen drei Geschehen hebt Ebeling den Begriff des Wortes bzw. Wortgeschehens hervor, indem er die Anwesenheit Gottes in Jesus als „Gottes Wort in Person“ bestimmt und das Geschehen der Menschwerdung Gottes wieder auf „das Evangelium“ (§18, B.I.3) bezieht und die Beschäftigung mit

\footnotetext{
${ }^{816}$ D II, 81.

${ }^{817}$ D II, 92.

${ }^{818}$ D II, 48.

${ }^{819}$ In Hinsicht auf die Aufteilung des Kapitels 5 „Gott in Christus“ kann man auch erkennen, dass sie gewiss „die Höhepunkte des Kirchenjahres“ betrifft. In der Einleitung sagt Ebeling, seine Intention, den ersten Teil der dogmatischen Christologie so zu konstituieren, liege darin, sich nicht lediglich an die Lehrtradition anzuschließen, sondern zu zeigen, ,was von der Kirche an Weihnacht, Karfreitag und Ostern verkündigt und gottesdienstlich begangen wird“ (D II, 48). Dadurch betont er, dass in den drei christlichen Hauptfesten das Geheimnis von Menschwerdung, Tod und Leben Gottes unmittelbar gegenwärtig ist, und auch versucht, ,eine entsprechende Bedeutung“ zu ergeben, dass der Gottesdienst ein „Prüfstein“ zur Christologie ist, so wie das Gebet einem Schlüssel zur Gotteslehre dient. (D II, 48).
} 
dem Thema des Kreuzestodes und der Auferstehung jeweils auf „das Wort vom Kreuz“ (§19, B.I.4) und auf „das Wort des Lebens“( $(20$, B.I.3) hinführt.

\subsubsection{Die Menschwerdung Gottes als „Gottes Wort in Person“}

Ebeling beginnt den Hauptteil der Christologie mit der Rede von der Menschwerdung Gottes in Jesus. Er hält diese für das „,christologische Grunddogma“"820 und nimmt sie, ähnlich wie Barth ${ }^{821}$ und anders als Pannenberg, ${ }^{822}$ als den Ansatzpunkt für seine Christologie. Er richtet seine Aufmerksamkeit darauf, dass sich die Menschwerdung Gottes in der Erscheinung Jesu Christi ereignet und formuliert dieses Ereignis in der Formel „Gottes Wort in Person“ um.

Mit dieser Formel versucht er einerseits zu bestimmen, wie sich die Anwesenheit Gottes in Jesus „von anderen Auffassungen und Weisen der Anwesenheit Gottes unterscheidet“, die er in vier Kategorien sortiert: „Die magische Anwesenheit des Göttlichen außerhalb des Menschlichen“, „die mythische Vermischung von Göttlichem und Menschlichem“, „die Inspiration und Autorisation von Menschen durch Gott“ und die Auffassung der Welt bzw. Kreatur als Ort der Anwesenheit Gottes. ${ }^{823}$ Der entscheidende Unterschied von diesen anderen Anwesenheiten Gottes liegt laut Ebeling darin, dass am Ort des Menschseins Jesu Christi Gott worthaft und personhaft, also in einer dem Menschsein entsprechenden Weise anwesend ist. Er will sich andererseits von den Ausdrücken abgrenzen, die die

\footnotetext{
${ }^{820} \mathrm{D}$ II, 128.
}

${ }^{821}$ Barth, KD I/2, 144: Dass „Jesus Christus, wahrer Gott und wahrer Mensch“ ist, ist „die Voraussetzung, von der alles weitere Nachdenken auszugehen hat [...] Diese Voraussetzung aber ist insofern eine echte, eigentliche Voraussetzung, als sie nicht von einer anderen überboten, von einer höheren Voraussetzung aus begründet und dann vielleicht doch auch angefochten werden kann.“; und dazu KD IV/1, 138f: „Jesus Christus ist also nicht, was er ist - wahrer Gott, wahrer Mensch, wahrer Gottmensch - um dann als solcher auch noch etwas zu bedeuten, zu tun und auszurichten, was nun eben die Versöhnung wäre. Sondern in der von ihm vollbrachten Tat der Versöhnung des Menschen mit Gott besteht auch sein Sein als Gott, als Mensch, als Gottmensch. “ Darüber hinaus behauptet Berthold W. Körber, dass Barth einen Schritt weiter gehe: Die Inkarnation ist für Barth „nicht nur der Ermöglichungsgrund der Versöhnung“, sondern „das Versöhnungsgeschehen selbst, das als solches zugleich das Sein Jesu Christus ist“". Darin liegt laut ihm der Unterschied von Ebeling und Barth. Ders., Sündlosigkeit und Menschsein Jesu Christi. Ihr Verständnis und ihr Zusammenhang mit der Zweinaturenlehre in der protestantischen Theologie der Gegenwart, Göttingen 1995, $95 \mathrm{f}$.

822 W. Pannenberg, Grundzüge der Christologie, Gütersloh 1976 (mit Nachwort), 291ff. Er verlässt hier den traditionellen Ausgangpunkt der Inkarnation, weil er glaubt, das Dilemma der Zweinaturenlehre und die darin enthaltene Teilung sei „unüberwindlich, solange man die Christologie vom Inkarnationsgedanken her entwickelt, statt sie umgekehrt in der Inkarnationsaussage als ihrem abschließenden Satz gipfeln zu lassen“ (300). Stattdessen geht er von der Auferstehung Jesu aus, weil die Einheit Jesu mit Gott bis zu seiner Auferstehung „,verborgen“ war und erst mit dieser „offenbar geworden ist“ (333); und weil die Aussage der Inkarnation nicht der historische Ausgangspunkt des christlichen Glaubens ist, sondern die Erfahrung der Auferstehung Jesu (334). Unter diesem Aspekt kritisiert er an Barth, dass dieser sich ,darauf beschränkt hat, von der $>$ Existenzeinheit des Sohnes Gottes mit dem Menschen Jesus von Nazareth $<(K D$ IV/2,55) zu sprechen, statt irgendwelche Zusammensetzungshypothesen zu konstruieren“ (334).

${ }^{823}$ D II, 66-69. 
Anwesenheit Gottes in Jesus ,in irgendeiner Weise naturhaft“ vorstellen. Gleichermaßen lehnt er die für die menschliche Vernunft unbegreifliche Formel „zwei Naturen in einer Person“ in der altkirchlichen Zweinaturenlehre oder die Darstellung „Gottesbewusstsein“ bei Schleiermacher ab, die seiner Ansicht nach beide der geschichtlichen und sachlichen christologischen Aussage nicht entsprechen. ${ }^{824}$

Was bedeutet es dann bei Ebeling, dass in Jesus die worthafte und personhafte Anwesenheit Gottes dem Menschensein entspricht? Was will er durch die Komposition von den Begriffen „Person“ und „Gottes Wort“ zeigen? Das hängt wahrscheinlich von seinem Verständnis der Begriffe von Person und Wort ab. Er erklärt: „Person ist hier nicht als innergöttliche Hypostase gedacht, sondern an der menschlichen Person orientiert, doch so, dass sie nicht subtanzhaft ihren Stand in sich selbst hat, daß vielmehr die Relation zu Gott für sie seinsbestimmend ist. Desgleichen meint Gottes Wort hier nicht primär das verbum aeternum als die zweite Person der Trinität, sondern das geschichtlich sich ereignende, im menschlichen Miteinander ergehende Wort, in dem Gott anwesend ist. Dennoch besteht in der entscheidenden Intention Gemeinsamkeit." ${ }^{285}$

Das Wort „Person“ wurde in der altkirchlichen Christologie unter dem trinitarischen Aspekt gedacht und als die innergöttliche Hypostase verstanden, die gegenüber dem Begriff von Ousia (Wesen) für die Bezeichnung der konkreten Wirklichkeit Jesu Christi verwendet wurde. Die Hypostase wurde dabei relational gefasst, im Verhältnis von Vater, Sohn und Geist, die nicht als subordinierte, sondern als gleichrangige und unterschiedliche Realisierungen des einen göttlichen Wesens bestimmt werden. Für die Bezeichnung der Person Jesu verwendet Ebeling aber nicht solchen traditionalen Hypostasebegriff, sondern einen ,an der menschlichen Person orientiert(en)“ Personenbegriff. Dieser ist auch relational, doch nicht im innergöttlichen Verhältnis, sondern im Verhältnis von Gott und Menschen. Während sich jede Hypostase, also was sie ist, dabei in perichoretischer Weise auf die anderen bezieht, bezieht Ebeling die Person Jesu, also wer er ist, in ,penetranter Weise ${ }^{\text {“626 }}$ auf das Menschsein. Was die penetrante Weise meint, wird von ihm nicht genau erklärt und doch ist sie hier als eine wesenhafte und stark beziehende Weise zu verstehen. Und diese Weise hat zuallererst mit der Existenz des Menschen zu tun. Denn Ebeling zeigt mit dem ,an der menschlichen Person orientierten Personsbegriff“ nicht die allgemeinen Gattungsmerkmale der menschlichen Person. Das heißt, er will damit nicht auf eine substantiale Deutung hinweisen, die das Verhältnis des Menschen zu sich selbst zeigt und oft die Vernünftigkeit oder die Selbständigkeit des Individuums meint. Genauso wenig will er eine moralische Deutung hervorheben, die oft als die Menschenwürde oder die dementsprechende Persönlichkeit zum Ausdruck kommt. Obwohl die beiden Deutungen bei Ebeling grundsätzlich nicht ausgeklammert sind, weil die Person Jesu als ein wirklicher Mensch die menschlichen Eigenschaften in sich enthält, betont er hier

\footnotetext{
${ }^{824}$ D II, 70.

${ }^{825}$ D II, 81.

${ }^{826}$ D II, 43.
} 
stärker die existentiale Deutung des Menschseins, dass dieses sich wesenhaft auf die Beziehung Gottes gründet und nur dadurch bestimmt.

Nach der Formel "Gottes Wort in Person“ bedeutet der Personsbegriff die wesentlich gottesbezogene Existenz des Menschen. Weil der Mensch existential als Sünder vor Gott besteht, meint „,in Person“ zu sein dann in dem „vom Widerspruch, vom Zerrissensein“ als Folge der Sünde charakterisierten Menschsein zu sein. ${ }^{827}$ Das heißt, durch seine Menschwerdung in Jesus übernimmt Gott die Situation des Menschenseins und erniedrigt sich in dieses Menschsein, ohne dadurch weder das wahre Menschsein Jesu noch sein wahres Gottessein aufzugeben, sondern das wahre, nämlich das von Gott geschaffene und gewollte Menschsein aufzurichten und darin selber als Liebe anwesend und erfahrbar zu sein. ${ }^{828}$ Gerade an diesem Punkt befindet sich die soteriologische Bedeutung der Menschwerdung Gottes in Jesus. Darüber hinaus ist der Begriff der Gottessohnschaft zur Sprache zu bringen. So wie das menschliche Personssein Jesu in seinem Verhältnis zum Vater Gott, also darin, dass er zugleich der Sohn Gottes ist, besteht, begründet sich unser menschliches Personssein geradezu in der Beziehung zu dem personhaft erfahrenen Gott. Für die ganze Christologie entscheidend ist laut Ebeling die Erkenntnis, dass „das rechte Verständnis von der Gotteskindschaft des Menschen“ allein vom Gottesverhältnis Jesu her sichergestellt werden kann, und dass auch umgekehrt „die exklusive christologische Titulierung“ Jesu als „Sohn Gottes“ nur von daher richtig interpretiert wird, dass die Gotteskindschaft aller Menschen sich ihm verdankt. ${ }^{829}$

Ähnlicherweise stellt Ebeling den Wortbegriff dem verbum aeternum gegenüber und hebt seine Bezogenheit auf den Menschen hervor. Im ersten Band der Dogmatik bestimmte er die vier Gestalten des Wortes Gottes, die bei ihm eigentlich zur Präzisierung des Offenbarungsbegriffs dienen, als verbum praedicatum, verbum scriptum, verbum incarnatum und verbum aeternum. ${ }^{830}$ Während Luther Jesus als das verbum aeternum versteht und das verbum incarnatum als das äußere verbum aeternum bezeichnet, ${ }^{831}$ unterscheidet Ebeling das verbum incarnatum von dem verbum aeternum, das er nur als „Gottes Wort in Gott“ bzw. sein „verbum internum“ bestimmt. ${ }^{832}$. Das verbum incarnatum hat bei Ebeling deshalb eine relative Selbstständigkeit gegenüber dem verbum aeternum und ist der Grund des

\footnotetext{
${ }^{827}$ D II, 88.

${ }^{828}$ D II, 87ff, bes. 88: „Das Anwesendwerden Gottes nicht im Menschsein an sich, sondern in dem vom Widerspruch, vom Zerrissensein gekennzeichneten Menschsein ist das Thema. Deshalb steht das, was Menschwerdung heißt, von vornherein im Zeichen der Widersprüchlichkeit des Menschseins und will daraufhin verstanden werden. Wie denn die alte Fragestellung, ob Christus auch dann hätte Mensch werden müssen, wenn Adam nicht gefallen wäre, mit aller Entschiedenheit zugunsten der infralapsarischen Begründung der Inkarnation zu beantworten ist. Dann haben aber die spezifischen Erniedrigungsaussagen mit den Bedingungen des sündigen Menschseins zu tun.“

${ }^{829}$ D II, 75.

${ }^{830} \mathrm{D}$ I, $258 \mathrm{f}$.

${ }^{831}$ Vgl. A. Beutel, Wort Gottes, in: Ders. (Hg.), Luther Handbuch, Tübingen 2005, 362-371.

${ }^{832}$ D I, 259.
} 
verbum praedicatum und verbum scriptum. Weiter im Teil über die Inkarnation im zweiten Band der Dogmatik sagt Ebeling deutlicher, Jesus als das Wortes Gottes sei „nicht primär das verbum aeternum als die zweite Person der Trinität", und charakterisiert es dementsprechend nicht als göttlich, sondern als „geschichtlich ereignend“, zwischenmenschlich „ergehend“ und damit von der Seite des Menschen zugänglich oder von Menschen erfahrbar. ${ }^{833}$

Diese geschichtliche Gegebenheit erläutert Ebeling durch die Verbindung zwischen Jesus und dem Evangelium, die eigentlich unter dem Gesichtspunkt der Menschwerdung Gottes besteht. ${ }^{834}$ Diese lässt sich laut ihm „nicht spekulativ“, sondern gebunden ,,an das geschichtliche Gegebene“ verstehen: „Für die Menschwerdung Gottes kann es nicht als zufällig und nebensächlich gelten, dass Jesus verkündigend auftrat und selbst zum Gegenstand der Verkündigung wurde. Aus seinem Menschsein ist nicht wegzudenken, dass er sich darein verströmte und sein Leben dafür einsetzte, Gott den Menschen anzusagen und zuzusagen. Desgleichen ist die Überlieferung seiner Erscheinung von dem Wortgeschehen nicht ablösbar, das von ihm herkommt und sich auf ihn beruft, zu ihm hinführt und ihn anruft.“ ${ }^{835}$ So betont Ebeling die sachlich und historisch untrennbare Verbindung zwischen der Inkarnation und dem Evangelium, das bei ihm zugleich als das Wortgeschehen verstanden wird, ${ }^{836}$ und bezeichnet Jesus als „Ursprung des Wortgeschehens“ ${ }^{837}$ Die Wendung „Gottes Wort in Person“ zielt laut ihm letztlich darauf ab: In dem Menschsein Jesu kommt Gott zur Sprache. Dieses Geschehen wird deshalb ,zur unerschöpflichen Quelle eines Wortgeschehens, durch das Gott beim Menschen und der Mensch bei Gott ist. Gott und Menschen kommen dadurch zusammen, dass sie im Medium des Wortes, in vollmächtigem Reden und andächtigem Hören beisammen sind.“ 838 Das persönliche Kommunikationsgeschehen zwischen Gott und Menschen hat dann seinen Ursprung in Jesus als dem Ort, ,wo wahrer Gott und wahrer Mensch vereint sind“‘839.

Im Anschluss an die Eigenart des Evangeliums bezeichnet Ebeling Jesus ferner auch als „Quelle befreiende(n) Wortes“. ${ }^{840}$ Das Evangelium gewinnt seine Eigenart als eine Freudenbotschaft nicht lediglich vor dem sprachlichen Hintergrund, sondern völlig aus dem Sachverhalt, dass die Erscheinung Jesu der Grund zum Evangelium als dem „,von Angst befreiende(n), zur Hoffnung ermutigende(n) Wort" ist und weil sie darauf weist, dass die Wiederherstellung des zerstörten Zusammenseins von Gott

\footnotetext{
${ }^{833}$ D II, 81.

${ }^{834}$ D II, $90-97$.

835 D II, 91.

${ }^{836}$ Ebeling erkannt in Luthers Lehre von Gesetz und Evangelium die Unterscheidung von Verkündigung der Rechtfertigungsbotschaft und menschlicher Lebenswirklichkeit. Das Evangelium bezeichnete er als das Wortgeschehen, also als das Wort, das sich an den Menschen orientiert und bei Menschen tatsächlich geschieht. Um Ebelings Verständnis des Evangeliums geht es näher in Kap. III.4.2.1.

${ }^{837}$ D II, 91 .

${ }^{838}$ D II, 92.

${ }^{839}$ D II, 92.

${ }^{840}$ D II, 93.
} 
und Menschen von jenem her selbst „bereits erfolgt ist“. ${ }^{841}$ Beim Beschreiben des Wortbegriffes verweist Ebeling auch auf die soteriologische Bedeutung, womit er die Menschwerdung Gottes dem Ermöglichungsgrund der Versöhnung dienen lässt.

\subsubsection{Der Kreuzestod und das Wort vom Kreuz}

In der „Einführung der Christologie“(§17) legt Ebeling das Gewicht zuallererst auf das Verhältnis von Christologie und Soteriologie. ${ }^{842}$ Er macht deutlich, dass er durch seine Christologie die Lehre der Versöhnung durchführt und behauptet, ,die soteriologische Ausrichtung tritt nicht als ein zweites zur Christologie hinzu, sondern bestimmt sie von Grund auf" ${ }^{843}$ Weil die Soteriologie das Werk Jesu Christi zum Gegenstand hat und dieses zuallererst die Versöhnung ${ }^{844}$ ist, mündet diese bei Ebeling in jeder christologischen Aussage.

Beim Beschreiben des Themas der Menschwerdung Gottes ist bereits der Begriff der Versöhnung gefallen. Diesen behandelt Ebeling nochmals, doch tiefer und im Zusammenhang mit dem Kreuzestod Jesu, durch den die Versöhnung in der Tat geschieht. Darüber hinaus entscheidet sich das rechte Verständnis der Menschwerdung Gottes in Jesus selbst auch am Verständnis seines Kreuzestodes. Denn die Frage, „was es mit dem Menschsein auf sich hat“ stellt sich nach Ebeling „mit äußerster Schärfe erst vom Tod her“. Gleichermaßen stellt sich ,so auch erst von Jesu Sterben am Kreuz her die Frage, was es mit der Menschwerdung Gottes auf sich hat: ob sie denn wirklich auch den Tod und warum eben diesen Tod mit einschließt.“ “. ${ }^{845}$ Der Sinn der Menschwerdung Gottes in Jesus als die Überwindung des Zwiespalts zwischen Gott und Menschen soll dann in dem Sterben Jesu am Kreuz nicht nur erhalten, sondern noch mehr verstärkt werden, also in der Weise, dass die Versöhnung von Gott und Menschen alles Begreifen übersteigt und sich erst dann vollends offenbart. ${ }^{846}$ In diesem Sinne charakterisiert

\footnotetext{
${ }^{841} \mathrm{D}$ II, $93 \mathrm{ff}$.

${ }^{842} \mathrm{Vgl}$. D II, 5, 12, 13.

843 D II, 41.

${ }^{844}$ In Hinsicht auf das Werk Jesu gibt es verschiedene Bezeichnungen, die sich an die unterschiedlichen biblischen Texte anschließen, z.B. Erlösung (Mk 10,45), Reinigung (1 Joh 1,7), Stellvertretung (2 Kor 5,21), Gabe bzw. Opfer (Eph 5,2) und Befreiung (Gal 5,1) etc. Der Begriff der Versöhnung, der sich an 1 Kor 5,19 oder 1 Joh 2,2 anschließt, wurde in der westlichen theologischen Tradition ausgewählt, um das Werk Jesu zusammenfassend zu charakterisieren, so wie W. Beinert sagt, weil die Versöhnung „stärker“ als die anderen Bezeichnungen darauf hinweist, „dass durch den Christus das gestörte, ,unversöhnte“ Verhältnis Gott und Welt, [...] zurechtgebracht wurde und eben dadurch Leben in Freiheit eröffnet ist." Ders./U. Kühn, Ökumenische Dogmatik, Leipzig 2013, 344f. Sofern die Versöhnung ein Verhältnisbegriff ist, scheint sie bes. für Ebeling gerecht zu sein, weil er die Ursache allen Unheils im von der Seite des Menschen gestörten Gottesbezug sieht. Vgl. D II, 16.

845 D II, 149.

${ }^{846}$ D II, 150.
} 
Ebeling die „Teilhabe Gottes am Kreuzgeschehen“ als „das Durchhalten der Vereinung Gottes und des Menschen in Jesus bis in den Tod hinein und als die sich darin vollziehende Liebe zum Sünder" ${ }^{847}$

Ebeling bestimmt den Tod Jesu am Kreuz als das „Versöhnungsgeschehen“. Das heißt, die Versöhnung von Gott und Menschen geschieht ,in Sterben Jesu“. ${ }^{848}$ Gerade in diesem vollzieht sich das Heilswerk Gottes, das das vom Menschen zerstörte Zusammensein seinerseits wiederherstellt. Unmittelbar und streng zielt es auf die Heilslosigkeit des Menschen, der in Widerspruch sowohl zum Gott auch zu sich selbst geraten ist. Das Kreuzgeschehen ist also auf die Sünde als den Fundamentalwiderspruch zwischen Gott und Menschen bezogen und bringt das Verhältnis zwischen ihnen bzw. zwischen Gottheit und Menschheit maßgebend in Hinblick auf die Sünde zur Sprache: „Im Kreuzesgeschehen geht es darum, dass und wie das unzerstörte Zusammensein von Gott und Mensch in Jesus unter den Bedingungen der sündigen Menschheit offenbar wird und allen zugute kommt.“849 Ebeling entwickelt dieses Problem weiter in Hinsicht auf die Begriffe „Sündlosigkeit“ und „Gottverlassenheit“. Er stellt ihnen die Aufgabe, das Spannungsverhältnis des Kreuzes zu erklären: dass die Tatsache der Gottesferne vom Kreuz nicht getrennt werden kann und damit Sünde und Tod ernstgenommen werden müssen einerseits; und dass der versöhnungsschaffende Gott und seine Verheißung des Heils gewährt werden sollen andererseits.

Die beiden Begriffe erklärt Ebeling zunächst in Bezug auf die oben erwähnten, doppelten Relationen Jesu zu Gott und Menschen: Jesus vertritt „Gott vor den Menschen und die Menschen vor Gott"“. Da das gegensätzliche Verhältnis von Gott und Menschen „durch die Sünde“ bestimmt ist und diese ihre Einheit bedroht, ist Jesus einerseits „,als Anwalt Gottes“ „der Sündlose, weil mit Gott eins“, und vereint sich andererseits „als Anwalt der Menschen“ mit den Sündern und wird „der von Gott Verlassene“ ${ }^{850}$ Mit dieser kurzen Vorstellung der Polarität darf man aber nicht urteilen, dass Ebeling das Thema der Sündlosigkeit Jesu lediglich auf die Beziehung mit Gott oder auf die Gottheit Jesu ausrichtet. Ebenso wenig bezieht er das Thema der Gottesverlassenheit Jesu nur auf die Beziehung mit Menschen oder auf die Menschheit Jesu. Im Blick auf die Vereinung Jesu, die besagt, dass er durch die in ihm geschehene Menschwerdung Gottes wahrer Gott und wahrer Mensch ist, ist das Kreuzesgeschehen konsequent zur Sprache zu bringen. Jesus ist dabei der Sündlose und der von Gott Verlassene als wahrer Gott und wahrer Mensch. Die entscheidende Intention Ebelingscher christologischer Aussagen besteht zuallererst in dem „Sachverhalt, dass Jesu Verhältnis zu Gott und sein Verhältnis zu den Menschen eine Einheit bilden“651.

\footnotetext{
${ }^{847}$ D II, 204.

${ }^{848}$ D II, $149 \mathrm{f}$.

${ }^{849}$ D II, 167.

${ }^{850}$ D II, 177.

${ }^{851}$ D II, 177.
} 
Beim Behandeln des Themas der Sündlosigkeit Jesu hebt Ebeling deshalb ihre Bedeutung als die Zuwendung zum Sünder hervor: Die Sündlosigkeit Jesu ist gewissermaßen der Sachgrund dafür, dass das Gottesverhältnis ausschließlich über Jesus definiert werden kann. Jesus ist der Sündlose, weil er wahrer Gott ist und die Gottheit in sich als seine Eigentümlichkeit besitzt. Das vere Deus ist ja der Seinsgrund der Sündlosigkeit Jesu. In diesem Fall kommt die Sündlosigkeit Jesu in Betracht, allerdings nicht „als eine reale menschliche Möglichkeit“, sondern nur als „das schlechthinnige Wunder der Gegenwart Gottes in dieser Person“852. Von daher fordert Ebeling, die Sündlosigkeit in einer anderen Struktur zu verstehen. Er sagt: „Das Sündersein aller ist nicht eine Aussage, die des vollständigen Einzelnachweises bedürfte, sondern dieser Sachverhalt ist durch die Erscheinung Jesus Christi als die menschliche Gesamtsituation offenbar geworden. “853 Er entfaltet die Bedeutung der Sündlosigkeit über „das negative Verständnis als Freisein von Sünde“ ${ }^{854}$ hinaus auf „das positive Verständnis als die Freiheit zum Sünder“. Denn „Sündlos ist nicht der, der es für sich ist gegen die anderen, die er dadurch um so mehr der Sünde überlässt. [...] Sündlos ist vielmehr der, der sich der Sünder annimmt, um sie von Sünde zu lösen“. ${ }^{855}$ Die Sündlosigkeit Jesu hat dabei nicht mehr „,den Charakter der Absonderung von

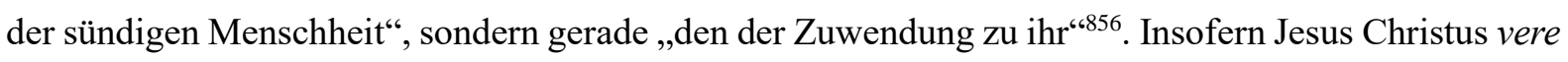
Deus damit sündlos ist, ereignet sich in ihm die Zuwendung Gottes zum Menschen, weil Gott in der Person Jesu anwesend ist und als das Subjekt des Versöhnungsgeschehens seinen Willen an den Menschen orientiert: „Wer sich angesichts der Macht der Sünde herausfordernd mit dem Willen Gottes identifiziert und vor der Welt Gott zu vertreten wagt, der gerät damit eben an den Ort, den Gott in dieser Welt der Sünde einnimmt: an den Ort seines Verachtet- und Ausgestoßenseins. “857 Radikal gesagt, Gott selbst macht Jesus als den Sündlosen zur Sünde, ja „für uns“ (2 Kor 5,21). ${ }^{858}$

Beim Behandeln des Themas der Gottverlassenheit legt Ebeling ein Akzent auf das Verhältnis Gottes zur Sünde, besonders auf das unter dem Nein zur Sünde verborgene Ja Gottes zum Sünder: Die biblische Darstellung des Sterben Jesu am Kreuz weist auf die Gottverlassenheit hin (Mk 15,34; Mt

\footnotetext{
${ }^{852} \mathrm{D}$ II, 181.

${ }^{853} \mathrm{D}$ II, 181.

${ }^{854} \mathrm{D}$ II, 179.

${ }^{855} \mathrm{D}$ II, 181.

${ }^{856} \mathrm{D}$ II, 181.

${ }^{857}$ D II, 186.

${ }^{858}$ Die Verbindung der Sündlosigkeit Jesu mit dem Willen Gottes findet Ebeling bes. im Sinne der „Hingabe für die Sünde“, z.B. in Blick auf das hyper hemon (Gott hat Jesus „für uns zur Sünde gemacht") in 2 Kor 5,21, das im Vergleich mit dem hyper ton hamartion hemon (Christus ist „für unsere Sünden“" gestorben) in 1 Kor 15,3 eine ,andere relationale Neuance“ hat (D II, 188). Aufgrund dieses von und in Jesus erfüllten Willen Gottes sagt er oft, dass das Subjekt des Heilsgeschehens allein Gott sei: „Im Verhältnis von Gott und Mensch kann sich vielmehr Versöhnung nur kraft eines einseitigen Aktes Gottes ereignen. [...] Versöhnt wird nicht Gott durch den Menschen mit der Welt, vielmehr werden der Mensch und die Welt durch Gott mit Gott versöhnt (2 Kor 5,18f).“(D II, 221); „Die Versöhnung zwischen Mensch und Gott ist Gottes Werk.“ (D II, 255). Ähnliches stellt er auch im Blick auf die Zweinaturen Jesu dar: „,das vere Deus“ ist „das tragende Subjekt des Christusgeschehens“ (D II, 536).
} 
27,46) ${ }^{859}$ Diese Gottverlassenheit charakterisiert sich dabei als das Urteil Gottes über die Sünde, weil Jesus an die Stelle der Sünde getreten, von Gott verurteilt und infolgedessen von Gott verlassen geworden ist. Die Gottverlassenheit meint dann den Gegensatz Gottes zur Sünde. Ist sie zugleich für den Gegensatz Gottes zum Sünder, damit zum Menschen zu halten? Ebeling bezeichnet das Verhältnis Gottes zur Sünde bemerkenswerterweise als „das doppelte Nein Gottes zur Sünde“, das einerseits „,das Nein zur Sünde als ein Nein zum Sünder“ und andererseits „das Nein zur Sünde als ein Ja zum Sünder“ umfasst. Gottes Nein zur Sünde als Nein zum Sünder bedeutet die Verurteilung über die Sünde selbst und den Tod des Sünders, während Gottes Nein zur Sünde als Ja zum Sünder dessen Trennung von der Sünde bedeutet und den Freispruch, Vergebung und das wiederhergestellte Zusammensein mit Gott in sich enthält: „Dieses Nein zur Sünde gereicht dem Sünder zum Leben, nicht zur Fortsetzung des bisherigen, sondern zum Anbruch eines neuen Lebens, zur Teilnahme am Leben Gottes, in das er durch die Vergebung hineingenommen ist. Denn dadurch ist das Vertrauen wieder gestiftet und das Zusammensein von Gott und Mensch wiederhergestellt, das seitens des Menschen hoffnungslos zerstört war, aber seitens Gottes verheißungsvoll festgehalten worden ist. “860

Ebeling sieht solcherweise nicht nur die Bedeutung der Gottverlassenheit als Gottes Verurteilung der Sünde bzw. Nein zur Sünde, sondern hebt noch viel mehr die Bedeutung des unter dem Nein zur Sünde verborgenen Ja zum Sünder hervor. Dieses doppelte Verhältnis Gottes zur Sünde darf keinesfalls auf ein einfaches Nein zur Sünde sowie auf ein einfaches Ja zum Sünder reduziert werden, sonst würde die Verheißung Gottes oder der Tod aus dem Verständnis des Heils ausgeschlossen werden. Das Verständnis des Kreuzesgeschehens als Heilsereignis hängt daran, „dass nicht etwa dem Kreuzesgeschehen als dem Nein Gottes erst nachträglich ein ihm widersprechendes Ja hinzugefügt worden ist, dass vielmehr das Ja Gottes bereits im Kreuzesgeschehen enthalten ist, obschon tief verborgen unter dem Nein.“861 Dieses unter dem Nein verborgene Ja ist, wie Paulus sagt, gerade in Jesus „Wirklichkeit geworden, nicht Ja und Nein (2 Kor 1,19), nicht etwas, worauf man sich nicht verlassen kann und wovon man nicht weiß, [...] sondern ein klares, entschiedenes Ja. ,Denn alle Verheißungen Gottes sind in ihm zum Ja geworden. ‘ (2 Kor 1,20)“. 862 Nur in einem solchen Ja Gottes ist Jesus als der Sündlose an die Stelle des Sünders getreten und das Heil kommt in seinem Kreuzestod „zur Vollendung ${ }^{6863}$.

Im Zusammenhang ist nun $\mathrm{zu}$ sagen: Das Kreuzesgeschehen ist bei Ebeling das Versöhnungsgeschehen, weil die Versöhnung als das Heil erst dadurch ein Ereignis wird, dass Jesus als der Sündlose am Kreuz, also an der den Sündern zukommenden Stelle von Gott verurteilt und verlassen

\footnotetext{
${ }^{859}$ D II, 191.

${ }^{860}$ D II, 197.

${ }^{861} \mathrm{Vgl}$. D II, 200.

862 D II, 202.

${ }^{863}$ D II, 218.
} 
worden ist. In der Verbindung von Sündlosigkeit und Gottverlassenheit kennzeichnet Ebeling den Kreuzestod Jesu als das Versöhnungsgeschehen zwischen Gott und den Menschen. Diese Bedeutung läuft auf „das Wort vom Kreuz“ hinaus: „Der Schritt vom Ereignis zur Botschaft, vom factum zum verbum gehört zum Wesen der Christologie.“" ${ }^{* 64}$ So wie schon die Überlegung über die Menschwerdung Gottes letztlich in der Verbindung von Erscheinung Jesu und Evangelium mündet, versucht er das Kreuzgeschehen und das Wort auch in einen Zusammenhang zu stellen. Denn das Kreuzesgeschehen als das Versöhnungsgeschehen darf keinesfalls ein einmaliges Ereignis bleiben, sondern es soll weiter wirken, also bei uns gegenwärtig sein. Dafür spielt das Wort die entscheidende Rolle als das Medium des „Weiterwirken(s) des Kreuzes“6855. Er bezeichnet das Wort vom Kreuz sogar als „die einzige echte Kreuzreliquie“. 866

Die Redewendung „das Wort vom Kreuz“ findet sich ursprünglich im ersten Brief des Paulus an die Korinther: „Denn das Wort vom Kreuz ist eine Torheit denen, die verloren werden; uns aber, die wir selig (od. gerettet) werden, ist es eine Gotteskraft“ (1 Kor 1,18). „Das Wort vom Kreuz“ ist wörtlich die Verkündigung des gekreuzigten Jesu Christi. In Hinsicht darauf, was Paulus hier unter dem logos tou stauro versteht, sagt Ebeling, dass das Erstaunliche doch darin besteht, „dass das Kreuzesgeschehen zu einem Kreuzeswort geworden ist, zu einem weitergehenden Wortgeschehen, das an dem einmaligen Kreuzesgeschehen beteiligt sein lässt““ ${ }^{867}$ Er weist mit Recht darauf hin, dass Paulus mit dem „Wort vom Kreuz" angeblich die Antithese zur Weltweisheit meint und doch vielmehr die Wirksamkeit des Evangeliums betont, durch das der Kreuzestod Jesu weiter verkündigt wird und wir selig bzw. gerettet werden, damit das Kreuz nicht zunichte wird und seine Intention zum Ziel gelangen kann. In diesem Sinne zeigt sich das Wort vom Kreuz als eine Gotteskraft selbst.

Unter solchem Aspekt verwendet Ebeling den Terminus „das Wort vom Kreuz“ nicht für den Ausdruck der ,äußerliche(n) Beziehung auf einen zufälligen Gegenstand der Rede“, sondern meint damit, dass das Kreuz ,in das Wort so eingegangen und mit dem Wort so vereint“ ist. ${ }^{868}$ Anders gesagt, für ihn ist das Wort vom Kreuz weder eine Darstellung eines vergangenen Ereignisses, noch ein über dies informierender Bericht, sondern selbst Vergegenwärtigung dieses Ereignisses. Wenn Ebeling sagt, der Kern des Wortes vom Kreuz sei, dass „ein für allemal der Tod Jesu Versöhnungsgeschehen ist“8699, weist er mit dem Ausdruck ,ein für allemal“ nicht nur auf eine etwas formelhafte Behauptung hin, wie ein biblisches Zitat oder eine traditionelle Bezeichnung für das vollkommene Opfer von Jesus. Stattdessen betrachtet er mit einem bestimmten Akzent den Charakter des Weiterwirkens des Wortes

\footnotetext{
${ }^{864}$ D II, 209.

865 D II, 211.

${ }^{866}$ D II, 211.

${ }^{867}$ D II, 210.

${ }^{868}$ D II, 211.

${ }^{869}$ D II, 218.
} 
vom Kreuz. Das Kreuz kommt laut ihm allein durch das Wort in den Kontext des Lebens hinein und wirkt so in der Weise des in die jeweilige Situation hineingesprochenen Wortes weiter, sodass die Heilsbedeutung des Kreuzes „der Magie entzogen“ und besser „im Horizont des Geheimnisses der Wirklichkeit erfasst“ werden kann. ${ }^{870}$ Er will dadurch zeigen, dass der Sinn des Wortes vom Kreuz „in einer explizierenden Rechenschaft“ darin besteht, ,inwiefern in dem Kreuzesgeschehen das Verhältnis von Gott und Mensch überhaupt repräsentiert und entschieden ist ${ }^{\star 6771}$.

Das Kreuz als den Kern der Theologie zu sehen und daran die ganze Theologie zu orientieren, hat Ebeling schon im Anschluss an Luther klar ausgemacht. In > Luther. Einführung in sein Denken< (1964) sagt er beispielsweise, dass obwohl Luther den Begriff Kreuzestheologie nicht als „Richtungsschlagwort in ständigen Gebrauch genommen hat“, er mit theologia crucis doch „,nicht ein Teilthema oder eine spezielle Art von Theologie“, sondern „das Kriterium und de(n) Ort wahrer Theologie überhaupt“ meinte. ${ }^{872}$ Solche Interpretation der Kreuzestheologie Luthers bringt Ebeling in seine Dogmatik hinein und stellt den Kreuzestod in den Mittelpunkt der Christologie mit der Ausrichtung auf die Versöhnung. Gleichermaßen wird „,das Wort vom Kreuz“ durch die Verbindung mit seinem hermeneutischen Verständnis des Wortes ins Zentrum der christlichen Verkündigung und Geschichte gerückt. $^{873}$

\subsubsection{Die Auferstehung und das Wort des Lebens}

Jesus ist am Kreuz gestorben und dennoch auferstanden. Genauer gesagt, „weil gekreuzigt, auferstanden. “874 Der Kreuzestod Jesu und seine Auferstehung gehören zusammen, insbesondere im soteriologischen Sinn, weil er durch die Auferstehung nicht nur seine Verkündigung als die Wahrheit, sondern auch seinen Kreuzestod als das Versöhnungsgeschehen bestätigte. Der Glaube an Jesus als den Versöhner verbindet sich darum unmittelbar mit der Auferstehung. Dieser Glaube ist aber noch genauer zu beschreiben: nach Ebeling unterscheidet sich „glauben an Jesus als den Auferstanden“ von „glauben an die Auferstehung Jesu““ ${ }^{875}$ Damit ist gemeint, dass die Glaubensaussage über die Auferstehung nicht

\footnotetext{
${ }^{870} \mathrm{D}$ II, 212.

871 D II, 218.

${ }^{872}$ Luther, 259f.

${ }^{873}$ Ebeling widmet dem Wort vom Kreuz so die spezielle Aufgabe, die theologische Verantwortung des christlichen Glaubens für die Gegenwart zu nehmen, und doch scheint er sich infolgedessen unter einen etwas beschränkten Gesichtspunkt zu stellen, wobei er eine Seite der Geschichte als die zur-Sprache-kommende Geschichte sieht. Die zur-Sprache-kommende Geschichte ist für Ebeling als die Geschichtlichkeit zu verstehen, die häufig in seinen frühen hermeneutischen Schriften thematisiert wurde. Er scheint den frühen Gesichtspunkt über die Geschichte hier fortzuführen. Zur nähren Untersuchung des Ebelingschen Geschichtsverständnisses und der Kritik über dieses siehe das Kap. II. 5.2.

${ }^{874}$ D II, 200.

${ }^{875}$ D II, 280.
} 
auf das vergangene Faktum der Auferstehung, sondern auf die Person Jesus als den Auferstandenen gerichtet werden soll. Die so an die Person Jesu anschließende Problematik ist bei Ebeling der Ansatzpunkt, seine Vorstellung der Auferstehung zu strukturieren und darzulegen. Er selbst formuliert sie in zwei Fragen: „Wie könnte von der Auferstehung eines Menschen von den Toten überhaupt im Sinne einer Vergangenheitsaussage die Rede sein? Und wie von einer Person, die vor fast 2000 Jahren lebte, als einer gegenwärtigen?“876 Die erste Frage bezieht sich „,auf ein datierbares Ereignis“ und damit auf eine Debatte über das Realitätsproblem der Auferstehung und ihren historischen Bezug, wobei das leere Grab und die Erscheinung häufig noch umstritten thematisiert werden. Die zweite Frage richtet sich „auf die Gegenwart des Auferstandenen“, die in der Verbindung mit einem weiteren Aspekt der Erhöhung betrachtet wird, so wie sich im Credo die Aussage über die Auferstehung Jesu in den über seine Himmelfahrt und Sitzen zur Rechten Gottes fortsetzt. ${ }^{877}$ Die beiden gehören offenbar zum Osterglauben und zielen letztlich darauf ab, auszuweisen, wer Jesus war und ist.

Man muss aber noch daran denken, dass Ebeling beim Beschreiben dessen, wer Jesus ist, vere Deus und vere homo stets nebeneinander setzt und die doppelten Beziehungen Jesu zu Gott und Menschen sowie das Zusammensein von Gott und Menschen in Jesus betont. Das gilt auch hier in den Aussagen über die Auferstehung, so wie in den oben aufgeführten Aussagen über die Menschwerdung Gottes in Jesus und dessen Tod am Kreuz. Insofern die Toten lebendig zu machen bzw. zu erwecken eigentlich zum Gottesattribut gehört (Röm 4, 17) und das Leben nach der Auferstehung keine Rückkehr in das menschliche Leben meint, sondern mit dem ewigen Leben Gottes zu tun hat, ${ }^{878}$ soll in die Problematik der Auferstehung das Gottesverständnis sowie das Leben Gottes mit hineingenommen werden. Die Auferstehung Jesu soll aber zugleich unbedingt voraussetzen, dass er wahrhaft gestorben ist. Ohne seinen Tod kann von Auferstehung keine Rede sein. Ebeling redet darum von dem doppelten Verhältnis des Auferstehungslebens. Dieses verdankt sich einerseits „der aus dem Tode zum Leben erweckenden Präsenz Gottes“ bzw. dessen lebenschaffender Tat. Andererseits steht es zugleich „,in einer Kontinuität mit dem Leben des irdischen Jesu“ bzw. einer bestimmten historischen Person. ${ }^{879}$ Ebeling will somit doch nicht von einer unverantwortlichen Äquivokation reden, sondern zeigen, dass die Auferstehung das Zusammensein von vere Deus und vere homo nicht auflöst. Gleichzeitig möchte er den soteriologischen Aspekt im Ostergeschehen verankern, so dass ,,sich das durch Jesus Christus eröffnete Heil“ letztlich ,als ein Teilgewinnen des Menschen an den göttlichen Attributen verstehen lässt““ 880 Solches Nachdenken erhält sich auch beim Beschäftigen mit den oben genannten zwei Fragen, jeweils

\footnotetext{
${ }^{876}$ D II, 280.

${ }^{877}$ D II, 280f.

${ }^{878}$ D II, 304.

${ }^{879}$ D II, 260.

${ }^{880}$ D II, 49.
} 
im Teil „Das Osterereignis“ und im Teil „Der Christus praesens“, das letztlich auf „,das Wort des Lebens" als die konstitutive Weise der Präsenz hingeführt wird.

Im Teil „Das Osterereignis“ hält Ebeling die Erscheinung zunächst für genügend und konstitutiv für die Wirklichkeit der Auferstehung und behauptet, dass durch sie Jesus selbst sowohl seine Gottheit als auch Menschheit bezeugte und als Glaubenszeuge damit Glaubensgrund geworden ist. Ebeling beschäftigt sich hier nicht nur mit der Frage nach dem Realitätsproblem der Auferstehung, also ob sie wirklich stattgefunden hat und worin sie ihren historischen Bezug hat, sondern entfaltet sie dahingehend, was das Osterereignis dann bedeutet, weil er die dogmatische Aufgabe von der historischen unterschiedet und jene als solches sieht, das auf die übrigen Glaubensaussagen, die biblischen Zeugnisse und die gesamte Überlieferung bezogen ist. ${ }^{881}$

Die Auferstehung Jesu ist in der Geschichte bezeugt. Sie als ein historisches Ereignis zu bezeichnen ist allerdings umstritten. Diese Streitigkeit hängt davon ab, wie „historisch“ definiert wird. „Was historisch in den Blick kommt“, ist für Ebeling „,nicht ein punktuelles Ereignis, sondern ein Ereigniskomplex“, also bezüglich der Auferstehung Jesu, „nicht das Ereignis der Auferstehung selbst, sondern die Vorgänge, in denen sich der Glaube an den Auferstandenen durchsetzt, artikuliert und Gestalt gewinnt. “ ${ }^{482}$ Daher lehnt Ebeling es im Unterschied zu Barth und Pannenberg ab, ${ }^{883}$ dem leeren Grab den Primat zu geben, das oft als ein handgreiflicher Beweis für die Realität der Auferstehung, besonders für die Leiblichkeit Jesu oder die Identität des Auferstandenen mit dem am Kreuz getöteten Jesus benannt wird. Er behauptet, dass für die Auferstehung Jesu der Bericht des leeren Grabes keineswegs als ein ausschlaggebendes Argument geführt und die Auferstehungsüberzeugung nicht

${ }^{881}$ Ebeling macht die Aufgabe seiner Untersuchung klar, indem er die dogmatische Aufgabe bezüglich des Osterereignisses von der historischen unterscheidet und jene wie folgt bestimmt: 1. „Zur dogmatischen Aufgabe gehört es, die Auferstehungsaussage zu den übrigen Glaubensaussagen in widerspruchslose Beziehung zu setzen [...] und dabei insbesondere den Bezug zum Grund des Glaubens zur Geltung kommen zu lassen. “; 2. „Zur dogmatischen Aufgabe gehört ferner, den Zusammenhang mit der Überlieferung zu reflektieren, [...] also primär mit dem neutestamentlichen Zeugnis von der Auferstehung Jesu. [...] Die Abgrenzung gegen ein biblizistisches und gegen ein historisches Verfahren kann etwas weiterhelfen“; 3. „Die dogmatische Aufgabe, die sich in bezug auf den Zusammenhang mit der Überlieferung stellt, ist jedenfalls erst dann von einer bloßen Wiederholung historischer Aufgabe unterschieden, wenn sich damit die Aufmerksamkeit auf den Zusammenhang mit der Erfahrung verbindet.“( (D II, 288ff).

${ }^{882}$ D II, 294.

${ }^{883}$ Das leere Grab ist für Barth eine „Nebenbestimmung“ des Zeugnisses vom „lebendig erweisenden Jesus Christus“, weil er glaubt, wenn das Grab nicht leer wäre, reduziere sich der Glaube auf bloße Innerlichkeit. (KD IV/1, 376f). Wie Barth die Rolle des leeren Grabes betont, erklärt W. Joest wie folgt: „Barth versteht das leere Grab, ähnlich wie die Jungfrauengeburt, als ein von Gott real gegebenes Zeichen seiner Auferweckungstat, ohne eine ontologische Notwendigkeit dafür zu postulieren. “ Ders./J.v. Lüpke, Dogmatik I: Die Wirklichkeit Gottes, Göttingen 52010, 249. Pannenberg weist der Tradition des leeren Grabes auch einen wichtigen Platz für die Auferstehung historisch zu, behauptend: „Ließe sich nämlich der Beweis für das leere Grab in jeder Hinsicht stringent führen, dann könnte man [...] die Tatsache der Auferstehung beinahe historisch beweisen. Das ist aber offensichtlich auch nach Gottes Willen nicht möglich. Sie soll ein Unerhörtes bleiben, das mit menschlichen Beweisen nicht zu erreichen ist.“ Ders., Grundzüge der Christologie, Gütersloh 1964, $184 f$. 
allein auf es gestützt werden darf. ${ }^{884}$ Die primäre Bindung an die Entdeckung des leeren Grabes würde laut ihm den christlichen Glauben sogar schwer machen. Daher erklärt er in zweierlei Hinsicht, dass sich der unmittelbare Anstoß zum Osterglauben „mit dem inneren Glaubensgrund historisch nicht deckt“, vielmehr „den Charakter des Glaubens verdunkeln“ würde; und auch dass „durch die Bindung des Osterglaubens an einen bestimmten physikalischen Vorstellungsgehalt" eine weitere schwerwiegende Belastung entstehen würde. ${ }^{885}$ Ebeling sagt, man soll dann das leere Grab nicht für den „Grund“, sondern lieber für „,die Folge des Auferstehungsglaubens“ halten. Er hält stattdessen die Berichte über die Erscheinungen des Auferstandenen sowohl für genügend als auch für konstitutiv und nimmt sie als „einen überraschend zuverlässigen Boden“8866 für die Auferstehung Jesu, vor allem im Anschluss an 1. Kor 15, 3ff. Während Bultmann die Bezeugung der Auferstehung in 1 Kor 15, $3 \mathrm{ff}$. bloß auf die Augenzeugenschaft bzw. „visionäre Erlebnisse“ beschränkt und an den Rand drängt, ${ }^{887}$ entwickelt Ebeling seinen eigenen Gebrauch des Zeugnisbegriffs. ${ }^{888}$

Die spezielle Stellung und Deutung der Erscheinung erläutert Ebeling in zwei Punkten: Erstens geht es um „das Erkennen“, besser um „das Wiedererkennen des Gekreuzigten“. ${ }^{889}$ Dieses charakterisiert sich sogar ,nicht in der Weise von etwas Rückwärtsgewandtem, eines Erinnerungsbildes, sondern als eines Gegenwärtigen, der in die Zukunft weist“ ${ }^{890}$ Dazu erklärt er weiter: „Darum gehört zu allen Erscheinungen, dass Jesus nicht nur als anwesend, sondern auch als sprechend und in Anspruch nehmend erfahren wird, doch so, dass dadurch seiner irdischen Erscheinung nicht widersprochen und vor allem sein Weg ans Kreuz nicht widerrufen wird. Vielmehr vollzieht sich in dem Erscheinungsgeschehen die Identifikation Jesu, so dass denjenigen, die das erfahren, erst aufgeht, wer er war und ist: dass er nun also nicht ein anderer, sondern derselbe ist und bleibt." ${ }^{\text {891 }}$ Die Jünger begegneten Jesus durch die Erscheinungen als demselben, der bei ihnen gewesen und am Kreuz

\footnotetext{
${ }^{884}$ D II, 296.

${ }^{885}$ D II, 296.

${ }^{886}$ D II, 298. Vgl. Wesen 82.

${ }^{887}$ R. Bultmann, Neues Testament und Mythologie. Das Problem der Entmythologisierung der neutestamentlichen Verkündigung, München 1988, 61f: „Das Osterereignis, sofern es als historisches Ereignis neben dem Kreuz genannt werden kann, ist ja nichts anderes als die Entstehung des Glaubens an den Auferstandenen, in dem die Verkündigung ihren Ursprung hat. Das Osterereignis als die Auferstehung Christi ist kein historisches Ereignis; als historisches Ereignis ist nur der Osterglaube der ersten Jünger faßbar. Der Historiker kann seine Entstehung bis zu einem gewissen Grade begreiflich machen durch Reflexion auf die ehemalige persönliche Verbundenheit der Jünger mit Jesus; für ihn reduziert sich das Osterereignis auf ihre visionären Erlebnisse.“; Vgl. Ders., Theologie des Neuen Testamentes, Tübingen ${ }^{9} 1984,305$ : „Die Wahrheit der Auferstehung Christi kann nicht vor dem Glauben, der den Auferstandenen als den Herrn anerkennt, eingehsehen werden. Die Tatsache der Auferstehung kann - trotz 1 Kor 15,3-8 - nicht als objektiv feststellbares Faktum, auf das hin man glauben kann, erwiesen oder einleuchtend gemacht werden.“

${ }^{888}$ D II, $298 \mathrm{ff}$.

${ }^{889}$ D II, 300.

${ }^{890}$ D II, 300.

${ }^{891}$ D II, 300.
} 
getöteten worden ist und zugleich als Christus und als Gottes Sohn. Die Erscheinung Jesu widerspricht somit nicht seinem Wesen von vere Deus und vere homo, sondern bestätigt es viel mehr. Obwohl Jesus schon früher mehrmals von Propheten so bezeugt geworden war und sich selbst mit Wort und Tat so bezeugte, ist die Auferstehung allein das echte Offenbarwerden Jesu. Ebeling bezeichnet sie darum als „Initialakte der Christusverkündigung“692. Jesus trat in Erscheinung als der, der er wirklich war. Umgekehrt konnten die Jünger nun erst richtig erkennen und bekennen, wer Jesus war. Da kommt der zweite Punkt zur Sprache, also „das Zum-Glauben-Kommen“ und „die Berufung zur Zeugenschaft“693. Denn die Jünger blieben dabei nicht lediglich Zuschauer der Erscheinungen Jesu, sondern hatten durch ihre Erfahrungen die Vergebungsgewissheit sowie den echten Glauben an Jesus als den Versöhner und wurden so zum apostologischen Auftrag gerufen. Sie wurden die Zeugen und die Verkündiger dessen, wer Jesus war, so dass sie ,an dem Durchbruchsgeschehen und dem Verkündbarwerden des Christusglaubens beteiligt gewesen" sind. ${ }^{894}$

Hier ist noch der zweifache Bezug Jesu auf den Glauben zur Sprache zu bringen: Im Osterereignis trat Jesus nicht als Glaubensgegenstand hervor, sondern einerseits als der Glaubenszeuge, der selbst darauf verwies, wer er war. Andererseits wurde er der Glaubensgrund, auf den die Zeugnisse der Jünger hinweisen und auf den sich der Glaube aller Christen gründet. Jesus ist ja schließlich der „Anführer und Vollender des Glaubens" (Heb 12, 2). Für Ebeling charakterisiert sich das Osterereignis deshalb als das Ereignis, das in der Geschichte, genauer in der Evangelienüberlieferung, den Übergang vom Zeugen des Glaubens zu dessen Grund markiert. Die Auferstehung dient schließlich dem Verkündbarwerden des Glaubens und auch der Konstituierung des christlichen Kerygmas. Und weiter: die Auferstehung als solches endete nicht als ein einmaliges Ereignis. Sie hat erst angefangen und wird durch die Verkündigung noch weitergegeben. Sofern der Osterglaube so auf Überlieferung angewiesen ist und von der Osterbotschaft lebt, ist das Wort als „das Medium des Osterglaubens“ zu bezeichnen, das nicht auf die Vermittlung des der Erkenntnisses reduziert werden darf, sondern mit der Präsenz Christi zu tun hat. ${ }^{895}$

In Hinsicht auf den „Christus praesens“ behandelt Ebeling ferner „das Sein Christi bei Gott" einerseits und „das Verhältnis zur Welt" andererseits und hebt dabei die Zusammengehörigkeit von beiden hervor, die er in drei Hinsichten entfaltet: Es geht zuerst um die biblische, nicht lokal fixierte Himmelsvorstellung. Diese versteht Ebeling im Sinne von Gottes Omnipräsenz und stellt wie folgt dar: „Nicht da, wo der Himmel ist, ist Gott, sondern da, wo Gott ist, ist der Himmel“" ${ }^{896}$ Sie hat mit keiner physikalischen Raumvorstellung zu tun. Unter diesem Aspekt sagt er weiter, dass bezüglich

\footnotetext{
892 D II, 301.

${ }^{893}$ D II, 300.

${ }^{894}$ D II, 301.

895 D II, 311.

${ }^{896}$ D II, 323.
} 
der Himmelfahrt des Auferstandenen und dessen Sitzen zur Rechten Gottes der Akzent dann nicht ,auf der Versetzung an einen fernen Ort“, sondern vielmehr auf „der Verheißung verlässlicher Nähe“ liegt, ja über alle Grenzen von Raum und Zeit, so wie Jesus selber versprochen hat: „Siehe, ich bin bei euch alle Tage bis an der Welt Ende“ (Mt 28,20). ${ }^{897}$

Es geht zweitens um die Kontinuität von der Menschwerdung Gottes in Jesus. Durch diese wird das Menschsein Jesu schon als die Anwesenheit Gottes darlegt, also bei Ebeling in der oben aufgezeigten Formel „Gottes Wort in Person“. Es wäre ein Irrtum, erst von der Auferstehung und Erhöhung das Erreichen des vere Deus zu erwarten oder noch schlimmer „ein Versuch einer

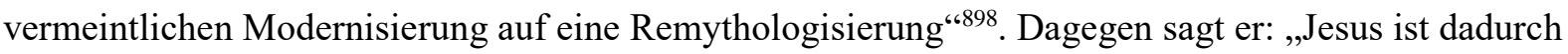
nicht zu Gott geworden, sondern er ist nun endgültig bei Gott “" ${ }^{899}$ Die Auferstehung Jesu und seine Erhöhung haben Sinn ,,̈̈berhaupt nur in Bezug auf das wirkliche Menschsein Jesu“ und zugleich „nur in Kontinuität mit dem Zusammensein Gottes und des Menschen in Jesus“ “.900 Das heißt, wo Jesus Christus anwesend ist, da ist Gott anwesend und umgekehrt. Das Beisammensein von Jesus Christus und Gott darf keinesfalls verletzt werden. Das am Erhöhten angesprochene göttliche Attribut wie „die Doxa Gottes, seine Ewigkeit und seine Schöpfermacht“ darf dementsprechend weder „zu der Anwesenheit Gottes in dem irdischen Jesus in einen ausschließenden Widerspruch treten, noch etwa die Attribute des Menschseins Jesu aufheben“. ${ }^{901}$ Was sich bei Jesus durch die Erhöhung gegenüber seiner irdischen Zeit geändert hat, betrifft weder das Zusammensein mit Gott noch das göttliche Attribut, sondern „das Kundwerden, das Gewißwerden, das Definitivwerden dieses seines Zusammenseins mit Gott, also die Proklamation seines Namens als eines Namens über alle Namen“، 902 Das schafft keine Veränderung des Inhaltes, sondern der Situation. Diese bestimmt Ebeling als „eine Veränderung der Gebetssituation“903, in der das Gebet zu Gott nun durch Jesus Christus vermittelt wird und nur in seinem Namen gilt.

Letztlich ist vor dem Hintergrund des relationalen Seinsverständnis als dem Prinzip von Ebelings Seinsbestimmung zu bedenken, dass im Sein des erhöhten Christus bei Gott „als einem Partizipieren am Sein Gottes“ schon „das Bezogensein auf die Welt“ mitgedacht ist. Das betont er hier noch einmal deutlich: „Das wirft ein Licht auf den biblischen Charakter relationaler Ontologie. Wird Jesus Christus als zur Rechten Gottes befindlich geglaubt, so ist er damit ebensowenig von der Welt abgewandt wie etwa gar an einen welthaften Ort verbannt, sondern in der Weise Gottes der Welt zugewandt. Das Verhältnis zur Welt, das damit gesetzt ist, widerspricht nicht etwa dem Verhältnis zur Welt, das in dem

\footnotetext{
${ }^{897}$ D II, 323.

${ }^{898}$ D II, 334.

${ }^{899}$ D II, 334.

900 D II, 334.

${ }^{901}$ D II, 334.

902 D II, 335.

903 D II, 330.
} 
Gottesverhältnis des irdischen Jesus mitgesetzt war. “904 Das heißt, das Verhältnis Jesu Christi zur Welt ist in seinem Gottesverhältnis mitgesetzt, indem Jesus so zur Welt zugewandt ist, wie Gott zur Welt. Insofern Gott als das Zusammensein auf die Welt bezogen ist, kann der Sitz des erhöhten Christus bei Gott ohne das Verhältnis zur Welt nicht in Betracht kommen. Unter diesem Aspekt interpretiert Ebeling die Deutung des Reiches bzw. der Herrschaft Christi in Joh 18,36 in paradoxer Weise als ein solches, „das nicht von dieser Welt ist, doch in dieser Welt ist“, sodass es nicht nur für den irdischen Jesus, sondern auch für den erhöhten Christus gilt. ${ }^{905}$

In diesem Zusammenhang ist nun zu sagen, dass Ebeling die Präsenz des erhöhten Christus bei Gott stark in Bezug auf sein Verhältnis zur Welt, also auf seine Präsenz bei uns interpretiert. Er versteht die Rede von der Präsenz Christi folglich dahingehend, wie oder wodurch Christus dann gegenwärtig ist, und stellt dabei nichts anderes als das Wort in den Mittelpunkt. Er bestimmt die Präsenz Christi mit drei Weisen, die er von den im Verlauf der urchristlichen Sprachwerdung herausgebildeten Begriffen entlehnt: der Leib Christi, der Geist Christi und das Wort Christi. Diese charakterisiert Ebeling allesamt mit dem Lebensbezug und erinnert mit jeder Weise doch an ein besonderes Merkmal des Lebens. Mit dem Leib Christi, der für Ebeling keinesfalls im biologischen, analogischen oder abstrakten Sinne steht, macht er auf ,die personale Identität und Kontinuität des Lebens Jesu Christi in seiner irdischen Erscheinung und in der fortdauernden Präsenz des Erhöhten“"906 aufmerksam. Während er mit dem Terminus des Leibes so die Lebensgestalt darstellt, verweist er mit dem des Geistes dagegen auf das Lebensprinzip. Insofern der Geist das Lebensprinzip ist, an dem sich „die Qualifikation des Leibes“ entscheidet, „welche Lebenskraft ihm innewohnt, ihn antreibt [...] und auf welches Ziel und Ende hin sie ihn ausrichtet", ${ }^{907}$ deutet der Geist Christi auf die Wirksamkeit des Lebens, dass der Lebensgestalt Christi eine Lebenskraft innewohnt, nämlich „der spritus creator, der vom Tode erweckt"“.908

Im Unterschied zu den ersten zwei Weisen bestimmt Ebeling das Wort Christi bemerkenswerterweise als „die schlechterdings konstitutive Weise, wie der Erhöhte präsent ist“. 909 Obwohl die drei Weisen nicht in Konkurrenz zueinander stehen und voneinander getrennt denkbar sind, schreibt er dem Wort Christi eine fundamentale Rolle zu. Denn „,der Geist kommt einem aus der Glaubensbotschaft zu (Gal 3,5)“, die wiederum ,aus dem Wort Christi (Röm 10,17)“ entspringt. Unter den verschiedenartigen Diensten, das Leben des Leibes Christi auszumachen, ist zuallererst „der Dienst mit dem Wort für die Existenz des Leibes Christi bestimmend““.910 Die Leibhaftigkeit und die

\footnotetext{
904 D II, 335.

905 D II, 335.

906 D II, 337

${ }^{907}$ D II, 338.

${ }^{908}$ D II, 339f.

909 D II, 340.

${ }^{910}$ D II, 340.
} 
Geistigkeit dienen dazu, das Wort Christi „vor einem verengten Wortverständnis“ zu schützen. Er will somit zeigen, dass Jesus Christus ,als Grund des Evangeliums zur Quelle wahren Lebens“"911 wird und dadurch die biblische Bezeichnung Jesu Christi als das Wort des Lebens (1 Joh 1,1) feststellen.

Die Bezeichnung „das Wort des Lebens“ hat eine eigenartige Bedeutung. Ebeling unterscheidet sie zuerst von den allgemeinen Erfahrungen des Verhältnisses zwischen Wort und Leben, nämlich von der Lebensnotwendigkeit des Wortes, mit der der Mensch als sprachbegabtes sowie rationales Lebewesen bzw. als ,zoon logon echon“ alltäglich konfrontiert wird. Er bringt stattdessen „das lebendigmachende Wort“ zum Ausdruck. Dadurch macht er klar, dass es „nicht um eine bloße Lebenshilfe, sondern um die Erschaffung neuen Lebens“ geht; und auch dass das Wort des Lebens „als das Evangelium dem Wort des Gesetzes gegenüber (tritt), das nicht das Leben zu geben vermag (Gal 3,21) “.912 Das Wort Christi als das Wort des Lebens meint nicht bloß ein Wort, das dem Leben des Menschen als Sprachwesen förderlich ist, sondern das von dem lebendigmachenden Wort, das auf die Grundsituation des Glaubenden bezogen ist und diesem ein neues Leben schafft. Diese Schaffung vollzieht sich durch die Sprache, die sich bei Ebeling an den Lebensbegriff anschließt und die er als „Lebensvorgang“ bezeichnet, ${ }^{913}$ weil die Grundstruktur des Wortes nicht Aussage, sondern „Mitteilung“ ist, „gewiß nicht in dem abgeblassten Sinne von Information, sondern in dem gefüllten Sinne von Partizipation und Kommunikation“, die beide in Lebenssituationen passieren. ${ }^{914}$ Das durch die Sprache vermittelte, bezeugte Wort Gottes ist für Ebeling dann ein konkretes Ereignis im Leben, das die faktische Situation des Menschen entscheidend ändern kann. ${ }^{915}$ Diese entscheidende Änderung zeigt sich letztlich in Tod und Leben. Er sagt: „Das Wort Gottes ist wesenhaft nicht ein solches, das den Kontext, in den es eintritt, bloß ergänzt. Viel mehr entscheidet es über ihn. Und das Verborgene, das durch das Wort Gottes in den Kontext hinein angesagt wird, betrifft deshalb nicht irgendetwas an ihm, sondern den Kontext selbst und im Ganzen. Es entscheidet über Tod und Leben. “916 In diesem Sinne gilt nun das alte Kirchenlied zum Osterfest „Jesu lebt, mit ihm auch ich“ bei Ebeling vornehmlich in Bezug auf das Wort Christi, das uns als das lebendigmachende Wort das neue Leben schenkt und in dem der erhöhte Christus gegenwärtig ist.

Darüber hinaus bringt Ebeling noch eine andere lebensbezogene Bezeichnung des Wortes zur Sprache, nämlich den „Lebensbezug des Wortes des Lebens“, der zeigt, wie „das Leben Christi“ „im Leben des Christen wirksam“ wird. ${ }^{917}$ Das referiert zuallererst auf die Aufgabe des Christen und

\footnotetext{
${ }^{911}$ D II, 340.

912 D II, $341 \mathrm{ff}$.

913 Sprachlehre, 195.

914 WG, 342.

${ }^{915}$ WG II, 429.

916 WG II, 427.

${ }^{917}$ D II, 344.
} 
seinem Glauben, dass er sich „an sein eigenes neues Leben halten“ soll. ${ }^{918}$ Hier spielt dann die Rede von dem heiligen Geist eine Rolle, der als der Geist Christi bei uns wirkt und uns hilft. Ebeling stellt der Verdoppelung der Lebensthematik „Lebensbezug des Wortes des Lebens“ die Aufgabe, die Frage nach dem Wort des Lebens in der Christologie in Verbindung mit der Pneumatologie und der Eschatologie zu setzen, ${ }^{919}$ allerdings nur in angedeuteter Weise. Das wird erst im dritten Band seiner Dogmatik richtig behandelt, wobei Ebeling sowohl die Zusammengehörigkeit von Pneumatologie und Eschatologie als auch ihren christologischen Charakter betont und sich hauptsächlich damit beschäftigt, wie der Heilige Geist in rein verbaler und in sakramentaler Gestalt des Wortes wirkt, dessen Fundament das Christuswort sein muss.

\subsection{Das Wort Jesu als Gottes Wort}

Der christliche Glaube sagt, dass Jesus Christus als ein Mensch geboren wurde und ein menschliches Leben lebte. „Der Mensch Jesus“ zeigt bei Ebeling gegenüber dem „Gott in Christus“ den anderen Aspekt der Christologie. Während das Zusammensein von Gott und Mensch in Jesus bisher in den drei Christusgeschehen von der Menschwerdung Gottes, Kreuzestod und Auferstehung aufgezeigt wurde, wird sie hier dagegen in Bezug auf den geschichtlichen Jesus bzw. dessen Leben betrachtet, die Ebeling durch die Vollmacht als Schlüsselbegriff kennzeichnet. Zuvor wird aber ein kurzer Blick auf das Problem des historischen Jesus sowie auf dessen Ort in der Dogmatik geworfen.

\subsubsection{Der historische Jesus in der Dogmatik}

Die Behandlung des Themas des historischen Jesu in der Dogmatik regt Frage an: Soll oder kann die Dogmatik den Menschen Jesu thematisieren? Ist die Aussage von der geschichtlichen Gestalt Jesus von Nazareth konstitutiv in der dogmatischen Christologie? Inwiefern soll sie dann darin behandelt werden? Solche Frage nach dem historischen Menschen Jesus wurde in der alten Dogmatik des 16. und 17. Jahrhunderts überhaupt nicht gestellt, während der Gedanke von Inkarnation, Sündlosigkeit und Versöhnung Jesu zeitlos wichtig behandelt wurde und immer noch wird. ${ }^{920}$ Sie rückte erst seit den 1780er Jahren zusammen mit der Entwicklung der historischen Kritik an den biblischen Schriften ins Zentrum der Christologie, in Deutschland insbesondere durch H. S. Reimarus. Dieser wollte hinter den

\footnotetext{
918 D II, 344.

${ }^{919}$ Vgl. D II, 344f: „Dafür ist die Polarität maßgebend, die dem Reden vom ewigen Leben unaufhebbar eignet: Es wird in diesem Leben so wirksam und gegenwärtig ist; und es treibt auf die Beendigung und Überwindung dieses Lebens hin, auf das, was den Menschen nach seinem Tode erwartet, wie der Christus praesens als der künftige erwartet wird. Daran, wie sich Pneumatologie und Eschatologie ineinanderfügen, entscheiden sich der Lebensbezug des Wortes des Lebens und damit das Verständnis des Glaubens an Jesus Christus.“

${ }^{920}$ C. Danz, Grundprobleme der Christologie, Tübingen 2013, $7 \mathrm{ff}$.
} 
biblischen wunderhaften Berichten den Menschen Jesus, „wie er wirklich war“ entdecken und glaubte, das wäre nur aus dem zeitgenössischen Kontext heraus möglich, sodass seine Überlegungen zum Ausgangspunkt für die nachfolgende sog. Leben-Jesu-Forschung wurden. ${ }^{921}$ Das Unternehmen der Leben-Jesu-Forschung wurde aber bald grundsätzlich in Frage gestellt, sodass sie von Martin Kähler als „Holzweg“ bezeichnet wurde. ${ }^{922}$ Vor allem Bultmann stellte sich gegen die historisch-kritische Forschung und versuchte, eine Lösung in der strengen Trennung der Sphären von Glaube und Historie zu finden. Die Frage nach dem historischen Jesus gehört laut ihm nicht in die christliche Theologie, sondern ist lediglich ihre Voraussetzung. Er richtete seine Aufmerksamkeit darum auf den verkündigten Christus bzw. das Kerygma, während er den historischen Jesus nur als das „Dass“ des Gekommenseins des Christi dachte. ${ }^{923}$ Entgegen Bultmanns Abweisung von dem historischen Jesus versuchten seine Nachfolger wie Käsemann, Fuchs und auch Ebeling, die Bedeutung der Geschichte und des historischen Jesus wiederherzustellen. ${ }^{924}$

In seinem frühen Aufsatz $>$ Die Frage nach dem historischen Jesus und das Problem der Christologie < (1959) formulierte Ebeling die Frage nach dem historischen Jesus als die Frage, ,was in Jesus zur Sprache gekommen ist", wodurch er die Geschichte in die dogmatische Christologie einbeziehen und durch den hermeneutischen Geschichtsbegriff den Historismus bzw. das durch dieses hervorgebrachte Nebeneinander von historischer Jesusforschung und dogmatischem Christusbild überwinden wollte. ${ }^{925}$ Die Frage nach dem historischen Jesus hat für den frühen Ebeling eine wichtige Funktion. Er will, so wie M. Laube mit Recht hinweist, „angesichts der drohenden Relativität des Historischen die normative Verbindlichkeit dogmatischen Arbeitens neu“926 einrichten und positioniert die Frage in der Mitte seiner frühen christologischen Entwürfe.

Ebeling hält das Problem des historischen Jesus auch in der $>$ Dogmatik des christlichen Glaubens $<$ für unverzichtbar und notwendig. Denn er hebt den Wirklichkeitsbezug der Dogmatik als der theologischen Rechenschaft des Glaubens hervor und versucht ihn für die Christologie ursprünglich beim historischen Jesus zu finden, also in seiner geschichtlichen Erscheinung und in den geschichtlichen Erfahrungen mit ihm. Er sagt, dass Christologie „bodenlos (wird), wenn sie an Jesus selbst keinen Anhalt hat““.927 Der Erörterung der an dem historischen Jesus haftenden Problematik

\footnotetext{
${ }^{921}$ H.S. Reimarus, Apologie oder Schutzschrift für die vernünftigen Verehrer Gottes, Gerhard Alexander (Hg.), Frankfurt 1972. Hier zitiert nach W. Joest/J.v. Lüpke, Dogmatik I: Die Wirklichkeit Gottes, Göttingen ${ }^{5} 2010,180$. ${ }_{922}$ M. Kähler, Der sogenannte historische Jesus und der geschichtliche biblische Christus, E. Wolf(Hg.), München ${ }^{2} 1956,10$.

${ }^{923}$ R. Bultmann, Kerygma und Mythos I, H.W. Bartsch (Hg.), Hamburg ${ }^{3} 1954$; Ders., Das Verhältnis der urchristlichen Christusbotschaft zum historischen Jesus, Heidelberg 1960.

${ }^{924}$ Zur nähren Untersuchung über Bultmann und seine Nachfolge siehe das Kap. II.5.1.

${ }^{925}$ WG, 300-318. Vgl. Wesen, 40-66; ThV, 19-82.

${ }_{926}$ M. Laube, Theologische Selbstklärung im Angesicht des Historismus, in: KuD (54) 2008, 114-137, 130.

927 D II, 41.
} 
widmet er sogar einen selbstständigen Teil (\$21) der Arbeit, wobei er versucht, die dogmatische Relevanz der historischen Jesusfrage zu formulieren und sich damit beschäftigt, wie sich die christologische und die historische Interpretation Jesu sinnvoll aufeinander beziehen. ${ }^{928}$ Dazu erklärt Ebeling: Jesus muss als Grund christologischer Aussagen erkennbar bleiben, was bedeutet, dass „christologische Aussagen von Jesus her kritisch“ zu interpretieren sind und dass die „,christologische Situation von Jesus her“ zu erschließen ist. Denn „Christologie kann auch gegenwärtig nur so weit verantwortet werden, wie die Erscheinung Jesus dazu provoziert, das, was er ist, in umfassendsten Horizont auszusagen, ihn also in Bezug auf unser eigenes Verhältnis zu Gott, zur Welt und zu den Mitmenschen entscheidend zu Worte kommen zu lassen.“929

Die Aufmerksamkeit ist aber zugleich darauf zu richten, dass Ebeling beim Beschreiben der christologischen Aussagen in der Dogmatik eine Reihenfolge festlegt: „Zunächst wird der überlieferten Christologie gefolgt, dann hält sich die Darlegung an die geschichtliche Erscheinung Jesu“. ${ }^{930}$ Mit dieser Reihenfolge kann man nicht nur von der oben aufgezeigten Kontinuität, sondern auch von einer Veränderung reden, so wie C. Danz sagt, dass Ebeling in seiner Dogmatik „nicht mehr wie in seinen frühen christologischen Überlegungen beim historischen Jesus“ einsetzt und sich nun stärker ,,an die christologische Lehrtradition“ anbindet. ${ }^{931}$ Dieses Urteil könnte von dem Hinweis M. Laubes motiviert werden, dass hinsichtlich des historischen Jesu eine Veränderung bei Ebeling wahrnehmbar ist und mit der Konsequenz seiner frühen hermeneutischen Arbeit zu tun hätte. Damit meint Laube, dass seinem Versuch, historische und dogmatische Theologie zu vermitteln, ,in der Folgezeit kein bleibender Einfluss“ gestattet sei und er auch die veränderte Tendenz zeige, dass das Interesse für den hermeneutischen Sinn des historischen Jesus selbst und die „Debatte um die ,neue Frage““ verebbt. ${ }^{932}$ $\mathrm{Zu}$ dieser veränderten Lage scheint es gewiss nicht ohne Beziehung zu sein, dass sich Ebeling in seinen späten Schriften tatsächlich wenig mit dem Problem des historischen Jesus beschäftigt. Es ist aber nicht einfach zu sagen, dass er sich schon in der Dogmatik vom Problem des historischen Jesus abwendet. Denn das Thema des historischen Jesus in die Dogmatik einzuordnen und ihm einen großen Teil zu

\footnotetext{
${ }^{928}$ D II, 368-408.

929 D II, $406 \mathrm{f}$.

930 D II, 43.

931 C. Danz, Grundprobleme der Christologie, Tübingen 2013, 162f.

${ }^{932}$ M. Laube, Theologische Selbstklärung im Angesicht des Historismus, in: KuD (54) 2008, 114-137, hier 130. Vgl. R. Zimmermann, Paradigmen einer metaphorischen Christologie. Eine Leseanleitung, in: J. Frey u.a. (Hg.), Metaphorik und Christologie, Berlin/New York 2003, 1-34, hier 18 f: „Während innerhalb der neutestamentlichen Wissenschaft die Diskussion um den so genannten , third quest' nach dem historischen Jesus im vollen Gang ist, stellt sich ein entsprechender Neuansatz im Blick auf die christologische Interpretation der Verkündigung und des Lebens Jesu nur zögerlich ein. In der Systematischen Theologie hat man den Eindruck, dass die Christologie als Teilaspekt der Trinitätslehre, Soteriologie oder Anthropologie behandelt wird, aber kaum eigenständige Aufmerksamkeit erhält.“"
} 
widmen, ist m.E. schon charakteristisch ${ }^{933}$ Dass Ebeling es in seiner Dogmatik nicht so intensiv wie in seinen frühen Schriften behandelt, scheint vielmehr auf dem Charakter der Dogmatik zu beruhen.

Mit Rücksicht darauf, dass Ebeling für die Bezeichnung seiner dogmatischen Arbeit trotz eines gewissen Naheseins zur Glaubenslehre auf den Ausdruck der „Dogmatik“ nicht verzichtet, ${ }^{934}$ kann man schon vermuten, dass er sich stark an die christologische Lehrtradition und die vorrangige Aufstellung der überlieferten Christologie anschließen würde. Im Nachwort zur Dogmatik zeigt er selbst deutlich: In der Dogmatik war er bestrebt, sich „so sehr auf die materiale Dogmatik zu konzentrieren, dass daraus ein Ganzes entstünde und nicht bloß, wie zuvor, eine Reihe exemplarischer Fragmente". ${ }^{935}$ Bei dieser Konzentration auf die materiale Dogmatik sind allerdings, so sagt er selbst, seine bisherigen hermeneutischen (und fundamentaltheologischen) Überlegungen notwendigerweise immer begleitend, „ohne dass derartige(r) Reflexion dabei zum Hauptthema aufrückten“. ${ }^{936}$ Angesichts der Reihenfolge muss man dann mehr darauf achten, dass bei Ebeling die Pointe im Zusammenhang von Christologie und dem historischen Jesus liegt: „Die Reihenfolge ergibt sich daraus, dass Christologie nicht ausschließlich vom historischen Jesus her konstituiert werden kann, sondern auf christologische Überlieferung angewesen ist, zu deren Verständnis und kritischer Interpretation man jedoch wiederum auf das angewiesen ist, was über Jesus geschichtlich zu erfahren ist. So drückt sich in der Reihenfolge der beiden Kapitel eine methodische Überlegung aus. Deren Ergebnis kommt zugleich dem grundlegenden Gesichtspunkt der Christologie entgegen, dass man in Christus Gott begegnet.“937

Dieser Punkt entscheidet darüber, wo Ebeling das Problem des historischen Jesus in der Struktur der Dogmatik behandelt wird. Er tut es unter der Überschrift „Gott in Christus“, in der er die überlieferte christologische Lehraussage behandelt, und am Anfang des Teils „der Mensch Jesus“. Er schreibt dem Thema des historischen Jesus dadurch nicht die Rolle einer Voraussetzung oder eines Exkurses zu. Der geschichtliche Jesus ist laut ihm der Ursprung bzw. Grund der im ersten Teil entfalteten christologischen Aussage und zeigt zugleich die Notwendigkeit eines weiteren Aspektes, indem es sich um „die

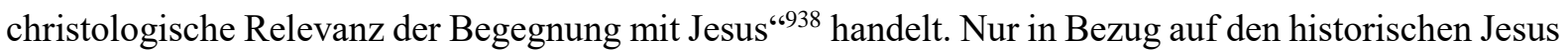
ergibt dann auch die Rede von der Vollmacht Sinn, die bei Ebeling gepaart mit ihrem Gegensatzbegriff der Ohnmacht das wahre Menschsein Jesu kennzeichnet.

\footnotetext{
${ }^{933}$ An diesem Punkt ist Ebelings Christologie mit anderen zu vergleichen, z.B. mit der Christologie von W. Härle, die ohne Erwähnung von der Problematik des historischen Jesus sowie der darauf bezogenen historischen Forschung nur mit dem christologischen Lehrschema der altlutherischen Dogmatik, also „de persona Christi“ und „de munere Christi“ aufgebaut ist. Ders., Dogmatik, Berlin/New York 2000, 303-356.

${ }^{934} \mathrm{Vgl}$. Kap. III.1.1.

935 WG IV, 478.

${ }^{936}$ WG IV, 478.

937 D II, 44.

${ }^{938}$ D II, 369.
} 


\subsubsection{Die Vollmacht Jesu im Wort}

Der Begriff der Vollmacht findet sich häufig in synoptischen Berichten über Jesus. Matthäus schließt z.B. den Bericht über die Bergpredigt mit dem folgenden Satz: „Er lehrte sie mit Vollmacht und nicht wie ihre Schriftgelehrten“ (Mt 7,29). Durch den Begriff der Vollmacht widmet er dem Lehren Jesu eine unvergleichbare Besonderheit. Markus und Lukas schreiben in ähnlicher Weise der Lehre Jesu im Kapernaum die Vollmacht zu (Mk 1,22; Lk 4,32). Vor allem verbindet Markus, in dessen ganzem Evangelium die Vollmacht als Motiv auftaucht, ${ }^{939}$ im Bericht über die Heilung eines Gelähmten die Vollmacht sogar mit der Sündenvergebung (Mk 2,10). Die Vollmacht ist gewiss als ein zentraler Begriff für die biblische Beschreibung des irdischen Lebens Jesu zu nennen.

Ebeling setzt das Wort der Vollmacht ins Zentrum seines Entwurfs über den Menschen Jesus. Um deutlich zu machen, was mit dem Begriff der Vollmacht gemeint ist, bringt er zunächst die Differenz zwischen dynamis und exousia zur Sprache, die beide die Züge der Macht Jesu tragen. Während es bei dynamis primär „um ein physisches Kräftepotential“ geht, „wobei die Überlegenheit in der Fähigkeit gründet, die einer besitzt“, hat exousia ihren Ort dagegen ,primär im Bereich des Rechts“, das nicht „eine erworbene oder angeborene Eigenschaft“ meint, sondern durch „Übertragung“ oder „Bevollmächtigung“ kommt, ${ }^{940}$ so wie Jesus selbst sagt: „Mir ist gegeben alle exousia im Himmel und auf Erden“ (Mt 28,18). In diesem Sinne behauptet Ebeling, dass das Phänomen der dynamis eigentlich vom Phänomen der exousia her verstanden werden soll und dieses den Primat hat, Jesu Machtworte und -taten zu kennzeichnen. ${ }^{941}$

Ebeling verwendet den Begriff der Vollmacht von Anfang an in seiner Christologie und hebt ihn doch, nach Meinung W. Greives, stärker in seinen späten christologischen Schriften hervor. In seinem Aufsatz über das Problem der Christologie Ebelings behauptet Greive, dass sein christologischer Entwurf unter dem Einfluss der Kritik Bultmanns seit der Antwortschrift >Theologie und Verkündigung $<$ verändert werde und diese Veränderung zuallererst darin bestehe, dass die „ zentrale Wendung: Jesus, der Zeuge des Glaubens nicht mehr erscheint ${ }^{\star ‘ 942}$ und somit „,nicht mehr vom Glauben Jesu, vielmehr von der Vollmacht Jesu“ geredet wird. ${ }^{943}$ Diese Behauptung wird aber von K. Zwanepol heftig kritisiert. Dieser sagt, dass obwohl der Begriff des Glaubenszeugen durch den Begriff der Vollmacht in den Hintergrund gerückt wird, sich daraus „keine inhaltliche Veränderung“ in Ebelings Christologie ableite. Zwanepol erklärt dazu über die Bezogenheit von der Vollmacht und dem

\footnotetext{
${ }^{939}$ Mk 1,22,27; 2,10; 3,15; 6,7; 11,28,29,33; 13,34 .

940 D II, 411.

941 D II, 411.

${ }^{942}$ W. Greive, Jesus und Glaube. Das Problem der Christologie G. Ebelings, in: KuD (22), 1976, 163-180, $170 \mathrm{ff}$.

${ }^{943}$ W. Greive, Jesus und Glaube. Das Problem der Christologie G. Ebelings, in: KuD (22), 1976, 163-180, 174.
} 
Glaubenszeugen bei Ebeling weiter: „Nicht nur weil ,Wort Gottes‘ als ,grundlegende Bestimmung sein Korrelat in der Vollmacht als Hauptmerkmal der ,Erscheinung Jesu' hat, sondern auch weil in der ,Vollmacht Jesu‘ ein ähnlicher Umschlag stattfindet wie der vom ,Zeugen des Glaubens` zum ,Grund des Glaubens، ““944 Unter diesem Aspekt behauptet Zwanepol, Greive hätte Ebelings Hervorhebung des Begriffs der Vollmacht ,als Signal für eine Verschiebung unter dem Einfluss Bultmanns“ aufgefasst und dadurch die Tatsache übersehen, dass Ebeling das Thema der Vollmacht gerade ,als Waffe gegen Bultmann“ verwendete. ${ }^{945}$ Weiter argumentiert er, dass Ebeling „der eschatologischen Macht des Kerygmas“ den historischen Jesus ,als Quelle der Vollmacht“ gegenüberstellt und dass die Betonung „nicht auf dem Besitz oder der Zurschaustellung der Vollmacht, sondern auf ihrer konkreten Ausübung, wie sie von seinen Zeitgenossen erfahren wurde“, liege. ${ }^{946}$

Auf der einen Seite stimme ich der Meinung von Zwanepol zu. Der Begriff des Glaubenszeugen hat bei Ebeling, so wie oben im Teil über Auferstehung aufgezeigt wurde, noch einen wichtigen Platz in seiner Christologie der $>$ Dogmatik des christlichen Glaubens $<$, die zehn Jahre nach der Schrift $>$ Theologie und Verkündigung < veröffentlicht wurde. Ebelings Fokussierung auf den Begriff der Vollmacht meint hier, den Platzt des Glaubenszeugen nicht zu untergraben, sondern ihn zu festigen, indem er die Vollmacht Jesu auf den Sachverhalt des Glaubens richtet und letztlich mit seinem Glauben als radikale „Hingabe an Gott“947 verbindet. Auf der anderen Seite ist es trotz keiner inhaltlichen Veränderung bemerkenswert, dass Ebeling in seiner Dogmatik das Wort der Vollmacht in der Beschreibung des Menschen Jesu optisch in einer repräsentativen Weise herausstellt, ihr den Titel als „Hauptnenner von Wort und Verhalten Jesu“ gibt und ihrem Begriff ein ganzes Kapitel unterlegt. Das ist eine bemerkenswerte Wendung in Ebelings dogmatischer Christologie.

Diesbezüglich ist m.E. eine Bemerkung über das Verhältnis von Gottheit und Menschheit zur Sprache zu bringen. So wie Ebeling im Teil „Gott in Christus“ versucht, Jesus immer als das Zusammenseins von Gott und Menschen vorzustellen und die wesentlichen doppelten Beziehungen Jesu zu Gott und Menschen bzw. die Untrennbarkeit von vere Deus und vere homo hervorzuheben, verarbeitet er den gleichen Aspekt im Teil „Der Mensch Jesus“ und versucht, im Wort und Verhalten des geschichtlichen Menschen Jesu dessen Gottesbezug aufzuzeigen. Ebeling scheint den Begriff der Vollmacht absichtlich im Begriffsnetz der Macht wie Allmacht, Ohnmacht und Vollmacht anzuwenden, um die Eigentümlichkeit des geschichtlichen Jesu zu beschreiben. Die Vollmacht Jesu manifestiert sich gerade im dialektischen Verhältnis von Allmacht als Gottes Macht und Ohnmacht als Menschenmacht, nämlich in der Unterscheidung zwischen ihnen und zugleich in einer gewissen Korrespondenz zwischen ihnen. Anders als die Autorität, die laut Ebeling formal anschließend an „die Anwendung des

\footnotetext{
${ }^{944}$ K. Zwanepol, Unterscheiden, Bern 1993, 109.

${ }^{945}$ K. Zwanepol, Unterscheiden, Bern 1993, 109.

${ }^{946}$ K. Zwanepol, Unterscheiden, Bern 1993, $109 \mathrm{f}$.

947 D II, 459.
} 
Anselmschen quo maius cognitari nequit“ begriffen wird und oft den „blinden Gehorsam“ erfordert, ${ }^{948}$ hat die Vollmacht ihren Ort zwischen Allmacht und Ohnmacht und damit zwischen Gott und Menschen. Die Vollmacht Jesu zeigt ursprünglich dessen göttliche Macht, weil ihre Quelle der allmächtige Gott ist. Damit verweist sie aber nicht nur auf die Seite Gottes, sondern auch auf die Seite des Menschen, weil sie eigentlich mit Menschen umgeht, d.h. an Mensch orientiert und auf Menschen ausgeübt wird. ${ }^{949}$ Beide Seite gehören zur Eigentümlichkeit der Vollmacht. Ebeling scheint durch die Verwendung des Begriffs der Vollmacht die Rede vom Menschen Jesu implizit die Bedeutung der doppelten Beziehungen Jesu zu Gott und Menschen enthalten zu lassen. Er stellt dabei die Worthaftigkeit Jesu in den Vordergrund. Das heißt, Ebeling zielt darauf ab, aufzuzeigen, dass sich die Vollmacht Jesu eigentümlich und tatsächlich in seinem Wort vollzieht.

In Hinsicht auf die Behandlung des Begriffs der Vollmacht muss man seine Aufmerksamkeit nun mehr darauf richten, dass Ebeling den Ort und die Bedeutung der Vollmacht in der Christologie auf Wort und Verhalten Jesu bezieht und dem Wort doch offensichtlich einen Primat gibt. Er bezeichnet das Phänomen der Vollmacht als das Sprachphänomen, weil sie „das Recht, etwas zu sagen zu haben, und zwar ein Recht, das mit der Tatsache identisch ist, dass man etwas zu sagen hat“, meint. ${ }^{950}$ Die Vollmacht wird charakteristisch durch das Wort ausgeübt und ist austauschbar mit dem vollmächtigen Wort. Das verknüpfte Verhältnis von Vollmacht und Wort ist Ebeling zufolge für die Christologie relevant. Er sagt, „In welcher Weise die Christologie tatsächlich an Jesus Anhalt hat“, würde „durch den Begriff der Vollmacht signalisiert“ und unter diesem Begriff werde „das Ganze von Wort und Verhalten Jesu in seiner inneren Stimmigkeit“ erfasst. ${ }^{951}$ In diesem Sinne bestimmt er die Vollmacht „als Hauptnenner von Wort und Verhalten Jesu“952 und betont dabei die Worthaftigkeit Jesu, behauptend, „Wenn nun der Begriff der Vollmacht als der Hauptnenner der Erscheinung Jesu erkannt ist, wird für die Zweiheit der Aspekte: Wort und Verhalten, wie sie im Überlieferungsbefund beieinander sind, auch ein innerer Sachgrund deutlich. Vollmacht ist wesenhaft Sache des Wortes, aber ebenso wesenhaft Sache der Person als ganzer. Auf diesen Zusammenhang ließ die Untersuchung des Wortes Jesu bereits wiederholt stoßen. “953

\footnotetext{
${ }^{948}$ D II, 421.

${ }^{949}$ D II, $420 \mathrm{ff}$.

${ }^{950} \mathrm{D}$ II, 414.

${ }^{951} \mathrm{D}$ II, 475.

952 D II, 409. Wie die Christologie am geschichtlichen Jesus Anhalt hat, gibt Ebeling weiter durch die Formel ,implizite Christologie“ (D II, 475) an. Christologie ist laut Ebeling nicht etwas, was unmittelbar bei Jesus zu beziehen ist, wohl aber ist sie die durch ihn selbst herausgeforderte Antwort auf ihn. Ebeling bezeichnet die Christologie darum sogar ,,als Antwort auf Jesu Vollmacht“ (D II, 473f). Daran erklärt er auch das Verhältnis von expliziter zu impliziter Christologie: „Würde uns nicht die Erscheinung Jesu, sein Wort und sein Verhalten, vor Augen sein und immer neu vor Augen treten, so verlöre die Christologie ihre Situierung im Leben. Denn sie hat nur dann Sinn, wenn sie die Antwort auf die Begegnung mit Jesus ist.“ (D II, 476).

${ }^{953}$ D II, 461.
} 
Diese primäre Betonung des Wortes Jesu geschieht eigentlich im Bewusstsein dessen, dass die Rede von der Vollmacht auf der Seite des Wortes Jesu bzw. in Bezug auf seine Verkündigung überzeugend ist und meistens Zustimmung gewinnt, während sie auf der Seite des Verhaltens Jesu Widerspruch herausfordert. Dieser Widerspruch liegt, wie Ebeling mit Recht herausstellt, nicht nur im übernatürlichen Wunderbegriff, sondern auch in synoptischen Wundergeschichten selbst. Allerdings wollte Jesus die Welt nicht durch Wundertraten verbessern und lehnte sogar die Zeichenforderung ab. Am wichtigsten ist aber, wobei der Gesichtspunkt „beachtlicherweise“ keinesfalls vorkommt, „dass Wunder geglaubt sein wollen und Glaube deshalb Wunderglaube sei“ und vielmehr, „dass der Glaube selbst von wunderbarer Macht ist". ${ }^{954}$ Ebeling gibt dem Machtwort, dem Wort Jesu einen Primat in Verbindung mit dem Glauben.

Darüber hinaus muss man an den Kontext denken, in dem das Machtwort bei Jesus steht. Sein Machtwort bezieht sich sowohl auf ,sein Gottesverhältnis“ als auch auf „die Art seines Daseins für den Mitmenschen“, anders gesagt: zugleich auf den „Gehorsam gegen Gott“ und den „Dienst am Mitmenschen“. Beides bestimmt laut Ebeling „miteinander“ gerade „die Funktion des Machtwortes“ Jesu. ${ }^{955}$ Was diese Funktion ist, erklärt er wie folgt: „Wenn sich nun jedoch im folgenden der Blick auf den historischen Jesus konzentriert, und zwar zunächst darauf, was uns über sein Lehren tradiert ist, so ergibt sich der Bezug zum Thema der Vollmacht inhaltlich von der Ausrichtung seines

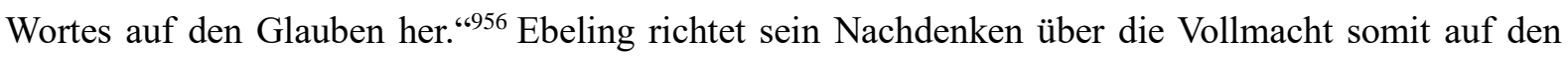
Glauben und versucht durch die Vollmacht den Sachverhalt des Glaubens zu erörtern.

Ebelings Versuch, durch den Begriff der Vollmacht den Sachverhalt des Glaubens zu erläutern, findet sich deutlicher im Teil über „Glaubenszumutung“ und deren Beifügung „Glaubenszuspruch“. Für beide stellt er die Kennzeichnung der Lehren Jesu ,nicht so sehr von dem gedanklichen Inhalt als vielmehr von seiner Intention her und somit im Hinblick auf die Situation, die es hervorruft“" heraus. ${ }^{957}$ Die Lehre bzw. Verkündigung Jesu vollzieht sich in drei Weisen, nämlich ,,als Auslegung des Gesetzes“, „als Aufdecken des Lebens“ und „als Ansage der Nähe Gottes“. ${ }^{958}$ Alles, was durch das Wort Jesu getragen und vollzogen wurde, alles von seiner Auslegung des Gesetzes, seinem Aufdecken des Lebens bis hin zu seiner Ansage der Nähe Gottes, richtet sich doch letztlich auf ein gleiches Ziel: die Glaubenszumutung. Jesu Wort entfaltet sich dadurch in der Situation des Glaubens, wo die Entscheidung zwischen Unglaube und Glaube fällt, und „wo alles, was den Menschen betrifft, in dem

\footnotetext{
954 D II, $463 \mathrm{f}$

955 D II, 411.

956 D II, 427.

957 D II, 427.

958 D II, 428.
} 
Betroffensein durch Gott begriffen ist““. ${ }^{959}$ Der Glaube entsteht dann ,als die Entsprechung zur Vollmacht Jesu“. .960

In Hinblick darauf, dass Ebeling die Eigentümlichkeit des Wortes Jesu so mit dem Phänomen der Vollmacht und letztlich mit dem Glauben verbindet, kann man sich an seine Warnung vor der Sprachkrise erinnern, die er in der $>$ Einführung in theologische Sprachlehre $<$ als den Anreiz zur Schwäche und Ohnmacht des Wortes und damit als die Bedrohung des christlichen Glaubens bezeichnet. ${ }^{961}$ Angesichts dieser Krise versucht Ebeling dort, das Wesen der Sprache als Wortgeschehen festzulegen und eine theologische Sprachlehre für die Beantwortung der fundamentaltheologischen Fragen zu entwickeln. Auf derselben Linie, auf der auch der Versuch, die Sprachkrise zu überwinden, liegt, befindet sich seine Betonung auf die Vollmacht des Wortes in der Christologie. Die Vollmacht des Wortes Jesu ist das vollmächtige Wortgeschehen, das im Lebenslauf des Menschen Jesu tatsächlich entstand und noch im Leben des Glaubenden entstehen kann und muss. Das von Jesus verkündigte Wort, das nicht mehr verstanden, darum nicht mehr in der uns in die Erfahrung des Glaubens transformierenden Vollmacht erfasst wird, würde nicht das Wort Gottes sein. Die Vollmacht des Wortes zeichnet sich bei Ebeling dann als eine bestimmte Glaubenserfahrung aus. Wenn wir uns auf die Vollmacht des Wortes Jesu verlassen, vollzieht sich die Korrelation von Wort und Glaube und entsteht der Übergang von der Ohnmacht der menschlichen Kraft zu der Allmacht Gottes, so wie Luther sagt: „Glaubst du, so hast du. Glaubst du nicht, so hast du nicht.“962 Die Allmacht Gottes, die von Ebeling als „nicht bloß potentielle, sondern faktisch geschehende Allmacht ${ }^{“ 963}$ bestimmt wird, beweist sich nun deutlicher an der Vollmacht des Wortes Jesu und damit auch in Bezug auf Sprache. Die Wendung auf die Vollmacht des Wortes Jesu gewinnt bei Ebeling einerseits Sinn für die christlichen Zeugnisse, die ihren Ursprung, ihre Berechtigung sowie Macht auf das Wort Jesu begründen. Andererseits scheint sie doch nicht darzulegen, wie das vollmächtige Wortgeschehen im Verhältnis zu anderen Wirklichkeitserfahrungen funktioniert. Damit könnte sie in Gefahr geraten, die Vollmacht Jesu bloß auf die Ebene der persönlichen Erfahrung zu beschränken.

\section{Sprache und Glaube an den heiligen Geist}

Ebelings Dogmatik wird, wie bereits aufgezeigt, gemäß der drei Artikel des Credos aufgebaut. Jeder Band hat dementsprechend eine zentrale Thematik, auch wenn die verschiedenen Themen dabei

\footnotetext{
959 D II, 456.

960 D II, 517.

${ }^{961}$ Sprachlehre, $3 \mathrm{f}$.

962 WA 7,24,13f.

${ }^{963}$ WG II, 281. Dazu erklärt er noch deutlicher: „Gott - das ist auch Auschwitz und Hiroshima oder die nüchterne, alltägliche Wirklichkeit also auch die Gottlosigkeit in allen Modifikationen. “( WG II, 282).
} 
untereinander berührt werden und jedes eng in Bezug auf die anderen betrachtet werden muss. Die zentrale Thematik jedes Bandes ist schon äußerlich erkennbar. Im ersten Band ist sie als Gotteslehre zu nennen, im zweiten als Christologie, und im dritten als Pneumatologie. Diese Einordnung der Pneumatologie als eine hauptsächliche Thematik der Dogmatik ist zuerst zur Sprache zu bringen. Denn in der traditionellen Dogmatik wurde sie als ein Unterthema in der Kategorie der Trinitätslehre oder der Soteriologie und neuzeitlich oft in der Kategorie der Ekklesiologie behandelt. Aber die zentrale Thematik des dritten Bands von Ebelings Dogmatik ist nichts anderes als Pneumatologie.

Um die Pneumatologie als dogmatischen Ort und Hauptgegenstand des letzten Bandes zu rechtfertigen, versucht Ebeling ihren Bezug auf die Eschatologie zu erläutern. Die Möglichkeit der Rede von ihrer engen Beziehung findet er im Credo selbst. Er richtet sich nach der Struktur des dritten Glaubensartikels des Credos, das der Glaubensaussage an den heiligen Geist andere Glaubensgegenstände in Reihe weiter folgen lässt, nämlich „die heilige christliche Kirche, Gemeinschaft der Heiligen, Vergebung der Sünden, Auferstehung der Toten und das ewige Leben“.964 Diese könnte man in Bezug auf den heiligen Geist wohl als Beschreibung seiner Wirkungen verstehen. Das scheint aber nicht alle zu umfassen. In dieser Reihe findet sich eher die Polarität von „Gegenwart des heiligen Geistes und der endgeschichtlichen Zukunft der Welt“, terminologisch ist es der Zusammenhang von „Pneumatologie und Eschatologie“, die „miteinander in einer gewissen Spannung" stehen. ${ }^{965}$

Hinsichtlich ihres spannungsvollen Verhältnisses bringt Ebeling zuerst ihre Gemeinsamkeit zur Sprache und erklärt, dass ,auf beide Weisen die Welt transzendiert wird“. ${ }^{966}$ Er beschreibt beide als „Transzendierung der Zeitlichkeit“ zur Ewigkeit, weil Pneuma und Eschaton ,im Gedanken des Ewigen konvergieren“"967. Trotz dieser Konvergenz besteht doch ein Unterschied zwischen ihnen, weil „die vom Pneuma erfüllte Gegenwart das Ewige schon als Gegenwart erfahren lässt, während in der anderen Sicht

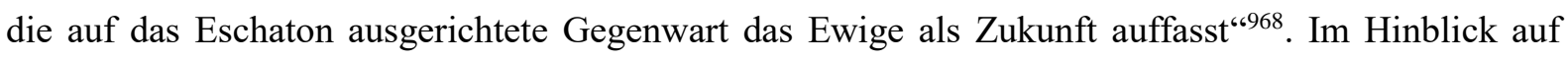
solchen spannungsvollen Sachverhalt von Pneumatologie und Eschatologie fordert Ebeling ihre „christologische Verklammerung“. ${ }^{969}$ Die Zusammengehörigkeit der beiden kann Ebeling zufolge erst durch christliche Verklammerung gesichert werden, weil nur in Jesus Christus das Reich Gottes Gegenwart und Zukunft zugleich ist und es nur durch den heiligen Geist geschehen kann. Das zeigt die

\footnotetext{
964 D III, 4.

965 D III, 4.

966 D III, 23: „Da sich nun dasjenige, was einen vom Eschaton her angeht, und dasjenige, was einem vom Pneuma her widerfährt, darin treffen, dass auf beide Weisen die Welt transzendiert wird, so ist es verständlich, dass ich auch beide Weisen miteinander verbinden kann. Intensive eschatologische Erwartung äußert sich in pneumatischen Erscheinungen.“

967 D III, 24.

968 D III, 24.

${ }^{969}$ D III, $31 \mathrm{f}$.
} 
Bibel deutlich, indem sie von der Gegenwart des Gottesreiches in der Person Jesu redet und in seinem Wirken die enge Verbindung mit dem Werk des heiligen Geistes sieht (Mt. 12, 28). Ebeling erklärt: „Wie das Bekenntnis zu Jesus, von dem dieses Geschehen ausgeht, den Charakter von Christologie hat, und das heißt: von perfektischer Eschatologie, so wird das Folgegeschehen im Zeichen des Christusbekenntnisses zu einem Ineinander präsentischer und futurischer Eschatologie. Die Aussagen darüber nehmen folgerichtig den Charakter von Pneumatologie an. Denn der heilige Geist macht das perfektische Eschaton, von dem er herkommt, gegenwärtig und richtet zugleich auf das eschatologische Futur aus, weil er selbst bereits dessen Präsenz ist."“770

Die Behauptung über die Zusammengehörigkeit von Pneumatologie und Eschatologie ist nicht umstritten, aber die über die christologische Verklammerung von ihnen könnte für eine Beschränkung gehalten werden. Z.B. sagt Pannenberg, ihr Zusammenhang hätte sich ,nicht nur christologisch, sondern auch trinitätstheologisch zu entfalten. Denn gerade die Vollendung der Welt und des Menschen muss als in Gott selbst begründet gedacht werden, obwohl das immer nur unter den Bedingungen der Endlichkeit des Menschen, der geschichtlichen Bedingtheit seiner Denkvollzüge und unter Voraussetzung der geschichtlichen Offenbarung Gottes inmitten dieser endlichen Welt geschehen kann“. ${ }^{971}$ Seiner Ansicht nach übersieht Ebeling jedoch diese Möglichkeit und folgt diesem Weg ,aus Sorge vor den von ihm befürchteten Gefahren eines spekulativen Vorgehens“ nicht und stellt die Trinitätslehre demzufolge ganz ans Ende seiner Dogmatik. ${ }^{972}$ Angesichts des Verhältnisses von Pneumatologie und Eschatologie unterstreicht Ebeling ihren Bezug auf die Christologie und betrachtet damit ihren Bezug auf die Trinitätslehre nicht genügend, obgleich diese durch die Begriffsbezeichnung des lebendigen Gottes im Teil der „Dreieinigkeit Gott“ (§42) behandelt werden könnte. Pannenbergs Meinung über die Stellung der Trinitätslehre bei Ebeling scheint aber die ganze Struktur seiner Dogmatik und seinen darin versteckten Willen außer Betracht zu lassen. Denn Ebeling will durch den Aufbau seiner Dogmatik darstellen, wie mehrmals gesagt, dass alle Glaubensaussagen in der Dogmatik vom Grund des Glaubens her miteinander zusammenhängen, besonders im in ihrer wechselseitigen Reihenfolge markierten Koordinatensystem verbunden sind und darauf hinführen, letztlich den einen Gott als den Schöpfer, Versöhner und Vollender zugleich zu bekennen. Wegen dieser Absicht stellt er die Dreieinigkeit Gottes ans Ende seiner Dogmatik, also nicht wegen der Unterschätzung des Gewichts der Trinitätslehre oder wegen der Nichtberücksichtigung ihres Bezugs zur Pneumatologie. Die Trinitätslehre in Ebelings Dogmatik darf keinesfalls für ein Zusätzliches oder einen Anhang gehalten werden, sondern für eine Zusammenfassung der ganzen dogmatischen Aussagen, so wie der Titel des letzten Kapitels „Gott alles im allem“ andeutet. Auf die Frage, was die Intention der Trinitätslehre sei,

\footnotetext{
970 D III, 46.

971 W. Pannenberg, Systematische Theologie III, Göttingen 1993, 597.

972 W. Pannenberg, Systematische Theologie III, Göttingen 1993, 597, Anm. 90.
} 
hätte Ebeling wohl geantwortet, sie liege nicht darin, das Innenverhältnis der Dreieinigkeit Gottes zu erklären, sondern den trinitarischen Glauben, bzw. einen ganzen Glauben an dem dreieinigen Gott bekennen zu lassen. Die Stelle der Trinitätslehre am Ende der Dogmatik bei Ebeling ist darum nicht weniger sinnvoll.

Der oben aufgezeigte Gesichtspunkt, dass Ebeling die Zusammenhörigkeit der pneumatologischen und eschatologischen Aussagen und dabei einen christologischen Charakter betonen will, wird schon durch den Begriff der Vollendung angedeutet, den er für den Titel des dritten Bandes verwendet. Der Begriff ist bei Ebeling nicht nur traditionell und typisch, sondern auch sehr zielgerichtet. Der Begriff der Vollendung enthält den umfassenden Charakter von Pneumatologie und Eschatologie. Und er bedeutet, etwas schon Begonnenes zum vollen Ende zu bringen. Das heißt, es handelt sich nicht um ein neues Gotteswerk, sondern um das schon begonnene Gotteswerk. Dieses wird durch den heiligen Geist geschaffen, ist jedoch ursprünglich mit dem Werk der Schöpfung Gottes und mit dem Werk der Versöhnung Jesu Christi verbunden. Ebeling legt aber mehr Betonung auf das Verhältnis von Christus und Geist. Dies bezeichnet er sogar als „ein(en) einzige(n) Geschehenszusammenhang“ aufgrund des „Charakter(s) des pro nobis“ (Rom. 8,26.34) und der Bezeichnung, dass Christus als der letzte Adam ein „lebendigmachender Geist“ sei $\left(1\right.$. Kor. 15,45). ${ }^{973}$ Der heilige Geist als der Vollender der Welt bedeutet dann, dass er uns über die zeitliche Verschränkung, also frei von der Vergangenheit und der Zukunft, für das Heute bereitet und das von Jesu vollbrachte Heil an uns vollstreckt und vollendet.

Die Pneumatologie ist, wie oben erwähnt, die hauptsächliche Thematik im dritten Band und die Rede vom heiligen Geist wird darum überall im ganzen Band gefunden. Ebelings Auffassung des heiligen Geistes ist in zwei Teilen besonders präsent, wobei verstärkt die auf das Wesen des heiligen Geistes bezogenen Fragen behandelt werden: Die erste Frage ist, wer der heilige Geist sei. Ebeling behandelt sie im Teil $\$ 31$ unter dem Titel „Heiliger Geist und Menschengeist“, was bereits andeutet, dass er den heiligen Geist im Verhältnis zum Menschen sieht, wobei die Personalität des Menschen und die Sprache im Zentrum stehen (4.1). Die zweite Frage betrachtet das Wirken des heiligen Geistes, das Ebeling primär als Sprachgeschehen von Wort und Glaube versteht. Es wird im Teil $§ 35$ unter dem Titel „Das Wort des Glaubens“ behandelt, näher unterteilt in „Gottes Wort als Gesetz und Evangelium“ und in „Gottes Wort in sakramentaler Gestalt“, die Ebeling beide als das intensiv auf den rechtfertigenden Glauben bezogene Werk des Geistes bezeichnet (4.2). Beim Behandeln dieser zwei Fragen richtet Ebeling seine Aufmerksamkeit viel mehr auf das Wirken des heiligen Geistes.

${ }^{973}$ D III, 67. 


\subsection{Die sprachliche Personalität des heiligen Geistes}

Der Personenbegriff wurde in der Theologiegeschichte lang im Zusammenhang mit der Trinität herausgearbeitet, um gegen Monotheismus und Tritheismus die unter der Einheit stehende Unterscheidung zwischen Gott, Sohn und dem heiligen Geist zu erklären, und hat seinen Ort traditionell in der Gotteslehre. Ebelings Personsverständnis zeigt sich schon im ersten Band über Gott, also grundsätzlich im Anschluss an Luther und speziell durch die Beschreibung des Gegenüberseins Gottes in der Relation des Gebets ${ }^{974}$ und hier wieder deutlicher durch die Charakterisierung des heiligen Geistes. Diesen in den Personenbegriff einzubinden wehrt „animistische“ und „dynamistische“ Vorstellungen des heiligen Geistes ab und kommt letztlich zum Verständnis des Personseins selbst. Es geht, laut Ebeling „nicht um einen entpersonalisierenden, sondern um einen personalisierenden Eingriff in das Personssein“. 975

In Hinsicht auf Ebelings Verständnis der Personalität des heiligen Geistes sind drei Kennzeichnungen zur Sprache zu bringen:

Erstens, Ebeling versteht die Personalität des heiligen Geistes als relational, konkreter in Bezug auf Menschen. Unter den zwei Aspekten von Selbststand und Relationalität für die Beschreibung des Personsbegriffs hebt Ebeling, so wie bereits in der Gotteslehre und in der Christologie aufgezeigt, immer den Aspekt des Relationalen hervor und legt dabei sogar einen besonderen Akzent auf die Relation mit dem Menschen. Diesen relationalen Personenbegriff gebraucht er hier wieder in Bezug auf das Verhältnis von dem heiligen Geist und Menschengeist: „Der heilige Geist wird nicht Dingen zuteil, sondern dem Menschen. Selbst wenn vom heiligen Geist auch in Verbindung mit Dingen die Rede sein mag, zielt er doch auch so allein auf den Menschen. Klammert man die trinitarische Frage der innergöttlichen Seinsweise des Geistes aus und hält man sich allein an den heiligen Geist in der Weise des geschichtlichen Gesandtwerdens, des Ausgegossenwerdens, des Gegebenwerdens, so ist der Adressat, der Empfänger der Mensch. [...] daß der heilige Geist auf den Menschen aus ist, weil der Mensch Geist hat. “976 Der Mensch als das Sein, das Geist hat, ist des heiligen Geistes bedürftig. Denn wenn der Mensch „auf einen anderen Geist angewiesen“ und unheilig ist, stimmt etwas mit seinem Geist nicht und etwas ist nicht in Ordnung. ${ }^{977}$ Der Unterschied zwischen Gottgeist und Menschgeist wird dabei auch nicht aufgehoben. Die Bezeichnung des Menschen als Adressat des heiligen Geistes verbindet sich eigentlich mit der Frage nach dem Worumwillen der Sendung des heiligen Geists und dem Ziel seines Werkes und gibt dann auch einen Hinweis einerseits auf die geschöpfliche Sonderstellung des Menschen, nämlich darauf, warum unter allen Geschöpfen der Mensch allein der

\footnotetext{
${ }^{974}$ D I, 224ff. Vgl. Kap. III, 2. 1.

975 D III, 114.

976 D III, 111.

${ }^{977}$ D III, 111.
} 
Empfänger des heiligen Geistes ist; und andererseits auf die Bedeutung des Titels des heiligen Geistes, also darauf, warum er der heilige Geist ist. Ebeling versucht solcherweise den Gegensatz von heiligem Geist und Menschengeist zu überwinden und beide im wesentlichen Bezug stehen zu lassen.

Zweitens, Ebeling sieht die Personalität des heiligen Geistes nicht in der rationalen oder moralischen Kategorie. Sofern der heilige Geist nicht als eine unpersönliche Kraft verstanden wird, sondern sich auf die Person des Menschen ausrichtet, verfährt er weder ,irrational“ noch „amoralisch“. Ebeling nimmt aber vornehmlich von der moralischen Kategorie Abstand, behauptend, der heilige Geist lasse sich „nicht in ein Moralsystem zwingen. Er sprengt moralische Gesetzlichkeit, nicht weil er die Freiheit der Selbstsucht und die Auflehnung gegen Gesetz und Ordnung an sich propagierte, sondern weil er der Geist der Liebe ist, die das Gesetz dadurch aufhebt, dass sie es erfüllt.“978 Dieser die moralische Gesetzlichkeit transzendierende Charakter manifestiert sich klar im auf das Evangelium bezogenen Wirken des heiligen Geistes.

Ebeling charakterisiert die Personalität des heiligen Geistes letztlich als sprachlich. Er scheint die menschenbezogene, weder irrationale noch amoralische Personalität geradezu durch die Sprachlichkeit zu bestätigen. Er erläutert, „,das Wort in verständlicher Sprache (sei) das Medium des heiligen Geistes. Er ist der Geist der Erkenntnis, der Weisheit und der Wahrheit, nicht aber der Ungeist eines agnostischen Skeptizismus.“"979 Der heilige Geist hat gewiss mit Wissen zu tun. Er lässt uns wissen, wer Gott ist und wer Jesus Christus ist (Kor 12,3). So führt uns der heilige Geist zur Wahrheit und auch zum Glauben, aber nichts anderes als die Sprache als das Medium seines Geschehens macht das möglich. Das Wirken des Geistes wird deshalb laut Ebeling „letztlich sprachlich erfahren, ob nun durch den Zuspruch von außen her oder durch das Sich-in-Erinnerung-Bringen und die überführende Macht in der inneren Zwiesprache des Herzens. “980 Das Geistwirken zeichnet sich laut ihm dadurch aus, dass es als Wortbzw. Sprachgeschehen zwischen Wort und Glaube entsteht.

\subsection{Das worthafte Wirken des heiligen Geistes}

Die Bibel sagt, wir werden „geheiligt, durch den heiligen Geist“. (Rom 15,16). Er ist heiliger Geist gerade „als heilig machender Geist. “981 Die Heiligung gehört eigentümlich zu seinem Wirken, das sich im Christusgeschehen begründet und sich am Menschen, an seinem wirklichen Leben vollzieht. ${ }^{982}$ Die Heiligung als das Wirken des heiligen Geistes hat eng mit der Rechtfertigung zu tun, die sich unmittelbar einerseits auf die Sünde und andererseits auf die Gerechtigkeit Jesu Christi bezieht. Die

\footnotetext{
${ }^{978}$ D III, 116.

${ }^{979}$ D III, 116.

${ }^{980}$ D III, 116.

${ }^{981}$ D III, 118.

982 D III, 118.
} 
Relation von Heiligung und Rechtfertigung ist in der Theologiegeschichte ein umstrittenes Thema und wird von Ebeling hier auf zweierlei Weise formuliert: beide gleichzusetzen oder Heiligung als Folge der Rechtfertigung zu sehen. ${ }^{983}$ Er hebt aber zuallererst die Zusammenwirkung von beiden hervor und richtet das Wirken des heiligen Geistes intensiv auf den rechtfertigenden Glauben.

Bezüglich der daran anschließenden Frage, wodurch der Geist wirkt und uns zum rechtfertigenden Glauben führt, beruft sich Ebeling auf eine traditionelle Methode. Er nutzt die meidia salutis von Wort und Sakrament, genauer gesagt, Gottes Wort in verbaler Gestalt und in sakramentaler Gestalt.

\subsubsection{Das Verhältnis von Gesetz und Evangelium}

Das oben genannte erste Medium besteht als Gesetz und Evangelium. Diese sind für Ebeling ,im theologischen Verständnis“ „Relationsbegriffe“ “984 Sofern sie Relationsbegriffe sind, werden sie immer in Bezug aufeinander betrachtet und behandelt. Das bedeutet, dass ihre Gemeinsamkeit sowie ihre Unterschiedlichkeit zugleich zur Sprache gebracht und dabei unterschiedliche Akzente gesetzt werden können.

\subsubsection{Gesetz und Evangelium als Relationsbegriffe}

Das Verhältnis von Gesetz und Evangelium ist etwas umstritten. Sie befinden sich beide in der heiligen Schrift. Nach dem biblischen Gebrauch bezieht sich das Wort „Gesetz“ ursprünglich auf die Tora im Judentum und das Wort „Evangelium“ auf die Verkündigung Jesu als die Botschaft vom Reich Gottes, damit unmittelbar auf das Christentum. Jesus als der Verkündiger und Begründer des Evangeliums selber hat das Gesetz weder verworfen noch aufgehoben. Im Hinblick auf die Stellung Jesu zum Gesetz (bzw. zur Tora) erklärt Hubert Frankemölle, es gehe Jesus so „immer um eine vertiefende theologische Neuakzentuierung der Tora aufgrund seines Glaubens an das gegenwärtige Handeln Gottes“. ${ }^{985}$ Jesus hat das Evangelium immer in Kontinuität mit dem Gesetz (bzw. der Tora) dargestellt und sich, nach dem Bericht Matthäus, selbst als einen vorgestellt, der das Gesetz erfüllt (Mt 5,17). Jesus selbst hat bewiesen, dass Gesetz und Evangelium keineswegs im Gegensatz stehen. Die Unterscheidung zwischen Gesetz und Evangelium und ihr Zusammenhang haben jeweils ihre eigenen Begründungen.

Die Formel von Gesetz und Evangelium und ihre Verhältnisbestimmung geht in der reformatorischen Theologie offenbar auf Luther zurück. Dieser rückt z.B. in seiner berühmten Predigt über Gal. 3,23.24 (1532) das Verhältnis von Gesetz und Evangelium ins Zentrum und äußert seine

\footnotetext{
${ }^{983}$ D III, $240 \mathrm{ff}$.

${ }^{984}$ D III, 291.

${ }^{985}$ H. Frankemölle, Das jüdische Neue Testament und der christliche Glaube. Grundlagenwissen für den jüdischchristlichen Dialog, Stuttgart 2009, 80.
} 
Meinung wie folgt: „Dass in der Christenheit soll beide von Predigern und Zuhörern ein gewisser Unterschied gelehrt und gefasst werden zwischen dem Gesetz und Evangelio, zwischen den Werken und dem Glauben; [...] Denn dieser Unterschied zwischen dem Gesetz und Evangelio ist die höchste Kunst in der Christenheit, die alle und jede, so sich des christlichen Namens rühmen, oder annehmen, können und wissen sollen. [...] Darum dringt St. Paulus so hart drauf, dass diese zwo Lehren, nämlich des Gesetzes und Evangeli, bei den Christen wohl und recht voneinander geschieden werden. Beides ist wohl Gottes Wort, das Gesetz oder die zehn Gebote, und Evangelium; dieses anfänglich im Paradies, jenes auf dem Berge Sinai, von Gott gegeben. “986 Luther hält Gesetz und Evangelium gemeinsam für Gottes Wort und legt den Akzent doch auf eine grundlegende Unterscheidung zwischen ihnen. Diese Unterscheidung verbindet sich bei ihm unmittelbar mit der Unterscheidung zwischen dem Alten und dem Neuen Testament bzw. Gebot und Verheißung, und weiter mit der Rechtfertigung allein durch den Glauben (sola fide) sowie der Gnade allein durch Christus (solus Christus), mit denen er gegen die katholische Kirche kämpft.

Die von Luther zentral behandelte, grundlegende Unterscheidung von Gesetz und Evangelium spielt bei Calvin eine relativ untergeordnete Rolle. Für Calvins Gesetzesverständnis ist die Erkenntnis grundlegend, wie W. Niesel mit Recht hinweist, „dass das Gesetz Bundesgesetz ist. “987 So wie Calvin nicht zwischen einem alten und einem neuen Bund unterscheidet, sondern von einem einzigen Gottesbund redet, versteht er das Evangelium im das Gesetz umfassenden Sinne. Das heißt, er ordnet das Evangelium dem Gesetz vor, ähnlich wie Luther, aber in anderer Weise. Bei Calvin hat das Evangelium, nach der Darstellung Körtners, ,insofern den Primat, als das Evangelium im weiteren Sinne des Begriffs die innere Einheit von Gesetz und neutestamentlicher Christuspredigt verbürgt ${ }^{\text {‘9988. }}$. Sein Gesichtspunkt wird vor allem von K. Barth übernommen. Dieser versteht Gesetz weder als Ausdruck des Zorns Gottes über die Sünder, noch als Mittel seines Gerichts, sondern als Zeugnis seiner „Gnadenwahl“. Er sagt: „Die Lehre von Gottes Gnadenwahl ist das eine und die Lehre von Gottes Gebot ist das andere Element des rechten, christlichen Begriffs vom Bunde Gottes mit dem Menschen. In diesem Begriff des Bundes erst vollendet sich der Begriff Gottes selbst." ${ }^{989}$ In seinem Vortrag $>$ Evangelium und Gesetz< $(1935)$ behauptet er noch stärker, das Gesetz sei ,nichts anderes als die notwendige Form des Evangeliums, dessen Inhalt die Gnade ist. ${ }^{\text {“990 }}$ Barth wendet sich damit gegen das lutherische antithetische Verständnis von Gesetz und Evangelium und kehrt absichtlich die lutherische

\footnotetext{
${ }^{986}$ Luthers Predigt vom Unterschied zwischen dem Gesetz und Evangelio über Gal 3,23.24. Gehalten den 1. Januar 1532; Wiederabdruck, in: J.G. Walch (Hg.), Martin Luthers sämtliche Schriften, 2. Aufl. Bd. IX, 798-811, 798.

${ }^{987}$ W. Niesel, Die Theologie Calvins, München ${ }^{2} 1957,86$.

${ }^{988}$ U.H.J. Körtner, Theologie des Wortes Gottes. Positionen, Probleme, Perspektiven. Göttingen 2001, 204.

989 K. Barth, KD n/2, 564.

${ }^{990}$ K. Barth, Evangelium und Gesetz (1935), in: E. Kinder/K. Haendler (Hg.), Gesetz und Evangelium. Beiträge zur gegenwärtigen theologischen Diskussion (WdF 142), Darmstadt ${ }^{2} 1986,1-29,9$.
} 
Reihenfolge um, nämlich als „Evangelium und Gesetz“, weil er im Evangelium ihre Einheit behauptet. ${ }^{991}$ Sein Ansatz findet sich zuallererst in der gemeinsamen Ursprung von Gesetz und Evangelium: „Wirklich als ein Zweites, Anderes tritt das Gesetz immer wieder neben das Evangelium, gleich wahr und gebieterisch und notwendig, weil der eine Gott hinter beiden steht, weil der eine Heilige Geist beides dem Menschen schenkt: die Gewissheit der Rechtfertigung des Sünders vor Gott und den Antrieb zur Heiligung desselben Sünders vor demselben Gott“. ${ }^{992}$ Er unterstreicht das eine einzige Subjekt, also den einen Gott, der uns Gesetz und Evangelium geschenkt hat.

Im Hinblick auf die theologische Diskussion über die Zuordnung von Gesetz und Evangelium im 20. Jahrhundert kann man zwei konträre Richtungen finden, die jeweils mit Nachdruck auf ihre Einheit oder Unterscheidung hinweisen. Zuerst gibt es die Integrationsmodelle, die sich, wie oben aufgezeigt, von K. Barth angeregt und von H.J. Iwand weitergeführt, der sie in der Christologie einerseits und in der Soteriologie andererseits, damit im Sinne des einen Christi pro me entfaltet. Demgegenüber stehen die Konfrontationsmodelle, die bei den lutherischen Theologen bemerkbar sind, so etwa in radikaler Weise bei W. Elert, der sie unter dem Oberbegriff von Offenbarung, also gepaart mit der Unterscheidung von Deus absconditus und Deus revelatus behandelt; ${ }^{993}$ und weiter bei F. Gogarten, der sie auf die Unterscheidung von den beiden Reichen bezieht, ${ }^{994}$ und auch bei Ebeling. ${ }^{995}$

In Bezug auf die Verhältnisbestimmung von Gesetz und Evangelium hebt Ebeling die Differenz zwischen Luther und Barth hervor. ${ }^{996}$ Er setzt sich selbst näher an Luther, auch wenn er die grundlegende Übereinstimmung zwischen Luther und Barth anerkennt ${ }^{997}$ und bezüglich der Vorrangstellung des Evangeliums sogar seine Übereinstimmung mit Barth äußert ${ }^{998}$. Er richtet ebenso wie Luther seine Aufmerksamkeit mehr auf die fundamentale Unterscheidung zwischen Gesetz und Evangelium. Wird von der Unterscheidung bei Luther geredet, geht es doch weder um einen Dualismus, in dem Gesetz und Evangelium einander nur feindlich gegenüberstehen, noch um eine Alternative, in der entweder Gesetz oder Evangelium ausgewählt werden soll. Es wäre ebenso falsch, die biblischen Schriften in Gesetz und Evangelium zu scheiden, denn „ein und dasselbe Wort kann als Gesetz treffen

\footnotetext{
${ }^{991} \mathrm{Vgl}$. WG, $278 f$.

${ }^{992}$ K. Barth, Reformierte Lehre, ihr Wesen und ihre Aufgabe, in: Ders., Vorträge und kleinere Arbeiten 1922-1925; Wiederausdruck, in: Holger Finze (Hg.), Karl-Barth-Gesamtausgabe, Zürich 1990, 202-247, 241.

993 W. Elert, Gesetz und Evangelium, in: Ders., Zwischen Gnade und Ungnade, München 1948, 132-169.

${ }^{994}$ F. Gogarten, Einheit von Evangelium und Volkstum?, Hamburg ${ }^{2} 1934$; Der Mensch zwischen Gott und Welt, Stuttgart ${ }^{4} 1967$.

${ }^{995}$ H.-M. Barth, Art. Gesetz und Evangelium I. Systematisch-theologisch, in: TRE 13 (1984), 126-142, 136. Trotz solcher Differenz darf man ihre grundlegende Übereinstimmung auch nicht außer Acht bleiben lassen, wie C. Schwöbel mit Recht hinweist, „dass das Gesetz streng als Gesetz Gottes begriffen werden muss und das Verhältnis von G. und E. allein in Christus (bei Barth: Erwählung und Bund; bei Elert: im Kreuz Christi) endgültig bestimmt ist.“ Ders., Art. Gesetz und Evangelium, in: RGG ${ }^{4}$ III (2000), 862-867, 865.

${ }^{996}$ LuSt III, 537f.

${ }^{997}$ LuSt III, 564.

${ }^{998}$ WG, 278f, Anm. 51.
} 
oder aber als Evangelium vernommen werden. "“999 Ebeling behauptet deshalb, weder ein bloßes Trennen noch ein bloßes Verbinden sei angemessen für das Verständnis lutherischer Unterscheidung. ${ }^{1000}$ Solcher Gedanke über ihr Verhältnis äußert sich in der $>$ Dogmatik des christlichen Glaubens $<$ deutlicher im Ausdruck „Relationsbegriffe“.

In der Dogmatik ist zunächst der Ort des Themas von Gesetz und Evangelium auffallend. Ebeling ordnet es in den Teil „Das Wort des Glaubens“(§35) ein und behandelt es unter dem Titel „Gottes Wort als Gesetz und Evangelium“. Damit ist gemeint, dass Ebeling es in der Oberkategorie des Wortes Gottes betrachtet. Er beginnt mit der Rede von Gottes Wort selbst, nicht direkt von Gesetz und Evangelium. Er scheint dadurch aufzuzeigen, dass ihre Gemeinsamkeit als Gottes Wort ihrer Unterscheidung vorliegt, oder anders gesagt, dass für ihre Unterscheidung der Begriff des Wort Gottes erforderlich ist. Dass der umfassende, also Gesetz und Evangelium enthaltende Begriff des Wortes Gottes Vorrang vor ihrer Unterscheidung hat, kommt laut ihm vom biblischen und vom daran anschließenden kirchlichen Sprachgebrauch her. Ebeling bringt die Kontinuität und die innere Bezogenheit zur Sprache: „Obwohl die Unterscheidung von Gesetz und Evangelium der unentbehrliche Schlüssel ist, um den Zugang zum Wort Gottes als dem Wort des Glaubens zu öffnen, setzen wir trotzdem zunächst bei Beobachtungen ein, die das Wort Gottes in seiner überlieferten Auffassung als Einheit betreffen. Dabei stoßen wir freilich ebenfalls sofort auf polare Unterscheidungen, die zwar nicht mit der von Gesetz und Evangelium identisch, wohl aber auf sie bezogen sind und auf sie hinweisen." ${ }^{1001}$

Gesetz und Evangelium als Gottes Wort sind für Ebeling deshalb Relationsbegriffe, die immer in ihrer Bezogenheit aufeinander bedacht werden und eine Spannung zwischen Unterscheidung und Zusammenhang in sich enthalten. Ihre „Sachrelation“ bestimmt er so: „dass das Gesetz zum Evangelium hintreibt und das Evangelium die Erfüllung des Gesetzes ist.“"1002 Die Deutung dieser Sachrelation darf man aber nicht missverstehen. Ebeling erklärt: Den ersten Satz, dass „das Gesetz zum Evangelium hintreibt“, darf man nicht im Sinne verstehen, dass das Gesetz „durch eine zumindest partielle Erfüllung“ eine Vorbereitung auf das Evangelium bewirkt, sondern umgekehrt im Sinne, dass das Gesetz dessen Präparation auf das Evangelium darin ausübt, dass es den Menschen „erst in qualifiziertem Sinne zum Sünder macht“, also ihm sein „Unwürdigsein“ damit „Angewiesensein auf Gnade allein“ bewusst macht. ${ }^{1003}$ Den zweiten Satz, dass „das Evangelium die Erfüllung des Gesetzes ist“", darf man auch nicht im Sinne verstehen, dass der Mensch durch das Evangelium irgendeine Kraft gewinnt, das Gesetz völlig zu erfüllen. Vielmehr ist es im Sinne zu verstehen, dass das Evangelium darin besteht, dass „das Gesetz in Jesus Christus ein für allemal erfüllt ist“ und durch die Teilhabe an

\footnotetext{
${ }^{999}$ Luther, 147.

${ }^{1000}$ Luther, $125 \mathrm{f}$.

${ }^{1001}$ D III, 252.

1002 D III, 292.

${ }^{1003}$ D III, 292 f.
} 
dessen Sieg über das Gesetz der Mensch vor Gott nun „keinen Verkläger“, sondern „einen Anwalt" hat. ${ }^{1004}$ Diese Sachrelation von Gesetz und Evangelium kristallisiert den Gedanken heraus, dass man sie keineswegs trennen oder vermischen darf, sondern vielmehr grundlegend richtig unterscheiden muss.

Parallel zu dem steigenden Interesse für den interkonfessionellen Dialog gibt es heute im theologischen Gebiet eine Tendenz, jüdisch und christlich sowie evangelisch und katholisch als unterschiedliche Führung der theologischen Reflexionen zu vermeiden und sie erneut zu bestimmen. Diese Tendenz manifestiert sich zuallererst in der zwischen dem katholischen und dem lutherischen Weltbund ausgehandelten $>$ Gemeinsame(n) Erklärung zur Rechtsfertigungslehre $<$ (2009), auch wenn es nicht um eine vollständige Vereinigung, sondern lediglich um eine Zustimmung in Grundwahrheiten der Rechtfertigungslehre geht. ${ }^{1005}$ Solcher integrativen Tendenz folgen weitere theologische Reflexionsarbeiten. Klaus Wengst versucht z.B. die Unterscheidung zwischen jüdischem und christlichem Verständnis des Gesetzes aufzuheben. Er behauptet, der antijüdische Ton komme aus Luthers Interpretation von Gesetz als „Leistungsgerechtigkeit“ her und das sei „die für den Protestantismus spezifische Judenfeindschaft. Sie ergibt sich gerade von seinem Zentrum her, der Rechtfertigungslehre. ,Die Juden` als Typen werden auf das negative Gegenteil dessen festgelegt, was einem selbst als das Positivste gilt.“" ${ }^{1006}$ Wengst versteht dagegen die Tora als Weisung und plädiert letztlich für ein „Christsein mit Tora und Evangelium“. Seine kritische Überlegung gegen Luther und seine daraus resultierende Intention wird durch den Untertitel seines Buches verdeutlicht: „Umbau christlicher Theologie“.

Gegen solche integrative Tendenz setzt sich beispielhaft Eberhard Jüngel. Dieser äußert im Vorwort zur ersten Auflage seines Buches über die Rechtsfertigungslehre seine kritische Meinung zur oben genannten >Gemeinsame(n) Erklärung zur Rechtsfertigungslehre $<$ und die daran geknüpften Problematiken. Denn unter Vorwand der Versöhnung zwischen katholischen und evangelischen Kirchen darf der Kern der evangelischen Rechtfertigungslehre wie sola fide keinesfalls übersehen oder beschädigt werden. Aber in der $>$ Gemeinsame(n) Erklärung zur Rechtsfertigungslehre $<$ waren nach der Meinung Jüngels ,jedenfalls auf lutherischer Seite gerade keine soliden theologischen Fundamente zur Überwindung der Kirchenspaltung gelegt worden. Denn hier waren entscheidende Einsichten der Reformation entweder verdunkelt oder ganz preisgegeben worden. “" ${ }^{1007}$ Er sieht die reformatorische

\footnotetext{
1004 D III, 293.

1005 F. Hauschildt u.a. (Hg.), Die Gemeinsame Erklärung zur Rechtfertigungslehre. Dokumentation des Entstehungs- und Rezeptionsprozesses, Göttingen 2009.

${ }^{1006}$ K. Wengst, Christsein mit Tora und Evangelium. Beiträge zum Umbau christlicher Theologie im Angesicht Israels, Stuttgart 2014, 43.

${ }^{1007}$ E. Jüngel, Das Evangelium von der Rechtfertigung des Gottlosen als Zentrum des christlichen Glaubens. Eine theologische Studie in ökumenischer Absicht, Tübingen ${ }^{3} 1999$, XIV.
} 
Rechtfertigung vornehmlich in Bezug auf das Evangelium bei Luther und sagt, dass er dabei Ebeling „in sachlicher Hinsicht verdanke“. 1008

\subsubsection{Die Unterscheidung zwischen Gesetz und Evangelium}

Im Hinblick auf Gesetz und Evangelium weist Ebeling immer auf Luthers Ansicht hin, dass „,die höchste Kunst in der Christenheit“ sowie die "Grundformel theologischen Verstehens“ geradezu in der Unterscheidung von ihnen besteht. ${ }^{1009}$ Die richtige Unterscheidung von Gesetz und Evangelium gilt nach Luther als die grundlegende Aufgabe der Theologie: „Wer das Evangelium recht vom Gesetz zu unterscheiden weiß, der danke Gott und darf wissen, dass er ein Theologe ist“1010 und „Nahezu die gesamte Schrift und die Erkenntnis der ganzen Theologie hängt an der rechten Erkenntnis von Gesetz und Evangelium.“1011 Ebeling sagt ähnlich aus, dass erst im Licht der Unterscheidung von Gesetz und Evangelium klar wird, ,was überhaupt Wort Gottes heißt“. ${ }^{1012}$

Angesichts dessen, worin sich Gottes Wort Gesetz und Evangelium voneinander unterscheiden, ist wahrscheinlich zuerst ihre inhaltliche Unterscheidung zur Sprache zu bringen. Nach dem strengen theologischen Sprachgebrauch ist Gesetz zu heißen, ,alles, was zur Forderung, zur Anklage, zur Verurteilung wird“, und Evangelium dagegen, ,alles, was Glauben weckt, aufrichtet, tröstet, Frieden schenkt, und zwar in Hinsicht auf das Sein vor Gott, das ist im Sinne Jesu Christi und gilt in seinem Namen“. ${ }^{1013}$ Sie haben jeweils ihren eigenen Wortschatz. Ferner zeichnen sie auch die zeitliche Unterscheidung aus, weil sich das Gesetz primär auf die Gabe des mosaischen Gesetzes im Alten Testament bezieht und das Evangelium dagegen auf die Offenbarung des Evangeliums in Jesus Christus im Neuen Testament. Vor diesem Hintergrund formuliert Ebeling ihre Relation so: „Das Gesetz geht dem Evangelium voraus. Das Evangelium ist das Ende des Gesetzes.“ ${ }^{1014}$ Diese gegenseitige Relationsbestimmung gilt aber nicht nur ,in chronologischem Sinne“, sondern auch ,,in soteriologischer Hinsicht", weil der Vergebung die Sünde vorausgeht und dem Lebendigmachen das Töten. ${ }^{1015} \mathrm{Da}$ kommt nun die „Sachrelation“ zum Tragen, wie oben erwähnt, „dass das Gesetz zum Evangelium hintreibt und das Evangelium die Erfüllung des Gesetzes ist.“1016

\footnotetext{
${ }^{1008}$ E. Jüngel, Das Evangelium von der Rechtfertigung des Gottlosen als Zentrum des christlichen Glaubens. Eine theologische Studie in ökumenischer Absicht, Tübingen ${ }^{3} 1999$, XVI.

${ }^{1009}$ Ebeling, Art. Luther, Martin II. Theologie, in: RGG ${ }^{3}$ IV (1960), 495-520, 507.

${ }^{1010}$ WA 40/I,207,17f.

1011 WA 7,502,34f.

1012 D III, 251.

${ }^{1013}$ D III, 291.

1014 D III, 291.

1015 D III, 292.

${ }^{1016}$ D III, 292.
} 
Ebelings Behandlung der Unterscheidung von Gesetz und Evangelium kennzeichnet sich deutlicher an den folgenden drei Punkten:

Erstens betrachtet Ebeling die Unterscheidung von Gesetz und Evangelium in Bezug auf die Lebenswirklichkeit. Während sich das Evangelium auf Jesus Christus konzentriert, steht das Gesetz immer in Verbindung mit dem Blick auf die gesamte Lebenswirklichkeit. Gerade in dieser Verbindung entdeckt er den theologischen Begriff des Gesetzes und erklärt: „Der theologische Begriff des Gesetzes entsteht weder durch eine bestimmte inhaltliche Füllung der Strukturen eines allgemeinen Gesetzesbegriffs noch ist er einfach der Bibel zu entnehmen“, weil die Bibel „in die veränderte Situation unserer Lebenswirklichkeit übersetzt werden muss. “1017 Stattdessen werden durch den theologischen Begriff des Gesetzes „alle Weisen der Erfahrung und Deutung der Lebenswirklichkeit daraufhin reflektiert, was sich darin vollzieht und so gewissermaßen in zweiter Potenz interpretiert. Als gemeinsamer Grundriss ergibt sich dabei die Tendenz, das Leben auf Letztgültiges zu beziehen.“1018 Ebeling sieht den primären Sinn des Gesetzes in der Lebenswirklichkeit, der alle Menschen unterworfen werden, und erörtert, was das Gesetz bei Paulus und Luther letztlich bedeutet.

Für Paulus bezieht sich nomos äußerlich unmittelbar auf die alttestamentliche Tora und hat somit keinen allgemeinen Charakter. Jedoch gibt es bei Paulus laut Ebeling eine Ausweitung des Gesetzesbegriffes, die durch das Gesetz Juden und Heiden vor Gott gleichstellt und das Gesetz über die jüdisch-alttestamentliche Grenze hinaus zur allgemeinen menschlichen Erfahrung macht (bes. Röm 2,14-16). Er beachtet vornehmlich die paulinische Wendung „Sein unter dem Gesetz“. Mit dieser stellt Paulus das Sein des allgemeinen Menschen dar, der noch keinen Glauben an den Herrn Jesus Christus hat: „Ehe denn aber der Glaube kam, wurden wir unter dem Gesetz verwahrt und verschlossen auf den Glauben, der da sollte offenbart werden.“ (Gal 3,23) Wenn man das Menschensein so als das Sein unter dem Gesetz charakterisiert, soll man beim Gesetz nicht in erster Linie an einem Kodex von bestimmten sittlichen Ideen, Regeln oder Prinzipien denken, sondern an ,etwas, was in und mit dem Leben selbst immer schon in Aktion ist “. ${ }^{1019}$ Der Hauptaspekt des Gesetzes verbindet sich bei Paulus dann nicht mit der „Frage nach dem, was das Gesetz enthält“, sondern mit der „Frage nach dem, was es wirkt.“1020 Auch wenn das Sein unter dem Gesetz je nachdem ,als ein Gefangen- und Versklavtsein unter bestimmten Mächten“ illustriert oder in Bezug auf ,die Mächte der inneren Unsicherheit und des Modischen“ verstanden werden könnte, zielt die Frage nach der Lebenswirklichkeit als Gesetzeserfahrung ,nicht auf die Geltung bestimmter Gesetzesinhalte, sondern darauf, wie das Sein unter dem Gesetz überhaupt zur Erfahrung kommt und den einzelnen Menschen trifft““ ${ }^{1021}$ Ebeling

\footnotetext{
1017 D III, 265.

${ }^{1018}$ D III, 279.

${ }^{1019}$ D III, 268.

${ }^{1020}$ D III, 270.

${ }^{1021}$ D III, $268 f$.
} 
schließt, bei Paulus komme dem Gesetz trotz seiner kulturell und weltanschaulich vielfaltigen Erscheinungsweisen gerade durch solche enge Verflochtenheit mit der Lebenswirklichkeit dann letztlich „strenge Singularität“" zu. ${ }^{1022}$

Indem der paulinische Gesetzbegriff existential interpretiert wird, wird er so verallgemeinert und universalisiert. Die existentiale Interpretation des paulinischen Gesetzbegriffs kann sich nach Ebeling auf Luther berufen. Er behauptet, dass Gesetz für Luther „eine existentiale Kategorie“ sei, welche „die Wirklichkeit des gefallenen Menschen beschreibt" ${ }^{1023}$ Insbesondere in Anlehnung an Luthers Worte „usus theologicus legis“ und „usus politicus legis“1024 erklärt Ebeling, dass das Gesetz als theologischer Begriff keineswegs im ethischen, kulturellen und politischen Sinne verstanden werden darf und „erst aus der theologischen Lehre vom Gesetz“ das richtige Verständnis seiner politischen Funktion erwachen kann. ${ }^{1025}$ Das heißt, beim Umgang mit dem Gesetz geht es nur um ein Nachdenken darüber, „,was Gott mit dem Gesetz vorhat“ und ,wie er durch das Gesetz mit dem Menschen umgeht“. ${ }^{1026}$ Ebeling erinnert dabei an die lutherische Darstellung der theologischen Funktion des Gesetzes. Vom Gesetz wird gefordert, was der Mensch tun soll und was sein soll. Es vermag aber nicht den Menschen zu erneuern, nicht „das Herz rein, den Willen willig, den Menschen gerecht zu machen. “1027 Das Gesetz ist unfähig zur Rechtfertigung. Gerade in dieser Ohnmacht entfaltet es seine spezifische Macht und Funktion. Das Gesetz enthält in sich die Diskrepanz zwischen Sein und Soll und wirkt „das Erkenntnis der Sünde“ (Röm 3,20). Ohne diese kann keine Rede von ihrer Lösung sein: „Durch das Gesetz wird die Sünde in der Tat so gewichtig, daß einem alle Ausflüchte vergehen, so ernstgenommen, daß die Sünde nicht geleugnet, sondern bekannt wird und das Gesetz als Heilsweg ausscheidet.“ ${ }^{1028}$ Der so beschriebene usus theologicus legis beschränkt sich nicht lediglich auf den christlichen Bereich wie die Verkündigung oder ihre Einwirkung, sondern vollzieht sich ,,ansatzweise überall da, wo es unter dem Druck der Lebenswirklichkeit zur Erfahrung dessen kommt, ihr nicht zu genügen“. ${ }^{1029}$

Gesetz hat für Ebeling darum ,nicht den Charakter eines religiösen Zeremonialgebotes, das zu den übrigen Gesetzesforderungen hinzukommt“, sondern die grundlegende Funktion, den Menschen „auf seine Grundsituation“ hinzuweisen und sie hineinzurufen und „letztlich und eben“ zuallererst den Glauben zu fordern. ${ }^{1030}$ Die Unterscheidung von Gesetz und Evangelium ist bei ihm nun so zu

\footnotetext{
1022 D III, 270f.

${ }^{1023}$ Zur Lehre vom teriplex usus legis in der reformatorischen Theologie, in: WG, 50-68, 65.

${ }^{1024} \mathrm{Vgl}$. D III, 288: Der usus pliticus bezieht sich für Ebeling nicht nur auf den Bereich des Politischen, sondern auf ,den gesamten Bereich ethischen und kulturellen Handelns“.

${ }^{1025}$ D III, $286 f f$.

${ }^{1026}$ D III, 283.

${ }^{1027}$ D III, 284.

${ }^{1028}$ D III, 285.

${ }^{1029}$ D III, $285 f$.

${ }^{1030}$ D III, 280.
} 
bestimmen: Gesetz ist die den Menschen so fordernde und antreibende Macht seiner Lebenswirklichkeit selbst, während das Evangelium als die Botschaft von Christus unmittelbar auf Jesus Christus bezogen ist. In der christlichen Verkündigung muss das Evangelium zur Sprache gebracht werden, was allein in Konfrontation mit der ihm entgegenstehende Lebenswirklichkeit möglich ist. Hans-Martin Barth würdigt, Ebeling gelinge „seine eigene Interpretation der Unterscheidung von Gesetz und Evangelium, indem er das Evangelium der Lebenswirklichkeit gegenüberstellt“. ${ }^{1031}$

Hier kommt nun die zweite Kennzeichnung zum Tragen, dass Ebeling die Unterscheidung von Gesetz und Evangelium am Gewissen findet. Als den gemeinsamen Adressaten von Gesetz und Evangelium sieht er theologisch das Gewissen des Menschen. Er erklärt: „Obwohl das Gesetz in seinem theologischen usus das äußere Gegenteil zu dem wirkt, was das Evangelium eröffnet, liegen doch diese beiden Wirkungsweisen als Aktionen des heiligen Geistes am Gewissen des Menschen sozusagen in einer Hand und sind aufeinander ausgerichtet. “1032 Der heilige Geist wirkt im Menschen, genauer an dessen Gewissen und doch wirkt er unterschiedlich durch Gesetz und Evangelium. Ebeling macht darauf aufmerksam, dass der eigentümliche Gegensatz von Gesetz und Evangelium immer wieder neu im Gewissen verhandelt wird. Denn der Forderung und Anklage des Gesetzes zu folgen und doch zugleich zu wissen, dass dies noch nicht die Glaubensgerechtigkeit selbst ist, geschieht nicht selbstverständlich, sondern erst in der Hinwendung zu dem Wort des Evangeliums. Das entsteht nicht aus dem Gesetz, sondern aus dem Evangelium; nicht aus der Fähigkeit des Menschen, sondern aus der Gnade Gottes, weil es nicht Menschenwerk, sondern Gotteswerk, ja, das Werk des heiligen Geistes ist. ${ }^{1033}$ Das Wirken des heiligen Geistes am Gewissen des Menschen bedeutet für den Prediger, dass es „unverfügbar ist, wie das Wort beim Hörer ankommt.“ ${ }^{1034}$ Die Unterscheidung von Gesetz und Evangelium ist für Ebeling ein Handeln des heiligen Geistes und hat darum seinen dogmatischen Ort innerhalb der Pneumatologie.

Ebeling hält daran fest: „Darum muss grundsätzlich der Unterschied gewahrt bleiben zwischen dem, was durch das Wort des Gesetzes am Gewissen geschieht, und dem, was durch das Wort des Evangeliums geschieht. “1035 Das Gesetz ist für ihn das ins Herz des Menschen geschriebene Gesetz, insofern es das Gewissen trifft und bindet. Darin befindet sich die Verbindlichkeit bzw. Verhaftung des Gewissens im Gesetz. ${ }^{1036}$ Das Evangelium verleiht dagegen die die Freiheit. In seinem Aufsatz $>$ Theologische Erwägungen über das Gewissen< (1960) weist Ebeling darauf hin, dass die Veränderung

\footnotetext{
${ }^{1031}$ H.-M. Barth, Art. Gesetz und Evangelium I. Systematisch-theologisch, in: TRE 13 (1984), 126-142, 138.

1032 D III, 293.

1033 D III, 293.

1034 D III, 294.

1035 D III, 294.

${ }^{1036}$ Vgl. WG 288: „Was den Menschen nicht in seinem Gewissen trifft, was ihn nicht unbedingt angeht in der Weise der Behaftung und Verhaftung, das ist nicht das Gesetz, wie es in der Interpretation der Paulinischen Lehre vom Gesetz verstanden werden muss.“
} 
am Gewissen zugleich eine Ortsveränderung des Menschen impliziert: vom „,im Gesetz sein“ zum „in Christus sein“. ${ }^{1037}$ Unter dem gleichen Aspekt behauptet Ebeling in der Dogmatik, der Glaubende als das Sein in Christus soll sich nicht nach „Geboten und Verboten“ richten, weil er laut Luther sogar vermag, „neue Dekaloge zu machen“ und weil er „,von aller Heteronomie befreit“ ist. ${ }^{1038}$ Diese Freiheit gründet ,im Ja zum Willen Gottes“ und ist dann als Theonomie zu nennen. Insofern das Ja zum Willen Gottes im Sinne des Einverständnisses verstanden wird, kann man hier auch von der Autonomie reden, weil die völlige Abhängigkeit von Gott „wahre Freiheit“ ist. ${ }^{1039}$ Ebeling setzt Gesetz und Evangelium solcherweise am Gewissen als ihren gemeinsamen Adressaten an und findet die Unterscheidung ihrer Wirkung am Gewissen, indem er das, was das Gesetz am Gewissen wirkt, als Verbindlichkeit charakterisiert und das, was das Evangelium am Gewissen wirkt, als Freiheit. In solcher Beschreibung der Unterscheidung von Gesetz und Evangelium verdeutlicht Ebeling die Vorrangstellung des Evangeliums einerseits und die Ablehnung gegen die sog. moralische Gewissensinterpretation andererseits $^{1040}$.

Letztlich beschreibt Ebeling die Unterscheidung von Gesetz und Evangelium in Bezug auf den Begriff des Wort- und Sprachgeschehens. Dieser Bezug befindet sich schon in seiner $>$ Einführung in theologische Sprachlehre< (1971). Dort erklärt er, dass die Sache der Theologie mit dem Wort bzw. der Sprache zu tun hat, weil sie einerseits ,als reflektierende Rechenschaft ein komplizierter Sprachvorgang“ selbst ist und weil sie sich andererseits auf „die christliche Sprachlieferung in ihrer kanonischen und nachkanonischen Gestalt" bezieht. Aber streng genommen ergeht nicht die Sache der Theologie selbst, sondern das Evangelium faktisch als Wort, „,weil das, was Evangelium enthält, gar

\footnotetext{
${ }^{1037} \mathrm{WG}, 432$.

${ }^{1038}$ D III, 294.

1039 D III, 294.

${ }^{1040}$ Im ersten Band der Dogmatik bestimmt Ebeling das Verhältnis zwischen Dogmatik und Ethik wie folgt: Die Dogmatik kann nicht innerhalb der Ethik behandelt werden. Stattdessen lässt es „,nur umgekehrt die Ethik in die Dogmatik aufnehmen. Dafür spricht die Notwendigkeit, das Ethische vom Glauben her sowohl zu beurteilen als auch zu realisieren.“(D I, 21) Unter diesem Aspekt grenzt sich Ebeling gegen ein ethisches Gewissensverständnis ab, das ,nur unter den Aspekten eines offenbarten und geglaubten Moralgesetzes sowie der vom Glauben motivierten Früchte erschiene“ (D I, 21). In Hinsicht auf den Ort des Gewissens in der Theologie erklärt Ebeling wie folgt: „Denn inwiefern Theologie auf den Horizont des Gewissens bezogen ist, lässt sich nur von dem bestimmten Wortgeschehen des Evangeliums her sagen. Darum ist auch schon die dabei leitende Interpretation des Gewissens und seines Verhältnisses zur Vernunft vom Evangelium her bestimmt. Sie unterscheidet sich fundamental von der moralischen Gewissensinterpretation, die ihren Ort im Horizont der Vernunft selbst hat. Nur vom Evangelium her eröffnet sich auch eine Unterscheidung der Horizonte, die beides berücksichtigt: inwiefern Vernunft und Gewissen untrennbar zusammengehören und inwiefern sie aufs schärfste zu unterscheiden sind“". Ders., Art. Theologie und Philosophie III. Dogmatisch, in: RGG ${ }^{3}$ VI (1962), 819-830, 828. Er gibt dem Gewissen sogar die Rolle einer Schlüsselfunktion für die „wahre Definition des Menschen“, behauptend: „Der Mensch ist ein Gewissensphänomen [...] Er ist letztlich Gewissen und geht letztlich das Gewissen an.“ WG, 434. Im dritten Band der Dogmatik entwickelt Ebeling das Thema des Gewissens selbst nicht weiter. Siehe zum Gewissensverständnis Ebelings die beiden Aufsätze: „Theologische Erwägungen über das Gewissen“ (1960) in: WG, 429-446 und „Das Gewissen in Luthers Verständnis“ (1984) in: LuSt III, 108-125.
} 
nicht anders begegnen kann denn als sprachliche Mitteilung “. ${ }^{1041}$ Ebeling unterstreicht dabei, dass das Evangelium sich nicht auf das isolierte Wort, sondern immer auf die zur Sprache gebrachte Wirklichkeit bezieht. An diesem Punkt erläutert er das Verhältnis von Gesetz und Evangelium wie folgt: „Bei diesem Sprachgeschehen handelt es sich um die in verworrener und vieldeutiger Sprache vorgebrachten Interpretationen des Gesetzes. Auf sie hin legt das Evangelium sich als solches aus und gelangt so zu seiner Artikulation“" ${ }^{1042}$ Die Unterscheidung von Gesetz und Evangelium hat laut Ebeling eine entscheidende Bedeutung für die theologische Sprachlehre. Denn sie leitet dazu an, „die Sprache des Glaubens in der ihr angemessenen Weise auf die Welterfahrung bezogen sein zu lassen. Wer sich solcher Anleitung zu theologischem Sachverstand und Urteilsvermögen wirklich unterzieht, dem wird dadurch die Zumutung gewissermaßen in sein Gewissen als Theologe eingebrannt, an dieser Durchdringung von Sprache des Glaubens und Welterfahrung ständig zu arbeiten und so sich am Fortgang der Sprachbildung des Glaubens gewissenhaft zu beteiligen“. ${ }^{1043}$ Die Unterscheidung von Gesetz und Evangelium wirkt sich nach Ansicht Ebelings geradezu in Bezug auf das Wort bzw. die Sprache aus.

Diesen Standpunkt führt Ebeling in der Dogmatik weiter aus, insbesondere in Bezug auf die Verkündigung. Er sagt, dass die Unterscheidung von Gesetz und Evangelium ,nicht auf einen einmaligen oder von Fall zu Fall zu wiederholenden Vorgang abzielt, sondern für das Christsein ständig präsent sein muss. “1044 Dieses ständige Präsens findet sich laut ihm vornehmlich in der Verkündigung. Die Unterscheidung von Gesetz und Evangelium verweist nicht auf einen Dualismus des Wortes Gottes, nicht auf dessen zweiteilige Formen, Inhalt oder Interpretationsweisen, sondern auf seine innere Struktur, in der das Wort Gottes als Wortgeschehen am Menschen besteht. Das heißt, im Verhältnis mit dem Gesetz gewinnt das Evangelium seinen bestimmten Ort, wo es sich in und mit der Lebenswirklichkeit des Menschen vollzieht; und umgekehrt gehört das Gesetz im Verhältnis mit dem Evangelium zur Verkündigung des Wortes Gottes. Erst in der Unterscheidung von Gesetz und Evangelium geht es um die rechte christliche Verkündigung. Er sagt, diese sei, „wenn sie von dem theologischen Urteilsvermögen der Unterscheidung von Gesetz und Evangelium geleitet ist, das andauernde Geschehen dieser Unterscheidung“. ${ }^{1045}$ Die Unterscheidung von Gesetz und Evangelium ist für Ebeling dann keine ruhig gedachte oder theoretisch behandelte Sache, sondern ein Vollzug eines Kampfgeschehens, das immer wieder in der christlichen Verkündigung entsteht.

Das Verhältnis von Gesetz und Evangelium zeigt zugleich ihren untrennbaren Bezug und Gegensatz, damit ihr „spannungsvolle(s) Beieinander“ ${ }^{1046}$ Ebeling behauptet allerdings, dass beide nicht „,so dicht

\footnotetext{
1041 Sprachlehre, 247.

1042 Sprachlehre, 248.

1043 Sprachlehre, 248f.

1044 D III, 294.

1045 D III, 294.

${ }^{1046}$ D III, 295.
} 
beieinander“ lägen, da das Gesetz sonst „seine Ausrichtung auf das Evangelium“ und dieses „seine Notwendigkeit und Verständlichkeit“ verlöre. ${ }^{1047}$ In der Verkündigung muss ihre Unterscheidung bewahrt werden. Er schließt: Die Unterscheidung von Gesetz und Evangelium fordert vom Theologen nicht, ,aus dem kritischen Beieinander von Gesetz und Evangelium herauszukommen“, sondern vielmehr, „in diesem Sachverhalt“ dafür zu sorgen, „,dass das Evangelium nicht eine unverbindliche Zutat wird, sondern zentral auf die Lebenswirklichkeit selbst bezogen ist." 1048 Angesichts der Unterscheidung von Gesetz und Evangelium unterstreicht Ebeling, dass sie nur dann erfasst ist, wenn sie nicht als solches gesehen wird, ,was sich ein für allemal begrifflich bestimmen und damit erledigen lasst“ und „wenn sie vielmehr ein Geschehen betrifft, das sich unaufhörlich zu vollziehen hat." ${ }^{1049}$ Die Theologie soll demnach der Verkündigung und damit der Wirklichkeit dienen, um sich der Anstrengung des Begriffs nicht zu entziehen. Die fundamentale Unterscheidung von Gesetz und Evangelium positioniert Ebeling demgemäß in der Verkündigung, bezieht sich damit auf die Lebenswirklichkeit und beschreibt letztlich, was durch das Wort Gottes geschieht, nämlich das Wortgeschehen.

Ist der Bezug des Lebensbegriffs von der Verkündigung, von dem Wortgeschehen befriedigend zu erklären? Gerade in diesem Punkt kritisiert U.H.J. Körtner, dass der Gesetzesbegriff Ebelings noch problematisch sei, weil er „die Vieldeutigkeit des Lebensbegriffs“ nicht richtig, sondern bloß in den begrifflich ungeklärten Wortkombinationen von Leben und anderen Termini zeige und damit „der Wirklichkeitsbegriff selbst" nicht genügend geklärt würde. So blieben laut ihm der Unterschied „Zwischen einer vorgängigen Wirklichkeitsinterpretation und dem durch den Glauben erschlossenen Wirklichkeitsverständnis“, genauso wie das Verhältnis „der unter der Predigt von Gesetz und Evangelium erwachsende(n) Wirklichkeit“ zur „Lebenswirklichkeit des Seins unter dem Gesetz“ ungeklärt. ${ }^{1050}$ Solche Probleme bleiben in der Tat ungelöst bei Ebeling.

\subsubsection{Das Verhältnis von Sakramenten und Wort}

Neben vom Wort Gottes als Gesetz und Evangelium behandelt Ebeling die Sakramente. Im Hinblick auf seine Behandlung des Themas der Sakramente in der Dogmatik kann man zwei äußerlich klare Kennzeichnungen finden:

Erstens, Ebeling behandelt das Thema der Sakramente auf einer gesamten und allgemeinen Ebene und scheint kein richtiges oder nur ein kleines Interesse für den einzelnen Sinn von Taufe und Abendmahl zu haben. Solche Behandlung ist nicht üblich, weil die allgemeine Sakramentslehre

\footnotetext{
1047 D III, 295.

1048 D III, 295.

1049 D III, 293.

${ }^{1050}$ U.H.J. Körtner, Theologie des Wortes Gottes. Positionen, Probleme, Perspektiven. Göttingen 2001, 223.
} 
lediglich einen sekundären Platz in traditionellen evangelischen Dogmatiken hat, während die Beschreibung der einzelnen Sakramente den zentralen Platz einnimmt. In der allgemeinen umfassenden Überlegung besteht wahrscheinlich die Gefahr, den Sinn der einzelnen Sakramente zu versäumen und den Begriff jeder eigenen Wirklichkeit sachlich unterzuordnen. Um solche Gefahr weiß auch Ebeling. Trotzdem hält er eine umfassende Bezeichnung der Sakramenten für theologisch notwendig, gerade aufgrund der Sonderstellung der allgemeinen Sakramentslehre im Urchristentum und der davon untrennbaren Bedeutsamkeit von Taufe und Abendmahl für den christlichen Glauben: „So berechtigt die Warnung vor den Gefahren einer allgemeinen Sakramentslehre ist, nehmen doch Taufe und Abendmahl in dem kirchlichen Leben schon von seinen urchristlichen Wurzeln her eine so offenkundige Sonderstellung ein, dass dieses Phänomen theologisch bedacht werden muss. [...] Das Verständnis von Taufe und Abendmahl könnte nur verflachen, wenn man die Überlieferung der allgemeinen Sakramentslehre einfach abschüttelte“. ${ }^{1051}$ Die Einzelsakramente von Taufe und Abendmahl darzustellen und jeden Sinn zu bestimmen, ist eine wichtige Aufgabe der Theologie. Aber um sie tiefer zu verstehen und genauer darzustellen, sollen ihre Sachverhalte angesprochen werden, die geradezu durch die Analyse des allgemeinen Sakramentsbegriffs entdeckt werden können. Die beiden Sakramenten zugehörende und konstitutive Problematik zu erläutern, hält Ebeling darum für eine notwendige und sogar vorrangige Aufgabe. Mit solcher methodischen Entscheidung richtet er seinen Blick von der Selbstständigkeit von Taufe und Abendmahl lieber auf ihre Gemeinsamkeit, Bezogenheit und Vergleichbarkeit und versucht, einen genügenden Raum für ihre grundsätzliche umfassende Besinnung zu schaffen, die sich vor allem auf die Frage nach „Begriff und Phänomen des Sakramentes“1052 bezieht. Der Beschreibung der einzelnen Sakramente widmet er dagegen nur ein paar Seiten, wobei es sich lediglich um die zeitliche Unterscheidung wie „die Einmaligkeit der Taufe“ und „die wiederholte Begehung des Abendmals“ sowie um das davon her kommende Verhältnis handelt, dass das Abendmahl die immer wiederholte Konfession zu dem ist, „was in der Taufe verheißen ist“ und diese wieder das Abendmahl „,vor der Verwechslung mit der Mysterien Feier“" schützt. ${ }^{1053}$

Zweitens ist die Stelle der Sakramentslehre zur Sprache zu bringen. Ebeling behandelt das Thema der Sakramente nicht im Abschnitt „Die Gemeinschaft des Glaubens“ (§36), terminologisch in der Kategorie von Ekklesiologie, sondern im Abschnitt „das Wort des Glaubens“( $(35)$. Dadurch wird sein grundlegender Standpunkt deutlich angezeigt, dass er im Hinblick auf den Sinn der Sakramente von der

\footnotetext{
${ }^{1051}$ D III, 307.

1052 D III, 301-325.

${ }^{1053}$ D III, 326-329. Das relativ geringe Interesse für die Beschreibung der einzelnen Sakramente wird im Vergleich mit anderen zeitgenössischen Dogmatikern verdeutlicht. z.B. Pannenberg behandelt in seiner systematischen Theologie III das Thema der Sakramente getrennt von Taufe und Abendmahl und jedes als ein einzelnes Thema und widmet jedem seinen eigenen Teil, nämlich die Taufe „als Konstitution christlicher Identität“ in s. 268-313; das Herrenmahl „als der christliche Gottesdienst“ in s. 314-369; W. Härle behandelt in seiner Dogmatik auch beide getrennt jedes als einzelnes Thema, die Taufe in s. 547-557 und das Abendmahl in s. 558-566.
} 
Kirche Abstand nehmen will. Damit ist gemeint, dass er das Verhältnis der Sakramente zur Kirche weder beachtet noch vernachlässigt. Im Teil der Sakramentslehre berührt Ebeling auch das Verhältnis zwischen „Sakramenten und Gemeinde" und redet von ihrer untrennbaren Bezogenheit und notwendigen Relation. ${ }^{1054}$ Sein Sakramentsverständnis entwickelt sich aber wesentlich aus dem evangelischen grundlegenden Standpunkt, der sich aus allen Entwürfen herausnimmt, die Sakramente als das zur Kirche bzw. ihrer eigenen Autorität oder Macht gehörende Werk zu sehen und damit das Heilsgeschehen irgendwie auf die Ebene der menschlich-kirchlichen Verfügung zu beziehen. Aus der Furcht heraus, dass die Sakramente so für das eigenmächtige Werk der Kirche oder für das Heilsgeschehen im menschlich-kirchlichen Bereich gehalten werden könnten, versucht die evangelische Theologie, ihren Charakter immer einzig auf der Ebene der uns zukommenden Gabe Gottes zu verorten. Auf solcher evangelischen Tradition stehend kritisiert Ebeling stark, dass in der katholischen Theologie mit der übermäßigen Betonung des Zusammenhangs zwischen Kirche und Sakramenten, die Kirche selbst als Sakrament und damit sogar als Heilsmittel verstanden wird. Das führt dazu, dass das katholische Sakramentsverständnis die fundamentale Unterscheidung zwischen Kirche und Christus als das streng genommen „einzige Sakrament“ ${ }^{\star 1055}$ verweigert. Ebeling erklärt: „In diesem Fall haben die Sakramente geradezu die Funktion, die Horizontverschmelzung von Christus und Kirche herbeizuführen. “" ${ }^{1056}$ Seiner Ansicht nach lässt das katholische Sakramentsverständnis die Kirche sogar „Zum Christus prolongatus werden“. ${ }^{1057}$ Unter diesem Gesichtspunkt führt er eine kritische Auseinandersetzung mit einigen katholischen Theologen ${ }^{1058}$ und bewirkt im Bereich katholischer Theologie infolgedessen beträchtliche Reaktionen ${ }^{1059}$. Solche Gedanken äußert er schon in seinen

${ }^{1054}$ In Bezug auf das Verhältnis von Kirche und Sakramenten bringt Ebeling drei Punkte zur Sprache: Der erste Punkt betont die Notwendigkeit der Sakramente für die Konstitution der Kirche. „Kirche konstituiert sich als geschichtliche Institution erst durch die Sakramente.“; Der zweite Punkt spricht die ekklesiologische Verankerung des konkreten sakramentalen Vollzugs an: „Die Gemeinde ist darum auch der Ort, wo die Sakramente vollzogen werden." Für die Feier der Sakramente ist dementsprechend eine bestimmte Ordnung nötig. Sakrament und Kirche sind also wechselseitig aufeinander bezogen und darum nicht voneinander getrennt zu verstehen. Der dritte Punkt schließlich spricht die kontroverstheologische Bedeutung der Sakramente an: „Die Sakramente markieren in Bezug auf das Problem der Kircheneinheit extreme Aspekte.“ (D III, 324).

1055 D III, 314.

${ }^{1056}$ D III, 315.

${ }^{1057}$ D III, 315.

${ }^{1058}$ Ebeling setzt sich in seinem Aufsatz, ,Worthafte und sakramentale Existenz“ z.B. mit Willem Hendrik van de Pol (197-206), K. Rahner (209-210) und O. Semmelroth (210-214) auseinander, in: WGT, 197-216.

${ }^{1059}$ Ebelings Ansatz wird z.B. von W. Kasper aufgenommen, der Ebelings Denken mit Ansätzen katholischer Theologie zu verbinden versucht. Ders., Glaube und Geschichte, Mainz 1970, 285-310. Eine negative Reaktion auf Ebelings Ansichten ist bei O. H. Pesch besonders erkennbar, der Ebelings Kritik gegen die katholische Sakramentslehre wieder verwirft: „Ich kann nicht beweisen, dass es keinen Katholiken auf der Welt gibt, der die Kirche im Sinne Ebelings für den ,Christus prolongatus' hält. Aber es muss und darf traurig stimmen, wenn man in dem, was Ebeling hier als katholisches Sakramentsverständnis und dessen ekklesiologische Implikationen vorstellt, nichts von dem wiedererkennt, was man von gegenwärtiger katholischer Sakramententheologie glaubt begriffen zu haben, und was schwerer wiegt, nichts von der eigenen, doch hoffentlich noch katholischen 
früheren Aufsätzen. ${ }^{1060}$ In der Dogmatik kommt das durch die Stellung der Sakramentslehre zum Ausdruck, indem Ebeling sie nicht im Bereich der Ekklesiologie, sondern innerhalb der Lehre des Wortes Gottes verortet. So steht sie sogar gerade nach oder neben dem Teil von „Gesetz und Evangelium“, der als eine typische Formel besonders beim Ausführen lutherischer Lehre von Gottes Wort verwendet wird. Das heißt, Ebelings Sakramentslehre in der Dogmatik soll unbedingt in der Verbindung mit dem Verständnis des Wortes betrachtet und verstanden werden.

Für das tiefere Verständnis von Ebelings Sakramentslehre ist es aber unerlässlich, das Verhältnis von Wort und Sakrament näher zu betrachten, weil es m.E. gerade in der Mitte seiner Sakramentsauffassung steht und ein noch umstrittenes Problem ist. Das wird in zwei Richtungen untersucht. Es geht also darum, dass Ebeling die Sakramente dem Wort unterordnet (4.2.2.1.) und dass er die Sakramente auf der ontologischen Ebene entfaltet und im Geschehenscharakter des Wortes versteht (4.2.2.2.).

\subsubsection{Die Unterordnung der Sakramente unter dem Wort}

Die Problematik rund um das Verhältnis zwischen Sakrament und Wort bezieht sich eng auf die Heilswirkung oder Vermittlung der Gnade Gottes. Luther entwickelt die seit Augustinus traditionell überlieferte Bedeutung des Sakramentes als visibile verbum weiter und versucht, keinen Gegensatz zwischen Wort und Sakrament aufzustellen, sondern die Gemeinsamkeit zwischen dem Wort der Predigt und dem Wort im Sakrament hervorzuheben. Wenn er sagt, die Predigt sei das wichtigste Gnadenmittel, meint er nicht, dass das Sakrament deswegen gering geachtet werden darf. Denn bei ihm ist das Sakrament ebenso wie die Predigt eine Gestalt des Verheißungswortes. Während die Verkündigung eine durch das hörbare Wort vermittelte Verheißung ist, ist das Sakrament die in sichtbare Zeichen gekleidete

Sakramentsfrömmigkeit wiederfindet.“ Ders., Das katholische Sakramentsverständnis im Urteil gegenwärtiger evangelischer Theologie, in: E. Jüngel u.a. (Hg.), Verifikation, Festschrift für G. Ebeling zum 70. Geburtstag, Tübingen 1982, 317-340, 337f. Anm. 69. Pesch verweist dabei auf die Untersuchung von M. Raske, der verwirft, dass Ebeling innerhalb des traditionell-konfessionellen Rahmens verbleibe und damit seine Kritik der modernen neuen Interpretation der katholischen Sakramentsauffassung nicht gerecht werde. Ders., Sakrament, Glaube, Liebe. Gerhard Ebelings Sakramentsverständnis. Eine Herausforderung an die katholische Theologie, Essen 1973, 216. Hinsichtlich solcher negativen Reaktionen von katholischer Seite kommentiert R. Hempelmann: „Mit Enttäuschung wird in katholischer Seite registriert, wie wenig die neuere Entwicklung der Sakramententheologie in Ebelings Dogmatik berücksichtigt wird. Hier liegt fraglos ein Defizit vor. Gleichwohl hilft die Schärfe seiner Analysen, sich keinem falschen ökumenischen Optimismus hinzugeben, und bewahrt vor der Illusion der Annahme, auf der Ebene theologischer Reflexion seien alle entscheidenden Verstehensbarrieren beseitigt. Ebeling versteht die kathologische Theologie auf dem Hintergrund der ,offiziellen“ katholischen Lehre.“ Ders., Sakrament als Ort der Vermittlung des Heils. Sakramententheologie im evangelisch-katholischen Dialog Göttingen 1992, 126.

1060 Die frühen Äußerungen Ebelings zur Sakramentsfrage befinden sich z.B. im Aufsatz „Worthafte und sakramentale Existenz. Ein Beitrag zum Unterschied zwischen den Konfessionen“, in: WGT, 197-216; „Erwägungen zum evangelischen Sakramentsverständnis“, in: WGT, 217-226. 
Verheißung. Es ist das Evangelium, ja, eine Gestalt der Ausrichtung des Evangeliums. Das Sakrament überbietet das Wort aber nicht und gibt nichts anderes und nicht mehr als dieses zu geben hat. Denn wer das Stiftungswort gläubig gehört hat, der hat eigentlich das Sakrament empfangen, da sich der Glaube wesentlich auf das Wort richtet. Der Sinn des Sakraments findet sich darum auch in seinem Bezug auf das Wort, also darin, dass es dem Glauben an das Wort eine Stütze gibt und seine Gewissheit stärkt. Wie eng Wort und Sakrament bei Luther zusammengehören und dass dem Wort ein Vorrang zukommt, sieht man daran, dass die Taufe als „das Wasser in Gottes Gebot gefasst und mit Gottes Wort verbunden“1061 und das Abendmahl als „Brot und Wein in Gottes Wort gefasst und daran gebunden“1062 wird. Das ist das Grundmotiv der Sakramentslehre Luthers, das sich bei Melanchton, Zwingli und Clavin fortsetzt. ${ }^{1063}$

Sowohl Luthers Sakramentsverständnis als auch seinen Grundaspekt über das Verhältnis von Wort und Sakrament nimmt Ebeling auf. Dieser ist grundsätzlich der Meinung, dass Wort und Sakrament keine Alternativen füreinander sind und dass die Sakramente getrennt von dem Wort keinen selbstständigen Platz haben und dass das Wort die Sakramente nicht überbieten kann. Das Sakrament kann laut ihm keine Ausnahme der reformatorischen exklusiven These „solo verbo - sola fide“ sein und muss auch in deren Sinne interpretiert werden. ${ }^{1064}$ Das ist schon, wie oben aufgezeigt, am Ort des Themas der Sakramente in seiner Dogmatik optisch erkennbar. Der dogmatische Ort als ein Unterthema im Teil „das Wort des Glaubens“ deutet an, dass das Sakrament unter dem Aspekt des Wortes gesehen wird und dass die Sakramente unmittelbar im Anschluss an das vorliegende Thema „Gottes Wort als Gesetz und Evangelium“ verstanden werden. Das Verständnis des Begriffes von Gesetz und Evangelium hilft, die Sakramente recht zu verstehen, sie z.B. gegen Missverständnisse und den Missbrauch der Sakramente lediglich als Ritusbegriff abzuschirmen. Die Sakramente in soziologischer oder sozialpsychologischer Kategorie zu betrachten und zu interpretieren, ist nach Ansicht Ebelings unzulänglich. Er behauptet, dass auch wenn formale Gemeinsamkeiten oder inhaltliche Ähnlichkeiten

${ }^{1061}$ M. Luther, Der Große und der Kleine Katechismus, K. Aland/H. Kunst (Hg.), Göttingen ${ }^{2} 1985$, 67. Dazu fügt Luther an: „Wasser tuts freilich nicht, sondern das Wort Gottes, das mit und bei dem Wasser ist, und der Glaube, der solchem Worte Gottes im Wasser trauet. Denn ohne Gottes Wort ist das Wasser schlicht Wasser und keine Taufe; aber mit dem Worte Gottes ists eine Taufe, das ist ein gnadenreiches Wasser des Lebens und ein Bad der neuen Geburt im Heiligen Geist.“ (68).

${ }^{1062}$ M. Luther, Der Große und der Kleine Katechismus, K. Aland/H. Kunst (Hg.), Göttingen ${ }^{2} 1985,78$.

${ }^{1063}$ Vgl. BSLK 292,41-293,6: „Wie aber das Wort in die Ohren gehet, also ist das äußerliche Zeichen für die Augen gestellt, als inwendig das Herz zu reizen und zu bewegen zum Glauben. Denn das Wort und das äußere Zeichen wirken einerlei im Herzen, wie Augustinus ein feines Wort geredet hat: ,Das Sakrament', sagt er ,ist ein sichtliches Wort““. Unter dem gemeinsamen Grundaspekt befinden sich bei den Reformatoren unterschiedliche Betonungen: Zwingli und Calvin zeigen z.B. die Tendenz, den Primat des gepredigten Wortes zu behaupten und die Sakramente als eine ergänzende Funktion einzuschränken, während Luther versucht, das äußere und objektive Wesen des Wortes sowohl in der Predigt als auch in den Sakramenten zu verteidigen. J. Finkenzeller, Die Lehre von den Sakramenten im Allgemeinen. Von der Reformation bis zur Gegenwart, Freiburg 1981, 25ff. ${ }^{1064}$ D III, 297. 
zwischen der Taufe und dem Beschneidungsritus oder den Initiationsriten der Mysterienreligionen sowie zwischen dem Abendmahl und dem jüdischen Passahmahl oder heidnischen Opfermahlen bestehen mögen, die Sakramenten keineswegs als solche verstanden werden dürften. Dies trete bloß an die Stelle des alttestamentlichen Ritus oder irgendwelcher mysterienreligiösen Initiationsriten und stelle ein neues Zeremonialgesetz dar. Auch wenn das Sakrament den „Charakter zeremonialengesetzer Notwendigkeit“ annimmt und durch eine relativ festgelegte Gestalt wie bestimmte Formeln oder Handlungsabläufe von einem „Ritus“ geprägt sein könnte, während die Predigt nur an wenige äußere Formen gebunden viel Spielraum hat, bestünde sein Wesen doch offenbar darin, das Evangelium zu bezeugen. ${ }^{1065}$ Die Sakramente können darum erst dann richtig verstanden werden, wenn man sie ,als Evangelium in die Relation von Wort und Glaube gefasst sieht". ${ }^{1066}$ Wenn man das Phänomen der Sakramente aber nur in der Kategorie des Ritusbegriffs erfasst oder bloß für eine neue Zeremonie der christlichen Religion hält, verkennt man die Unterscheidung zwischen Gesetz und Evangelium und verbleibt nur auf der Ebene des Gesetzes, ohne das Evangelium als „Erfüllung der Verheißung “ ${ }^{“ 1067}$ zu erfahren. ${ }^{1068}$

Soll das Sakrament unter oder innerhalb der Kategorie des Wortes gesehen werden, kommt nun die Frage auf, worin das Sakrament dann seinen eigenen Platz oder seinen speziellen Dienst für den christlichen Glauben hat. Das Sakrament hat seinen Sinn darin, dass es als das äußerliche Zeichen dem Glauben an das Wort eine Stütze gibt und seine Gewissheit stärkt. Es dient der Präzisierung des Wortes, indem es einen bestimmten Aspekt zum Ausdruck bringt, nämlich die Leiblichkeit des Wortes. Diese kann laut Ebeling in den Sakramenten besonders stark betont werden. Er sagt, „Taufe und Abendmahl haben dies gemeinsam, dass sie als elementare leibliche Vollzüge in geistlicher Hinsicht gewichtig und erheblich sind. Ihr Gehalt hat sich mit ihrer Gestalt eng vermählt. Ihre Leiblichkeit hat nicht den Charakter der Dinglichkeit. Sie eignet vielmehr dem Handlungsbezug um seiner Ausrichtung auf den menschlichen Leib willen, nicht in dessen abstrakter Unterscheidung von der Seele, sondern im Hinblick auf die leibhaftige Ganzheit der Person. “1069 Beim Verstehen der Leiblichkeit legt Ebeling die Akzentuierung weder auf Materialien wie Wasser, Brot und Wein, noch auf ihre symbolischen Bedeutungen. Stattdessen macht er ihren Bezug auf den menschlichen Leib stark, besser gesagt, den ganzen Handlungsprozess der Sakramente, dass diese durch ihre Leiblichkeit zum Menschen die Verheißung Gottes tragen. Das, was vom Sakrament getragen wird, ist aber keine andere Gabe als das, was durch die Verkündigung vermittelt wird, obwohl es sein Spezifisches hat. ${ }^{1070}$ Sakrament und

\footnotetext{
${ }^{1065}$ D III, 300.

${ }^{1066}$ D III, 300.

1067 D III, 292.

${ }^{1068}$ Vgl. R. Hempelmann, Sakrament als Ort der Vermittlung des Heils. Sakramententheologie im evangelischkatholischen Dialog, Göttingen 1992, $118 \mathrm{f}$.

${ }^{1069}$ D III, 318.

${ }^{1070} \mathrm{Vgl}$. D III, $322 \mathrm{f}$.
} 
Verkündigung tragen also den gleichen Inhalt wie das Wort Gottes und jenes schenkt es in anderer Gestalt als dieses. In diesem Sinne bezeichnet Ebeling die Sakramente als „Gottes Wort in sakramentaler Gestalt“ im Unterscheid zu der Verkündigung als der verbalen Gestalt. ${ }^{1071}$

Ein ähnlicher Gesichtspunk über das Verhältnis von Wort und Sakrament begegnet beispielweise bei Paul Althaus, der die untrennbare Verbindung von Wort und Sakrament betont. Er behauptet, die Sakramente dürften nicht für eine andere Gnade als das verkündigte Evangelium gehalten werden. Denn „Gottes persönliches Handeln mit uns, das ,Wort` tritt in mehreren Gestalten an uns heran. Die erste und grundlegende ist die mündliche Verkündigung. Neben ihr steht das Sakrament. Nicht Wort und Sakrament stehen also nebeneinander, sondern mündliche Verkündigung und Sakrament, beide als Gestalten des Wortes.“1072 Schließlich sagt er; „Das Sakrament kommt nicht als ein anderes neben dem Worte zu stehen, sondern als eine bestimmte Gestalt des Wortes. Das Besondere des Sakramentes gegenüber der Verkündigung des Evangeliums liegt nicht im Gehalt, sondern in der Gestalt. "1073 Werner Elert stellt sich aber dagegen, das Sakrament unter dem Aspekt des Wortes zu sehen, aus der Befürchtung, dass dadurch die Eigenständigkeit des Sakraments beschädigt werden könnte. Weil er das Sakrament selbst als eine von Gott auf uns zukommende Gabe des Heils sieht, richtet er seine Aufmerksamkeit mehr darauf, die Eigenständigkeit des sakramentalen Handelns gegenüber falschen Deduktionen oder Relativierungen hervorzuheben. Er stellt sogar die extravagant klingende Behauptung auf: ,Weder aus der Lehre von der Schöpfung und vom Weltregiment Gottes noch aus der Christologie oder Pneumatologie, noch aus der Lehre von der Versöhnung, Rechtfertigung, Erlösung oder vom Existenzwandel lassen sie sich deduzieren. [...] Der einzig systematische Gesichtspunkt, der bei der Lehre von den Sakramenten vorauszusetzen ist, kann nur sein, dass sie mit dem Kerygma der Kirche und also auch mit dem ihrem sonstigen Dogma nicht in Widerspruch stehen kann. " 1074 Sein Gesichtspunkt scheint das Sakrament aber in einer isolierten und eingeschränkten Kategorie zu verhandeln und damit die Möglichkeit für die Analyse des Sachverhaltes und die dadurch zustande kommende tiefere Anschauung zu versperren.

Darüber hinaus ist noch die Meinung Pannenbergs zur Sprache zu bringen. Dieser wendet sich ebenfalls dagegen, die Sakramentslehre der Auffassung vom wirksamen Gottes Wort unterzuordnen. Seine Motivation ist die Befürchtung, dass ,ihre eigenständige Begründung von Jesus her aber an Gewicht" verlieren werden könnte. ${ }^{1075}$ Jedoch muss man auch daran denken, dass Pannenberg selbst die Sakramente nicht auf den ausdrücklich geäußerten Befehl Jesu begründet. Stattdessen sagt er, „dass Herrenmahl und Taufe in der Weise auf Jesus zurückgehen, dass ihre urchristlichen Anfänge sich als

\footnotetext{
${ }^{1071}$ D III, 295.

1072 P. Althaus, Die christliche Wahrheit. Lehrbuch der Dogmatik, Gütersloh ${ }^{6} 1962,538$.

1073 P. Althaus, Die christliche Wahrheit. Lehrbuch der Dogmatik, Gütersloh ${ }^{6} 1962,542$.

${ }^{1074}$ W. Elert, Der christliche Glaube, Hamburg ${ }^{3} 1956,356$.

1075 W. Pannenberg, Systematische Theologie III, Göttingen 1993, 376.
} 
Konsequenz des in Jesu Verhalten und Geschichte Vorgegebenen im Lichte des Ostergeschehens verstehen lassen. “1076 Seine Behauptung scheint sich aber eigentlich nicht weit von Ebelings Meinung zu entfernen, worauf Neumann mit Recht hinweist, weil Ebeling auch die Autorität von Taufe und Abendmahl am historischen Jesus haften lässt. ${ }^{1077}$ Ebeling fundiert beide Handlungen auf in bestimmten Lebenssituationen Jesu entstandene, historische Ereignisse, also auf seine Taufe durch Johannes und das Abschiedsmahl mit seinen Jüngern. Er sieht dabei die Auferstehung Christi aus dem Tode als den wesentlichen Grund dafür, Taufe und Abendmahl ,als ein weitergehendes Geschehen“ zu bezeugen und zu autorisieren. ${ }^{1078}$ Neumann schließt darum mit der Behauptung, dass bei den Positionen von Ebeling und Pannenberg gemeinsam die Frage entsteht, ,aus welchen Gründen sich die Legitimität der Fortführung bestimmter im Leben Jesu verankerten Zeichenhandlungen durch die Kirche theologisch rechtfertigen lässt“ ${ }^{1079}$ Solche Berufung auf den historischen Jesus erscheint in Ebelings Dogmatik deutlicher als im früheren Aufsatz $>$ Erwägungen zum evangelischen Sakramentsverständnis $<$ (1964), der aus der Vorlesung über Ekklesiologie stammt und als eine der wichtigen Schriften über sein Sakramentsverständnis gilt.

\subsubsection{Das Verständnis des Sakraments im Geschehenscharakter des Wortes}

In seinem Aufsatz $>$ Erwägungen zum evangelischen Sakramentsverständnis $<$ behauptet Ebeling, dass die Sakramente ,weder als symbolischer Ersatz für das Wortgeschehen noch als angebliche Überbietung des Wortgeschehens, sondern selbst als Wortgeschehen im strengen Sinn“ ${ }^{\star 1080}$ verstanden werden sollten. Auch wenn er in der Dogmatik die Bezeichnung des Sakraments als Wortgeschehen so wörtlich nicht zum Ausdruck bringt, scheint er den gleichen Aspekt noch zu behalten und den Sinn des Sakraments als Wortgeschehen, anders gesagt seinen existentiellen Sinn, mehr zu betonen. Es handelt sich eingehend um den Sakramentsbezug auf die grundlegenden Situationen und die Sakramentswirkung als das Wirken des heiligen Geistes.

Zuerst leitet Ebeling das Verständnis des Sakraments als das Wortgeschehen von dem Sachverhalt der Situationsüberlegenheit und -bezogenheit des Sakraments ab: Der Begriff des Wortgeschehens ist mittels der polaren Spannung zwischen Wort und Situation zu bestimmen. Ebeling lehnt das Wort- und Sprachverständnis im Rahmen der Signifikationshermeneutik ab. Er sieht das Wort darum nicht als solches, das etwas zeigt oder Informationen über eine andere Sache gibt, sondern als solches, das sich

\footnotetext{
1076 W. Pannenberg, Systematische Theologie III, Göttingen 1993, 377.

1077 B. Neumann, Sakrament und Ökumene. Studien zur deutschsprachigen evangelischen Sakramententheologie der Gegenwart, Paderborn 1997, 150.

1078 D III, 317.

1079 B. Neumann, Sakrament und Ökumene. Studien zur deutschsprachigen evangelischen Sakramententheologie der Gegenwart, Paderborn 1997, 150.

1080 WGT, 217.
} 
selbst ereignet, genauer gesagt, das immer in einer bestimmten Situation geschieht, und dessen Inhalt darum in der Zusammengehörigkeit von Wort und Situation verstanden werden kann und muss. Sein Verständnis des Sakraments als Wortgeschehen ist demgemäß zuerst in Bezug auf die Situation zur Sprache zu bringen.

In der Dogmatik bringt Ebeling den Bezug des Sakraments auf die Situation in besonderer Weise zur Geltung. Unter dem allgemeinen Aspekt könnte die Anführung des Begriffs der Situation in Bezug auf das Sakrament etwa für unverträglich gehalten werden, denn es ist keinesfalls situativ und wird in der jeweiligen Lage fast nicht verändert, weil Taufe und Abendmahl eine relativ festgelegte Gestalt, nämlich bestimmte Formeln und Handlungsabläufe haben. Diesbezüglich sagt Ebeling selber, dass dem Sakrament eine „Situationsüberlegenheit“ zukommt. ${ }^{1081}$ Damit meint er aber nicht, dass das Sakrament völlig unabhängig von der Situation ist, sondern dass es sich in seiner eigenen Weise auf die Situation bezieht und „seine eigene Situationsgestalt mit sich“ bringt, weil die Situationsüberlegenheit „bei allem Anschein der Situationsferne doch eminent situationsbezogen ist, wie eine Herberge bei allem Wind und Wetter Schutz bietet oder wie ein Ring an der Hand daran erinnert, wem man bei allen Wandlungen des Lebens ein für allemal gehört". 1082

Solche Situationsgestalt des Sakraments unterscheidet sich laut Ebeling gewiss von der Predigt, also von ihrer Situationsabhängigkeit bzw. „Situationsempfindlichkeit“ und davon, dass sie „,immer wieder neu werden (soll), je nachdem, was die Stunde geschlagen hat und wem und wie das Evangelium zu sagen an der Zeit ist“" ${ }^{1083}$ Diese unterschiedlichen Situationsbezüge haben Vorteile und Nachteile. Die Verbundenheit mit einer konkreten Situation verleiht der Predigt Stärke für die Anforderung, in der jeweiligen aktuellen Situation das richtige Wort zu finden, aber zugleich birgt sie die Gefahr, dass es der Predigt nicht gelingen könnte, das der Situation angemessene Wort auszusprechen. Von solchem Missklang zwischen dem Wort und der Situation ist das Sakrament aber befreit. Das erklärt Ebeling wie folgt: „Die Situationsüberlegenheit des Sakraments ist darin begründet, dass dem, der an Christus glaubt, in der Situation das Erinnertwerden an diesen Grund des Glaubens und das Versetztwerden in die durch Christus bestimmte Grundsituation dazu helfen kann, die gegenwärtige Situation durchzustehen und zu bestehen, ihr standzuhalten, ihr Widerstand zu leisten oder auch sich von ihr völlig freizumachen, je nachdem, wozu das Sein in Christus der jeweiligen Situation gegenüber ermächtigt." 1084 Die Sakramente sind für Ebeling nicht abhängig von der normalen, konkreten Situation, in der sie ausgeführt werden, damit befreit von den Bedingungen und dem geschichtlichen Wandel, sondern beziehen sich auf zwei spezielle und zugrunde liegende Situationen, nämlich auf die Lebenssituation Jesu und die durch Christus bestimmte Grundsituation des Menschen, indem der Gläubige in der Situation des

\footnotetext{
${ }^{1081}$ D III, 319.

1082 D III, $319 f$.

1083 D III, 319.

${ }^{1084}$ D III, 320.
} 
Sakraments an jene erinnert und in diese versetzt wird. Denn die Grundsituation des Menschen, die Ebeling ontologisch als „Sprachsituation“ bestimmt, ${ }^{1085}$ geht über die konkrete Situation der Anrede hinaus und ist in dieser immer schon wirksam. Durch solchen Sachverhalt von Situationsüberlegenheit und -bezogenheit versucht Ebeling den existentiellen Sinn und Lebensbezug des Sakraments aufzuzeigen, ohne es von der zeitlichen und örtlichen Veränderung berührt oder beschädigt werden zu lassen.

Von dem Bezug des Sakraments auf beide Situationen sind noch zwei weitere Aspekte zur Sprache zu bringen. Erstens dient es der Gewissheit des In-Christus-Seins des individuellen Gläubigen und damit dem Glauben. Ebeling sagt, dass sich das Sakrament „vielmehr auf die Festigung der Glaubensgewissheit im Hinblick auf das Sein in Christus“ richtet. ${ }^{1086}$ Das Sakrament als Wortgeschehen ist solcherweise auf den Glauben bezogen, nicht im Sinne, dass es durch den Glauben konstituiert, sondern im Sinne, dass es als Zusage Gottes auf den Glauben des Empfängers zielt. Durch die Sakramente ereignet sich dasjenige, ,was der Glaube ist, nämlich Sein in Christus, in der Weise leiblicher Handlung als Einbeziehung in bestimmter Situation des Lebens Jesu, und zwar in diejenigen, in denen sich sein Leben und Sterben als ein Ganzes darstellt, als Hingabe für die anderen. “1087 Zweitens kommen dann die Punkte der Lebenssituation Jesu, dessen Taufe und des letzten Abendmahls vor seinem Kreuzestod zum Tragen. Sie stimmen auch mit den Grundgegebenheiten der menschlichen Existenz, nämlich Tod und Leben, überein, sodass vom soteriologischen Sinn des Sakraments geredet werden kann. Das Sakrament steht bei Ebeling auf dem Boden des soteriologischen Verhältnisses von Christologie und Anthropologie, während sich die katholische Sakramentslehre in der Kategorie von der „Soteriologie und Ekklesiologie“ entfaltet. ${ }^{1088}$ Es ist für ihn darum prinzipiell unmöglich, die Erweiterung der Anzahl von zwei Sakramenten einzuwenden. Diese dienen dazu, dass das, was in Jesus geschieht, an und für uns weiter geschehen soll.

Ferner betont Ebelings Verständnis des Sakraments als Wortgeschehen seine Wirkung, die als die Vergegenwärtigung des Christusgeschehens am Wirken des heiligen Geistes im Verhältnis von Wort und Glaube ausgerichtet ist. Er entwickelt den Begriff des Wortgeschehens eigentlich aus der Frage über das Wesen des Wortes, die daran liegt, nicht, „was das Wort enthält“, sondern „was das Wort wirkt. “1089 Das Verständnis des Sakraments als Wortgeschehen richtet sich dementsprechend auf seine Wirkung und Vollmacht.

Die Fokussierung auf die Wirkung und Vollmacht des Sakraments könnte man für ungewöhnlich oder unangemessen für einen evangelischen Theologen halten. In seinem Aufsatz $>$ Worthafte und

\footnotetext{
1085 D I, 189.

${ }^{1086}$ D III, 313.

${ }^{1087}$ D III, 323.

${ }^{1088}$ D III, 308.

1089 Wesen, 183.
} 
sakramentale Existenz< $<1963)$ richtet er durch die Auseinandersetzung mit katholischen Theologen wie K. Rahner und O. Semmerlroth seine Aufmerksamkeit mehr auf den Unterschied zwischen katholischen und evangelischen Aspekten und bezeichnet ihn als „übernatürliche Vervollkommnung oder worthafte Glaubensgewissheit" ${ }^{1090}$ Dieser Unterschied beruht auf der soteriologischen Differenz: was im Sinne des „solo verbo“ in der evangelischen Kirche gilt, trägt in der katholischen Kirche im Sinne des „solo sacramento“. Den Gegensatz zwischen beiden Seiten beschreibt Ebeling in seiner Dogmatik. Er behandelt dabei einen traditionellen Topos über die unterschiedlichen Wirkungsweisen der Sakramente, nämlich „ex opere operantis“ und „ex opere operato“. Das katholische Sakramentsverständnis ist laut ihm ,in ein Wirklichkeitsverständnis hineingebunden, das an dem menschlichen Tun orientiert ist.“" ${ }^{1091}$ Beim evangelischen Verständnis des Sakraments ist dessen Wirkung aber keinesfalls mit dem menschlichen Tun verbunden. Die Wirkung des Sakraments kommt eigentlich nicht von der menschlichen Seite heraus, also weder von der vom Menschen getätigten Handlung noch von dem das Sakrament zum Sakrament selbst machenden Glauben. Es wird also nicht auf Subjektivität hingewiesen, sondern es ist die Rede von der „Objektivität“ des Vollzugs und der ,ihr entsprechende(n) Externität“, die sich auf das Christusgeschehen bezieht. ${ }^{1092}$ Ebeling erklärt: „Während das katholische Sakramentsverständnis auf eine perfectio des Menschen ausgerichtet ist, lässt sich nach evangelischen Verständnis nur in dem Sinne von perfectio reden, daß Gott das Werk, das in Jesus Christus ein für allemal vollbracht ist, in Hinsicht auf die Welt vollendet. “" ${ }^{1093}$ Ebeling hat daher kein Interesse an der Perfektion des Menschen, sondern ist nur am Perfektum des Christusgeschehens interessiert.

Die Vollmacht des Sakraments verbindet sich für ihn so unmittelbar mit dem Christusgeschehen, aber weder im Sinne, dass Jesus Christus dem Sakrament dient und sich in diesem erfüllt, noch im Sinne, dass das Sakrament als die Vermittlung der durch Christus eröffneten Gnadenwirklichkeit und ihr Verhältnis als „Bedingungsverhältnis“ entsteht, sondern im Sinne, dass „Jesus Christus sich selbst im Sakrament gibt" und damit Sakramentsgeschehen begründet. ${ }^{1094}$ Dieser Bezug des Sakraments auf das Christusgeschehen selbst entspricht laut Ebeling „dem solo verbo - sola fide“. ${ }^{1095}$ Denn die Vergegenwärtigung des Christusgeschehen geschieht durch das Wort allein und für den Glauben allein. Weil Wort und Glaube allein die Brücke für die Gegenwart des Heils bilden, kann bei Ebeling nicht vom Sakrament gesprochen werden, ohne auch Wort und Glaube zu meinen. Hier kommt dann noch die entscheidende Unterscheidung vom evangelischen und katholischen Sakramentsverständnis zur

\footnotetext{
${ }^{1090}$ D III, 202.

${ }^{1091}$ D III, 312.

1092 D III, $312 f$.

1093 D III, 313.

${ }^{1094}$ D III, 313.

1095 D III, 313.
} 
Sprache, die anzeigt, „dass es statt am Besitz heiligmachender Gnade an dem Wirken des heiligen Geistes ausgerichtet ist“, das im Verhältnis von Wort und Glauben wirkt. ${ }^{1096}$

In diesem Sinne bezeichnet Ebeling das Sakrament „als Wegzeichen des heiligen Geistes“ ${ }^{1097}$ Die Bedeutung dieser Bezeichnung erklärt Ebeling wie folgt: „Durch den Hinweis auf den heiligen Geist ist auf die Frage nach der Wirksamkeit der Sakramente eine Antwort gegeben. Sie besteht einerseits darin, dass die Einverleibung in Christus und die Teilhabe an seiner leibhaftigen Gegenwart nicht in dem Glauben des Empfängers gründet, sondern in der Verheißung, auf die sich die sakramentale Handlung beruft. Die Wirksamkeit der Sakramente besteht andererseits darin, dass dieses ,objektive' Sakramentsgeschehen nur kraft des heiligen Geistes zum Heil dient. Durch den Ausdruck Wegzeichen endlich wird dies angedeutet: Wer sich an Taufe und Abendmahl hält, ist auf sein Unterwegssein angesprochen, auf das Leben als Ganzes bis in den Tod hinein. Für dieses Unterwegssein wird ihm die Vergewisserung zugesprochen in Christus zu sein.“" ${ }^{1098}$ Die Rolle des Sakraments für den christlichen Glauben hat dann mit dem Leben des Gläubigen als des Seins in Christus zu tun, wobei die Hilfe des heiligen Geistes überhaupt notwendig ist.

In Hinsicht auf Ebelings Sakramentsverständnis wiest z.B. Michael Raske auf seine Schwäche hin und stellt die kritische Frage, ob Ebeling in der „existentialtheologische(n) Kategorie“ „die soziale, ekklesiologische Bedeutung der Sakramente und ihrer besonderen Eigenart gegenüber predigtartiger Verkündigung“" angemessen darstellt. ${ }^{1099}$ Reinhard Hempelmann äußert ebenfalls Kritik an Ebeling. Auch wenn dieser das Spezifische des Sakraments gegenüber der Predigt in der Leiblichkeit findet und daraus den Sinn der Glaubensgewissheit entwickelt, verhindert sein Verständnis des Sakraments als Wortgeschehen nach Ansicht Hempelmanns das Nachdenken darüber, ob es im Sakrament eigentümlich um die „erfahrbare Gestalt der Gnade und die konkret ergehende Zusage des Heils“ gehe. ${ }^{1100}$ Damit laufe es laut Hempelmann Gefahr, ,in ein zur Abstraktion und Verallgemeinerung neigendes Sakramentsverständnis eingeebnet zu werden, welches ganz auf das Wortgeschehen konzentriert ist und dem ,Element‘ keinen eigenständigen Raum gewährt.“" ${ }^{1101}$ Solche Probleme bleiben ungelöst bei Ebeling. Er richtet sein Bemühen zuallererst darauf, die Rezeption des reformatorischen Sakramentsverständnisses zur Geltung zu bringen und die Priorität des Wortes nicht zu verlieren. Dabei

\footnotetext{
${ }^{1096}$ D III, 313.

1097 D III, 330.

1098 D III, 330.

${ }^{1099}$ M. Raske, Sakrament, Glaube, Liebe. Gerhard Ebelings Sakramentsverständnis - eine Herausforderung an die katholische Theologie, Essen 1973, 17.

1100 R. Hempelmann, Sakrament als Ort der Vermittlung des Heils. Sakrametentheolgie im evangelischkatholischen Dialog, Göttingen 1992, 125.

1101 R. Hempelmann, Sakrament als Ort der Vermittlung des Heils. Sakrametentheolgie im evangelischkatholischen Dialog, Göttingen 1992, 125.
} 
schwächt seine starke Betonung auf die Worthaftigkeit der Sakramente gewissermaßen ihre Grenze von der Predigt und ihre eigene Stellung für die Theologie und für die christliche Gemeinde. 


\section{ZUSAMMENFASSUNG UND AUSBLICK}

1.

Das Thema der Sprache scheint bei Ebeling nicht von Anfang an von der Intention geleitet zu sein, es systematisch zu entwickeln. Stattdessen führen die hermeneutischen und fundamentaltheologischen Fragen bei ihm notwendig zum Nachdenken über die Sprache. Sein Sprachdenken findet sich deshalb zunächst in seinen hermeneutischen Arbeiten, in denen er der Wortstruktur des Offenbarungsgeschehens sowie dem hermeneutischen Charakter der Sprache seine Aufmerksamkeit schenkt, und in den fundamentaltheologischen Enzelbeiträgen, in denen er die Sprache auf die fundamentaltheologischen Fragen bezieht.

In der Dissertation als seinem ersten offiziellen Werk nimmt Ebeling Luthers Auslegung in Anspruch, um die grundlegende Frage zu beantworten, was die evangelische Evangelienauslegung sei. Er hält die Auslegung der biblischen Schriften für untrennbar von der Frage nach der Beziehung des gegenwärtigen Menschen zum Christusereignis. Solches Verständnis der Hermeneutik dient bei ihm später dazu, dass die Sprache ihren Ort und ihre Funktion im Prozess von Wort und Glaube hat. Das wird insbesondere im Begriff des Wortgeschehens konkretisiert, der in der biblischen Darstellung wurzelt und von Ebeling einen neuen Sinn gewinnt. Diesbezüglich bringt Ebeling in seinen frühen Schriften die Kompositionen des Geschehensbegriffs wie Offenbarungs- und Christusgeschehen zum Ausdruck. Der Terminus „Wortgeschehen“ selbst findet sich erst in seinem Aufsatz über „die nichtreligiöse Interpretation biblischer Begriffe“ aus dem Jahr 1955, in dem Ebeling den in vorliegenden Untersuchungen entwickelten Geschehensbegriff in Verbindung mit der Verkündigung auf dem Wort selbst beruhen lässt. Der Terminus „Wortgeschehen“ wird bei ihm seitdem in vollem Maße verwendet, um das Wesen des Wortes bzw. der Sprache darzustellen.

Seit der Mitte der 1950er, als sein Fach- und Ortswechsel miteinander zusammenhängend einen Wendepunkt seiner Forschungsrichtung markiert und sich der hermeneutische Charakter seiner Theologie verstärkt, macht Ebeling bezüglich der Sprachauffassung parallel einen Fortschritt. Um diesen herauszustellen, betrachte ich drei wichtige Aufsätze, in denen er seine Sprachauffassung durch die Gegenüberstellung der theologisch grundlegenden Themen konkretisiert: Zuerst wird die Sprache dem Wort Gottes gegenübergestellt. Ebeling betont nicht ihren wesentlichen Unterschied, sondern den Standpunkt, dass das schon zur Sprache gekommene Wort Gottes wieder neu zur Sprache kommen werden kann und muss. Er will dadurch aufzeigen, dass die menschliche Sprache sowohl die Hoffnung auf Gotteswort hat als auch die Verantwortung für dieses trägt. Zweitens handelt es sich um das Verhältnis von Hermeneutik und Sprache. Ebeling bestimmt hier die Hermeneutik als die Verstehenslehre und das primäre Verstehensphänomen nicht als das Verstehen von Sprache, sondern bemerkenswerterweise als das Verstehen durch Sprache. Während beim Verstehen von Sprache das Wort der Verstehensgegenstand ist und die Hermeneutik als seine Lösung erforderlich ist, bedeutet 
dagegen das Verstehen durch Sprache, dass das Wort selbst das Verstehen ermöglicht. Gerade an diesem Punkt ist Ebelings zentraler Gedanke für die Hermeneutik wahrnehmbar, dass das Wort selbst dabei die hermeneutische Funktion hat und keine Verstehenshilfe gebraucht wird. Von diesem Standpunkt aus behauptet Ebeling, dass das reformatorische Schriftprinzip sola scriptura als eine hermeneutische These bestimmt werden muss, also im lutherischen Sinne, dass die Heilige Schrift sui ipsius interpres sei. Letztlich wird die Sprache in Bezug auf das Wort „Gott“ behandelt. Ebeling erklärt, dass mit dem Wort „Gott““ als dem Anruf Gottes die Grundsituation des Menschen als Wort- bzw. Sprachsituation angegeben wird. Er will damit aufzeigen, dass der Mensch durch seine Sprachlichkeit definiert wird und gerade in seiner Sprachlichkeit wesenhaft ist. Mit dem Begriff des Wortes „Gott“, in dem die Macht und zugleich die Ohnmacht des Menschenwortes gezeigt werden, versucht er eine Vermittlung in der Unterscheidung zwischen Gottes Wort und Menschenwort auszuüben. Ebelings Sprachauffassung steht so im existenziell untrennbaren Wort-Zusammenhang von Gott und Mensch, der auf ihrer relationsontologischen Beziehung beruht.

Erst in der $>$ Einführung der theologischen Sprachlehre $<$ (1971) macht Ebeling seine Sprachlehre als eine Prinzipienlehre für die Theologie fest. Er bezeichnet hier zuerst das gegenwärtige Hauptproblem des Christentums sowie der protestantischen Theologie als die Sprachkrise, an der ihm zufolge die dialektische Theologie schuld ist. Denn diese lässt mit der überwiegenden Betonung auf die absolute Autorität Gottes die Lebens- und Situationsbezogenheit des Wortes Gottes außer Betracht und bildet einen verkümmerten Begriff des Wortes heraus, der letztlich zur Schwäche des Wortes führt. Angesichts solcher Sprachkrise stellt sich Ebeling eine Frage: Wie kann man dann gegen die Sprachverwirrung den christlichen Glauben in die rechten Worte erwecken? Dafür erörtert er zuerst die Notwendigkeit der theologischen Sprachlehre, in der die fundamentaltheologischen Gegenstände im Zusammenhang mit dem Leben bzw. der Welterfahrung neu reflektiert werden.

Ebeling versucht weiter, einen möglichst umfassenden Horizont der theologischen Sprachlehre zu bilden. Sein Versuch findet sich m.E. in den folgenden drei Richtungen: Erstens versucht er, die Besonderheit der theologischen Sprachlehre zu bewahren und ihre Bezogenheit auf die allgemeine Gültigkeit nicht auszuschließen. Er behauptet, dass die theologische Sprachlehre vorrangig Besonderes enthalten soll, weil sie als ein besonderes Unternehmen gegenüber der allgemeinen Wissenschaft zur Theologie gehört; und dass sie doch noch Allgemeines enthalten soll, weil sie mit einer allgemeinen, für alle besonderen Sprachlehren relevanten Sprachlehre zu tun hat. Er kann allerdings nicht erklären, welche Begrenzung beide voneinander haben und in welchem Kooperationsverhältnis sie stehen. Zweitens versucht Ebeling die theologische Sprachlehre über den Bereich der Theorie hinaus auf die Praxis zu entfalten. Hinsicht des Begriffs der Praxis wendet sich er gegen den ideologischen Missbrauch der Praxis und plädiert für Luther, bei dem das Praktische das Leben bzw. Lebenserfahrung selbst bedeutet. Ebeling sieht die Praxis weder als den Gegensatz zur theoretischen Haltung, noch als eine bestimmte Verhaltensweise des Menschen, sondern bestimmt sie als die Wirklichkeit des Lebens selbst. 
Von diesem Lebensbezug heraus sucht er den wesentlich notwendigen Praxisbezug für die theologische Sprachlehre herauszuführen, obwohl er dabei nicht von der sachlichen Praxis, wie der Methodik oder der praktischen Anwendung der Sprache redet. Letztlich nimmt Ebeling die Hermeneutik als seine Betrachtungsweise der Sprache an. Denn die Hermeneutik ist für ihn nichts anderes als „Bemühung um eine Sprachlehre von umfassendstem Horizont“ ${ }^{1102}$. Die hermeneutische Sicht stellt sich der semantischen gegenüber und lenkt unseren Blick über die Form und den Inhalt der Sprache hinaus auf die Funktion und die Kraft der Sprache. Diese Kraft hat ihren Sinn, nach der Meinung Ebelings, zuallererst darin, das Verborgene zu präsentieren. Das verborgene Geheimnis der Wirklichkeit Gottes kann durch sie nun dem Menschen zugänglich werden. Das heißt, die Hermeneutik gibt der Sprache einen neuen Horizont, der über die Begrenzung des Verhältnisses zur Sache und den zeitlichen Abstand zwischen dem Gesprochenen und dem Sprechenden hinaus ihre Problemdimension zur religiösen Dimension erweitert.

2.

Das Sprachdenken hat bei Ebeling eine enge Beziehung zu seinem Weg zur Hermeneutik. Diese enge Beziehung findet sich jedoch nicht nur bei ihm. Auch im Hinblick auf die Entwicklungsgeschichte der Hermeneutik ist wahrnehmbar, dass sich die über ein Teilgebiet hinaus auf ein umfangreiches Wissenschaftsgebiet und damit auf Allgemeinheit und Universalisierung richtende Hermeneutik gerade an der Sprache orientiert. Die Sprache ist bei Schleiermacher die Totalität des hermeneutischen Untersuchungsgegenstandes und von der Allgemeinheit der Sprache her entwickelt er die allgemeine Hermeneutik. Die Sprache ist für Dilthey ein einziges Medium für das objektive Verstehen des menschlichen Geistes, das uns durch schriftliche Äußerungen vererbt wird. Heidegger entfaltet über das Subjekt-Objekt-Schema hinaus seine Hermeneutik auf die ontologische Ebene. Das Verstehen ist für ihn die konstitutive Weise, das Da zu sein, und die Sprache ist dementsprechend nicht mehr eine methodologische Basis, sondern charakterisiert sich existenziell und gleichursprünglich. Er bezieht die Sprache später unmittelbar auf das Sein selbst und bezeichnet sie sogar als „,das Haus des Seins“"1103, durch welches das Sein sich offenbart. Diesem ontologischen Sprachverständnis folgt Gadamer und betont insbesondere die Welterfahrung in der Sprache, dass sich die Welt selbst in der Sprache darstellt und die Menschen die Welt allein durch die Sprache erfahren können, sodass er die Hermeneutik zum universalen Aspekt der Philosophie werden lässt.

Die so an der Sprache orientierte Hermeneutik findet sich im Bereich der Theologie vor allem bei Ebeling und Fuchs. Sie verknüpft sich einerseits mit der reformatorischen Fortschreibung der Theologie Bultmanns und andererseits mit der ontologischen Umwendung der philosophischen Hermeneutik

\footnotetext{
1102 Sprachlehre, 188.

${ }^{1103}$ M. Heidegger, Über den Humanismus, Frankfurt a.M. 1949, 5.
} 
Heideggers. Ich erklärte darum Ebelings Position durch den Vergleich mit Fuchs, Bultmann und Heidegger:

Fuchs und Ebeling stimmen darin überein, dass die Sprache das einzige Verstehensmedium ist. Sie wollen beide die theologische Aufmerksamkeit mehr auf die Sprache bzw. ihre hermeneutische Funktion richten. Dafür verwendet jeder aber seinen eigenen Terminus, Ebeling „Sprach- bzw. Wortgeschehen“ und Fuchs „Sprachereignis“. Beide Begriffe zeigen das kreative Geschehen des Wortes Gottes in konkreten Situationen des menschlichen Lebens. Fuchs als Neutestamentler legt den Akzent mehr auf den Text, während Ebelings Wortverständnis dagegen grundsätzlich vom gesprochenen Wort ausgeht, in dem das Wort dynamisch und prozesshaft ist. Diese Eigenschaft scheint Ebeling mit dem Wort „Geschehen“ deutlicher darzustellen, weil das Wort „Ereignis“ als ein singulärer und instanter Akt verstanden werden könnte. Im Hinblick auf das Verhältnis von Ebeling und Fuchs soll aber ihre große Gemeinsamkeit vorrangig sein, denn das, was sie mit ihrem je eigenen Terminus erreichen wollen, ist keine begriffliche Distanz zum anderen.

Ebeling geht so wie Bultmann in seiner Hermeneutik von der Fraglichkeit der Existenz aus. Bultmann sieht das Wort Gottes als „Anrede“, der in einer gehorsamen Entscheidung Folge geleistet werden kann. Die Macht des Wortes basiert bei Ebeling aber nicht auf der autoritären Anrede, sondern auf der Tatsache, dass das Wort Verstehen selbst bewirkt. Die Sprachlichkeit der menschlichen Existenz wird bei Bultmann aus Sicht Ebelings (u. Fuchs) nicht genügend berücksichtigt. Ihre unterschiedliche Würdigung der Sprache bringt auch eine erneuerte Bedeutung für Begriffe wie Verkündigung oder Überlieferung, die durch Sprache vermittelt werden, hervor. Als ein Grund dieses Unterschieds ist ein je unterschiedlicher Einfluss Heideggers zu nennen. Denn während Bultmann von dem frühen Heidegger beeinflusst wird, steht Ebeling dagegen mehr unter dem Einfluss des späten, der sein Interesse von dem Dasein vielmehr auf die Sprache richtet. Heidegger und Ebeling positionieren sich gemeinsam zuallererst gegen das moderne Subjekt-Objekt-Denken, in dem die Sprache zum Zeichensystem instrumentalisiert wird und sich das moderne Subjekt der Wirklichkeit bemächtigt. Ebelings Sprachverständnis hat seine ontologische Grundlage gewiss auf der spät-heideggerischen Betrachtung der Sprache als Selbstauslegung des Seins. Es gibt aber eine entscheidende Differenz zwischen ihnen. Ebeling selber sieht seinen Differenzpunkt zu Heidegger darin, dass er sich auf den Vorrang der Theologie bezieht, indem er die Unterscheidung von Gesetz und Evangelium als Art und Weise des Theologietreibens zum Ausdruck bringt.

Die Reflexion über die Hermeneutik ist bei Ebeling, so wie oben erwähnt, keineswegs von seinem Sprachdenken getrennt zu betrachten. Das besteht nicht nur in dem Faktum, dass man da, wo in seinen zahlreichen Aufsätzen die Rede von der Hermeneutik ist, gleichsam die Rede von der Sprache finden kann. Man muss vielmehr m.E. daran denken, dass sein Sprachdenken entscheidend auf die Charakterisierung seiner Hermeneutik wirkt. Dieser Dienst der Sprache erscheint im jeweiligen Bezug 
auf das Verstehen als die grundlegende Frage der Hermeneutik, die Auslegung als die wirkliche hermeneutische Arbeit und die Verkündung als die völlige Erfüllung der Aufgabe der Hermeneutik.

Sprache und Verstehen: Ebelings Verständnis des Verstehens ist näher mit den drei Begriffen von Wirklichkeitsverständnis, Verifikation und Einverständnis zu erfassen und als antimetaphysisch und relationalontologisch zu charakterisieren. Ich versuchte nachzuweisen, dass Sprache mit jedem Begriff verbunden und somit für den Totalbegriff des Verstehens konstitutiv ist.

Das hermeneutische Problem erfordert bei Ebeling zuallererst eine Besinnung auf die Wirklichkeit, weil das, was durch Sprache zum Verstehen kommt, gerade die Wirklichkeit selbst ist. Er sucht das metaphysische Wirklichkeitsverständnis anhand der Begriffe von Existenz und Erfahrung zu überwinden. Beide stehen für ihn eigentlich in einem untrennbaren Zusammenhang, weil die Wirklichkeit immer unter Einschluss der menschlichen Existenz gedacht werden muss und diese wiederum durch Erfahrung auf die Wirklichkeit bezogen ist. Ebeling legt den Akzent in seinen frühen Arbeiten auf den Existenzbezug, seit Anfang der 1970er Jahre allerdings verstärkt auf den Erfahrungsbezug, um den Lebensbezug stärker hervorzuheben und seinen Standpunkt gegenüber der rationalen oder abstrakten Erfassung der Wirklichkeit deutlicher aufzuzeigen. Er bestimmt die Wirklichkeit als Erfahrungsraum, der für den Menschen in allen Momenten seines Lebens vorgegeben ist. Er will mit dem so durch Erfahrung gewonnenen Wirklichkeitsverständnis ein realistisches und auch ganzheitliches Verstehen darstellen. In solcher Erfahrungs- und Wirklichkeitsproblematik hat sein Sprachkonzept einen zentralen Platz. Er charakterisiert die Erfahrung sprachlich und erklärt ihre Sprachlichkeit mit den Begriffen von Erfassung und Vermittlung. Er sagt, dass die Erfahrung nur durch sprachliche Vermittlung gesammelt werden und dann zur Erschließung von Wirklichkeit führen kann. Denn die Möglichkeiten eigener Erfahrung sind durch die Teilnahme an sprachlicher Überlieferung bedingt. Alles, was in einer bestimmten Erfahrung in verschiedener Weise wahrgenommen wird, kann laut ihm auch allein durch den Sprachvorgang wahrgenommen werden. Weil sich die Erfahrung einerseits so durch sprachlich vermittelte Überlieferung erschließt und weil sie andererseits so durch die Sprache zur Deutlichkeit gebracht wird, geschieht sie keineswegs unabhängig von der Sprache. Das Kommen zur eigenen Erfahrung bedeute, nach Ebeling schon die Durchführung des sprachlich gearteten Prozesses.

Ebelings Verständnis des Verstehens kennzeichnet sich noch am Begriff der Verifikation. Mit dieser meint er keine logisch oder empirisch nachweisbare Richtigkeit. Der Vorgang der Verifizierung erscheint ihm unter dem theologischen Aspekt nicht als vernünftiger Akt, sondern als existentialer Vollzug, der den Ruf des Gewissens bzw. das Wahrsein der Existenz betrifft und schließlich zum Glauben als fiducia, nämlich als dem völligen Vertrauen auf Gott führt. Er unterscheidet somit zwischen erkenntnismäßigem und verifizierendem Verstehen. Er will durch den so gearteten Verifikationsbegriff zeigen, dass das wahre, theologisch sinnvolle Verstehen nicht mit der Erkenntnis, sondern mit der Existenz und weiter mit der Tat und Verantwortung zu tun hat. Im Gebiet der Theologie erscheint das 
Verifikationsproblem einerseits als die Überprüfung des Wahrheitsanspruches der christlichen Rede von Gott und diesbezüglichen Begriffen und andererseits als das Geschehen, das die Wahrheit für den Menschen manifestiert. Ebeling hält diese als Geschehen erwiesene Verifikation für grundlegend und nennt sie als das Wort-Geschehen. Hinsichtlich des Verifikationsproblems gründet sich sein Standpunkt auf nichts anderes als darauf, dass das Wort Gottes selbst Verifikation ist. Das Wort Gottes bedarf keiner anderen Bestätigung und der Mensch gewinnt durch das sich verifizierte Wort Gottes ein grundlegendes Verständnis über sich selbst sowie die Wirklichkeit und letztlich die Verifikation. Diese hat ihren eigentlichen Ort deshalb nicht im Menschen, sondern im Wort Gottes. Ebeling widersetzt sich solcherweise dem Impuls, das Verifikationsproblem in Bezug auf den Sinn oder die Faktizität des Sachverhalts zu betrachten und richtet seine Aufmerksamkeit stattdessen darauf, dass sich das, was Wahrheit meint, nur im Horizont von Sprache erschließen lässt.

Im Vergleich mit den oben aufgezeigten Begriffen von Wirklichkeit und Verifikation ist die Rede von dem Begriff des Einverständnisses bei Ebeling relativ beschränkt. Es ist m.E. dennoch bemerkenswert, dass er für den Begriff des zum Einverständnis führenden Verstehens plädiert. Zum einen sieht Ebeling das Einverständnis als ein selbstverantwortliches Einstimmen, das sich im historischen Abstand und im gegenwärtigen Widerstand vollzieht. Er stellt solches Einverständnis auf die Basis der Sprachbewegung, weil die Sprache selbst in ihrer geschichtlichen Konstanz sowie Wandelbarkeit für alle Möglichkeiten von Interpretation plädiert. Zum anderen sieht er das Einverständnis als Einklang in einer kommunikativen Ebene und bezieht es auf die sprachliche Kommunikation zwischen Personen. Auch wenn die Sprache eine Ursache von Nicht- und Missverstehen und sogar ein Mittel für Missverständigung oder Täuschung sein könnte, legt Ebeling eine Betonung darauf, dass sie eigentlich dazu dient, die Kommunikation und die Partizipation im Zusammenleben mit anderen Menschen zu ermöglichen und letztlich zum Einverständnis zu führen. Er will damit die Sprache nicht lediglich als ein einfaches Kommunikationsmittel bestimmen, sondern auf eine theologische Ebene bringen. Er bezieht die Ursache für die Störung der Kommunikation auf Sünde, die er als Ursache für alle Verwicklungen bestimmt, und bezeichnet Sprachvollmacht sowie Einverständnis als Einklang im Verhältnis zu Gott. Weil sich Gott im sprachlich kommunikativen Verhältnis mit Menschen immer als Person offenbart, zielt Ebeling in seiner theologischen Hermeneutik auf eine Begegnung von Person und Person ab, die sich mittels der Sprache vollzieht.

Sprache und Auslegung: Ebelings Auslegungsprinzip ist die existentiale Interpretation, die er von seinem Lehrer Bultmann übernimmt. Die existentiale Interpretation bezieht sich bei Bultmann gewissenmaßen auf sein Entmythologisierungsprogramm und mehr noch auf seine Kritik an der historischen Jesusforschung. Bultmann behauptet, während die historischen Methode uns vom eigentlichem Sinn der Bibel und damit von dem Wesen des Glaubens entfernt, stelle die existentiale Interpretation die in der historischen Kritik beschädigten Aussagen der Bibel erneut im Selbstverständnis des Gläubigen wieder her. Die von Bultmann entwickelte existentiale Interpretation 
wird von einer Gruppe Theologen aufgenommen. Darin findet sich aber nicht nur Übereinstimmung mit Bultmann, sondern auch Widerspruch. Der Unterschied besteht zuerst in der neuen Frage nach dem historischen Jesus, die mit der Frage nach einem angemessenen Geschichtsverständnis verbunden ist und auch eine methodische Erneuerung bringt. Die nach Bultmann neu geleistete Jesusforschung hat ihr entscheidendes Merkmal doch darin, die sachliche Kontinuität zwischen dem vorösterlichen Jesus und dem dogmatischen Christus festzulegen.

Ebeling will über die existentiale Interpretation Bultmanns hinausgehen. Er stellt sich die Frage, ob eine existentiale Interpretation des Christusgeschehens die Verbindung mit der geschichtlich Vorhandenes aufgeben muss. Um diese Frage zu beantworten, erörtert er zuerst erneut die Anwendung der historisch-kritischen Methode in der Theologie. Er plädiert für die Notwendigkeit der historischen Methode für die Interpretation der Bibel als des historischen Textes. Für die rechte Anwendung der historisch-kritischen Methode muss man aber darauf achten, dass sie weder einer statistischen Sammlung der Geschichtsfakten noch einer kritiklosen Zustimmung mit der Geschichte, sondern dem kritischen Korrektiv des geschichtlichen Verstehens dienen soll. Ebeling behauptet, die unablässige kritische Selbstkorrektur gehöre zum Wesen der historisch-kritischen Methode. Gegen den historischen Geschichtsbegriff, der an der Tatsache orientiert ist, schlägt er den hermeneutischen Geschichtsbegriff vor, der sich am Wortgeschehen orientiert. Die sachgemäße Frage lautet demnach nicht, was passiert sei, sondern, was zur Sprache gekommen sei. In Hinsicht auf den historischen Jesus soll dann nicht nach seinen biografischen oder objektiven Daten gefragt werden, sondern danach, was in Jesus zur Sprache gekommen ist, damit man richtig verstehen kann, welche Bedeutung das Leben Jesu in der Geschichte gewinnen.

Ebeling versucht durch die so korrigierte Fragestellung eine Brücke zwischen der historischen und der dogmatischen Untersuchung über Jesus zu bauen. Solcher Versuch besteht genauer darin, den Horizont der historischen Jesusforschung vom bloßen Dass, nämlich vom zur Historizität geführten Faktum, auf die umfassende Untersuchung über Jesus zu erweitern. Die Untersuchung über Jesus soll nach der Meinung Ebelings umfassend mit seinem Reden, Tun und Verhalten, also mit seinem ganzen Leben zu tun haben. Das Leben Jesu muss daraufhin befragt werden, wie es zum Glauben herausfordert. Die Relevanz des historischen Jesus für den Glauben sieht Ebeling darin, dass Jesus der Zeuge und der Grund des Glaubens ist und beide eine Einheit bilden. Mit der Bezeichnung Jesu als Zeuge des Glaubens redet er nicht von dem Glauben Jesu selbst, sondern von der Bedeutung Jesu für den Glauben der anderen, und meint damit, dass die ganze Existenz Jesu auf die Erweckung des Glaubens abzielt. Der Grund des Glaubens bedeutet bei ihm das, was den Glauben Glauben sein lässt, und ist dann einfach als das Wort Gottes zu nennen. Denn Jesus selbst bringt Gott zum Verstehen und ist das Ereignis des Wortes Gottes. Ebeling wendet die Frage nach dem Grund des Glaubens von dem Kerygma (bei Bultmann) lieber zum historischen Jesus. In der Bezeichnung Jesu als Glaubenszeugen und -grund 
findet man Ebelings Absicht, den historischen Jesus in das dogmatische Christusbild einzubeziehen und die Zusammengehörigkeit von Jesus und Glauben im Wortgeschehen zu begründen.

Darin, dass Ebeling so durch die umformulierte Frage nach der Geschichte und der Relevanz des historischen Jesus auf etwas geschichtlich Vorhandenes für die existentiale Interpretation des Christusgeschehens nicht verzichten will, besteht aber nicht nur die Möglichkeit der existentialen Interpretation, sondern auch ihre Grenze. Er will durch das am Wortgeschehen orientierte Geschichtsverständnis historische Arbeit als hermeneutische Arbeit erforderlich machen und die historische Beschränktheit des Geschehens überwinden. Das, was von ihm behandelt wird, ist doch streng genommen nicht Geschichte, sondern Geschichtlichkeit, die das auf der Zeitlichkeit der Existenz basierende Verhältnis zur Geschichte bedeutet. Im dem Sinne, dass die Geschichte durch die Sprache übertragen und in der Sprache gesammelt wird, könnte man sie als Sprachgeschehen bezeichnen - doch ist das ausreichend? Ebelings Betrachtungsweise, die Geschichte in den Bereich der Existenz und in deren Sprachlichkeit einzubeziehen, wird dann erstmal vor die grundlegende Frage gestellt, ob das Problem der Geschichtlichkeit mit dem der Geschichte zusammenfällt. Tut es das nicht, findet sie sich mit der typischen Frage nach der Grenze der existentialen Interpretation konfrontiert, die erörtert, ob diese den Horizont der biblischen Aussagen in eine Beschränkung führt.

Sprache und Verkündigung: Ebeling sieht die Verkündigung als ein Teilgebiet der Hermeneutik, weil sie in einer hermeneutischen Bewegung steht, die vom Text der Heiligen Schrift zur Predigt führt. Die Predigt steht laut Ebeling in einer engen Beziehung zu der Theologie, weil sie gemeinsam am Verantworten des Wortes Gottes teilhaben, und weil sie sich in der Geschichte zueinander entsprechend entwickeln. Er unterscheidet sie zugleich durch ihre Ortsbestimmung und ordnet die Theologie in Wissenschaft und die Verkündigung in Kirche ein. Unter der Voraussetzung solcher Gemeinsamkeit und Unterschiedlichkeit unterstreicht Ebeling den Zusammenhang ihrer Aufgabe. Er bezeichnet die Verkündigung auch als die Existenz der Kirche, die er in erster Linie als Wortkirche versteht. Die Verkündigung bzw. Predigt hat laut ihm eng mit der Sprache zu tun, weil ihre Durchführung grundsätzlich eine sprachliche Aufgabe ist. Ebeling erläutert vornehmlich ihre spannungsreiche Struktur in Bezug auf den hermeneutischen Charakter der Sprache:

Das erste Spannungsfeld der Predigt ergibt sich laut Ebeling zwischen überliefertem und gegenwärtigem Wort. Die Predigt hat den biblischen Text als anspruchsvollen Maßstab und kann von der biblischen Auslegung, damit nicht von der Kirchengeschichte sowie von der christlichen Tradition getrennt sein. Sie ist dennoch keine einfache Wiederholung des überlieferten Wortes, sondern wendet sich in immer neuen Formen und Gedanken an die Gegenwart. Sie hat deshalb eine Verantwortung gegenüber den Bedingungen historischen Denkens und den geschichtlichen Veränderungen. In diesem Sinne behauptet Ebeling einerseits, dass die Predigt ohne Rücksicht auf ihren Zeitbezug weder für eine individuelle Interpretation, noch für eine reine Lehre gehalten werden dürfe. Andererseits führt er aus, dass sie nicht bloß für ein historisches Produkt oder für die nur zu einem bestimmten Zeitraum 
gehörende Sache gehalten werden dürfe. Angesichts dieses zeitbezogenen Sachverhaltes bringt er das Verhältnis von Zeit und Wort zur Sprache, also in den folgenden drei Schritten: die Sprachlichkeit der Zeit, die Zeitlichkeit des Wortes und die Zeitmacht des Wortes. Mit der Sprachlichkeit der Zeit zeigt er den existentialen Sprachbezug der Zeit bzw. die sprachliche Zeiterfahrung des Menschseins; mit der Zeitlichkeit des Wortes erklärt er, dass das Wort die Struktur der Zeitlichkeit hat und sich als zeitliches Geschehen ereignet; und letztlich hebt er mit der Zeitmacht des Wortes hervor, dass das Wort eigentlich und letztlich dem Menschen Zukunft gewähren und ihn für die Gegenwart frei machen muss, weil die Eröffnung wahrer Zukunft die höchste Möglichkeit des Wortes sei. Auf die so auf die Zeit bezogene doch nicht geschlossene, schöpferische Macht der Sprache gründet Ebeling die Eigenart der Predigt.

Das zweite Spannungsfeld der Predigt findet Ebeling im Ringen zwischen Glaubensinhalt und Lebenserfahrung, wobei ein Prediger wegen der veränderlichen Situationen und der daraus gewonnenen verschiedenen Erfahrungen auf Schwierigkeiten stößt. Die Predigt hat ihre Aufgabe laut ihm in der Frage, wie bei einem Ernstnehmen des Erfahrungsbezuges die Sache des Glaubens als der Kern der Predigt unbeschädigt bleiben kann. Es geht bei ihm nicht bloß um die Hinzufügung der situationsbezogenen Anwendung zum fixierten Glaubensinhalt, sondern um den wesentlichen Lebensbezug des Glaubens. Diesen Bezug beschreibt Ebeling folgendermaßen: Der Glaube kann nur in seinem Lebensbezug recht erfasst werden und ist nur als Lebensbezug Glaube. Mit diesem grundlegenden Bezug zeigt Ebeling auf, dass die Predigt mit der Lebenssituation verantwortlich umgehen muss. Die Predigt vermittelt ihren Hörern laut ihm nicht lediglich Glaubensvorstellung, sondern Glaubenserfahrung und zielt darauf $a b$, den Lebensvollzug des Glaubens weiter in ein Lebensverhältnis zu Gott hineinzuführen. Der Predigtarbeit kann man aber, nach Ansicht Ebelings, allein unter der Voraussetzung des vereinten Moments von Erfahrung und Überlieferung nachgehen, die in einer durch Sprache aneinanderhängenden Beziehung stehen. Er lässt den Charakter der Sprachlichkeit so der Verbindung zwischen ihnen dienen. Darüber hinaus wird bei ihm die Situationsbezogenheit der Predigt auch von der Situationsbezogenheit der Sprache unterstützt. Das bedeutet, dass die Sprache bzw. ein Wort selbst untrennbar von der Situation des Sprechens ist und verantworten muss.

Das dritte Spannungsfeld der Predigt zeigt Ebeling mit dem Verhältnis von Glaubensgrund und Glaubensäußerung, das bereits in der Rede von der zeit- und situationsbezogenen Predigt impliziert wurde, weil sich die Glaubensäußerung als ein auf den Kontext bezogener Akt des Sprechens erweist. Ebeling will mit dem dritten Spannungsfeld nochmal den widersprechenden Charakter der Predigt behandeln und formuliert diesen mit drei Polaritäten: Unbedingtheit und Bedingtheit, das Eine und die Vielfalt und Gebundensein und Freiheit. Solcher widersprechende Charakter kommt ursprünglich von dem Sachverhalt her, dass die Predigt zwei unvereinbare Worte in sich enthält, nämlich Gotteswort und Menschenwort. Es geht dann um die alte Frage, wie der Mensch überhaupt eine Predigt halten kann. Ebeling ist grundsätzlich der Meinung, dass in der Predigt das Reden von Gott zugänglich ist und die 
Predigt ihren eigentlichen Wert in der durch Mitteilung des Wortes Gottes den Glauben weckenden Aufgabe hat. Ebelings hermeneutisches Sprachkonzept für die Predigt wird ambivalent bewertet: Einerseits wird es als ein Ansatz zu einer nеuen Homiletik geschätzt, wodurch eine neue Anerkennung von Sprache und damit die Würdigung von der Predigt als Partizipation am Wort Gottes entsteht. Andererseits wird das unbegrenzte Vertrauen auf die Macht der Sprache oder die Verschiebung der übermäßigen Verantwortung zu dem die Sprache sagenden Prediger kritisiert.

3.

Im Hinblick auf den Titel und die Struktur der $>$ Dogmatik des christlichen Glaubens $<$ ist wahrnehmbar, dass Ebeling, ähnlich wie Schleiermacher und doch äußerlich klarer als dieser, für das konkurrenzlose, wesentlich zusammengehörende Verhältnis von Dogmatik und Glauben plädiert. Er verwendet darum die Zusammenstellung von Dogmatik und Glauben für den Titel seiner dogmatischen Arbeit und stellt jeden Band seiner Dogmatik unter das Vorzeichen des Glaubens. Beim Aufbau seiner Dogmatik nimmt er die drei Artikel des Credos als Gliederungsprinzip und zielt darauf ab, alle Glaubensaussagen von Gott, Welt und Menschen vom Grund des Glaubens her miteinander zusammenhängen und auf ihn hin führen zu lassen und den Glauben als einen Gesamtaspekt darzustellen. In diesem Sinne stellt er die Dreieinigkeit Gottes als eine Zusammenfassung aller seiner dogmatischen Aussagen unter dem Titel „Gott alles im allem“ an das Ende seiner Dogmatik. Insbesondere der Begriff der Relation betrifft sein Ziel, den christlichen Glauben unter dem gesamten Aspekt zu betrachten und damit als ein Ganzes zu erweisen. Der christliche Glaube steht laut ihm in den drei Relationen coram Deo, coram Mundo und coram meipso. Den coram-Relationsbegriff übernimmt Ebeling von Luther, der neben Schleiermacher den anderen großen Einfluss auf Ebelings Dogmatik hat. Der coram-Relationsbegriff dient bei Ebeling als Quelle der relationalen Ontologie, die er als Gegenentwurf zur Substanzontologie entwickelt, in der ein Mensch primär ein Einzelner ist und die mit Anderen verbundenen Relationen für sekundär gehalten werden. Er erachtet solche Relationalität als einen Zentralbegriff seiner gesamten Dogmatik und stellt sie immer mit der Betonung auf ihre Sprachlichkeit dar.

Im ersten Band strukturiert Ebeling die grundlegende Aussage von Gott als Schöpfer in Gestalt des Redens und setzt damit das Sprachlichsein Gottes voraus. Insbesondere unter dem Aspekt des Gebets als Sprachphänomens beschreibt er seine Gotteslehre. Er versteht das Gebet keinesfalls nur als einen bestimmten Akt der Frömmigkeit, sondern als ein menschliches und religiöses Grundphänomen. Es erscheint als das mit der Geschichte selbst gegebene menschliche Urphänomen und hat somit in der sprachlichen Verfasstheit der Wirklichkeit des Menschen seinen Grund. Es erweist sich auch als ein religiöses Grundphänomen, weil es allen Religionen eigen ist und zu jeder Religion als zentrale sprachliche Äußerungsform gehört. Aufgrund solchen Gebetsverständnisses nutzt Ebeling dieses als Einstieg in die Gotteslehre, um ihren Wirklichkeitsbezug zur Geltung zu bringen. Anschließend an Luthers Verständnis vom Gott als das Werdende sieht Ebeling das Gebet als solches, das zeigt, „dass 
und wie Gott zur Erfahrung kommt" 1104 und bezeichnet es schließlich als „das Ganze des Gottesverhältnisses" ${ }^{1105}$. Er versucht dadurch entgegen der metaphysischen Gotteslehre, die von der transzendenten Evidenz Gottes ausgeht, die Bedeutung der Rede von Gott im Hinblick auf die jedem zugängliche Wirklichkeit nachzuweisen.

Ebeling sichert dem Thema des Gebets einen festen Ort innerhalb der Dogmatik und setzt es sogar vor die Rede vom Sein und den Attributen Gottes. Er will damit jedoch nicht ausdrücken, dass durch das Phänomen des Gebets Gottes Sein selbst bewiesen wird. Er will hervorheben, dass im Gebet von Gott immer nur in bestimmter Weise geredet wird, und dass wir durch solche Rede den Glauben an Gott am besten beglaubigen, ja wahrscheinlich viel besser als durch irgendeinen theoretischen Gottesbeweis. Er bezeichnet das Gebet sogar als Schlüs sel zur Gotteslehre, weil sich das Verständnis Gottes, sein zugesprochenes Sein und die zugesprochenen Attribute im Gebet eröffnen. Dazu erklärt er, dass durch die Konzentration auf das Gebet die Gotteslehre tatsächlich zu ihrer Verifizierung hingeführt werden kann und der Glaube in Bezug auf das Leben letztlich als fiducia wahrgenommen werden kann.

Beim Behandeln des Gebets interessiert sich Ebeling vor allem dafür, in welcher Beziehung Gott und Menschen unter dem Aspekt des Gebets zueinanderstehen. Diese Beziehung bezeichnet er mit der Passivität (bzw. Abhängigkeit) und dem Angesprochensein des Menschen und mit der Nichtobjektivierbarkeit Gottes, die alle eigentlich auf Relational-Ontologie beruhen. Deren Ansatzpunkt befindet sich darin, dass sich Gott und Menschen ontologisch aufeinander beziehen. Ebeling behauptet, dass Gottes Sein „nichts Getrenntes neben dem Sein der Welt“, sondern „das Zusammensein Gottes und der Welt" sei. ${ }^{1106}$ Die relationale Ontologie ist seiner Ansicht nach schriftmäßig und konstituiert durch den Schöpfungsgedanken. Die ontologische Relation von Gott und Menschen wird durch nichts anders als durch den Schöpfungsakt aufgebaut, wodurch sie sich als Schaffendsein und als Geschaffensein aufeinander beziehen und sich einander gegenüber stellen. Solche Relation wird laut Ebeling gerade durch das Phänomen des Betens geäußert. Radikal gesagt: Weil wir von Gott geschaffen sind, beten wir an Gott. Insofern steht die Sprachlichkeit Gottes im Zentrum der Gotteslehre unter dem Aspekt des Gebets. Sie besteht bei Ebeling aber nur in Externrelation. Er redet nicht von der Sprachlichkeit Gottes an sich und bringt sie darum einseitig zur Geltung.

In Hinsicht auf die Attribute Gottes lehnt Ebeling es ab, sie in irgendeiner abstrakten Weise zu beschreiben und versucht sie in Bezug auf die Erfahrung zur Ausführung zu bringen. Er hält „die Konfrontation Gottes mit der den Menschen angehenden Wirklichkeit“ für „die Ursprungssituation der

\footnotetext{
${ }^{1104}$ D I, 199.

1105 D I, 208f.

1106 D I, 222.
} 
göttlichen Attribute“"1107. Er entwirft die Lehre von den Eigenschaften Gottes insbesondere in Korrelation zur Gebetslehre und hebt den Sprachcharakter der göttlichen Attribute hervor. Diesen erklärt er mit einer doppelten Sprachbewegung, die im Gebet entsteht. Die Sprache bewegt sich dabei einerseits in der Prädikation Gottes darüber, was Gott schon immer eigen ist, und andererseits in der Zurückstrahlung der Gottesprädikationen auf den Betenden und die ihn angehende Wirklichkeit. Ebeling beschreibt die Attribute Gottes konkret in Verbindung mit den Hauptelementen des Gebets wie Anrede, Lob und Bitte.

Im zweiten Band behandelt Ebeling die Christologie als Hauptthema. Er versucht zunächst die in der Zweinaturenlehre enthaltene Teilung von Gottheit und Menschheit Jesu sowie das davon herkommende Schema einer Christologie „von oben“ oder „von unten“ zu überwinden. Beim Beschreiben der drei Christusgeschehen von Inkarnation, Kreuzestod und Auferstehung versucht Ebeling den Menschenbezug aufzuweisen (Kap. 5), umgekehrt beim Beschreiben des geschichtlichen Menschen Jesu dessen Gottesbezug hervorzuheben (Kap.6). Er bringt dazu die Formel „Zusammensein von Gott und Mensch in Jesus“"1108 für die Bestimmung des Seins Jesu Christi zur Sprache. Er will damit einerseits die Darstellung Jesu als ein magisches oder mythisches Wesen ablehnen und andererseits den in der Teilung von zwei Naturen in Jesu implizierten Gegensatz zwischen Gott und Menschen überwinden. Er charakterisiert das Zusammensein von Gott und Mensch in Jesus insbesondere ,als ein kommunikatives Zusammensein “1109 und kennzeichnet den Sachverhalt, der in Jesus kraft der Präsenz des Wortes Gottes gegeben ist. Gerade darin findet sich die Grundlage der Worthaftigkeit Jesu. Diese manifestiert sich im Christusgeschehen von Inkarnation, Kreuzestod und Auferstehung und auch im Leben des geschichtlichen Jesu.

Ebeling hält die Menschwerdung Gottes in Jesus für das christologische Grunddogma. Er fokussiert sich darauf, dass sich die Menschwerdung Gottes in der Erscheinung Jesu Christi ereignet, und stellt dieses Ereignis mit der Formel „Gottes Wort in Person“1110 dar. Mit dieser Formel versucht er zu bestimmen, wie sich die Anwesenheit Gottes in Jesus von anderen Auffassungen und Weisen der Anwesenheit Gottes unterscheidet. Der Unterscheid besteht in der Komposition der Begriffe von Person und Wort. Ebeling versteht die Person nicht als den traditionalen Hypostasenbegriff, sondern als einen an der menschlichen Person orientierten Personenbegriff, den er wiederum als die wesentlich gottesbezogene Existenz des Menschen bezeichnet. Er sieht das Wort auch in Bezug auf den Menschen und charakterisiert es als geschichtlich ereignend. Diese geschichtliche Gegebenheit erläutert Ebeling durch die sachlich und historisch untrennbare Verbindung zwischen der Inkarnation und dem

\footnotetext{
1107 D I, 237.

1108 D II, 81.

1109 D II, 81.

${ }^{1110}$ D II, 69.
} 
Evangelium und bezeichnet Jesus als „Ursprung des Wortgeschehens““. ${ }^{1111}$ Die Wendung „Gottes Wort in Person" zielt bei ihm letztlich darauf ab, anzuzeigen, dass Gott in dem Menschsein Jesu zur Sprache kommt.

Der Kreuzestod Jesu steht bei Ebeling nicht nur äußerlich im Mittelpunkt der Christologie, sondern hat auch einen inhaltlichen Höhepunkt, auf den sich die Aussagen von der Menschenwerdung sowie der Auferstehung richten. Denn er legt das Gewicht auf das Verhältnis von Christologie und Soteriologie und richtet sich darauf, durch seine Christologie die Lehre der Versöhnung zu realisieren. Er bestimmt den Tod Jesu am Kreuz als das Versöhnungsgeschehen. Dieses Kreuzgeschehen bezieht sich dann auf die Sünde als den Fundamentalwiderspruch zwischen Gott und Menschen und bringt das Verhältnis von ihnen in Hinblick auf die Sünde zur Sprache. Ebeling erläutert diesen Sachverhalt näher an den Begriffen von der Sündlosigkeit und der Gottverlassenheit, weil die Versöhnung als das Heil erst dadurch ein Ereignis wird, dass Jesus als der Sündlose am Kreuz, also anstelle der Sünder, von Gott verurteilt und verlassen wurde. In Hinsicht auf die Sündlosigkeit Jesu hebt er ihre Bedeutung als die Zuwendung zum Sünder hervor, indem er die Bedeutung der Sündlosigkeit über „,das negative Verständnis als Freisein von Sünde“ hinaus auf „das positive Verständnis als die Freiheit zum Sünder" entfaltet. ${ }^{1112}$ In Hinsicht auf die Gottverlassenheit bezeichnet Ebeling das Verhältnis Gottes zur Sünde als „das doppelte Nein Gottes zur Sünde“, also „das Nein zur Sünde als ein Nein zum Sünder“ (Verurteilung bzw. Tod) und „das Nein zur Sünde als ein Ja zum Sünder“ (Trennung der Sünder von der Sünde, Vergebung). ${ }^{1113}$ Und dieses Ja Gottes zum Sünder ist, nach der Meinung Ebelings, bereits im Kreuzgeschehen enthalten. Er versucht das Kreuzgeschehen und das Wort weiterhin in einen Zusammenhang zu stellen. Denn das Kreuzgeschehen als das Versöhnungsgeschehen darf keinesfalls ein einmaliges Ereignis bleiben, sondern soll weiterhin wirken. Ebeling lässt das Wort als Medium des Weiterwirkens des Kreuzes dienen und bezeichnet das Wort vom Kreuz als „die einzige echte Kreuzreliquie“". 1114

Die Glaubensaussage über die Auferstehung richtet sich, nach der Meinung Ebelings, nicht auf das vergangene Faktum der Auferstehung, sondern auf die Person Jesus selbst als den Auferstandenen. Diesbezüglich kommt dann die Frage auf, wer Jesus war und ist. Diese Frage beantwortet Ebeling einmal in Bezug auf das Realitätsproblem der Auferstehung (das Osterereignis), andermal in Bezug auf das Problem der Gegenwart des Auferstandenen (Christus praesens). Im Hinblick auf das Osterereignis hält er die Erscheinung zunächst für genügend und konstitutiv für die Wirklichkeit der Auferstehung, während der Bericht des leeren Grabes keineswegs als ein ausschlaggebendes Argument geführt werden darf. Denn Jesus bezeugte erst durch die Erscheinung selbst sowohl seine Gottheit als auch

\footnotetext{
1111 D II, 91.

1112 D II, 179ff.

${ }^{1113}$ D II, $196 \mathrm{ff}$.

${ }^{1114}$ D II, 211.
} 
Menschheit völlig und ist als Glaubenszeuge damit Glaubensgrund geworden, auf den sich der Glaube aller Menschen gründet. Im Hinblick auf Christus praesens erläutert Ebeling einerseits das Sein Christi bei Gott und andererseits sein Verhältnis zur Welt und unterstreicht dabei die Zusammengehörigkeit von beiden. Er erklärt die Mode der Präsenz Christi mit drei traditionellen Weisen, nämlich der Leib Christi, der Geist Christi und das Wort Christi. Er bestimmt doch das Wort Christi als die schlechterdings konstitutive Weise, wie der erhöhte Christus präsent ist.

Im zweiten Teil der Christologie geht es dann um den geschichtlichen Menschen Jesu. Auch wenn sich Ebeling in seiner Dogmatik stark an die christologische Lehrtradition und die vorrangige Aufstellung der überlieferten Christologie bindet, hält er das Problem des historischen Jesus noch für unverzichtbar und sogar notwendig. Er bringt das Thema des historischen Jesus in die Dogmatik ein und setzt es an den Anfang des Teils über den „Menschen Jesu“, weil der historische Jesus der Ursprung der christologischen Aussage ist und zugleich die Notwendigkeit eines weiteren Aspektes zeigt, bei dem es sich um die christologische Relevanz der Begegnung mit dem Menschen Jesus handelt. Er lässt bemerkenswert durch den Begriff der Vollmacht den Menschen Jesu im dialektischen Verhältnis von Allmacht als Gottes Macht und Ohnmacht als Menschen Macht stehen. In welcher Weise die Christologie tatsächlich an den geschichtlichen Menschen Jesu Anhalt hat, wird nach der Meinung Ebelings durch den Begriff der Vollmacht signalisiert. Und unter diesem Begriff kann ihm zufolge „das Ganze von Wort und Verhalten Jesu in seiner inneren Stimmigkeit“ erfasst werden. ${ }^{1115}$ Er bezeichnet die Vollmacht deshalb ,als Hauptnenner von Wort und Verhalten Jesu“1116. Er gibt aber dem Wort Jesu stets einen Primat, weil seine Vollmacht eigentlich und absichtsvoll durch das Wort ausgeübt wird. Ebeling entfaltet das Nachdenken über die Vollmacht weiter im Glauben und erläutert den Sachverhalt, dass sich alles, was durch das Wort Jesu getragen wird, letztlich auf das gleiche Ziel der Glaubenszumutung richtet.

In dritten Band behandelt Ebeling die Pneumatologie als Hauptthematik und erklärt ihren Charakter einerseits in Bezug auf die Zusammenhörigkeit der pneumatologischen und eschatologischen Aussagen und andererseits in Bezug auf ihre christologische Verklammerung. In der Darlegung des Heiligen Geistes lenkt er die Aufmerksamkeit mehr auf sein worthaftes Wirken, da sich die Sprachlichkeit des Heiligen Geistes, durch die Ebeling seine weder irrationale noch amoralische Personalität bestätigen will, dann manifestiert. Die Heiligung gehört eigentümlich zu seinem Wirken und hat eng mit der Rechtfertigung zu tun. Ebeling richtet sein Augenmerk darauf, wodurch der Geist wirkt und uns zum rechtfertigenden Glauben führt, und beruft sich dafür auf die traditionelle Methode, nämlich Gottes Wort in verbaler und in sakramentaler Gestalt zu betrachten.

\footnotetext{
1115 D II, 475.

${ }^{1116}$ D II, 409.
} 
Zuerst geht es als Gottes Wort in verbaler Gestalt um Gesetz und Evangelium. Die Formel von beiden und ihre Verhältnisbestimmung geht in der reformatorischen Theologie auf Luther zurück, der beide für Gottes Wort hält und seinen Akzent doch auf ihre grundlegende Unterscheidung legt. Es geht dennoch weder um einen Dualismus noch um eine Alternative zwischen ihnen. Bloßes Trennen oder bloßes Verbinden gilt keinesfalls für das Verständnis lutherischer Unterscheidung. Ebeling bringt deshalb Relationsbegriffe zum Ausdruck, die eine Spannung zwischen Unterscheidung und Zusammenhang in sich enthalten und darum immer in ihrer Bezogenheit betrachtet werden müssen. Die Sachrelation von Gesetz und Evangelium verläuft laut ihm nicht im chronologischen Sinne, sondern im soteriologischen.

Ebeling behauptet ähnlich wie Luther, dass das, was überhaupt Gottes Wort heißt, erst im Licht ihrer Unterscheidung zu erkennen ist. Bezüglich dessen, worin sie sich voneinander unterscheiden, macht Ebeling m.E. die folgenden drei Punkte aus: Erstens betrachtet er die Unterscheidung von Gesetz und Evangelium in Bezug auf die Lebenswirklichkeit, der alle Menschen unterworfen sind. Im Anschluss an Paulus und Luther erklärt er, dass das Gesetz die den Menschen fordernde und antreibende Macht seiner Lebenswirklichkeit selbst ist, während das Evangelium als die Botschaft von Christus unmittelbar auf Jesus Christus bezogen ist. Zweitens erläutert Ebeling die Unterscheidung von Gesetz und Evangelium mit dem Gewissen. Er setzt beide am Gewissen als ihren gemeinsamen Adressaten an und findet ihre Unterscheidung in ihrer Wirkung am Gewissen. Er charakterisiert die Wirkung des Gesetzes als Verbindlichkeit und die des Evangeliums als Freiheit. Drittens beschreibt Ebeling die Unterscheidung von Gesetz und Evangelium in Bezug auf das Wortgeschehen. Er behauptet, dass ihre Unterscheidung ,nicht auf einen einmaligen oder von Fall zu Fall zu wiederholenden Vorgang abzielt, sondern für das Christsein ständig präsent sein muss.“"1117 Diese ständige Präsenz findet sich vornehmlich in der Verkündigung. Er will somit zeigen, dass die Unterscheidung von Gesetz und Evangelium nicht auf die Formen, Inhalten oder Interpretationsweisen des Wortes Gottes verweist, sondern auf dessen innerliche Struktur, in der das Wort Gottes als Wortgeschehen am Menschen besteht.

In Hinsicht auf Ebelings Behandlung des Themas der Sakramente in der Dogmatik erläuterte ich zuerst die zwei äußerlich klaren Kennzeichnungen: Erstens behandelt er das Thema der Sakramente auf einer gesamten und allgemeinen Ebene und scheint kein richtiges Interesse an dem einzelnen Sinn von Taufe und Abendmahl zu haben. Zweitens behandelt er das Thema der Sakramente nicht in der Kategorie von Ekklesiologie, sondern im Teil über das Wort des Glaubens. Dadurch war sein grundlegender Standpunkt ersichtlich, dass er alle Versuche ablehnen will, die Sakramente als das zur Kirche bzw. ihrer eigenen Autorität oder Macht gehörende Werk zu sehen und das Heilsgeschehen irgendwie auf die Ebene der menschlich-kirchlichen Verfügung zu beziehen.

${ }^{1117}$ D III, 294. 
Ebeling nimmt Luthers Verhältnisverständnis von Wort und Sakrament auf, das besagt, dass beide keine Alternative bilden und dass die Sakramente getrennt von dem Wort keinen selbstständigen Platz haben und das Wort nicht überbieten können. Das Sakrament kann für Ebeling keine Ausnahme der reformatorischen exklusiven These solo verbo - sola fide sein und muss auch in deren Sinne interpretiert werden. Soll das Sakrament unter oder innerhalb der Kategorie des Wortes gesehen werden, kommt nun die Frage auf, worin das Sakrament dann seinen eigenen speziellen Dienst für den christlichen Glauben hat. Das Sakrament dient als das äußerliche Zeichen laut Ebeling zur Präzisierung des Wortes, indem es einen bestimmten Aspekt zum Ausdruck bringt, nämlich die Leiblichkeit des Wortes. Das Verständnis des Sakraments ist bei Ebeling auch im Sinne des Wort-geschehens zu verstehen. Einerseits redet er von der Situationsbezogenheit des Sakraments, die sich der Situationsempfindlichkeit der Predigt gegenüberstellt. Er erklärt, dass es nicht abhängig von der normalen, konkreten Situation, in die es getragen wird, ist. Stattdessen bezieht es sich auf zwei spezielle und grundlegende Situationen, nämlich auf die Lebenssituation Jesu und die durch Christus bestimmte Grundsituation des Menschen, indem der Gläubige in der Situation des Sakraments an jene erinnert und in diese versetzt wird. Andererseits legt Ebeling ein Gewicht auf die Wirkung und Vollmacht des Sakraments, die als die Vergegenwärtigung des Christusgeschehens am Wirken des Heiligen Geistes im Verhältnis von Wort und Glaube ausgerichtet ist.

Im Verlauf dieser Untersuchung wurde aufgezeigt, wie Ebeling das Konzept der Sprache bzw. Sprachlichkeit in seiner Hermeneutik und Dogmatik entfaltet. Dabei steht im Zentrum der Begriff des Wortgeschehens, das er als das Wesen der Sprache bestimmt, und das als ein worthaftes Geschehen in der Beziehung von Gott und Mensch entsteht und sich im Zusammenhang mit der Erfahrung im menschlichen Leben vollzieht. In seiner an der Sprache orientierten Hermeneutik finde ich eine Veränderung des Gesichtspunktes. Es geht um das Verständnis der Hermeneutik selbst, weil er durch die Hervorhebung des hermeneutischen Charakters der Sprache das Subjekt, die Methode, den Inhalt und das Ziel der Hermeneutik und damit ihre Definition erneut zur Sprache bringt. Ebeling will aufzeigen, dass die Aufgabe der theologischen Hermeneutik eher darin bestehen sollte, zu fragen, wie sie zum gegenwärtigen Wortgeschehen dienen kann, anstatt darauf zu achten, wie sie die von der Sprache hingewiesene Sache erklären soll. Wir müssen uns nun fragen, was für die theologische Arbeit wichtiger oder sinnvoller ist: entweder das geschehende Wirken der Sprache zu erfassen oder die Faktizität des Geschehens durch die Sprache zu entdecken. Diese Frage soll auch mit Rücksicht auf den christlichen Glauben bedacht werden.

Ebeling versucht mit seinem Sprachkonzept eine hermeneutische Legitimität für die dogmatischen Entwürfe darin zu bilden, dass Gott personal erfahrbar ist und die Menschen durch die Sprache personal trifft. Seine Hervorhebung der sprachlichen Erfahrungen mit Gott und dem göttlichen Geschehen, zeigt ihre Grenze an. Wenn man die Offenbarung in der Kategorie des Wortgeschehens einordnet, könnte man dann den wichtigen Sinn der geschichtlichen Offenbarung vernachlässigen? Und kann sie in der 
Tat die Wirklichkeit Gottes völlig enthalten? Ebeling legt unter dem relationalontologischen Aspekt eine überwiegende Betonung auf den Begriff der Relation und das Limit der menschlichen Sprache und kann den Zwiespalt zwischen ihr und Gottes Wort nicht deutlich erklären. Vielleicht könnte man sagen, Ebeling stelle, nach der radikalen Darstellung Peter Knauers, „die Beziehung Gottes zur Kreatur und der Kreatur zu Gott auf dieselbe Ebene“. ${ }^{1118}$ Theologie hat laut Ebeling die Aufgabe, Gott in Bezug auf die ganze Wirklichkeit der Welt zu erläutern, und kann dabei kein anderes Medium als die Sprache auswählen. Seine Behandlung der Sprache zeigt, dass wir die Sprache mehr berücksichtigen müssen, weil wir durch die Sprache die persönliche Beziehung mit Gott haben können. In dieser Beziehung können wir zu Gott sprechen und an der Versöhnung Jesu Christi und dem Wirken des Heiligen Geistes teilnehmen.

In der asiatischen Kultur wird der Begriff der Relation sehr stark betont. Diese Betonung der Relation ist auch in der koreanischen Kirche in Bezug auf das Verhältnis zu Gott und auch zu anderen Mitgliedern der Gemeinde wahrnehmbar. Das Christentum in Korea kann längst nicht auf eine so lange Geschichte zurückblicken wie das in Deutschland oder in anderen europäischen Ländern. Der Katholizismus kam 1784 nach Korea und der Protestantismus 1884. Trotz seiner jungen Geschichte wuchs das Christentum in Korea sehr schnell, was große Auswirkungen im In- und Ausland hat. Hier kommt zuerst die große Anzahl der Christen zur Sprache. Etwa 27 Prozent der Südkoreaner gehören heute einer christlichen Kirche an. Dieser Zahl ist ziemlich groß, wenn man bedenkt, dass Korea traditionell stark von anderen Religionen wie Buddhismus, Konfuzianismus und Schamanismus geprägt wurde. Auch im Vergleich mit Japan (ca. 1,3\%) und China (ca. 5-10\%) ist der Anteil der Christen in Südkorea hoch. Es ist auch bemerkenswert, dass das Christentum in Südkorea nicht lokal, sondern landesweit verbreitet ist. Das heißt, dass sich die christlichen Gemeinden überall befinden und in großen und kleinen Städten sowie Dörfern und Inseln vorkommen. Darüber hinaus ist die Zahl der Missionare zur Sprache zu bringen. Nach den USA sendet die südkoreanische Kirche, insbesondere die evangelische Gemeinde, die meisten Missionare aus. ${ }^{1119}$

Da kommt nun die Frage auf, wie sich das Christentum in Südkorea so schnell und stark entwickeln konnte. Ein Grund ist unbestritten die eigentümliche koreanische Kultur des Gottesdienstes. Koreanische Gläubige versammeln sich sehr häufig und beten für gewöhnlich zusammen. Wir nennen die Menschen, die einmal getauft wurden, obwohl sie durch die Taufe zum Mitglied einer Gemeinde geworden sind, allgemein und offiziell nicht Christen. Als Christen werden stattdessen nur die Menschen bezeichnet, die nicht nur den Glauben an Jesus Christus offen bekennen, sondern auch tatsachlich regelmäßig, d.h. zumindest am Sonntag zum Gottesdienst kommen. Die koreanische

\footnotetext{
1118 P. Knauer, Zu Gerhard Ebelings „Dogmatik des christlichen Glaubens“, in: ThPh 59, 1984, 393 -413, 393f.

1119 J.-A. Han-Rhinow, Die Situation der protestantischen Kirche Südkoreas Heute, Kerygma und Dogma 53, 2007, Göttingen 2007, 189-207, 192.
} 
Gemeinde beginnt jeden Tag normalerweise gegen 6 Uhr mit einem Frühmorgengebet. Gottesdienste werden jeden Mittwoch abgehalten, gewöhnlich vormittags für die nicht Berufstätigen, abends für die anderen. Zusätzlich wird an jedem Freitagabend ein Gottesdienst oder eine Gebetsversammlung abgehalten. Und selbstverständlich gibt es auch den Sonntagsgottesdienst. Koreanische Gläubige besuchen in der Tat regelmäßig den Gottesdienst und nehmen meiner Erfahrung nach aktiver an ihm teil, also im Vergleich mit deutschen Gläubigen, die ihre Religion als Christentum aussprechen. ${ }^{1120}$

Die aktive Teilnahme am Gottesdienst zeigt sich auf verschiedenste Weisen und doch eindrücklicher durch das Tongseong-Gebet als eine Gebetsform, bei der alle laut oder leise mit ihrer eigenen Stimme sprechen. Diese Gebetsform wurde zum ersten Mal in den Pfingstkirchen praktiziert und hat sich mittlerweile auf andere evangelische Kirchen übertragen. Sie ist heute eine allgemeine Gebetsform in evangelischen Gemeinden in Korea. Wegen des Wortes „Pfingstgemeinde“ könnte man an die Sprache in Zungen denken, doch auf diese beschränkt sich das Tongseong-Gebet nicht. Dieses meint alle Formen des kollektiven aussprechenden Betens außer die gemeinsamen formellen Bekenntnisse wie Vaterunser, Credo oder biblische Sprüche. Wegen der so häufigen und intensiven Teilnahme am Gottesdienst und am gemeinsamen Beten ist der christliche Glaube für koreanische Gläubige sehr relational. Für sie ist die sprachliche Kommunikation mit Gott weder abstrakt noch metaphysisch, sondern ein wirkliches Moment, das sie erfahren. Das dient gewiss der positiven Verstärkung des Glaubens des koreanischen Gläubigen, so wie oben aufgezeigt, letztlich der unglaublichen Entwicklung des koreanischen Christentums. In solchem Kontext der koreanischen Kirche hat die Theologie nun die Aufgabe, die sprachliche Beziehung mit Gott sachgemäß zu interpretieren, anstatt sich an den sprachlichen Phänomenen selbst zu orientieren. Wir können dabei an die theologische Bedeutung der Sprache denken, die Ebeling entdeckt und hervorhebt: Der Glaube ist die Relation mit Gott, die mittels der Sprache erfahrbar und beweisbar ist. Darüber hinaus ist es erforderlich, zu untersuchen, wie sich diese sprachliche Relation mit Gott auf die sprachliche Relation mit anderen Gläubigen bezieht.

\footnotetext{
${ }^{1120}$ Etwa 40\% von den Mitgliedern der Kirche besuchen in Korea zum Sonntagsgottesdienst. Z.B. besuchen in meiner heimlichen Kirche, Yoido Full Gopel Church in Seoul etwa 230,000 von einer halben Million Mitgliedern regemäßig den Sonntagsgottesdienst. Vgl. Y. Hong, The Backgrounds and Characteristics of Charismatic MagaChurches in Korea, in: Asian Journal of Pentecostal Studies 1, 99-118; Thomas Kern, Mega-Kirchen in Südkorea. Eine Fallstudie am Beispiel der Yoido Full Gospel Church, in: Patrick Köllner (Hg.), Jahrbuch Korea 2002, Politik - Wirtschaft - Gesellschaft, Hamburg, 165-196. In Deutschland besuchen durchschnittlich 3,4\% von den Mitgliedern der Kirche regelmäßig zum Sonntagsgottesdienst. Evangelische Kirche in Deutschland. Die Äußerungen des kirchlichen Lebens im Jahr 2015, Statistik, EKD, Feb. 2017, 20.
} 


\section{LITERATURVERZEICHNIS}

\section{LITERATUR VON GERHARD EBELING}

Die Geschichtlichkeit der Kirche und ihrer Verkündigung als theologisches Problem, Tübingen 1954.

Art. Hermeneutik, in: RGG ${ }^{3}$ III, Tübingen 1959, 242-262.

Art. Luther, Martin II. Theologie, in: RGG ${ }^{3}$ IV, Tübingen 1960, 495-520.

Wort und Glaube, Tübingen ${ }^{2} 1962$ [WG].

Theologie und Verkündigung. Ein Gespräch mit Rudolf Bultmann, Tübingen 1962 [ThV].

Art. Theologie I. Begriffsgeschichtlich, in: RGG ${ }^{3}$ VI, Tübingen 1962, 754-769.

Art. Theologie und Philosophie I-III, in: RGG ${ }^{3}$ VI, Tübingen 1962, 782-830.

Art. Tradition VII. Dogmatisch, in: RGG ${ }^{3}$ VI, Tübingen 1962, 976-984.

Vom Gebet. Predigten über das Unser-Vater, Tübingen 1963.

Wort Gottes und Tradition, Göttingen 1964 [WGT].

Wort Gottes und Hermeneutik, in: J.M. Robinson/J.B. Cobb (Hg.), Die neue Hermeneutik, Zürich 1965, 109-146.

Das Wesen des christlichen Glaubens, München/Hamburg ${ }^{2} 1965$ [Wesen].

Evangelische Evangelienauslegung. Eine Untersuchung zu Luthers Hermeneutik, Darmstadt 1969, ${ }^{3} 1991$ (mit Nachwort) [EEA, EEA $\left.{ }^{3}\right]$.

Wort und Glaube, Bd. II: Beiträge zur Fundamentaltheologie und zur Lehre von Gott, Tübingen 1969 [WG II].

Einführung in theologische Sprachlehre, Tübingen 1971 [Sprachlehre].

Lutherstudien, Bd. I, Tübingen 1971 [LuSt I].

Kritischer Rationalismus? Zu Hans Alberts >Traktat über kritische Vernunft<, Tübingen 1973.

Studium der Theologie. Eine enzyklopädische Orientierung, Tübingen 1975.

Wort und Glaube, Bd. III: Beiträge zur Fundamentaltheologie, Soteriologie und Ekklesiologie, Tübingen 1975 [WG III].

Lutherstudien, Bd. II: Disputatio de homine, 1. Teil: Text und Traditionshintergrund, Tübingen 1977 [LuSt II/1].

Luther. Einführung in sein Denken, Tübingen ${ }^{4} 1981$ [Luther].

Die Wahrheit des Evangeliums. Eine Lesehilfe zum Galaterbrief, Tübingen 1981.

Lutherstudien, Bd. II: Disputatio de homine, 2. Teil: Die philosophische Definition des Menschen. Kommentar zu These 1-19, Tübingen 1982 [LuSt II/2]. 
Dogmatik des christlichen Glaubens, Bd. I: Prolegomena. Erster Teil: Der Glaube an Gott den Schöpfer der Welt, Tübingen ${ }^{2} 1982$ [D I].

Dogmatik des christlichen Glaubens, Bd. II: Zweiter Teil: Der Glaube an Gott den Versöhner der Welt, Tübingen ${ }^{2} 1982$ [D II].

Dogmatik des christlichen Glaubens, Bd. III: Dritter Teil: Der Glaube an Gott den Vollender der Welt, Tübingen ${ }^{2} 1982$ [D III].

Umgang mit Luther, Tübingen 1983.

Lutherstudien, Bd. III: Begriffsuntersuchungen - Textinterpretationen - Wirkungsgeschichtliches, Tübingen 1985 [LuSt III].

Wort und Glaube, Bd. IV: Theologie in den Gegensätzen des Lebens, Tübingen 1995 [WG IV].

Mein theologischer Weg, in: Gerhard Ebeling. Mein theologischer Weg, Hermeneutische Blätter, Sonderheft Okt. 2006, 5-67.

\section{SEKUNDÄRLITERATUR}

Althaus, P., Die christliche Wahrheit, Gütersloh 1948, ${ }^{6} 1962$.

, Gerhard Ebelings Luther, in: ThLZ 90, 1965, 801-808.

Apel, K.-O., Transformation der Philosophie, Bd. 1. Sprachanalytik, Semiotik, Hermeneutik. Frankfurt a.M. 1973.

Assel, H., So schwer wie nötig! So schwierig wie möglich? - Hermeneutik einst und jetzt. Was Bibeltexte fremd belässt und was sie unnötig schwierig macht, in: Verkündigung und Forschung 58, Heft 2, 82-110.

Austin, J.L., How to Do Things with Words, Oxford 1962.

Bader, G., Erfahrung mit der Erfahrung, in: H.F. Geisser/W. Moster (Hg.), Wirkungen hermeneutischer Theologie. Eine Zürcher Festgabe zum 70. Geburtstag Gerhard Ebelings, Zürich 1983, 137-153.

, Art. Sprache/Sprachwissenschaft/Sprachphilosophie, VI. Systematisch-theologisch, in: TRE 31, Berlin/New York 2000, 765-781.

Barth, H.-M., Art. Gesetz und Evangelium, I. Systematisch-theologisch, in: TRE 13, Berlin/New York 1984, 126142.

Barth, K., Das Wort Gottes und die Theologie. Gesammelte Vorträge, München 1924.

, Reformierte Lehre, ihr Wesen und ihre Aufgabe (1923), in: Ders., Vorträge und kleinere Arbeiten 1922-1925, Wiederausdruck, in: Holger Finze (Hg.), Karl-Barth-Gesamtausgabe, Zürich 1990, 202-247.

— Kirchliche Dogmatik, Bd. I/1, Zürich 1932, 1964 [KD I/1].

_. Kirchliche Dogmatik Bd. III, Zürich 1957, ${ }^{10} 1981$ [KD III].

Evangelium und Gesetz (1935), in: E. Kinder/K. Haendler (Hg.), Gesetz und Evangelium. Beiträge zur gegenwärtigen theologischen Diskussion (WdF 142), Darmstadt ${ }^{2} 1986,1-29$. 
Bayer, O., Promissio. Geschichte der reformatorischen Wende in Luthers Theologie, Göttingen 1971.

, Martin Luthers Theologie. Eine Vergegenwärtigung, Tübingen 2003.

Beinert, W./ Kühn, U., Ökumenische Dogmatik, Leipzig 2013.

Benckert, H., Das Gebet als Gegenstand der Dogmatik, in: EvTh 15, 1955, 535-552.

Berger, K., Art. Gebet, IV. Neues Testament, in: TRE 12, Berlin/New York 1984, 47-60.

Bethge, E. Dietrich Bonhoeffer. Eine Biologie, München 1967.

Beutel, A., Protestantische Konkretionen. Studien zur Kirchengeschichte, Tübingen 1998. , In memoriam Gerhard Ebeling, in: Lutherjahrbuch 69, 2002, 13-19.

, Wort Gottes, in: Ders. (Hg.), Luther Handbuch, Tübingen 2005, 362-371.

_. Gerhard Ebeling. Eine Biographie, Tübingen 2012.

Bieri, P., Zeit und Zeiterfahrung. Exposition eines Problembereichs, Heidelberg 1972,

Birkel, H.F., Das Verhältnis von existentialer Interpretation und historischer Jesusfrage als Problem des Verstehens in der Theologie bei Bultmann und Ebeling, Diss., Erlangen-Nürnberg 1974.

Birkner, H.-J., Beobachtungen zu Schleiermachers Programm der Dogmatik (1963), in: Hermann Fischer (Hg.), Schleiermacher-Studien, Berlin/New York 1996, 99-123.

Birus, H., Hermeneutische Positionen, Göttingen 1982.

Schleiermachers Begriff der „Technischen Interpretation“, in: K.-V. Selge (Hg.), Internationaler Schleiermacher-Kongreß. Berlin 1984, Bd. I, Berlin/New York 1985, 591-600.

Biser, E., Theologische Sprachtheorie und Hermeneutik, München 1970.

Block, J., Die Rede von Sünde in der Predigt der Gegenwart, Zürich 2012.

Bohren, R., Die Differenz zwischen Meinen und Sagen. Anmerkungen zu Ernst Lange, Predigen als Beruf, in: WPKG 70, 1981, 416-430.

Bonhoeffer, D., Widerstand und Ergebung, München/Hamburg 1965.

Boor, Friedrich d., Kirchengeschichte oder Auslegungsgeschichte?, in: ThLZ 97, 1972, 401-414.

Bormann, Claus v., Art. Hermeneutik, I. Philosophisch-theologisch, in: TRE 15, Berlin/New York 1986, 108-137.

Bornkamm, G./Barth, G./Held, H.J., Überlieferung und Auslegung im Matthäusevangelium, Neukirchen-Vluyn 1960.

Bornkamm, G./Klaas, W., Mythos und Evangelium. Zum Programm R. Bultmanns (ThEx 26), München 1951.

Brunner, E., Dogmatik I, Zürich ${ }^{3} 1960$, III, Zürich 1960.

Bühler, P., Wort Gottes und Hermeneutik. Gerhard Ebelings Erbe aus heutiger Sicht, in: I.U. Dalferth u.a. (Hg.), Hermeneutische Theologie - heute?, Tübingen 2013, 39-54. 
Bullinger, H., Confessio Helvetica Posterior (1562/66), in: P. Jacobs (Hg.), Reformierte Bekenntnisschriften und Kirchenordnung in deutscher Übersetzung, Neukirchen 1949.

Bultmann, R., Jesus, Tübingen 1951.

Kerygma und Mythos. Bd. I, Ein theologisches Gespräch, H.W. Bartsch (Hg.), Hamburg ${ }^{3} 1954$; Bd. II, Diskussionen und Stimmen zum Problem der Entmythologisierung, Hamburg 1952 [KuM].

Glauben und Verstehen, Gesammelte Aufsätze, Bd. I, Tübingen ${ }^{3} 1958$; Bd. II, 1952; Bd. III, 1960; Bd. IV, ${ }^{2} 1967[\mathrm{GuV}]$.

_ Das Verhältnis der urchristlichen Christusbotschaft zum historischen Jesus, Heidelberg 1960.

Das Problem einer theologischen Exegese des Neuen Testaments, in: J. Moltmann (Hg.), Anfänge der dialektischen Theologie Teil II, München ${ }^{3} 1977$, 47-72.

, Theologie des Neuen Testamentes, Tübingen ${ }^{9} 1984$.

, Neues Testament und Mythologie. Das Problem der Entmythologisierung der neutestamentlichen Verkündigung, München 1988.

Conzelmann, H., Die Mitte der Zeit. Studien zur Theologie des Lukas. Tübingen 1954.

Craddock, F.B., As One Without Authority, St. Louis, 1971.

Cramer, K., Art. Erleben, Erlebnis, in: J. Ritter u.a. (Hg.), Historisches Wörterbuch der Philosophie, Bd. 2, Basel 1972, 702-711.

Crossan, J.D., Der historische Jesus, München ${ }^{2} 1995$.

Daiber, K.-F., Religion in multikulturellen und multireligiösen Staaten Ostasiens, Frankfurt a.M. 2014.

Dalferth, I.U., Der auferweckte Gekreuzigte. Zur Grammatik der Christologie, Tübingen 1994.

, Die Wirklichkeit des Möglichen. Hermeneutische Religionsphilosophie, Tübingen 2003.

, Radikale Theologie, Leipzig 2010.

Dalferth, I.U./Bühler, P./Hunziker, A. (Hg), Hermeneutische Theologie - heute?, Tübingen 2013.

Danz, C., Grundprobleme der Christologie, Tübingen 2013.

Dilthey, W., Die geistige Welt. Einleitung in die Philosophie des Lebens: 1. Abhandlungen zur Grundlegung der Geisteswissenschaften, Gesammelte Schriften Bd. V, Leipzig/Berlin 1924 [GS V].

Die geistige Welt. Einleitung in die Philosophie des Lebens: 2. Abhandlungen zur Poetik, Ethik und Pädagogik, Gesammelte Schriften Bd. VI, Leipzig/Berlin 1924 [GS VI].

Der Aufbau der geschichtlichen Welt in den Geisteswissenschaften, Gesammelte Schriften Bd. VII, Leipzig/Berlin 1927 [GS VII].

_ Leben Schleiermachers, Gesammelte Schriften Bd. XIV, Göttingen 1966 [GS XIV].

Die Entstehung der Hermeneutik, in: Reiß, G. (Hg.), Materialien zur Ideologiegeschichte der deutschen Literaturwissenschaft, Bd. 1, Tübingen 1973, 55-68.

Dinkler, E., Im Zeichen des Kreuzes, O. Merk/M. Wolter (Hg.), Berlin/New York 1992. 
Dockhorn, Klaus., Luthers Glaubensbegriff und die Rhetorik. Zu Gerhard Ebelings Buch „Einführung in theologische Sprachlehre“, in: Linguistica biblica 3, 1973, 19-39.

Eichholz G., Die Grenze der existentialen Interpretation, in: EvTh 22, 1962, 565-579.

Elert, W., Zwischen Gnade und Ungnade, München 1948.

, Der christliche Glaube, Hamburg ${ }^{3} 1956$, Erlangen ${ }^{5} 1988$.

Emoto, Masaru, Die Antwort des Wassers, Koha-Verlag 2002.

Feil, E., Die Theolgie Dietrich Bonhoeffers. Hermeneutik, Christologie, Weltverständnis, München 1971.

Filser, H., Dogma, Dogmen, Dogmatik, Münster u.a. 2001.

Finkenzeller, J., Die Lehre von den Sakramenten im Allgemeinen. Von der Reformation bis zur Gegenwart, Freiburg 1981.

Fischer, H., Glaubensaussage und Sprachstruktur, Hamburg 1972.

Luthers Sicht des Menschen im Spannungsfeld von philosophischer und theologischer Definition. Erwägungen zu Gerhard Ebelings Kommentar über Luthers Disputationsthesen „De homine“, in: Theologische Rundschau 57, 1992, 305-317.

, Systematische Theologie. Konzeptionen und Probleme im 20. Jahrhundert, Stuttgart u.a. 1992.

Frankemölle, H., Das jüdische Neue Testament und der christliche Glaube. Grundlagenwissen für den jüdischchristlichen Dialog, Stuttgart 2009.

Frey, J., Der historische Jesus und der Christus der Evangelien, in: J. Schröter/R. Brucker (Hg.), Der historische Jesus. Tendenzen und Perspektiven der gegenwärtigen Forschung, Berlin/New York 2002, 273-336.

Fuchs, E., Hermeneutik, Bad Cannstatt 1954.

, Zum hermeneutischen Problem in der Theologie. Die existentiale Interpretation, Gesammelte Aufsätze I, Tübingen 1959 [GA I].

_. Zur Frage nach dem historischen Jesus, Gesammelte Aufsätze II, Tübingen 1960 [GA II].

, Die Spannung im neutestamentlichen Christusglauben, in: ZThK 59, 1962, 32-45.

, Das hermeneutische Problem, in: E. Dinkler (Hg.), Zeit und Geschichte, Tübingen 1964, 357-366.

, Glaube und Erfahrung. Zum christologischen Problem im Neuen Testament, Gesammelte Aufsätze III, Tübingen 1965 [GA III].

Brief an Gerhard Ebeling vom 8.12.1959, in: Ebeling/E. Jüngel/G. Schunack (Hg.), Festschrift für Ernst Fuchs, Tübingen 1973, 1-66.

Gadamer, H.-G., Hermeneutik I. Wahrheit und Methode. Grundzüge einer philosophischen Hermeneutik, Bd. I, Tübingen ${ }^{2} 1965,{ }^{4} 1975,{ }^{5} 1986$; Bd. II, Ergänzungen, Tübingen 1986 [WM].

Gardt, A., Geschichte der Sprachwissenschaft in Deutschland. Vom Mittelalter bis ins 20. Jahrhundert, Berlin/New York 1999.

Geense, A., Auferstehung und Offenbarung. Über den Ort der Frage nach der Auferstehung Jesu Christi in der heutigen deutschen evangelischen Theologie, Diss., Göttingen 1971. 
Gelder, K., Glaube und Erfahrung. Eine kritische Auseinandersetzung mit G. Ebelings Dogmatik des christlichen Glaubens im Kontext der gegenwärtigen evangelisch-theologischen Diskussion, Neukirchen-Vluyn 1992.

Gelsetzer, L., De ratione cognoscendi sacras literas. Über den Erkenntnisgrund der Heiligen Schrift, Düsseldorf 1968.

Gestrich, Christof, Die Sprache der Versöhnung. Theologie und Sprachphilosophie in Begegnung. Erwägungen zu G.W.F. Hegel und W. von Humboldt über die Frage der Verhinderung destruktiver Gewalt, in: ZThK 94, 1997, 488-510.

Gibson, A., An Exhibition of theological Fallacies. A Critique of Gerhard Ebeling's Analysis of Language, in: The Heythrop Journal Vol. 15(4), 1974, 423-440.

Gmainer-Pranzl, F., Glaube und Geschichte bei Karl Rahner und Gerhard Ebeling. Ein Vergleich transzendentaler und hermeneutischer Theologie, Innsbruck/Wien, 1996.

Goebel, H.Th. Wort Gottes als Auftrag, Zur Theologie von Rudolf Bultmann, Gerhard Ebeling und Wolfhart Pannenberg, Neukirchen 1972.

Gogarten, F., Einheit von Evangelium und Volkstum?, Hamburg ${ }^{2} 1934$.

, Der Mensch zwischen Gott und Welt, Stuttgart ${ }^{4} 1967$.

Goltz, R., Das Werden der Gewissheit. Eine Untersuchung zum protestantischen Verständnis von Offenbarung als Grund des Glaubens im Anschluss an die Theologien von Barth, Ebeling und Herms, Leipzig 2008.

Gordin, J., Einführung in die philosophische Hermeneutik, Darmstadt 2001.

Görnadt, R. Die Metaphysikkritik Gerhard Ebelings und ihre Vorgeschcihte, Tübingen 2016.

Graf, D., Unterwegs zu einer biblischen Theologie. Perspektiven der Konzeption von Peter Stuhlmacher, Göttingen 2011.

Greive, W., Jesus und Glaube. Das Problem der Christologie G. Ebelings, in: KuD 22, 1976, 163-180.

Güttgemanns, E., Theologie als sprachbezogene Wissenschaft, in: Studia Linguistica Neotestamentica. Gesammelte Aufsätze zur linguistischen Grundlage einer neutestamentlichen Theologie, 1971, 184-230.

Habermas, J., Universalitätsanspruch der Hermeneutik, in: R. Bubner u.a. (Hg.), Hermeneutik und Dialektik Bd. 1, Tübingen 1970, 73-104 u. in: K.-Otto Apel u.a. (Hg.), Hermeneutik und Ideologiekritik, Frankfurt a.M. 1971, 120-159.

_, Der philosophische Diskurs der Moderne, Frankfurt a.M. 1985.

Han-Rhinow, J.-A., Die Situation der protestantischen Kirche Südkoreas Heute, Kerygma und Dogma 53, 2007, Göttingen 2007, 189-207.

Häring, B., Gebet in einer weltlichen Welt, München 1972.

Härle, W., Dogmatik, Berlin ${ }^{3} 2007$.

Hauschildt, F. u.a. (Hg.), Die Gemeinsame Erklärung zur Rechtfertigungslehre. Dokumentation des Entstehungsund Rezeptionsprozesses, Göttingen 2009.

Heidegger, M., Über den Humanismus, Frankfurt a.M. 1949. 
, Sein und Zeit, GA., Bd. 2, Frankfurt a.M. 1977 [SZ].

_ Erläuterungen zu Hölderins Dichtung, GA., Bd. 4, Frankfurt a.M. 1981.

, Unterwegs zur Sprache, GA., Bd. 12, Frankfurt a.M. 1985.

— Vorträge und Aufsätze, GA. Bd. 7, Frankfurt a.M., 2000.

Heiler, F., Das Gebet. Eine religionsgeschichtliche und religionspsychologische Untersuchung, München/Basel ${ }^{5} 1969$.

Heinz, K., The Linguisticality of God and Faith in Gerhard Ebeling, in: Lutheran Quarterly 23, 1971, 289-298.

Hempelmann, R., Sakrament als Ort der Vermittlung des Heils. Sakramententheologie im evangelischkatholischen Dialog, Göttingen 1992.

Herder, J.G., Abhandlung über den Ursprung der Sprache, Berlin ${ }^{4} 2017$.

Hermelink, J., Die homiletische Situation. Zur jüngeren Geschichte eines Predigtproblems, Göttingen 1992.

Hermanns, F., Linguistische Hermeneutik. Überlegungen zur überfälligen Einrichtung eines in der Linguistik bisher fehlenden Teilfachs, in: A. Linke u.a., (Hg.), Sprache und mehr. Ansichten einer Linguistik der sprachlichen Praxis, Tübingen 2003, 125-163.

Hermann, W., Christus der Grund unseres Glaubens, in: ZThK 2, 1892, 232-273.

Heussi, K., Schriften zur Geschichtslogik und zur Geschichtstheologie II, in: ThLZ 73, 1948, 393-398.

Hiller, D., Konkretes Erkennen. Glaube und Erfahrung als Kriterien einer im Gebet begründeten theologischen Erkenntnistheorie. Ausgeführt in Auseinandersetzung mit der Theologie Gerhard Ebelings, Diss., Uni. Jena 1997.

Hirschler, H., In welchem Sinne hilft Ebelings Dogmatik dem Prediger heute?, in: ZThK 78, 1981, 491-513.

Hong, Y., The Backgrounds and Characteristics of Charismatic Maga-Churches in Korea, in: Asian Journal of Pentecostal Studies 1, 99-118.

Hohmeier, F., Das Schriftverständnis in der Theologie Rudolf Bultmanns, Berlin 1964.

Iserloh, E., Existentiale Interpretation in Luthers erster Psalmenvorlesung?, in: Theologische Revue 59 (1963), 73-84.

Jäger, A., Gott, Nochmals Martin Heidegger, Tübingen 1978.

Janke, W., Art., Wirklichkeit, I. Philosophisch, in: TRE 36, Berlin/New York 2004, 114-120.

Jetter, W., Redliche Rede vor Gott - über den Zusammenhang zwischen Predigt und Gebet. Eine Erinnerung an Gerhard Ebelings Beitrag zur Predigtlehre, in: E. Jüngel u.a. (Hg.), Verifikationen. Festschrift für Gerhard Ebeling zum 70. Geburtstag, Tübingen 1982, 385-424.

Joest, W./Lüpke, J.v., Dogmatik I: Die Wirklichkeit Gottes, Göttingen ${ }^{5} 2010$.

Jüngel, E., Unterwegs zur Sache. Theologische Bemerkungen, München 1972.

Das Evangelium von der Rechtfertigung des Gottlosen als Zentrum des christlichen Glaubens. Eine theologische Studie in ökumenischer Absicht, Tübingen ${ }^{3} 1999$.

Erfahrungen mit der Erfahrung. Unterwegs bemerkt, Stuttgart 2008. 
Kähler, M., Der sogenannte historische Jesus und der geschichtliche biblische Christus, E. Wolf (Hg.), München ${ }^{2} 1956$.

Käsemann, E., Exegetische Versuche und Besinnungen, Bd. 1, Göttingen ${ }^{6} 1970$.

Kasper W., Glaube und Geschichte, Mainz 1970.

Kempski, J.v., Kritische Versuche zur Philosophie der Gegenwart, Reinbek 1974.

Kern, Thomas, Mega-Kirchen in Südkorea. Eine Fallstudie am Beispiel der Yoido Full Gospel Church, in: Patrick Köllner (Hg.), Jahrbuch Korea 2002, Politik - Wirtschaft - Gesellschaft, Hamburg, 165-196.

Kim, E., Wort und Glaube. Fundamentaltheologische Erörterungen Gerhard Ebelings in theologischen Krisenzeiten, Frankfurt a.M. 2017.

Kimmerle, H., Hermeneutische Theorie oder ontologische Hermeneutik, in: ZThK 59, 1962, 114-130.

Kistenbrügge, A., Das Gebet in der Dogmatik. Untersucht am Beispiel von Gerhard Ebelings Dogmatik des christlichen Glaubens, Frankfurt a.M./Berlin, 2000.

Knauer, P. Rez. G. Ebeling, Einführung in theologische Sprachlehre, 1971. in: ThPh 47, 1972, 299-230. , Der Glaube kommt vom Hören, Ökumenische Fundamentaltheologie, Bamberg ${ }^{5} 1986$.

Knuth, H.C., Verstehen und Erfahrung. Hermeneutische Beiträge zur empirischen Theologie, Hannover 1986.

Koh, Bong-ik, Confucianism in Contemporary Korea. in: Tu Wei-ming (Hg), Confucian Traditions in East Asian Modernity, Harvard University Press, 1996.

Körber, B.W., Sündlosigkeit und Menschsein Jesu Christi. Ihr Verständnis und ihr Zusammenhang mit der Zweinaturenlehre in der protestantischen Theologie der Gegenwart, Göttingen 1995.

Körtner, U.H.J., Der inspirierte Leser. Zentrale Aspekte biblischer Hermeneutik, Göttingen 1994.

, Art., Schriftauslegung, IV. Systematisch-theologisch, in: TRE 30, Berlin/New York 1999, 489-495.

_. Theologie des Wortes Gottes. Positionen, Probleme, Perspektiven. Göttingen 2001.

, Jesus im 21. Jahrhundert. Bultmanns Jesusbuch und die heutige Jesusforschung, Neukirchen-Vluyn 2001.

, Einführung in die theologische Hermeneutik, Darmstadt 2006.

Krötke, W., Die Attribute Gottes in der neueren deutschsprachigen evangelischen Dogmatik. Vortrag bei einer internationalen Tagung der Katholisch-Theologischen Fakultät Augsburg am 25. 07. 2013. http://wolfkroetke.de/vortraege/ansicht/eintrag/67.html.

Kubik, J., Kirche in der Moderne - moderne Kirche, in: G. Koretzki/R. Tammeus (Hg.), Werkbuch 11: Religion entdecken, verstehen, gestalten, Göttingen 2003, 108-120.

Landmesser, C., Wahrheit als Grundbegriff neutestamentlicher Wissenschaft, Tübingen 1999.

Lange, D., Kirche im Zeichen der Zwei-Reiche-Lehre. Ein Beitrag zur Ekklesiologie Gerhard Ebelings, in: ZThK $108,2011,72-87$.

Lange, E., Zur Theorie und Praxis der Predigtarbeit, in: Rüdiger Schloz (Hg.), Predigen als Beruf. Aufsätze zur Homiletik, Liturgie und Pfarramt, München 1982, 9-51. 
Lau, V., Erzählen und Verstehen. Historische Perspektiven der Hermeneutik, Würzburg 1999.

Laube, M., Theologische Selbstklärung im Angesicht des Historismus. Überlegung zur theologischen Funktion der Frage nach dem historischen Jesus, in: KuD 54, 2008, 114-137.

Lauster, J., Religion als Lebensdeutung. Theologische Hermeneutik heute, Darmstadt 2005.

Lindbeck, G.A., Ebeling. Climax of a Great Tradition in: The Journal of Religion 61, 1981, 309-314.

Lorenz, R., Die unvollendete Befreiung vom Nominalismus. Martin Luther und die Grenzen hermeneutischer Theologie bei Gerhard Ebeling, Gütersloh 1973.

Lorenzmeier, T., Exegese und Hermeneutik. Eine vergleichende Darstellung der Theologie Rudolf Bultmanns, Herbert Brauns und Gerhard Ebelings, Hamburg 1968.

Lose, D., Whither Hence, New Homiletic?, in: The Papers of the annual meeting of the American Academy of Homiletics, Dec. 2000, 255-265.

Lohmeyer, E., Rez. R. Bultmann, Jesus, in: ThLZ 52, 1927, 433-439.

Luck, U., Heideggers Ausarbeitung der Frage nach dem Sein und die existentialanalytische Begrifflichkeit in der evangelischen Theologie. Das Problem der ontologischen Konsequenzen der existentialen Interpretation (1956), in: G. Noller (Hg.), Heidegger und die Theologie, München 1967, 226-248.

Luther, M., Die Predigt vom Unterschied zwischen dem Gesetz und Evangelio über Gal 3,23.24 (1532), in: J.G. Walch (Hg.), Martin Luthers sämtliche Schriften, 2. Aufl. Bd. IX, 798-811.

_ Der Große und der Kleine Katechismus, K. Aland/H. Kunst (Hg.), Göttingen ${ }^{2} 1985$.

Matteucci, G., Dilthey. Das Ästhetische als Relation, Würzburg 2004.

Manzke, K.H., Ewigkeit und Zeitlichkeit. Aspekte für eine theologische Deutung der Zeit, Göttingen 1992.

Marxen, W., Der Evangelist Markus. Studien zur Redaktionsgeschichte des Evangeliums, Göttingen 1956.

Meier, Paul J., Fundamental ontology and positive theology: Martin Heidegger's way of thinking, in: Journal of Religious Thought, vol. 17, 1960, 101-115.

Mildenberger F., Die halbe Wahrheit oder die ganze Schrift. Zum Streit zwischen Bibelglauben und historischer Kritik, in: BEvTh 46, München 1967.

, Kleine Predigtlehre, Stuttgart u.a. 1984.

Moltmann, J., Anfrage und Kritik zu Gerhard Ebelings Theologie und Verkündigung, EvTh 24, 1964, 25-34.

Müller, G., Art. Gebet, VIII. Dogmatische Probleme gegenwärtiger Gebetstheologie, in: TRE 12, Berlin/New York 1984, 84-94.

Müller, H.M., Homiletik. Eine evangelische Predigtlehre, Berlin/New York 1996.

Müller, H.-P., Albert Schweitzer und Rudolf Bultmann. Theologische Paradigmen unter der Herausforderung durch den Säkularismus, in: ZThK 93, 1996, 101-123.

Müller, M., Ende der Metaphysik? Für Martin Heidegger zum 75. Geburtstag am 26. 9. 1964, in: Philosophisches Jahrbuch 72, 1964/65, 1-48.

Nethöfel, W., Theologische Hermeneutik. Vom Mythos zu den Medien, Neukirchen-Vluyn, 1992. 
Neumann, B., Sakrament und Ökumene. Studien zur deutschsprachigen evangelischen Sakramententheologie der Gegenwart, Paderborn 1997.

Nicol M., Preaching from Within. Homiletische Positionslichter aus Nordamerika, in: Pastoraltheologie 86, 1997, 295-309.

_. Homiletik. Positionsbestimmung in den neunziger Jahren, in: ThLZ 123, 1998, 1049-1066.

Niesel, W., Die Theologie Calvins, München ${ }^{2} 1957$.

Noack, H., Sprache und Offenbarung. Zur Grenzbestimmung von Sprachphilosophie und Sprachtheologie, Gütersloher 1960.

Oeming, M., Biblische Hermeneutik, Darmstadt 1998.

Osteen, Joel, Your Best Life Now, Faith Words 2015.

Ott, H., Was ist systematische Theologie?, in: J.M. Robinson/J.B. Cobb (Hg.), Der spätere Heidegger und die Theologie, Zürich/Stuttgart 1964, 65-133.

Ozment, S.E., Ders., Homo Spiritualis. A Comparative Study of the anthropology of Johannes Tauler, Jean Gerson and Martin Luther (1509-16) in the context of their theological Thought, Netherland, 1969.

Palmer, R.E., Hermeneutics. Interpretation Theory in Schleiermacher, Dilthey, Heidegger and Gadamer, Evanston 1969.

Pannenberg, W., Wissenschaftstheorie und Theologie, Frankfurt a.M. 1973.

, Grundzüge der Christologie, Gütersloh 1976.

_. Systematische Theologie III, Göttingen 1993.

, Anthropologie in theologischer Perspektive, Göttingen ${ }^{2} 2011$.

Pech, O.H., Das katholische Sakramentsverständnis im Urteil gegenwärtiger evangelischer Theologie, in: E. Jüngel u.a. (Hg.), Verifikation, Festschrift für G. Ebeling zum 70. Geburtstag, Tübingen 1982, 317-340.

Petzoldt M., Kommunikations- und medientheoretische Anmerkungen zur subjektivitätstheoretischen Kritik an der Wort-Gottes-Theologie, in: I.U. Dalferth (Hg.), Krisen der Subjektivität, Tübingen 2005, 417-453.

Pilnei, O. Wie entsteht christlicher Glaube? Untersuchungen zur Glaubenskonstitution in der hermeneutischen Theologie bei Rudolf Bultmann, Ernst Fuchs und Gerhard Ebeling, Tübingen 2007.

Pöhlmann, H.G., Abriss der Dogmatik, Gütersloh 1973.

Rahner, K./Vorgrimler, H., Kleines Theologisches Wörterbuch, Freiburg ${ }^{15} 1985$.

Randolph, D., The Renewal of Preaching, Philadelphia 1969.

Raske, M., Sakrament, Glaube, Liebe. Gerhard Ebelings Sakramentsverständnis. Eine Herausforderung an die katholische Theologie, Essen 1973.

Reinhardt, K., Der dogmatische Schriftgebrauch in der katholischen und protestantischen Christologie von der Aufklärung bis zur Gegenwart, München u.a. 1970. 
Ricoeur, P., Philosophische und theologische Hermeneutik, in: Ders./E. Jüngel (Hg.), Metapher. Zur Hermeneutik religiöser Sprache, München 1974, 24-45.

Foreword, in: J.C. Staten, Conscience and the Reality of God. An Essay on the Experiential Foundation of Religious Knowledge. Berlin u.a. 1988.

Gerhard Ebeling. Rüchwendung zur Reformation und Wortgeschehen, in: Gerhard Ebeling. Mein theologischer Weg, Hermeneutische Blätter, Sonderheft Okt. 2006, 75-94.

Ringleben, J., In Einsamkeit mein Sprachgesell. Das Gebet als Thema der Dogmatik, in: ZThK 79, 1982, 230248.

Gott im Wort. Luthers Theologie von der Sprache her, Tübingen 2010.

Robinson, J.M., Die Hermeneutik seit Karl Barth, in: Ders./J.B. Cobb (Hg), Die neue Hermeneutik, Zürich 1965 , 13-108.

Rohls, Jan, Protestantische Theologie der Neuzeit II. Das 20. Jahrhundert, Tübingen 1997.

Rothgangel, M., Naturwissenschaft und Theologie. Wissenschaftstheoretische Gesichtspunkte im Horizont religionspädagogischer Überlegungen, Göttingen 1999.

Ruokanen, M., Hermeneutics as an Ecumenical Method in the Theology of Gerhard Ebeling, Helsinki 1982.

, Das Problem der Gnadenlehre in der Dogmatik Gerhard Ebelings, in: KuD 35, 1989, 2-22.

Sauter, G., Zur Herkunft und Absicht der Formel „Nicht-religiöse Interpretation biblischer Begriffe“ bei Dietrich Bonhoeffer, in: EvTh 25, 1965, 283-297.

Schäfer, R., Der evangelische Glaube, Tübingen 1973.

Schleiermacher, F., Hermeneutik, H. Kimmerle (Hg.), Heidelberg 1959.

, Hermeneutik und Kritik, M. Frank (Hg.), Frankfurt a.M. 1977.

Der christliche Glaube nach den Grundsätzen der der evangelischen Kirche im Zusammenhange dargestellt. 2. Aufl. (1830/31), Bd. I/II, R. Schäfer (Hg.), Berlin/New York 2008 [CG].

Schlögel, H., Nicht moralisch, sondern theologisch. Zum Gewissenverständnis von Gerhard Ebeling, Mainz 1992.

Scholz, O.R., Verstehen und Rationalität. Untersuchungen zu den Grundlagen von Hermeneutik und Sprachphilosophie, Frankfurt a.M. 2001.

Schröter, J., Jesus von Nazareth. Jude aus Galiläa - Retter der Welt, Leipzig 2006.

Schwöbel, C., Art. Gesetz und Evangelium, in: RGG4 III, Tübingen 2000, 862-867.

Selvatico, P., Glaubensgewissheit. Eine Untersuchung zur Theologie von Gerhard Ebeling, Freiburg/Schweiz, 1977.

, Theologie der Relation, in: Freiburger Zeitschrift für Philosophie und Theologie, 1980/27, 265-275.

Sohns, R., Verstehen als Zwiesprache. Hermeneutische Entwürfe in Exegese und Religionspädagogik, Münster/Hamburg/London 2003.

Steiger, L., Sprachschule des christlichen Glaubens. Zur Theologie Gerhard Ebelings, in: Kirche in der Zeit 17, 1962, 105-113. 
Stellmacher, D., Zum Sprachverständnis Ebelings, in: U. Gerber/E. Güttgemanns (Hg.), Linguistische Theologie. Biblische Texte, christliche Verkündigung und theologische Sprachtheorie, Bonn ${ }^{3} 1975,56-58$.

Stephan, H., Glaubenslehre, Gießen 1920, Berlin ${ }^{3} 1941$.

Stirnimann, H., Zu Ebelings Dogmatik I, in: Freiburger Zeitschrift für Philosophie und Theologie 26, 1979, 573 588.

Stoellger, P., Passivität aus Passion. Zur Problemgeschichte einer , categoria non grata‘, Tübingen 2010.

Stuhlmacher, P., Schriftauslegung auf dem Wege zur biblischen Theologie, Göttingen 1975.

Exegese und Erfahrung, in: E. Jüngel u.a. (Hg.), Verifikation. Festschrift für Gerhard Ebeling zum 70. Geburtstag, Tübingen 1982, 62-89.

, Biblische Theologie des Neuen Testaments I, Göttingen 1992.

Süßmlich, J.P., Versuch eines Beweises, daß die erste Sprache ihren Ursprung nicht von Menschen, sondern allein vom Schöpfer erhalten habe, Berlin 1766.

Thaidigsmann, E., Auf der Suche nach dem Fundamentalen. Zum Thema „Wirklichkeit“ in der Theologie Gerhard Ebelings, in: EvTh 42, 1982, 350-366.

Thielicke, H., Der evangelische Glaube, 3 Bde., Tübingen 1968-1978.

Thiselton, A.C., The New Hermeneutic, in: I.H. Marshall (Hg.), New Testament Interpretation. Essays on Principles and Methods I, Carlisle UK (Paternoster) 1972, 308-333.

, The two horizons. New Testament Hermeneutics and Philosophical Description, Grand Rapids 1980.

Tillich, P. Systematische Theologie, Bd. II, Stuttgart 1958.

Trillhaas, W., Dogmatik, Berlin 1962.

Troeltsch, E., Glaubenslehre, München/Leipzig 1925.

Über historische und dogmatische Methode der Theologie (1900), in: F. Voigt (Hg.), Ernst Troeltsch Lesebuch, Tübingen 2003, 2-25.

Toit, D. du, Erneut auf der Suche nach Jesus. Eine kritische Bestandsaufnahme der Jesusforschung am Anfang des 21. Jahrhunderts, in: U.H.J. Körtner (Hg.), Jesus im 21. Jahrhundert. Bultmanns Jesusbuch und die heutige Jesusforschung, Neukirchen-Vluyn 2001, 91-134.

Vermes, G., Jesus der Jude. Ein Historiker liest die Evangelien, Neukirchen-Vluyn 1993.

Wach, J., Die theologische Hermeneutik von Schleiermacher bis Hofmann Bd. I, Tübingen 1929.

Weber, O., Grundlagen der Dogmatik Bd. I, Neukirchen ²1959, Bd. II, Berlin 1962.

Wengst, K., Christsein mit Tora und Evangelium. Beiträge zum Umbau christlicher Theologie im Angesicht Israels, Stuttgart 2014.

Werbick, J., Die Aporetik des Ethischen und der christliche Glaube. Studien zur Fundamentaltheologie Gerhard Ebelings, München 1976.

Wüstenberg, R.K., Christologie. Wie man heute theologisch von Jesus sprechen kann, Gütersloh 2009. 
Zimmermann, R., Paradigmen einer metaphorischen Christologie. Eine Leseanleitung, in: J. Frey u.a. (Hg.), Metaphorik und Christologie, Berlin/New York 2003, 1-34.

Zwanepol, Klaas, Unterscheiden, Eine Studie über den Hintergrund, das Motiv und die Methode der Theologie Gerhard Ebeling, Bern 1993.

Art. Dogmatik, in: Duden Online Wörterbuch. http://www.duden.de/suchen/dudenonline/dogmatik.

Art. Einverständnis, in: Duden online Wörterbuch.

http://www.duden.de/suchen/dudenonline/Einverst $\% \mathrm{C} 3 \% \mathrm{~A} 4$ ndnis. 